\title{
The influence of body size on adult skeletal age estimation methods.
}

by

Catherine E Merritt

A thesis submitted in conformity with the requirements

for the degree of Doctor of Philosophy

Department of Anthropology

University of Toronto

C) Copyright by Catherine E Merritt 2014 


\title{
The influence of body size on adult skeletal age estimation methods.
}

\author{
Catherine E Merritt \\ Doctor of Philosophy \\ Department of Anthropology \\ University of Toronto
}

2014

\begin{abstract}
When human skeletal remains are found in prehistoric, historic, or forensic contexts, establishing age at death is an important step in reconstructing life histories, building demographic profiles, and identifying victims. Reliability for adult skeletal age estimations is generally lower than ideal, especially for individuals over the age of 40 years. A factor rarely considered in age estimation is that of body size; namely, how individuals of varying body sizes experience skeletal aging. This thesis explores the variables of BMI, stature, and body mass to quantify the influence of error from body size on adult skeletal age estimates.
\end{abstract}

Eight age estimation methods were tested on 764 adult skeletons from the Hamann-Todd and William Bass Collections. These individuals were documented to have ranged in stature from $1.30 \mathrm{~m}$ to $1.93 \mathrm{~m}$ and body mass from $24.0 \mathrm{~kg}$ to $99.8 \mathrm{~kg}$. Each age estimation method was evaluated separately.

Analyses show that underweight individuals have the most error associated with their age estimations for all methods. All methods under-age underweight individuals by 5 to 15 years compared to average and obese individuals. The Kunos et al. method is the most reliable rib method, and the Lovejoy et al. and Suchey-Brooks methods are the most reliable pelvic methods. 
The İşcan et al. fourth rib method under-ages individuals by the highest degree compared to all other methods. The DiGangi et al. method is the most unreliable method with low accuracy (over twenty years) and high bias scores (under-aging individuals by almost 20 years).

Body mass has a stronger influence on age estimation than stature. Studies have shown that body mass has a strong impact on bone resorption and remodelling rates, regardless of nutrition, and that tissue type (i.e. fat vs. muscle), physical activity, and mechanical loading influence bone remodelling. Skeletal remains of underweight individuals have fewer age markers while obese individuals show an increase in surface texture degeneration and osteophytic lipping. This is the first study to show that body size influences skeletal age estimation, and that age estimations are significantly different between weight-bearing and non-weight-bearing joints. 


\section{Acknowledgements}

I am profoundly grateful to the many people who supported me over the course of my doctoral research. First and foremost, I must thank my supervisor, Susan Pfeiffer, who has perfected the art of mentorship. She always made the time to act as a sounding board for my ideas, and, during a critical phase in my writing, she met with me weekly to help keep me motivated. I deeply appreciate her thoughtful responses, her strategic advice, her enthusiastic support, and her words of encouragement. I couldn't have asked for a better supervisor-thank you, Susan.

I also would like to thank my thesis committee members, Tracy Rogers and Shawn Lehman. Tracy's attention to detail and thoughtful comments helped to strengthen the final dissertation. Shawn's statistical expertise and perenial cheerfulness were resources I deeply appreciated as I wrestled with my overwhelming amount of data. As Dolly Parton would say, "If you want the rainbow, you have to put up with the rain."

I would like to acknowledge the sources of funding for my dissertation: Social Sciences and Humanities Research Council of Canada Doctoral Fellowship, University of Toronto Fellowship, General Motor's Women in Mathematics and Science Award, University of Toronto Department of Anthropology Pilot Dissertation Funds, and University of Toronto School of Graduate Studies Travel Grant. Without this support, I would not have been able to do this research.

I am also deeply indebted to the following individuals and institutions for granting me permission to use their collections for this project: Lyman Jellema at the Cleveland Museum of Natural History, Ohio; Lee Meadows Jantz at the University of Tennessee, Knoxville; Sarah Wurz and Petro Keene at the Iziko Museum, Cape Town, South Africa; Johan Binneman at the Albany Museum, Grahamstown, South Africa; James Brink at the National Museum, Florisbad, South Africa; Alan Morris at the University of Cape Town, South Africa; and David Morris at the McGregor Museum, Kimberley, South Africa. I appreciate the many kindnesses you showed me as a visiting scholar, and I appreciate the time you took to orient me to your collections. Many thanks as well to Nancy Tang, who provided invaluable support in data collection at the Cleveland Museum of Natural History. 
The most common metaphor used to describe the $\mathrm{PhD}$ process is a journey. This journey is filled with twists and turns, trials and tribulations, and successes and celebrations. I would like to thank the following people who have made this journey one to remember: Karyne Rabey, Bess Doyle, Jarred Heinrich, Lesley Harrington, Isabelle Guimont, Stephanie Calce, Lelia Watamaniuk, Crystal Forrest, Janie Smith, Nicole Moreau, Michelle Quick, Rachele Labrecque, and The Posse JR. They never stopped believing. I would also like to thank past and present members of the Pfeiffer Lab for their support and feedback on my work throughout this journey.

Finally, thank you to my family who have given me so much love and support through the years: Deborah and Bob Landry, Wayne Merritt, Lorraine Janzen Kooistra and John Kooistra, and my Slywchuk, Merritt, Landry, Janzen, and Kooistra supporters. Thanks especially for your efforts in helping me plan for my career and develop a "critical path." And thank you to Alison Kooistra, my rock through everything.

I dedicate this dissertation to my grandmother, Elizabeth Slywchuk, who taught me that you are never alone when you have a book. 


\section{Table of Contents}

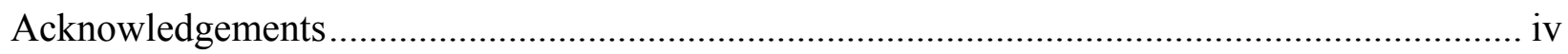

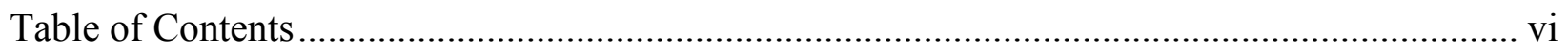

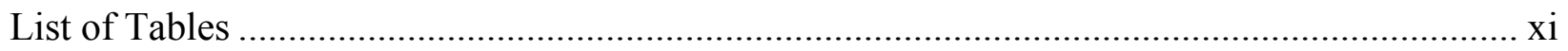

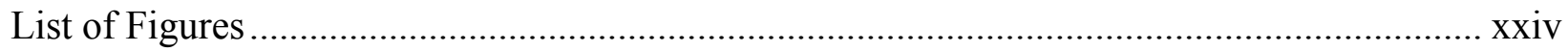

List of Appendices .......................................................................................................

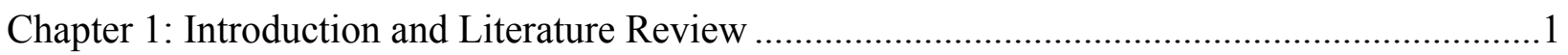

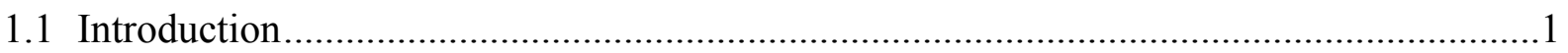

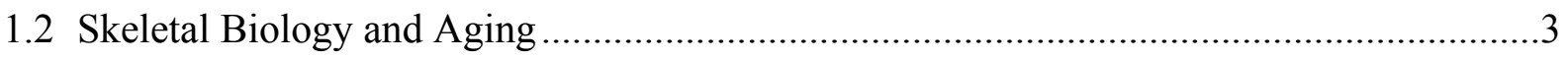

1.2.1 Organic and Inorganic Bone Matrix Aging ………...............................................

1.2.2 Trabecular Bone Aging ..............................................................................

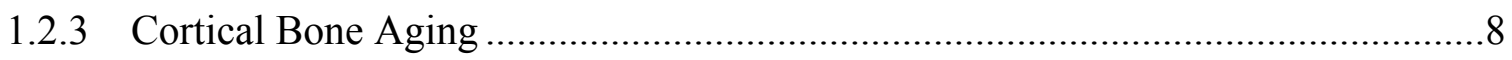

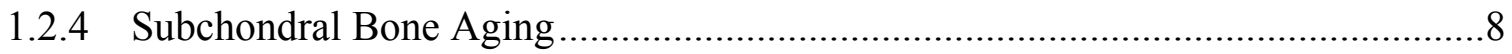

1.2.5 Bone Mineral Content (BMC) and Bone Mineral Density (BMD) ........................9

1.2.6 Summary of Skeletal Aging Processes .................................................................10

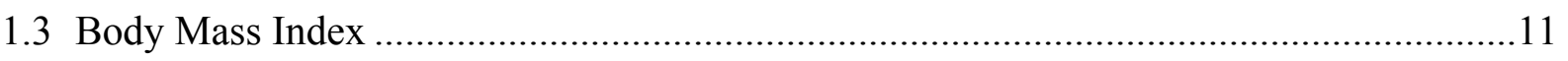

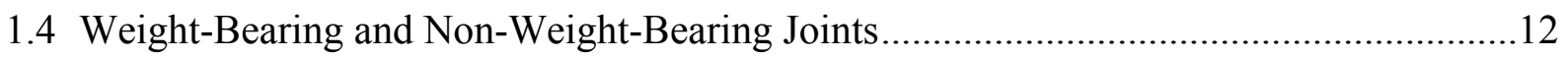

1.5 Adult Skeletal Age Estimation...................................................................................

1.5.1 Adult Age Estimation Using Rib Morphology ....................................................20

1.5.2 Adult Age Estimation Using Sacrum Morphology ...............................................22

1.5.3 Adult Age Estimation Using Auricular Surface Morphology ...............................22

1.5.4 Adult Age Estimation Using Acetabular Morphology …….....................................24

1.5.5 Adult Age Estimation Using Pubic Symphysis Morphology ……………............25

1.6 Application of Body Size to Age Estimation in Paleodemography,

Paleoanthropology, and Forensic Anthropology .........................................................26 
Chapter 2: Materials and Methods

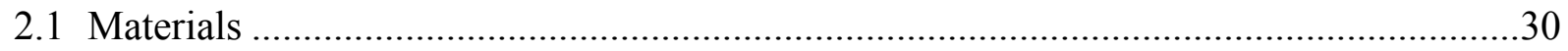

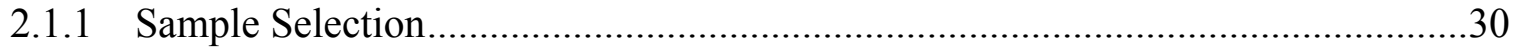

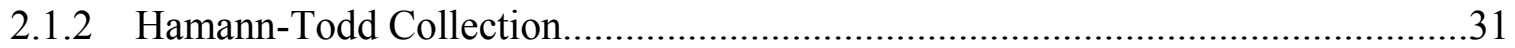

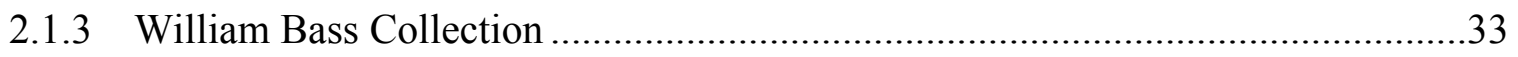

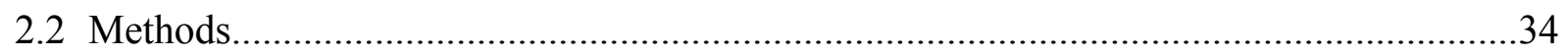

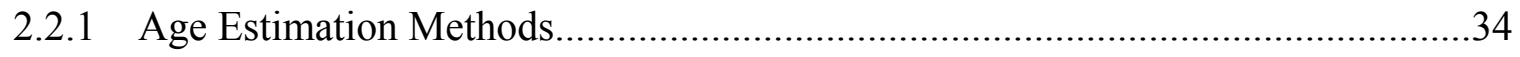

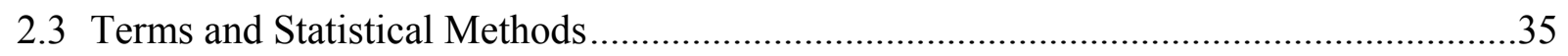

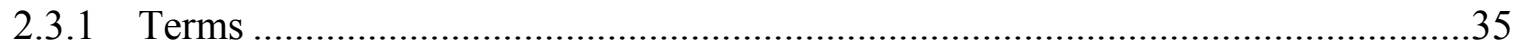

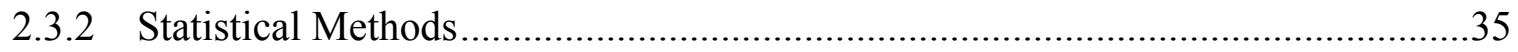

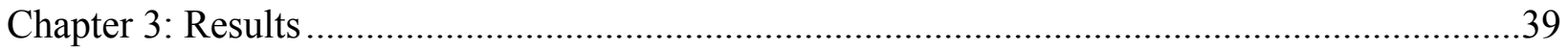

3.1 Comparison of the Individuals from the Hamann-Todd and William Bass Collections ...39

3.1.1 Descriptive Differences Between the Collections ...........................................39

3.1.2 The Combined Sample from the Hamann-Todd and William Bass Collections ...43

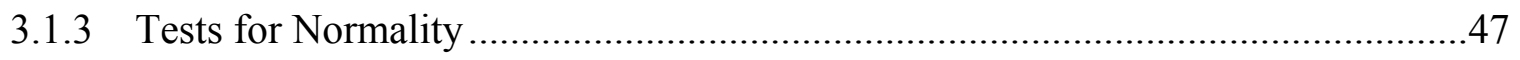

3.2 Tests of the Age Estimation Methods ........................................................................49

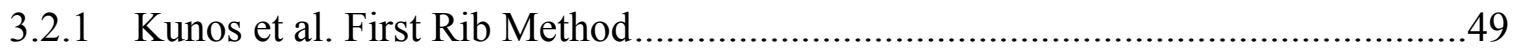

3.2.2 DiGangi et al. First Rib Method ................................................................. 51

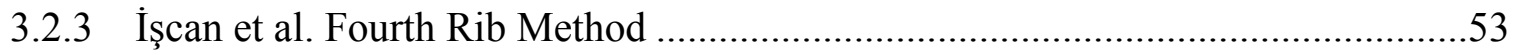

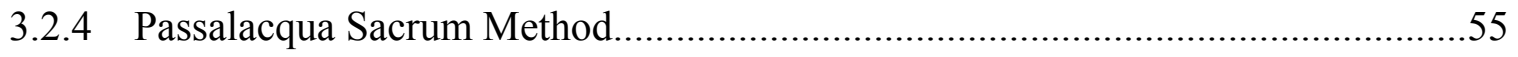

3.2.5 Lovejoy et al. Auricular Surface Method ....................................................57

3.2.6 Buckberry and Chamberlain Auricular Surface Method ....................................60

3.2.7 Rougé-Maillart et al. Acetabulum and Auricular Surface Method......................62

3.2.8 Suchey-Brooks Pubic Symphysis Method ...................................................64

3.2.9 Descriptive Statistics for the Final Sample and Each Age Estimation Method.....66 
3.3 Research Question I: Does BMI influence skeletal age estimation?

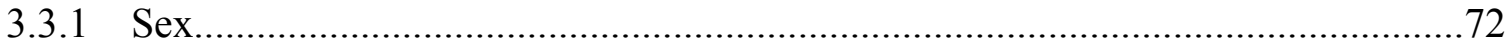

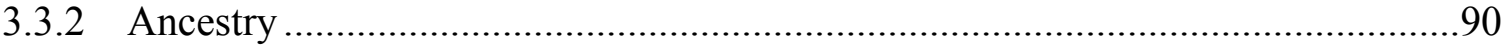

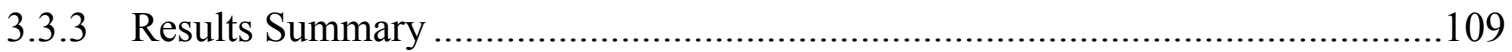

3.4 Research Question II: Does stature influence skeletal age estimation?........................121

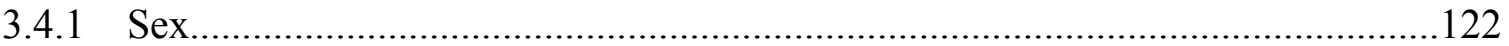

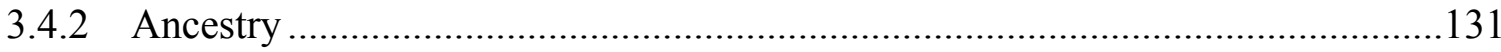

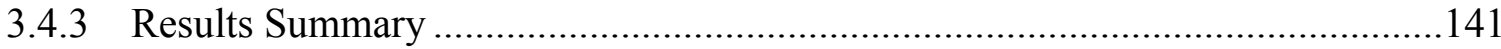

3.5 Research Question III: Does body mass influence skeletal age estimation? ..................150

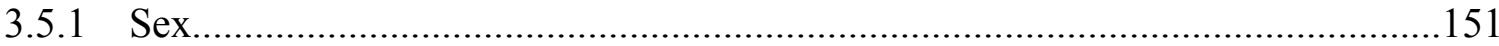

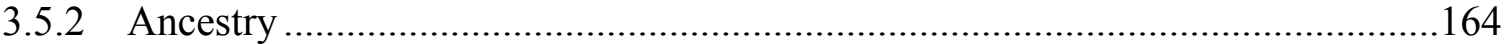

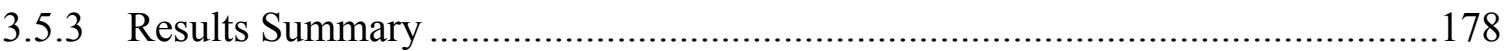

3.6 Research Question IV: Are there differences between non-weight-bearing and

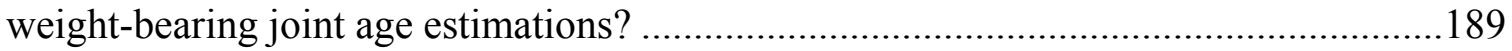

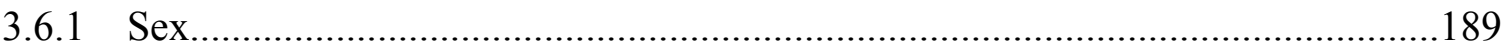

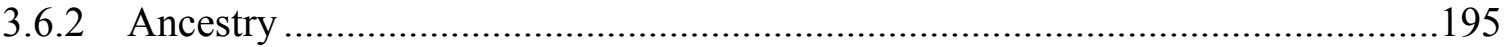

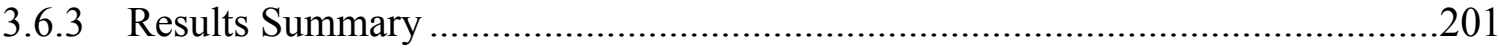

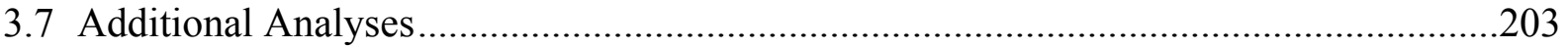

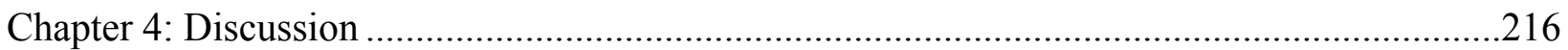

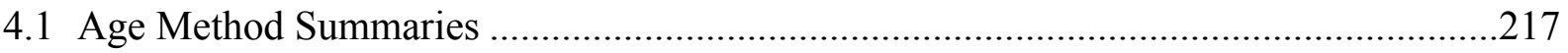

4.1.1 Kunos et al. First Rib Method....................................................................217

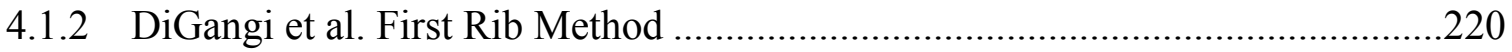

4.1.3 İşcan et al. Fourth Rib Method .....................................................................224

4.1.4 Passalacqua Sacrum Method.............................................................................227

4.1.5 Lovejoy et al. Auricular Surface Method ..................................................229

4.1.6 Buckberry and Chamberlain Auricular Surface Method ..................................232 
4.1.7 Rougé-Maillart et al. Auricular Surface and Acetabulum Method

4.1.8 Suchey-Brooks Pubic Symphysis Method...................................................238

4.2 BMI, Stature, and Body Mass Influence Skeletal Age Estimation................................244

4.2.1 The Influence of Stature on Age Estimation..............................................24

4.2.2 The Influence of Body Mass on Age Estimation...........................................245

4.2.3 The Influence of BMI on Age Estimation .....................................................245

4.2.4 The Influence of Joint Surfaces on Age Estimation .......................................246

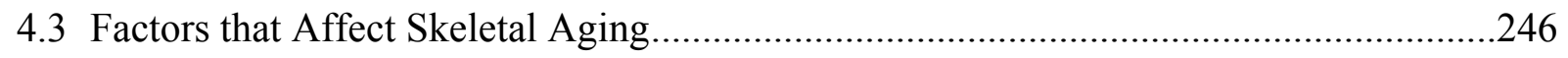

4.3.1 Bone Remodelling Rates and Bone Mineral Density (BMD) ..........................246

4.3.2 Sex and Ancestry Differences in BMD .....................................................247

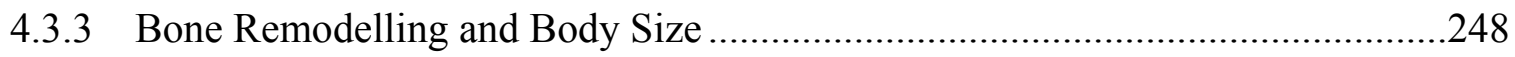

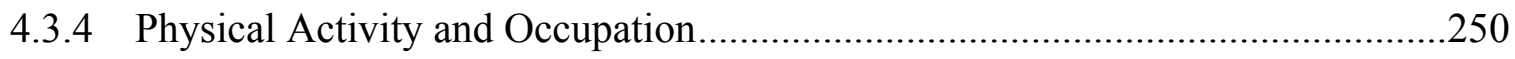

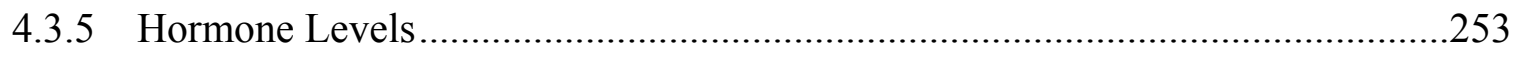

4.4 Implications of Study Results for Paleodemography, Paleoanthropology, and Forensic

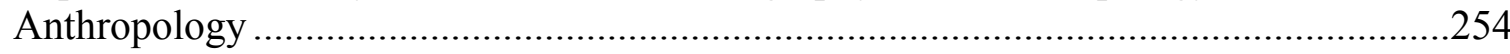

4.5 Estimating Body Size of Skeletal Remains ......................................................255

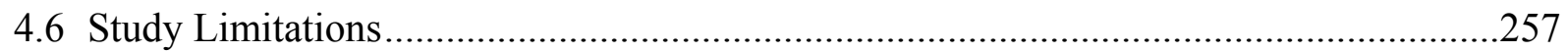

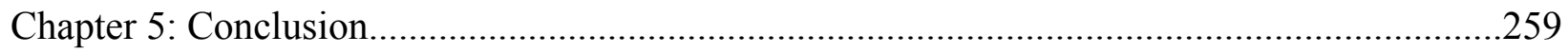

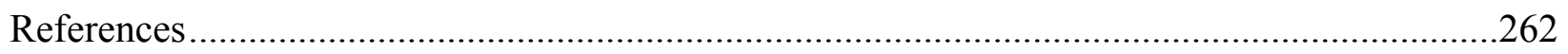

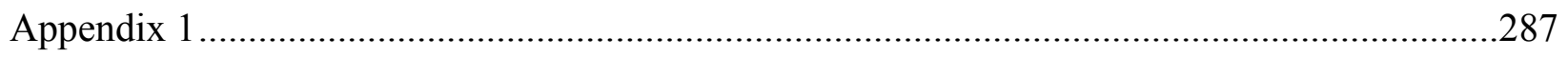

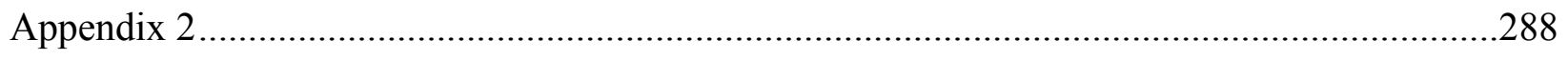

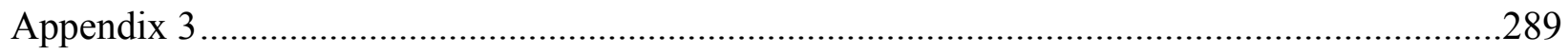

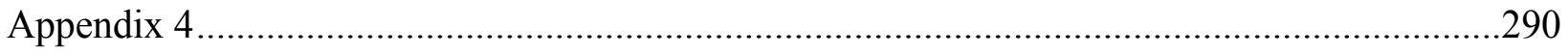

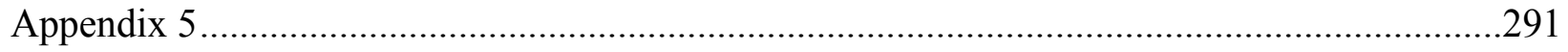

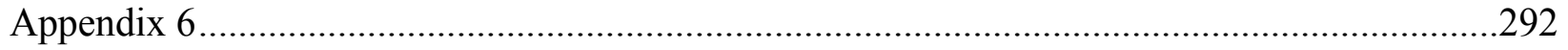

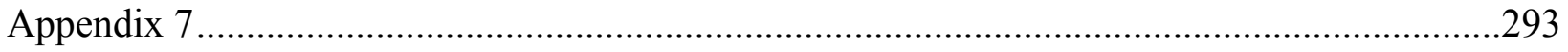


Appendix 8

Appendix 9

Appendix 10 .296

Appendix 11 .297

Appendix 12..

Appendix 13 .

Appendix 14 . .300

Appendix 15 . .301

Appendix 16 . .302

Appendix 17 . .303

Appendix 18 .304

Appendix 19. .305

Appendix 20 .306

Appendix 21. .307

Appendix 22.... .308

Appendix 23 . .309

Appendix 24. 310

Appendix 25.

Appendix 26 .312

Appendix 27 . 


\section{List of Tables}

Table 1: Number of individuals and percentage of samples with ages at death of 60 years or more

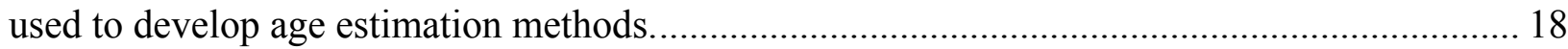

Table 2: List of each age estimation method, composition of the sample used for development, tests of each method, and comments from the literature on each method's overall performance.20

Table 3: Stature and body mass estimations of hominin species. Stature is estimated from long bones, body mass is predicted by femoral head diameter or bi-iliac breadth (adapted from (McHenry, 1992, 2005; Kappelman, 1996; Helmuth, 1998; Holliday, 2002; Ruff, 2010). 29

Table 4: Number of skeletons in 29 stature and mass categories from the Hamann-Todd and William Bass Collections as categorized prior to arriving at the collections. Skeletons were subsequently excluded based on questionable age estimates and inadequate preservation of skeletal elements.

Table 5: Sample distribution of skeletons selected from the Hamann-Todd Collection, including age at death, ancestry, reported stature and body mass at time of death.

Table 6: Sample distribution of skeletons selected from the William Bass Collection, including age, ancestry, reported stature and body mass at time of death.

Table 7: Mann-Whitney U tests for significance for age at death, sex, and ancestry between samples from the Hamann-Todd and William Bass Collections.

Table 8: Number of individuals in each ancestry category for samples from the Hamann-Todd and William Bass Collections.

Table 9: Mann-Whitney $U$ tests for significance between stature and body mass for the samples from the Hamann-Todd and William Bass Collections.

Table 10: Mann-Whitney U Tests showing significant differences among BMI categories between the samples from the Hamann-Todd and William Bass Collections. 
Table 11: Sample distribution by sex, ancestry, and age categories.

Table 12: Distribution of the combined sample by stature and body mass categories. 45

Table 13: Distribution of the combined sample by BMI, including number of individuals in each category, average recorded stature and body mass, and stature and body mass ranges. 46

Table 14: Inaccuracy and bias scores from the Kunos et al. first rib age estimates for males and females. All values are in years.

Table 15: Inaccuracy and bias scores from the Kunos et al. first rib age estimates separated by ancestry. All values are in years.

Table 16: Inaccuracy and bias scores from the DiGangi et al. first rib age estimates for males and females. All values are in years.

Table 17: Inaccuracy and bias scores from the DiGangi et al. first rib age estimates separated by ancestry. All values are in years. 52

Table 18: Inaccuracy and bias scores from the İşcan et al. fourth rib age estimates for males and females. All values are in years.

Table 19: Inaccuracy and bias scores from the İşcan et al. fourth rib age estimates separated by ancestry. All values are in years.

Table 20: Inaccuracy and bias scores from the Passalacqua sacrum age estimates for males and females. All values are in years.

Table 21: Inaccuracy and bias scores from the Passalacqua sacrum age estimates separated by ancestry. All values are in years. 56

Table 22: Inaccuracy and bias scores from the Lovejoy et al. auricular surface age estimates for males and females. All values are in years.

Table 23: Inaccuracy and bias scores from the Lovejoy et al. auricular surface age estimates separated by ancestry. All values are in years. 
Table 24: Inaccuracy and bias scores from the Buckberry and Chamberlain auricular surface age estimates for males and females. All values are in years.

Table 25: Inaccuracy and bias scores from the Buckberry and Chamberlain auricular surface age estimates separated by ancestry. All values are in years.

Table 26: Inaccuracy and bias scores from the Rougé-Maillart et al. acetabulum and auricular surface age estimates for males and females. All values are in years.

Table 27: Inaccuracy and bias scores from the Rougé-Maillart et al. acetabulum and auricular surface age estimates separated by ancestry. All values are in years.

Table 28: Inaccuracy and bias scores from the Suchey-Brooks pubic symphysis age estimates for males and females. All values are in years.

Table 29: Inaccuracy and bias scores from the Suchey-Brooks pubic symphysis age estimates separated by ancestry. All values are in years. 65

Table 30: Final sample distribution by sex, ancestry, and age categories. 67

Table 31: Total number of males, females, and individuals of European and African ancestry.. 68

Table 32: Final number of individuals from 29 stature and body mass categories. 68

Table 33: Sample distribution by BMI for the total number of individuals in the sample. 68

Table 34: Age estimation methods mean age at death, inaccuracy, and bias scores for the final sample of 764 individuals. All age, inaccuracy, and bias values are in years.

Table 35: Differences between original collective sample and new collective sample. All age, inaccuracy, and bias values are in years. 70

Table 36: Pearson Correlations, Means, and Standard Deviations of the accuracy scores for males for each age estimation method for males. P-values are in brackets. 
Table 37: Discriminant function coefficients associated with the MANOVA for males. Note: Raw $=$ unstandardized coefficients, Stand. $=$ standardized coefficients, Struc. $=$ structure coefficients.

Table 38: Means and Standard Deviations for the male canonically derived variables. 75

Table 39: Tukey's $b$ post-hoc test results for male accuracy scores separated by BMI. Note: alpha level $=0.05$ 76

Table 40: Pearson Correlations, Means, and Standard Deviations of the accuracy scores for females for each age estimation method for females. P-values are in brackets. 78

Table 41: Discriminant function coefficients associated with the MANOVA for females. Note: Raw $=$ unstandardized coefficients, Stand. $=$ standardized coefficients, Struc. $=$ structure coefficients.

Table 42: Means and Standard Deviations for the female canonically derived variables 79

Table 43: Tukey's $b$ post-hoc test results for female accuracy scores separated by BMI. Note: alpha level $=0.05$

Table 44:Pearson Correlations, Means, and Standard Deviations of the bias scores for males for each age estimation method for males. P-values are in brackets. 82

Table 45: Discriminant function coefficients associated with the MANOVA for males. Note: Raw $=$ unstandardized coefficients, Stand. = standardized coefficients, Struc. $=$ structure coefficients. 83

Table 46: Means and Standard Deviations for the male canonically derived variables. 84

Table 47: Tukey's $b$ post-hoc test results for male bias scores separated by BMI. Note: alpha level $=0.05$ 85

Table 48: Pearson Correlations, Means, and Standard Deviations of the bias scores for females for each age estimation method for females. 87 
Table 49: Discriminant function coefficients associated with the MANOVA for females. Note: Raw $=$ unstandardized coefficients, Stand. $=$ standardized coefficients, Struc. $=$ structure coefficients.

Table 50: Means and Standard Deviations for the female canonically derived variables 88

Table 51: Tukey's $b$ post-hoc test results for female bias scores separated by BMI. Note: alpha level $=0.05$ 89

Table 52: Pearson Correlations, Means, and Standard Deviations of the accuracy scores for males for each age estimation method for individuals of European ancestry. P-values are in brackets.

Table 53: Discriminant function coefficients associated with the MANOVA for individuals of European ancestry. Note: Raw $=$ unstandardized coefficients, Stand. = standardized coefficients, Struc. $=$ structure coefficients. 92

Table 54: Means and Standard Deviations for the European canonically derived variables 92

Table 55: Tukey's $b$ post-hoc test results for European accuracy scores separated by BMI. Note: alpha level $=0.05$ 94

Table 56: Pearson Correlations, Means, and Standard Deviations of the accuracy scores for each age estimation method for individuals of African ancestry. P-values are in brackets.

Table 57: Discriminant function coefficients associated with the MANOVA for individuals of African ancestry. Note: Raw $=$ unstandardized coefficients, Stand. = standardized coefficients, Struc. $=$ structure coefficients.

Table 58: Means and Standard Deviations for the individuals of African ancestry canonically derived variables.

Table 59: Tukey's $b$ post-hoc test results for individuals of African ancestry accuracy scores separated by BMI. Note: alpha level $=0.05$ 
Table 60: Pearson Correlations, Means, and Standard Deviations of the bias scores for each age estimation method for individuals of European ancestry.

Table 61: Discriminant function coefficients associated with the MANOVA for individuals of European ancestry. Note: Raw $=$ unstandardized coefficients, Stand. = standardized coefficients, Struc. $=$ structure coefficients. 101

Table 62: Means and Standard Deviations for the European canonically derived variables...... 101

Table 63: Tukey's $b$ post-hoc test results for European bias scores separated by BMI. Note: alpha level $=0.05$ 103

Table 64: Pearson Correlations, Means, and Standard Deviations of the bias scores for each age estimation method for individuals of African ancestry. 105

Table 65: Discriminant function coefficients associated with the MANOVA for individuals of African ancestry. Note: Raw = unstandardized coefficients, Stand. = standardized coefficients, Struc. $=$ structure coefficients. 106

Table 66: Means and Standard Deviations for the canonically derived variables for individuals of African ancestry 106

Table 67: Tukey's $b$ post-hoc test results for individuals of African ancestry bias scores separated by BMI. Note: alpha level $=0.05$ 108

Table 68: Inaccuracy scores (in years) for each age-at-death estimation method separated by BMI for males, females, individuals of European ancestry, and individuals of African ancestry. Significant differences are noted by boxes.

Table 69: Bias scores (in years) for each age-at-death estimation method separated by BMI for males and females. Significant differences are noted by boxes. 118

Table 70: Stature group descriptive statistics. 
Table 71: Discriminant function coefficients associated with the MANOVA for males. Note: Raw $=$ unstandardized coefficients, Stand. $=$ standardized coefficients, Struc. $=$ structure coefficients.

Table 72: Means and Standard Deviations for the male canonically derived variables.

Table 73: Tukey's $b$ post-hoc test results for male accuracy scores separated by stature. Note: alpha level $=0.05$

Table 74: Discriminant function coefficients associated with the MANOVA for males. Note: Raw $=$ unstandardized coefficients, Stand. $=$ standardized coefficients, Struc. $=$ structure coefficients.

Table 75: Means and Standard Deviations for the male canonically derived variables. 128

Table 76: Tukey's $b$ post-hoc test results for male bias scores separated by stature. Note: alpha level $=0.05$ 129

Table 77: Discriminant function coefficients associated with the MANOVA for individuals of European ancestry. Note: Raw $=$ unstandardized coefficients, Stand. = standardized coefficients, Struc. $=$ structure coefficients.

Table 78: Means and Standard Deviations for individuals of European ancestry canonically derived variables.

Table 79: Tukey's $b$ post-hoc test results for European accuracy scores separated by stature.

Note: alpha level $=0.05$

Table 80: Discriminant function coefficients associated with the MANOVA for individuals of European ancestry. Note: Raw $=$ unstandardized coefficients, Stand. = standardized coefficients, Struc. $=$ structure coefficients.

Table 81: Means and Standard Deviations for individuals of European ancestry canonically derived variables. 
Table 82: Tukey's $b$ post-hoc test results for European bias scores separated by stature. Note: alpha level $=0.05$.

Table 83: Inaccuracy scores (in years) for each age-at-death estimation method separated by stature for males, females, individuals of European ancestry, and individuals of African ancestry. Significant differences are noted by boxes.

Table 84: Bias scores (in years) for each age-at-death estimation method separated by stature for males, females, individuals of European ancestry, and individuals of African ancestry. Significant differences are noted by boxes.

Table 85: Body mass descriptive statistics. 150

Table 86: Discriminant function coefficients associated with the MANOVA for males. Note: Raw $=$ unstandardized coefficients, Stand. $=$ standardized coefficients, Struc. $=$ structure coefficients.

Table 87: Means and Standard Deviations for the male canonically derived variables. 152

Table 88: Tukey's $b$ post-hoc test results for male accuracy scores separated by body mass. Note: alpha level $=0.05$. 154

Table 89: Discriminant function coefficients associated with the MANOVA for males. Note: Raw $=$ unstandardized coefficients, Stand. $=$ standardized coefficients, Struc. $=$ structure coefficients.

Table 90: Means and Standard Deviations for the male canonically derived variables.

Table 91: Tukey's $b$ post-hoc test results for male bias scores separated by body mass. Note: alpha level $=0.05$

Table 92: Discriminant function coefficients associated with the MANOVA for females. Note: Raw $=$ unstandardized coefficients, Stand. $=$ standardized coefficients, Struc. $=$ structure coefficients. 161

Table 93: Means and Standard Deviations for the female canonically derived variables. 162 
Table 94: Tukey's $b$ post-hoc test results for female bias scores separated by body mass. Note: alpha level $=0.05$ 163

Table 95: Discriminant function coefficients associated with the MANOVA for individuals of European ancestry. Note: Raw $=$ unstandardized coefficients, Stand. = standardized coefficients, Struc. $=$ structure coefficients. 166

Table 96: Means and Standard Deviations for individuals of European ancestry canonically derived variables. 166

Table 97: Tukey's $b$ post-hoc test results for European accuracy scores separated by body mass. Note: alpha level $=0.05$ 167

Table 98: Discriminant function coefficients associated with the MANOVA for individuals of European ancestry. Note: Raw $=$ unstandardized coefficients, Stand. = standardized coefficients, Struc. $=$ structure coefficients. 170

Table 99: Means and Standard Deviations for individuals of European ancestry canonically derived variables.

Table 100: Tukey's $b$ post-hoc test results for European bias scores separated by body mass. Note: alpha level $=0.05$ 172

Table 101: Discriminant function coefficients associated with the MANOVA for individuals of African ancestry. Note: Raw $=$ unstandardized coefficients, Stand. = standardized coefficients, Struc. $=$ structure coefficients. 175

Table 102: Means and Standard Deviations for the canonically derived variables for individuals of African ancestry. 175

Table 103: Tukey's $b$ post-hoc test results for individuals of African ancestry bias scores separated by body mass. Note: alpha level $=0.05$. 177 
Table 104: Inaccuracy scores (in years) for each age-at-death estimation method separated by body mass for males, females, individuals of European ancestry, and individuals of African ancestry. Significant differences are noted by boxes.

Table 105: Bias scores (in years) for each age-at-death estimation method separated by body mass for males, females, individuals of European ancestry, and individuals of African ancestry. Significant differences are noted by boxes.

Table 106: Average accuracy and bias scores for the Non-Weight-Bearing and Weight-Bearing Joint groups. 189

Table 107: Average accuracy scores for the Non-Weight-Bearing and Weight-Bearing Joint groups for males.

Table 108: Paired t-test results for male inaccuracy scores comparing NWB and WB joints separated by BMI, stature, and body mass.

Table 109: Average accuracy scores for the Non-Weight-Bearing and Weight-Bearing Joint groups for females.

Table 110: Paired t-test results for female inaccuracy scores comparing NWB and WB joints separated by BMI, stature, and body mass.

Table 111: Average bias scores for the Non-Weight-Bearing and Weight-Bearing Joint groups for males.

Table 112: Paired t-test results for male bias scores comparing NWB and WB joints separated by BMI, stature, and body mass.

Table 113: Average bias scores for the Non-Weight-Bearing and Weight-Bearing Joint groups for females. 194

Table 114: Paired t-test results for female bias scores comparing NWB and WB joints separated by BMI, stature, and body mass. 194 
Table 115: Average accuracy scores for the Non-Weight-Bearing and Weight-Bearing Joint groups for individuals of European ancestry.

Table 116: Paired t-test results for European accuracy scores comparing NWB and WB joints separated by BMI, stature, and body mass.

Table 117: Average accuracy scores for the Non-Weight-Bearing and Weight-Bearing Joint groups for individuals of African ancestry.

Table 118: Paired t-test results for individuals of African ancestry accuracy scores comparing NWB and WB joints separated by BMI, stature, and body mass.

Table 119: Average bias scores for the Non-Weight-Bearing and Weight-Bearing Joint groups for individuals of European ancestry.

Table 120: Paired t-test results for European bias scores comparing NWB and WB joints separated by BMI, stature, and body mass.

Table 121: Average bias scores for the Non-Weight-Bearing and Weight-Bearing Joint groups for individuals of African ancestry.

Table 122: Paired t-test results for individuals of African ancestry bias scores comparing NWB and WB joints separated by BMI, stature, and body mass.

Table 123: One-way ANOVA results for the Passalacqua sacrum method individual scoring features for BMI groups.

Table 124: Tukey's $b$ post-hoc tests for the Passalacqua method individual scoring features for BMI.

Table 125: One-way ANOVA results for the Passalacqua sacrum method individual scoring features for stature groups.

Table 126: Tukey's $b$ post-hoc tests for the Passalacqua method individual scoring features for stature. 
Table 127: One-way ANOVA results for the Passalacqua sacrum method individual scoring features for body mass groups.

Table 128: One-way ANOVA results for the Buckberry and Chamberlain method individual scoring features for BMI groups.

Table 129: Tukey's $b$ post-hoc tests for the Buckberry and Chamberlain method individual scoring features for BMI.

Table 130: One-way ANOVA results for the Buckberry and Chamberlain method individual scoring features for stature groups.

Table 131: Tukey's $b$ post-hoc tests for the Buckberry and Chamberlain method individual scoring features for stature.

Table 132: One-way ANOVA results for the Buckberry and Chamberlain method individual scoring features for body mass groups.

Table 133: Tukey's $b$ post-hoc tests for the Buckberry and Chamberlain method individual scoring features for body mass.

Table 134: One-way ANOVA results for the Rougé-Maillart et al. method individual scoring features for BMI groups

Table 135: Tukey's $b$ post-hoc tests for the Rougé-Maillart et al. method individual scoring features for BMI.

Table 136: One-way ANOVA results for the Rougé-Maillart et al. method individual scoring features for stature groups.

Table 137: Tukey's $b$ post-hoc tests for the Rougé-Maillart et al. method individual scoring features for stature.

Table 138: One-way ANOVA results for the Rougé-Maillart et al. method individual scoring features for body mass groups. 
Table 139: Tukey's $b$ post-hoc tests for the Rougé-Maillart et al. method individual scoring

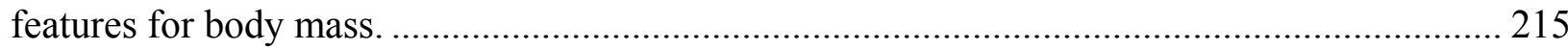

Table 140: Summary of findings for the Kunos et al. method................................................... 220

Table 141: Summary of findings for the DiGangi et al. method. ............................................... 224

Table 142: Summary of findings for the İşcan et al. method....................................................... 227

Table 143: Summary of findings for the Passalacqua method. ................................................... 229

Table 144: Summary of findings for the Lovejoy et al. method................................................. 232

Table 145: Summary of findings for the Buckberry and Chamberlain method. ........................ 235

Table 146: Summary of findings for the Rougé-Maillart et al. method. ..................................... 238

Table 147: Summary of findings for the Suchey-Brooks method............................................. 241

Table 148: Summary of reliability for all age estimation methods separated by body size, sex,

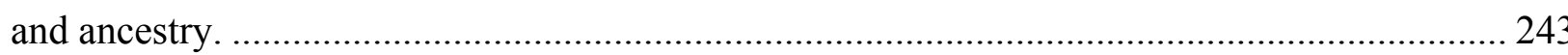




\section{List of Figures}

Figure 1: Age at death distribution for the samples from the Hamann-Todd and William Bass Collections.

Figure 2: Distribution of stature and body mass for the samples from the Hamann-Todd and William Bass Collections

Figure 3: Distribution of BMI categories between the samples from the Hamann-Todd and William Bass Collections. 43

Figure 4: Distribution of the combined sample by stature 45

Figure 5: Distribution of the combined sample by body mass. 46

Figure 6: Histogram showing total sample size by age with a normal distribution curve. 47

Figure 7: Q-Q Plot for Age showing a normal distribution. 48

Figure 8: Detrended normal Q-Q Plot for age showing a normal distribution. 48

Figure 9: Mean bias scores for the Kunos et al. method categorized by age at death. 50

Figure 10: Mean bias scores for the DiGangi et al. method categorized by age at death. 53

Figure 11: Bias scores for the İşcan et al. method categorized by age at death. 55

Figure 12: Mean bias scores for the Passalacqua method categorized by age at death. 57

Figure 13: Mean bias scores for the Lovejoy et al. method categorized by age at death. 59

Figure 14: Mean bias scores for the Buckberry and Chamberlain method categorized by age at death. 62

Figure 15: Mean bias scores for the Rougé-Maillart et al. method categorized by age at death.. 64 
Figure 16: Mean bias scores for the Suchey-Brooks method categorized by known age at death.

Figure 17: Age distribution of individuals by BMI category. Age categories are in years. ......... 71

Figure 18: Distribution of individuals by BMI category for stature and mass............................ 72

Figure 19: Canonically derived centroids for the BMI groups for males.................................... 77

Figure 20: Canonically derived centroids for the BMI groups for females................................. 81

Figure 21: Canonically derived centroids for the BMI groups for males.................................... 86

Figure 22: Canonically derived centroids for the BMI groups for females................................... 90

Figure 23: Canonically derived centroids for the BMI groups for individuals of European

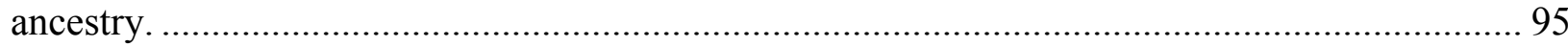

Figure 24: Canonically derived centroids for the BMI groups for individuals of African ancestry.

Figure 25: Canonically derived centroids for the BMI groups for individuals of European ancestry. 104

Figure 26: Canonically derived centroids for the BMI groups for individuals of African ancestry. 109

Figure 27: Mean inaccuracy scores for the age estimation methods categorized by BMI for males.

Figure 28: Mean inaccuracy scores for the age estimation methods categorized by BMI for females.

Figure 29: Mean inaccuracy scores for the age estimation methods categorized by BMI for individuals of European ancestry. 
Figure 30: Mean inaccuracy scores for the age estimation methods categorized by BMI for individuals of African ancestry.

Figure 31: Mean bias scores for the age estimation methods categorized by BMI for males.... 118 Figure 32: Mean bias scores for the age estimation methods categorized by BMI for females. 119 Figure 33: Mean bias scores for the age estimation methods categorized by BMI for individuals of European ancestry. 119

Figure 34: Mean bias scores for the age estimation methods categorized by BMI for individuals of African ancestry. 120

Figure 35: Stature distribution of the sample by age at death. Lines demarcate cluster analysis cut-off points. 121

Figure 36: Canonically derived centroids for the stature groups for males. 125

Figure 37: Canonically derived centroids for the stature groups for males. 130

Figure 38: Canonically derived centroids for the stature groups for individuals of European ancestry.

Figure 39: Canonically derived centroids for the stature groups for individuals of European ancestry. 140

Figure 40: Mean inaccuracy scores for the age estimation methods categorized by stature for males.

Figure 41: Mean inaccuracy scores for the age estimation methods categorized by stature for females.

Figure 42: Mean inaccuracy scores for the age estimation methods categorized by stature for individuals of European ancestry.

Figure 43: Mean inaccuracy scores for the age estimation methods categorized by stature for individuals of African ancestry. 
Figure 44: Mean bias scores for the age estimation methods categorized by stature for males. 148

Figure 45: Mean bias scores for the age estimation methods categorized by stature for females.

Figure 46: Mean bias scores for the age estimation methods categorized by stature for individuals of European ancestry. 149

Figure 47: Mean bias scores for the age estimation methods categorized by stature for individuals of African ancestry

Figure 48: Body mass distribution of the sample by age at death. Lines demarcate cluster analysis cut-off points. 150

Figure 49: Canonically derived centroids for the body mass groups for males. 155

Figure 50: Canonically derived centroids for the body mass groups for males. 160

Figure 51: Canonically derived centroids for the body mass groups for females. 164

Figure 52: Canonically derived centroids for the body mass groups for individuals of European ancestry. 168

Figure 53: Canonically derived centroids for the body mass groups for individuals of European ancestry. 173

Figure 54: Canonically derived centroids for the body mass groups for individuals of African ancestry.

Figure 55: Mean inaccuracy scores for the age estimation methods categorized by body mass for males. 181

Figure 56: Mean inaccuracy scores for the age estimation methods categorized by body mass for females. 181

Figure 57: Mean inaccuracy scores for the age estimation methods categorized by body mass for individuals of European ancestry. 182 
Figure 58: Mean inaccuracy scores for the age estimation methods categorized by body mass for

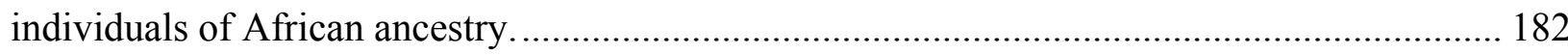

Figure 59: Mean bias scores for the age estimation methods categorized by body mass for males.

Figure 60: Mean bias scores for the age estimation methods categorized by body mass for females.

Figure 61: Mean bias scores for the age estimation methods categorized by body mass for individuals of European ancestry. 188

Figure 62: Mean bias scores for the age estimation methods categorized by body mass for individuals of African ancestry. 188 


\section{List of Appendices}

Appendix 1: Stature and body mass distribution of the Hamann-Todd Collection.

Appendix 2: Stature and body mass distribution of the William Bass Collection..... 288

Appendix 3: Stature and body mass distribution of the final sample selected from the Hamann-

Todd Collection. 289

Appendix 4: Stature and body mass distribution of the final sample selected from the William

Bass Collection. 290

Appendix 5: Descriptive statistics for the Kunos et al. method. 291

Appendix 6: Descriptive statistics for the DiGangi et al. method. 292

Appendix 7: Descriptive statistics for the İşcan et al. method.

Appendix 8: Descriptive statistics for the Passalacqua method. 294

Appendix 9: Descriptive statistics for the Lovejoy et al. method. 295

Appendix 10: Descriptive statistics for the Buckberry and Chamberlain method. 296

Appendix 11: Descriptive statistics for the Rougé-Maillart et al. method.

Appendix 12: Descriptive statistics for the Suchey-Brooks et al. method. 298

Appendix 13: Covariance matrix for males separated by BMI for accuracy scores. 299

Appendix 14: Covariance matrix for males separated by BMI for bias scores. 300

Appendix 15: Covariance matrix for females separated by BMI for bias scores.

Appendix 16: Covariance matrix for individuals of European ancestry separated by BMI for accuracy scores. 
Appendix 17: Covariance matrix for individuals of European ancestry separated by BMI for bias scores.

Appendix 18: Covariance matrix for individuals of African ancestry separated by BMI for bias scores 304

Appendix 19: Covariance matrix for males separated by stature for accuracy scores. 305

Appendix 20: Covariance matrix for individuals of European ancestry separated by stature for accuracy scores. 306

Appendix 21: Covariance matrix for males separated by body mass for accuracy scores. 307

Appendix 22: Covariance matrix for females separated by body mass for accuracy scores...... 308

Appendix 23: Covariance matrix for males separated by body mass for bias scores. 309

Appendix 24: Covariance matrix for individuals of European ancestry separated by body mass for accuracy scores 310

Appendix 25: Covariance matrix for individuals of African ancestry separated by body mass for accuracy scores. 311

Appendix 26: Covariance matrix for individuals of European ancestry separated by body mass for bias scores. 312

Appendix 27: Covariance matrix for individuals of African ancestry separated by body mass for bias scores. 


\section{Chapter 1: Introduction and Literature Review}

\subsection{Introduction}

When human skeletal remains are found in prehistoric, historic, or forensic contexts, establishing age at death is an important step to reconstruct life histories, build demographic profiles, and identify victims of mass disasters, genocides, and homicides. The most common methods used to estimate age at death are based on changes to dental and skeletal features; these indicators provide relatively accurate and precise age estimations for juveniles who died during the period of growth and development (Crowder and Austin, 2005; Cameriere and Ferrante, 2008; Cardoso, 2008 a; b; Lee et al., 2008; Meinl et al., 2008), but are less accurate and precise for adult age estimations (Saunders et al., 1992; Bednarek and Sliwka, 2004; Martrille et al., 2007; Storey, 2007; Dorandeu et al., 2008; Konigsberg et al., 2008; Meinl et al., 2008).

The age phases of adult age estimation methods follow a typical pattern: the younger phases tend to have smaller age ranges because they are based on clear, time-limited indicators of the maturation processes, while the older phases tend to have larger age ranges because they are based on degenerative and remodelling processes. The changes associated with maturation occur in a fairly predictable pattern until individuals reach the age of 40 years; once over the age of 40 years, degenerative changes are not always associated with specific stages of aging and ages are more difficult to assess (Falys and Lewis, 2011). The reliance on degenerative processes to assess adult age at death results in two main problems: first, the age categories of current protocols are very inclusive for older individuals (e.g. "24-92 years"), and are often vague (e.g. "60+"); second, while methods tend to work well on the collections on which they were developed, they fail to work as well on other cadaver or archaeological collections (Bedford et al., 1993; Bocquet-Appel and Masset, 1996).

The most commonly used age estimation standards were developed using skeletons of varying body sizes from North American skeletal collections without controlling for body size. Often, when our age standards are applied to early populations of Homo sapiens, as well as our hominin ancestors, the trend shows a higher than expected young adult mortality, i.e., their adult ages at death are between 20 and 35 years of age (Storey, 2007; Roksandic and Armstrong, 2011). If 
body size does play a role in adult age estimation, and, for example, individuals with smaller body sizes have different patterns of aging compared with average or heavier individuals, then we may need to reconsider the mortality curves of small bodied hominin and Homo sapiens ancestors. The interaction between body size and skeletal aging has been largely neglected, yet it could be highly relevant to our reconstruction of the population history of our species.

In all biological studies of whole organisms it is important to control for body size (i.e. stature, body mass, body mass index [BMI]) when analyzing and interpreting data (Stillwell et al., 2011); however, in biological anthropology, age estimation studies have not systematically considered body size as a variable that could influence our standards. Understanding how the predicted modifications of joints that occur during the skeletal aging process differ among individuals with varying statures and body masses may help explain some of the unattributed variance in skeletal age estimations. For example, do individuals of the same stature but different body masses show the same patterns of skeletal aging? Similarly, do individuals of the same body mass but different statures show the same patterns of skeletal aging?

This thesis will quantify the influence of body size on individual adult skeletal age estimation methods, using current standard assessment methods, with the goal of determining the ways in which body size affects skeletal aging. The central research questions are:

(1) Does the body mass index influence skeletal age estimations?

(2) Does stature influence skeletal age estimations?

(3) Does body mass influence skeletal age estimations?

(4) Are there differences between non-weight-bearing and weight-bearing joint age estimations?

The study sample includes 764 adult skeletons with a broad range of sizes. The skeletons are from the Hamann-Todd Collection and the William Bass Collection, two North American skeletal collections of known individuals with documented age, sex, stature, body mass, and cause of death. Eight age estimation methods were used for this project: the Kunos et al. (1999) first rib method, the DiGangi et al. (2009) first rib method, the İşcan et al. $(1984,1985)$ fourth rib method, the Passalacqua sacrum method (2009), the Lovejoy et al. (1985) auricular surface 
method, the Buckberry and Chamberlain (2002) auricular surface method, the Rougé-Maillart et al. (2009) auricular surface and acetabulum method, and the Suchey-Brooks (1990) pubic symphysis method. These age estimation methods were selected based on element preservation, and how often researchers reported using certain age estimation methods (to be explained further in Section 1.5).

\subsection{Skeletal Biology and Aging}

The process of skeletal aging is universal and cumulative, but age-related processes show great variation among individuals and populations in the level and degree of change. Individual biological aging is determined by a complex set of ongoing interactions among genes, culture, health, and environment that contribute to their specific life history, and this variation has significant effects on an individual's chronological age at death assessment (Harper and Crews 2000). The relationship between chronological age and biological age is neither constant nor linear, which is the reason adult age at death cannot be estimated with great accuracy from skeletal data (Cox, 2000). This is not to discount the fact that, indeed, changes to the skeleton are related to chronological age; however, researchers must take into account that this relationship is influenced by factors that are difficult to assess in a linear equation, Bayesian statistic, or morphological feature. Most adult age estimation methods are based on maturation and degenerative forces acting on the particular skeletal feature being examined; for example, methods assessing the pubic symphysis, auricular surface, acetabulum, sacrum, first rib, or fourth rib are based primarily on the ossification or breakdown of features that occur as an individual ages. These maturational changes occur in a fairly predictable, yet variable, pattern until individuals reach the age of 40 years; however, over the age of 40 years, degenerative changes tend to be difficult to assess and are not always associated with specific stages of aging (Franklin, 2010).

The skeleton is a dynamic organ that provides the foundation for a number of mechanical and homeostatic functions, including the protection of internal organs, locomotion and load-bearing, haematopoiesis, and it is the reservoir for calcium homeostasis (Boskey and Coleman, 2010). As a person ages, these functions can become impaired, bone becomes more fragile and less able to perform its mechanical functions, and the calcium stores can become depleted (Chan and Duque, 
2002); however, the factors that control these aging processes are variable and are not completely understood.

Bone has a hierarchical structure: at the level of the skeleton, there are different types of boneslong, short, flat, irregular, and sesamoid; at the tissue level, bone is arranged into cortical (compact), trabecular (cancellous), and subchondral structures; at the microscopic level, bone consists of organic and inorganic matrices; and at the nanometer level, the individual mineral crystals and collagen fibrils are woven together to form a triple helix (Boskey and Coleman, 2010). The composition of bone varies with species, tissue site, health and disease, body size, and age, but it is the variation with age at both the micro- and macro-level in humans that is the focus of this thesis.

There are four major types of bone cells: chondrocytes, osteoblasts, osteocytes, and osteoclasts. Of these four, three are of mesenchymal cell origin: chondrocytes, osteoblasts, and osteocytes. Chondrocytes are the cells that deposit the growth plate and are responsible for its subsequent remodelling; osteoblasts are the cells that synthesize the bone matrix and facilitate the mineralization process; and osteocytes are the cells that respond to load and regulate bone resorption and formation (Adachi et al., 2009). Osteoclasts, on the other hand, are of hematopoietic origin. They are large, multinucleated cells responsible for removing bone (resorption) following signals from osteoblasts and osteocytes (Bar-Shavit, 2007). In studies using animal models, older animals have impaired osteoclast differentiation compared to younger animals, and the relative rates of bone removal in older animals far exceeds the rates of new bone formation (Cao et al., 2005, 2007; Pietschmann et al., 2007). Similarly, a study using bovine bone in vitro has shown that osteoclast resorption occurs at a much higher rate on older bone than on young bone, indicating that older bone may be preferentially selected for resorption (Henriksen et al., 2007). Compounded with the increased osteoclast resorption of older bone cells, as an individual ages, the amount of bone deposited by osteoblasts decreases with each cycle of remodelling (Lee et al., 2005; Szulc and Seeman, 2009); therefore, the rate of bone removal occurs faster than bone deposition throughout the aging process. All older humans experience this shift in tissue balance, but the shift presents most clearly in post-menopausal women (Kaptoge et al., 2003). 
All normal cells in the human body, including the bone cells, have a limited lifespan. The Hayflick limit of cell division has shown that cells can only undergo a certain number of divisions and replications (i.e. mitosis) before mistakes occur (Hayflick, 1965). As an individual ages, cell divisions and replications begin to accumulate errors at the ends of chromosomes (telomeres); each time a cell undergoes mitosis, the telomeres decrease in length because of the cell's inability to fully replicate in this region, and after an unknown number of divisions and replications (determined by genetic, health, and environmental factors), the telomere length reaches a point where the errors begin to jeopardize the stability of the cell (Calado, 2009). Age estimation methods using telomere length have been developed but they are still in the testing phase (Meissner and Ritz-Timme, 2010).

Not only do cells have a limited number of divisions and replications, studies have shown that cell differentiation and proliferation is age dependent. Jiang et al. (2008) used a sample of 80 patients between the ages of 15 and 79 years to examine the potential of bone marrow stem cells to differentiate into chondrocytes, osteoblasts, or osteoclasts by measuring changes in the gene expression of major lineage-defining factors. Their data suggest that aging affects gene expressions differently, and that as a person ages, the lineage of bone marrow cells is modified. These modifications include a decrease in bone marrow osteoblastogenesis and an increase in osteoclastogenesis, corroborating evidence that bone resorption occurs at a faster rate than bone deposition in older individuals. Similarly, Zhou et al. (2008) report age-related decreases in osteoblast proliferation and differentiation in human cells both in vivo and in vitro, as well as an increase in cell apoptosis in older individuals.

Apoptosis, programmed cell death, is a regulatory mechanism in most tissues and it plays a role in normal tissue maintenance. When apoptosis becomes dysregulated, this can cause an imbalance between bone resorption and formation, as well as cause changes in tissue mechanical properties in the affected areas (Carrington, 2005). Studies have found that osteocyte apoptosis increases with tissue age, causing a weakening of the bone independent of bone mineral density (BMD). Jilka et al. (2007) and Manolagas and Parfitt (2010) have postulated that this occurs through two mechanisms. First is the process of micropetrosis, a bone condition associated with aging where the canaliculae and empty lacunae are filled with mineralized tissue instead of bone matrix after osteocyte apoptosis has occurred; although this increases the fragility of bone, it 
does not decrease BMD. An early study by Frost (1960) found that almost no micropetrosis exists at birth, whereas an average of $15 \%$ of the volume of bone from patients over the age of 70 years was micropetrotic; in three cases, $40 \%$ of the volume was micropetrotic. The second process is the disruption of the canalicular system by apoptosis, thereby decreasing the repair of microcracks. The canaliculi are responsible for communication between the bone cells, and once this system becomes disrupted, responses to events such as microcracks are impaired.

\subsubsection{Organic and Inorganic Bone Matrix Aging}

The organic matrix of bone accounts for $35 \%$ of the dry mass of bone. Ninety percent of this dry body mass consists of protein collagen, mainly type I, and approximately 5\% consists of noncollagenous proteins (Chan and Duque, 2002). Type 1 collagen is the most abundant protein collagen in the body, comprising about $36 \%$ of the volume of compact bone, and of all the collagen types it has the lowest rate of turnover during remodelling (Collins et al., 2002). Collagen gives the bone structure its flexibility, and it is this flexibility that provides resistance to impact loading, and serves as a template for the oriented deposition of mineral crystals. Collagen is secreted from the osteoblasts as triple-helix fibrils which self-associate to form larger fibrils and then fibers. The three helixes are held together by hydrogen bonds, giving collagen much of its stability and elasticity (Collins et al., 1995).

Collagen helixes are bonded together through cross-links, and they vary with age. There are two different types of cross-links: enzyme and non-enzyme cross-links. The enzyme cross-links are originally formed by two enzymes, lysyl hydroxylase and lysyloxidase, and they connect the Nor C-terminus of one collagen molecule to the helical region of another. Once catalyzed, they become pyridinoline (PYD) and pyrrole (PYL) cross-links, and this increases the stiffness of the collagen molecule (Vashishth et al., 2001). The increased presence of PYD and PYL in blood or urine typically signifies the degradation of bone, and this begins to occur in older individuals (Samma et al., 1997). The non-enzyme cross-links are formed by glycation or oxidation induced non-enzymatic processes, and the presence of advanced glycation endproducts (AGEs) increase as the collagen molecules age. The formation and accumulation of AGEs have been implicated in the progression of age-related diseases (Tan et al., 2006) 
Studies investigating the relationship between aging and collagen cross-links using human samples (Viguet-Carrin et al., 2010) and bovine samples (Tang et al., 2007) report that the rate of enzymatic cross-linking decreases with age while the non-enzymatic cross-linking increases with age. With the collagen fibers at the terminus ends of the molecule becoming weaker, combined with the increasing number of AGEs, the accumulated effect is a decrease in bone strength and toughness and, ultimately, decreased resistance to crack propagation. Viguet-Carrin et al.'s (2010) study also found evidence to suggest that the accumulated AGEs within bone tissue can only be removed by bone resorption, and their presence increases osteoclast activity while decreasing formation by osteoblasts, thereby contributing to the fragility of bone with increasing age.

The organic matrix of bone also contains non-collagenous proteins that are synthesized and secreted by osteoblasts, and they produce, nurture, and remodel the extracellular matrix by responding to mechanical and homeostatic signals. Decreased non-collagenous protein production is associated with aging (Grynpas et al., 1994; Kloss and Gassner, 2006). Grynpas and colleagues (1994) compared the composition of proteins in the trabecular bone of the femoral neck from individuals of varying ages, and their results showed that individuals under the age of 40 years had more extracellular bone matrix proteins than individuals over the age of 50 years, and that there was an increase in bone matrix protein fragments in the older group. As an individual ages, non-collagenous proteins decrease in number, thereby impairing their ability to respond to mechanical and homeostatic signals.

The inorganic matrix of bone accounts for approximately $65 \%$ of its dry body mass and consists primarily of calcium hydroxyapatite and osteocalcium phosphate, or brushite (White and Folkens, 2000). In bone, the collagen triple helix is interspersed with the inorganic matrix of hydroxyapatite and brushite and gives bone its strength (in other cells of the body, the triple helix is interspersed with water). During the process of growth and development, the mineral content of bone increases until the age of 30 to 35 years, and studies have shown that as an individual ages, the breaking stress of bone increases exponentially with mineral content while the toughness of bone declines, thus making the bone more brittle and less resistant to fractures (Currey, 1969; Zioupos and Currey, 1998; Manjubala et al., 2009). These results are confirmed with BMD; BMD measurements have been compared using a variety of techniques for a variety 
of species, demonstrating the increase in mineral content during growth and development, and the decline with later aging (Cerroni et al., 2000; Somerville et al., 2004).

\subsubsection{Trabecular Bone Aging}

A decrease in trabecular bone volume and the number of connectivity networks along with the increase in trabecular bone microcracks have been well documented in older individuals (Parfitt et al., 1983; Bergot et al., 1988; Mosekilde, 1998). These changes are due to a variety of factors, including hormones, nutrition, health, and physical activity. Furthermore, in post-menopausal women, there is a reduction in estrogen levels, which leads to slower bone remodelling (Kaptoge et al., 2003). Ascádi and Nemeskéri (1970) and Szilvassy and Kritscher (1990) proposed methods of age estimation using trabecular bone involution; however, these methods have been proven unreliable (Walker and Lovejoy, 1985; Gehring et al., 2002; Jones, 2003) and they are not widely used by biological anthropologists (Falys and Lewis, 2011; Garvin and Passalacqua, 2012).

\subsubsection{Cortical Bone Aging}

In addition to a decrease in overall trabecular bone in older individuals, there is also a decrease in overall cortical bone (McCalden et al., 1993). As an individual ages, the decrease in cortical bone is primarily attributed to resorption on the endosteal surface, which occurs at a faster rate than periosteal growth (Tsuboyama et al., 1989). This loss of cortical bone manifests itself both by texture and body mass. With age, a bone becomes more brittle, the texture becomes roughened, there is an increase in porosity, and the bone is lighter in body mass. These agerelated changes to cortical bone occur on a spectrum, and because there is so much variation in the timing of these events, predicting age at death from skeletal markers is a difficult task. Most adult age estimation methods are based on changes to the periosteal surface of the bone, and the degenerative forces acting on the skeletal features are assessed.

\subsubsection{Subchondral Bone Aging}

Subchondral bone is found immediately deep to the articular cartilage of a synovial joint surface. It is a complex structure comprising of two mineralized layers; one of calcified cartilage and the other of osseous material. Collagen fibrils from the non-calcified cartilage extend into the 
calcified cartilage to create a strong bond between the two layers. The calcified cartilage extends towards the marrow cavity where it is remodelled and replaced by woven/lamellar bone. These layers of lamellar bone are stacked like sheets rather than latticed like the structure of the supporting trabecular bone below. Subchondral bone is highly vascularized with many nerves and blood vessels nourishing the joint tissues (Madry et al., 2010). With age, and the effects of loading, synovial joints are subject to osteoarthritis, a degenerative process resulting in the loss of cartilage and sclerosis of the underlying subchondral bone (Cox et al., 2013). The subchondral bone volume and trabecular thickness significantly increase as cartilage degenerates, while the number of trabecular strata and degree of trabecular bone separation decrease (Bobinac et al., 2003).

\subsubsection{Bone Mineral Content (BMC) and Bone Mineral Density (BMD)}

Bone mineral content (BMC) is the amount of mineral in one gram of bone. BMD is the amount of BMC measured in one square centimetre of bone (Anon, 2012). The most common method of measuring BMD is dual energy x-ray absorptiometry (DXA or DEXA), a scan where x-ray beams are projected onto the area in question (typically the spine or hip), and BMD and BMC can be calculated (Anon, 2012). BMD is one of the most common variables studied in relation to body size, especially in older individuals where loss of BMD results in osteoporosis and increased rates of fractures. BMD is used to assess the strength of bones. As an individual ages, bone becomes thinner with the increase in osteoclast resorption and decrease in osteoblast deposition (described in Section 1.2.1). As a result, the mineral concentration decreases, causing the bone to become light in body mass, less dense, and more fragile, and these factors can be assessed with skeletal age estimation methods. However, it is well documented that there is a positive relationship between body mass and BMD; as body mass increases, there is increased mechanical stress on bone, resulting in decreased bone resorption and higher BMD in heavier individuals (Felson et al., 1993; Looker et al., 2001; Lim et al., 2004).

Studies have shown that the correlations between BMD and age, and BMD and body mass are similar (Felson et al., 1993; Britz et al., 2009), suggesting that body mass is just as important as age when predicting BMD. For individuals categorized as having a normal BMI, BMD decreases with age, and they will exhibit the age related changes of increased fragility, loss of bone mass, and decreased bone density. However, for individuals with an obese BMI, BMD is maintained or 
even increased (Felson et al., 1993; Albala et al., 1996); therefore, heavier individuals may not exhibit the age related changes of decreased fragility, body mass, and bone density, suggesting that body mass is an important variable to consider in age estimation. Conversely, recent studies have shown that men and women with high BMIs have low BMD scores (Zhao et al., 2008; Greco et al., 2010).

A study by Britz et al. (2009) investigated the relationship of osteon size to stature and body mass. Using a sample of 87 femora sections and controlling for sex and age, the authors found that body mass has a positive significant effect on osteon size, but stature does not. When the effect of BMI on osteon size was calculated, the trend was less significant. The authors suggest that inhibitory activity of osteoclasts reduces the diameter of bone multicellular unit (BMU) resorptive areas, thus maintaining the integrity of the bone. Research by van Oers et al. (2008) found an inverse relationship between osteon size and bone strain, which might provide a partial explanation for Britz et al.'s findings. One of the limitations of using skeletal materials is the inability to account for lean body mass (LBM) vs. fat mass (FM). As the authors point out, although both LBM and FM contribute to the mechanical loading of the skeleton, FM has an additional effect on bone (Britz et al., 2009). As body mass in the form of FM increases, bone mass increases through a series of endocrine changes, a plausible explanation for increased osteon size in heavier individuals who have more FM, and supports previous studies on the relationship between body size and BMD.

\subsubsection{Summary of Skeletal Aging Processes}

Age changes in bone at the micro-level are a complex interaction between bone cells and the organic and inorganic matrix. As an individual ages, osteocyte apoptosis in bone tissue becomes more probable. Bone cell differentiation is modified with age, and there is an increase in the number of osteoclasts and decrease in the number of osteoblasts produced. This impaired cell differentiation increases the relative rates by which bone is removed and decreases the rates by which new bone is formed. Compounded with this, evidence suggests that older bone may be targeted for resorption and the amount of bone deposited by osteoblasts decreases with each cycle of remodelling. Part of this targeting of older bone for osteoclast resorption may have to do with the increase in AGEs in the collagen protein, which can only be removed by osteoclasts. Increased osteoclast activity vacates a number of lacunae, and often these spaces become filled 
with mineral content, thus increasing the breaking stress and decreasing the toughness of the bone, causing the bone to become more brittle and less resistant to fractures. These changes at the micro-level occur in trabecular, cortical, and subchondral bone. The age changes expressed at the cellular level are also expressed at the surface level, and these are the changes that are being evaluated when assessing skeletal age.

For skeletal age estimation studies, it is important to remember that bone aging does not occur in a vacuum - cartilage, connective tissue, and bone are one functioning unit with inter-related cell types, and these changes are influenced by external and internal factors, including body mass and BMI.

\subsection{Body Mass Index}

Body size plays an important role in many physiological functions, and should also be considered as a potential factor influencing our age estimation methods. Body size in this study will be measured by stature, body mass, and body mass index (BMI). Stature and body mass were recorded post-mortem, while BMI was calculated using these two measurements. BMI was calculated for each individual using the formula:

$$
\frac{\text { body mass }(\mathrm{kg})}{\text { stature }(\mathrm{m})^{2}}
$$

where an individual's body mass is divided by stature squared in order to estimate body fat (Keys, 1972). Calculations for BMI classify individuals into one of four main categories, with the cut-off points in this study based on the World Health Organization (WHO) standards (World Health Organization, 2013): underweight $(<18.49)$, normal (18.50 to 24.99), overweight (25.00 to 29.99), or obese (>30.00).

A potentially problematic area with BMI is ancestry. BMI was developed on individuals of European ancestry from North America, and its applicability to other populations has been questioned. It has been acknowledged that BMI calculators do not work as well for individuals of African, Asian, and Pacific Island ancestries (Jackson et al., 2002; Rush et al., 2009); however, there are no recognized standards available to account for these variations. The WHO conducted an international expert consultation in 2002 to review the applicability of the BMI calculator to other populations, specifically Asia and the Pacific Islands; they concluded that, based on the 
incidence of type 2 diabetes and cardiovascular disease in each BMI group, the current standards in use are applicable to all populations (WHO Expert Consultation, 2004).

BMI is not always the best measure of body fat composition. Since the BMI formula depends only upon stature and body mass, the assumptions made about the distribution between lean mass and fat tissue are only an approximation. BMI generally overestimates body fat on those with more lean body mass and underestimates excess body fat on those with less lean body mass (Romero-Corral et al., 2008). A study by Romero-Corral and colleagues (2008) examined 13,601 individuals from the United States' third National Health and Nutrition Examination Survey and report that BMI obesity (BMI > 30) was present in $21 \%$ of men and $31 \%$ of women. Using body fat percentages $(\mathrm{BF} \%), \mathrm{BF} \%$ obesity was found to be significantly higher in men and women (50\% for men and $62 \%$ for women). Despite this underrepresentation of BMI obesity, BMI values in the intermediate BMI range of 20 to 30 were found to be associated with a wide range of body fat percentages. For men with a BMI of 25 , about $20 \%$ have a body fat percentage below $20 \%$ and about $10 \%$ have body fat percentage above $30 \%$.

BMI is particularly inaccurate for athletes and individuals who regularly exercise, as higher muscle mass tends to classify these individuals in the overweight BMI category, even though their body fat percentages frequently fall between $10-15 \%$, which is below that of a sedentary person who has a normal BMI (Ode et al., 2007). Body composition for athletes is often better calculated using measures of body fat, as determined by skin-fold measurements. Alternative methods to measure obesity, such as the body volume index and body frame size (Frisancho, 1984; Heuberger et al., 2007), have been proposed. Unfortunately these alternative measures to estimate body size are not available for use on skeletal remains; therefore, BMI is used in this study.

\subsection{Weight-Bearing and Non-Weight-Bearing Joints}

In the assessment of adult age at death, morphological age estimation methods do not take into account the influence of body size, nor do they differentiate between factors influencing weightbearing and non-weight-bearing joint surfaces, and how they are affected differently by skeletal aging. The most common sites used by biological and forensic anthropologists to assess age are the pubic symphysis and auricular surface, both weight-bearing joints, as well as the fourth rib, a non-weight-bearing joint (Falys and Lewis, 2011; Garvin and Passalacqua, 2012). When 
comparing weight-bearing and non-weight-bearing surfaces in relation to BMD, there are significant differences between the two sites. Mikkola et al. (2008) compared the tibia and radius BMD from 217 older female twins and were able to show that the weight-bearing tibia is affected by the environment significantly more than the non-weight-bearing radius. These findings indicate that researchers should be aware that there are bone remodelling differences between the two sites, and this may affect skeletal age estimations.

Activity level also has different responses on weight-bearing and non-weight-bearing bones. Tommerup et al. (1993) studied the effect of weight-bearing activities on weight-bearing verses non-weight-bearing bone; their results show that weight-bearing exercise is sufficient to stimulate periosteal bone formation in the femur, but not in the ribs, indicating that bone response to weight-bearing exercises is specific to the loaded, weight-bearing bones. Similarly, Nikander et al.'s 2006 study comparing the BMD of weight-bearing and non-weight-bearing bones of elite female athletes found that bone mass was substantially higher at the loaded bone sites compared to nonathletic individuals. For the non-weight-bearing surfaces (radius and humerus), athletes had a higher BMD than nonathletes, indicating that with increased activity, loaded non-weight-bearing bone that can also have increased BMD. The only morphological, non-weight-bearing sites used in age estimation are the ribs, which are typically not subject to external loading factors.

Age also appears to influence weight-bearing and non-weight-bearing bone differently. A study by McNeil and colleagues (2009) compared the cross-section geometry of the tibia (weightbearing) and fibula (non-weight-bearing) in 39 men who were categorized as young (aged 23-31 years), old (aged 61-69 years), and very old (aged 80-91 years). With increasing age, they found that there were greater differences in bone geometry in the tibia compared to the fibula, suggesting that the weight-bearing role of the tibia makes it more susceptible than the fibula to the reduced activity typically associated with aging.

Obese individuals have an increased risk of osteoarthritis at weight-bearing joints (Felson, 1996). Osteoarthritis is characterized by the decrease of cartilage in a joint. As the cartilage breaks down, the space in the joint capsule between the two bones decreases until eventually the cartilage is completely destroyed and the bones are in contact with each other. This typically 
results in an increase in osteophytic activity around the joint capsule to compensate for the loss of cartilage. The hip joint is an area where osteoarthritis commonly develops, and three methods of age estimation using the acetabulum have been developed over the past decade (Rissech et al., 2006; Rougé-Maillart et al., 2007; Calce, 2012). For all three methods, osteophytic activity along the apex and lunate surface are used as markers of aging; however, these factors may be accelerated in obese individuals who are more prone to osteoarthritis, potentially resulting in over-age assessments of obese individuals. Therefore, it is important to understand the ways in which body size, especially mass, may influence the ways in which bone responds to external forces that are not directly related to the aging process, but could be interpreted as such.

\subsection{Adult Skeletal Age Estimation}

Adult skeletal age estimation methods quantify changes from the tissue level to the morphological level. To be considered a reliable age estimation method, the osseous feature being evaluated must display the following three features: first, there should be visible, progressive, unilateral degenerative changes; second, these progressive, unilateral changes should occur at approximately the same time in all individuals; and third, the traits scored should be easily identified and show low intra- and inter-observer error (Milner and Boldsen, 2012). Of these three features, the most difficult to quantify is the second: that degenerative changes should occur at the same time in all individuals. Often, there are differences between sexes (Işcan et al., 1984 a, 1985; Brooks and Suchey, 1990), populations (Işcan et al., 1987; Oettlé and Steyn, 2000; Bednarek et al., 2002; Djurić et al., 2007), and even socio-economic classes of the same population (Harper and Crews, 2000), making the creation of one universal system of age estimation difficult to establish.

There have been many historical developments and paradigm shifts over the past century in the ways biological anthropologists approach skeletal age estimation. As Rogers (2009) notes, the historical developments in skeletal age estimation studies follow a similar trajectory to the theoretical shifts in the field of biological anthropology. Prior to the 1940's, much of the field of anthropology was concerned with typology, and the first pubic symphysis and cranial suture closure age estimation methods described by Todd and Lyon in the 1920's followed this trend (Todd, 1920; Todd and Lyon, 1925). Although the two authors did note differences between 
sexes and populations, individuals who did not follow what they determined as "normal" aging were eliminated from their sample (Todd, 1920).

As the field of biological anthropology continued to focus on typological differences between sexes and ancestral groups throughout the 1930's and 1940's, there was a theoretical shift in the 1950's. Instead of focusing on descriptive typologies, Sherwood Washburn stated that anthropologists needed to move towards an understanding the evolutionary processes and functional morphology of traits, rather than description (Van Gerven and Armelagos, 2003). For biological anthropologists, this shift in theoretical approaches brought to the forefront two major problems researchers had been trying to resolve for 30 years; first, paleodemographic analyses of archaeological populations almost always yielded mean ages at death around 30 years of age, and second, rarely were individuals over the age of 40 years recorded in these populations. Brooks (1955) opened this conversation through the first critical analysis of the Todd methods on samples from Aboriginal populations from California and samples from the Hamann-Todd Collection. Her results were significant because they showed that cranial suture closure and pubic symphyseal changes were not as strongly correlated with age at death as originally thought, especially cranial suture closure, and that applying these methods to individuals of differing populations yielded poor results.

In response to this new theoretical shift focusing on functional morphology, the 1950's to 1970's saw a change in the study of skeletal age estimation. The methods that were developed during this time period focused on the process of development and degeneration (for example, the McKern, Stewart, and Gilbert pubic symphysis methods [McKern and Stewart, 1957; Gilbert and McKern, 1973]), and population studies became commonplace. Though the methods were still descriptive, researchers attempted to explain the evolutionary adaptations of the observed changes. Combined with the new theoretical approaches in archaeology proposed by Binford and Binford in the 1960's (Binford and Bindford, 1968), biological anthropologists began to apply a biocultural approach to their analyses, and in 1977 Buikstra coined the term "bioarchaeology" to encompass this holistic approach. The bioarchaeological approach of incorporating culture and biology to explain evolutionary adaptation and functional morphology began to emerge as a theme in age estimation studies, and remains an important aspect of age estimation studies today (Rogers, 2009). 
The 1980's saw another paradigm shift in age estimation. In 1982, Bocquet-Appel and Masset's article "Farewell to Paleodemography" (Bocquet-Appel and Masset, 1982) brought to the forefront two major issues in archaeological skeletal age estimation studies: first, the age structures of archaeological skeletal samples often reflected the age structures of the reference populations used to create the age estimation standards; and second, the estimated ages at death of archaeological skeletons were not reliable enough to allow researchers to conduct paleodemographic analyses. Though van Gervin and Armelagos vehemently opposed these findings (van Gervin and Armelagos, 1983), skeletal age estimation studies began to move in a new direction. First, researchers started to investigate other areas of the skeleton that could be used for age estimation, i.e. fourth rib, auricular surface, trabecular bone involution (Işcan et al., 1984 b; Meindl et al., 1985; Walker and Lovejoy, 1985). Second, researchers began to see the potential advantage of combining several methods in principal component analysis (PCA) multifactorial analyses instead of single element analyses (Lovejoy et al., 1985 a). Third, Lovejoy, Meindl, and colleagues advocated for blind testing of age methods, and they were the first to introduce a new way expressing the relationship between chronological age and skeletal age - by the degree and direction of bias. Fourth, sex and population variation differences in age estimation studies became a common theme addressed by researchers. And fifth, researchers began to attribute health, diet, disease, genetics, and activity as factors that influence the correlations between chronological age and biological age.

The 1990's ushered in a self-reflective era in skeletal age estimation. In spite of the improvements brought about by the 1970's and 1980's, biological anthropologists began to acknowledge the limitations of the age estimation methods. First, the statistical methods used to develop the methods came under question. As noted by Aykroyd et al. (1997), the common age estimation methods used by biological anthropologists were created using linear regression models, and these methods tend to over-age younger individuals and under-age older individuals, and typically the majority of individuals cluster between the ages of 35 to 50 years. These are inherent problems in using linear regression formulae to create models, and because they were used as the foundation for the majority of the age estimation methods, and they do not reflect true population parameters. Several solutions have been proposed to overcome the limitations of regression models, including classical calibration (Aykroyd et al., 1997), likelihood estimations (Paine, 1989), Bayesian statistics (Hoppa and Vaupel, 2002 a), transition analysis (Boldsen et al., 
2002), and the Sugeno fuzzy integral (Anderson et al., 2010); however, few researchers report using these new statistical methods, and few researchers use multivariate statistics when reporting their findings (Falys and Lewis, 2011; Garvin and Passalacqua, 2012). Second, most age estimation methods were developed on two North American skeletal collections of individuals who died in the early- to mid-20th century, and researchers began to question the applicability of the methods created on these populations to past and contemporary populations. Early 20th century populations differ from both past and modern populations in terms of health, diet, lifestyle, and occupations - all factors that affect skeletal aging. Even the applicability of skeletal age estimation methods developed on one collection to other skeletal collections from similar time periods has been problematic (Saunders et al., 1992; Bedford et al., 1993).

To address these issues, researchers have proposed new or revised age estimation methods since the turn of the century in an attempt to improve age estimation accuracy and precision (Kunos et al., 1999; Buckberry and Chamberlain, 2002; DiGangi et al., 2009; Passalacqua, 2009; RougéMaillart et al., 2009). One area that new age estimation methods address more than the older methods is the issue of under-aging older individuals, and a common trend among newer methods is to include more individuals over the age of 60 years in the sample (see Table 1). All of the original age estimation methods were developed on samples with fewer than $25 \%$ of the studied individuals having ages at death older than 60 years; the method with the highest proportion of individuals over the age of 60 years is the Todd method. Despite having $24 \%$ of the sample over the age of 60 years, the final age phase of the Todd method is simply " $50+$ " with no description of the degenerative changes that occur once an individual has reached full maturity. Most of the newer methods (i.e. methods created or revised in the last fifteen years) were developed using samples where more than $25 \%$ of their sample consisted of individuals over the age of 60 years; three consisted of samples with more than $40 \%$ of individuals older than 60 years. Increasing the number of individuals over the age of 60 years has decreased the range of statistical biases for older individuals (Schmitt and Murail, 2004; Kurki, 2005; Mulhern and Jones, 2005; Falys et al., 2006; Nagaoka and Hirata, 2008; Rougé-Maillart et al., 2009; Hens and Belcastro, 2012), but the overall contribution of genetics, environment, disease, and lifestyle to skeletal aging are still poorly understood. 


\begin{tabular}{|l|lcc|}
\hline \multicolumn{2}{|c}{} & N & $\begin{array}{c}\text { \%o of sample over } \\
\text { age 60 years }\end{array}$ \\
\hline New and Revised & DiGangi et al. & N/A & N/A \\
& Methods & $216 / 635$ & $34 \%$ \\
& Passalacqua & $86 / 180$ & $48 \%$ \\
& Buckberry \& Chamberlain & $12 / 52$ & $23 \%$ \\
\hline \multirow{2}{*}{ Original Methods } & Rougé-Maillart et al. & $16 / 74$ & $22 \%$ \\
& Kunos et al. & $23 / 118$ & $19 \%$ \\
& İşcan et al. & N/A & $13 \%$ b \\
& Lovejoy et al. & $151 / 1012$ & $15 \%$ \\
\hline
\end{tabular}

${ }^{\mathrm{a}} \mathrm{N} / \mathrm{A}=$ not available

${ }^{\mathrm{b}}$ Personal communication, Owen Lovejoy.

Table 1: Number of individuals and percentage of samples with ages at death of 60 years or more used to develop age estimation methods.

To work around these problems of unreliable statistical models, population and sex differences, and under-aging of older individuals, some researchers have suggested shifting to life history models as methods of age estimation, as they do not require point ages, nor do they reflect the biases of the methods and reference samples. Life history theory considers the interaction of the trade-offs between growth, reproduction, and maintenance (McDade, 2003), and how these factors affect the evolution of a life history pattern. Roksandic and Armstrong (2011) suggest using life history models based on skeletal start- and end-points that reflect biologically meaningful stages to classify individuals at first, and then assign chronological ages. Although they argue their model carries sufficient age information to build mortality profiles, this has not been systematically tested with a large sample, and it still does not address the issues of estimating the ages of older individuals.

Overall, attempting to quantify morphological skeletal age changes to chronological age is a difficult task, especially since chronological age is not always related to biological age, and there are intra- and inter-population differences that need to be considered. The timing of specific stages of aging are difficult to predict, and not everyone will go through all the stages of aging at the same time, or even go through all the stages. For example, most age estimation methods characterize osseous material in their oldest age phases as "irregular" with "pitting and porosity" and "lipping"; however, not all older individuals will exhibit these age changes, and these age markers may be observed in younger individuals. Conversely, they may not necessarily reflect the aging process, but rather responses to loading or disease, making it difficult to always equate these changes to chronological age (Franklin, 2010). 
For this project, only macroscopic age estimation methods were used, and only the methods used will be reviewed. Cranial suture closure and methods based on changes to teeth were not applied. Cranial suture closure has been shown to be an unreliable method of age estimation (Singer, 1953; Brooks, 1955; Powers, 1962; Gruspier and Mullen, 1991; Hershkovitz et al., 1997; Galera et al., 1998; Ginter, 2005; Beauthier et al., 2010) and is rarely used (Garvin and Passalacqua, 2012); and dental wear age methods are population specific and are not reliable when used on modern populations (Scott, 1979; Kieser et al., 1983; Lovejoy, 1985; Solheim, 1993). While it has been argued that the Lamedin method or methods assessing cementum annulations are reliable ways to estimate dental age (Baccino et al., 1999; Jankauskas et al., 2001; Martrille et al., 2007; Meinl et al., 2008; Robbins Schug et al., 2012), they are destructive methods and require the presence of specific teeth.

The eight age estimation methods used in this study were purposely selected to encompass a wide range of non-weight-bearing and weight-bearing sites; specifically, the ribs and pelvis. There are very few age estimation methods developed on non-weight-bearing joints that are reliable, and those selected for this study are all based on the ribs. The three non-weight-bearing rib methods selected were the Kunos et al. (1999) and DiGangi et al. (2009) first rib methods and the İşcan et al. $(1984,1985)$ fourth rib methods. Cranial suture closure and dental age estimation methods were avoided for the reasons reviewed in the above paragraphs (poor performance and population specific). For the weight-bearing joints, all aspects of the pelvis with new or reliable age estimations methods were considered: the Passalacqua (2009) sacrum method; the Lovejoy et al. (1985) and Buckberry and Chamberlain (2002) auricular surface methods; the RougéMaillart et al. acetabulum and auricular surface method (2007); and the Suchey-Brooks pubic symphysis method (1990). Age estimation methods that were developed on Asian or Balkan populations were not used in this study. The Rissech et al. acetabulum method was not selected as Calce and Rogers (2011) report poor replicability of the method on North American collections, specifically the J.C.B. Grant Collection curated at the University of Toronto. The Todd (1920) and McKern and Stewart (1957) and Gilbert and McKern (1973) pubic symphysis methods were also not included in the study because they perform poorly on older individuals. The Hartnett rib and pubic symphysis methods had not been published when the study data collection began in early 2010 , so they were not included. 
Multifactorial methods and statistical analyses were not used for this project, as the purpose was to evaluate each method individually. Multifactorial methods combine the scores of many age estimation methods to produce a final age, which is inconsistent with the goal of this research.

See Table 2 for a list of methods used for this project.

\begin{tabular}{|c|c|c|c|}
\hline Methods & Sample & Tests & Overall \\
\hline DiGangi et al., 2009 & $\begin{array}{l}\mathrm{N}=74 \\
\text { European/African(M/F) } \\
\mathrm{N}=470 \\
\text { European }(\mathrm{M})\end{array}$ & $\begin{array}{l}\text { Kurki 2005, Getz 2011; Merritt } \\
2013\end{array}$ & $\begin{array}{l}\text { Kunos et al. method more } \\
\text { precise for older individuals; } \\
\text { DiGangi et al. method } \\
\text { performs poorly on older } \\
\text { individuals. }\end{array}$ \\
\hline İşcan et al.,1984; 1985 & $\begin{array}{l}\mathrm{N}=204 \\
\text { European }(\mathrm{M} / \mathrm{F})\end{array}$ & $\begin{array}{l}\text { Dudar et al. 1993, Russell et al. } \\
\text { 1993, Loth 1995, Yavuz et al. } \\
\text { 1998, Oettle and Steyn 2000, } \\
\text { Fanton et al. 2010; Merritt } 2013\end{array}$ & $\begin{array}{l}\text { Potential population } \\
\text { differences; some inter/intra- } \\
\text { observer discrepancies; } \\
\text { generally accurate. }\end{array}$ \\
\hline Passalacqua, 2009 & $\begin{array}{l}\mathrm{N}=633 \\
\text { European/African(M/F) }\end{array}$ & Merritt 2013 & $\begin{array}{l}\text { More precise for older } \\
\text { individuals; large age ranges; } \\
\text { generally works well. }\end{array}$ \\
\hline $\begin{array}{l}\text { Buckberry and } \\
\text { Chamberlain, } 2002\end{array}$ & $\begin{array}{l}\mathrm{N}=764 \\
\text { European/African(M/F) } \\
\mathrm{N}=180 \\
\text { European }(\mathrm{M} / \mathrm{F})\end{array}$ & $\begin{array}{l}\text { Murray and Murray 1991, } \\
\text { Schmitt 2004, Osborne et al. } \\
\text { 2004, Mulhern and Jones 2005, } \\
\text { Falys et al. 2006, Nagaoka and } \\
\text { Hirata 2008, Merritt } 2013\end{array}$ & $\begin{array}{l}\text { Potential population } \\
\text { differences; large range of } \\
\text { error with Lovejoy method but } \\
\text { better with younger } \\
\text { individuals; Buckberry and } \\
\text { Chamberlain more accurate } \\
\text { with older individuals. }\end{array}$ \\
\hline $\begin{array}{l}\text { Rougé-Maillart et al., } \\
2007\end{array}$ & $\begin{array}{l}\mathrm{N}=52 \\
\text { European }(\mathrm{M} / \mathrm{F})\end{array}$ & $\begin{array}{l}\text { Rougé-Maillart et al. 2009, } \\
\text { Merritt } 2013\end{array}$ & $\begin{array}{l}\text { Rougé-Maillart over } 80 \% \\
\text { accurate with European } \\
\text { sample. }\end{array}$ \\
\hline Suchey Brooks, 1990 & $\begin{array}{l}\mathrm{N}=1012 \\
\text { European/African/ } \\
\text { Asian/Hispanic }(\mathrm{M} / \mathrm{F})\end{array}$ & $\begin{array}{l}\text { Meindl et al. 1985, Katz and } \\
\text { Suchey 1989, Klepinger et al. } \\
\text { 1992, Hoppa 2000, Djuric et al. } \\
\text { 2007, Kimmerle et al. 2008, } \\
\text { Schmitt 2004, Berg 2008, } \\
\text { Merritt 2013 }\end{array}$ & $\begin{array}{l}\text { Potential population } \\
\text { differences; females have most } \\
\text { variability; generally accurate } \\
\text { and precise. }\end{array}$ \\
\hline
\end{tabular}

Table 2: List of each age estimation method, composition of the sample used for development, tests of each method, and comments from the literature on each method's overall performance.

\subsubsection{Adult Age Estimation Using Rib Morphology}

The ribs have one primary centre of ossification on the body and three areas of epiphyseal ossification - one for the rib head and two for the articular and non-articular parts of the tubercle facet - except for the 11th and 12th ribs, which only have two epiphyseal centres. The epiphyses appear between the ages of 12 and 18 years, and fusion is complete by the age of 25 years (Scheuer and Black, 2000). As an individual ages, mineralization of the costal cartilage occurs. McCormick (1980) was the first to create a grading system to assess the mineralization of costal 
cartilage from thoracic x-rays. He observed that mineralization of the costal cartilage did not occur before the age of 15 years, it was rarely visible before the age of 50 years, and dense mineralization was typically only seen in individuals over the age of 55 years. In 1984 and 1985, basing their research on the original observations of McCormick, İşcan, et al. created a system to estimate adult skeletal age at death using the sternal rib ends (İşcan et al., 1984, 1985). They observed morphological changes at the sternal end of the fourth ribs that were consistent with the aging process, and developed an eight-phase system using the fourth ribs from 93 males between the ages of 17 and 90 years, and 86 females between the ages of 14 and 90 years, all of European ancestry. Their method has been widely tested and accepted as a reliable, replicable, single indicator for estimating age (Dudar et al., 1993; Russell et al., 1993; Yavuz et al., 1998; Yoder et al., 2001). In 2010, Hartnett revised the İşcan et al. methods by combining the male and female methods and reducing the number of phases from eight to seven, truncating the younger phases; however, this method was not used in this project as it was not published at the time of data collection.

Researchers have cited the frequent occurrence of damage to the sternal rib ends in archaeological or forensic contexts, and the dangers inherent in relying solely on the morphological changes of the costal face of the rib, while ignoring other aspects of the rib that change throughout life as concerns in relying upon the fourth ribs as age estimation methods (Kunos et al., 1999). Kunos and colleagues (1999) created a new method of age estimation based on three aspects of first rib development - the costal face, rib head, and tubercle facet. They developed their method on the Hamann-Todd skeletal collection, with a reference sample size of 74 individuals and a test sample size of 182 individuals. Using the first rib has several advantages over the fourth rib method: it is easily identifiable and recognizable; it is not influenced by mechanical stress (respiration) in the same manner as the lower ribs; it is more likely to be preserved intact in forensic and archaeological contexts; and it exhibits a prolonged span of remodelling into the eighth decade of life (Kunos et al., 1999; Kurki, 2005). Tests of the Kunos et al. method have brought about two concerns; first, the length of time required to assess each age marker, and second, the amount of subjectivity required in scoring several traits for each feature (Schmitt and Murail, 2004; Kurki, 2005). However, the scoring is very thorough and allows researchers the flexibility of assessing each feature individually rather than forcing them into phases. 
DiGangi and colleagues (2009) introduced a revised first rib method using the traits as described by Kunos et al. (1999), but the authors applied a Bayesian statistical approach to determine the two most accurate features to establish age at death (DiGangi et al., 2009). They determined that the geometric shape of the costal face in conjunction with the tubercle facet surface texture produced the most reliable age estimations. Recently, the DiGangi et al. method was tested by Getz (2011) and found to perform at the same level as the commonly used age estimation methods, yet few researchers report using this method (Garvin and Passalacqua, 2012).

\subsubsection{Adult Age Estimation Using Sacrum Morphology}

The sacrum is has 21 primary ossification centres and three areas of articulation to other surfaces used for age estimation: the auricular surfaces, the lumbar vertebral plate. Both McKern and Stewart (1957) and Lovejoy et al. (1985) identified the patterns of fusion on the sacral body but concluded that, while definable morphological changes occur on the lateral auricular joints, it was not possible to use them for adult age at death estimations. Scheuer and Black (2000) describe the growth and development of the sacrum up to the age of 25 years. The sacrum exhibits age related changes in childhood, adolescence, and early adulthood. Before the age of 6 years, the 21 segments fuse into five central bodies; at the age of 14 years, the lateral elements forming the sacro-iliac joint at S3 and S5 fuse; during puberty, the vertebral plates between the epiphyses of the vertebral bodies begin to fuse; and after the age of 25 years the vertebral bodies between S1 and S2 fuse, completing the sacrum.

In 2009, Passalacqua developed a method of adult age estimation using the sacrum. Using 249 males from the Hamann-Todd Collection and William Bass Collection, he identified changes to the sacrum based on vertebral body fusion, porosity, vertebral ring fusion, and osteophytic activity. This method was tested by Merritt (2014); the author was able to correctly classify over $90 \%$ of individuals into the correct phase; however, a major drawback of this method is the large age ranges and confidence intervals associated with the age phases.

\subsubsection{Adult Age Estimation Using Auricular Surface Morphology}

The auricular surface forms part of the primary centre of ossification of the ilium, and articulates with the sacrum through the sacro-iliac joint. It is a large joint surface on the posterior/inferior region of the ilium (Scheuer and Black, 2000). The assessment of the auricular surface as a 
method of age estimation was established by Lovejoy and colleagues, who used approximately 250 male and female skeletons from the Libben archaeological population, and 512 skeletons from the Hamann-Todd collection to create the method (Lovejoy et al., 1985 b). By observing age changes in the surface texture, organization, and degeneration of the auricular surface, they created an eight-phase system for age intervals between 20 and 59 years, with an age category for those over 60 years. This method was tested by Murray and Murray (1991) with 189 individuals from the Terry Collection and they concluded that when used on its own, the auricular surface is not a reliable indicator of age and should be used in conjunction with other methods; however, the method has the beneficial feature that sex and ancestry do not significantly affect age estimations (Bedford et al., 1993; Osborne et al., 2004). Bedford and colleagues tested the method on the University of Toronto's J.C.B. Grant Collection and found that adults between the ages of 49 and 60 years were typically over-aged by 5 to 7 years, and individuals over the age of 60 years were under-aged by 10 years (Bedford et al., 1993). Osborne et al. (2004) tested the Lovejoy et al. method on 266 male and female skeletons from the Bass Collection and Terry Collection and report that only 33\% of the sample is correctly aged when using the 5 year age ranges. When tested on an Asian population from Thailand, the accuracy of the method decreases (Schmitt, 2004). In spite of the critiques of this method, it is still widely used (Falys and Lewis, 2011; Garvin and Passalacqua, 2012).

Buckberry and Chamberlain (2002) created a new system of auricular surface age scoring using 180 individuals from the Spitalfields Collection. Instead of using a defined 5-year phase system, they developed a scoring system for individual morphological features of the auricular surface, resolving previous issues with forcing traits into one category. The sum of scores are calculated to give a total score and subsequently they are assigned to a phase. Falys et al. (2006) tested the Buckberry and Chamberlain method on a sample from 167 males and females from St. Bride's, London, a documented skeletal assemblage from the late $17^{\text {th }}$ to early $19^{\text {th }}$ century. They looked at the correlation of the traits used by Buckberry and Chamberlain to age at death and found that only three of the traits have a high correlations with aging. When comparing the Lovejoy et al. and Buckberry and Chamberlain methods, Mulhern and Jones (2005), Nagaoka and Hirata (2008), and Hens and Belcastro (2012) found that Lovejoy et al.'s method was more accurate for individuals between 20 and 49 years of age, and Buckberry and Chamberlain's method was more accurate for older individuals (50+ years). 


\subsubsection{Adult Age Estimation Using Acetabular Morphology}

Similar to the auricular surface, the acetabulum begins as part of the primary ossification centre of the ilium, and after the age of 10 years it starts to fuse with the ischium and pubis. Typically, the ilium, ischium, and pubis are fully fused by the age of 19 years (Scheuer and Black, 2000). Because the acetabulum is commonly preserved in archaeological and forensic contexts and it shows age-related changes, it is an ideal area to assess age. In a preliminary study of 30 male os coxae conducted by Rougé-Maillart et al. in 2004, they reported observable age-related changes such as osteophytes and osteoarthritis on the rim of the acetabulum, the breakdown of the acetabular fossa, porosity of the lunate surface, and arthritic lipping on the apex of the posterior cornu. Rougé-Maillart et al. observed that these acetabular aging traits complemented Lovejoy et al.'s (1985) auricular surface method to estimate age, but they use Buckberry and Chamberlain's scoring method to record the auricular surface changes. Stull and James (2010) evaluated RougéMaillart et al.'s original 2004 method and found that, although acetabular features demonstrate the capability to estimate age, an improved coding system and percent correct classification approach is necessary to determine accuracy and precision. Two of the authors on the original 2004 paper, Rougé-Maillart and Rissech, developed differing methods using the acetabulum. Rougé-Maillart continued to use the acetabulum in conjunction with the auricular surface, while Rissech focused solely on the acetabulum. In 2011, Rissech et al.'s method was tested by Calce and Rogers on the J.C.B. Grant Collection curated at the University of Toronto, and the authors reported low intra- and inter-observer reliability, and poor accuracy and precision on this North American collection. The authors conclude that the Rissech et al. method, which was developed on Iberian and Portuguese collections, is inappropriate to use on North American populations due to differences in physical activity, diet, health, and disease; therefore, this method was not used for this study. Rougé-Maillart and colleagues revised their original 2004 method and tested it on a sample 514 males of known age from Portugal and France (Rougé-Maillart et al., 2007, 2009), reporting high intra-observer agreement as well as high precision and accuracy. This revised method was evaluated by Merritt (2014) on the J.C.B. Grant Collection and the author found that, similar to Passalacqua's sacrum method, the majority of individuals were scored into the correct age phase and there was high intra- and inter-observer reliability. Therefore, the revised Rougé-Maillart et al. method was used for this study. 


\subsubsection{Adult Age Estimation Using Pubic Symphysis Morphology}

The pubic symphysis is part of the primary centre of ossification of the pubis, and forms the midline cartilaginous joint that unities the superior rami of the left and right pubic bones (Scheuer and Black, 2000). The pubic symphysis has been considered one of the most reliable sites for adult age estimation. First described by Todd (1920, 1921), he observed age-related changes on the pubic symphyses of 306 male skeletons and 47 females housed at the Western Reserve University, now known as the Hamann-Todd Collection. He established a ten-phase system of age estimation, focusing on the early- and mid-adult changes to the pubic symphysis. He divided this observations into three major phases: the post-adolescent phase (18 to 24 years), where the symphyseal face is rugged with horizontal ridges, deep grooves, and no margins or ossific nodules, and progresses to one where ossific nodules fill in the deep grooves and the face becomes bevelled, and there is a formation of a dorsal plateau and dorsal margin; the buildup phase (25 to 35 years), where the symphyseal face is granular and there is a completion of the oval outline of the face, along with the near completion of the ventral rampart and dorsal margin; and the degenerative phase (35 years and over), where the symphyseal face becomes fine-grained to dense, the ventral rampart and dorsal margin progress from completion to lipping on the edges, and eventually the symphyseal face itself is marked by irregular ossification. The Todd method remains one of the most widely used age estimation methods in spite of the critiques of narrow age ranges (e.g. 18-19 years), a tendency to over-age individuals in their 30's and 40's, and inability to account for variability in individuals over the age of 50 years. Brooks (1955) found that the Todd ten-phase system was accurate only $30 \%$ of the time when applied to the same skeletal collection. She revised the Todd phase system (Brooks, 1955) and later collaborated with Suchey (Brooks and Suchey, 1990) on refinements to the method using a large sample of 739 males and 273 females of different ancestral backgrounds with age ranges from 14 to 92 years. This resulted in a new series of pubic symphyseal age standards, which incorporated an approach focusing on the total pattern of the symphyseal face. Using this system requires comparison of the morphology of the symphysis of interest to six sex-specific reference phases (both early and late), each of which has accompanying descriptions, photographs, and casts available for purchase. A reference table corresponding to the phase to which the unknown specimen appears to most clearly fit provides the necessary statistics, including a mean age estimate, standard deviation, and 95\% confidence interval range (albeit broad). This method has 
been widely tested (Saunders et al., 1992; Sinha and Gupta, 1995; Bednarek et al., 2002; Sitchon and Hoppa, 2005; Djurić et al., 2007; Hens et al., 2008; Kimmerle et al., 2008) and is the method used most frequently by researchers and forensic anthropologists (Falys and Lewis, 2011; Garvin and Passalacqua, 2012)

Several other methods of pubic symphysis age estimation have been developed. For example, McKern, Stewart, and Gilbert formulated a three-component method using the dorsal plateau, ventral rampart, and symphyseal rim (McKern and Stewart, 1957; Gilbert and McKern, 1973); however, subsequent testing by a large cohort of experienced anthropologists yielded unfavorable results (Suchey, 1979; Suchey et al., 1986), and few researchers use this method (Falys and Lewis, 2011; Garvin and Passalacqua, 2012). In 2010, Hartnett published revisions of the Suchey-Brooks pubic symphysis method. Hartnett expanded the Suchey-Brooks method by including a seventh phase to account for individuals over the age of 70 years, similar to Berg (2008). The Hartnett method was not used for this study as it was not published at the time of data collection. The Suchey-Brooks method was selected over the Berg method for evaluation as it is the more commonly used method (Falys and Lewis, 2011; Garvin and Passalacqua, 2012).

\subsection{Application of Body Size to Age Estimation in Paleodemography, Paleoanthropology, and Forensic Anthropology}

Understanding the role of body size in skeletal age estimation will be useful for biological anthropologists, particularly those who study paleodemography, paleoanthropology, and forensic anthropology. Accurate age-at-death estimations are the foundation of all work that interprets health, disease, and adaptation in past populations and communities. With accurate age at death estimations, researchers can explore life expectancy and population structure; for example, the presence or absence of older adults in the skeletal record affects the interpretation of roles and dynamics within a group, as adult longevity is a measure of a population's success. In both prehistorical and historical skeletal collections, the under-representation of infants or older adults seriously affects paleodemographic interpretations of fertility rates, death rates, mortality curves, and general health of past populations (see Cipriano-Betchtle et al., 1996; Guy et al., 1997; Paine and Harpending, 1998). Paine and Harpending (1998) observed that the lack of older individuals (i.e. individuals over the age of 45 years) in paleodemographic studies inflates birth rates by $10 \%$ 
to $20 \%$. In historical collections, it is common for researchers to compare the representativeness of their sample to documented historical accounts; however, this does not alleviate the problem of under-representation of individuals in skeletal assemblages. New biostatistical approaches to estimating age at death have helped researchers focus more on mortality distribution of samples on the basis of individual age indicators (Hoppa and Vaupel, 2002 b); however, if these age indicators are inaccurate, the problem is cyclical (i.e. inaccurate age estimations lead to inaccurate biostatistical data which lead to inaccurate interpretations of the assemblage). My research assesses the effects of body size on skeletal age estimation methods, and this will help researchers determine which age methods should be relied upon more heavily during analyses.

The reconstruction of mortality patterns is important to understanding the living conditions and environment of past human populations. Body size is an important factor when considering health and environmental adaptation in human history because it correlates well with the ways in which habitat, life history, and life span affect skeletal biology. Demands for improved methods to obtain mortality data at both the individual and population levels have increased in recent years, especially as current studies illustrate the impact of individual age estimation methods on population analyses (Nagar and Hershkovitz, 2004; Bonneuil, 2005; Nagaoka and Hirata, 2007, 2008). For example, debates about the life conditions of past populations often cite the absence of older individuals from the archaeological record. However, this presumed absence may not exist, since our current age standards may not be adequate to account for the lighter, leaner body composition of our ancestors. Body size plays an important role in changes to skeletal morphology, but it has never been systematically assessed as a factor in skeletal age estimation. We know that body size composition has changed over time (McHenry, 1992; Ruff et al., 1997; Katzmarzyk and Leonard, 1998; Ruff, 2002; Rosenberg et al., 2006; Leonard and Katzmarzyk, 2010), and recently it has been shown that body mass does affect the skeletal morphology (Agostini and Ross, 2011). If body mass influences the morphology of long bones, it is important to consider the ways body mass may influence the skeletal elements used for age estimation.

Understanding the influence of body size on age estimation could re-position theories on human small-bodied ancestors and could give anthropologists and evolutionary biologists a new perspective on their interpretations of human history. Important information regarding human biology, adaptation, and migratory history has be derived from studying our smaller, leaner 
ancestors (Holliday, 1997, 2002; Holliday and Ruff, 1997; Ruff et al., 1997). With new information about the ways in which body size impacts our age standards, researchers will have an opportunity to re-examine these skeletal materials and more accurately determine age at death, with the possibility of refining our knowledge base about the lifespan of past human and ancestral populations.

As previous research has shown, modern human populations are generally taller and heavier than most past populations of Homo sapiens, as well as the majority of our hominin ancestors. Hominin ancestors and early Homo sapiens populations were generally short and light (see Table 3). Our current age standards were developed on North American skeletal collections of individuals that are generally tall and heavy, and they are often applied to these smaller, lighter individuals with the understanding that there are differences in the life histories, lifestyles, and environments, as well as body size. Often, when our age standards are applied to hominin ancestors and early populations of Homo sapiens, the trend is thought to demonstrate that populations experienced substantial young adult mortality, i.e., samples show most of their adult ages at death between 30 and 45 years of age. However, if body size does play a role in adult age estimation, and individuals with smaller body sizes are, for example, under-aged, then we may need to reconsider the mortality curves of small bodied hominin and Homo sapiens ancestors.

Forensic anthropologists rely on accurate age estimations to create biological profiles and to narrow searches for missing persons as accurate age-at-death estimations assist law enforcement agencies in the identification of skeletal remains. This is important for not only identifying victims of crime, but also casualties of war. For example, the US Army's Central Identification Laboratory and the Physicians for Human Rights are dedicated to recovering and identifying the war dead from conflicts all over the world; reliable osteological age at death estimation methods are critical to this important work. With obesity rates in Canada and the USA steadily increasing, understanding the ways in which modern populations age, and the ways in which skeletal aging is affected by body size, is an important topic that has not been considered systematically in forensic anthropology. 


\begin{tabular}{|c|c|c|}
\hline Species & Stature $(\mathrm{cm})$ & Body mass (kg) \\
\hline $\begin{array}{l}\text { A. afarensis } \\
\bar{x} \\
\text { s.d. } \\
n\end{array}$ & $\begin{array}{l}128.0 \\
- \\
9\end{array}$ & $\begin{array}{l}37.0 \\
- \\
9\end{array}$ \\
\hline $\begin{array}{l}\text { A. africanus } \\
\bar{x} \\
\text { s.d. } \\
n \\
\end{array}$ & $\begin{array}{l}126.5 \\
- \\
12\end{array}$ & $\begin{array}{l}35.5 \\
- \\
12 \\
\end{array}$ \\
\hline $\begin{array}{l}P . \text { robustus } \\
\bar{x} \\
\text { s.d. } \\
n\end{array}$ & $\begin{array}{l}121.0 \\
- \\
4\end{array}$ & $\begin{array}{l}36.0 \\
- \\
4\end{array}$ \\
\hline $\begin{array}{l}\text { P. bosei } \\
\bar{x} \\
\text { s.d. } \\
n\end{array}$ & $\begin{array}{l}130.5 \\
- \\
2\end{array}$ & $\begin{array}{l}41.5 \\
- \\
2\end{array}$ \\
\hline $\begin{array}{l}\text { A. sediba } \\
\bar{x} \\
\text { s.d. } \\
n\end{array}$ & $\begin{array}{l}130.0 \\
- \\
2\end{array}$ & $\begin{array}{l}44.2 \\
- \\
2\end{array}$ \\
\hline $\begin{array}{l}\text { H. habilis } \\
\bar{x} \\
\text { s.d. } \\
n\end{array}$ & $\begin{array}{l}141.0 \\
- \\
5\end{array}$ & $\begin{array}{l}47.0 \\
- \\
5\end{array}$ \\
\hline $\begin{array}{l}\text { H. erectus } \\
\bar{x} \\
\text { s.d. } \\
n\end{array}$ & $\begin{array}{l}170.0 \\
- \\
2\end{array}$ & $\begin{array}{l}68.0 \\
- \\
2\end{array}$ \\
\hline $\begin{array}{l}\text { H. neanderthalensis } \\
\bar{x} \\
\text { s.d. } \\
n\end{array}$ & $\begin{array}{l}162.4 \\
3.6 \\
17\end{array}$ & $\begin{array}{l}71.0 \\
10.5 \\
12\end{array}$ \\
\hline $\begin{array}{l}\text { H. floresiensis } \\
\bar{x} \\
\text { s.d. } \\
n\end{array}$ & $\begin{array}{l}106.0 \\
- \\
2\end{array}$ & $\begin{array}{l}30.0 \\
- \\
2\end{array}$ \\
\hline $\begin{array}{l}\text { H. sapiens (Paleolithic European) } \\
\bar{x} \\
\text { s.d. } \\
n\end{array}$ & $\begin{array}{l}163.6 \\
6.0 \\
41\end{array}$ & $\begin{array}{l}63.4 \\
6.6 \\
17\end{array}$ \\
\hline $\begin{array}{l}\text { H. sapiens (modern European) } \\
\bar{x} \\
\text { s.d. } \\
n\end{array}$ & $\begin{array}{l}164.4 \\
5.6 \\
482\end{array}$ & $\begin{array}{l}63.8 \\
6.2 \\
213\end{array}$ \\
\hline $\begin{array}{l}\text { H. sapiens (modern Sub-Saharan Africa) } \\
\bar{x} \\
\text { s.d. } \\
n\end{array}$ & $\begin{array}{l}158.5 \\
7.8 \\
109\end{array}$ & $\begin{array}{l}51.5 \\
7.5 \\
78\end{array}$ \\
\hline
\end{tabular}

Table 3: Stature and body mass estimations of hominin species. Stature is estimated from long bones, body mass is predicted by femoral head diameter or bi-iliac breadth (adapted from (McHenry, 1992, 2005; Kappelman, 1996; Helmuth, 1998; Holliday, 2002; Ruff, 2010). 


\section{Chapter 2: Materials and Methods}

\subsection{Materials}

There are several human skeletal collections with known age and stature at death; however, there are very few established skeletal collections with known body mass at death. In North America, there are only two: the Hamann-Todd Collection curated at the Cleveland Museum of Natural History in Cleveland, Ohio and the William Bass Collection curated at the University of Tennessee in Knoxville, Tennessee. Both were used for this project.

\subsubsection{Sample Selection}

Prior to visiting each collection, skeletons were age and size selected to ensure representation from a broad spectrum of stature and body mass categories. Age, sex, ancestry, stature, body mass, and cause of death were known for most individuals in both collections. Individuals with unknown statures, body masses, and causes of death were eliminated from the collection samples, leaving available approximately 2700 individuals from the Hamann-Todd Collection and 550 individuals from the William Bass Collection.

Skeletons from both collections were classified into arbitrary groups based on their stature, body mass, and combination of stature and body mass to evaluate the range of body sizes potentially available for study (see Appendix 1 for the Hamann-Todd Collection; see Appendix 2 for the William Bass Collection). There were 49 stature and mass categories created. Individuals were then eliminated from the sample based on the following criteria:

1. Skeletons of persons who had a stature greater than $1.64 \mathrm{~m}(5.4 \mathrm{ft})$ and body mass less than $45.35 \mathrm{~kg}$ (100lbs), as the cause of death for the majority of these individuals was a wasting disease (i.e. cancer, tuberculosis, etc.);

2. Skeletons of persons who had a stature greater than $1.95 \mathrm{~m}(6.4 \mathrm{ft})$ and body mass more than $102.1 \mathrm{~kg}$ (225lbs) based on low sample sizes;

3. Skeletons of persons who had a stature of less than $1.60 \mathrm{~m}(5.4 \mathrm{ft})$ and body mass more than $79.35 \mathrm{~kg}$ (175lbs) based on low sample sizes;

4. Skeletons of persons who died of cancer, tuberculosis, or any other wasting disease. 
Once these skeletons were removed from the sample, 29 stature and mass groups were represented (see Table 4). Several groups had high representation; therefore, subsets were selected. Skeletons were not excluded based on sex or ancestry; however, the collections are mostly comprised of older North American males of European descent, and the sample used for this project reflects these characteristics.

\begin{tabular}{|c|c|c|c|c|c|c|c|}
\hline & $\begin{array}{l}<1.54 \mathrm{~m} \\
(<5.0 \mathrm{ft})\end{array}$ & $\begin{array}{c}1.55-1.62 \mathrm{~m} \\
(5.1-5.3 \mathrm{ft})\end{array}$ & $\begin{array}{c}1.63-1.70 \mathrm{~m} \\
(5.4-5.6 \mathrm{ft})\end{array}$ & $\begin{array}{c}1.72-1.78 \mathrm{~m} \\
(5.7-5.9 \mathrm{ft})\end{array}$ & $\begin{array}{l}1.79-1.84 \mathrm{~m} \\
(5.10-6.0 \mathrm{ft})\end{array}$ & $\begin{array}{c}1.85-1.92 \mathrm{~m} \\
(6.1-6.3 \mathrm{ft})\end{array}$ & Total \\
\hline $\begin{array}{l}<45.0 \mathrm{~kg} \\
(<100 \mathrm{lbs})\end{array}$ & 54 & 106 & 0 & 0 & 0 & 0 & 160 \\
\hline $\begin{array}{l}45.4-56.5 \mathrm{~kg} \\
(100-124 \mathrm{lbs})\end{array}$ & 44 & 132 & 243 & 254 & 104 & 0 & 777 \\
\hline $\begin{array}{l}56.7-67.6 \mathrm{~kg} \\
(125-149 \mathrm{lbs}) \\
\end{array}$ & 29 & 102 & 373 & 408 & 164 & 35 & 1111 \\
\hline $\begin{array}{l}68.0-79.0 \mathrm{~kg} \\
(150-174 \mathrm{lbs})\end{array}$ & 8 & 34 & 147 & 174 & 118 & 39 & 520 \\
\hline $\begin{array}{l}\text { 79.4-89.8kg } \\
\text { (175-199lbs) }\end{array}$ & 0 & 5 & 20 & 42 & 44 & 26 & 137 \\
\hline $\begin{array}{l}\text { 90.2-101.6kg } \\
(200-224 \mathrm{lbs})\end{array}$ & 0 & 0 & 20 & 34 & 38 & 16 & 108 \\
\hline Total & 135 & 379 & 803 & 912 & 468 & 140 & 2813 \\
\hline
\end{tabular}

Table 4: Number of skeletons in 29 stature and mass categories from the Hamann-Todd and William Bass Collections as categorized prior to arriving at the collections. Skeletons were subsequently excluded based on questionable age estimates and inadequate preservation of skeletal elements.

Skeletal inventories were not available before visits to each collection; therefore, inventories were conducted on site at the Hamann-Todd and William Bass Collections prior to data collection. To be considered in the study, each sample skeleton had to contain at least one rib to assess age (i.e. a first rib or fourth rib), and at least one pelvic element to assess age (i.e. sacrum, pubic symphysis, auricular surface, acetabulum). Skeletons who did not meet these inventory requirements were removed from the planned sample; when possible, they were replaced with skeletons of similar statures and body masses.

\subsubsection{Hamann-Todd Collection}

The Hamann-Todd Collection was established in 1839 and skeletons were collected until 1938 by Carl August Hamann and T. Wingate Todd. The collection consists of approximately 3100 human skeletons with both males and females represented. Ages at death range from fetal to 105 years, and most are of European or African-American descent. Most of these skeletons were 
derived from positively identified individuals of known age, but some of the skeletons are derived from individuals where age was determined through soft tissue markers (Meindl et al., 1990). For this project, cases where ages at death were estimated by soft tissue markers were not used. Table 5 shows the sample distribution of skeletons from the Hamann-Todd Collection that were used for this project. The mean age at death is 49.6 years, with a range of 19 to 87 years. The average recorded stature at time of death is $1.69 \mathrm{~m}(5.6 \mathrm{ft})$ with a range of $1.30 \mathrm{~m}$ to $1.92 \mathrm{~m}$ (4.3ft to $6.3 \mathrm{ft})$, and the average recorded body mass at time of death is $62.6 \mathrm{~kg}(138 \mathrm{lbs})$, with a range of $24.0 \mathrm{~kg}$ to $99.8 \mathrm{~kg}$ (531bs to $220 \mathrm{lbs}$ ).

\begin{tabular}{|c|c|c|c|c|c|c|}
\hline & n & $\begin{array}{c}\text { Mean } \\
\text { Age (yrs) }\end{array}$ & $\begin{array}{c}\text { Average } \\
\text { Stature } \\
(\mathbf{m} / \mathbf{f t})\end{array}$ & $\begin{array}{c}\text { Stature Range } \\
(\mathbf{m} / \mathbf{f t})\end{array}$ & $\begin{array}{c}\text { Average } \\
\text { Body Mass } \\
\text { (kg/lbs) }\end{array}$ & $\begin{array}{c}\text { Body Mass } \\
\text { Range (kg/lbs) }\end{array}$ \\
\hline Males & 373 & 50.4 & $1.73 / 5.7$ & $\begin{array}{c}1.30-1.92 / \\
4.3-6.3\end{array}$ & $65.9 / 145$ & $\begin{array}{c}32.2-99.8 / \\
71-220\end{array}$ \\
\hline Females & 163 & 47.8 & $1.60 / 5.3$ & $\begin{array}{c}1.30-1.83 / \\
4.3-6.0\end{array}$ & $54.9 / 121$ & $\begin{array}{c}24.0-90.7 / \\
53-200\end{array}$ \\
\hline European Ancestry & 334 & $\overline{52.6}$ & $1.68 / 5.5$ & $\begin{array}{c}1.30-1.92 / \\
4.3-6.3\end{array}$ & $62.7 / 138$ & $\begin{array}{c}26.3-99.8 / \\
58-220\end{array}$ \\
\hline African Ancestry & 199 & 44.6 & $1.71 / 5.6$ & $\begin{array}{c}1.50-1.92 / \\
4.9-6.3\end{array}$ & $62.5 / 138$ & $\begin{array}{c}24.0-99.8 / \\
53-220\end{array}$ \\
\hline Other Ancestry & 3 & 43.0 & $1.65 / 5.4$ & $\begin{array}{c}1.59-1.80 / \\
5.2-5.9\end{array}$ & $56.3 / 124$ & $\begin{array}{c}42.6-64.4 / \\
94-142\end{array}$ \\
\hline 19-29 years & 47 & 24.7 & $1.70 / 5.6$ & $\begin{array}{c}1.37-1.90 / \\
4.5-6.2\end{array}$ & $61.2 / 135$ & $\begin{array}{c}37.2-89.8 / \\
82-198\end{array}$ \\
\hline 30-39 years & 120 & 34.9 & $1.70 / 5.6$ & $\begin{array}{c}1.30-1.92 / \\
4.3-6.3\end{array}$ & $65.1 / 143$ & $\begin{array}{c}24.0-90.7 / \\
53-200\end{array}$ \\
\hline $40-49$ years & 106 & 43.8 & $1.69 / 5.6$ & $\begin{array}{c}1.44-1.90 / \\
4.7-6.2\end{array}$ & $64.1 / 141$ & $\begin{array}{c}27.7-99.8 / \\
61-220\end{array}$ \\
\hline $50-59$ years & 89 & 53.5 & $1.70 / 5.6$ & $\begin{array}{c}1.30-1.92 / \\
4.3-6.1\end{array}$ & $64.4 / 144$ & $\begin{array}{c}27.7-93.0 / \\
61-205\end{array}$ \\
\hline $60-69$ years & 103 & 63.8 & $1.70 / 5.6$ & $\begin{array}{c}1.50-1.90 / \\
4.9-6.3\end{array}$ & $60.5 / 133$ & $\begin{array}{c}30.4-99.8 / \\
67-220\end{array}$ \\
\hline $70-79$ years & 67 & 73.8 & $1.65 / 5.4$ & $\begin{array}{c}1.38-1.86 / \\
4.5-6.1\end{array}$ & $57.6 / 127$ & $\begin{array}{c}26.3-93.9 / \\
58-207\end{array}$ \\
\hline $80-89$ years & 4 & 82.0 & $1.63 / 5.3$ & $\begin{array}{c}1.55-1.74 / \\
5.1-5.7\end{array}$ & $56.1 / 124$ & $\begin{array}{c}31.3-97.5 / \\
69-215\end{array}$ \\
\hline Total & 2536 & 499.6 & $101.69 / 5.6$ & $\begin{array}{c}1.30-1.92 / \\
4.3-6.3\end{array}$ & $62.6 / 138$ & $\begin{array}{c}24.0-99.8 / \\
53-220\end{array}$ \\
\hline
\end{tabular}

Table 5: Sample distribution of skeletons selected from the Hamann-Todd Collection, including age at death, ancestry, reported stature and body mass at time of death. 


\subsubsection{William Bass Collection}

The William Bass Collection was established in 1981 by William Bass as a donor program in Knoxville, Tennessee, and the Anthropology Research Facility at the University of Tennessee continues to accept donors. Currently, the collection houses approximately 1000 skeletons, both males and females, with birth years ranging from 1892 to 2011. Most individuals were born after 1940 and most are of European or African-American ancestry. Table 6 shows the sample distribution of skeletons from the William Bass Collection used for this project. The mean age at death is 57.4 years, with a range of 19 to 89 years. The average recorded stature at time of death is $1.70 \mathrm{~m}(5.6 \mathrm{ft})$ with a range of $1.47 \mathrm{~m}$ to $1.93 \mathrm{~m}(4.8 \mathrm{ft}$ to $6.3 \mathrm{ft})$; the average recorded body mass at time of death is $71.7 \mathrm{~kg}$ (1581bs) with a range of $32.0 \mathrm{~kg}$ to $99.8 \mathrm{~kg}$ (71lbs to $220 \mathrm{lbs}$ ).

\begin{tabular}{|c|c|c|c|c|c|c|}
\hline & $\mathbf{n}$ & $\begin{array}{c}\text { Mean } \\
\text { Age (yrs) }\end{array}$ & $\begin{array}{c}\text { Average } \\
\text { Stature } \\
(\mathbf{m} / \mathbf{f t})\end{array}$ & $\begin{array}{c}\text { Stature } \\
\text { Range } \\
(\mathrm{m} / \mathrm{ft})\end{array}$ & $\begin{array}{c}\text { Average } \\
\text { Body Mass } \\
\text { (kg/lbs) }\end{array}$ & $\begin{array}{c}\text { Body Mass } \\
\text { Range } \\
\text { (kg/lbs) }\end{array}$ \\
\hline Males & 74 & 55.5 & $1.75 / 5.7$ & $\begin{array}{c}1.55-1.93 / \\
5.1-6.3\end{array}$ & $74.9 / 165$ & $\begin{array}{c}45.4-99.8 / \\
100-220\end{array}$ \\
\hline Females & 186 & 63.8 & $1.62 / 5.3$ & $\begin{array}{c}1.47-1.87 / \\
4.8-6.1\end{array}$ & $63.8 / 141$ & $\begin{array}{c}32.0-99.8 / \\
71-220 \\
\end{array}$ \\
\hline European Ancestry & 235 & $\overline{58.5}$ & $101.70 / 5.6$ & $\begin{array}{c}1.47-1.93 / \\
4.8-6.3\end{array}$ & $72.1 / 159$ & $\begin{array}{c}32.0-99.8 / \\
71-220\end{array}$ \\
\hline African Ancestry & 18 & 53.6 & $1.75 / 5.7$ & $\begin{array}{c}1.65-1.90 / \\
5.4-6.24\end{array}$ & $69.6 / 154$ & $\begin{array}{l}48.5-93 / \\
107-205\end{array}$ \\
\hline Other Ancestry & 7 & 58.0 & $1.59 / 5.2$ & $\begin{array}{c}1.52-1.74 / \\
5.0-5.7\end{array}$ & $59.3 / 132$ & $\begin{array}{c}44.5-93 / \\
98-205\end{array}$ \\
\hline 19-29 years & $\overline{77}$ & 24.6 & $101.74 / 5.7$ & $\begin{array}{c}1.57-1.90 / \\
5.2-6.2\end{array}$ & $71.8 / 158$ & $\begin{array}{c}54.4-79.4 / \\
120-175\end{array}$ \\
\hline $30-39$ years & 18 & 35.7 & $1.78 / 5.8$ & $\begin{array}{c}1.63-1.87 / \\
5.3-6.14\end{array}$ & $78.1 / 172$ & $\begin{array}{c}48.5-99.8 / \\
107-220\end{array}$ \\
\hline $40-49$ years & 54 & 45.4 & $1.73 / 5.7$ & $\begin{array}{c}1.54-1.93 / \\
5.1-6.3\end{array}$ & $71.5 / 157$ & $\begin{array}{c}40.8-99.8 / \\
90-220\end{array}$ \\
\hline $50-59$ years & 63 & 54.3 & $1.72 / 5.6$ & $\begin{array}{c}1.50-1.88 / \\
4.9-6.2\end{array}$ & $76.1 / 168$ & $\begin{array}{c}43.5-99.8 / \\
96-220\end{array}$ \\
\hline $60-69$ years & 58 & 64.2 & $1.70 / 5.6$ & $\begin{array}{c}1.50-1.93 / \\
5.0-6.3\end{array}$ & $71.0 / 157$ & $\begin{array}{c}32.0-99.8 / \\
71-220\end{array}$ \\
\hline $70-79$ years & 41 & 74.2 & $1.68 / 5.5$ & $\begin{array}{c}1.47-1.86 / \\
4.8-6.1\end{array}$ & $67.0 / 148$ & $\begin{array}{c}33.1-99.8 / \\
73-220 \\
\end{array}$ \\
\hline $80-89$ years & 19 & 83.4 & $1.65 / 5.4$ & $\begin{array}{c}1.47-1.85 / \\
4.8-6.1 \\
\end{array}$ & $63.8 / 141$ & $\begin{array}{c}35.8-99.8 / \\
79-220 \\
\end{array}$ \\
\hline Total & 260 & 57.9 & $1.70 / 5.6$ & $\begin{array}{c}1.47-1.93 / \\
4.8-6.3\end{array}$ & $71.7 / 158$ & $\begin{array}{c}32.0-99.8 / \\
71-220\end{array}$ \\
\hline
\end{tabular}

Table 6: Sample distribution of skeletons selected from the William Bass Collection, including age, ancestry, reported stature and body mass at time of death. 


\subsection{Methods}

\subsubsection{Age Estimation Methods}

The rib age estimation methods used for this project were developed by Kunos et al. (1999), DiGangi et al. (2009), and İşcan et al. (1984, 1985). The pelvic age estimation methods were developed by Passalacqua (2009), Lovejoy, et al. (1985), Buckberry and Chamberlain (2002), Rougé-Maillart et al. (2009), and Suchey and Brooks (1990). Age assessments were performed on each skeleton without knowledge of the age, ancestry, stature, body mass, or cause of death for the specimen under consideration; the author had a research assistant for data collection at the Hamann-Todd Collection to help with this process. Sex was known for all individuals as the İşcan et al. and Suchey-Brooks methods have sex-specific criteria. All methods were applied as described by the authors. Casts for the Suchey-Brooks method were used, and colour image slides of the auricular surface for the Lovejoy et al. method were available. In all cases, the authors' specifications with regard to the side to be used were followed. When scoring the pubic symphysis, auricular surface, sacrum, and acetabulum, the methods were applied to the left side; with the right side used if the left was unavailable. When scoring the first ribs, the Kunos et al. (1999) and DiGangi et al. (2009) methods were applied to the right first ribs; if unavailable, the left ones were assessed. When scoring the fourth ribs, the ribs were seriated by the author, and the İşcan et al. (1984; 1985) method was applied to the right fourth ribs; if the right fourth rib was unavailable or damaged, the right third or fifth ribs were used. Each individual was assigned to an age phase, as specified by each method. The mean age at death within each phase for each method was then compared to the actual age at death recorded in the Hamann-Todd and William Bass collection documentation.

Prior to data collection, the author performed an intra- and inter-observer error study using the J.C.B Grant Collection curated at the University of Toronto. The purpose of this study was to become familiar with the age methods and ensure that the age estimations generated using each method were reliable. Results from the study show a high level of both intra- and inter-observer agreement (Merritt, 2013). 


\subsection{Terms and Statistical Methods}

\subsubsection{Terms}

Reliability is the degree to which a method produces the same results when used at different times, either by multiple observers or the same observer (Nance, 1987). A highly reliable age estimation method produces consistent age estimates for the same sample when applied by the same observer and different observers. Reliability for a method is tested by conducting interobserver or intra-observer variation studies to determine error rates. Low inter- or intra- observer variation (or error) indicates high reliability. Reliability can also be referred to as repeatability, indicating that the technique or method applied produces similar measurements of the same quantity or entity being measured (Adams and Byrd, 2002).

Accuracy is the degree of error in a measurement as calculated from the true value or the closeness of agreement between a quantity value obtained by measurement and the true value of the measure (Youden, 1998). For skeletal age estimation, this is the ability of a method to continually and consistently provide age intervals that encompass the true age at death of individuals. Calculations of inaccuracy, the absolute difference between actual and estimated ages at death, and bias, the directionality of these differences, are used to measure error and determine the validity of a method.

Precision is linked to accuracy and can be defined as the degree to which repeated measurements in the same conditions yield similar results (White and Folkens, 2005). Precision is determined by the number of deviations of an individual measurement from the average of the total measurements expressed as a standard deviation or variance (Youden, 1998). An age estimation method is considered precise if the estimated age at death has a small standard deviation from the average value measured for a sample.

\subsubsection{Statistical Methods}

The age distribution of the sample was tested for normalcy using the Shapiro-Wilk test. MannWhitney U nonparametric tests were used to compare the Hamann-Todd and William Bass Collection data to determine the likelihood that the individuals from the two collections come from the same population. More specifically, Mann-Whitney U tests were used to assess the differences between the descriptive statistics between the two collections. Univariate models, 
including descriptive statistics, and the analysis of variance (ANOVA) were used to evaluate differences between the two skeletal collections.

Reliability was calculated for each method by evaluating the inaccuracy and bias. Inaccuracy is the average absolute error of the age estimation, without reference to over- or under-prediction:

$$
\sum \text { estimated age - actual age } \mid / n \text {; }
$$

whereas bias is the mean over- or under- prediction of the individual:

$$
\sum \text { (estimated age - actual age) } / \mathrm{n}
$$

(Lovejoy et al., 1985 a). Accuracy and bias were calculated for each method on the entire sample, as well as by sex and ancestry.

Multivariate analysis of variance (MANOVA) and discriminant function analysis (DFA) were used to assess influence of the dependent variables (BMI, stature, body mass, and weight-bearing joints) on the independent variables (inaccuracy and bias of each method). MANOVA and DFA use the same statistical principles, which are similar to multiple linear regression, to predict an outcome. However, multiple linear regression is limited to cases where the DV is a continuous or interval variable so that the combination of predictors will, through the regression equation, produce estimated mean population numerical Y values (DV) for given values of weighted combinations of X (IV) values. MANOVA and DFA perform similar analyses, but for categorical DV. MANOVAs differ from DFAs as they examine the effect of an IV on a number of DVs, whereas DFA examines which combination of IV is best able to predict a DV.

Prior to conducting the MANOVA, a series of Pearson correlations were performed between all of the DVs in order to test the MANOVA assumption that the DVs would be correlated with each other in the moderate range of 0.20 to 0.60 (Meyers et al., 2006). Box's M $p$-values were considered non-significant at $p<0.005$ based on Huberty and Petoskey's (2000) guidelines. Pillai's Trace was used to report the ANOVA results as it is the most robust to violations of the covariation assumption (Johnson and Field, 1993). As the IVs in this study have three or more levels, eigenvalues and canonical correlations could be extracted by the MANOVA and used to calculate how much of the variance in the discriminant function derived scores can be accounted 
for by BMI, stature, and body mass. To interpret the MANOVA effects, the standardized discriminant function coefficients were used to calculate the correlations between the subscale scores and the canonically derived scores. To estimate the group centroids (i.e. canonically derived group means) for the IV categories (for example, underweight, normal, overweight, and obese for the BMI IV), the sample subscale scores were multiplied by the corresponding subscale unstandardized discriminant function coefficients and then averaged across the entire sample. In accordance with Enders (2003), an ANOVA was performed on the canonically derived data. However, because the sampling distribution associated with multivariate derived data is known to be different from univariate derived data (Neufeld and Gardner, 1990), a conservative approach to statistical significance testing was applied. Specifically, an alpha level of 0.001 was specified for the ANOVA. Cohen's $d$-values were evaluated to determine effect size. Effect size was evaluated as small $=0.2$, medium $=0.5$, and large $=0.8($ Cohen, 1992) .

Tukey Honestly Significant Difference (HSD), or Tukey $b$ in cases of uneven sample sizes, posthoc tests were used to determine significant differences between IV categories for each DV. Fisher's Least Significant Differences (LSD) tests are associated with increased type I errors (Hayter, 1986) and Bonferonni Corrections have been criticized for being too conservative (Nakagawa, 2004).

A random sample of 200 individuals was assessed to control for intra-observer error; a reliability analysis using the Kappa statistic was performed to determine consistency, with the exception of the Kunos et al. method. The Kappa statistic measures inter- and intra-observer agreement for categorical data. The Kappa evaluation criteria are based on the following: $0.41-0.60=$ moderate agreement, $0.61-0.80=$ substantial agreement, $0.81-1.00=$ near perfect agreement (Landis and Koch, 1977). For the Kunos et al. method, three traits are scored and assigned an age range; each trait assessment takes into account multiple features and results in a new age range rather than a set, previously defined phase. Because the Kunos et al. method does not have categorical age phases, interclass correlation coefficients (ICC) were used to evaluate the repeatability of this method. ICC measures how similar two or more repeated observations on continuous data are to each other rather than comparing categorically structured observations. ICC evaluation criteria are based on the following: $0.5-0.6=$ moderate agreement, $0.7-0.8=$ strong agreement, and > 
$0.8=$ near perfect agreement $($ Bartko, 1976). All statistical tests were performed with SPSS 20.0 (IBM Corp, 2012) 


\section{Chapter 3: Results}

The results chapter is divided into seven sections. Section 3.1 presents the comparisons between the individuals from the Hamann-Todd and William Bass collections to evaluate whether they can be used as one pooled sample. Section 3.2 presents the test results from the eight age estimation methods, and the descriptive statistics of the final, combined sample. Section 3.3 presents the results from the first research question: does BMI influences skeletal age estimations? Section 3.4 presents the results from the second research question: does stature influences skeletal age estimations? Section 3.5 presents the results from the third research question: does body mass influences skeletal age estimations? Section 3.6 presents the results from the fourth research question: are there differences between weight-bearing and non-weightbearing joint age estimations? Section 3.7 presents additional analyses of the skeletal materials.

\subsection{Comparison of the Individuals from the Hamann-Todd and William Bass Collections}

\subsubsection{Descriptive Differences Between the Collections}

Mann-Whitney U tests show there are significant differences between the individuals selected from each of the collections with regard to age at death and ancestry, but not sex (Table 7). The samples used from the William Bass Collection largely consists of older individuals of European descent, while the samples used from the Hamann-Todd Collection are younger with more African-Americans represented (Figure 1 and Table 8). This is to be expected as the William Bass Collection is a donor collection from Tennessee with an average age at death over 50 years of age, with most donors self-identified as "white" males. The Hamann-Todd Collection consists of migrant workers who lived during the late 19th and early 20th centuries and died in the Cuyahoga County of Ohio and whose bodies were not claimed at time of death. 


\begin{tabular}{|ll|c|c|c|c|c|c|c|}
\hline \multicolumn{1}{|c|}{ Collection } & N & $\begin{array}{c}\text { Mean } \\
\text { Rank }\end{array}$ & $\begin{array}{c}\text { Sum of } \\
\text { Ranks }\end{array}$ & $\begin{array}{c}\text { Mann- } \\
\text { Whitney U }\end{array}$ & Wilcoxon W & Z & $\begin{array}{c}\text { Sig. } \\
(\mathbf{2} \text {-tail) }\end{array}$ \\
\hline Sex & Hamann-Todd Collection & 536 & 401.03 & 214954.00 & & & & \\
& William Bass Collection & 260 & 393.28 & 102252.00 & & & & \\
& Total & 796 & & & 68322.000 & 102252.000 & -0.564 & 0.573 \\
Ancestry & Hamann-Todd Collection & 536 & 433.75 & 232490.50 & & & & \\
& William Bass Collection & 260 & 325.83 & 84715.50 & & & & \\
& Total & 796 & & & 50785.500 & 84715.500 & -7.923 & $<0.001$ \\
\hline & Hamann-Todd Collection & 536 & 359.61 & 192748.50 & & & & \\
& William Bass Collection & 260 & 478.68 & 124457.50 & & & & \\
& Total & 796 & & & 48832.500 & 192748.500 & -6.854 & $<0.001$ \\
\hline
\end{tabular}

Table 7: Mann-Whitney $U$ tests for significance for age at death, sex, and ancestry between samples from the Hamann-Todd and William Bass Collections.

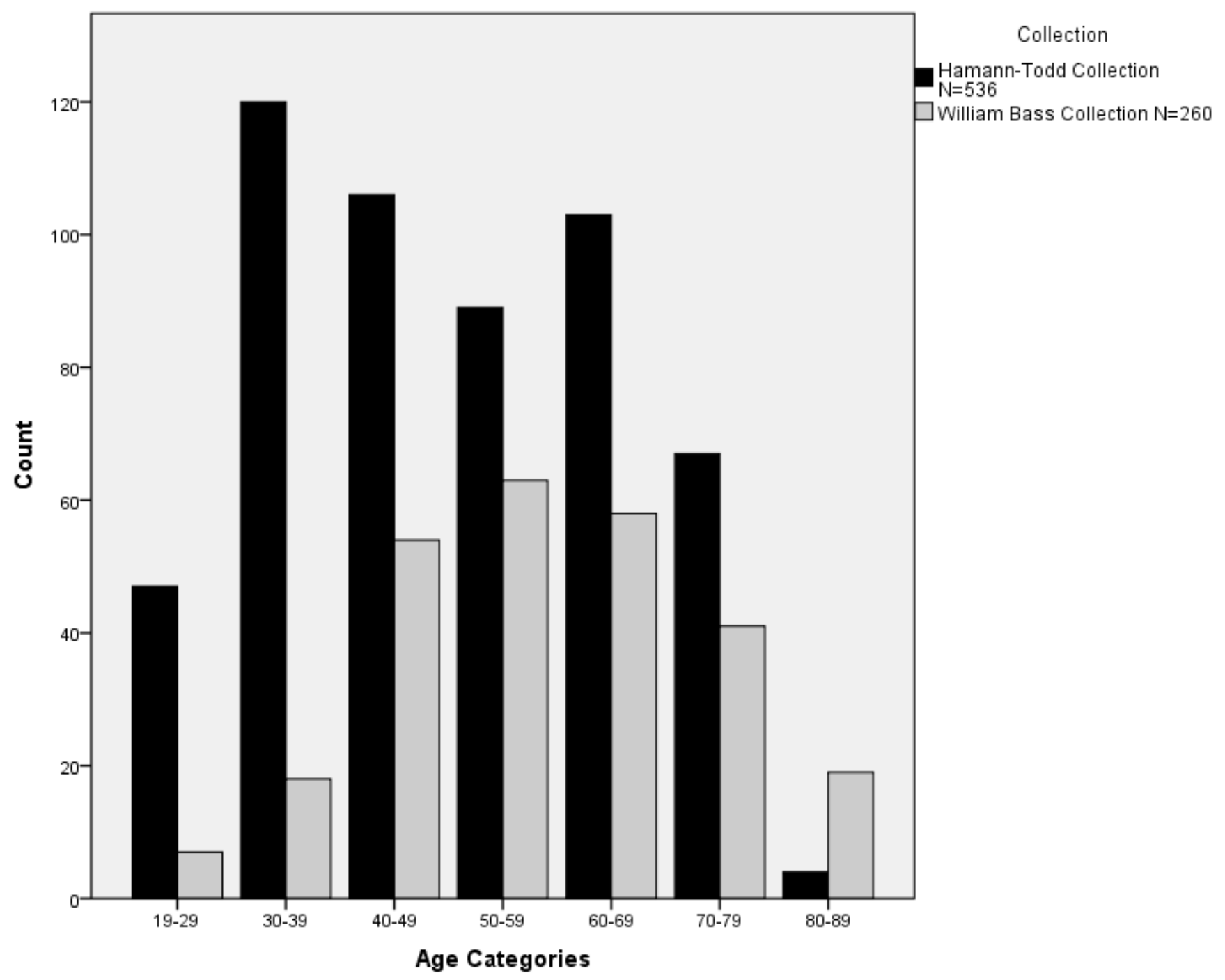

Figure 1: Age at death distribution for the samples from the Hamann-Todd and William Bass Collections. 


\begin{tabular}{|l|c|c|c|}
\hline Ancestry & Hamann-Todd Collection & William Bass Collection & Total \\
\hline European & 334 & 235 & 569 \\
African & 199 & 18 & 217 \\
Hispanic & 0 & 4 & 4 \\
Asian & 1 & 1 & 2 \\
Aboriginal & 0 & 1 & 1 \\
Other & 2 & 1 & 3 \\
\hline
\end{tabular}

Table 8: Number of individuals in each ancestry category for samples from the HamannTodd and William Bass Collections.

Mann-Whitney $U$ tests show there are no significant differences in stature between the samples from the two collections (Table 9); however, there are significant differences in body mass, with individuals from the William Bass Collection heavier on average compared to individuals from the Hamann-Todd Collection. The distribution of stature and mass from the sample is illustrated in Figure 2.

\begin{tabular}{|c|c|c|c|c|c|c|c|c|}
\hline & Collection & $\mathbf{n}$ & Mean Rank & Sum of Ranks & $\begin{array}{c}\text { Mann-Whitney } \\
\text { U }\end{array}$ & $\begin{array}{c}\text { Wilcoxon } \\
\text { W }\end{array}$ & $\mathbf{Z}$ & $\begin{array}{c}\text { Sig. } \\
\text { (2-tail) }\end{array}$ \\
\hline \multirow[t]{3}{*}{$\overline{\text { Stature }(\mathrm{m})}$} & Hamann-Todd Collection & 536 & 388.03 & 207982.00 & \multirow{5}{*}{64066.000} & \multirow{5}{*}{207982.000} & \multirow{5}{*}{-1.845} & \multirow{5}{*}{0.065} \\
\hline & William Bass Collection & 260 & 420.09 & 109224.00 & & & & \\
\hline & Total & 796 & & & & & & \\
\hline \multirow{3}{*}{ Mass (kg) } & Hamann-Todd Collection & 536 & 355.68 & 190647.00 & & & & \\
\hline & William Bass Collection & 260 & 486.77 & 126559.00 & & & & \\
\hline & Total & 796 & & & 46731.000 & 190647.000 & -7.545 & $<0.001$ \\
\hline
\end{tabular}

Table 9: Mann-Whitney $U$ tests for significance between stature and body mass for the samples from the Hamann-Todd and William Bass Collections. 


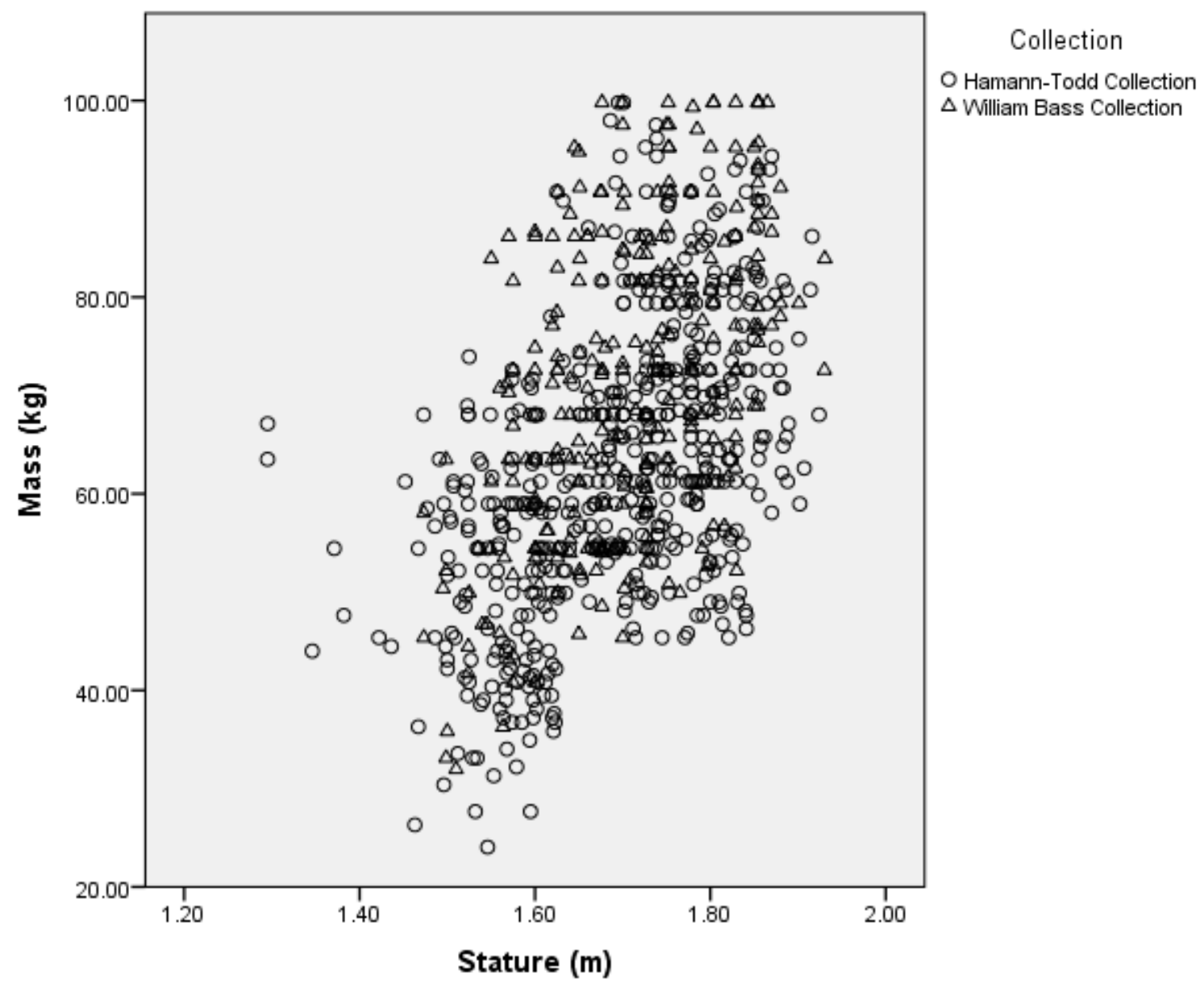

Figure 2: Distribution of stature and body mass for the samples from the Hamann-Todd and William Bass Collections.

As described in Chapter 2, each individual was classified into a BMI group based on stature and body mass. Mann-Whitney $U$ tests show there are significant differences between the two skeletal collections for BMI. There are more overweight and obese individuals from the William Bass Collection sample while the Hamann-Todd Collection sample has a higher proportion of individuals in the underweight and normal-sized BMI categories (Table 10 and Figure 3).

\begin{tabular}{|ll|c|c|c|c|c|c|c|}
\hline \multicolumn{1}{|c|}{ Collection } & $\mathbf{n}$ & $\begin{array}{c}\text { Mean } \\
\text { Rank }\end{array}$ & Sum of Ranks & $\begin{array}{c}\text { Mann-Whitney } \\
\text { U }\end{array}$ & $\begin{array}{c}\text { Wilcoxon } \\
\text { W }\end{array}$ & Z & $\begin{array}{c}\text { Sig. } \\
\text { (2-tail) }\end{array}$ \\
\hline BMI & Hamann-Todd Collection & 536 & 358.68 & 192253.50 & & & & \\
& William Bass Collection & 260 & 480.59 & 124952.50 & & & & \\
\multicolumn{2}{l|}{ Total } & 796 & & & 48337.500 & 192253.500 & -7.676 & $<0.001$ \\
\hline
\end{tabular}

Table 10: Mann-Whitney U Tests showing significant differences among BMI categories between the samples from the Hamann-Todd and William Bass Collections. 


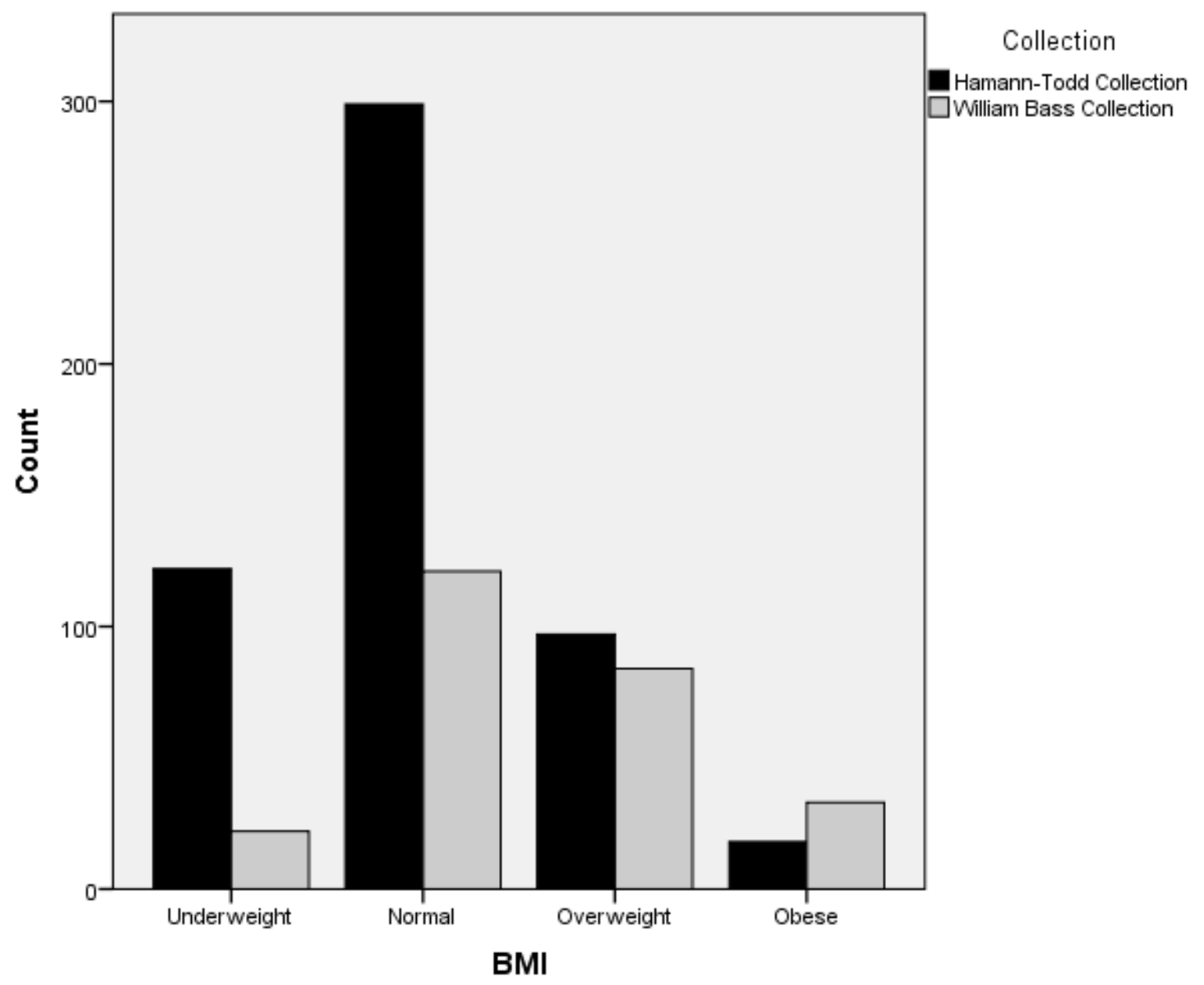

Figure 3: Distribution of BMI categories between the samples from the Hamann-Todd and William Bass Collections.

Individuals were chosen based on strict inclusion criteria for this project; therefore, any discrepancies between the samples from the two collections reflects decisions made to meet the parameters of this project.

\subsubsection{The Combined Sample from the Hamann-Todd and William Bass Collections}

Table 11 shows the combined sample composition of the 796 individuals from the Hamann-Todd and William Bass Collections. The mean age at death is 52.1 years, with a range of 19 to 89 years; the average stature is $1.70 \mathrm{~m}(5.6 \mathrm{ft})$, with a range of $1.30 \mathrm{~m}$ to $1.93 \mathrm{~m}(4.3 \mathrm{ft}$ to $6.3 \mathrm{ft})$; and the average body mass is $65.5 \mathrm{~kg}$ (145lbs), with a range of $25.0 \mathrm{~kg}$ to $99.8 \mathrm{~kg}$ (53lbs to $220 \mathrm{lbs}$ ). Most individuals are North American of European ancestry, and more males than females are represented. 


\begin{tabular}{|c|c|c|c|c|c|c|}
\hline & $\mathbf{n}$ & $\begin{array}{c}\text { Mean } \\
\text { Age (yrs) }\end{array}$ & $\begin{array}{c}\text { Average } \\
\text { Stature }(\mathrm{m} / \mathrm{ft})\end{array}$ & $\begin{array}{c}\text { Stature Range } \\
(\mathrm{m} / \mathrm{ft})\end{array}$ & $\begin{array}{l}\text { Average Body } \\
\text { Mass (kg/lbs) }\end{array}$ & $\begin{array}{c}\text { Body Mass } \\
\text { Range (kg/lbs) }\end{array}$ \\
\hline Males & 559 & 52.1 & $1.74 / 5.7$ & $\begin{array}{c}1.30-1.93 / \\
4.3-6.3\end{array}$ & $68.9 / 152$ & $\begin{array}{c}32.2-99.8 / \\
71-220\end{array}$ \\
\hline Females & 237 & 52.8 & $1.60 / 5.3$ & $\begin{array}{c}1.30-1.87 / \\
4.3-6.1\end{array}$ & $57.7 / 127$ & $\begin{array}{c}24.0-99.8 / \\
53-220\end{array}$ \\
\hline European Ancestry & 569 & 55.1 & $1.69 / 5.6$ & $\begin{array}{c}1.30-1.93 / \\
4.3-6.3\end{array}$ & $66.6 / 147$ & $\begin{array}{c}26.3-99.8 / \\
58-220\end{array}$ \\
\hline African Ancestry & 217 & 45.4 & $1.72 / 5.6$ & $\begin{array}{c}1.50-1.92 / \\
4.9-6.3\end{array}$ & $63.1 / 139$ & $\begin{array}{c}24.0-99.8 / \\
53-220 /\end{array}$ \\
\hline Other Ancestry & 10 & 50.7 & $1.60 / 5.3$ & $\begin{array}{c}1.50-1.92 / \\
5.0-6.3\end{array}$ & $57.5 / 127$ & $\begin{array}{c}42.6-99.8 / \\
94-220\end{array}$ \\
\hline $18-29$ years & 54 & 24.7 & $1.71 / 5.6$ & $\begin{array}{c}1.37-1.90 / \\
4.5-6.2\end{array}$ & $62.5 / 138$ & $\begin{array}{c}37.2-89.8 / \\
82-198\end{array}$ \\
\hline $30-39$ years & 138 & 35.0 & $1.71 / 5.6$ & $\begin{array}{c}1.30-1.92 / \\
4.3-6.3\end{array}$ & $66.8 / 147$ & $\begin{array}{c}24.0-99.8 / \\
53-220\end{array}$ \\
\hline $40-49$ years & 160 & 44.3 & $1.70 / 5.6$ & $\begin{array}{c}1.44-1.93 / \\
4.7-6.3\end{array}$ & $66.6 / 147$ & $\begin{array}{c}27.7-99.8 / \\
61-220 \\
\end{array}$ \\
\hline $50-59$ years & 152 & 53.8 & $1.70 / 5.6$ & $\begin{array}{c}1.30-1.92 / \\
4.3-6.3 \\
\end{array}$ & $69.3 / 153$ & $\begin{array}{c}27.7-99.8 / \\
61-220 \\
\end{array}$ \\
\hline $60-69$ years & 161 & 64.0 & $1.70 / 5.6$ & $\begin{array}{c}1.49-1.93 / \\
4.9-6.3\end{array}$ & $64.3 / 142$ & $\begin{array}{c}30.4-99.8 / \\
67-220\end{array}$ \\
\hline $70-79$ years & 108 & 74.0 & $1.66 / 5.5$ & $\begin{array}{c}1.38-1.86 / \\
4.5-6.1 \\
\end{array}$ & $61.1 / 135$ & $\begin{array}{c}26.3-99.8 / \\
58-220 \\
\end{array}$ \\
\hline $80-89$ years & 23 & 83.0 & $1.65 / 5.4$ & $\begin{array}{c}1.47-1.85 / \\
4.8-6.1 \\
\end{array}$ & $62.5 / 138$ & $\begin{array}{c}31.3-99.8 / \\
69-220 \\
\end{array}$ \\
\hline Total & 796 & 52.1 & $1.70 / 5.6$ & $\begin{array}{c}1.30-1.93 / \\
4.3-6.3\end{array}$ & $65.5 / 145$ & $\begin{array}{c}24.0-99.8 / \\
53-220\end{array}$ \\
\hline
\end{tabular}

Table 11: Sample distribution by sex, ancestry, and age categories.

Table 12 shows the total number of individuals from each stature and body mass category included in the combined sample to be evaluated (see Appendix 3 for the composition of individuals from the Hamann-Todd Collection; see Appendix 4 for the composition of individuals from the William Bass Collection). The distribution of individuals by stature and body mass shows a wide range of body sizes in the sample, with most individuals falling within a normal distribution (Figure 4 and Figure 5). 


\begin{tabular}{|c|c|c|c|c|c|c|c|}
\hline & $\begin{array}{l}<1.54 \mathrm{~m} \\
(<5.0 \mathrm{ft})\end{array}$ & $\begin{array}{c}1.55-1.62 \mathrm{~m} \\
(5.1-5.3 \mathrm{ft})\end{array}$ & $\begin{array}{c}1.63-1.70 \mathrm{~m} \\
(5.4-5.6 \mathrm{ft})\end{array}$ & $\begin{array}{c}1.72-1.78 \mathrm{~m} \\
(5.7-5.9 \mathrm{ft})\end{array}$ & $\begin{array}{l}1.79-1.84 m \\
(5.10-6.0 f t)\end{array}$ & $\begin{array}{c}1.85-1.92 m \\
(6.1-6.3 f t)\end{array}$ & Total \\
\hline $\begin{array}{l}<45.0 \mathrm{~kg} \\
(<100 \mathrm{lbs})\end{array}$ & 24 & 47 & 0 & 0 & 0 & 0 & 71 \\
\hline $\begin{array}{l}45.4-56.5 \mathrm{~kg} \\
(100-124 \mathrm{lbs})\end{array}$ & 26 & 37 & 41 & 36 & 29 & 0 & 169 \\
\hline $\begin{array}{l}56.7-67.6 \mathrm{~kg} \\
(125-149 \mathrm{lbs})\end{array}$ & 20 & 37 & 43 & 46 & 38 & 13 & 197 \\
\hline $\begin{array}{l}68.0-79.0 \mathrm{~kg} \\
(150-174 \mathrm{lbs})\end{array}$ & 5 & 23 & 44 & 42 & 44 & 19 & 177 \\
\hline $\begin{array}{l}\text { 79.4-89.8kg } \\
\text { (175-199lbs) }\end{array}$ & 0 & 6 & 19 & 40 & 38 & 21 & 124 \\
\hline $\begin{array}{l}\text { 90.2-101.6kg } \\
\text { (200-224lbs) }\end{array}$ & 0 & 0 & 15 & 15 & 15 & 13 & 58 \\
\hline Total & 75 & 150 & 162 & 179 & 164 & 66 & 796 \\
\hline
\end{tabular}

Table 12: Distribution of the combined sample by stature and body mass categories.

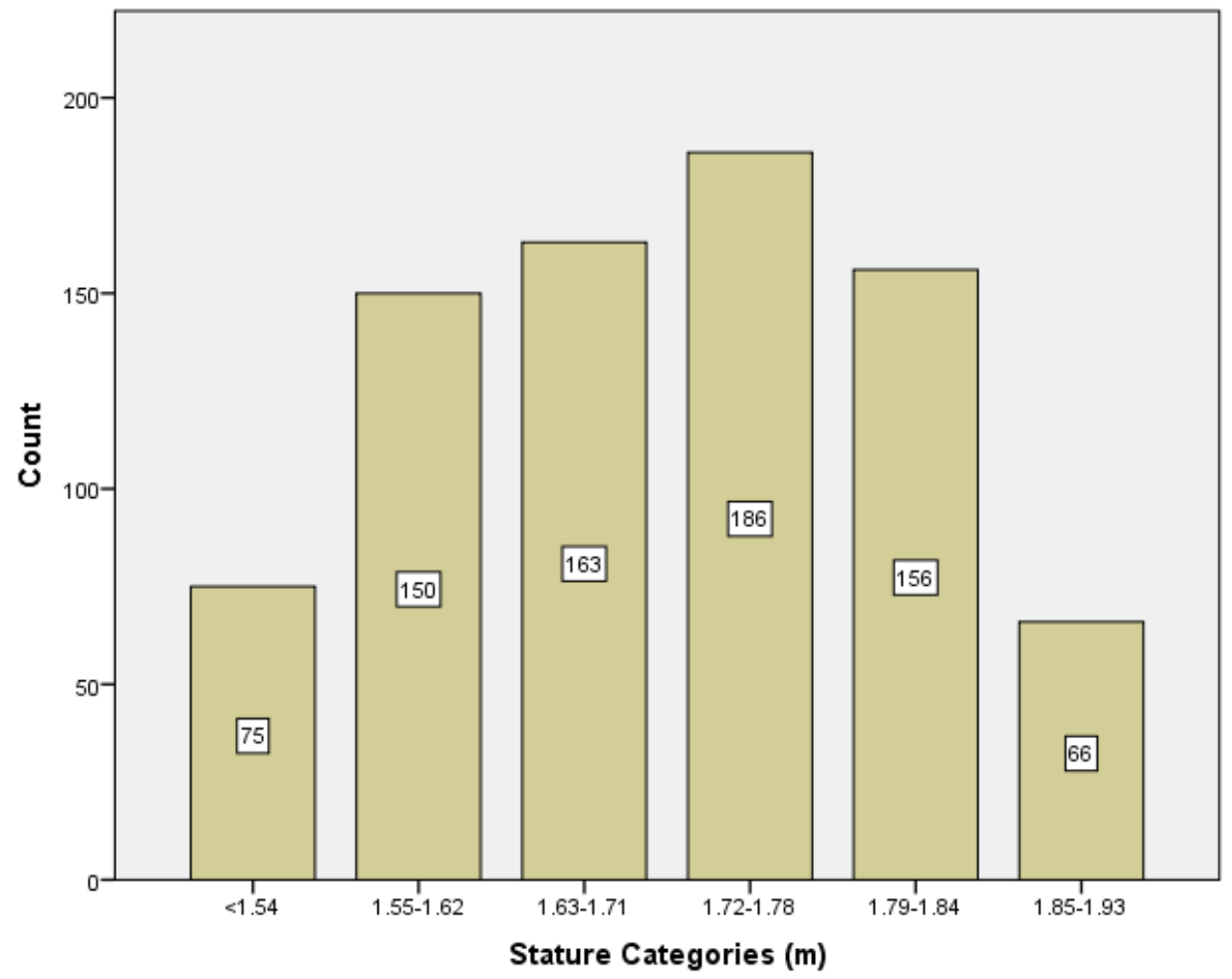

Figure 4: Distribution of the combined sample by stature. 


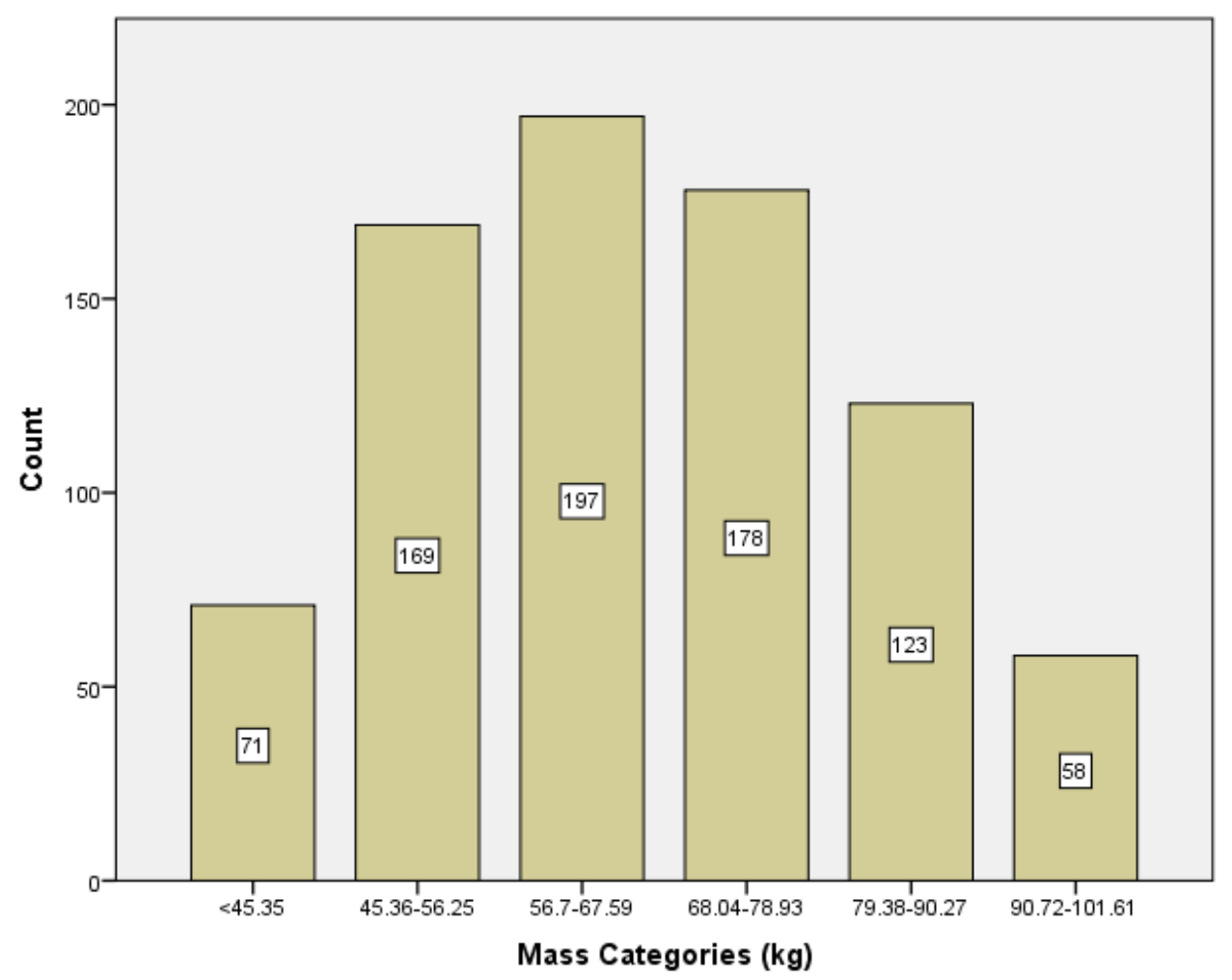

Figure 5: Distribution of the combined sample by body mass.

When separated by BMI, 420 individuals are classified as normal-sized, 144 individuals as underweight, 181 individuals as overweight, and 51 individuals as obese, as defined by the WHO (Table 13).

\begin{tabular}{|l|c|c|c|c|c|c|}
\hline \multicolumn{1}{|c|}{ BMI } & $\mathbf{n}$ & $\begin{array}{c}\text { Mean Age } \\
(\mathbf{y r s})\end{array}$ & $\begin{array}{c}\text { Average Stature } \\
(\mathbf{m} / \mathbf{f t})\end{array}$ & $\begin{array}{c}\text { Stature Range } \\
(\mathbf{m} / \mathbf{f t})\end{array}$ & $\begin{array}{c}\text { Average Body Mass } \\
(\mathbf{k g} / \mathbf{l b s})\end{array}$ & $\begin{array}{c}\text { Body Mass Range } \\
(\mathbf{k g} / \mathbf{l b s})\end{array}$ \\
\hline Underweight & 144 & 54.0 & $1.68 / 5.5$ & $1.46-1.92 /$ & $46.5 / 103$ & $24.0-83.9 /$ \\
& & & & $4.8-6.3$ & & $53-185$ \\
\hline Normal & 420 & 51.9 & $1.70 / 5.6$ & $\begin{array}{c}1.35-1.93 / \\
4.2-6.3\end{array}$ & $63.6 / 140$ & $\begin{array}{c}42.2-97.5 / \\
93-215\end{array}$ \\
\hline Overweight & 181 & 50.7 & $1.70 / 5.6$ & $1.40-1.90 /$ & $78.1 / 172$ & $51.3-99.8 /$ \\
& & & & $4.5-6.2$ & & $113-220$ \\
\hline Obese & 51 & 56.6 & $1.67 / 5.5$ & $1.30-1.87 /$ & $90.7 / 200$ & $63.5-99.8 /$ \\
& & & & $4.3-6.1$ & & $140-220$ \\
\hline
\end{tabular}

Table 13: Distribution of the combined sample by BMI, including number of individuals in each category, average recorded stature and body mass, and stature and body mass ranges. 


\subsubsection{Tests for Normality}

The Shapiro-Wilk test shows the age at death is not normally distributed $(0.983, p<0.001)$; however, the histogram (Figure 6), Q-Q Plots (Figure 7), and Detrended normal Q-Q Plots of Age (Figure 8) show that the data is normally distributed. The Central Limit Theorum states that the larger the number of individuals in a sample, the more likely the sample mean will represent a normal distribution, even when the sample itself is not an independent sample. Also, with large datasets, normality tests are often over-powered and give significant results. Therefore, both parametric and non-parametric tests will be used for the analysis, with more focus on the parametric results as they are more robust to deviations with large datasets.

In order to use the inaccuracy and bias scores in MANOVA and DFA analyses, the results were tested for tested for multivariate normality. Mardia's tests show that both the inaccuracy ( $p=$ $0.065)$ and bias values $(p=0.078)$ are normally distributed for multivariate analyses.

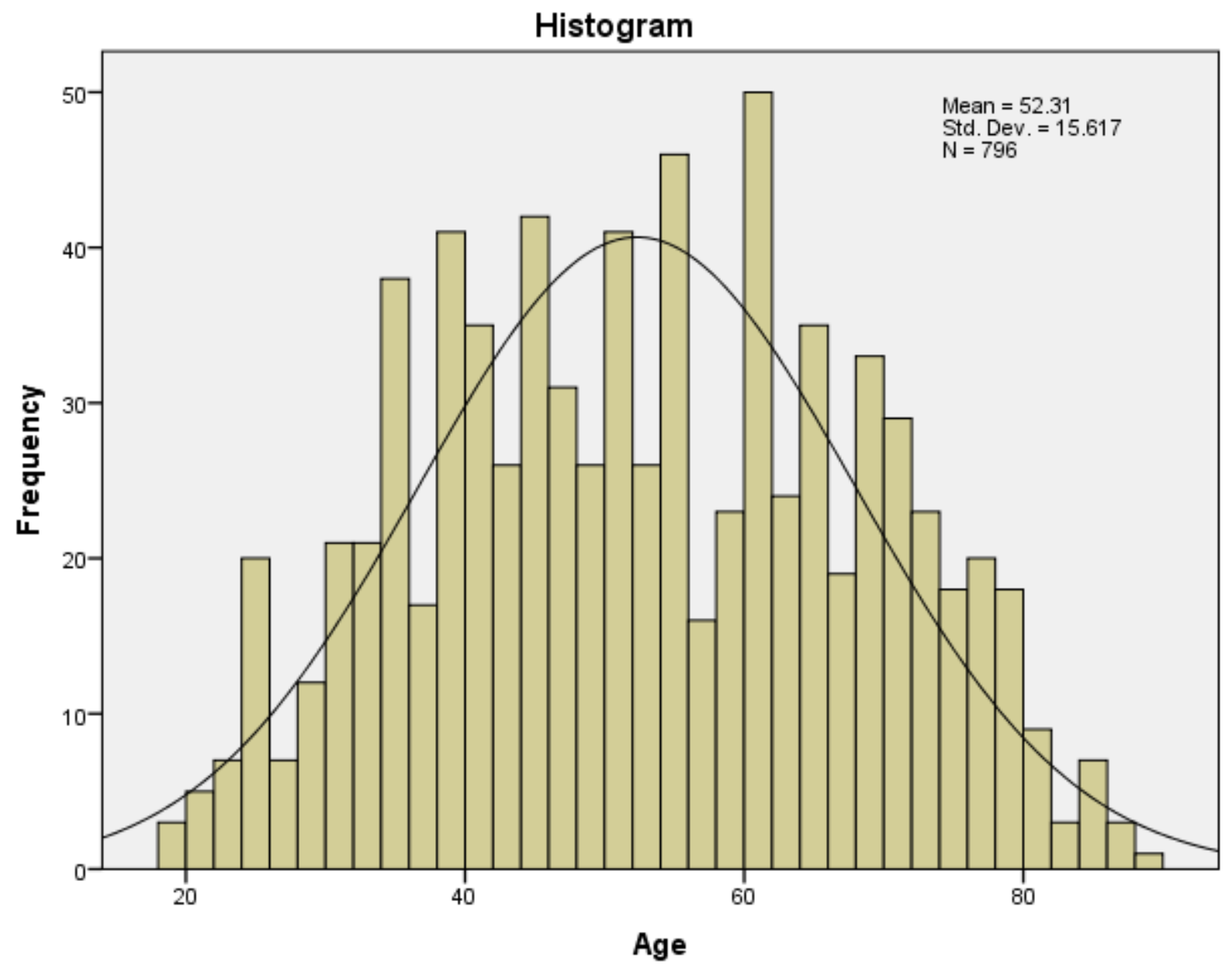

Figure 6: Histogram showing total sample size by age with a normal distribution curve. 


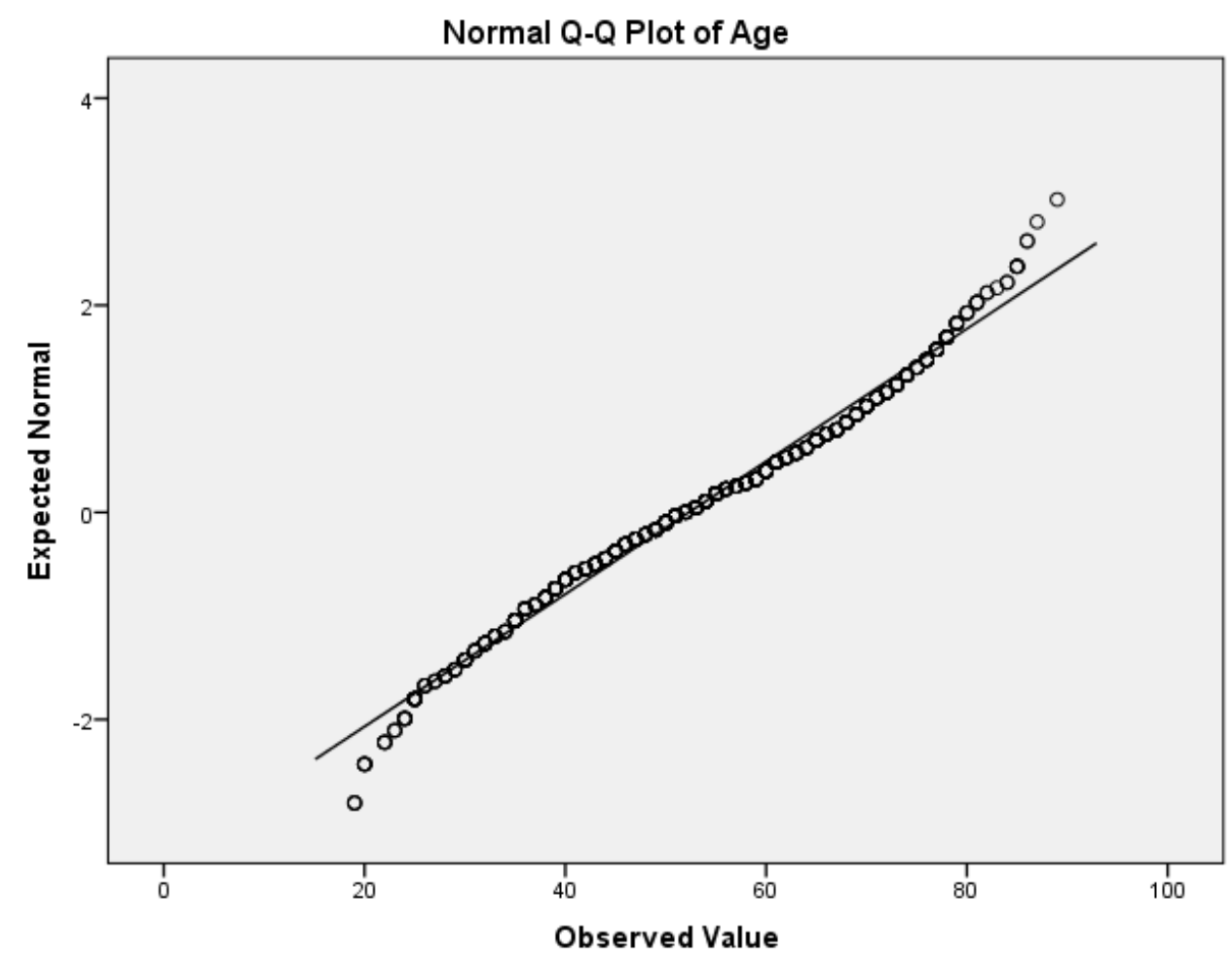

Figure 7: Q-Q Plot for Age showing a normal distribution.

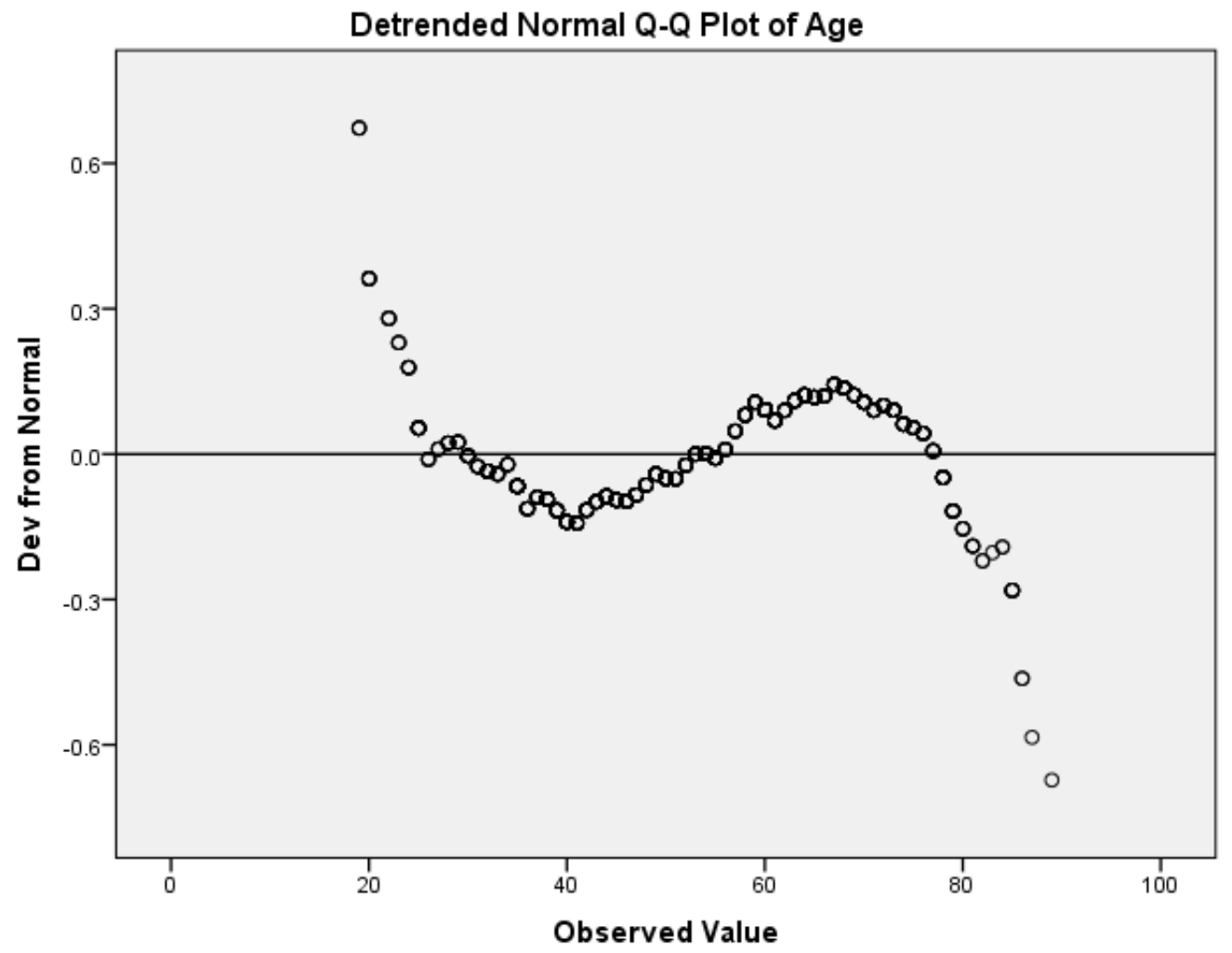

Figure 8: Detrended normal Q-Q Plot for age showing a normal distribution. 


\subsection{Tests of the Age Estimation Methods}

\subsubsection{Kunos et al. First Rib Method}

Appendix 5 provides the descriptive statistics for the Kunos et al. (1999) method. Intra-observer reliability shows a high level of agreement for the randomly selected test sample [ICC $=0.799$ (F $=8.950, \mathrm{df}=212, p<0.001)]$; therefore, the age estimations are considered reliable.

Table 14 and Table 15 present the accuracy and bias scores for the Kunos et al. method. Parametric, independent samples t-tests show there are no significant differences between males and females for accuracy $(\mathrm{t}=-1.398, \mathrm{df}=778, p=0.163)$; however, there are significant differences between males and females for bias $(\mathrm{t}=3.897, \mathrm{df}=390.864, p<0.001)$. Similar results are generated from non-parametric Mann-Whitney $\mathrm{U}$ tests (inaccuracy: $\mathrm{U}=66,437, p=$ 0.346 ; bias: $\mathrm{U}=53,951.50, p=0.001)$. Females are typically under-aged $(\bar{x}=-0.39$ years, $s . d .=$ 13.84 years), while males are over-aged by approximately 3.5 years $(\bar{x}=3.68$ years, $s . d .=12.13$ years).

When accuracy and bias are compared by ancestry, independent sample t-tests indicate there are no significant differences between individuals of European and African ancestry for accuracy $(\mathrm{t}$ $=-1.070, \mathrm{df}=768, p=0.285)$, but there are for bias $(\mathrm{t}=-4.089, \mathrm{df}=768, p<0.001)$. These results are similar when using non-parametric Mann-Whitney $\mathrm{U}$ tests (inaccuracy: $\mathrm{U}=63,446, p$ $=0.152$; bias: $\mathrm{U}=70,849, p<0.001)$. Individuals of European ancestry are typically over-aged by approximately one year ( $\bar{x}=1.24$ years, s.d. $=12.860$ years $)$ while individuals of African ancestry are typically over-aged by approximately 5.5 years $(\bar{x}=5.41$ years, $s . d .=12.089$ years).

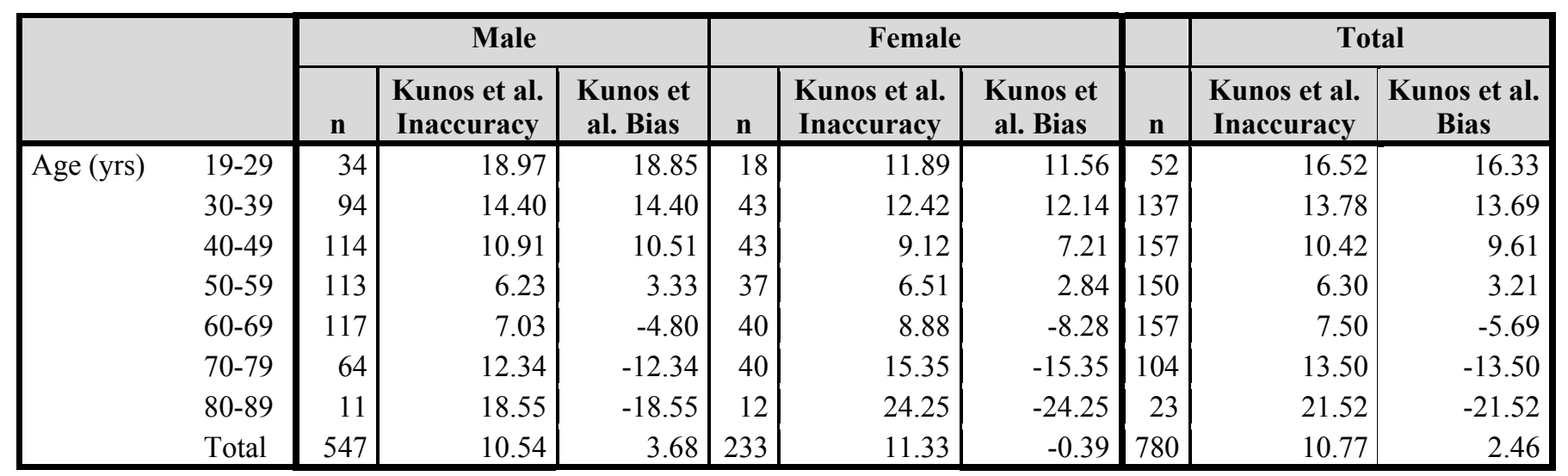

Table 14: Inaccuracy and bias scores from the Kunos et al. first rib age estimates for males and females. All values are in years. 


\begin{tabular}{|c|c|c|c|c|c|c|c|c|c|c|}
\hline & & \multicolumn{3}{|c|}{ European } & \multicolumn{3}{|c|}{ African } & & \multicolumn{2}{|c|}{ Other Ancestry } \\
\hline & & $\mathbf{n}$ & $\begin{array}{l}\text { Kunos et al. } \\
\text { Inaccuracy }\end{array}$ & $\begin{array}{l}\text { Kunos et } \\
\text { al. Bias }\end{array}$ & $\mathbf{n}$ & $\begin{array}{l}\text { Kunos et al. } \\
\text { Inaccuracy }\end{array}$ & $\begin{array}{l}\text { Kunos et } \\
\text { al. Bias }\end{array}$ & $\mathbf{n}$ & $\begin{array}{l}\text { Kunos et al. } \\
\text { Inaccuracy }\end{array}$ & $\begin{array}{c}\text { Kunos et al. } \\
\text { Bias }\end{array}$ \\
\hline \multirow{8}{*}{ Age (yrs) } & $19-29$ & 21 & 18.48 & 18.48 & 29 & 14.76 & 14.41 & 2 & 21.50 & 21.50 \\
\hline & $30-39$ & 73 & 14.92 & 14.92 & 62 & 12.39 & 12.19 & 2 & 15.50 & 15.50 \\
\hline & $40-49$ & 106 & 10.57 & 10.00 & 49 & 10.00 & 8.61 & 2 & 13.00 & 13.00 \\
\hline & $50-59$ & 123 & 6.01 & 3.60 & 25 & 8.00 & 1.68 & 2 & 3.00 & -2.00 \\
\hline & $60-69$ & 132 & 7.55 & -5.62 & 24 & 7.33 & -6.08 & 1 & 5.00 & -5.00 \\
\hline & $70-79$ & 82 & 13.89 & -13.89 & 22 & 12.05 & -12.05 & 0 & N/A & N/A \\
\hline & $80-89$ & 19 & 21.42 & -21.42 & 3 & 23.33 & -23.33 & 1 & 18.00 & -18.00 \\
\hline & Total & 556 & 10.57 & 1.24 & 214 & 11.20 & 5.41 & 10 & 12.90 & 7.30 \\
\hline
\end{tabular}

Table 15: Inaccuracy and bias scores from the Kunos et al. first rib age estimates separated by ancestry. All values are in years.

When known age at death is plotted against bias, the whisker-box plots show that younger individuals are over-aged and older individuals are under-aged (Figure 9). Individuals between the ages of 30 and 39 years, and 60 and 79 years have the most outliers at four each, and most are under-aged. Overall, the Kunos et al. method follows the expected bias patterns in age estimation with younger individuals over-aged and older individuals under-aged.

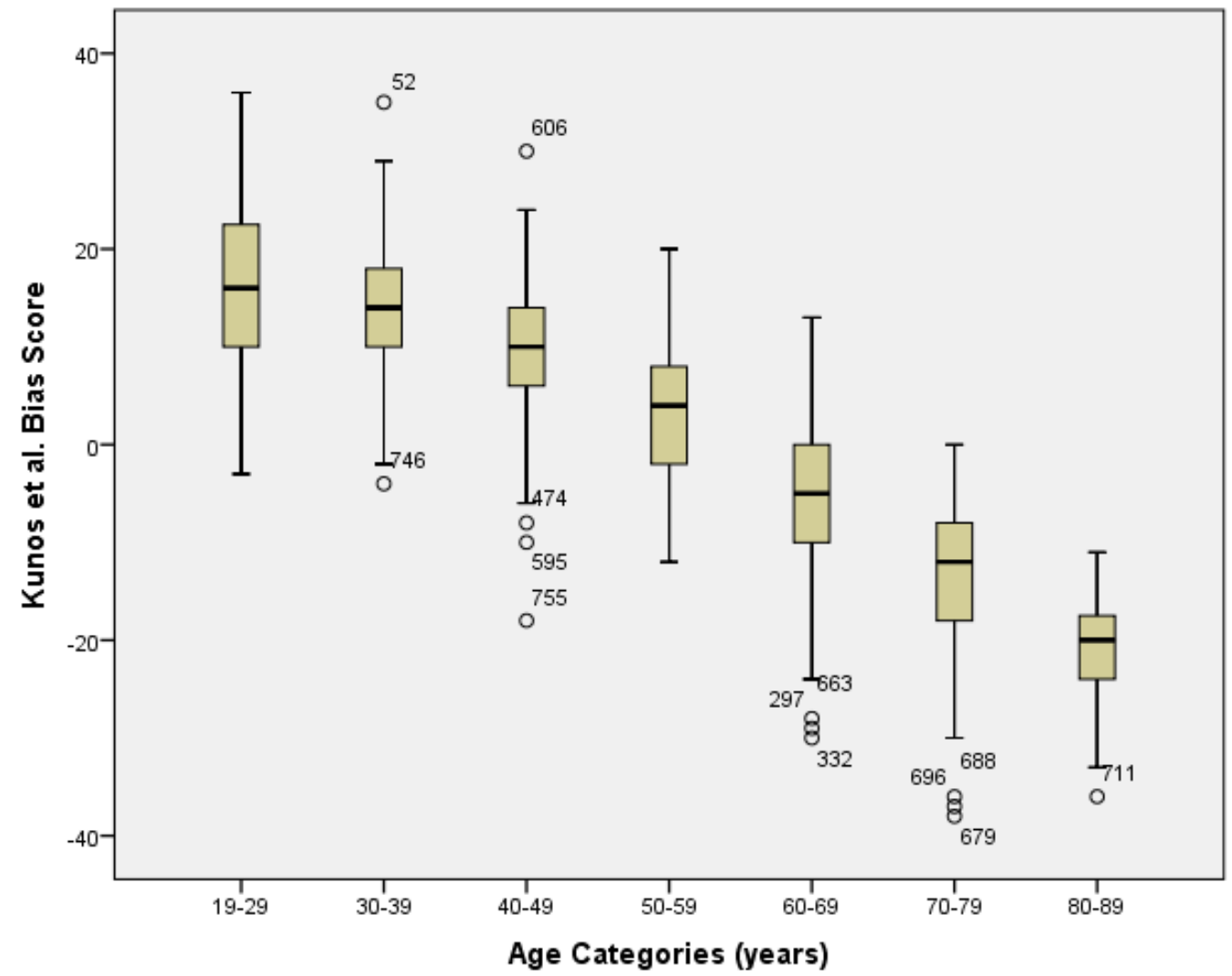

Figure 9: Mean bias scores for the Kunos et al. method categorized by age at death. 


\subsubsection{DiGangi et al. First Rib Method}

Appendix 6 provides the descriptive statistics for the DiGangi et al. method. Intra-observer reliability shows a high level of agreement for the randomly selected test sample [Kappa $=0.659$, $95 \%$ CI $(0.591-0.728)]$; therefore, the age estimations are considered reliable.

Table 16 and Table 17 present the accuracy and bias scores for the DiGangi et al. method. Parametric, independent samples t-tests show there are significant differences between males and females for accuracy $(\mathrm{t}=-3.692, \mathrm{df}=362.381, p<0.001)$ and bias $(\mathrm{t}=4.146, \mathrm{df}=764, p<$ 0.001). Similar results are generated from non-parametric Mann-Whitney $U$ tests (inaccuracy: $U$ $=52,303.00, p=0.001$; bias: $\mathrm{U}=51,309.00, p<0.001)$. Inaccuracy is 14.90 years for males $(s . d .=10.75$ years) and 18.55 years for females (s.d. $=13.23$ years), with males under-aged by approximately 12 years $(\bar{x}=-12.34$ years, $s . d .=13.63$ years $)$ and females under-aged by almost 17 years $(\bar{x}=-16.96$ years, $s . d .=15.23$ years $)$.

When accuracy and bias are compared by ancestry, independent sample t-tests indicate there are significant differences between individuals of European and African ancestry for accuracy $(\mathrm{t}=$ 4.931, $\mathrm{df}=464.68, p<0.001)$, and bias $(\mathrm{t}=-4.890, \mathrm{df}=425.33, p<0.001)$. These results are similar when using non-parametric Mann-Whitney $\mathrm{U}$ tests (inaccuracy: $\mathrm{U}=45,912.50, p<$ 0.001 ; bias: $\mathrm{U}=45,263.50, p<0.001$ ). Inaccuracy is 17.20 years for individuals of European descent (s.d. $=12.06$ years) and 12.99 years for individuals of African ancestry descent (s.d. $=$ 9.90 years). Individuals of European ancestry are typically under-aged by approximately 15 years $(\bar{x}=-15.21$ years, $s . d .=14.50$ years $)$ while individuals of African ancestry are typically under-aged by approximately 10 years $(\bar{x}=-9.89$ years, $s . d$. $=13.02$ years). 


\begin{tabular}{|c|c|c|c|c|c|c|c|c|c|c|}
\hline & \multicolumn{3}{|c|}{ Male } & \multicolumn{3}{|c|}{ Female } & \multicolumn{3}{|c|}{ Total } \\
\hline & & n & $\begin{array}{c}\text { DiGangi et al. } \\
\text { Inaccuracy }\end{array}$ & $\begin{array}{l}\text { DiGangi } \\
\text { et al. Bias }\end{array}$ & $\mathbf{n}$ & $\begin{array}{l}\text { DiGangi et al. } \\
\text { Inaccuracy }\end{array}$ & $\begin{array}{l}\text { DiGangi } \\
\text { et al. Bias }\end{array}$ & n & $\begin{array}{l}\text { DiGangi et al. } \\
\text { Inaccuracy }\end{array}$ & $\begin{array}{l}\text { DiGangi } \\
\text { et al. Bias }\end{array}$ \\
\hline \multirow[t]{8}{*}{ Age (yrs) } & $19-29$ & 33 & 8.45 & 3.12 & 18 & 6.11 & -4.33 & 51 & 7.63 & 0.49 \\
\hline & $30-39$ & 92 & 7.42 & -2.16 & 43 & 9.12 & -4.74 & 135 & 7.96 & -2.99 \\
\hline & $40-49$ & 111 & 9.30 & -5.69 & 43 & 13.21 & -10.88 & 154 & 10.39 & -7.14 \\
\hline & $50-59$ & 112 & 13.00 & -12.20 & 36 & 14.81 & -13.53 & 148 & 13.44 & -12.52 \\
\hline & $60-69$ & 116 & 20.84 & -20.65 & 39 & 26.95 & -26.95 & 155 & 22.37 & -22.23 \\
\hline & 70-79 & 62 & 28.35 & -28.35 & 39 & 29.54 & -29.54 & 101 & 28.81 & -28.81 \\
\hline & $80-89$ & 11 & 34.27 & -34.27 & 11 & 40.27 & -40.27 & 22 & 37.27 & -37.27 \\
\hline & Total & 537 & 14.90 & -12.34 & 229 & 18.55 & -16.96 & 766 & 15.99 & -13.72 \\
\hline
\end{tabular}

Table 16: Inaccuracy and bias scores from the DiGangi et al. first rib age estimates for males and females. All values are in years.

\begin{tabular}{|c|c|c|c|c|c|c|c|c|c|c|}
\hline & \multicolumn{3}{|c|}{ European } & \multicolumn{3}{|c|}{ African } & \multicolumn{3}{|c|}{ Other Ancestry } \\
\hline & & $\mathbf{n}$ & $\begin{array}{c}\text { DiGangi et al. } \\
\text { Inaccuracy }\end{array}$ & $\begin{array}{c}\text { DiGangi } \\
\text { et al. Bias }\end{array}$ & $\mathbf{n}$ & $\begin{array}{l}\text { DiGangi et al. } \\
\text { Inaccuracy }\end{array}$ & $\begin{array}{l}\text { DiGangi } \\
\text { et al. Bias }\end{array}$ & n & $\begin{array}{l}\text { DiGangi et al. } \\
\text { Inaccuracy }\end{array}$ & $\begin{array}{l}\text { DiGangi et } \\
\text { al. Bias }\end{array}$ \\
\hline \multirow[t]{8}{*}{ Age (yrs) } & $19-29$ & 21 & 8.19 & 2.95 & 29 & 7.41 & -1.21 & 1 & 2.00 & -2.00 \\
\hline & $30-39$ & 71 & 7.65 & -2.35 & 62 & 8.40 & -3.63 & 2 & 5.50 & -5.50 \\
\hline & $40-49$ & 104 & 10.93 & -7.49 & 48 & 9.56 & -6.60 & 2 & 2.00 & -2.00 \\
\hline & $50-59$ & 121 & 13.05 & -12.26 & 25 & 14.76 & -13.16 & 2 & 20.50 & -20.50 \\
\hline & $60-69$ & 130 & 22.22 & -22.05 & 24 & 23.00 & -23.00 & 1 & 28.00 & -28.00 \\
\hline & $70-79$ & 79 & 29.56 & -29.56 & 22 & 26.14 & -26.14 & 0 & N/A & N/A \\
\hline & $80-89$ & 19 & 37.95 & -37.35 & 2 & 31.50 & -31.50 & 1 & 36.00 & -36.00 \\
\hline & Total & 545 & 17.20 & -15.21 & 212 & 12.99 & -9.89 & 9 & 13.56 & -13.56 \\
\hline
\end{tabular}

Table 17: Inaccuracy and bias scores from the DiGangi et al. first rib age estimates separated by ancestry. All values are in years.

When known age at death is plotted against bias, the pattern shows that individuals are almost always under-aged for all age categories (Figure 10). Individuals in the younger age categories (19 to 39 years) have a large number of outliers, and most are over-aged. Older individuals between the ages of 70 and 89 years have negatively-skewed bias scores. Overall, the bias values follow the expected trend of under-aging individuals in older age categories. 


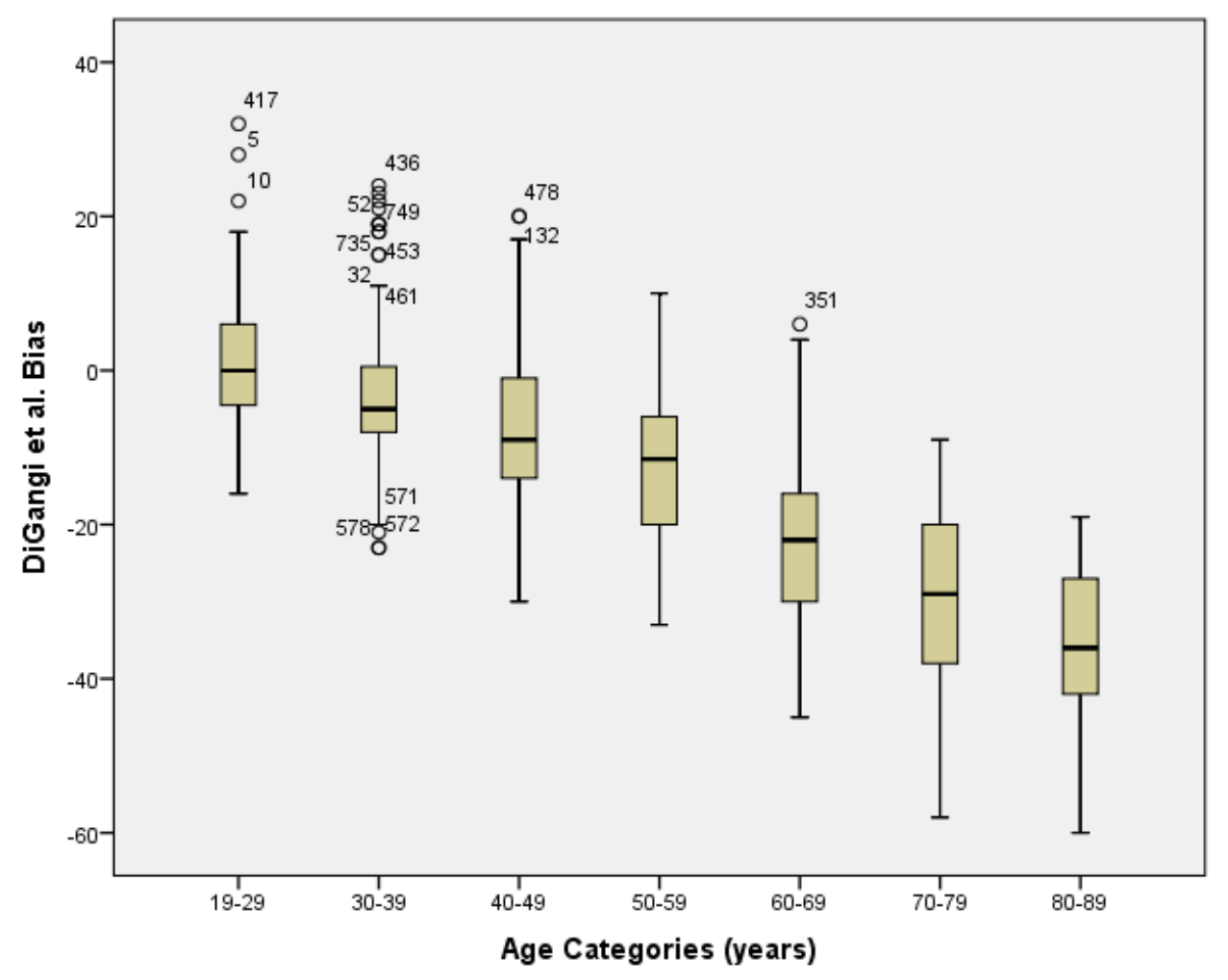

Figure 10: Mean bias scores for the DiGangi et al. method categorized by age at death.

\subsection{3 İşcan et al. Fourth Rib Method}

Appendix 7 provides the descriptive statistics for the İşcan et al. method. Intra-observer reliability shows a high level of agreement for the randomly selected test sample [Kappa $=0.898$, $95 \%$ CI $(0.853-0.943)]$; therefore, the age estimations are considered reliable.

Table 18 and Table 19 present the accuracy and bias scores for the İşcan et al. method.

Parametric, independent samples t-tests show there are significant differences between males and females for accuracy $(\mathrm{t}=-2.986, \mathrm{df}=310.034, p=0.003)$ and bias $(\mathrm{t}=5.495, \mathrm{df}=338.510 p<$ $0.001)$. Similar results are generated from non-parametric Mann-Whitney $U$ tests (inaccuracy: $U$ $=52,403.50, p=0.038$; bias: $\mathrm{U}=43,629.50, p<0.001$ ). Inaccuracy is 10.75 years for males ( $s . d$. $=8.31$ years) and 13.31 years for females $(s . d .=11.46$ years $)$, with males over-aged by one year $(\bar{x}=0.77$ years, $s . d .=13.58$ years $)$ and females under-aged by almost 6 years $(\bar{x}=-6.18$ years, s.d. $=16.47$ years).

When accuracy and bias are compared by ancestry, independent sample t-tests indicate there are no significant differences between individuals of European and African ancestry for accuracy $(\mathrm{t}$ 
$=0.900, \mathrm{df}=741, p=0.368)$, and bias $(\mathrm{t}=-0.355, \mathrm{df}=741, p=0.723)$. These results are similar when using non-parametric Mann-Whitney $U$ tests (inaccuracy: $U=53,541.50, p=0.357$; bias: $\mathrm{U}=53,940.50, p=0.442)$. Inaccuracy is 11.77 years for individuals of European descent (s.d. $=$ 9.43 years) and 11.06 years for individuals of African ancestry descent (s.d. $=9.35$ years).

Individuals of European and African ancestry are typically under-aged by 1 to 1.5 years (European ancestry: $\bar{x}=-1.57$ years, s.d. $=14.96$ years; African ancestry: $\bar{x}=-1.03$ years, $s . d .=$ 14.42 years).

\begin{tabular}{|c|c|c|c|c|c|c|c|c|c|c|}
\hline & \multicolumn{3}{|c|}{ Male } & \multicolumn{3}{|c|}{ Female } & \multicolumn{3}{|c|}{ Total } \\
\hline & & n & $\begin{array}{l}\text { İşcan et al. } \\
\text { Inaccuracy }\end{array}$ & $\begin{array}{c}\text { İşcan et al. } \\
\text { Bias }\end{array}$ & n & $\begin{array}{l}\text { İșcan et al. } \\
\text { Inaccuracy }\end{array}$ & $\begin{array}{c}\text { İşcan et al. } \\
\text { Bias }\end{array}$ & $\mathbf{n}$ & $\begin{array}{l}\text { İşcan et al. } \\
\text { Inaccuracy }\end{array}$ & $\begin{array}{c}\text { İşcan et al. } \\
\text { Bias }\end{array}$ \\
\hline \multirow[t]{8}{*}{ Age (yrs) } & $19-29$ & 34 & 8.03 & 3.62 & 19 & 9.74 & 6.89 & 53 & 8.64 & 4.79 \\
\hline & $30-39$ & 92 & 9.45 & 5.40 & 43 & 10.23 & 0.88 & 135 & 9.70 & 3.96 \\
\hline & $40-49$ & 111 & 10.19 & 4.19 & 42 & 9.10 & -4.71 & 153 & 9.89 & 1.75 \\
\hline & $50-59$ & 110 & 10.17 & 0.81 & 34 & 9.85 & -3.26 & 144 & 10.10 & -0.15 \\
\hline & $60-69$ & 116 & 12.06 & -2.23 & 35 & 16.66 & -11.00 & 151 & 13.13 & -4.26 \\
\hline & $70-79$ & 63 & 12.76 & -5.30 & 32 & 17.88 & -13.44 & 95 & 14.48 & -8.04 \\
\hline & $80-89$ & 11 & 16.27 & -15.18 & 11 & 34.45 & -34.45 & 22 & 25.36 & -24.82 \\
\hline & Total & 537 & 10.75 & 0.77 & 216 & 13.31 & -6.18 & 753 & 11.49 & -1.22 \\
\hline
\end{tabular}

Table 18: Inaccuracy and bias scores from the İşcan et al. fourth rib age estimates for males and females. All values are in years.

\begin{tabular}{|c|c|c|c|c|c|c|c|c|c|c|}
\hline & \multicolumn{3}{|c|}{ European } & \multicolumn{3}{|c|}{ African } & \multicolumn{3}{|c|}{ Other Ancestry } \\
\hline & & n & $\begin{array}{l}\text { İscan et al. } \\
\text { Inaccuracy }\end{array}$ & \begin{tabular}{|c}
$\begin{array}{c}\text { İşcan et al. } \\
\text { Bias }\end{array}$ \\
\end{tabular} & n & $\begin{array}{l}\text { İşean et al. } \\
\text { Inaccuracy }\end{array}$ & $\begin{array}{c}\text { İşcan et al. } \\
\text { Bias }\end{array}$ & $\mathbf{n}$ & $\begin{array}{l}\text { İscan et al. } \\
\text { Inaccuracy }\end{array}$ & $\begin{array}{c}\text { İşcan et al. } \\
\text { Bias }\end{array}$ \\
\hline \multirow[t]{8}{*}{ Age (yrs) } & $19-29$ & 21 & 9.00 & 4.71 & 30 & 8.80 & 5.00 & 2 & 2.50 & 2.50 \\
\hline & $30-39$ & 73 & 10.67 & 5.77 & 61 & 8.74 & 1.59 & 2 & 3.50 & 3.50 \\
\hline & $40-49$ & 103 & 9.81 & 2.58 & 50 & 10.34 & -1.30 & 2 & 13.00 & 12.00 \\
\hline & $50-59$ & 119 & 9.48 & -0.27 & 25 & 12.32 & 0.00 & 2 & 17.00 & -3.00 \\
\hline & $60-69$ & 129 & 12.69 & -3.50 & 21 & 15.48 & -8.24 & 1 & 20.00 & -20.00 \\
\hline & $70-79$ & 77 & 14.99 & -8.96 & 21 & 14.71 & -7.67 & 0 & N/A & N/A \\
\hline & $80-89$ & 18 & 25.50 & -25.50 & 3 & 26.00 & -22.00 & 1 & 21.00 & -21.00 \\
\hline & Total & 540 & 11.77 & -1.57 & 211 & 11.06 & -1.03 & 10 & 11.30 & -0.90 \\
\hline
\end{tabular}

Table 19: Inaccuracy and bias scores from the İşcan et al. fourth rib age estimates separated by ancestry. All values are in years.

When known age at death is plotted against bias, the whisker box plot pattern shows very little variation in the age at death estimations for younger individuals and older individuals up to the age of 79 years (Figure 11). Individuals between the ages of 30 and 39 years have the greatest number of outliers, and most are under-aged. Individuals in the oldest age categories have a 
larger amount of error associated with their bias scores compared to younger individuals, and generally the mean bias scores decrease as age increases.

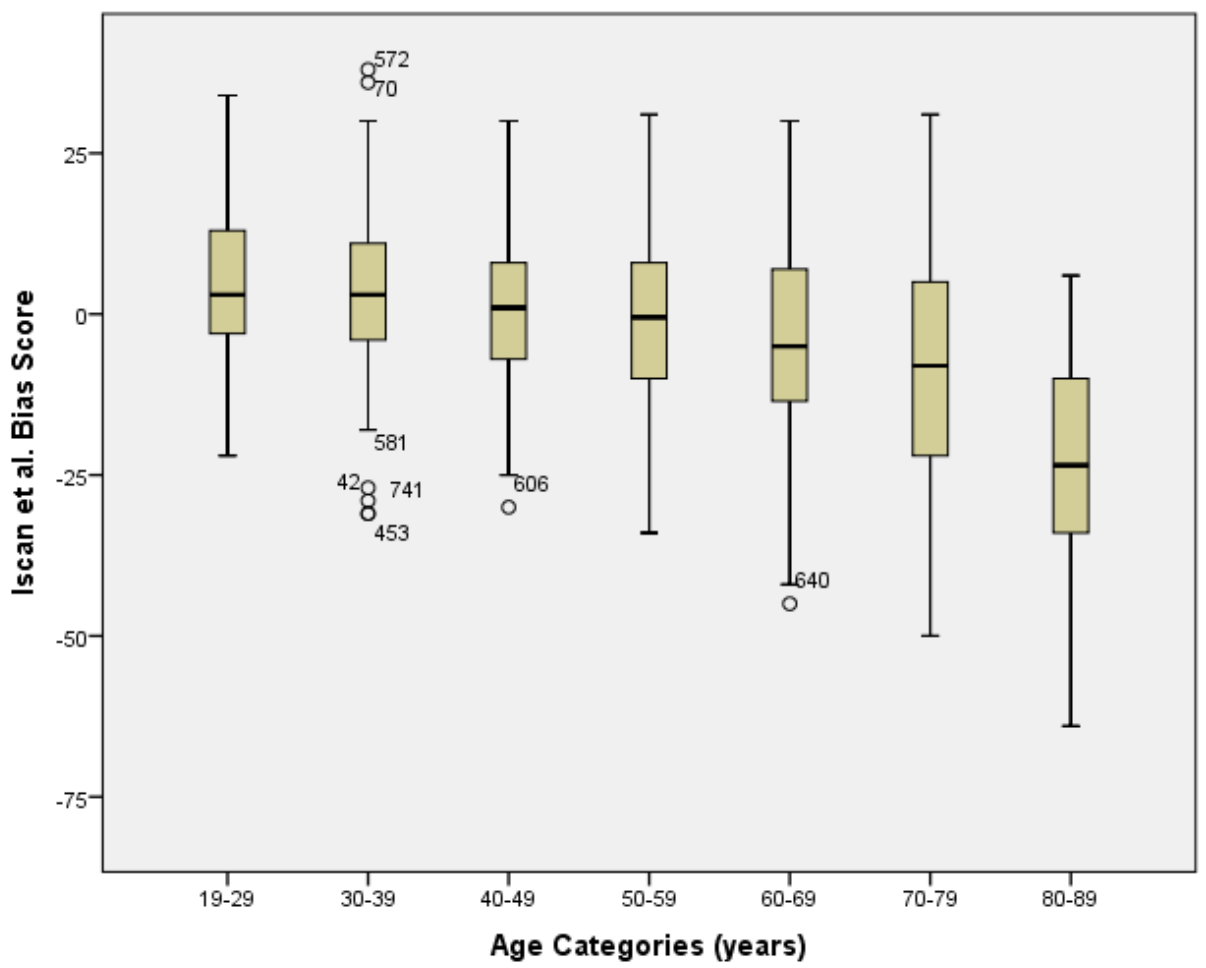

Figure 11: Bias scores for the İşcan et al. method categorized by age at death.

\subsubsection{Passalacqua Sacrum Method}

Appendix 8 provides the descriptive statistics for the Passalacqua method. Intra-observer reliability shows a high level of agreement for the randomly selected test sample [Kappa $=0.923$, $95 \%$ CI (0.878 - 0.968)]; therefore, the age estimations are considered reliable.

Table 20 and Table 21 present the accuracy and bias scores for the Passalacqua method. Parametric, independent samples t-tests show there are no significant differences between males and females for accuracy $(\mathrm{t}=-1.559, \mathrm{df}=784, p=0.119)$ and bias $(\mathrm{t}=1.265, \mathrm{df}=784, p=$ 0.206). Similar results are generated from non-parametric Mann-Whitney $U$ tests (inaccuracy: $U$ $=59,657.50, p=0.101$; bias: $\mathrm{U}=59,353.50, p=0.081)$. Inaccuracy is 11.50 years for males $(s . d$. $=8.48$ years) and 12.55 years for females $(s . d .=8.70$ years $)$, with males under-aged by approximately one year $(\bar{x}=-1.23$ years, $s . d .=14.25$ years $)$ and females under-aged by almost 3 years $(\bar{x}=-2.67$ years, $s . d .=15.05$ years $)$. 
When accuracy and bias are compared by ancestry, independent sample t-tests indicate there are no significant differences between individuals of European and African ancestry for accuracy $(\mathrm{t}$ $=0.129, \mathrm{df}=774, p=0.897)$, but there are for bias $(\mathrm{t}=-3.980, \mathrm{df}=774, p<0.001)$. These results are similar when using non-parametric Mann-Whitney $U$ tests (inaccuracy: $U=$ 59,616.50, $p=0.805$; bias: $\mathrm{U}=49,403.00, p<0.001)$. Inaccuracy is 11.81 years for individuals of European descent (s.d. $=8.50$ years) and 11.72 years for individuals of African ancestry descent $(s . d .=8.64$ years). Individuals of European ancestry are typically under-aged by approximately 3 years $(\bar{x}=-3.01$ years, $s . d .=14.25$ years $)$, while individuals of African ancestry are typically over-aged by approximately 1.5 years $(\bar{x}=1.56$ years, $s . d .=14.50$ years $)$.

\begin{tabular}{|c|c|c|c|c|c|c|c|c|c|c|}
\hline & \multicolumn{3}{|c|}{ Male } & \multicolumn{3}{|c|}{ Female } & \multicolumn{3}{|c|}{ Total } \\
\hline & & n & $\begin{array}{c}\text { Passalacqua } \\
\text { Inaccuracy }\end{array}$ & $\begin{array}{c}\text { Passalacqua } \\
\text { Bias }\end{array}$ & n & $\begin{array}{l}\text { Passalacqua } \\
\text { Inaccuracy }\end{array}$ & $\begin{array}{c}\text { Passalacqua } \\
\text { Bias } \\
\end{array}$ & $\mathrm{n}$ & $\begin{array}{l}\text { Passalacqua } \\
\text { Inaccuracy }\end{array}$ & $\begin{array}{c}\text { Passalacqua } \\
\text { Bias }\end{array}$ \\
\hline \multirow{8}{*}{$\begin{array}{l}\text { Age } \\
\text { (yrs) }\end{array}$} & $19-29$ & 35 & 12.54 & 10.94 & 18 & 16.11 & 15.00 & 53 & 13.75 & 12.32 \\
\hline & $30-39$ & 95 & 11.86 & 9.38 & 43 & 14.26 & 10.81 & 138 & 12.61 & 9.83 \\
\hline & $40-49$ & 112 & 10.85 & 4.60 & 45 & 7.87 & 0.09 & 157 & 9.99 & 3.31 \\
\hline & $50-59$ & 114 & 9.50 & -0.83 & 37 & 9.05 & -1.97 & 151 & 9.39 & -1.11 \\
\hline & $60-69$ & 119 & 9.32 & -8.29 & 40 & 10.58 & -9.48 & 159 & 9.64 & -8.59 \\
\hline & 70-79 & 67 & 16.58 & -16.58 & 39 & 17.23 & -17.23 & 106 & 16.82 & -16.82 \\
\hline & $80-89$ & 11 & 25.27 & -25.27 & 11 & 21.45 & -21.45 & 22 & 23.36 & -23.36 \\
\hline & Total & 553 & 11.50 & -1.23 & 233 & 12.55 & -2.67 & 786 & 11.81 & -1.66 \\
\hline
\end{tabular}

Table 20: Inaccuracy and bias scores from the Passalacqua sacrum age estimates for males and females. All values are in years.

\begin{tabular}{|c|c|c|c|c|c|c|c|c|c|c|}
\hline & \multicolumn{3}{|c|}{ European } & \multicolumn{3}{|c|}{ African } & \multicolumn{3}{|c|}{ Other Ancestry } \\
\hline & & $\mathbf{n}$ & $\begin{array}{l}\text { Passalacqua } \\
\text { Inaccuracy }\end{array}$ & \begin{tabular}{|} 
Passalacqua \\
Bias
\end{tabular} & n & $\begin{array}{l}\text { Passalacqua } \\
\text { Inaccuracy }\end{array}$ & $\begin{array}{c}\text { Passalacqua } \\
\text { Bias }\end{array}$ & $\mathbf{n}$ & $\begin{array}{l}\text { Passalacqua } \\
\text { Inaccuracy }\end{array}$ & $\begin{array}{c}\text { Passalacqua } \\
\text { Bias }\end{array}$ \\
\hline$\overline{\text { Age }}$ & $19-29$ & 22 & 12.82 & 11.82 & 29 & 13.45 & 11.59 & 2 & 28.50 & 28.50 \\
\hline \multirow[t]{7}{*}{ (yrs) } & $30-39$ & 74 & 12.88 & 10.01 & 62 & 12.24 & 9.47 & 2 & 14.00 & 14.00 \\
\hline & $40-49$ & 105 & 9.69 & 4.92 & 50 & 10.72 & 0.32 & 2 & 8.00 & -7.00 \\
\hline & $50-59$ & 124 & 9.73 & -1.36 & 25 & 7.68 & 0.40 & 2 & 9.50 & -4.50 \\
\hline & $60-69$ & 132 & 9.46 & -8.49 & 24 & 10.88 & -9.63 & 1 & 3.00 & 3.00 \\
\hline & $70-79$ & 84 & 17.85 & -17.85 & 22 & 12.91 & -12.91 & 0 & N/A & $\mathrm{N} / \mathrm{A}$ \\
\hline & $80-89$ & 18 & 22.17 & -22.17 & 3 & 32.67 & -32.67 & 1 & 17.00 & -17.00 \\
\hline & Total & 561 & 11.81 & -3.01 & 215 & 11.72 & 1.56 & 10 & 14.00 & 4.80 \\
\hline
\end{tabular}

Table 21: Inaccuracy and bias scores from the Passalacqua sacrum age estimates separated by ancestry. All values are in years.

When known age at death is plotted against bias, the pattern generally follows the expected overaging of younger individuals and under-aging of older individuals (Figure 12); however, there are several deviations in the pattern. There are a large number of outliers in the 30 to 39 year old 
age category in both directions (i.e. under- and over-aging); individuals over the age of 40 years show a negatively-skewed bias; the mean bias score for individuals between the ages of 50 and 59 years and 60 and 69 years are almost equal; and the age estimations of individuals in the 80 to 89 year age category show very little variation with a large number of outliers.

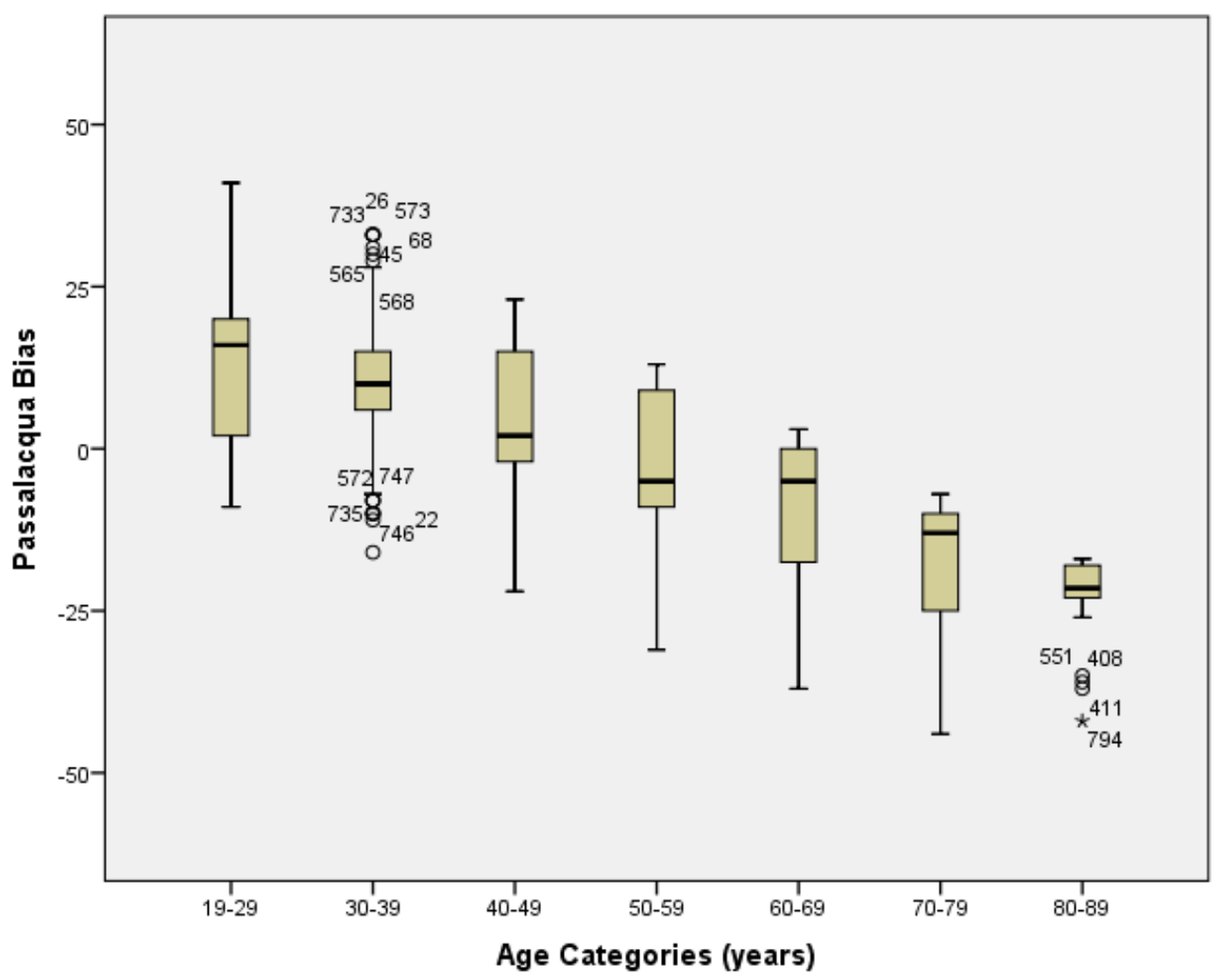

Figure 12: Mean bias scores for the Passalacqua method categorized by age at death.

\subsubsection{Lovejoy et al. Auricular Surface Method}

Appendix 9 provides the descriptive statistics for the Lovejoy et al. method. Intra-observer reliability shows a high level of agreement for the randomly selected test sample [Kappa $=0.916$, $95 \% \mathrm{CI}(0.875-0.957)]$; therefore, the age estimations are considered reliable.

Table 22 and Table 23 present the accuracy and bias scores for the Lovejoy et al. method. Parametric, independent samples t-tests show there are no significant differences between males and females for accuracy $(\mathrm{t}=-0.823, \mathrm{df}=792, p=0.411)$, but there are significant differences for bias ( $\mathrm{t}=2.456, \mathrm{df}=792, p=0.014)$. The results generated from non-parametric MannWhitney $\mathrm{U}$ tests are different from those of the parametric tests. There are no significant differences between males and females for accuracy $(\mathrm{U}=65,713.00, p=0.921)$ or bias $(\mathrm{U}=$ 
$60,257.00, p=0.052)$. Inaccuracy is 8.97 years for males (s.d. $=7.04$ years) and 9.44 years for females $(s . d .=8.14$ years $)$, with males under-aged by approximately 5 years $(\bar{x}=-5.35$ years, s.d. $=10.07$ years $)$ and females under-aged by approximately 7 years $(\bar{x}=-7.27$ years, s.d. $=$ 10.13 years).

When accuracy and bias are compared by ancestry, independent sample t-tests indicate there are significant differences between individuals of European and African ancestry for accuracy $(\mathrm{t}=$ 4.620, $\mathrm{df}=484.395, p<0.001)$, and bias $(\mathrm{t}=-6.145, \mathrm{df}=425.617, p<0.001)$. These results are similar when using non-parametric Mann-Whitney $\mathrm{U}$ tests (inaccuracy: $\mathrm{U}=50,455.00, p<$ 0.001; bias: $\mathrm{U}=44,642.00, p<0.001)$. Inaccuracy is 9.74 years for individuals of European descent (s.d. $=7.67$ years) and 7.31 years for individuals of African descent $(s . d .=6.15$ years). Individuals of European ancestry are typically under-aged by approximately 7 years $(\bar{x}=-7.21$ years, $s . d .=10.09$ years), while individuals of African ancestry are typically under-aged by approximately 2.5 years $(\bar{x}=-2.57$ years, s.d. $=9.21$ years $)$.

\begin{tabular}{|c|c|c|c|c|c|c|c|c|c|c|}
\hline & \multicolumn{3}{|c|}{ Male } & \multicolumn{3}{|c|}{ Female } & \multicolumn{3}{|c|}{ Total } \\
\hline & & $\mathrm{n}$ & $\begin{array}{c}\text { Lovejoy et al. } \\
\text { Inaccuracy }\end{array}$ & $\begin{array}{l}\text { Lovejoy } \\
\text { et al. Bias }\end{array}$ & $\mathbf{n}$ & $\begin{array}{l}\text { Lovejoy et al. } \\
\text { Inaccuracy }\end{array}$ & $\begin{array}{c}\text { Lovejoy } \\
\text { et al. Bias }\end{array}$ & $\mathbf{n}$ & $\begin{array}{c}\text { Lovejoy et al. } \\
\text { Inaccuracy }\end{array}$ & $\begin{array}{l}\text { Lovejoy } \\
\text { et al. Bias }\end{array}$ \\
\hline \multirow[t]{8}{*}{ Age (yrs) } & $19-29$ & 33 & 6.97 & 6.91 & 19 & 4.89 & 4.58 & 52 & 6.21 & 6.06 \\
\hline & $30-39$ & 95 & 5.14 & 3.54 & 43 & 3.84 & 0.44 & 138 & 4.73 & 2.57 \\
\hline & $40-49$ & 115 & 4.67 & -1.19 & 45 & 4.93 & -3.91 & 160 & 4.74 & -1.96 \\
\hline & $50-59$ & 115 & 7.48 & -5.13 & 37 & 7.41 & -5.51 & 152 & 7.46 & -5.22 \\
\hline & $60-69$ & 120 & 11.80 & -11.27 & 41 & 11.56 & -10.73 & 161 & 11.74 & -11.13 \\
\hline & 70-79 & 68 & 17.84 & -17.84 & 40 & 17.73 & -17.73 & 108 & 17.80 & -17.80 \\
\hline & $80-89$ & 11 & 22.82 & -22.82 & 12 & 25.0 & -25.00 & 23 & 23.96 & -23.96 \\
\hline & Total & 557 & 8.97 & -5.35 & 237 & 9.44 & -7.27 & 794 & 9.11 & -5.92 \\
\hline
\end{tabular}

Table 22: Inaccuracy and bias scores from the Lovejoy et al. auricular surface age estimates for males and females. All values are in years. 


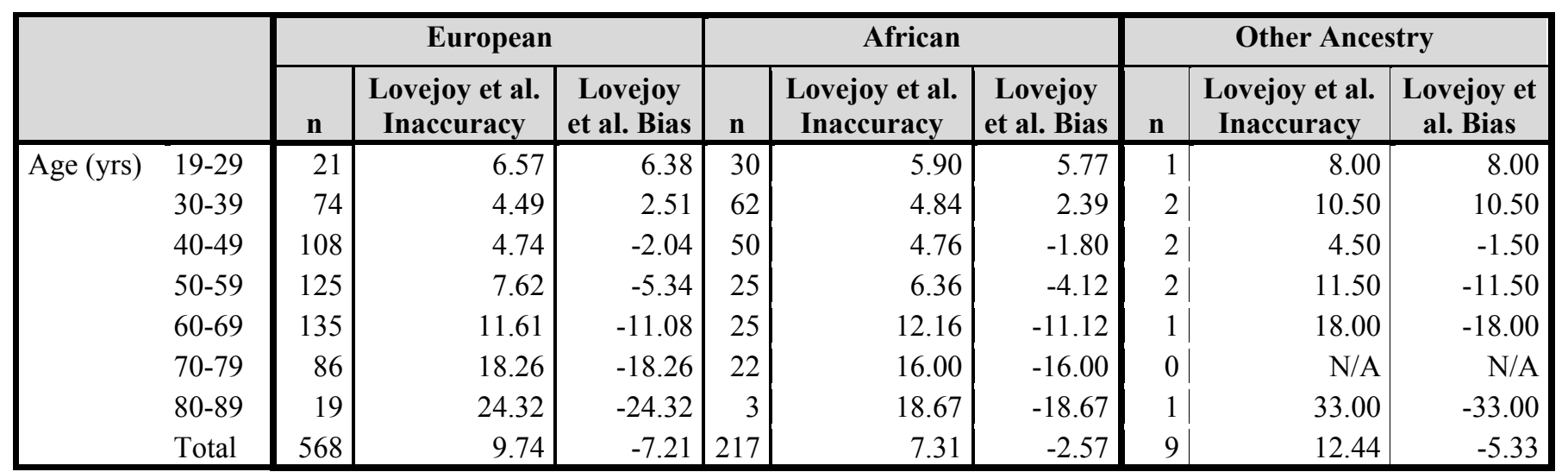

Table 23: Inaccuracy and bias scores from the Lovejoy et al. auricular surface age estimates separated by ancestry. All values are in years.

When known age at death is plotted against bias, the whisker box-plots show that age at death estimations for younger individuals are over-estimated and age at death estimations of older individuals are under-estimated (Figure 13). The majority of outliers are for individuals between the ages of 40 and 49 years, and all are over-aged. The youngest age category has the least amount of variation, and the range of bias scores increase as age increases.

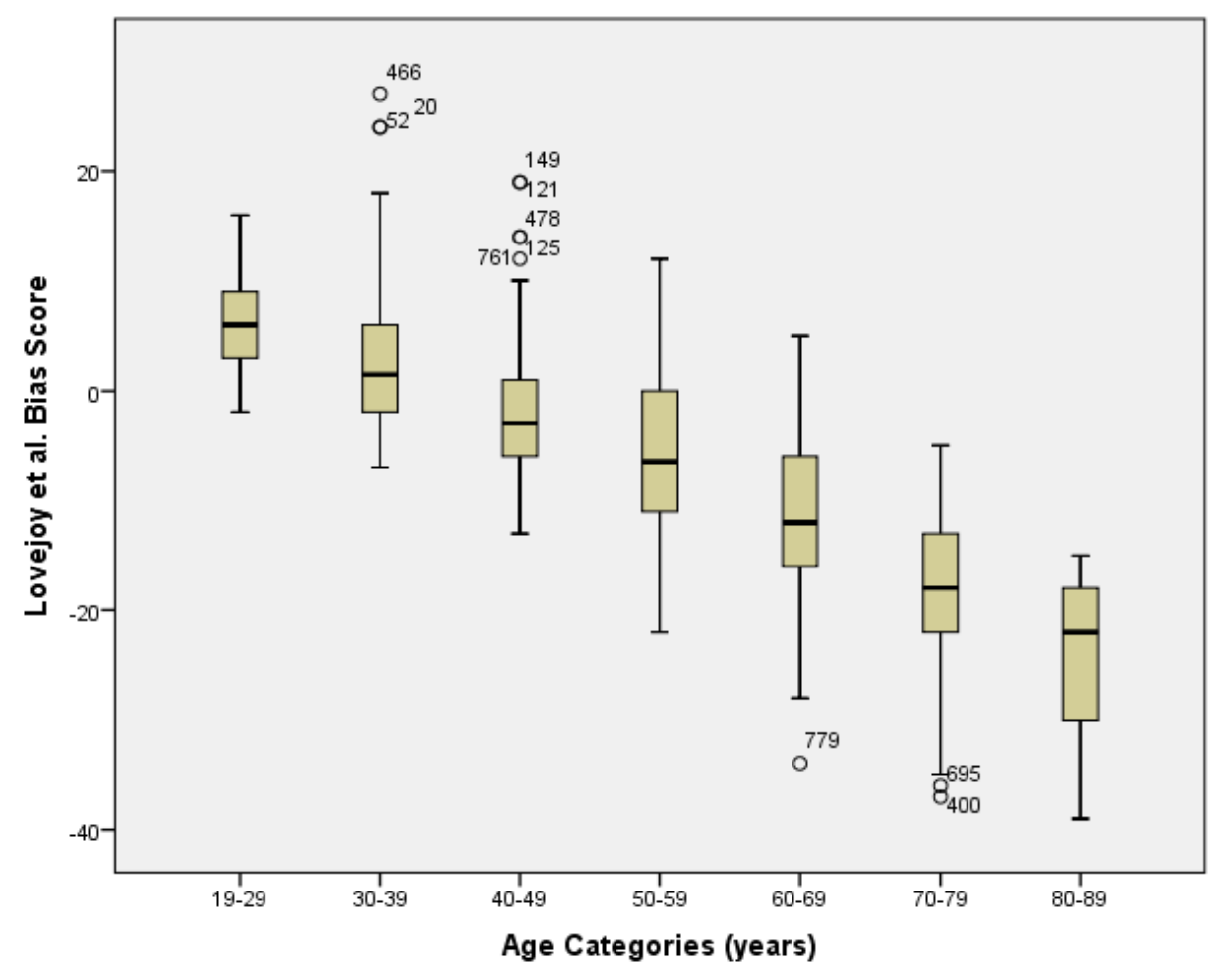

Figure 13: Mean bias scores for the Lovejoy et al. method categorized by age at death. 


\subsubsection{Buckberry and Chamberlain Auricular Surface Method}

Appendix 10 provides the descriptive statistics for the Buckberry and Chamberlain method.

Intra-observer reliability shows a high level of agreement for the randomly selected test sample $[$ Kappa $=0.864,95 \% \mathrm{CI}(0.813-0.915)]$; therefore, the age estimations are considered reliable.

Table 24 and Table 25 present the accuracy and bias scores for the Buckberry and Chamberlain method. Parametric, independent samples t-tests show there are significant differences between males and females for accuracy $(\mathrm{t}=2.757, \mathrm{df}=493.120, p=0.006)$ and bias $(\mathrm{t}=3.250, \mathrm{df}=791$, $p=0.001)$. The results generated from non-parametric Mann-Whitney $\mathrm{U}$ tests are similar to those of the parametric tests (inaccuracy: $\mathrm{U}=58,645.50, p=0.016$; bias: $\mathrm{U}=55,660.00, p=0.001$ ). Inaccuracy is 12.03 years for males ( $s . d .=7.04$ years) and 10.30 years for females $(s . d .=8.14$ years), with males over-aged by approximately 7 years $(\bar{x}=6.75$ years, $s . d .=13.24$ years $)$ and females over-aged by approximately 3.5 years ( $\bar{x}=3.46$ years, s.d. $=12.44$ years).

When accuracy and bias are compared by ancestry, independent sample t-tests indicate there are significant differences between individuals of European and African ancestry for accuracy $(\mathrm{t}=\mathrm{-}$ 2.652, $\mathrm{df}=336.383, p=0.008)$, and bias $(\mathrm{t}=-3.614, \mathrm{df}=782, p<0.001)$. These results are similar when using non-parametric Mann-Whitney $\mathrm{U}$ tests (inaccuracy: $\mathrm{U}=55,274.50, p=$ 0.032; bias: $\mathrm{U}=51,612.00, p=0.001$ ). Inaccuracy is 10.95 years for individuals of European descent ( $s . d .=7.97$ years) and 12.88 years for individuals of African descent ( $s . d .=9.50$ years). Individuals of European ancestry are typically over-aged by approximately 4.5 years $(\bar{x}=4.66$ years, $s . d .=12.73$ years), while individuals of African ancestry are typically over-aged by approximately 8.5 years $(\bar{x}=8.41$ years, $s . d .=13.64$ years $)$. 


\begin{tabular}{|c|c|c|c|c|c|c|c|c|c|c|}
\hline & \multicolumn{3}{|c|}{ Male } & \multicolumn{3}{|c|}{ Female } & \multicolumn{3}{|c|}{ Total } \\
\hline & & n & $\begin{array}{c}\text { Buckberry- } \\
\text { Chamberlain } \\
\text { Inaccuracy }\end{array}$ & $\begin{array}{c}\text { Buckberry- } \\
\text { Chamberlain } \\
\text { Bias }\end{array}$ & $\mathrm{n}$ & $\begin{array}{c}\text { Buckberry- } \\
\text { Chamberlain } \\
\text { Inaccuracy }\end{array}$ & $\begin{array}{c}\text { Buckberry- } \\
\text { Chamberlain } \\
\text { Bias }\end{array}$ & n & $\begin{array}{l}\text { Buckberry- } \\
\text { Chamberlain } \\
\text { Inaccuracy }\end{array}$ & $\begin{array}{c}\text { Buckberry- } \\
\text { Chamberlain } \\
\text { Bias }\end{array}$ \\
\hline$\overline{A g}$ & $19-29$ & 32 & 16.94 & 16.44 & 18 & 7.67 & 7.11 & 51 & 13.41 & 12.90 \\
\hline (yrs) & $30-39$ & 95 & 18.23 & 17.37 & 43 & 14.16 & 9.88 & 138 & 16.96 & 15.04 \\
\hline & $40-49$ & 115 & 14.61 & 12.78 & 45 & 12.58 & 8.71 & 160 & 14.04 & 11.64 \\
\hline & $50-59$ & 115 & 10.24 & 8.47 & 37 & 11.73 & 8.59 & 152 & 10.61 & 8.50 \\
\hline & $60-69$ & 120 & 6.69 & 0.99 & 41 & 5.32 & 0.29 & 161 & 6.34 & -0.66 \\
\hline & 70-79 & 68 & 8.94 & -8.76 & 40 & 7.85 & -7.65 & 108 & 8.54 & -8.35 \\
\hline & $80-89$ & 11 & 13.82 & -13.82 & 12 & 12.67 & -12.67 & 23 & 13.22 & -13.22 \\
\hline & Total & 557 & 12.03 & 6.75 & 236 & 10.30 & 3.46 & 793 & 11.51 & 5.77 \\
\hline
\end{tabular}

Table 24: Inaccuracy and bias scores from the Buckberry and Chamberlain auricular surface age estimates for males and females. All values are in years.

\begin{tabular}{|rr|r|r|r|r|r|r|r|r|r|}
\hline & & \multicolumn{4}{c|}{ European } & \multicolumn{3}{c|}{ African } & \multicolumn{3}{c|}{ Other Ancestry } \\
\cline { 2 - 10 } & & $\mathbf{n}$ & $\begin{array}{c}\text { Buckberry- } \\
\text { Chamberlain } \\
\text { Inaccuracy }\end{array}$ & $\begin{array}{c}\text { Buckberry- } \\
\text { Chamberlain } \\
\text { Bias }\end{array}$ & \multicolumn{1}{c|}{$\begin{array}{c}\text { Buckberry- } \\
\text { Chamberlain } \\
\text { Inaccuracy }\end{array}$} & $\begin{array}{c}\text { Buckberry- } \\
\text { Chamberlain } \\
\text { Bias }\end{array}$ & $\begin{array}{c}\text { Buckberry- } \\
\text { Chamberlain } \\
\text { Inaccuracy }\end{array}$ & $\begin{array}{c}\text { Buckberry- } \\
\text { Chamberlain } \\
\text { Bias }\end{array}$ \\
\hline Age & $19-29$ & 21 & 15.10 & 14.14 & 29 & 12.17 & 11.97 & 1 & 14.00 & 14.00 \\
$($ yrs) & $30-39$ & 74 & 15.92 & 14.19 & 62 & 17.95 & 15.73 & 2 & 25.00 & 25.00 \\
& $40-49$ & 108 & 13.81 & 12.08 & 50 & 14.30 & 10.34 & 2 & 20.00 & 20.00 \\
& $50-59$ & 125 & 10.85 & 8.82 & 25 & 9.84 & 7.20 & 2 & 5.00 & 5.00 \\
& $60-69$ & 135 & 6.38 & -0.78 & 25 & 6.12 & -0.36 & 1 & 7.00 & 7.00 \\
& $70-79$ & 86 & 8.90 & -8.76 & 22 & 7.14 & -6.77 & 0 & N/A & N/A \\
& $80-89$ & 19 & 13.21 & -13.21 & 3 & 15.00 & -15.00 & 1 & 8.00 & -8.00 \\
& Total & 568 & 10.95 & 4.66 & 216 & 12.88 & 8.41 & 9 & 14.33 & 12.56 \\
\hline
\end{tabular}

Table 25: Inaccuracy and bias scores from the Buckberry and Chamberlain auricular surface age estimates separated by ancestry. All values are in years.

When known age at death is plotted against bias, the pattern generally shows that age at death estimations for younger individuals are over-estimated and age at death estimations of older individuals are under-estimated (Figure 14). However, individuals in the youngest age category have a lower bias score than expected, and individuals under the age of 49 years have a larger amount of variation associated with their bias scores. Individuals between the ages of 50 and 69 years have the greatest number of outliers, and there is very little variation in the bias scores for individuals between the oldest age category. The bias scores are negatively skewed for individuals between the ages of 40 and 79 years. 


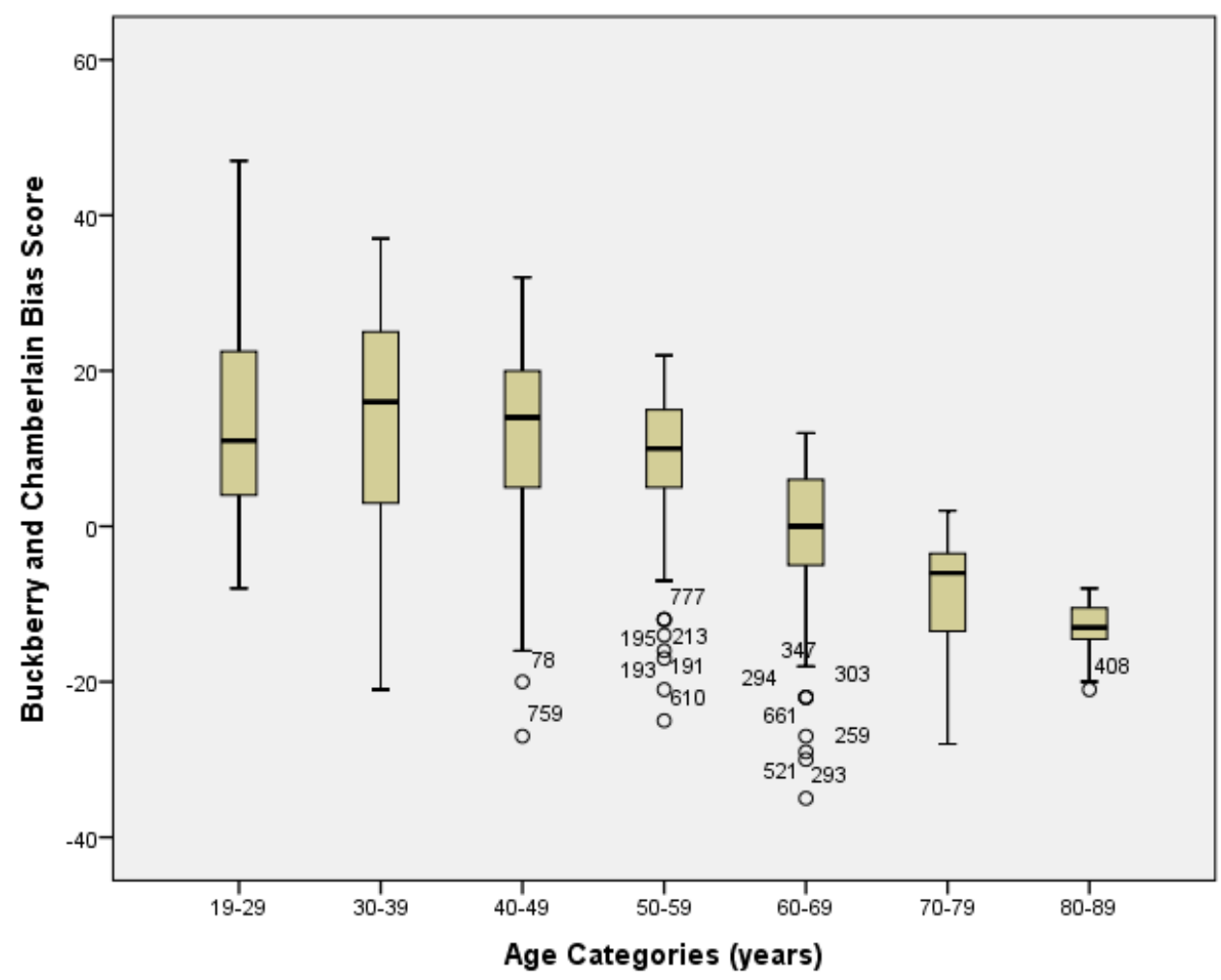

Figure 14: Mean bias scores for the Buckberry and Chamberlain method categorized by age at death.

\subsubsection{Rougé-Maillart et al. Acetabulum and Auricular Surface Method}

Appendix 11 provides the descriptive statistics for the Rougé-Maillart et al. method. Intraobserver reliability shows a high level of agreement for the randomly selected test sample $[$ Kappa $=0.919,95 \%$ CI $(0.876-0.962)]$; therefore, the age estimations are considered reliable.

Table 26 and Table 27 present the accuracy and bias scores for the Rougé-Maillart et al. method. Parametric, independent samples t-tests show there are no significant differences between males and females for accuracy $(\mathrm{t}=-0.205, \mathrm{df}=791, p=0.838)$, but there are for bias $(\mathrm{t}=2.029, \mathrm{df}=$ $791, p=0.043)$. The results generated from non-parametric Mann-Whitney $\mathrm{U}$ tests are different from those of the parametric tests. There are no significant differences between males and females for accuracy $(\mathrm{U}=64,820.50, p=0.759)$ or bias $(\mathrm{U}=60,418.00, p=0.072)$. Inaccuracy is 10.66 years for males $(s . d .=8.15$ years) and 10.79 years for females $(s . d .=8.91$ years), with males under-aged by approximately 5 years $(\bar{x}=-4.83$ years, $s . d .=12.53$ years $)$ and females under-aged by approximately 7 years $(\bar{x}=-6.79$ years, $s . d .=12.25$ years $)$. 
When accuracy and bias are compared by ancestry, independent sample t-tests indicate there are significant differences between individuals of European and African ancestry for inaccuracy $(\mathrm{t}=$ $2.800 \mathrm{df}=781, p=0.005)$, and bias scores $(\mathrm{t}=-5.587, \mathrm{df}=781, p<0.001)$. These results are similar when using non-parametric Mann-Whitney $\mathrm{U}$ tests (inaccuracy: $\mathrm{U}=52,344.00, p=$ 0.002; bias: $\mathrm{U}=44,673.50, p<0.001)$. Inaccuracy is 11.20 years for individuals of European descent (s.d. $=8.44$ years) and 9.33 years for individuals of African descent $(s . d .=8.06$ years). Individuals of European ancestry are typically under-aged by 7 years $(\bar{x}=-7.00$ years, s.d. $=$ 12.16 years), while individuals of African ancestry are typically under-aged by approximately 1.5 years $(\bar{x}=-1.55$ years, s.d. $=12.24$ years $)$.

\begin{tabular}{|c|c|c|c|c|c|c|c|c|c|c|}
\hline & \multicolumn{3}{|c|}{ Male } & \multicolumn{3}{|c|}{ Female } & \multicolumn{3}{|c|}{ Total } \\
\hline & & $\mathrm{n}$ & $\begin{array}{c}\text { Rougé- } \\
\text { Maillart } \\
\text { et al. } \\
\text { Inaccuracy }\end{array}$ & $\begin{array}{l}\text { Rougé- } \\
\text { Maillart } \\
\text { et al. Bias }\end{array}$ & $\mathrm{n}$ & $\begin{array}{c}\text { Rougé- } \\
\text { Maillart } \\
\text { et al. } \\
\text { Inaccuracy }\end{array}$ & $\begin{array}{l}\text { Rougé- } \\
\text { Maillart } \\
\text { et al. Bias }\end{array}$ & $\mathrm{n}$ & $\begin{array}{l}\text { Rougé- } \\
\text { Maillart } \\
\text { et al. } \\
\text { Inaccuracy }\end{array}$ & $\begin{array}{l}\text { Rougé- } \\
\text { Maillart } \\
\text { et al. Bias }\end{array}$ \\
\hline \multirow[t]{8}{*}{ Age (yrs) } & $19-29$ & 34 & 10.38 & 10.21 & 18 & 5.94 & 4.94 & 52 & 8.85 & 8.38 \\
\hline & $30-39$ & 94 & 7.56 & 5.33 & 43 & 6.09 & 2.47 & 137 & 7.10 & 4.43 \\
\hline & $40-49$ & 115 & 6.23 & 1.00 & 45 & 6.49 & -2.80 & 160 & 6.31 & -0.07 \\
\hline & $50-59$ & 115 & 8.25 & -4.58 & 37 & 7.81 & -4.19 & 152 & 8.14 & -4.49 \\
\hline & $60-69$ & 120 & 13.09 & -12.44 & 41 & 12.41 & -10.56 & 161 & 12.92 & -11.96 \\
\hline & 70-79 & 68 & 20.41 & -20.38 & 40 & 20.15 & -20.05 & 108 & 20.31 & -20.26 \\
\hline & $80-89$ & 11 & 22.55 & -22.55 & 12 & 23.50 & -23.50 & 23 & 23.04 & -23.04 \\
\hline & Total & 557 & 10.66 & -4.83 & 236 & 10.79 & -6.79 & 793 & 10.70 & -5.41 \\
\hline
\end{tabular}

Table 26: Inaccuracy and bias scores from the Rougé-Maillart et al. acetabulum and auricular surface age estimates for males and females. All values are in years.

\begin{tabular}{|c|c|c|c|c|c|c|c|c|c|c|}
\hline & \multicolumn{3}{|c|}{ European } & \multicolumn{3}{|c|}{ African } & \multicolumn{3}{|c|}{ Other Ancestry } \\
\hline & & $\mathbf{n}$ & $\begin{array}{c}\text { Rougé- } \\
\text { Maillart } \\
\text { et al. } \\
\text { Inaccuracy }\end{array}$ & $\begin{array}{l}\text { Rougé- } \\
\text { Maillart } \\
\text { et al. Bias }\end{array}$ & n & $\begin{array}{c}\text { Rougé- } \\
\text { Maillart } \\
\text { et al. } \\
\text { Inaccuracy }\end{array}$ & $\begin{array}{l}\text { Rougé- } \\
\text { Maillart } \\
\text { et al. Bias }\end{array}$ & $\mathrm{n}$ & $\begin{array}{c}\text { Rougé- } \\
\text { Maillart } \\
\text { et al. } \\
\text { Inaccuracy }\end{array}$ & $\begin{array}{l}\text { Rougé- } \\
\text { Maillart } \\
\text { et al. Bias }\end{array}$ \\
\hline \multirow[t]{8}{*}{ Age (yrs) } & $19-29$ & 21 & 8.76 & 8.48 & 29 & 8.59 & 7.97 & 2 & 13.50 & 13.50 \\
\hline & $30-39$ & 74 & 7.00 & 3.76 & 61 & 7.16 & 5.10 & 2 & 9.00 & 9.00 \\
\hline & $40-49$ & 108 & 6.29 & -0.05 & 50 & 6.42 & -0.30 & 2 & 4.50 & 4.50 \\
\hline & $50-59$ & 125 & 8.32 & -4.58 & 25 & 7.08 & -3.56 & 2 & 10.50 & -10.50 \\
\hline & $60-69$ & 135 & 12.99 & -12.38 & 25 & 12.56 & -10.72 & 1 & 13.00 & 13.00 \\
\hline & 70-79 & 86 & 20.60 & -20.68 & 22 & 19.18 & -19.00 & 0 & $\mathrm{~N} / \mathrm{A}$ & N/A \\
\hline & $80-89$ & 19 & 21.74 & -21.74 & 3 & 28.33 & -28.33 & 1 & 32.00 & -32.00 \\
\hline & Total & 568 & 11.20 & -7.00 & 215 & 9.33 & -1.55 & 10 & 12.00 & 1.40 \\
\hline
\end{tabular}

Table 27: Inaccuracy and bias scores from the Rougé-Maillart et al. acetabulum and auricular surface age estimates separated by ancestry. All values are in years. 
When known age at death is plotted against bias, the whisker box-plots show the typical pattern of over-aging younger individuals and under-aging older individuals (Figure 15). There is a large amount of variation in the bias scores for individuals between the ages of 50 and 79 years, and individuals in the oldest age category have a the greatest number of outliers.

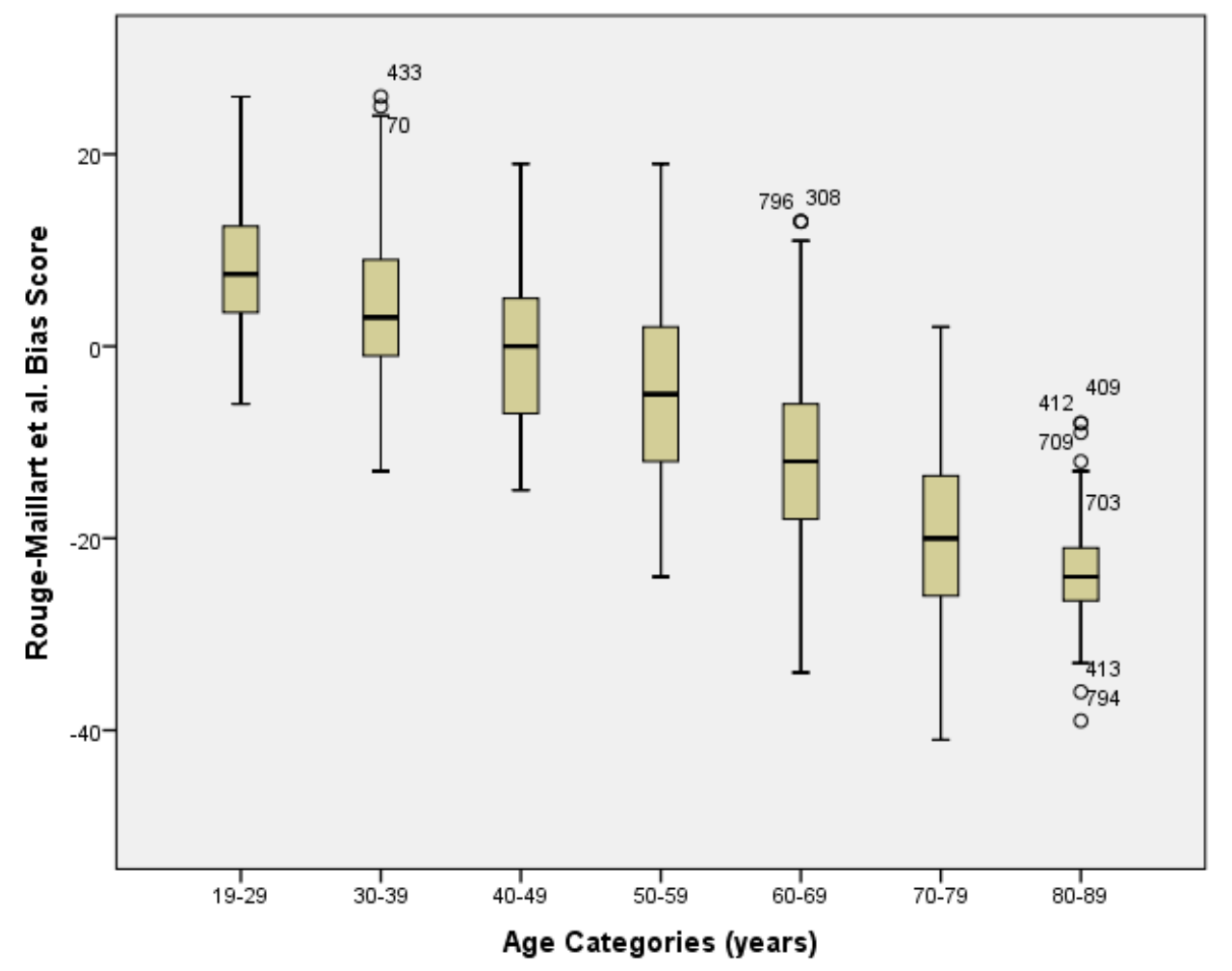

Figure 15: Mean bias scores for the Rougé-Maillart et al. method categorized by age at death.

\subsubsection{Suchey-Brooks Pubic Symphysis Method}

Appendix 12 provides the descriptive statistics for the Suchey-Brooks method. Intra-observer reliability shows a high level of agreement for the randomly selected test sample [Kappa $=0.962$, $95 \%$ CI (0.935 - 0.989)]; therefore, the age estimations are considered reliable.

Table 28 and Table 29 present the accuracy and bias scores for the Suchey-Brooks method. Parametric, independent samples t-tests show there are no significant differences between males and females for accuracy $(\mathrm{t}=-0.510, \mathrm{df}=791, p=0.542)$ and bias $(\mathrm{t}=0.483, \mathrm{df}=791, p=$ 0.392). The results generated from non-parametric Mann-Whitney $U$ tests are similar to the parametric tests (inaccuracy: $\mathrm{U}=63,793.50, p=0.584$; bias: $\mathrm{U}=64,470.00, p=0.751$ ). Inaccuracy is 9.59 years for males (s.d. $=7.74$ years) and 9.96 years for females $(s . d .=7.99$ 
years), with males and females under-aged by approximately 7 years (males $\bar{x}=-6.71$ years, s.d. $=10.40$ years; females $\bar{x}=-7.10$ years, $s . d .=10.62$ years $)$.

When accuracy and bias are compared by ancestry, independent sample t-tests indicate there are significant differences between individuals of European and African ancestry for accuracy $(\mathrm{t}=$ $3.418 \mathrm{df}=444.711, p<0.001)$, and bias $(\mathrm{t}=-4.246, \mathrm{df}=781, p<0.001)$. These results are similar when using non-parametric Mann-Whitney $\mathrm{U}$ tests (inaccuracy: $\mathrm{U}=51,663.00, p=$ 0.001; bias: $\mathrm{U}=49,408.50, p<0.001)$. Inaccuracy is 10.29 years for individuals of European descent (s.d. $=8.03$ years) and 8.17 years for individuals of African descent $(s . d .=6.91$ years). Individuals of European ancestry are typically under-aged by 8 years $(\bar{x}=-7.79$ years, s.d. $=$ 10.47 years), while individuals of African ancestry are typically under-aged by approximately 4 years $(\bar{x}=-4.29$ years, $s . d .=9.81$ years $)$.

\begin{tabular}{|c|c|c|c|c|c|c|c|c|c|c|}
\hline & \multicolumn{3}{|c|}{ Male } & \multicolumn{3}{|c|}{ Female } & \multicolumn{3}{|c|}{ Total } \\
\hline & & $\mathrm{n}$ & $\begin{array}{l}\text { Suchey- } \\
\text { Brooks } \\
\text { Inaccuracy }\end{array}$ & $\begin{array}{c}\text { Suchey- } \\
\text { Brooks } \\
\text { Bias }\end{array}$ & $\mathrm{n}$ & $\begin{array}{l}\text { Suchey- } \\
\text { Brooks } \\
\text { Inaccuracy }\end{array}$ & $\begin{array}{l}\text { Suchey- } \\
\text { Brooks } \\
\text { Bias }\end{array}$ & $\mathrm{n}$ & $\begin{array}{l}\text { Suchey- } \\
\text { Brooks } \\
\text { Inaccuracy }\end{array}$ & $\begin{array}{l}\text { Suchey- } \\
\text { Brooks } \\
\text { Bias }\end{array}$ \\
\hline \multirow[t]{8}{*}{ Age (yrs) } & $19-29$ & 35 & 5.17 & 3.17 & 19 & 4.95 & 4.00 & 54 & 5.09 & 3.46 \\
\hline & $30-39$ & 95 & 4.16 & 1.13 & 43 & 4.58 & 1.05 & 138 & 4.29 & 1.10 \\
\hline & $40-49$ & 115 & 5.66 & -1.21 & 45 & 7.00 & -4.16 & 160 & 6.04 & -2.04 \\
\hline & $50-59$ & 115 & 8.79 & -6.18 & 37 & 7.76 & -4.24 & 152 & 8.54 & -5.71 \\
\hline & $60-69$ & 120 & 13.26 & -13.21 & 40 & 10.83 & -10.83 & 160 & 12.65 & -12.61 \\
\hline & 70-79 & 68 & 18.25 & -18.25 & 38 & 18.24 & -18.24 & 106 & 18.25 & -18.25 \\
\hline & $80-89$ & 11 & 26.45 & -26.45 & 12 & 26.00 & -26.00 & 23 & 26.22 & -26.22 \\
\hline & Total & 559 & 9.59 & -6.71 & 234 & 9.96 & -7.10 & 793 & 9.70 & -6.82 \\
\hline
\end{tabular}

Table 28: Inaccuracy and bias scores from the Suchey-Brooks pubic symphysis age estimates for males and females. All values are in years.

\begin{tabular}{|c|c|c|c|c|c|c|c|c|c|c|}
\hline & \multicolumn{3}{|c|}{ European } & \multicolumn{3}{|c|}{ African } & \multicolumn{3}{|c|}{ Other Ancestry } \\
\hline & & $\mathbf{n}$ & $\begin{array}{c}\text { Suchey- } \\
\text { Brooks } \\
\text { Inaccuracy }\end{array}$ & $\begin{array}{c}\text { Suchey- } \\
\text { Brooks } \\
\text { Bias }\end{array}$ & $\mathbf{n}$ & $\begin{array}{c}\text { Suchey- } \\
\text { Brooks } \\
\text { Inaccuracy }\end{array}$ & $\begin{array}{c}\text { Suchey- } \\
\text { Brooks } \\
\text { Bias }\end{array}$ & $\mathbf{n}$ & $\begin{array}{c}\text { Suchey- } \\
\text { Brooks } \\
\text { Inaccuracy }\end{array}$ & $\begin{array}{l}\text { Suchey- } \\
\text { Brooks } \\
\text { Bias }\end{array}$ \\
\hline \multirow{8}{*}{ Age (yrs) } & $19-29$ & 22 & 4.77 & 3.68 & 30 & 5.37 & 3.30 & 2 & 4.50 & 3.50 \\
\hline & $30-39$ & 74 & 4.32 & 1.05 & 62 & 4.35 & 1.16 & 2 & 1.00 & 1.00 \\
\hline & $40-49$ & 108 & 5.87 & -1.76 & 50 & 6.54 & -2.82 & 2 & 2.50 & 2.50 \\
\hline & $50-59$ & 125 & 8.20 & -5.13 & 25 & 9.48 & -7.64 & 2 & 18.00 & -18.00 \\
\hline & $60-69$ & 135 & 12.21 & -12.17 & 24 & 14.71 & -14.71 & 1 & 22.00 & -22.00 \\
\hline & $70-79$ & 85 & 18.76 & -18.76 & 21 & 16.14 & -16.14 & 0 & N/A & N/A \\
\hline & $80-89$ & 19 & 27.05 & -27.05 & 3 & 23.00 & -23.00 & 1 & 20.00 & -20.00 \\
\hline & Total & 568 & 10.29 & -7.79 & 215 & 8.17 & -4.29 & 10 & 9.40 & -6.40 \\
\hline
\end{tabular}

Table 29: Inaccuracy and bias scores from the Suchey-Brooks pubic symphysis age estimates separated by ancestry. All values are in years. 
When known age at death is plotted against bias, the whisker box-plots show the expected pattern of over-aging younger individuals and under-aging older individuals (Figure 16). The least amount of variation is seen in the youngest age category, and the most number of outliers are between the ages of 40 and 59 years, and the largest variation in bias scores are for individuals between the ages of 40 and 69 years. The bias scores are negatively skewed between the ages of 60 and 89 years.

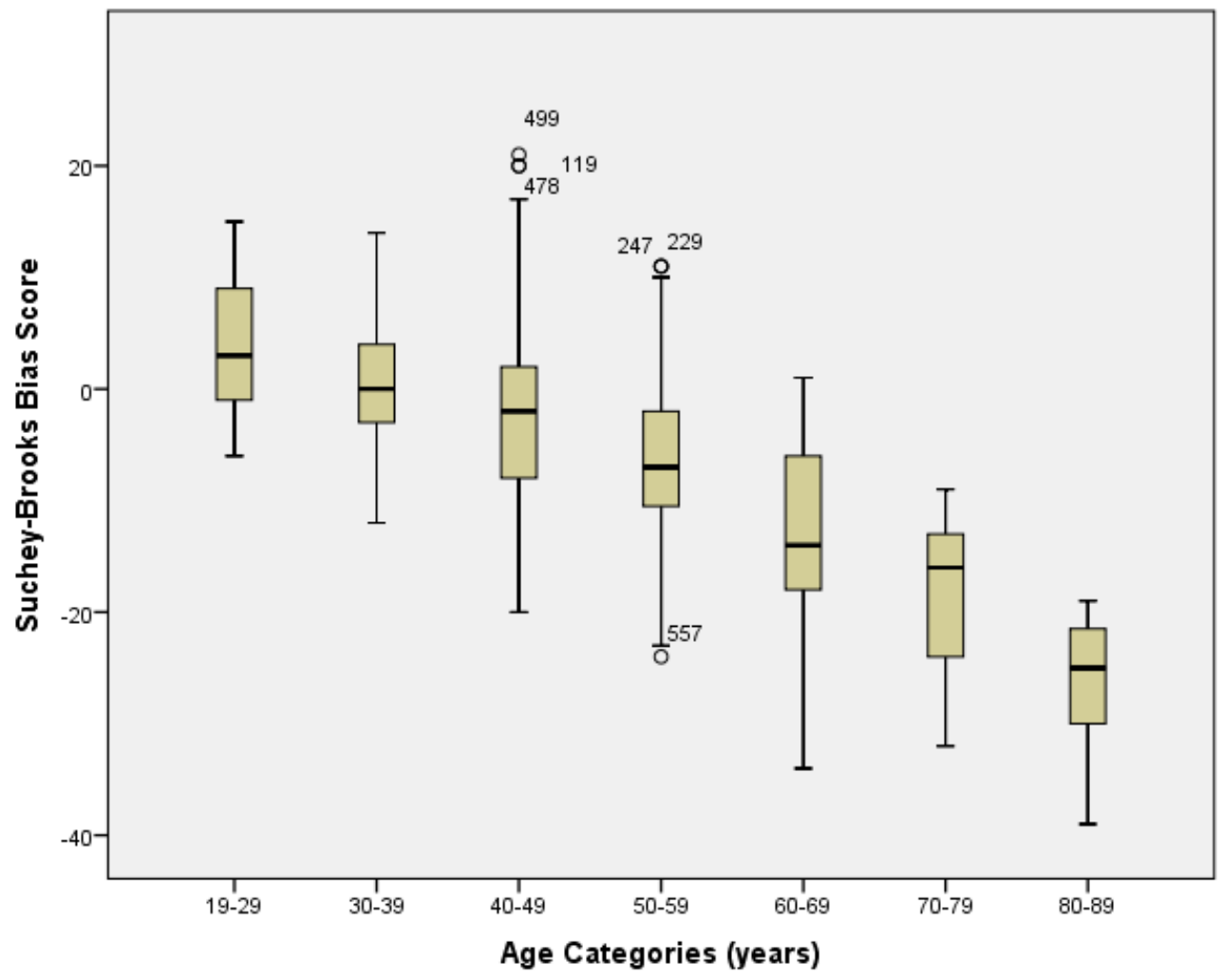

Figure 16: Mean bias scores for the Suchey-Brooks method categorized by known age at death.

\subsubsection{Descriptive Statistics for the Final Sample and Each Age Estimation Method}

Based on the evaluation of the age estimation methods, analyses will be divided by sex and ancestry as there were significant interactions between the age estimations generated for each method and sex and ancestry. Only individuals of European and African ancestry will be evaluated in the following sections as there are too few individuals of Asian, Hispanic, Aboriginal, and mixed ancestry to assess their influence on age standards. Individuals over the 
age of 80 years will also be eliminated from further analysis as their accuracy and bias scores are unreliable for all age estimation methods.

The descriptive statistics of the final sample, including the final number of individuals in the BMI, stature, and body mass categories, can be seen in Table 30, Table 31, Table 32, and Table 33. Thirty-two individuals were removed from the study; 23 individuals between the ages of 80 and 89 years and nine individuals of Asian, Hispanic, Aboriginal, and mixed ancestry (note: one Asian male over the age of 80 years was eliminated in the 80 to 89 year old category), leaving a total of 764 individuals to be included in further analyses. Of the 540 males, 407 are of European ancestry (75.4\%) and 133 of are of African ancestry (24.6\%). Of the 224 females, 143 are of European ancestry (63.8\%) and 81 are of African ancestry (36.2\%). Of the 550 individuals of European ancestry, 407 are male (74\%) and 143 are female (26\%). Of the 214 individuals of African ancestry, 133 are male (62.2\%) and 81 are female $(37.8 \%)$.

\begin{tabular}{|l|c|c|c|c|c|c|}
\hline & $\mathbf{n}$ & $\begin{array}{c}\text { Mean } \\
\text { Age }\end{array}$ & $\begin{array}{c}\text { Average } \\
\text { Stature (m/ft) }\end{array}$ & $\begin{array}{c}\text { Stature } \\
\text { Range (m/ft) }\end{array}$ & $\begin{array}{c}\text { Average Body } \\
\text { Mass (kg/lbs) }\end{array}$ & $\begin{array}{c}\text { Body Mass } \\
\text { Range (kg/lbs) }\end{array}$ \\
\hline Males & 540 & 52.6 & $1.74 / 5.7$ & $\begin{array}{c}1.30-1.93 / \\
4.3-6.3\end{array}$ & $68.9 / 152$ & $\begin{array}{c}32.2-99.8 / \\
71-220\end{array}$ \\
\hline Females & 224 & 51.2 & $1.60 / 5.3$ & $\begin{array}{c}1.30-1.87 / \\
4.3-6.1\end{array}$ & $57.7 / 127$ & $24.0-99.8 /$ \\
& & & & & $53-220$ \\
\hline European Ancestry & 550 & 54.1 & $1.69 / 5.6$ & $1.30-1.93 /$ & $66.7 / 147$ & $26.3-99.8 /$ \\
& & & & $4.3-6.3$ & & $58-220$ \\
\hline African Ancestry & 214 & 45.0 & $1.72 / 5.6$ & $\begin{array}{c}1.50-1.92 / \\
4.9-6.3\end{array}$ & $63.1 / 139$ & $24.0-99.8 /$ \\
& & & & & $53-220$ \\
\hline \hline 18-29 years & 52 & 24.7 & $1.71 / 5.6$ & $1.37-1.90 /$ & $62.5 / 138$ & $37.2-89.8 /$ \\
& & & & $4.5-6.24$ & & $82-198$ \\
\hline 30-39 years & 136 & 35.0 & $1.71 / 5.6$ & $1.30-1.92 /$ & $66.8 / 147$ & $24.0-99.8 /$ \\
& & & & $4.3-6.3$ & & $53-220$ \\
\hline $40-49$ years & 158 & 44.3 & $1.70 / 5.6$ & $1.44-1.93 /$ & $66.6 / 147$ & $27.7-99.8 /$ \\
& & & & $4.7-6.3$ & & $61-220$ \\
\hline 50-59 years & 150 & 53.8 & $1.70 / 5.6$ & $1.30-1.92 /$ & $69.3 / 153$ & $27.7-99.8 /$ \\
& & & & $4.3-6.3$ & & $61-220$ \\
\hline $60-69$ years & 160 & 64.0 & $1.70 / 5.6$ & $1.49-1.93 /$ & $64.3 / 142$ & $30.4-99.8 /$ \\
& & & & $4.9-6.3$ & & $67-220$ \\
\hline $70-79$ years & 108 & 74.0 & $1.66 / 5.5$ & $1.38-1.86 /$ & $61.1 / 135$ & $26.3-99.8 /$ \\
& & & & $4.5-6.1$ & & $58-220$ \\
\hline Total & 764 & 51.5 & $1.70 / 5.6$ & $1.30-1.93 /$ & $65.5 / 145$ & $24.0-99.8 /$ \\
& & & & $4.3-6.3$ & & $53-220$ \\
\hline
\end{tabular}

Table 30: Final sample distribution by sex, ancestry, and age categories. 


\begin{tabular}{|l|ccc|}
\hline & Males & Females & Total \\
\hline European Ancestry & 407 & 143 & 550 \\
African Ancestry & 133 & 81 & 214 \\
Total & 540 & 224 & 764 \\
\hline
\end{tabular}

Table 31: Total number of males, females, and individuals of European and African ancestry.

\begin{tabular}{|c|c|c|c|c|c|c|c|}
\hline & $\begin{array}{l}<1.54 \mathrm{~m} \\
(<5.0 \mathrm{ft})\end{array}$ & $\begin{array}{c}1.55-1.62 \mathrm{~m} \\
(5.1-5.3 \mathrm{ft})\end{array}$ & $\begin{array}{c}1.63-1.70 \mathrm{~m} \\
(5.4-5.6 \mathrm{ft})\end{array}$ & $\begin{array}{l}1.72-1.78 \mathrm{~m} \\
(5.7-5.9 \mathrm{ft})\end{array}$ & $\begin{array}{l}1.79-1.84 m \\
(5.10-6.0 f t)\end{array}$ & $\begin{array}{c}1.85-1.92 \mathrm{~m} \\
(6.1-6.3 \mathrm{ft})\end{array}$ & Total \\
\hline $\begin{array}{l}<45.0 \mathrm{~kg} \\
(<100 \mathrm{lbs})\end{array}$ & 22 & 42 & 0 & 0 & 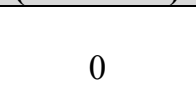 & 0 & 64 \\
\hline $\begin{array}{l}45.4-56.5 \mathrm{~kg} \\
(100-124 \mathrm{lbs})\end{array}$ & 25 & 34 & 40 & 35 & 29 & 0 & 163 \\
\hline $\begin{array}{l}56.7-67.6 \mathrm{~kg} \\
(125-149 \mathrm{lbs})\end{array}$ & 18 & 33 & 43 & 45 & 37 & 13 & 189 \\
\hline $\begin{array}{l}68.0-79.0 \mathrm{~kg} \\
(150-174 \mathrm{lbs})\end{array}$ & 5 & 22 & 42 & 41 & 43 & 19 & 172 \\
\hline $\begin{array}{l}\text { 79.4-89.8kg } \\
(175-199 \mathrm{lbs})\end{array}$ & 0 & 6 & 19 & 39 & 37 & 20 & 121 \\
\hline $\begin{array}{l}\text { 90.2-101.6kg } \\
(200-224 \mathrm{lbs})\end{array}$ & 0 & 0 & 14 & 14 & 14 & 13 & 55 \\
\hline Total & 70 & 137 & 158 & 174 & 160 & 65 & 764 \\
\hline
\end{tabular}

Table 32: Final number of individuals from 29 stature and body mass categories.

\begin{tabular}{|l|c|c|c|c|c|c|}
\hline \multicolumn{1}{|c|}{ BMI } & $\mathbf{n}$ & Mean Age & $\begin{array}{c}\text { Average Stature } \\
\mathbf{m} / \mathbf{f t}\end{array}$ & $\begin{array}{c}\text { Stature Range } \\
\mathbf{( m / f t )}\end{array}$ & $\begin{array}{c}\text { Average Body Mass } \\
\mathbf{( k g / l b s )}\end{array}$ & $\begin{array}{c}\text { Body Mass Range } \\
(\mathbf{k g} / \mathbf{l b s})\end{array}$ \\
\hline Underweight & 137 & 52.9 & $1.69 / 5.5$ & $1.46-1.92 /$ & $46.7 / 103$ & $24.0-68.0 /$ \\
& & & & $4.3-6.3$ & & $53-150$ \\
\hline Normal & 406 & 51.1 & $1.71 / 5.6$ & $\begin{array}{c}1.35-1.93 / \\
4.3-6.3\end{array}$ & $63.5 / 141$ & $\begin{array}{c}42.2-86.4 / \\
93-191\end{array}$ \\
\hline Overweight & 172 & 50.2 & $1.70 / 5.6$ & $1.40-1.90 /$ & $78.9 / 173$ & $54.4-99.8 /$ \\
& & & & $4.5-6.2$ & & $120-220$ \\
\hline Obese & 49 & 55.4 & $1.67 / 5.5$ & $1.30-1.88 /$ & $90.1 / 199$ & $63.5-99.8 /$ \\
& & & & $4.3-6.1$ & & $140-220$ \\
\hline
\end{tabular}

Table 33: Sample distribution by BMI for the total number of individuals in the sample.

Table 34 displays the descriptive statistics for the eight age estimation methods. Paired t-tests between the mean age at death, inaccuracy, and bias scores for all methods are not significantly different from the results for the age estimation analyses in Section 3.2 (see Table 35). The nine individuals of Hispanic, Asian, Aboriginal, and mixed ancestry did not influence the overall sample statistics; they were simply removed to eliminate any possible confounding factors and create a parsimonious sample. 


\begin{tabular}{|c|c|c|c|c|c|c|c|c|c|}
\hline Age Method & $\mathbf{n}$ & $\begin{array}{l}\text { Mean } \\
\text { age at } \\
\text { death }\end{array}$ & Inaccuracy & Bias & Age Method & $\mathbf{n}$ & $\begin{array}{l}\text { Mean } \\
\text { age at } \\
\text { death }\end{array}$ & Inaccuracy & Bias \\
\hline Kunos et al. & 748 & 54.50 & 10.43 & 3.11 & DiGangi et al. & 736 & 38.31 & 15.41 & -13.04 \\
\hline Males & 528 & 55.48 & 10.33 & 4.02 & Males & 519 & 39.53 & 14.58 & -11.92 \\
\hline Females & 220 & 52.18 & 10.66 & 0.93 & Females & 217 & 35.40 & 17.41 & -15.72 \\
\hline European & 537 & 56.01 & 10.19 & 2.05 & European & 526 & 39.57 & 16.45 & -14.39 \\
\hline African & 211 & 50.70 & 11.03 & 5.82 & African & 210 & 35.15 & 12.81 & -9.68 \\
\hline $19-29$ years & 50 & 40.78 & 16.32 & 16.12 & $19-29$ years & 50 & 25.28 & 7.74 & 0.54 \\
\hline $30-39$ years & 135 & 48.62 & 13.76 & 13.67 & $30-39$ years & 133 & 32.12 & 8.00 & -2.95 \\
\hline $40-49$ years & 155 & 53.94 & 10.39 & 9.56 & $40-49$ years & 152 & 37.09 & 10.50 & -7.21 \\
\hline $50-59$ years & 148 & 56.98 & 6.34 & 3.28 & $50-59$ years & 146 & 41.33 & 13.34 & -12.41 \\
\hline $60-69$ years & 156 & 58.28 & 7.51 & -5.69 & $60-69$ years & 154 & 41.70 & 22.34 & -22.19 \\
\hline $70-79$ years & 104 & 60.44 & 13.50 & -13.50 & $70-79$ years & 101 & 45.22 & 28.81 & -28.81 \\
\hline Age Method & $\mathrm{n}$ & $\begin{array}{l}\text { Mean } \\
\text { age at } \\
\text { death }\end{array}$ & Inaccuracy & Bias & Age Method & $\mathrm{n}$ & $\begin{array}{l}\text { Mean } \\
\text { age at } \\
\text { death }\end{array}$ & Inaccuracy & Bias \\
\hline İşcan et al. & 722 & 43.90 & 11.08 & -0.53 & Passalacqua & 755 & 50.35 & 11.45 & -1.13 \\
\hline Males & 518 & 45.92 & 10.66 & 1.06 & Males & 534 & 50.73 & 11.17 & -0.87 \\
\hline Females & 204 & 38.89 & 12.14 & -4.58 & Females & 221 & 49.42 & 12.14 & -1.76 \\
\hline European & 515 & 46.52 & 11.20 & -0.50 & European & 543 & 51.69 & 11.47 & -2.37 \\
\hline African & 207 & 37.43 & 10.78 & -0.61 & African & 212 & 46.92 & 11.42 & 2.05 \\
\hline $19-29$ years & 51 & 28.86 & 8.88 & 4.88 & $19-29$ years & 51 & 36.43 & 13.18 & 11.69 \\
\hline $30-39$ years & 133 & 36.78 & 9.79 & 3.97 & 30-39 years & 136 & 44.81 & 12.59 & 9.76 \\
\hline $40-49$ years & 151 & 42.41 & 9.85 & 1.60 & $40-49$ years & 155 & 47.83 & 10.02 & 3.44 \\
\hline $50-59$ years & 142 & 46.90 & 10.00 & -0.11 & $50-59$ years & 149 & 52.69 & 9.39 & -1.07 \\
\hline $60-69$ years & 150 & 49.69 & 13.08 & -4.16 & $60-69$ years & 158 & 55.31 & 9.68 & -8.66 \\
\hline $70-79$ years & 95 & 50.77 & 14.48 & -8.04 & 70-79 years & 106 & 57.13 & 16.82 & -16.82 \\
\hline Age Method & n & $\begin{array}{l}\text { Mean } \\
\text { age at } \\
\text { death }\end{array}$ & Inaccuracy & Bias & Age Method & $\mathbf{n}$ & $\begin{array}{l}\text { Mean } \\
\text { age at } \\
\text { death }\end{array}$ & Inaccuracy & Bias \\
\hline Lovejoy et al. & 763 & 46 & 8.65 & -5.42 & $\begin{array}{l}\text { Buckberry and } \\
\text { Chamberlain }\end{array}$ & 762 & 57.8 & 11.42 & 6.24 \\
\hline Males & 539 & 46.50 & 8.69 & -5.07 & Males & 539 & 58.73 & 11.94 & 7.04 \\
\hline Females & 224 & 44.81 & 8.57 & -6.27 & Females & 223 & 55.62 & 10.19 & 4.34 \\
\hline European & 549 & 47.42 & 9.24 & -6.62 & European & 549 & 59.43 & 10.87 & 5.28 \\
\hline African & 214 & 42.40 & 7.15 & -2.35 & African & 213 & 53.68 & 12.85 & 8.74 \\
\hline $19-29$ years & 51 & 30.82 & 6.18 & 6.02 & $19-29$ years & 50 & 37.74 & 13.40 & 12.88 \\
\hline $30-39$ years & 136 & 37.49 & 4.65 & 2.46 & $30-39$ years & 136 & 49.93 & 16.85 & 14.89 \\
\hline $40-49$ years & 158 & 42.35 & 4.75 & -1.96 & 40-49 years & 158 & 55.89 & 13.96 & 11.53 \\
\hline $50-59$ years & 150 & 48.46 & 7.41 & -5.14 & 50-59 years & 150 & 62.29 & 10.68 & 8.55 \\
\hline $60-69$ years & 160 & 52.66 & 11.70 & -11.09 & $60-69$ years & 160 & 63.26 & 6.34 & -0.71 \\
\hline $70-79$ years & 108 & 55.99 & 17.80 & -17.80 & $70-79$ years & 108 & 65.60 & 8.54 & -8.35 \\
\hline
\end{tabular}




\begin{tabular}{|lcccc|lcccc|}
\hline \multicolumn{1}{|c}{ Age Method } & nean & $\begin{array}{l}\text { Mea } \\
\text { age } \\
\text { death }\end{array}$ & Inaccuracy & Bias & Age Method & n & $\begin{array}{l}\text { Mean } \\
\text { age at } \\
\text { death }\end{array}$ & Inaccuracy & Bias \\
\hline $\begin{array}{l}\text { Rougé-Maillart } \\
\text { et al. }\end{array}$ & 761 & 46.60 & 10.34 & -5.01 & Suchey-Brooks & 761 & 45.20 & 9.22 & -6.26 \\
Males & 538 & 47.12 & 10.43 & -4.60 & Males & 540 & 45.26 & 9.29 & -6.39 \\
Females & 223 & 45.33 & 10.10 & -5.98 & Females & 221 & 44.93 & 9.04 & -6.00 \\
European & 549 & 47.66 & 10.83 & -6.49 & European & 549 & 46.93 & 9.70 & -7.12 \\
African & 212 & 43.81 & 9.06 & -1.17 & African & 212 & 40.58 & 7.96 & -4.02 \\
19-29 years & 50 & 33.04 & 8.66 & 8.18 & $19-29$ years & 52 & 28.08 & 5.12 & 3.46 \\
30-39 years & 135 & 39.40 & 7.07 & 4.36 & $30-39$ years & 136 & 36.15 & 4.34 & 1.10 \\
40-49 years & 158 & 44.23 & 6.33 & -0.13 & $40-49$ years & 158 & 42.26 & 6.08 & -2.09 \\
50-59 years & 150 & 49.34 & 8.11 & -4.41 & $50-59$ years & 150 & 48.20 & 8.41 & -5.55 \\
60-69 years & 160 & 51.86 & 12.92 & -12.12 & $60-69$ years & 159 & 51.42 & 12.59 & -12.55 \\
$70-79$ years & 108 & 53.69 & 20.31 & -20.26 & $70-79$ years & 106 & 55.75 & 18.25 & -18.25 \\
\hline
\end{tabular}

Table 34: Age estimation methods mean age at death, inaccuracy, and bias scores for the final sample of 764 individuals. All age, inaccuracy, and bias values are in years.

\begin{tabular}{|c|c|c|c|c|}
\hline Method & & Mean age at death & Inaccuracy & Bias \\
\hline \multirow[t]{3}{*}{ Kunos et al. } & Collective Sample & 54.70 & 10.77 & 2.46 \\
\hline & New Collective Sample & 54.51 & 10.43 & 3.11 \\
\hline & Paired t-test & $\mathrm{t}=0.412, p=0.681$ & $\mathrm{t}=0.923, p=0.356$ & $\mathrm{t}=1.015, p=0.310$ \\
\hline \multirow[t]{3}{*}{ DiGangi et al. } & Collective Sample & 38.48 & 15.99 & -13.72 \\
\hline & New Collective Sample & 38.31 & 15.41 & -13.04 \\
\hline & Paired t-test & $\mathrm{t}=0.291, p=0.771$ & $\mathrm{t}=0.989, p=0.323$ & $\mathrm{t}=0.511, p=0.610$ \\
\hline \multirow[t]{3}{*}{ İşcan et al. } & Collective Sample & 44.22 & 11.57 & -1.41 \\
\hline & New Collective Sample & 43.93 & 11.17 & -0.74 \\
\hline & Paired t-test & $\mathrm{t}=0.401, p=0.688$ & $\mathrm{t}=0.841, p=0.400$ & $\mathrm{t}=0.887, p=0.375$ \\
\hline \multirow[t]{3}{*}{ Passalacqua } & Collective Sample & 50.60 & 11.81 & -1.66 \\
\hline & New Collective Sample & 50.35 & 11.45 & -1.13 \\
\hline & Paired t-test & $\mathrm{t}=0.404, p=0.687$ & $\mathrm{t}=0.836, p=0.403$ & $\mathrm{t}=0.727, p=0.468$ \\
\hline \multirow[t]{3}{*}{ Lovejoy et al. } & Collective Sample & 46.35 & 9.11 & -5.92 \\
\hline & New Collective Sample & 46.01 & 8.65 & -5.42 \\
\hline & Paired t-test & $\mathrm{t}=0.679, p=0.498$ & $\mathrm{t}=1.266, p=0.206$ & $\mathrm{t}=0.996, p=0.320$ \\
\hline Buckberry \& & Collective Sample & 58.19 & 11.51 & 5.77 \\
\hline \multirow[t]{2}{*}{ Chamberlain } & New Collective Sample & 57.82 & 11.42 & 6.24 \\
\hline & Paired t-test & $\mathrm{t}=0.581, p=0.562$ & $\mathrm{t}=0.208, p=0.835$ & $\mathrm{t}=0.715, p=0.475$ \\
\hline \multirow{3}{*}{$\begin{array}{l}\text { Rougé-Maillart et } \\
\text { al. }\end{array}$} & Collective Sample & 47.00 & 10.70 & -5.41 \\
\hline & New Collective Sample & 46.57 & 10.34 & -5.01 \\
\hline & Paired t-test & $\mathrm{t}=0.768, p=0.443$ & $\mathrm{t}=0.860, p=0.390$ & $\mathrm{t}=0.640, p=0.522$ \\
\hline \multirow[t]{3}{*}{ Suchey-Brooks } & Collective Sample & 45.42 & 9.70 & -6.82 \\
\hline & New Collective Sample & 45.16 & 9.22 & -6.26 \\
\hline & Paired t-test & $\mathrm{t}=0.479, p=0.632$ & $\mathrm{t}=1.252, p=0.211$ & $\mathrm{t}=1.044, p=0.297$ \\
\hline
\end{tabular}

Table 35: Differences between original collective sample and new collective sample. All age, inaccuracy, and bias values are in years. 


\subsection{Research Question I: Does BMI influence skeletal age estimation?}

BMI was calculated by dividing body mass by stature squared to estimate body fat, as described in Section 3.1. Figure 17 and Figure 18 illustrate the age distribution and stature and mass distribution for individuals in each BMI category. The age distribution for individuals in each BMI category follows a normal distribution, except for the underweight category where there are fewer individuals in the 40 to 59 year age range. The stature and body mass ranges for all individuals in Figure 18 illustrate the demarcations for each BMI group, and the number of individuals in each group. The normal-sized BMI category has more than double the number of individuals than the other BMI categories (see Table 33), as would be expected in a normally distributed population.

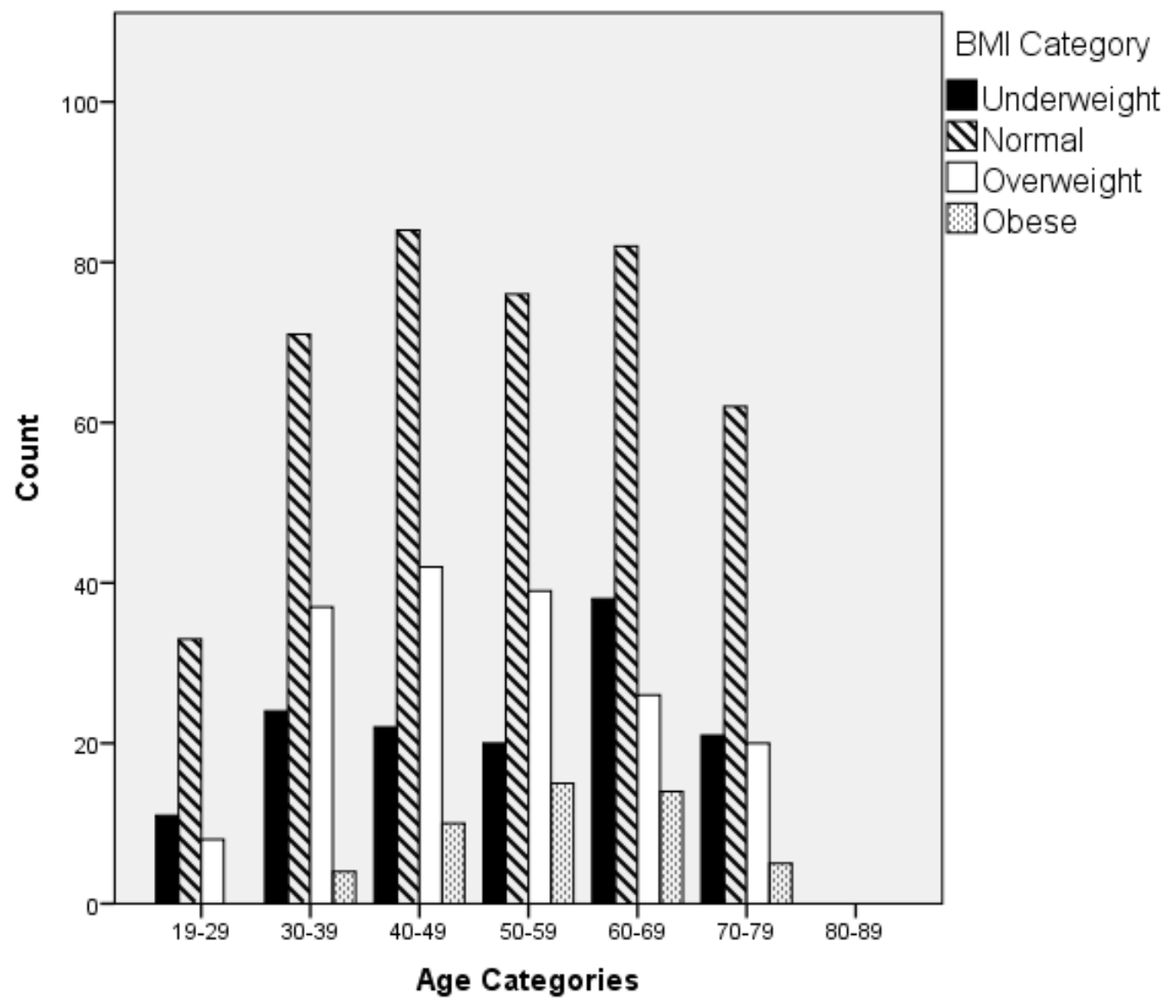

Figure 17: Age distribution of individuals by BMI category. Age categories are in years. 


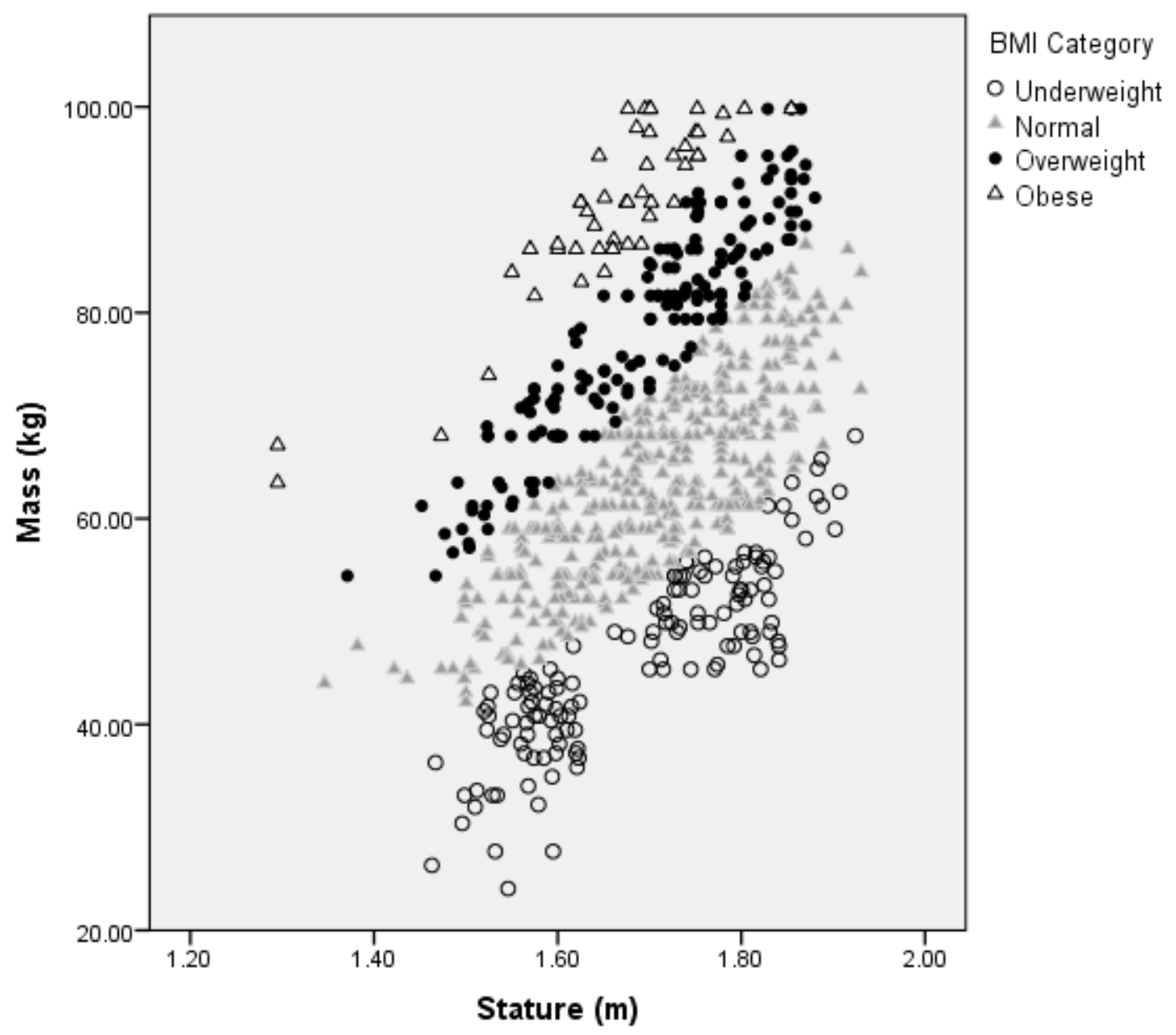

Figure 18: Distribution of individuals by BMI category for stature and mass.

This section will test the influence of BMI on age at death estimations. The sample will be separated by sex and ancestry, and differences between accuracy and bias scores between BMI groups will be evaluated for each method using MANOVA and DFA.

\subsubsection{Sex}

\subsubsection{Accuracy}

\section{Males}

A series of Pearson correlations were performed between the accuracy scores for each age method. Table 36 shows that the pattern of correlations observed among the accuracy scores are generally lower than ideal for a MANOVA, and the Box's M value of 195.455 is associated with a $p$-value of $<0.001$, which is significant. A covariance matrix (Appendix 13) was run to ensure 
that no covariance values were more than four times greater than each other (Howell, 2007). Although there are instances where the covariance values are greater than four times their value, typically associated with the DiGangi et al., Passalacqua, and Buckberry and Chamberlain methods, overall the covariance matrices between the BMI groups were assumed to be equal for the purposes of the MANOVA.

\begin{tabular}{|c|c|c|c|c|c|c|c|c|c|c|}
\hline & 1. & 2. & 3. & 4. & 5. & 6. & 7. & 8. & $\begin{array}{l}\text { Mean } \\
\text { (yrs) }\end{array}$ & $\begin{array}{l}\text { S.D. } \\
\text { (yrs) }\end{array}$ \\
\hline 1. Kunos et al. & 1.00 & & & & & & & & 10.33 & 6.975 \\
\hline $\begin{array}{l}\text { 2. DiGangi et } \\
\text { al. }\end{array}$ & $\begin{array}{l}0.01 \\
(0.948)\end{array}$ & 1.00 & & & & & & & 14.58 & 10.430 \\
\hline 3. İşcan et al. & $\begin{array}{l}0.12 \\
(0.008)\end{array}$ & $\begin{array}{l}0.29 \\
(<0.001)\end{array}$ & 1.00 & & & & & & 10.76 & 8.374 \\
\hline 4. Passalacqua & $\begin{array}{l}0.18 \\
(<0.001)\end{array}$ & $\begin{array}{l}0.16 \\
(<0.001)\end{array}$ & $\begin{array}{l}0.10 \\
(0.024)\end{array}$ & 1.00 & & & & & 11.17 & 8.235 \\
\hline $\begin{array}{l}\text { 5. Lovejoy et } \\
\text { al. }\end{array}$ & $\begin{array}{l}0.04 \\
(0.380)\end{array}$ & $\begin{array}{l}0.50 \\
(<0.001)\end{array}$ & $\begin{array}{l}0.11 \\
(0.009)\end{array}$ & $\begin{array}{l}0.22 \\
(<0.001)\end{array}$ & 1.00 & & & & 8.69 & 6.802 \\
\hline $\begin{array}{l}\text { 6. Buckberry } \\
\text { \& Chamberlain }\end{array}$ & $\begin{array}{l}0.42 \\
(<0.001)\end{array}$ & $\begin{array}{l}-0.30 \\
(<0.001)\end{array}$ & $\begin{array}{l}0.01 \\
(0.769)\end{array}$ & $\begin{array}{l}0.10 \\
(0.028)\end{array}$ & $\begin{array}{l}-0.05 \\
(0.212)\end{array}$ & 1.00 & & & 11.94 & 8.757 \\
\hline $\begin{array}{l}\text { 7. Rougé- } \\
\text { Maillart et al. }\end{array}$ & $\begin{array}{l}0.12 \\
(0.005)\end{array}$ & $\begin{array}{l}0.50 \\
(<0.001)\end{array}$ & $\begin{array}{l}0.21 \\
(<0.001)\end{array}$ & $\begin{array}{l}0.23 \\
(<0.001)\end{array}$ & $\begin{array}{l}0.62 \\
(<0.001)\end{array}$ & $\begin{array}{l}0.12 \\
(0.006)\end{array}$ & 1.00 & & 10.43 & 7.983 \\
\hline $\begin{array}{l}\text { 8. Suchey- } \\
\text { Brooks }\end{array}$ & $\begin{array}{l}-0.02 \\
(0.594)\end{array}$ & $\begin{array}{l}0.54 \\
(<0.001)\end{array}$ & $\begin{array}{l}0.16 \\
(<0.001)\end{array}$ & $\begin{array}{l}0.15 \\
(0.001)\end{array}$ & $\begin{array}{l}0.49 \\
(<0.001)\end{array}$ & $\begin{array}{l}-0.23 \\
(<0.001)\end{array}$ & $\begin{array}{l}0.46 \\
(<0.001)\end{array}$ & 1.00 & 9.29 & 7.356 \\
\hline
\end{tabular}

Table 36: Pearson Correlations, Means, and Standard Deviations of the accuracy scores for males for each age estimation method for males. P-values are in brackets.

A MANOVA was conducted to test the hypothesis that there would be differences between BMI categories (underweight, normal, overweight, obese) and accuracy scores for each method. The MANOVA was statistically significant with Pillai's Trace $=0.359, \mathrm{~F}(27,1476)=7.433, p<$ 0.001, indicating there are differences among BMI group accuracy scores. The multivariate effect size is estimated at 0.12 , which implies that $12 \%$ of the variance in the canonically derived DV is accounted for by BMI.

As the IV was associated with four levels, three eigenvalues and canonical correlations were extracted by the MANOVA. The first eigenvalue is 0.050 and accounts for $49.0 \%$ of the model variance. The canonical correlation associated with the first eigenvalue is 0.218 , where $4.8 \%$ of the variance in the discriminant function derived scores is accounted for by BMI. The second eigenvalue is 0.043 and accounts for $42.2 \%$ of the model variance with a corresponding canonical correlation of 0.203 . The third eigenvalue is 0.009 and accounts for $8.8 \%$ of the model 
variance and a corresponding canonical correlation of 0.095 , which is not statistically significant [Wilks $\Lambda=0.991, \mathrm{~F}(6,495)=0.618, p=0.687]$.

The standardized discriminant function coefficients from the first and second eigenvalues were used to determine the statistical significance of the MANOVA. As seen in Table 37, the Function 1 standardized discriminant function coefficients suggest that the four BMI groups were maximally differentiated by a canonical variate with significant weightings from the DiGangi et al. (0.633), Passalacqua (0.408), Rougé-Maillart et al. (0.377), and Kunos et al. (0.331) methods accuracy scores. The standardized coefficients suggest relatively minimal individual contributions to the MANOVA effect from all other accuracy scores, except for the Buckberry and Chamberlain method, which has almost no contribution (0.007). The correlations between the accuracy scores and the canonically derived scores for all methods are positive and with moderate scores (range $=0.273$ to 0.693 ), except for the Buckberry and Chamberlain method, which has a weak correlation (0.090). The Function 2 standardized discriminant function coefficients suggest that the four BMI groups were maximally differentiated by a canonical variate with significant weightings from the İşcan et al. (0.756), Suchey-Brooks (0.640), and DiGangi et al. (-0.562) methods accuracy scores. The standardized coefficients suggest minimal individual contributions to the MANOVA effect from all other methods. The correlations between accuracy scores and the canonically derived scores are weak to moderate for all methods. The scores from Function 1 were used in further analyses as the results from Function 2 are not as strong as those from Function 1.

\begin{tabular}{|l|l|l|l|l|l|l|}
\hline & \multicolumn{3}{|c|}{ Function 1 } & \multicolumn{3}{c|}{ Function 2 } \\
& Raw & Stand. & Struc. & Raw & Stand. & Struc. \\
\hline Kunos et al. & 0.048 & 0.331 & 0.468 & -0.052 & -0.361 & -0.225 \\
DiGangi et al. & 0.061 & 0.633 & 0.693 & -0.055 & -0.562 & 0.061 \\
İşcan et al. & 0.020 & 0.160 & 0.440 & 0.093 & 0.756 & 0.637 \\
Passalacqua & 0.050 & 0.408 & 0.575 & 0.015 & 0.123 & 0.165 \\
Lovejoy et al. & -0.046 & -0.307 & 0.273 & 0.064 & 0.430 & 0.363 \\
Buckberry \& Chamberlain & 0.001 & 0.007 & 0.090 & 0.013 & 0.116 & -0.057 \\
Rougé-Maillart et al. & 0.049 & 0.377 & 0.596 & -0.033 & -0.255 & 0.143 \\
Suchey-Brooks & -0.020 & -0.142 & 0.280 & 0.088 & 0.640 & 0.528 \\
\hline
\end{tabular}

Table 37: Discriminant function coefficients associated with the MANOVA for males. Note: Raw $=$ unstandardized coefficients, Stand. = standardized coefficients, Struc. $=$ structure coefficients.

To estimate the group centroids for Function 1 (i.e. the canonically derived group means) for the four BMI groups, the sample inaccuracy scores were multiplied by the corresponding inaccuracy 
unstandardized discriminant function coefficients and then averaged across the samples. The means and standard deviations are listed in Table 38. An ANOVA with four levels in the IV (underweight, normal, overweight, obese) was performed on the canonically derived accuracy score DV, and is significant $[\mathrm{F}(3,8.273)=8.303, p<0.001]$.

\begin{tabular}{|l|c|c|c|}
\hline & n & Mean & S.D. \\
\hline Underweight & 80 & 2.39 & 1.29 \\
Normal & 286 & 2.17 & 0.99 \\
Overweight & 110 & 1.77 & 0.78 \\
Obese & 26 & 1.66 & 0.87 \\
\hline
\end{tabular}

Table 38: Means and Standard Deviations for the male canonically derived variables.

The Cohen's $d$ absolute values were as follows, from highest to lowest: underweight vs. obese $=$ 0.519; underweight vs. overweight $=0.450$; normal-sized vs. obese $=0.337$; normal-sized vs . overweight $=0.244$; underweight vs. normal-sized $=0.213$; and overweight vs. obese $=0.098$. The differences between underweight and obese, and underweight and overweight males are suggestive of a medium effect size, while the differences between normal-sized and obese, normal-sized and overweight, and underweight and normal-sized males are suggestive of a small effect size. There is no discernible difference between overweight and obese males.

Table 39 shows the results from Tukey's $b$ post-hoc tests for unequal sample sizes. There are no significant differences among the BMI group inaccuracy scores for males using the Kunos et al., Lovejoy et al., and Buckberry and Chamberlain methods. The DiGangi et al. method inaccuracy scores for obese male are significantly lower compared to normal-sized and underweight males; underweight male inaccuracy scores are significantly higher compared to obese and overweight males. The İşcan et al. inaccuracy scores for underweight males are significantly higher than obese, normal-sized, and overweight males. The Passalacqua inaccuracy scores for underweight males are significantly higher compared to overweight males. The Rougé-Maillart et al. inaccuracy scores for obese males are significantly lower compared to normal-sized and underweight males. The Suchey-Brooks inaccuracy scores for underweight males are significantly higher than normal-sized and overweight males. 


\begin{tabular}{|c|c|c|c|c|c|}
\hline \multirow[b]{2}{*}{ Method } & \multirow{2}{*}{$\begin{array}{c}\text { BMI } \\
\text { Categories }\end{array}$} & \multirow[b]{2}{*}{ n } & \multicolumn{3}{|c|}{ Subset (yrs) } \\
\hline & & & 1 & 2 & 3 \\
\hline Kunos et al. & $\begin{array}{l}\text { Obese } \\
\text { Overweight } \\
\text { Underweight } \\
\text { Normal }\end{array}$ & $\begin{array}{l}26 \\
110 \\
80 \\
286\end{array}$ & $\begin{array}{l}8.58 \\
9.02 \\
10.58 \\
10.74\end{array}$ & & \\
\hline DiGangi et al. & $\begin{array}{l}\text { Obese } \\
\text { Overweight } \\
\text { Normal } \\
\text { Underweight }\end{array}$ & $\begin{array}{l}26 \\
110 \\
286 \\
80 \\
\end{array}$ & $\begin{array}{l}11.54 \\
12.45\end{array}$ & $\begin{array}{l}12.45 \\
15.10\end{array}$ & $\begin{array}{l}15.10 \\
16.99 \\
\end{array}$ \\
\hline İşcan et al. & $\begin{array}{l}\text { Obese } \\
\text { Normal } \\
\text { Overweight } \\
\text { Underweight }\end{array}$ & $\begin{array}{l}26 \\
286 \\
110 \\
80 \\
\end{array}$ & $\begin{array}{l}9.46 \\
10.07 \\
10.18\end{array}$ & 13.74 & \\
\hline Passalacqua & $\begin{array}{l}\text { Overweight } \\
\text { Obese } \\
\text { Normal } \\
\text { Underweight }\end{array}$ & $\begin{array}{l}110 \\
26 \\
286 \\
80 \\
\end{array}$ & $\begin{array}{l}9.36 \\
10.88 \\
11.41\end{array}$ & $\begin{array}{l}10.88 \\
11.41 \\
13.03\end{array}$ & \\
\hline Lovejoy et al. & $\begin{array}{l}\text { Obese } \\
\text { Normal } \\
\text { Overweight } \\
\text { Underweight }\end{array}$ & $\begin{array}{l}26 \\
286 \\
110 \\
80 \\
\end{array}$ & $\begin{array}{l}7.85 \\
8.38 \\
8.44 \\
10.15 \\
\end{array}$ & & \\
\hline Buckberry and Chamberlain & $\begin{array}{l}\text { Obese } \\
\text { Overweight } \\
\text { Underweight } \\
\text { Normal }\end{array}$ & $\begin{array}{l}26 \\
110 \\
80 \\
286 \\
\end{array}$ & $\begin{array}{l}10.69 \\
11.75 \\
11.89 \\
11.94 \\
\end{array}$ & & \\
\hline Rougé-Maillart et al. & $\begin{array}{l}\text { Obese } \\
\text { Overweight } \\
\text { Normal } \\
\text { Underweight }\end{array}$ & $\begin{array}{l}26 \\
110 \\
286 \\
80 \\
\end{array}$ & $\begin{array}{l}7.27 \\
9.39\end{array}$ & $\begin{array}{l}9.39 \\
10.49 \\
12.19 \\
\end{array}$ & \\
\hline Suchey-Brooks & $\begin{array}{l}\text { Overweight } \\
\text { Normal } \\
\text { Obese } \\
\text { Underweight }\end{array}$ & $\begin{array}{l}110 \\
286 \\
26 \\
80 \\
\end{array}$ & $\begin{array}{l}8.73 \\
8.83 \\
9.85\end{array}$ & $\begin{array}{l}9.85 \\
11.31 \\
\end{array}$ & \\
\hline
\end{tabular}

Table 39: Tukey's $b$ post-hoc test results for male accuracy scores separated by BMI. Note: alpha level $=\mathbf{0 . 0 5}$

A discriminant function analysis (DFA) was applied to assess how well BMI could be predicted from the accuracy scores of the eight age estimation methods. The DV is BMI (i.e. underweight, normal, overweight, obese), and the IVs are the accuracy scores generated from the age methods. Since the MANOVA and DFA use the same statistical models and produce the same results, only the cross-validated classification are reported. The cross-validated classification shows that only $34.3 \%$ of males are correctly classified into their BMI group based on accuracy scores. Underweight males are classified correctly at a rate of $36.3 \%$, normal-sized males at a rate of $34.3 \%$, overweight males at a rate of $30.9 \%$, and obese males at a rate of $42.3 \%$. 
The discriminant scores from Function 1 and Function 2 were used to plot the sample on the discriminant dimensions. The underweight group is associated with the largest group centroid (0.294), the normal-sized group is associated with the next largest group centroid (0.080), the overweight group is associated with the second smallest centroid (-0.320) and, finally, the obese group is associated with the smallest group centroid (-0.434) (see Figure 19).

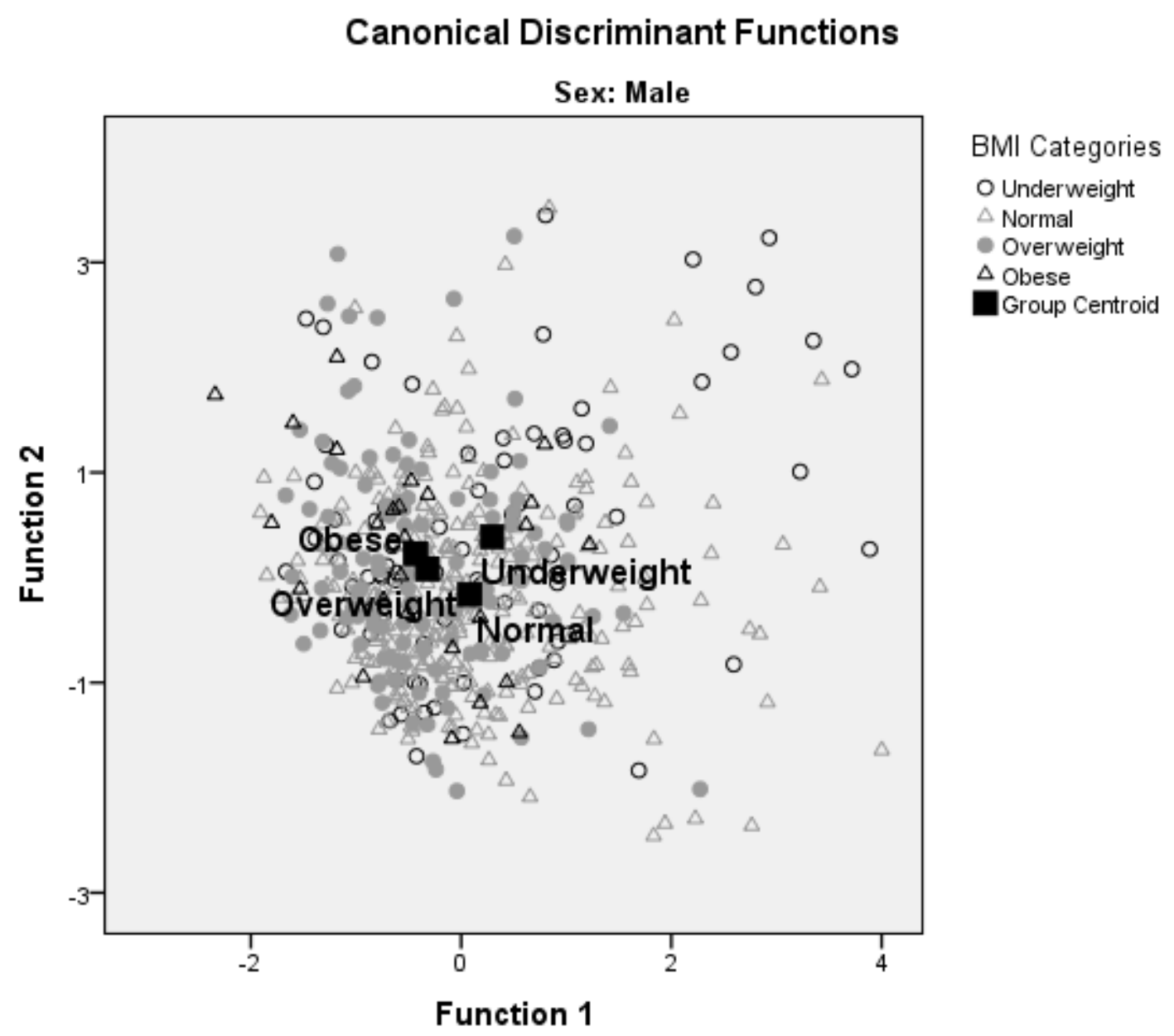

Figure 19: Canonically derived centroids for the BMI groups for males.

\section{Females}

A series of Pearson correlations were performed between the accuracy scores for each age method. Table 40 shows that the pattern of correlations observed among the accuracy scores are generally lower than ideal for a MANOVA, but the Box's M value of 208.675 is associated with a $p$-value of 0.013 , which is not significant. Therefore, the covariance matrices between the BMI groups were assumed to be equal for the purposes of the MANOVA. 


\begin{tabular}{|c|c|c|c|c|c|c|c|c|c|c|}
\hline & 1. & 2. & 3. & 4. & 5. & 6. & 7. & 8. & $\begin{array}{l}\text { Mean } \\
\text { (yrs) }\end{array}$ & $\begin{array}{l}\text { S.D. } \\
\text { (yrs) }\end{array}$ \\
\hline 1. Kunos et al. & 1.00 & & & & & & & & 10.57 & 7.210 \\
\hline 2. DiGangi et al. & $\begin{array}{l}0.27 \\
(<0.001)\end{array}$ & 1.00 & & & & & & & 16.64 & 11.920 \\
\hline 3. İşcan et al. & $\begin{array}{l}0.11 \\
(0.113)\end{array}$ & $\begin{array}{l}0.35 \\
(<0.001)\end{array}$ & 1.00 & & & & & & 12.03 & 10.047 \\
\hline 4. Passalacqua & $\begin{array}{l}0.26 \\
(<0.001)\end{array}$ & $\begin{array}{l}0.06 \\
(0.381)\end{array}$ & $\begin{array}{l}0.15 \\
(0.033)\end{array}$ & 1.00 & & & & & 11.98 & 8.536 \\
\hline 5. Lovejoy et al. & $\begin{array}{l}0.20 \\
(0.003)\end{array}$ & $\begin{array}{l}0.49 \\
(<0.001)\end{array}$ & $\begin{array}{l}0.26 \\
(<0.001)\end{array}$ & $\begin{array}{l}0.21 \\
(0.002)\end{array}$ & 1.00 & & & & 7.99 & 6.898 \\
\hline $\begin{array}{l}\text { 6. Buckberry \& } \\
\text { Chamberlain }\end{array}$ & $\begin{array}{l}0.12 \\
(0.073)\end{array}$ & $\begin{array}{l}-0.19 \\
(0.005)\end{array}$ & $\begin{array}{l}-0.06 \\
(0.361)\end{array}$ & $\begin{array}{l}0.05 \\
(0.483)\end{array}$ & $\begin{array}{l}-0.05 \\
(0.423)\end{array}$ & 1.00 & & & 10.45 & 7.989 \\
\hline $\begin{array}{l}\text { 7. Rougé- } \\
\text { Maillart et al. }\end{array}$ & $\begin{array}{l}0.25 \\
(<0.001)\end{array}$ & $\begin{array}{l}0.48 \\
(<0.001)\end{array}$ & $\begin{array}{l}0.27 \\
(<0.001)\end{array}$ & $\begin{array}{l}0.30 \\
(<0.001)\end{array}$ & $\begin{array}{l}0.66 \\
(<0.001)\end{array}$ & $\begin{array}{l}0.08 \\
(0.243)\end{array}$ & 1.00 & & 9.55 & 8.065 \\
\hline $\begin{array}{l}\text { 8. Suchey- } \\
\text { Brooks }\end{array}$ & $\begin{array}{l}0.19 \\
(0.004)\end{array}$ & $\begin{array}{l}0.49 \\
(<0.001)\end{array}$ & $\begin{array}{l}0.30 \\
(<0.001)\end{array}$ & $\begin{array}{l}0.23 \\
(0.001)\end{array}$ & $\begin{array}{l}0.51 \\
(<0.001)\end{array}$ & $\begin{array}{l}-0.07 \\
(0.322)\end{array}$ & $\begin{array}{l}0.57 \\
(<0.001)\end{array}$ & 1.00 & 8.68 & 6.959 \\
\hline
\end{tabular}

Table 40: Pearson Correlations, Means, and Standard Deviations of the accuracy scores for females for each age estimation method for females. P-values are in brackets.

A MANOVA was conducted to test the hypothesis that there would be differences between BMI group accuracy scores for each method. The MANOVA was statistically significant with Pillai's Trace $=0.687, \mathrm{~F}(27,564)=6.207, p<0.001$, indicating that there are differences among the BMI group accuracy scores. The multivariate effect size is estimated at 0.229 , which implies that $22.9 \%$ of the variance in the canonically derived DV is accounted for by BMI groups.

As the IV was associated with four levels, three eigenvalues and canonical correlations were extracted by the MANOVA. The first eigenvalue is 0.100 and accounts for $56.2 \%$ of the model variance. The canonical correlation associated with the first eigenvalue is 0.301 , where $9.1 \%$ of the variance in the discriminant function derived scores is accounted for by BMI group. The second eigenvalue is 0.058 and accounts for $33.0 \%$ of the model variance with a corresponding canonical correlation of 0.235 . The third eigenvalue is 0.019 and accounts for $10.8 \%$ of the model variance and a corresponding canonical correlation of 0.137 , which is not statistically significant [Wilks $\Lambda=0.981, \mathrm{~F}(6,189)=0.604, p=0.727$ ].

The standardized discriminant function coefficients from the first eigenvalue were used to determine the statistical significance of the MANOVA. As seen in Table 41, the standardized discriminant function coefficients suggest that the four BMI groups were maximally differentiated by a canonical variate with significant weightings from the Lovejoy et al. (-0.996), Rougé-Maillart et al. (0.472), İşcan et al. (0.470), and Kunos et al. (0.462) methods accuracy 
scores. The standardized coefficients suggest relatively minimal individual contributions to the MANOVA effect from all other accuracy scores. The correlations between the accuracy scores and the canonically derived scores for all methods are weak to moderate (range $=-0.366$ to $0.484)$.

\begin{tabular}{|l|l|l|l|}
\hline & \multicolumn{3}{|c|}{ Function 1 } \\
& Raw & Stand. & Struc. \\
\hline Kunos et al. & 0.064 & 0.462 & -0.366 \\
DiGangi et al. & 0.022 & 0.264 & -0.200 \\
İşcan et al. & 0.048 & 0.470 & -0.383 \\
Passalacqua & -0.027 & -0.229 & 0.129 \\
Lovejoy et al. & -0.146 & -0.996 & 0.484 \\
Buckberry \& Chamberlain & -0.038 & -0.308 & 0.211 \\
Rougé-Maillart et al. & 0.058 & 0.472 & 0.349 \\
Suchey-Brooks & -0.034 & -0.235 & 0.162 \\
\hline
\end{tabular}

Table 41: Discriminant function coefficients associated with the MANOVA for females. Note: Raw $=$ unstandardized coefficients, Stand. $=$ standardized coefficients, Struc. $=$ structure coefficients.

To estimate the group centroids for the four BMI groups, the sample inaccuracy scores were multiplied by the corresponding inaccuracy unstandardized discriminant function coefficients and then averaged across the samples. The means and standard deviations for each BMI group are in Table 42. An ANOVA with four levels in the IV (underweight, normal, overweight, obese) was performed on the canonically derived accuracy score DV, and is statistically significant $[\mathrm{F}(3,6.46)=6.433, p<0.001]$.

\begin{tabular}{|l|c|c|c|}
\hline & n & Mean & S.D. \\
\hline Underweight & 38 & 2.41 & 1.053 \\
Normal & 102 & 2.35 & 1.230 \\
Overweight & 45 & 2.26 & 0.100 \\
Obese & 13 & 1.75 & 0.767 \\
\hline
\end{tabular}

Table 42: Means and Standard Deviations for the female canonically derived variables.

The Cohen's $d$ absolute values were as follows, from highest to lowest: overweight vs. obese $=$ 1.056 ; underweight vs. obese $=0.666$; normal-sized vs. obese $=0.552$; underweight vs. overweight $=0.205$; normal-sized vs. overweight $=0.096$; and underweight vs. normal-sized $=$ 0.055. The differences between overweight and obese females are suggestive of a large effect size; the differences between underweight and obese, and normal-sized and obese females are suggestive of a medium effect size; the differences between underweight and overweight females 
are suggestive of a small effect size. There is no discernible difference between normal-sized and overweight, and underweight and normal-sized females.

Table 43 shows the results from Tukey's $b$ post-hoc tests for unequal sample sizes. There are no significant differences among the BMI group accuracy scores for females using the Kunos et al., DiGangi et al., Passalacqua, Buckberry and Chamberlain, Rougé-Maillart et al., and SucheyBrooks methods. The İşcan et al. method accuracy scores for underweight females are significantly lower than obese and overweight females. The Lovejoy et al. method obese female accuracy scores are significantly higher compared to overweight, underweight, and normal-sized females.

\begin{tabular}{|l|l|l|ll|}
\hline \multicolumn{1}{|c|}{ Method } & \multicolumn{1}{c|}{ BMI } & \multicolumn{2}{|c|}{ Subset (yrs) } \\
& Categories & \multicolumn{1}{c|}{$\mathbf{n}$} & \multicolumn{1}{c|}{$\mathbf{1}$} & $\mathbf{2}$ \\
\hline Kunos et al. & Obese & 13 & 6.69 \\
& Underweight & 38 & 10.42 \\
& Overweight & 45 & 10.93 \\
& Normal & 102 & 10.95 \\
\hline DiGangi et al. & Obese & 13 & 13.31 \\
& Overweight & 45 & 15.58 \\
& Underweight & 38 & 17.08 \\
& Normal & 102 & 17.36 \\
\hline İşcan et al. & Overweight & 45 & 9.42 \\
& Obese & 13 & 9.85 & \\
& Normal & 102 & 12.05 & 12.05 \\
& Underweight & 38 & & 15.82 \\
\hline Passalacqua & Underweight & 38 & 11.26 \\
& Normal & 102 & 11.85 \\
& Overweight & 45 & 12.60 \\
& Obese & 13 & 13.00 \\
\hline Lovejoy et al. & Overweight & 45 & 6.38 \\
& Underweight & 38 & 7.37 \\
& Normal & 102 & 8.48 \\
& Obese & 13 & & 11.62 \\
\hline Buckberry and Chamberlain & Underweight & 38 & 9.68 \\
& Overweight & 45 & 9.98 \\
& Normal & 102 & 10.76 \\
& Obese & 13 & 11.92 \\
\hline Rougé-Maillart et al. & Overweight & 45 & 8.20 \\
& Obese & 13 & 9.54 \\
& Underweight & 38 & 9.55 \\
& Normal & 102 & 10.14 \\
\hline Suchey-Brooks & Underweight & 38 & 7.66 \\
& Overweight & 45 & 7.80 & \\
& Obese & 13 & 8.92 & \\
& Normal & 102 & 9.42 \\
\hline
\end{tabular}

Table 43: Tukey's $b$ post-hoc test results for female accuracy scores separated by BMI. Note: alpha level $=\mathbf{0 . 0 5}$ 
A DFA was applied to assess how well BMI could be predicted from the accuracy scores of the eight age estimation methods. The cross-validated classification shows that only $37.4 \%$ of females are correctly classified into their BMI group based on accuracy scores. Underweight females are classified correctly at a rate of $57.9 \%$, normal-sized females at a rate of $19.6 \%$, overweight females at a rate of $51.1 \%$, and obese females at a rate of $69.2 \%$.

The discriminant scores from Function 1 and Function 2 were used to plot the sample on the discriminant dimensions. The obese group is associated with the largest group centroid (1.046), the normal group is associated with the next largest group centroid (0.028), the overweight group is associated with the second smallest centroid (-0.065) and, finally, the underweight group is associated with the smallest group centroid (-0.365) (see Figure 20).

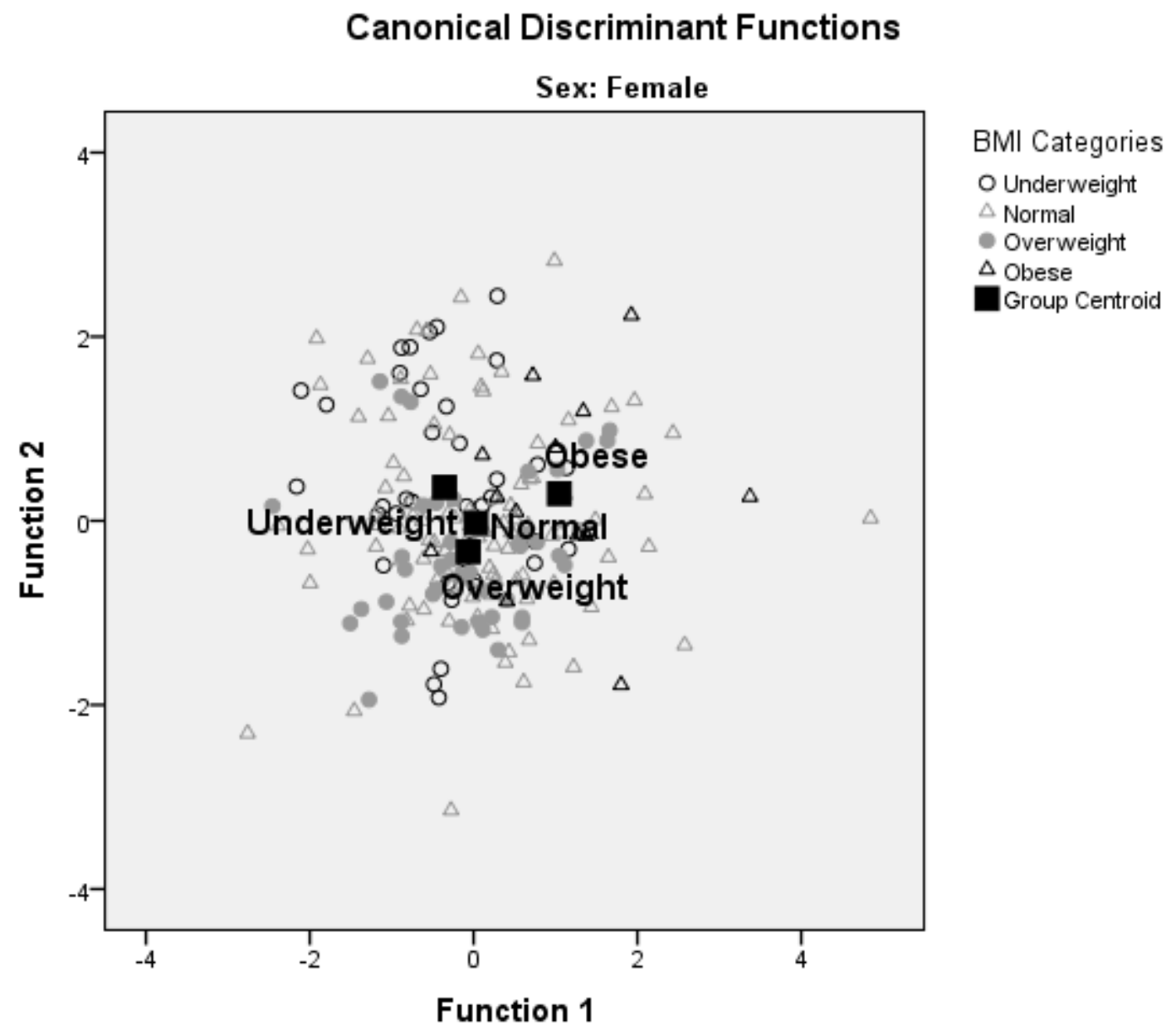

Figure 20: Canonically derived centroids for the BMI groups for females. 


\subsubsection{Bias}

\section{Males}

A series of Pearson correlations were performed between the bias scores for each age method.

Table 44 shows that the pattern of correlations observed among the bias scores are generally strong for a MANOVA, and the Box's M value of 250.604 is associated with a $p$-value of $<$ 0.001, which is significant. A covariance matrix (Appendix 14) was run to ensure that no covariance values were more than four times greater than each other. Although there are instances where the covariance values are greater than four times their value, typically associated with the DiGangi et al. method, overall the covariance matrices between the BMI groups were assumed to be equal for the purposes of the MANOVA.

\begin{tabular}{|c|c|c|c|c|c|c|c|c|c|c|}
\hline & 1. & 2. & 3. & 4. & 5. & 6. & 7. & 8. & $\begin{array}{l}\text { Mean } \\
\text { (yrs) }\end{array}$ & $\begin{array}{l}\text { S.D. } \\
\text { (yrs) }\end{array}$ \\
\hline 1. Kunos et al. & 1.00 & & & & & & & & 4.02 & 11.804 \\
\hline $\begin{array}{l}\text { 2. DiGangi et } \\
\text { al. }\end{array}$ & $\begin{array}{l}0.86 \\
(<0.001)\end{array}$ & 1.00 & & & & & & & -11.92 & 13.390 \\
\hline 3. İşcan et al. & $\begin{array}{l}0.20 \\
(<0.001)\end{array}$ & $\begin{array}{l}0.05 \\
(0.292)\end{array}$ & 1.00 & & & & & & 0.83 & 13.614 \\
\hline 4. Passalacqua & $\begin{array}{l}0.61 \\
(<0.001)\end{array}$ & $\begin{array}{l}0.52 \\
(<0.001)\end{array}$ & $\begin{array}{l}0.20 \\
(<0.001)\end{array}$ & 1.00 & & & & & -0.87 & 13.857 \\
\hline $\begin{array}{l}\text { 5. Lovejoy et } \\
\text { al. }\end{array}$ & $\begin{array}{l}0.70 \\
(<0.001)\end{array}$ & $\begin{array}{l}0.60 \\
(<0.001)\end{array}$ & $\begin{array}{l}0.30 \\
(<0.001)\end{array}$ & $\begin{array}{l}0.58 \\
(<0.001)\end{array}$ & 1.00 & & & & -5.07 & 9.807 \\
\hline $\begin{array}{l}\text { 6. Buckberry \& } \\
\text { Chamberlain }\end{array}$ & $\begin{array}{l}0.70 \\
(<0.001)\end{array}$ & $\begin{array}{l}0.59 \\
(<0.001)\end{array}$ & $\begin{array}{l}0.25 \\
(<0.001)\end{array}$ & $\begin{array}{l}0.56 \\
(<0.001)\end{array}$ & $\begin{array}{l}0.76 \\
(<0.001)\end{array}$ & 1.00 & & & 7.04 & 13.028 \\
\hline $\begin{array}{l}\text { 7. Rougé- } \\
\text { Maillart et al. }\end{array}$ & $\begin{array}{l}0.72 \\
(<0.001)\end{array}$ & $\begin{array}{l}0.63 \\
(<0.001)\end{array}$ & $\begin{array}{l}0.26 \\
(<0.001)\end{array}$ & $\begin{array}{l}0.58 \\
(<0.001)\end{array}$ & $\begin{array}{l}0.80 \\
(<0.001)\end{array}$ & $\begin{array}{l}0.86 \\
(<0.001)\end{array}$ & 1.00 & & -4.60 & 12.312 \\
\hline $\begin{array}{l}\text { 8. Suchey- } \\
\text { Brooks }\end{array}$ & $\begin{array}{l}0.68 \\
(<0.001)\end{array}$ & $\begin{array}{l}0.61 \\
(<0.001)\end{array}$ & $\begin{array}{l}0.25 \\
(<0.001)\end{array}$ & $\begin{array}{l}0.50 \\
(<0.001)\end{array}$ & $\begin{array}{l}0.62 \\
(<0.001)\end{array}$ & $\begin{array}{l}0.61 \\
(<0.001)\end{array}$ & $\begin{array}{l}0.66 \\
(<0.001)\end{array}$ & 1.00 & -6.36 & 10.003 \\
\hline
\end{tabular}

Table 44:Pearson Correlations, Means, and Standard Deviations of the bias scores for males for each age estimation method for males. P-values are in brackets.

A MANOVA was conducted to test the hypothesis that there would be differences between BMI group bias scores for each method. The MANOVA was statistically significant with Pillai's Trace $=0.191, \mathrm{~F}(24,1479)=4.196, p<0.001$, indicating there are differences among the BMI group bias scores. The multivariate effect size is estimated at 0.064 , which implies that $6.4 \%$ of the variance in the canonically derived DV is accounted for by the BMI groups.

Three eigenvalues and canonical correlations were extracted by the MANOVA. The first eigenvalue is 0.173 and accounts for $79.2 \%$ of the model variance. The canonical correlation associated with the first eigenvalue is 0.384 , where $14.8 \%$ of the variance in the discriminant 
function derived scores is accounted for by BMI group. The second eigenvalue is 0.035 and accounts for $16.4 \%$ of the model variance with a corresponding canonical correlation of 0.184 . The third eigenvalue is 0.010 and accounts for $4.7 \%$ of the model variance and a corresponding canonical correlation of 0.100 , which is not statistically significant [Wilks $\Lambda=0.990, F(6,493)=$ $0.835, p=0.544]$.

The standardized discriminant function coefficients from the first eigenvalue were used to determine the statistical significance of the MANOVA, as it is the strongest. As seen in Table 45, the standardized discriminant function coefficients suggest that the four BMI groups are maximally differentiated by a canonical variate with significant weightings from the İşcan et al. (0.946), Rougé-Maillart et al. (-0.442), and Kunos et al. (0.413) methods bias scores. The standardized coefficients suggest relatively minimal individual contributions to the MANOVA effect from all other bias scores. The correlations between the bias scores and the canonically derived scores for all methods are positive with weak to strong correlations (range $=0.168$ to $0.900)$.

\begin{tabular}{|l|l|l|l|}
\hline & \multicolumn{3}{|c|}{ Function 1 } \\
& Raw & Stand. & Struc. \\
\hline Kunos et al. & 0.035 & 0.413 & 0.331 \\
DiGangi et al. & 0.001 & 0.016 & 0.182 \\
İşcan et al. & 0.075 & 0.946 & 0.900 \\
Passalacqua & 0.022 & 0.297 & 0.365 \\
Lovejoy et al. & -0.031 & -0.298 & 0.195 \\
Buckberry \& Chamberlain & 0.017 & 0.218 & 0.226 \\
Rougé-Maillart et al. & -0.036 & -0.442 & 0.168 \\
Suchey-Brooks & -0.007 & -0.065 & 0.247 \\
\hline
\end{tabular}

Table 45: Discriminant function coefficients associated with the MANOVA for males. Note: Raw = unstandardized coefficients, Stand. = standardized coefficients, Struc. = structure coefficients.

To estimate the group centroids (i.e. the canonically derived group means) for the four BMI groups, the sample bias scores were multiplied by the corresponding bias unstandardized discriminant function coefficients and then averaged across the samples. The means and standard deviations are listed in Table 46. An ANOVA with four levels in the IV (underweight, normal, overweight, obese) was performed on the canonically derived bias score DV, and is statistically significant $[\mathrm{F}(3,28.512)=28.650, p<0.001]$. 


\begin{tabular}{|l|c|c|c|}
\hline & n & Mean & S.D. \\
\hline Underweight & 80 & -0.29 & 1.274 \\
Normal & 286 & 0.87 & 0.913 \\
Overweight & 110 & 0.77 & 1.002 \\
Obese & 26 & 0.71 & 0.902 \\
\hline
\end{tabular}

Table 46: Means and Standard Deviations for the male canonically derived variables.

The Cohen's $d$ absolute values were as follows, from highest to lowest: underweight vs. normalsized $=1.165$; underweight vs. overweight $=1.003$; underweight vs. obese $=0.919$; normal-sized vs. obese $=0.168$; normal-sized vs. overweight $=0.103$; and overweight vs. obese $=0.061$. The differences between underweight and normal-size, underweight and overweight, and underweight and obese males are suggestive of a large effect size, while the differences between normal-sized and obese, and normal-sized and overweight males are suggestive of a small effect size. There is no discernible difference between overweight and obese males.

Table 47 shows the results from Tukey's $b$ post-hoc tests for unequal sample sizes. There are no significant differences among the BMI group bias scores for males using the Lovejoy et al., Buckberry and Chamberlain, and Rougé-Maillart et al. methods. The Kunos et al. and DiGangi et al. methods under-age underweight males significantly compared to obese males. The İşcan et al. method under-ages underweight males significantly compared to obese, normal-sized, and overweight males. The Passalacqua and Suchey-Brooks methods under-age underweight males significantly compared to overweight males.

A DFA was applied to assess how well BMI group could be predicted from the bias scores of the eight age estimation methods. The cross-validated classification shows that only $40.0 \%$ of males are correctly classified into their BMI group based on bias scores. Underweight males are classified correctly at a rate of $57.5 \%$, normal-sized males at a rate of $37.8 \%$, overweight males at a rate of $35.5 \%$, and obese males at a rate of $30.8 \%$.

The discriminant scores from Function 1 and Function 2 were used to plot the sample on the discriminant dimensions. The normal-sized group is associated with the largest group centroid (0.214), the overweight group is associated with the next largest group centroid (0.116), the obese group is associated with the second smallest centroid (0.062) and, finally, the underweight group is associated with the smallest group centroid (-0.944) (see Figure 21). 


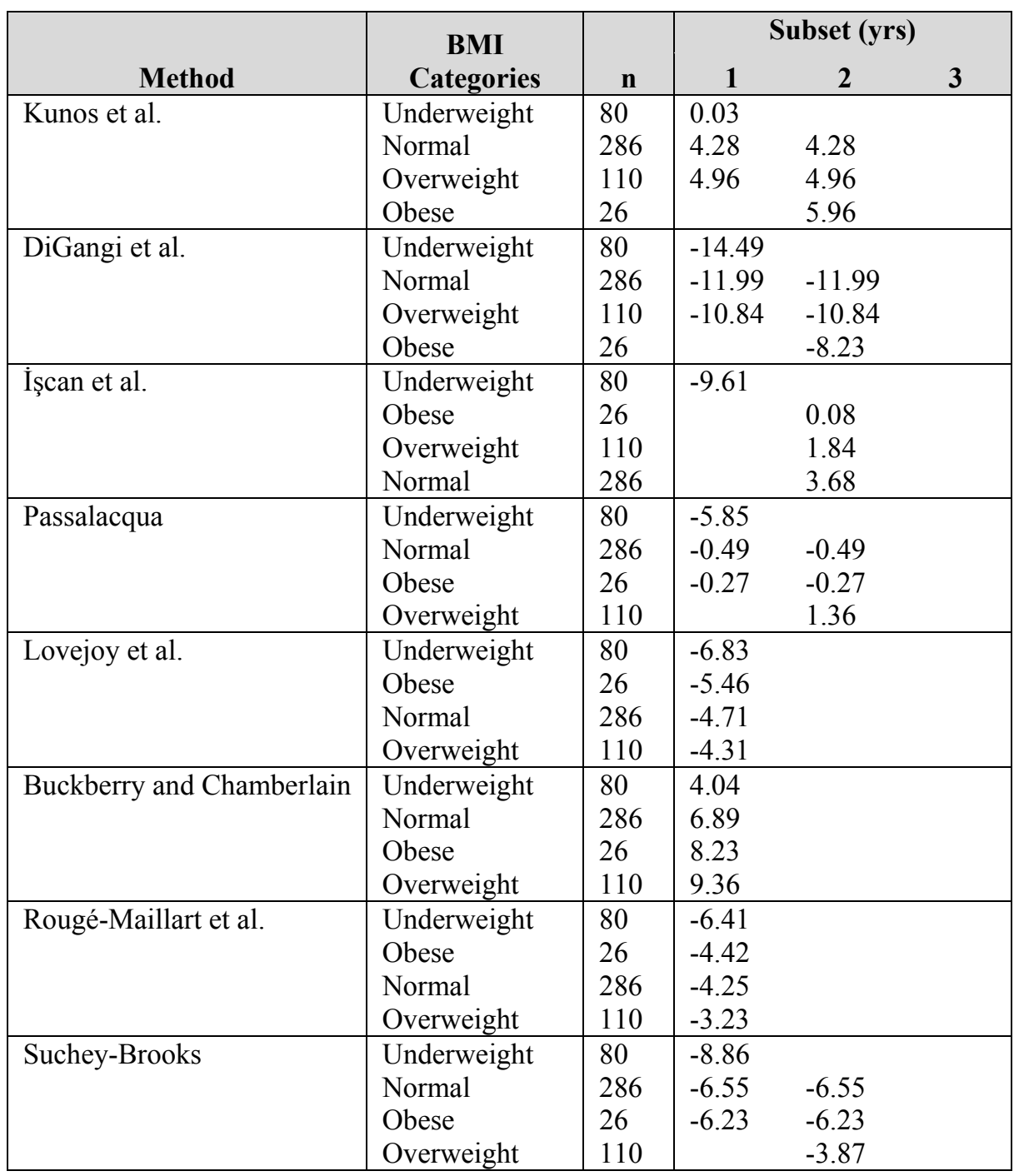

Table 47: Tukey's $b$ post-hoc test results for male bias scores separated by BMI. Note: alpha level $=\mathbf{0 . 0 5}$ 


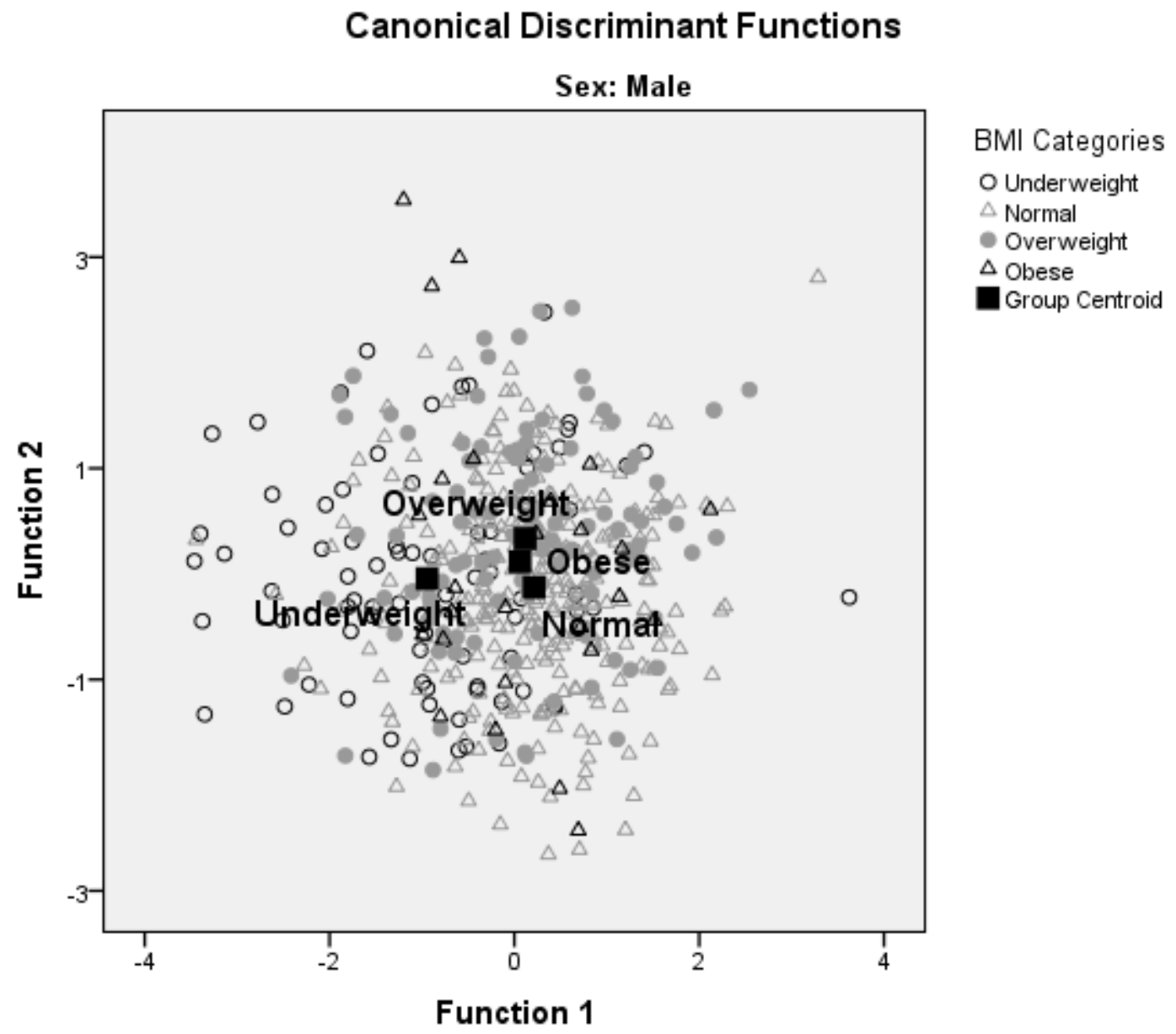

Figure 21: Canonically derived centroids for the BMI groups for males.

\section{Females}

A series of Pearson correlations were performed between the bias scores for each age method. Table 48 shows that the pattern of correlations observed among the bias scores are generally strong for a MANOVA, and the Box's M value of 194.558 is associated with a $p$-value of $<$ 0.001, which is significant. A covariance matrix (Appendix 15) was run to ensure that no covariance values were more than four times greater than each other (Howell, 2007). Although there are instances where the covariance values are greater than four times their value, typically associated with the DiGangi et al. method, overall the covariance matrices between the BMI groups were assumed to be equal for the purposes of the MANOVA. 


\begin{tabular}{|c|c|c|c|c|c|c|c|c|c|c|}
\hline & 1. & 2. & 3. & 4. & 5. & 6. & 7. & 8. & $\begin{array}{l}\text { Mean } \\
\text { (yrs) }\end{array}$ & $\begin{array}{l}\text { S.D. } \\
\text { (yrs) }\end{array}$ \\
\hline 1. Kunos et al. & 1.00 & & & & & & & & 0.93 & 12.917 \\
\hline $\begin{array}{l}\text { 2. DiGangi et } \\
\text { al. }\end{array}$ & $\begin{array}{l}0.86 \\
(<0.001)\end{array}$ & 1.00 & & & & & & & -15.72 & 14.331 \\
\hline 3. İşcan et al. & $\begin{array}{l}0.24 \\
(0.001)\end{array}$ & $\begin{array}{l}0.20 \\
(0.005)\end{array}$ & 1.00 & & & & & & -4.73 & 15.114 \\
\hline 4. Passalacqua & $\begin{array}{l}0.65 \\
(<0.001)\end{array}$ & $\begin{array}{l}0.57 \\
(<0.001)\end{array}$ & $\begin{array}{l}0.30 \\
(<0.001)\end{array}$ & 1.00 & & & & & -1.76 & 14.764 \\
\hline $\begin{array}{l}\text { 5. Lovejoy et } \\
\text { al. }\end{array}$ & $\begin{array}{l}0.63 \\
(<0.001)\end{array}$ & $\begin{array}{l}0.53 \\
(<0.001)\end{array}$ & $\begin{array}{l}0.38 \\
(<0.001)\end{array}$ & $\begin{array}{l}0.58 \\
(<0.001)\end{array}$ & 1.00 & & & & -6.27 & 9.320 \\
\hline $\begin{array}{l}\text { 6. Buckberry } \\
\text { \& Chamberlain }\end{array}$ & $\begin{array}{l}0.56 \\
(<0.001)\end{array}$ & $\begin{array}{l}0.46 \\
(<0.001)\end{array}$ & $\begin{array}{l}0.29 \\
(<0.001)\end{array}$ & $\begin{array}{l}0.50 \\
(<0.001)\end{array}$ & $\begin{array}{l}0.61 \\
(<0.001)\end{array}$ & 1.00 & & & 4.31 & 12.178 \\
\hline $\begin{array}{l}\text { 7. Rougé- } \\
\text { Maillart et al. }\end{array}$ & $\begin{array}{l}0.65 \\
(<0.001)\end{array}$ & $\begin{array}{l}0.55 \\
(<0.001)\end{array}$ & $\begin{array}{l}0.41 \\
(<0.001)\end{array}$ & $\begin{array}{l}0.61 \\
(<0.001)\end{array}$ & $\begin{array}{l}0.77 \\
(<0.001)\end{array}$ & $\begin{array}{l}0.77 \\
(<0.001)\end{array}$ & 1.00 & & -5.98 & 11.748 \\
\hline $\begin{array}{l}\text { 8. Suchey- } \\
\text { Brooks }\end{array}$ & $\begin{array}{l}0.67 \\
(<0.001)\end{array}$ & $\begin{array}{l}0.55 \\
(<0.001) \\
\end{array}$ & $\begin{array}{l}0.36 \\
(<0.001) \\
\end{array}$ & $\begin{array}{l}0.65 \\
(<0.001) \\
\end{array}$ & $\begin{array}{l}0.58 \\
(<0.001)\end{array}$ & $\begin{array}{l}0.51 \\
(<0.001)\end{array}$ & $\begin{array}{l}0.64 \\
(<0.001)\end{array}$ & 1.00 & -6.00 & 9.837 \\
\hline
\end{tabular}

Table 48: Pearson Correlations, Means, and Standard Deviations of the bias scores for females for each age estimation method for females.

A MANOVA was conducted to test the hypothesis that there would be differences between BMI group bias scores for each method. The MANOVA is statistically significant with Pillai's Trace $=0.291, \mathrm{~F}(24,567)=2.536, p<0.001$, indicating there are differences among the BMI group bias scores. The multivariate effect size is estimated at 0.097 , which implies that $9.7 \%$ of the variance in the canonically derived DV is accounted for by the BMI groups.

Three eigenvalues and canonical correlations were extracted by the MANOVA. The first eigenvalue is 0.295 and accounts for $81.7 \%$ of the model variance. The canonical correlation associated with the first eigenvalue is 0.477 , where $22.8 \%$ of the variance in the discriminant function derived scores is accounted for by BMI group. The second eigenvalue is 0.051 and accounts for $14.2 \%$ of the model variance with a corresponding canonical correlation of 0.221 . The third eigenvalue is 0.015 and accounts for $4.1 \%$ of the model variance and a corresponding canonical correlation of 0.121 , which is not statistically significant [Wilks $\Lambda=0.986, F(6,189)=$ $0.466, p=0.833]$.

The standardized discriminant function coefficients from the first eigenvalue were used to determine the statistical significance of the MANOVA as it was the strongest. As seen in Table 49, the standardized discriminant function coefficients suggest that the four BMI groups were maximally differentiated by a canonical variate with significant weightings from the İşcan et al. (-1.028), DiGangi et al. (-0.856), and Kunos et al. (0.713) methods bias scores. The standardized 
coefficients suggest moderate individual contributions to the MANOVA effect from several bias scores (i.e. Passalacqua, Lovejoy et al., and Buckberry and Chamberlain methods), with minimal contribution from the Suchey-Brooks method. The correlations between the bias scores and the canonically derived scores are weak for all methods (range $=-0.086$ to 0.186 ) except the İşcan et al. method, which has a moderate negative correlation (-0.690).

\begin{tabular}{|l|l|l|l|}
\hline & \multicolumn{3}{|c|}{ Function 1 } \\
& Raw & Stand. & Struc. \\
\hline Kunos et al. & 0.056 & 0.713 & 0.130 \\
DiGangi et al. & -0.061 & -0.856 & -0.056 \\
İşcan et al. & -0.072 & -1.028 & -0.690 \\
Passalacqua & 0.031 & 0.453 & 0.186 \\
Lovejoy et al. & 0.014 & 0.130 & 0.056 \\
Buckberry \& Chamberlain & -0.037 & -0.458 & -0.086 \\
Rougé-Maillart et al. & 0.039 & 0.445 & 0.031 \\
Suchey-Brooks & 0.006 & 0.053 & 0.102 \\
\hline
\end{tabular}

Table 49: Discriminant function coefficients associated with the MANOVA for females. Note: Raw $=$ unstandardized coefficients, Stand. = standardized coefficients, Struc. $=$ structure coefficients.

To estimate the group centroids for the four BMI groups, the sample bias scores were multiplied by the corresponding bias unstandardized discriminant function coefficients and then averaged across the samples. The means and standard deviations for each BMI group are in Table 50. An ANOVA with four levels in the IV (underweight, normal, overweight, obese) was performed on the canonically derived bias score $\mathrm{DV}$, and is significant $[\mathrm{F}(3,19.041)=19.041, p<0.001]$.

\begin{tabular}{|l|c|c|c|}
\hline & n & Mean & S.D. \\
\hline Underweight & 38 & 1.87 & 0.746 \\
Normal & 102 & 0.45 & 1.064 \\
Overweight & 45 & 0.90 & 1.014 \\
Obese & 13 & 0.53 & 1.027 \\
\hline
\end{tabular}

Table 50: Means and Standard Deviations for the female canonically derived variables.

The Cohen's $d$ absolute values were as follows, from highest to lowest: underweight vs. obese $=$ 1.484; underweight vs. normal-sized $=1.435$; underweight vs. overweight $=1.027$; normal-sized vs. overweight $=0.439$; overweight vs. obese $=0.437$; and normal-sized vs. obese $=0.078$. The differences between underweight and obese, underweight and normal-sized, and underweight and overweight females are suggestive of a large effect size; the differences between overweight and obese females are suggestive of a medium effect size. There is no discernible difference between normal-sized and obese females. 
Table 51 shows the results from Tukey's $b$ post-hoc tests for unequal sample sizes. There are no significant differences among the BMI group bias scores for females using any method except the İşcan et al. method. The İşcan et al. method under-ages underweight females significantly compared to overweight, obese, and normal-sized females.

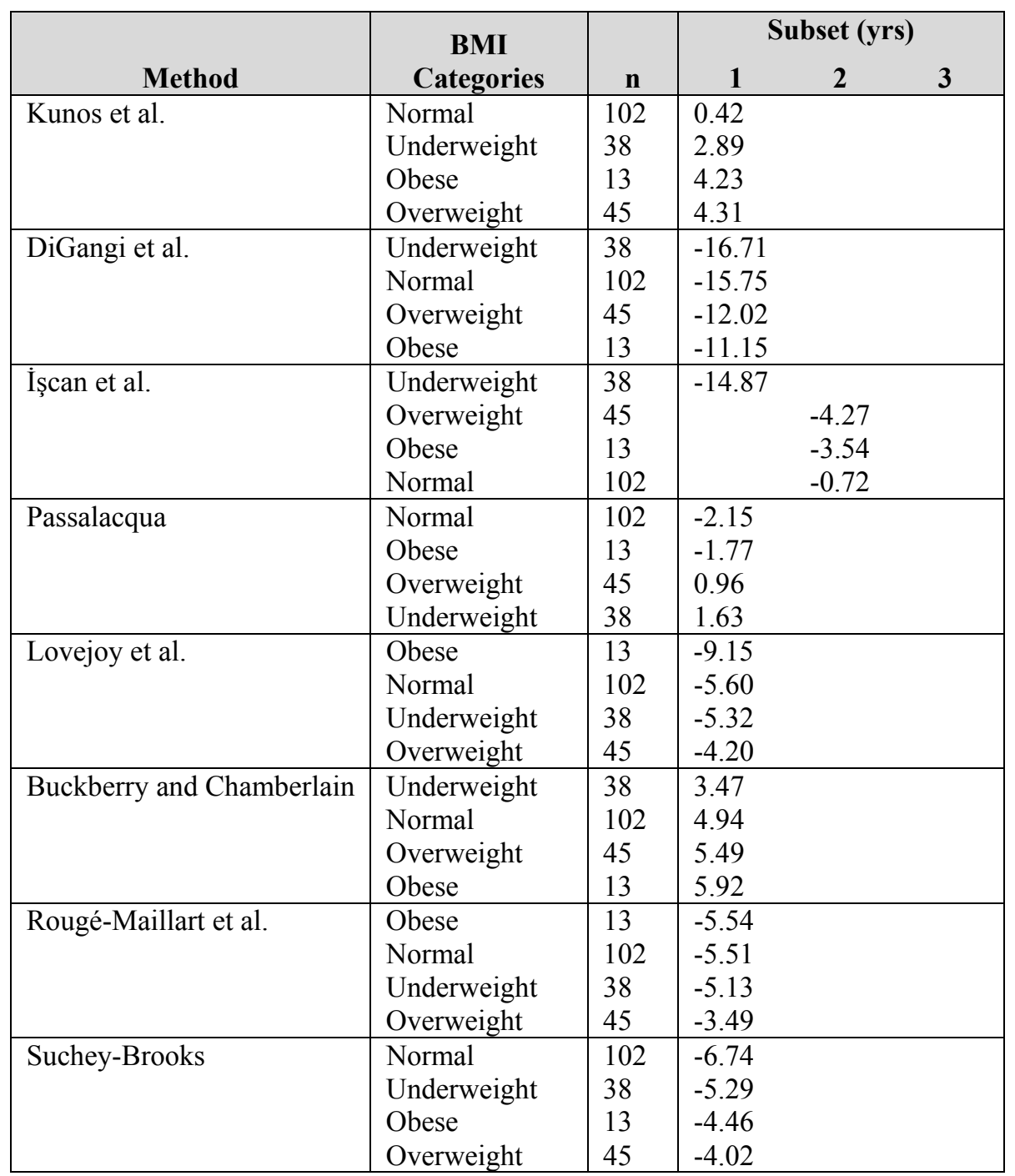

Table 51: Tukey's $b$ post-hoc test results for female bias scores separated by BMI. Note: alpha level $=\mathbf{0 . 0 5}$

A DFA was applied to assess how well BMI group could be predicted from the bias scores of the eight age estimation methods. The cross-validated classification shows that only $40.9 \%$ of females are correctly classified into their BMI group based on bias scores. Underweight females are classified correctly at a rate of $65.8 \%$, normal-sized females at a rate of $40.2 \%$, overweight females at a rate of $20 \%$, and obese females at a rate of $46.2 \%$. 
The discriminant scores from Function 1 and Function 2 were used to plot the sample on the discriminant dimensions. The normal-sized group is associated with the largest group centroid (0.377), the obese group is associated with the next largest group centroid (0.301), the overweight group is associated with the second smallest centroid (-0.062) and, finally, the underweight group is associated with the smallest group centroid (-1.042) (see Figure 22).

\section{Canonical Discriminant Functions}

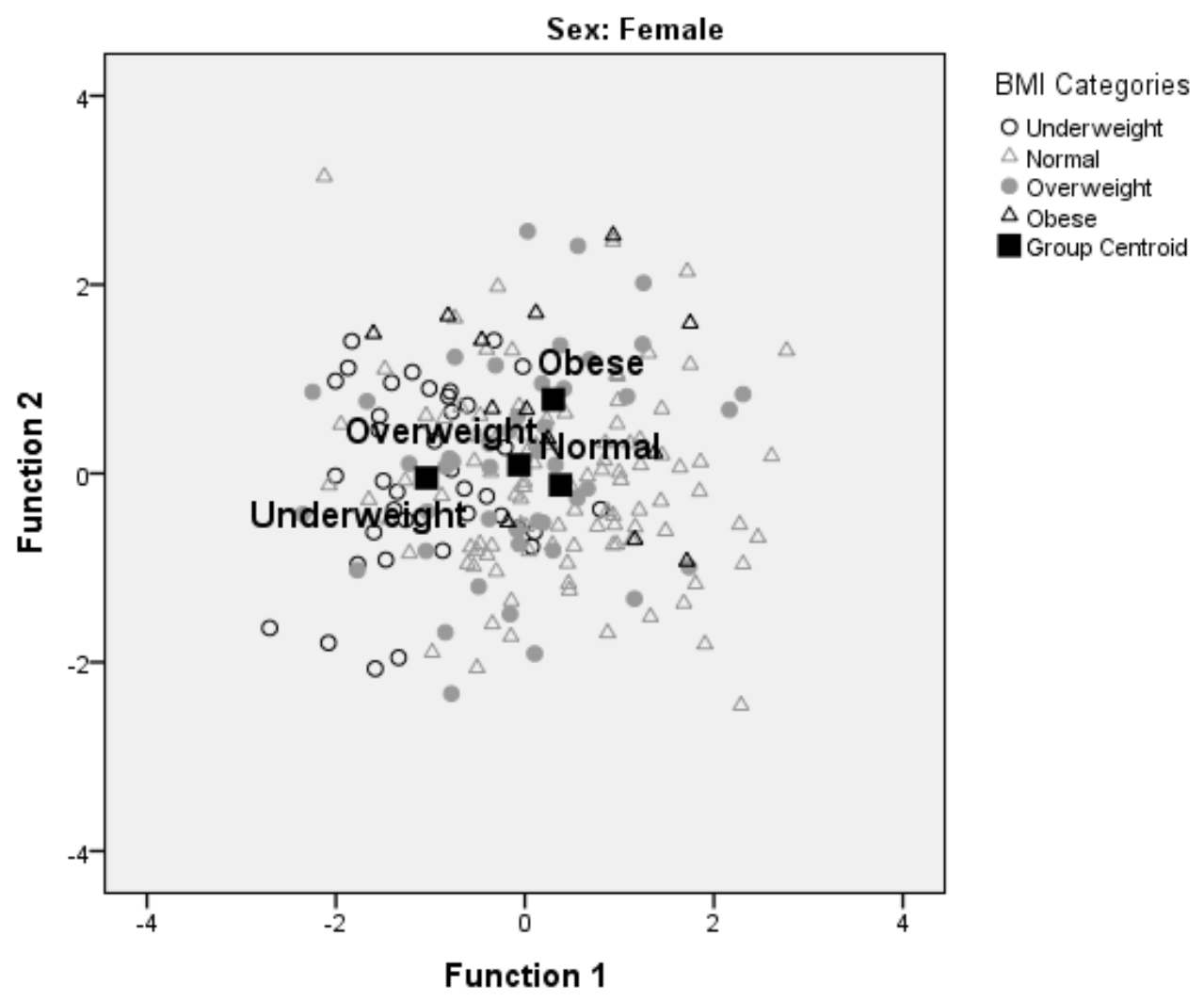

Figure 22: Canonically derived centroids for the BMI groups for females.

\subsubsection{Ancestry}

\subsubsection{Accuracy}

\section{European Ancestry}

A series of Pearson correlations were performed between the accuracy scores for each age method. Table 52 shows that the pattern of correlations observed among the accuracy scores are generally lower than ideal for a MANOVA, and the Box's M value of 177.830 is associated with a $p$-value of $<0.001$, which is significant. A covariance matrix (Appendix 16) was run to ensure 
that no covariance values were more than four times greater than each other. Although there are instances where the covariance values are greater than four times their value, typically associated with the İşcan et al. and Buckberry and Chamberlain methods, overall the covariance matrices between the BMI groups were assumed to be equal for the purposes of the MANOVA.

\begin{tabular}{|c|c|c|c|c|c|c|c|c|c|c|}
\hline & 1. & 2. & 3. & 4. & 5. & 6. & 7. & 8. & $\begin{array}{l}\text { Mean } \\
\text { (yrs) }\end{array}$ & $\begin{array}{l}\text { S.D. } \\
\text { (yrs) }\end{array}$ \\
\hline 1. Kunos et al. & 1.00 & & & & & & & & 10.19 & 7.139 \\
\hline $\begin{array}{l}\text { 2. DiGangi et } \\
\text { al. }\end{array}$ & $\begin{array}{l}0.15 \\
(0.001)\end{array}$ & 1.00 & & & & & & & 16.45 & 11.370 \\
\hline 3. İşcan et al. & $\begin{array}{l}0.09 \\
(0.039)\end{array}$ & $\begin{array}{l}0.30 \\
(<0.001)\end{array}$ & 1.00 & & & & & & 11.30 & 8.983 \\
\hline 4. Passalacqua & $\begin{array}{l}0.20 \\
(<0.001)\end{array}$ & $\begin{array}{l}0.15 \\
(<0.001)\end{array}$ & $\begin{array}{l}0.12 \\
(0.005)\end{array}$ & 1.00 & & & & & 11.47 & 8.365 \\
\hline $\begin{array}{l}\text { 5. Lovejoy et } \\
\text { al. }\end{array}$ & $\begin{array}{l}0.08 \\
(0.054)\end{array}$ & $\begin{array}{l}0.48 \\
(<0.001)\end{array}$ & $\begin{array}{l}0.14 \\
(0.002)\end{array}$ & $\begin{array}{l}0.23 \\
(<0.001)\end{array}$ & 1.00 & & & & 9.24 & 7.177 \\
\hline $\begin{array}{l}\text { 6. Buckberry } \\
\text { \& Chamberlain }\end{array}$ & $\begin{array}{l}0.30 \\
(<0.001)\end{array}$ & $\begin{array}{l}-0.24 \\
(<0.001)\end{array}$ & $\begin{array}{l}-0.01 \\
(0.954)\end{array}$ & $\begin{array}{l}0.06 \\
(0.162)\end{array}$ & $\begin{array}{l}-0.06 \\
(0.137)\end{array}$ & 1.00 & & & 10.87 & 8.072 \\
\hline $\begin{array}{l}\text { 7. Rougé- } \\
\text { Maillart et al. }\end{array}$ & $\begin{array}{l}0.15 \\
(0.001)\end{array}$ & $\begin{array}{l}0.49 \\
(<0.001)\end{array}$ & $\begin{array}{l}0.24 \\
(<0.001)\end{array}$ & $\begin{array}{l}0.29 \\
(<0.001)\end{array}$ & $\begin{array}{l}0.63 \\
(<0.001)\end{array}$ & $\begin{array}{l}0.08 \\
(0.050)\end{array}$ & 1.00 & & 10.83 & 8.218 \\
\hline $\begin{array}{l}\text { 8. Suchey- } \\
\text { Brooks }\end{array}$ & $\begin{array}{l}0.05 \\
(0.281) \\
\end{array}$ & $\begin{array}{l}0.49 \\
(<0.001)\end{array}$ & $\begin{array}{l}0.17 \\
(<0.001)\end{array}$ & $\begin{array}{l}0.21 \\
(<0.001)\end{array}$ & $\begin{array}{l}0.49 \\
(<0.001)\end{array}$ & $\begin{array}{l}-0.19 \\
(<0.001)\end{array}$ & $\begin{array}{l}0.50 \\
(<0.001)\end{array}$ & 1.00 & 9.70 & 7.448 \\
\hline
\end{tabular}

Table 52: Pearson Correlations, Means, and Standard Deviations of the accuracy scores for males for each age estimation method for individuals of European ancestry. P-values are in brackets.

A MANOVA was conducted to test the hypothesis that there would be differences between BMI accuracy scores for each method. The MANOVA was statistically significant with Pillai's Trace $=0.076, \mathrm{~F}(24,1464)=1.596, p=0.034$, indicating there are differences among the BMI group accuracy scores. The multivariate effect size is estimated at 0.025 , which implies that $2.5 \%$ of the variance in the canonically derived DV is accounted for by the BMI groups.

Three eigenvalues and canonical correlations were extracted by the MANOVA. The first eigenvalue is 0.045 and accounts for $57.4 \%$ of the model variance. The canonical correlation associated with the first eigenvalue is 0.208 , where $4.3 \%$ of the variance in the discriminant function derived scores is accounted for by BMI group. The second eigenvalue is 0.024 and accounts for $30.9 \%$ of the model variance with a corresponding canonical correlation of 0.155 . The third eigenvalue is 0.009 and accounts for $11.7 \%$ of the model variance and a corresponding canonical correlation of 0.096 , which is not statistically significant [Wilks $\Lambda=0.991, F(6,488)=$ $0.755, p=0.606]$. 
The standardized discriminant function coefficients from the first eigenvalue were used to determine the statistical significance of the MANOVA. As seen in Table 53, the standardized discriminant function coefficients suggest that the four BMI groups were maximally differentiated by a canonical variate with significant weightings from the DiGangi et al. (0.622), Rougé-Maillart et al. (0.608), and Lovejoy et al. (-0.475) methods accuracy scores. The standardized coefficients suggest moderate individual contributions to the MANOVA effect from the Kunos et al., Passalacqua methods, with minimal contributions from the İşcan et al. and Suchey-Brooks methods (0.044 and -0.072). The correlations between the accuracy scores and the canonically derived scores for all methods are positive and moderate to strong (range $=0.223$ to 0.756 ), except for the Buckberry and Chamberlain method, which has negative, weak correlations (-0.054).

Table 53: Discriminant function coefficients associated with the MANOVA for individuals of European ancestry. Note: Raw $=$ unstandardized coefficients, Stand. $=$ standardized coefficients, Struc. $=$ structure coefficients.

To estimate the group centroids for the four BMI groups, the sample inaccuracy scores were multiplied by the corresponding inaccuracy unstandardized discriminant function coefficients and then averaged across the samples. The means and standard deviations are listed in Table 54. An ANOVA with four levels in the IV (underweight, normal, overweight, obese) was performed on the canonically derived accuracy score DV, and is statistically significant $[\mathrm{F}(3,14.196)=$ $5.688, p=0.001]$.

\begin{tabular}{|l|c|c|c|}
\hline & n & Mean & S.D. \\
\hline Underweight & 69 & -1.363 & 1.544 \\
Normal & 272 & -0.791 & 1.704 \\
Overweight & 122 & -0.493 & 1.377 \\
Obese & 34 & -0.262 & 1.260 \\
\hline
\end{tabular}

Table 54: Means and Standard Deviations for the European canonically derived variables. 
The Cohen's $d$ absolute values were as follows, from highest to lowest: underweight vs. obese $=$ 0.955 ; underweight vs. overweight $=0.743$; normal-sized vs. obese $=0.577$; underweight vs. normal-sized $=0.447$; and overweight vs. obese $=0.285$; and normal-sized vs. overweight $=$ 0.258 . The differences between underweight and obese, and underweight and overweight individuals of European ancestry are suggestive of a large effect size; the differences between normal-sized and obese, underweight and normal-sized individuals of European ancestry are suggestive of a medium effect size; and the differences between normal-sized and overweight individuals of European ancestry are suggestive of a small effect size.

Table 55 shows the results from Tukey's $b$ post-hoc tests for unequal sample sizes. There are no significant differences among the BMI group accuracy scores for individuals of European ancestry using the Kunos et al., İşcan et al., Passalacqua, Lovejoy et al., Buckberry and Chamberlain, and Suchey-Brooks methods. The DiGangi et al. method accuracy scores for underweight individuals of European ancestry are significantly higher than obese and overweight individuals of European ancestry. The Rougé-Maillart et al. method accuracy scores for underweight individuals of European ancestry are significantly higher compared to obese and overweight individuals of European ancestry.

A DFA was applied to assess how well BMI could be predicted from the accuracy scores of the eight age estimation methods. The cross-validated classification shows that only $29.0 \%$ of individuals of European ancestry are correctly classified into their BMI group based on accuracy scores. Underweight individuals of European ancestry are classified correctly at a rate of 39.1\%, normal-sized individuals of European ancestry at a rate of $21.7 \%$, overweight individuals of European ancestry at a rate of $33.6 \%$, and obese individuals of European ancestry at a rate of $50.0 \%$.

The discriminant scores from Function 1 and Function 2 were used to plot the sample on the discriminant dimensions. The underweight group is associated with the largest group centroid (0.201), the normal-sized group is associated with the next largest group centroid (0.118), the overweight group is associated with the second smallest centroid (-0.229) and, finally, the obese group is associated with the smallest group centroid (-0.527) (see Figure 23). 


\begin{tabular}{|c|c|c|c|c|c|}
\hline \multirow[b]{2}{*}{ Method } & \multirow{2}{*}{$\begin{array}{c}\text { BMI } \\
\text { Categories }\end{array}$} & \multirow[b]{2}{*}{$\mathbf{n}$} & \multicolumn{3}{|c|}{ Subset (yrs) } \\
\hline & & & 1 & 2 & 3 \\
\hline \multirow[t]{4}{*}{ Kunos et al. } & Obese & 34 & 7.88 & & \\
\hline & Overweight & 122 & 9.25 & & \\
\hline & Underweight & 69 & 9.55 & & \\
\hline & Normal & 272 & 10.90 & & \\
\hline \multirow[t]{4}{*}{ DiGangi et al. } & Obese & 34 & 13.09 & & \\
\hline & Overweight & 122 & 13.89 & & \\
\hline & Normal & 272 & 17.23 & 17.23 & \\
\hline & Underweight & 69 & & 18.75 & \\
\hline \multirow[t]{4}{*}{ İşcan et al. } & Obese & 34 & 9.56 & & \\
\hline & Overweight & 122 & 10.60 & & \\
\hline & Normal & 272 & 11.07 & & \\
\hline & Underweight & 69 & 13.14 & & \\
\hline \multirow{4}{*}{ Passalacqua } & Overweight & 122 & 10.06 & & \\
\hline & Normal & 272 & 11.62 & & \\
\hline & Obese & 34 & 11.76 & & \\
\hline & Underweight & 69 & 12.67 & & \\
\hline \multirow[t]{4}{*}{ Lovejoy et al. } & Overweight & 122 & 8.12 & & \\
\hline & Normal & 272 & 9.15 & & \\
\hline & Obese & 34 & 9.74 & & \\
\hline & Underweight & 69 & 10.38 & & \\
\hline \multirow[t]{4}{*}{ Buckberry and Chamberlain } & Underweight & 69 & 10.39 & & \\
\hline & Normal & 272 & 10.93 & & \\
\hline & Obese & 34 & 10.97 & & \\
\hline & Overweight & 122 & 10.99 & & \\
\hline \multirow[t]{4}{*}{ Rougé-Maillart et al. } & Obese & 34 & 8.38 & & \\
\hline & Overweight & 122 & 9.35 & & \\
\hline & Normal & 272 & 10.96 & 10.96 & \\
\hline & Underweight & 69 & & 12.84 & \\
\hline \multirow{4}{*}{ Suchey-Brooks } & Overweight & 122 & 8.66 & & \\
\hline & Obese & 34 & 9.56 & & \\
\hline & Normal & 272 & 9.56 & & \\
\hline & Underweight & 69 & 11.74 & & \\
\hline
\end{tabular}

Table 55: Tukey's $b$ post-hoc test results for European accuracy scores separated by BMI. Note: alpha level $=\mathbf{0 . 0 5}$ 


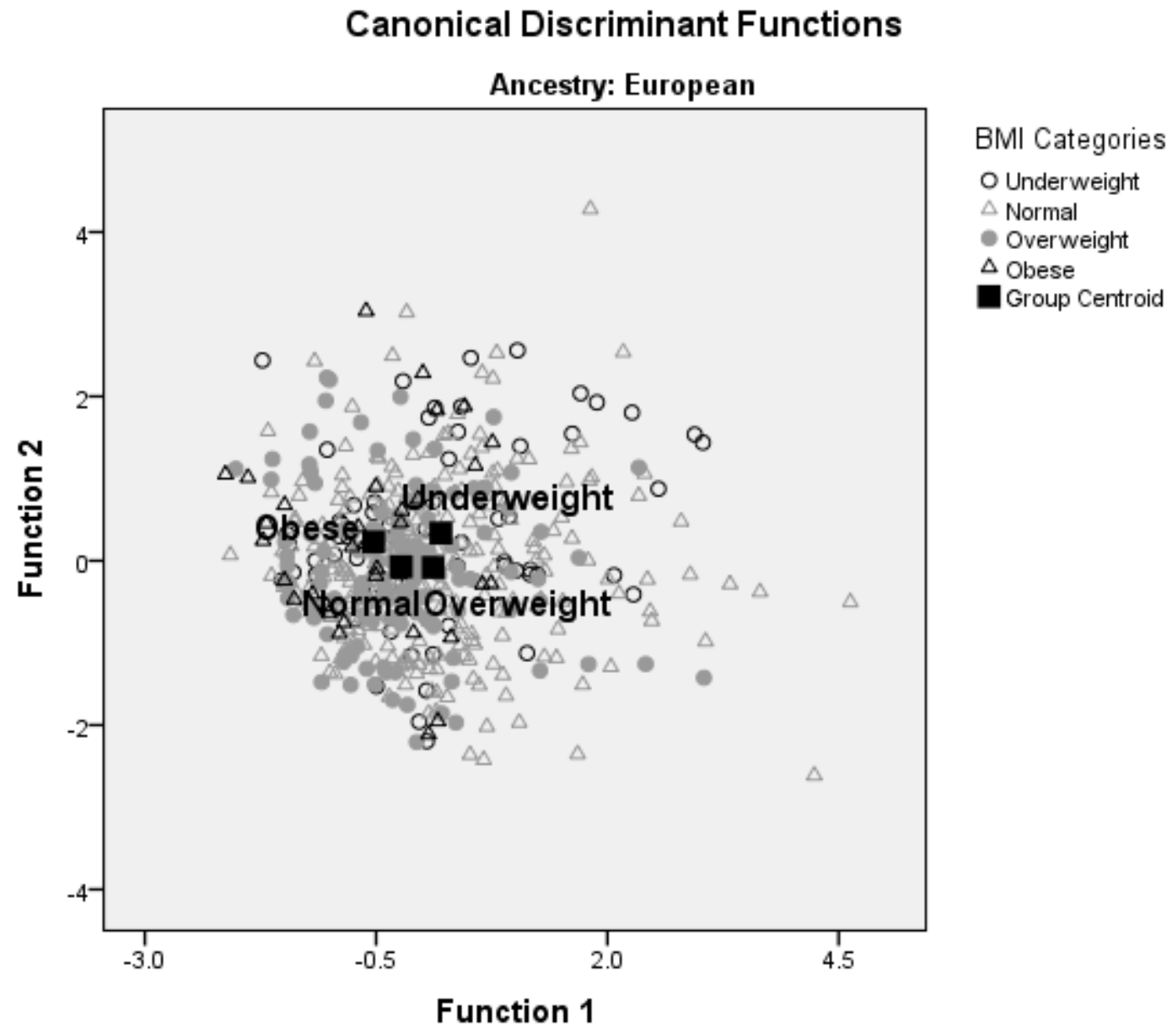

Figure 23: Canonically derived centroids for the BMI groups for individuals of European ancestry.

\section{African Ancestry}

A series of Pearson correlations were performed between the accuracy scores for each age method. Table 56 shows that the pattern of correlations observed among the accuracy scores are generally lower than ideal for a MANOVA, and the Box's M value of 96.973 is associated with a $p$-value of 0.083 , which is not significant. Therefore, the covariance matrices between the BMI groups were assumed to be equal for the purposes of the MANOVA. 


\begin{tabular}{|c|c|c|c|c|c|c|c|c|c|c|}
\hline & 1. & 2. & 3. & 4. & 5. & 6. & 7. & 8. & $\begin{array}{l}\text { Mean } \\
\text { (yrs) }\end{array}$ & $\begin{array}{l}\text { S.D. } \\
\text { (yrs) }\end{array}$ \\
\hline 1. Kunos et al. & 1.00 & & & & & & & & 11.03 & 6.889 \\
\hline 2. DiGangi et al. & $\begin{array}{l}-0.02 \\
(0.807)\end{array}$ & 1.00 & & & & & & & 12.81 & 9.772 \\
\hline 3. İşcan et al. & $\begin{array}{l}0.19 \\
(0.008)\end{array}$ & $\begin{array}{l}0.37 \\
(<0.001)\end{array}$ & 1.00 & & & & & & 10.85 & 8.683 \\
\hline 4. Passalacqua & $\begin{array}{l}0.24 \\
(<0.001)\end{array}$ & $\begin{array}{l}0.07 \\
(0.318)\end{array}$ & $\begin{array}{l}0.11 \\
(0.129)\end{array}$ & 1.00 & & & & & 11.42 & 8.265 \\
\hline 5. Lovejoy et al. & $\begin{array}{l}0.15 \\
(0.031)\end{array}$ & $\begin{array}{l}0.47 \\
(<0.001)\end{array}$ & $\begin{array}{l}-0.21 \\
(0.002)\end{array}$ & $\begin{array}{l}0.16 \\
(0.017)\end{array}$ & 1.00 & & & & 7.15 & 6.028 \\
\hline $\begin{array}{l}\text { 6. Buckberry \& } \\
\text { Chamberlain }\end{array}$ & $\begin{array}{l}0.39 \\
(<0.001)\end{array}$ & $\begin{array}{l}-0.30 \\
(<0.001)\end{array}$ & $\begin{array}{l}-0.04 \\
(0.569)\end{array}$ & $\begin{array}{l}0.11 \\
(0.098)\end{array}$ & $\begin{array}{l}0.02 \\
(0.754)\end{array}$ & 1.00 & & & 12.85 & 9.555 \\
\hline $\begin{array}{l}\text { 7. Rougé- } \\
\text { Maillart et al. }\end{array}$ & $\begin{array}{l}0.23 \\
(0.001)\end{array}$ & $\begin{array}{l}0.44 \\
(<0.001)\end{array}$ & $\begin{array}{l}0.17 \\
(0.013)\end{array}$ & $\begin{array}{l}0.14 \\
(0.047)\end{array}$ & $\begin{array}{l}0.63 \\
(<0.001)\end{array}$ & $\begin{array}{l}0.20 \\
(0.003)\end{array}$ & 1.00 & & 9.06 & 7.734 \\
\hline $\begin{array}{l}\text { 8. Suchey- } \\
\text { Brooks }\end{array}$ & $\begin{array}{l}0.05 \\
(<0.001)\end{array}$ & $\begin{array}{l}0.55 \\
(<0.001)\end{array}$ & $\begin{array}{l}0.29 \\
(<0.001)\end{array}$ & $\begin{array}{l}0.07 \\
(0.284)\end{array}$ & $\begin{array}{l}0.49 \\
(<0.001)\end{array}$ & $\begin{array}{l}-0.16 \\
(0.021)\end{array}$ & $\begin{array}{l}0.45 \\
(<0.001)\end{array}$ & 1.00 & 7.96 & 6.717 \\
\hline
\end{tabular}

Table 56: Pearson Correlations, Means, and Standard Deviations of the accuracy scores for each age estimation method for individuals of African ancestry. P-values are in brackets.

A MANOVA was conducted to test the hypothesis that there would be differences between BMI accuracy scores for each method. The MANOVA was statistically significant with Pillai's Trace $=0.192, \mathrm{~F}(24,582)=1.659, p=0.026$, indicating there are differences among the BMI group accuracy scores. The multivariate effect size is estimated at 0.064 , which implies that $6.4 \%$ of the variance in the canonically derived DV is accounted for by the BMI groups.

Three eigenvalues and canonical correlations were extracted by the MANOVA. The first eigenvalue is 0.173 and accounts for $79.1 \%$ of the model variance. The canonical correlation associated with the first eigenvalue is 0.384 , where $9.1 \%$ of the variance in the discriminant function derived scores is accounted for by BMI. The second eigenvalue is 0.034 and accounts for $15.7 \%$ of the model variance with a corresponding canonical correlation of 0.182 . The third eigenvalue is 0.011 and accounts for $5.2 \%$ of the model variance and a corresponding canonical correlation of 0.106 , which is not statistically significant [Wilks $\Lambda=0.989, \mathrm{~F}(6,194)=0.365, p$ $=0.900]$.

The standardized discriminant function coefficients from the first eigenvalue were used to determine the statistical significance of the MANOVA. As seen in Table 57, the standardized discriminant function coefficients suggest that the four BMI groups were maximally differentiated by a canonical variate with significant weighting from the İşcan et al. (0.965) method accuracy scores. The standardized coefficients suggest relatively minimal individual 
contributions to the MANOVA effect from all other method accuracy scores, except the SucheyBrooks method (-0.497). The correlations between the accuracy scores and the canonically derived scores for all methods are weak to moderate (range $=0 .-0.050$ to 0.322 ), except the İşcan et al. method, which has a strong, positive correlation (0.919).

\begin{tabular}{|l|l|l|l|}
\hline & \multicolumn{3}{|c|}{ Function 1 } \\
& Raw & Stand. & Struc. \\
\hline Kunos et al. & 0.012 & 0.080 & 0.210 \\
DiGangi et al. & 0.021 & 0.199 & 0.322 \\
İşcan et al. & 0.118 & 0.965 & 0.919 \\
Passalacqua & 0.001 & 0.001 & 0.115 \\
Lovejoy et al. & 0.028 & 0.160 & 0.195 \\
Buckberry \& Chamberlain & -0.010 & -0.098 & -0.050 \\
Rougé-Maillart et al. & -0.002 & -0.013 & 0.108 \\
Suchey-Brooks & -0.074 & -0.497 & 0.015 \\
\hline
\end{tabular}

Table 57: Discriminant function coefficients associated with the MANOVA for individuals of African ancestry. Note: Raw = unstandardized coefficients, Stand. = standardized coefficients, Struc. $=$ structure coefficients.

To estimate the group centroids for the four BMI groups, the sample inaccuracy scores were multiplied by the corresponding inaccuracy unstandardized discriminant function coefficients and then averaged across the samples. The means and standard deviations for each BMI group are in Table 58. An ANOVA with four levels in the IV (underweight, normal, overweight, obese) was performed on the canonically derived accuracy score DV, and is statistically significant $[\mathrm{F}(3,32.297)=14.558, p<0.001]$.

\begin{tabular}{|l|c|c|c|}
\hline & $\mathbf{n}$ & Mean & S.D. \\
\hline Underweight & 49 & -1.245 & 1.997 \\
Normal & 116 & 0.402 & 1.293 \\
Overweight & 33 & 0.252 & 1.137 \\
Obese & 5 & -0.172 & 2.038 \\
\hline
\end{tabular}

Table 58: Means and Standard Deviations for the individuals of African ancestry canonically derived variables.

The Cohen's $d$ absolute values were as follows, from highest to lowest: underweight vs. overweight $=2.500$; underweight vs. normal-sized $=2.230$; underweight vs. obese $=1.092$; normal-sized vs. obese $=0.849$; overweight vs. obese $=0.632$; and normal-sized vs. overweight $=0.145$. The differences between underweight and overweight, underweight and normal-sized, underweight and obese, and normal-sized and obese individuals of African ancestry are suggestive of a large effect size; the difference between underweight and overweight individuals 
of African ancestry is suggestive of a medium effect size; the difference between normal-sized and overweight individuals of African ancestry is suggestive of a small effect size.

Table 59 shows the results from Tukey's $b$ post-hoc tests for unequal sample sizes. There are no significant differences among the BMI group accuracy scores for individuals of African ancestry using the Kunos et al., Passalacqua, Lovejoy et al., Buckberry and Chamberlain, Rougé-Maillart et al., and Suchey-Brooks methods. The DiGangi et al. method accuracy scores for underweight individuals of African ancestry are significantly lower than obese individuals of African ancestry. The İşcan et al. method accuracy scores for underweight individuals of African ancestry are significantly lower than overweight individuals of African ancestry.

\begin{tabular}{|c|c|c|c|c|c|}
\hline \multirow[b]{2}{*}{ Method } & \multirow{2}{*}{$\begin{array}{c}\text { BMI } \\
\text { Categories }\end{array}$} & \multirow[b]{2}{*}{ n } & \multicolumn{3}{|c|}{ Subset (yrs) } \\
\hline & & & 1 & 2 & 3 \\
\hline Kunos et al. & $\begin{array}{l}\text { Obese } \\
\text { Normal } \\
\text { Overweight } \\
\text { Underweight }\end{array}$ & $\begin{array}{l}5 \\
116 \\
33 \\
49\end{array}$ & $\begin{array}{l}8.40 \\
10.57 \\
10.76 \\
11.90\end{array}$ & & \\
\hline DiGangi et al. & $\begin{array}{l}\text { Obese } \\
\text { Overweight } \\
\text { Normal } \\
\text { Underweight }\end{array}$ & $\begin{array}{l}5 \\
33 \\
116 \\
49 \\
\end{array}$ & $\begin{array}{l}5.60 \\
11.39 \\
12.11\end{array}$ & $\begin{array}{l}11.39 \\
12.11 \\
14.57\end{array}$ & \\
\hline İşcan et al. & $\begin{array}{l}\text { Overweight } \\
\text { Normal } \\
\text { Obese } \\
\text { Underweight }\end{array}$ & $\begin{array}{l}33 \\
116 \\
5 \\
49\end{array}$ & $\begin{array}{l}7.61 \\
9.47 \\
9.80\end{array}$ & $\begin{array}{l}9.47 \\
9.80 \\
16.18\end{array}$ & \\
\hline Passalacqua & $\begin{array}{l}\text { Obese } \\
\text { Overweight } \\
\text { Normal } \\
\text { Underweight }\end{array}$ & $\begin{array}{l}5 \\
33 \\
116 \\
49 \\
\end{array}$ & $\begin{array}{l}10.40 \\
11.21 \\
11.31 \\
12.16 \\
\end{array}$ & & \\
\hline Lovejoy et al. & $\begin{array}{l}\text { Obese } \\
\text { Normal } \\
\text { Overweight } \\
\text { Underweight }\end{array}$ & $\begin{array}{l}5 \\
116 \\
33 \\
49\end{array}$ & $\begin{array}{l}4.80 \\
6.66 \\
6.79 \\
7.67\end{array}$ & & \\
\hline Buckberry and Chamberlain & $\begin{array}{l}\text { Obese } \\
\text { Overweight } \\
\text { Underweight } \\
\text { Normal }\end{array}$ & $\begin{array}{l}5 \\
33 \\
49 \\
116 \\
\end{array}$ & $\begin{array}{l}12.00 \\
12.12 \\
12.29 \\
13.26 \\
\end{array}$ & & \\
\hline Rougé-Maillart et al. & $\begin{array}{l}\text { Obese } \\
\text { Overweight } \\
\text { Normal } \\
\text { Underweight }\end{array}$ & $\begin{array}{l}5 \\
33 \\
116 \\
49\end{array}$ & $\begin{array}{l}5.60 \\
7.91 \\
9.09 \\
9.22 \\
\end{array}$ & & \\
\hline Suchey-Brooks & $\begin{array}{l}\text { Normal } \\
\text { Overweight } \\
\text { Underweight } \\
\text { Obese }\end{array}$ & $\begin{array}{l}116 \\
33 \\
49 \\
5\end{array}$ & $\begin{array}{l}7.62 \\
7.33 \\
7.88 \\
9.40\end{array}$ & & \\
\hline
\end{tabular}

Table 59: Tukey's $b$ post-hoc test results for individuals of African ancestry accuracy scores separated by BMI. Note: alpha level $=0.05$ 
A DFA was applied to assess how well BMI could be predicted from the accuracy scores of the eight age estimation methods. The cross-validated classification shows that only $34.5 \%$ of individuals of African ancestry are correctly classified into their BMI group based on accuracy scores. Underweight individuals of African ancestry are classified correctly at a rate of $46.9 \%$, normal-sized individuals of African ancestry at a rate of $25.9 \%$, overweight individuals of African ancestry at a rate of $42.4 \%$, and obese individuals of African ancestry at a rate of $60.0 \%$.

The discriminant scores from Function 1 and Function 2 were used to plot the sample on the discriminant dimensions. The underweight group is associated with the largest group centroid (0.714), the normal-sized group is associated with the next largest group centroid $(-0.170)$, the overweight group is associated with the second smallest centroid (-0.394) and, finally, the obese group is associated with the smallest group centroid (-0.460) (see Figure 24).

\section{Canonical Discriminant Functions}

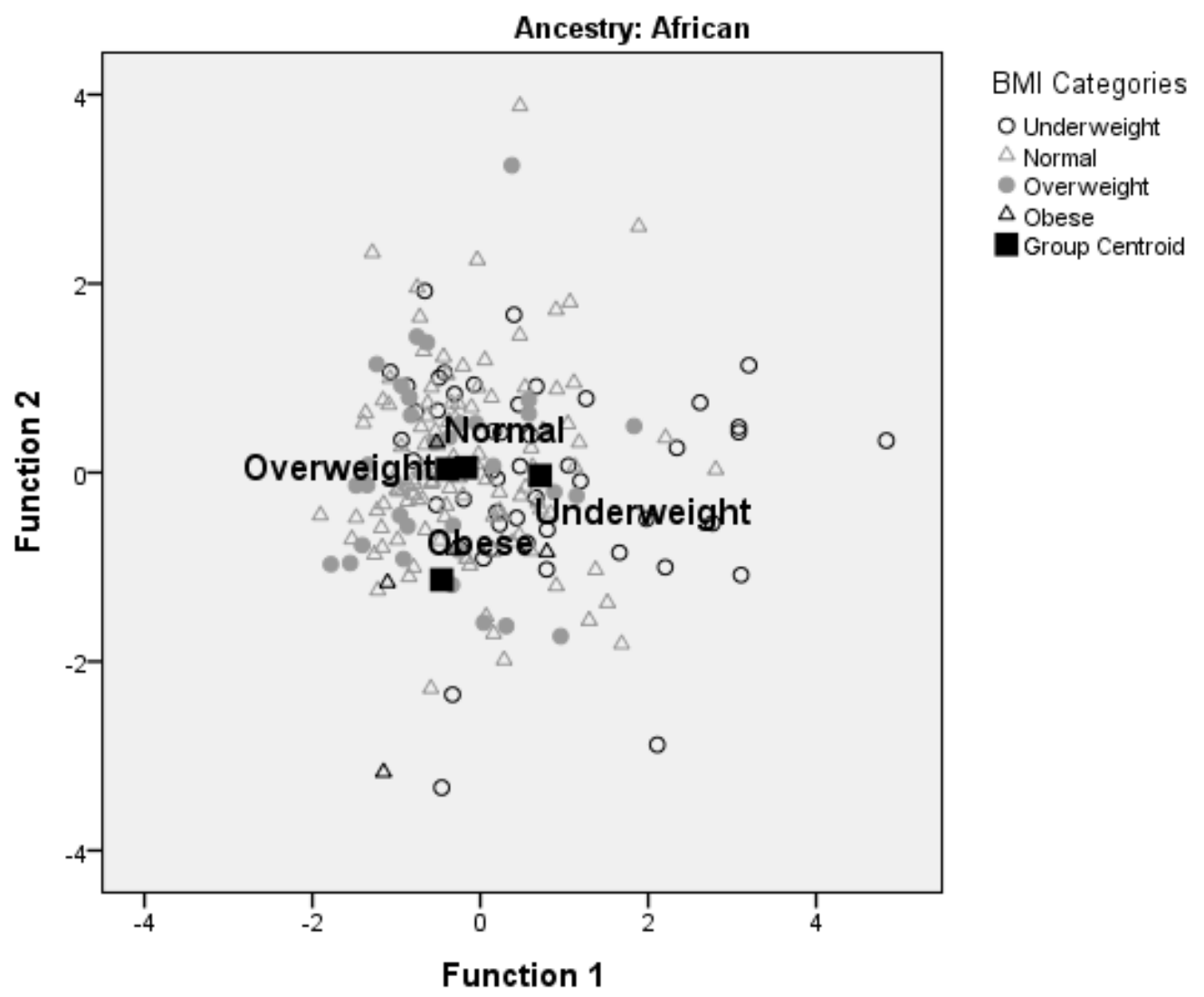

Figure 24: Canonically derived centroids for the BMI groups for individuals of African ancestry. 


\subsubsection{Bias}

\section{European Ancestry}

A series of Pearson correlations were performed between the bias scores for each age method.

Table 60 shows that the pattern of correlations observed among the bias scores are generally strong for a MANOVA, and the Box's M value of 196.319 is associated with a $p$-value of $<$ 0.001, which is significant. A covariance matrix (Appendix 17) was run to ensure that no covariance values were more than four times greater than each other. Although there are instances where the covariance values are greater than four times their value, typically associated with the İscan et al. method, overall the covariance matrices between the BMI groups were assumed to be equal for the purposes of the MANOVA.

\begin{tabular}{|c|c|c|c|c|c|c|c|c|c|c|}
\hline & 1. & 2. & 3. & 4. & 5. & 6. & 7. & 8. & $\begin{array}{l}\text { Mean } \\
\text { (yrs) }\end{array}$ & $\begin{array}{l}\text { S.D. } \\
\text { (yrs) }\end{array}$ \\
\hline 1. Kunos et al. & 1.00 & & & & & & & & 2.05 & 12.278 \\
\hline 2. DiGangi et al. & $\begin{array}{l}0.85 \\
(<0.001)\end{array}$ & 1.00 & & & & & & & -14.39 & 13.895 \\
\hline 3. İşcan et al. & $\begin{array}{l}0.23 \\
(<0.001)\end{array}$ & $\begin{array}{l}0.11 \\
(0.012)\end{array}$ & 1.00 & & & & & & -0.74 & 14.423 \\
\hline 4. Passalacqua & $\begin{array}{l}0.63 \\
(<0.001)\end{array}$ & $\begin{array}{l}0.52 \\
(<0.001)\end{array}$ & $\begin{array}{l}0.25 \\
(<0.001)\end{array}$ & 1.00 & & & & & -2.37 & 14.002 \\
\hline 5. Lovejoy et al. & $\begin{array}{l}0.67 \\
(<0.001)\end{array}$ & $\begin{array}{l}0.56 \\
(<0.001)\end{array}$ & $\begin{array}{l}0.34 \\
(<0.001)\end{array}$ & $\begin{array}{l}0.57 \\
(<0.001)\end{array}$ & 1.00 & & & & -6.62 & 9.650 \\
\hline $\begin{array}{l}\text { 6. Buckberry \& } \\
\text { Chamberlain }\end{array}$ & $\begin{array}{l}0.66 \\
(<0.001)\end{array}$ & $\begin{array}{l}0.55 \\
(<0.001)\end{array}$ & $\begin{array}{l}0.30 \\
(<0.001)\end{array}$ & $\begin{array}{l}0.56 \\
(<0.001)\end{array}$ & $\begin{array}{l}0.73 \\
(<0.001)\end{array}$ & 1.00 & & & 5.28 & 12.477 \\
\hline $\begin{array}{l}\text { 7. Rougé- } \\
\text { Maillart et al. }\end{array}$ & $\begin{array}{l}0.68 \\
(<0.001)\end{array}$ & $\begin{array}{l}0.57 \\
(<0.001)\end{array}$ & $\begin{array}{l}0.33 \\
(<0.001)\end{array}$ & $\begin{array}{l}0.59 \\
(<0.001)\end{array}$ & $\begin{array}{l}0.78 \\
(<0.001)\end{array}$ & $\begin{array}{l}0.84 \\
(<0.001)\end{array}$ & 1.00 & & -6.49 & 11.953 \\
\hline $\begin{array}{l}\text { 8. Suchey- } \\
\text { Brooks }\end{array}$ & $\begin{array}{l}0.65 \\
(<0.001)\end{array}$ & $\begin{array}{l}0.60 \\
(<0.001)\end{array}$ & $\begin{array}{l}0.29 \\
(<0.001)\end{array}$ & $\begin{array}{l}0.54 \\
(<0.001)\end{array}$ & $\begin{array}{l}0.57 \\
(<0.001)\end{array}$ & $\begin{array}{l}0.58 \\
(<0.001)\end{array}$ & $\begin{array}{l}0.62 \\
(<0.001)\end{array}$ & 1.00 & -7.12 & 9.951 \\
\hline
\end{tabular}

Table 60: Pearson Correlations, Means, and Standard Deviations of the bias scores for each age estimation method for individuals of European ancestry.

A MANOVA was conducted to test the hypothesis that there would be differences among the BMI group bias scores for each method. The MANOVA was statistically significant with Pillai's Trace $=0.180, \mathrm{~F}(24,1464)=3.884, p<0.001$, indicating there are differences among the BMI group bias scores. The multivariate effect size is estimated at 0.060 , which implies that $6.0 \%$ of the variance in the canonically derived DV is accounted for by the BMI groups.

Three eigenvalues and canonical correlations were extracted by the MANOVA. The first eigenvalue is 0.148 and accounts for $73.8 \%$ of the model variance. The canonical correlation associated with the first eigenvalue is 0.359 , where $12.9 \%$ of the variance in the discriminant 
function derived scores is accounted for by BMI group. The second eigenvalue is 0.039 and accounts for $19.6 \%$ of the model variance with a corresponding canonical correlation of 0.194 . The third eigenvalue is 0.013 and accounts for $6.6 \%$ of the model variance and a corresponding canonical correlation of 0.114 , which is not statistically significant [Wilks $\Lambda=0.987, F(6,488)=$ $1.076, p=0.376]$.

The standardized discriminant function coefficients from the first eigenvalue was used to determine the statistical significance of the MANOVA, as it is the strongest. As seen in Table 61, the standardized discriminant function coefficients suggest that the four BMI groups are maximally differentiated by a canonical variate with significant weighting from the İşcan et al. (1.013) method bias scores. The standardized coefficients suggest relatively minimal individual contributions to the MANOVA effect from all other bias scores, and the correlations between the bias scores and the canonically derived scores for all methods are positive and with weak scores (range $=0.136$ to 0.300 ), except for the İşcan et al. method, which has a strong correlation (0.917).

\begin{tabular}{|l|l|l|l|}
\hline & \multicolumn{3}{|c|}{ Function 1 } \\
& Raw & Stand. & Struc. \\
\hline Kunos et al. & 0.017 & 0.204 & 0.300 \\
DiGangi et al. & 0.019 & 0.253 & 0.245 \\
İşcan et al. & 0.075 & 1.013 & 0.917 \\
Passalacqua & -0.001 & -0.015 & 0.210 \\
Lovejoy et al. & -0.047 & -0.446 & 0.136 \\
Buckberry \& Chamberlain & 0.024 & 0.290 & 0.271 \\
Rougé-Maillart et al. & -0.017 & -0.194 & 0.214 \\
Suchey-Brooks & -0.012 & -0.117 & 0.203 \\
\hline
\end{tabular}

Table 61: Discriminant function coefficients associated with the MANOVA for individuals of European ancestry. Note: Raw = unstandardized coefficients, Stand. = standardized coefficients, Struc. $=$ structure coefficients.

To estimate the group centroids for the four BMI groups, the sample bias scores were multiplied by the corresponding bias unstandardized discriminant function coefficients and then averaged across the samples. The means and standard deviations are listed in Table 62. An ANOVA with four levels in the IV (underweight, normal, overweight, obese) was performed on the canonically derived bias score DV, and is statistically significant $[\mathrm{F}(3,24.163)=24.292, p<0.001]$.

\begin{tabular}{|l|c|c|c|}
\hline & $\mathbf{n}$ & Mean & S.D. \\
\hline Underweight & 69 & -0.570 & 0.999 \\
Normal & 272 & 0.572 & 1.019 \\
Overweight & 122 & 0.325 & 1.000 \\
Obese & 32 & 0.475 & 0.777 \\
\hline
\end{tabular}

Table 62: Means and Standard Deviations for the European canonically derived variables. 
The Cohen's $d$ absolute values were as follows, from highest to lowest: underweight vs. normalsized $=1.134$; underweight vs. obese $=1.084$; underweight vs. overweight $=0.985$; normal-sized vs. overweight $=0.245$; overweight vs. obese $=0.154$; and normal-sized vs. obese $=0.097$. The differences between underweight and normal-size, underweight and obese, and underweight and overweight individuals of European ancestry are suggestive of a large effect size, while the differences between normal-sized and overweight, and overweight and obese individuals of European ancestry are suggestive of a small effect size. There is no discernible difference between normal-sized and obese individuals of European ancestry.

Table 63 shows the results from Tukey's $b$ post-hoc tests for unequal sample sizes. There are no significant differences among the BMI group bias scores for individuals of European ancestry using the Lovejoy et al. method. The Kunos et al. and DiGangi et al. methods significantly under-age underweight individuals of European ancestry compared to overweight and obese individuals of European ancestry. The İşcan et al. method under-ages underweight individuals of European ancestry compared to obese, overweight, and normal-sized individuals of European ancestry. The Passalacqua, Rougé-Maillart et al., and Suchey-Brooks methods significantly under-age underweight individuals of European ancestry compared to overweight individuals of European ancestry. The Buckberry and Chamberlain method significantly under-ages underweight individuals of European ancestry compared to overweight and obese individuals. 


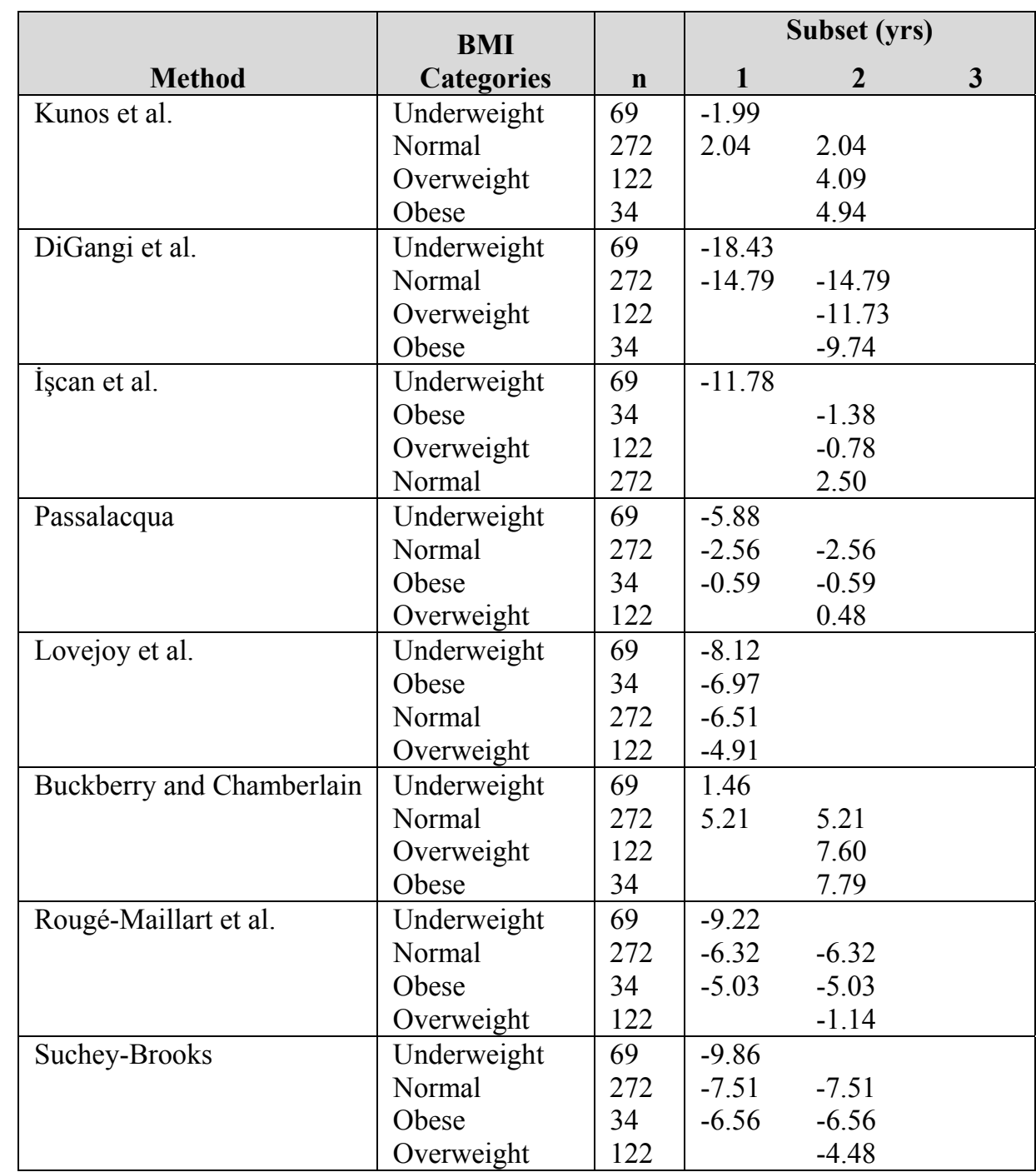

Table 63: Tukey's $b$ post-hoc test results for European bias scores separated by BMI. Note: alpha level $=0.05$

A DFA was applied to assess how well BMI group could be predicted from the bias scores of the eight age estimation methods. The cross-validated classification shows that only $39.6 \%$ of individuals of European ancestry are correctly classified into their BMI group based on bias scores. Underweight individuals of European ancestry are classified correctly at a rate of 56.5\%, normal-sized individuals of European ancestry at a rate of $39.3 \%$, overweight individuals of European ancestry at a rate of $31.1 \%$, and obese individuals of European ancestry at a rate of $38.2 \%$.

The discriminant scores from Function 1 and Function 2 were used to plot the sample on the discriminant dimensions. The normal-sized group is associated with the largest group centroid 
$(0.227)$, the obese group is associated with the next largest group centroid $(0.125)$, the overweight group is associated with the second smallest centroid (-0.022) and, finally, the underweight group is associated with the smallest group centroid (-0.919) (see Figure 25).

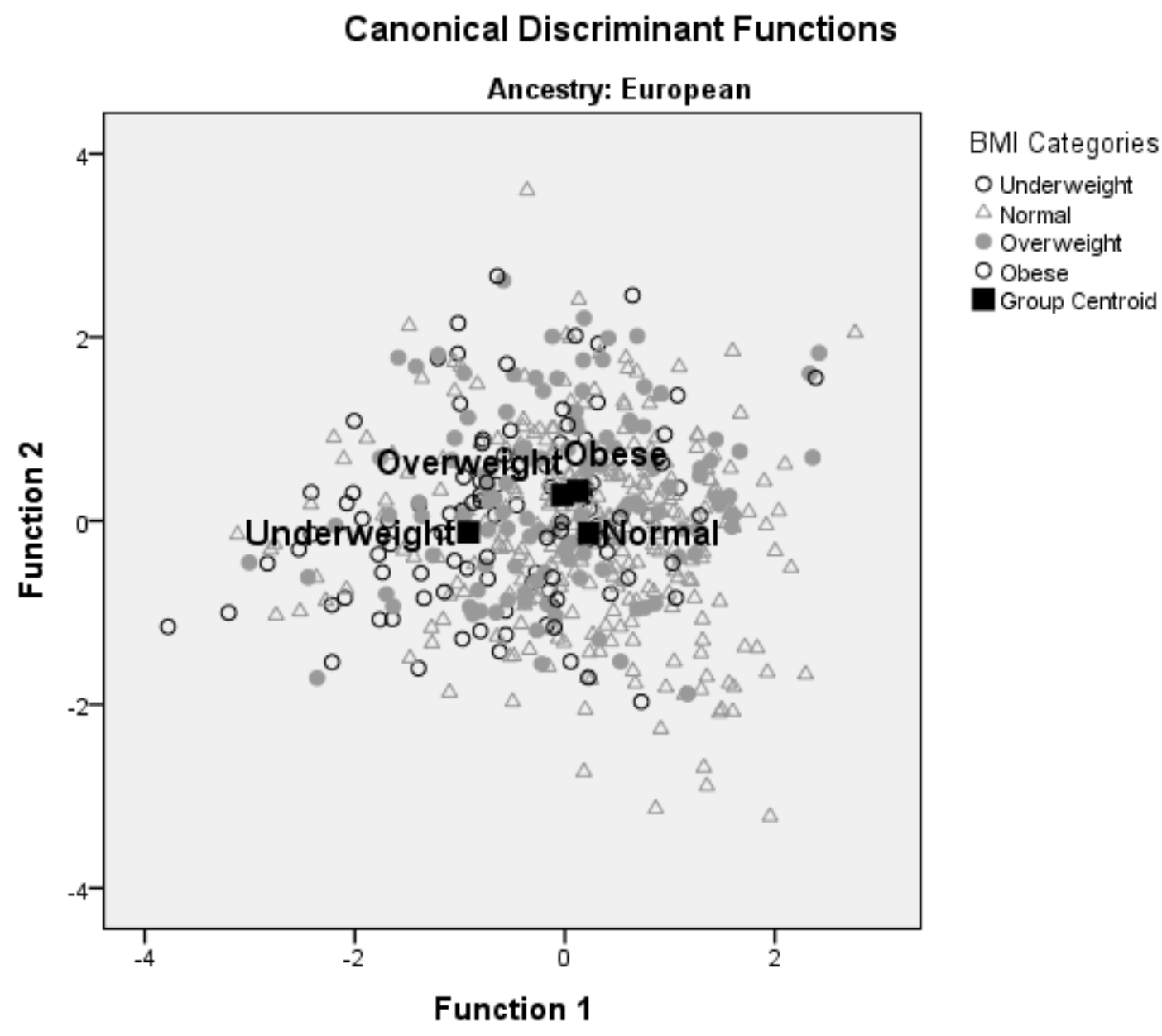

Figure 25: Canonically derived centroids for the BMI groups for individuals of European ancestry.

\section{African Ancestry}

A series of Pearson correlations were performed between the bias scores for each age method. Table 64 shows that the pattern of correlations observed among the bias scores are generally strong for a MANOVA, and the Box's M value of 121.864 is associated with a $p$-value of 0.002 , which is significant. A covariance matrix (Appendix 18) was run to ensure that no covariance values were more than four times greater than each other (Howell, 2007). Although there are instances where the covariance values are greater than four times their value, typically associated 
with the İşcan et al. method, overall the covariance matrices between the BMI groups were assumed to be equal for the purposes of the MANOVA.

\begin{tabular}{|c|c|c|c|c|c|c|c|c|c|c|}
\hline & 1. & 2. & 3. & 4. & 5. & 6. & 7. & 8. & $\begin{array}{l}\text { Mean } \\
\text { (yrs) }\end{array}$ & $\begin{array}{l}\text { S.D. } \\
\text { (yrs) }\end{array}$ \\
\hline 1. Kunos et al. & 1.00 & & & & & & & & 5.82 & 11.648 \\
\hline $\begin{array}{l}\text { 2. DiGangi et } \\
\text { al. }\end{array}$ & $\begin{array}{l}0.87 \\
(<0.001)\end{array}$ & 1.00 & & & & & & & -9.68 & 12.897 \\
\hline 3. İşcan et al. & $\begin{array}{l}0.20 \\
(0.004)\end{array}$ & $\begin{array}{l}0.12 \\
(0.099)\end{array}$ & 1.00 & & & & & & -0.73 & 13.895 \\
\hline 4. Passalacqua & $\begin{array}{l}0.59 \\
(<0.001)\end{array}$ & $\begin{array}{l}0.54 \\
(<0.001)\end{array}$ & $\begin{array}{l}0.18 \\
(0.009)\end{array}$ & 1.00 & & & & & 2.05 & 13.972 \\
\hline $\begin{array}{l}\text { 5. Lovejoy et } \\
\text { al. }\end{array}$ & $\begin{array}{l}0.68 \\
(<0.001)\end{array}$ & $\begin{array}{l}0.60 \\
(<0.001)\end{array}$ & $\begin{array}{l}0.30 \\
(<0.001)\end{array}$ & $\begin{array}{l}0.55 \\
(<0.001)\end{array}$ & 1.00 & & & & -2.35 & 9.064 \\
\hline $\begin{array}{l}\text { 6. Buckberry } \\
\text { \& Chamberlain }\end{array}$ & $\begin{array}{l}0.63 \\
(<0.001)\end{array}$ & $\begin{array}{l}0.55 \\
(<0.001)\end{array}$ & $\begin{array}{l}0.19 \\
(0.006)\end{array}$ & $\begin{array}{l}0.47 \\
(<0.001)\end{array}$ & $\begin{array}{l}0.69 \\
(<0.001)\end{array}$ & 1.00 & & & 8.74 & 13.435 \\
\hline $\begin{array}{l}\text { 7. Rougé- } \\
\text { Maillart et al. }\end{array}$ & $\begin{array}{l}0.72 \\
(<0.001)\end{array}$ & $\begin{array}{l}0.66 \\
(<0.001)\end{array}$ & $\begin{array}{l}0.27 \\
(<0.001)\end{array}$ & $\begin{array}{l}0.54 \\
(<0.001)\end{array}$ & $\begin{array}{l}0.79 \\
(<0.001)\end{array}$ & $\begin{array}{l}0.82 \\
(<0.001)\end{array}$ & 1.00 & & -1.17 & 11.868 \\
\hline $\begin{array}{l}\text { 8. Suchey- } \\
\text { Brooks }\end{array}$ & $\begin{array}{l}0.71 \\
(<0.001)\end{array}$ & $\begin{array}{l}0.63 \\
(<0.001)\end{array}$ & $\begin{array}{l}0.24 \\
(<0.001)\end{array}$ & $\begin{array}{l}0.52 \\
(<0.001)\end{array}$ & $\begin{array}{l}0.66 \\
(<0.001)\end{array}$ & $\begin{array}{l}0.55 \\
(<0.001)\end{array}$ & $\begin{array}{l}0.69 \\
(<0.001)\end{array}$ & 1.00 & -4.02 & 9.616 \\
\hline
\end{tabular}

Table 64: Pearson Correlations, Means, and Standard Deviations of the bias scores for each age estimation method for individuals of African ancestry.

A MANOVA was conducted to test the hypothesis that there would be differences between BMI group bias scores for each method. The MANOVA effect was statistically significant with Pillai's Trace $=0.274, \mathrm{~F}(24,582)=2.438, p<0.001$, indicating there are differences among the BMI group bias scores. The multivariate effect size is estimated at 0.091, which implies that $9.1 \%$ of the variance in the canonically derived DV is accounted for by the BMI groups.

Three eigenvalues and canonical correlations were extracted by the MANOVA. The first eigenvalue is 0.257 and accounts for $77.8 \%$ of the model variance. The canonical correlation associated with the first eigenvalue is 0.452 , where $20.4 \%$ of the variance in the discriminant function derived scores is accounted for by BMI group. The second eigenvalue is 0.055 and accounts for $16.8 \%$ of the model variance with a corresponding canonical correlation of 0.229 . The third eigenvalue is 0.018 and accounts for $5.4 \%$ of the model variance and a corresponding canonical correlation of 0.121 , which is not statistically significant [Wilks $\Lambda=0.982, F(6,194)=$ $0.578, p=0.748]$.

The standardized discriminant function coefficients from the first eigenvalue was used to determine the statistical significance of the MANOVA as it was the strongest. As seen in Table 
65, the standardized discriminant function coefficients suggest that the four BMI groups were maximally differentiated by a canonical variate with significant weightings from the İşcan et al. (0.996), DiGangi et al. (0.525), and Rougé-Maillart et al. (-0.679) methods bias scores. The standardized coefficients suggest moderate individual contributions to the MANOVA effect from all other bias scores. The correlations between the bias scores and the canonically derived scores for all methods are positive and weak (range $=0.060$ to 0.241 ), except the İşcan et al. method (0.888), which has a strong correlation.

\begin{tabular}{|l|l|l|l|}
\hline & \multicolumn{3}{|c|}{ Function 1 } \\
& Raw & Stand. & Struc. \\
\hline Kunos et al. & -0.035 & -0.401 & 0.093 \\
DiGangi et al. & 0.042 & 0.525 & 0.122 \\
İşcan et al. & 0.078 & 0.996 & 0.888 \\
Passalacqua & 0.011 & 0.154 & 0.190 \\
Lovejoy et al. & 0.038 & 0.327 & 0.241 \\
Buckberry \& Chamberlain & 0.025 & 0.340 & 0.138 \\
Rougé-Maillart et al. & -0.058 & -0.679 & 0.074 \\
Suchey-Brooks & -0.028 & -0.263 & 0.060 \\
\hline
\end{tabular}

Table 65: Discriminant function coefficients associated with the MANOVA for individuals of African ancestry. Note: Raw = unstandardized coefficients, Stand. = standardized coefficients, Struc. = structure coefficients.

To estimate the group centroids for the four BMI groups, the sample bias scores were multiplied by the corresponding bias unstandardized discriminant function coefficients and then averaged across the samples. The means and standard deviations for each BMI group are in Table 66. An ANOVA with four levels in the IV (underweight, normal, overweight, obese) was performed on the canonically derived bias score DV, and is statistically significant $[\mathrm{F}(3,16.933)=17.015, p<$ $0.001]$.

\begin{tabular}{|l|c|c|c|}
\hline & $\mathbf{n}$ & Mean & S.D. \\
\hline Underweight & 49 & -1.203 & 1.340 \\
Normal & 116 & -0.014 & 0.861 \\
Overweight & 33 & -0.092 & 0.855 \\
Obese & 5 & -0.388 & 0.894 \\
\hline
\end{tabular}

Table 66: Means and Standard Deviations for the canonically derived variables for individuals of African ancestry.

The Cohen's $d$ absolute values were as follows, from highest to lowest: underweight vs. normalsized $=1.232$; underweight vs. overweight $=1.089$; underweight vs. obese $=0.724$; normal-sized vs. obese $=0.403$; overweight vs. obese $=0.319$; and normal-sized vs. overweight $=0.084$. The differences between underweight and normal-sized and underweight and overweight individuals 
of African ancestry are suggestive of a large effect size; the difference between underweight and obese and normal-size and obese individuals of African ancestry are suggestive of a medium effect size; the difference between overweight and obese individuals of African ancestry is suggestive of a small effect size. There is no discernible difference between normal-sized and overweight individuals of African ancestry.

Table 67 shows the results from Tukey's $b$ post-hoc tests for unequal sample sizes. There are no significant differences among the BMI group bias scores for individuals of African ancestry using any method except the İşcan et al. method. The İşcan et al. method under-ages underweight individuals of African ancestry significantly compared to obese, normal-sized, and overweight individuals of African ancestry.

A DFA was applied to assess how well BMI could be predicted from the bias scores of the eight age estimation methods. The cross-validated classification shows that only $50.2 \%$ of individuals of African ancestry are correctly classified into their BMI group based on bias scores.

Underweight individuals of African ancestry are classified correctly at a rate of $69.4 \%$, normalsized individuals of African ancestry at a rate of $45.7 \%$, overweight individuals of African ancestry at a rate of $36.4 \%$, and obese individuals of African ancestry at a rate of $60.0 \%$.

The discriminant scores from Function 1 and Function 2 were used to plot the sample on the discriminant dimensions. The normal-sized group is associated with the largest group centroid (0.309), the overweight group is associated with the next largest group centroid (0.233), the obese group is associated with the second smallest centroid (-0.067) and, finally, the underweight group is associated with the smallest group centroid (-0.882) (see Figure 26). 


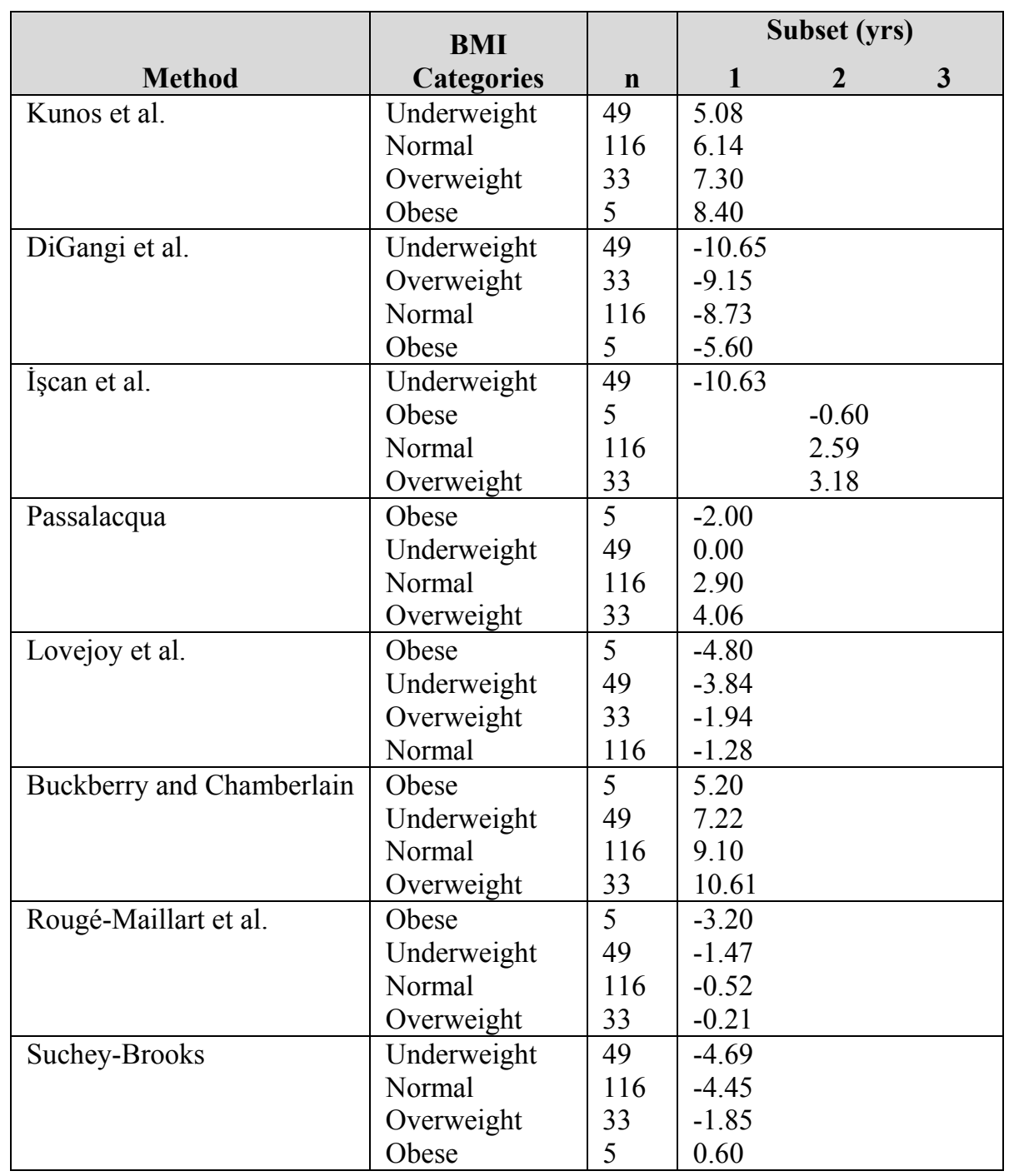

Table 67: Tukey's $b$ post-hoc test results for individuals of African ancestry bias scores separated by BMI. Note: alpha level $=0.05$ 


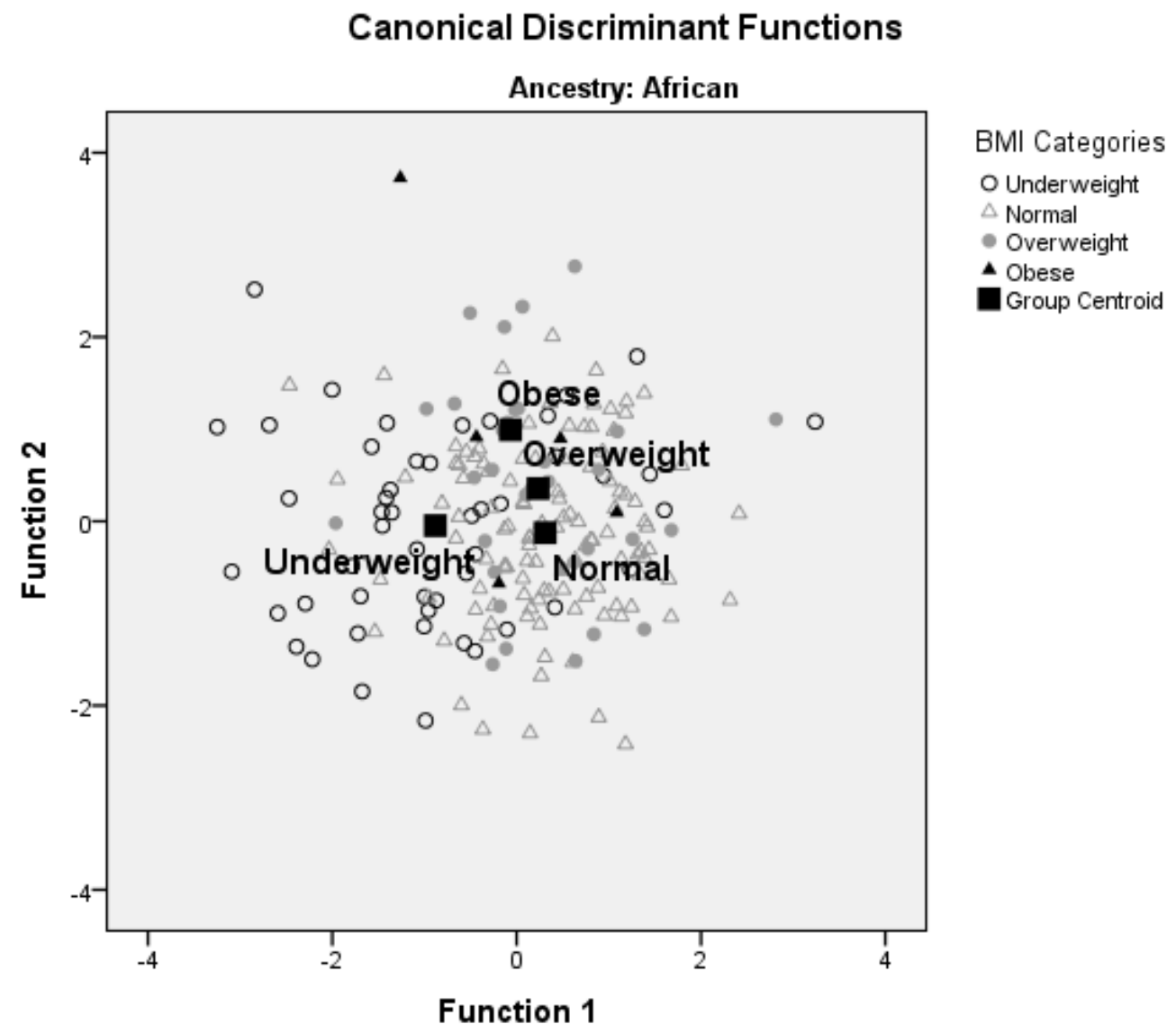

Figure 26: Canonically derived centroids for the BMI groups for individuals of African ancestry.

\subsubsection{Results Summary}

\subsubsection{Accuracy}

For males, females, individuals of European ancestry, and individuals of African ancestry, there are statistically significant differences among the BMI group accuracy scores. The MANOVA effect size is estimated at $12 \%$ for males and $22.9 \%$ for females, suggesting that the BMI accuracy scores for females show more variance than males using this model, though both have low effect sizes. Similarly, the MANOVA effect size is estimated at $2.5 \%$ for individuals of European ancestry and $6.4 \%$ for individuals of African ancestry, suggesting that the BMI accuracy scores for individuals of African ancestry show more variance than individuals of European ancestry using this model, though both have low effect sizes. Although females and individuals of African ancestry have stronger differences among the mean accuracy scores of 
each BMI group according to the MANOVA, they are not as statistically significant as those of males and individuals of European ancestry because of small sample sizes in the obese group.

Using the standardized coefficients from the MANOVA:

- Males have the highest contribution to the model from the Kunos et al., DiGangi et al., Passalacqua, and Rougé-Maillart et al. methods, which have the most variance in their BMI accuracy scores. The Buckberry and Chamberlain method has the lowest contributions to the MANOVA model, and the least amount of variance in its BMI group accuracy scores. The İşcan et al., Lovejoy et al., and Suchey-Brooks methods have moderate contributions to the model, indicating that there are differences among the BMI group accuracy scores, but they are not as substantial as those from the Kunos et al., DiGangi et al., Passalacqua, and Rougé-Maillart et al. methods (see Table 37).

- Females have the highest contribution to the model from the Kunos et al., İşcan et al., Lovejoy et al., and Rougé-Maillart et al. methods, which have the greatest variance in the BMI group accuracy scores. The DiGangi et al., Passalacqua, Buckberry and Chamberlain, and Suchey-Brooks methods have moderate contributions to the model, indicating that there are differences among the BMI group accuracy scores, but they are not as substantial as those from the other four methods (see Table 41).

- Individuals of European ancestry have the highest contribution to the model from the Kunos et al., DiGangi et al., and Rougé-Maillart et al. methods, which have the greatest variance in their BMI group accuracy scores. The Buckberry and Chamberlain method has the lowest contributions to the MANOVA model, and the least amount of variance in its BMI group accuracy scores. The İşcan et al., Passalacqua, Lovejoy et al., and SucheyBrooks methods have moderate contributions to the model, indicating that there are differences among the BMI group accuracy scores, but they are not as substantial as those from the Kunos et al., DiGangi et al., and Rougé-Maillart et al. methods (see Table 53).

- Individuals of African ancestry have the have the highest contribution to the model from the İscan et al. method, which has the greatest variance in the BMI group accuracy scores. The Buckberry and Chamberlain and Suchey-Brooks methods have little contribution to the model, indicating that they have the least amount of variance in their BMI group accuracy scores. The Kunos et al., DiGangi et al., Passalacqua, Lovejoy et al., 
and Rougé-Maillart et al. methods have moderate contributions to the model, indicating that there are differences among the BMI group accuracy scores, but they are not as substantial as those from the İşcan et al. method (see Table 57).

There are significant differences in group centroid values generated from the MANOVA for the male, female, European ancestry, and African ancestry accuracy scores. Underweight males have significantly lower accuracy scores compared to overweight and obese males, and the Cohen's $d$ values indicate this is a medium effect size. Normal-sized males have significantly lower accuracy scores compared to obese males, but the effect size is small. Obese females have significantly higher accuracy scores compared to underweight, normal-sized, and overweight females. There is a large effect size between the accuracy scores of obese females and underweight and overweight females, and a medium effect size between the accuracy scores of obese females and normal-sized females. Underweight individuals of European ancestry have significantly lower accuracy scores compared to overweight and obese individuals of European ancestry, and the Cohen's $d$ values indicate these are both large effect sizes. Underweight individuals of African ancestry have significantly lower accuracy scores compared to normalsized and overweight individuals of African ancestry, with large effect sizes.

The results from the group centroid and Cohen's $d$ analyses are corroborated by the discriminant function canonical results: underweight males have lower accuracy scores than obese and overweight males, with normal-sized males between the two (see Figure 19); obese females have higher accuracy scores, while the underweight, normal-sized, and overweight females cluster together with lower accuracy scores (see Figure 20); underweight individuals of European ancestry have lower accuracy scores than obese and normal-sized individuals of European ancestry (see Figure 23); and underweight individuals of African ancestry have lower accuracy scores, while the underweight normal-sized and overweight individuals of African ancestry cluster together with higher accuracy scores, and obese individuals of African ancestry have the farthest distance from the underweight group (see Figure 24).

Table 68 shows the inaccuracy scores for males, females, individuals of European ancestry, and individuals of African ancestry separated by BMI for each age method. The Kunos et al. method has higher accuracy scores for obese individuals of European ancestry compared to underweight 
and normal-sized individuals of European ancestry. The DiGangi et al. method has lower accuracy scores for underweight males and individuals of European ancestry compared to overweight and obese males individuals of European ancestry. The İşcan et al. method has lower accuracy scores for underweight males, females, and individuals of African ancestry compared to individuals in the other BMI groups. The Passalacqua method has lower accuracy scores for underweight males compared to overweight and obese males. The Lovejoy et al. method has lower bias scores for obese females compared to females in the other BMI groups. The Buckberry and Chamberlain method has no significant differences among BMI group accuracy scores for all individuals. The Rougé-Maillart et al. method has higher accuracy scores for obese males and individuals of European ancestry compared to normal-sized and underweight males and individuals of European ancestry. The Suchey-Brooks method has lower accuracy scores for males compared to overweight males. For all methods, the İşcan et al. method performs poorly on underweight individuals, and the DiGangi et al. method performs poorly overall (see Figure 27, Figure 28, Figure 29, and Figure 30).

\begin{tabular}{|c|c|c|c|c|c|c|c|c|c|}
\hline & BMI & $\begin{array}{l}\text { Kunos } \\
\text { et al. }\end{array}$ & $\begin{array}{c}\text { DiGangi } \\
\text { et al. }\end{array}$ & $\begin{array}{l}\text { İşcan } \\
\text { et al. }\end{array}$ & $\begin{array}{l}\text { Passal- } \\
\text { acqua }\end{array}$ & $\begin{array}{c}\text { Lovejoy } \\
\text { et al. }\end{array}$ & $\begin{array}{l}\text { Buckberry \& } \\
\text { Chamberlain }\end{array}$ & $\begin{array}{c}\text { Rougé-Maillart } \\
\text { et al. }\end{array}$ & $\begin{array}{l}\text { Suchey- } \\
\text { Brooks }\end{array}$ \\
\hline \multirow{4}{*}{ Males } & Underweight & 10.58 & \begin{tabular}{|l|}
16.99 \\
\end{tabular} & \begin{tabular}{|l|}
13.74 \\
\end{tabular} & 13.03 & 10.15 & 11.89 & 12.19 & \begin{tabular}{|l|}
11.31 \\
\end{tabular} \\
\hline & Normal & 10.74 & 15.10 & 10.07 & 11.41 & 8.38 & 11.94 & 10.46 & 8.83 \\
\hline & Overweight & 9.02 & 12.45 & 10.18 & 9.36 & 8.44 & 11.75 & 9.39 & 8.73 \\
\hline & Obese & 8.58 & 11.54 & 9.46 & 10.88 & 7.85 & 10.69 & 7.27 & 9.85 \\
\hline \multirow[t]{4}{*}{ Females } & Underweight & 10.42 & 17.08 & \begin{tabular}{|l|}
15.82 \\
\end{tabular} & 11.26 & 7.37 & 9.68 & 9.55 & 7.66 \\
\hline & Normal & 10.95 & 17.36 & 12.05 & 11.85 & 8.48 & 10.76 & 10.14 & 9.42 \\
\hline & Overweight & 10.93 & 15.58 & 9.42 & 12.60 & 6.38 & 9.98 & 7.80 & 7.80 \\
\hline & Obese & 6.69 & 13.31 & 9.85 & 13.00 & 11.62 & 11.92 & 8.92 & 8.92 \\
\hline \multirow[t]{4}{*}{ European } & Underweight & 9.55 & 18.75 & 13.14 & 12.67 & 10.38 & 10.39 & 12.84 & \begin{tabular}{|l|}
11.74 \\
\end{tabular} \\
\hline & Normal & 10.90 & 17.23 & 11.07 & 11.62 & 9.15 & 10.93 & 10.96 & 9.56 \\
\hline & Overweight & 9.25 & 13.89 & 10.60 & 10.06 & 8.12 & 10.99 & 9.35 & 8.66 \\
\hline & Obese & 7.88 & 13.09 & 9.56 & 11.76 & 9.74 & 10.97 & 8.38 & 9.56 \\
\hline \multirow[t]{4}{*}{ African } & Underweight & 11.90 & \begin{tabular}{|l|}
14.57 \\
\end{tabular} & \begin{tabular}{|l|}
16.18 \\
\end{tabular} & 12.16 & 7.67 & 12.29 & 9.22 & 7.88 \\
\hline & Normal & 10.57 & 12.11 & 9.47 & 11.31 & 6.66 & 13.26 & 9.09 & 7.62 \\
\hline & Overweight & 11.76 & 11.39 & 7.61 & 11.21 & 6.79 & 12.12 & 7.91 & 7.33 \\
\hline & Obese & 8.40 & 5.60 & 9.80 & 10.40 & 4.80 & 12.00 & 5.60 & 9.40 \\
\hline
\end{tabular}

Table 68: Inaccuracy scores (in years) for each age-at-death estimation method separated by BMI for males, females, individuals of European ancestry, and individuals of African ancestry. Significant differences are noted by boxes.

Discriminant function analyses show that accuracy scores are poor predictors of BMI for all individuals. Overweight males (30.9\%), normal-sized females (19.6\%), normal-sized individuals of European ancestry (21.7\%), and individuals of African ancestry (25.9\%) have the lowest classification scores. Obese males (42.3\%), females (69.2\%), individuals of European ancestry 
(50.0\%), and individuals of African ancestry (60.0\%) have the highest classification scores.

These results indicate that accuracy scores cannot be used reliably to predict BMI groups.

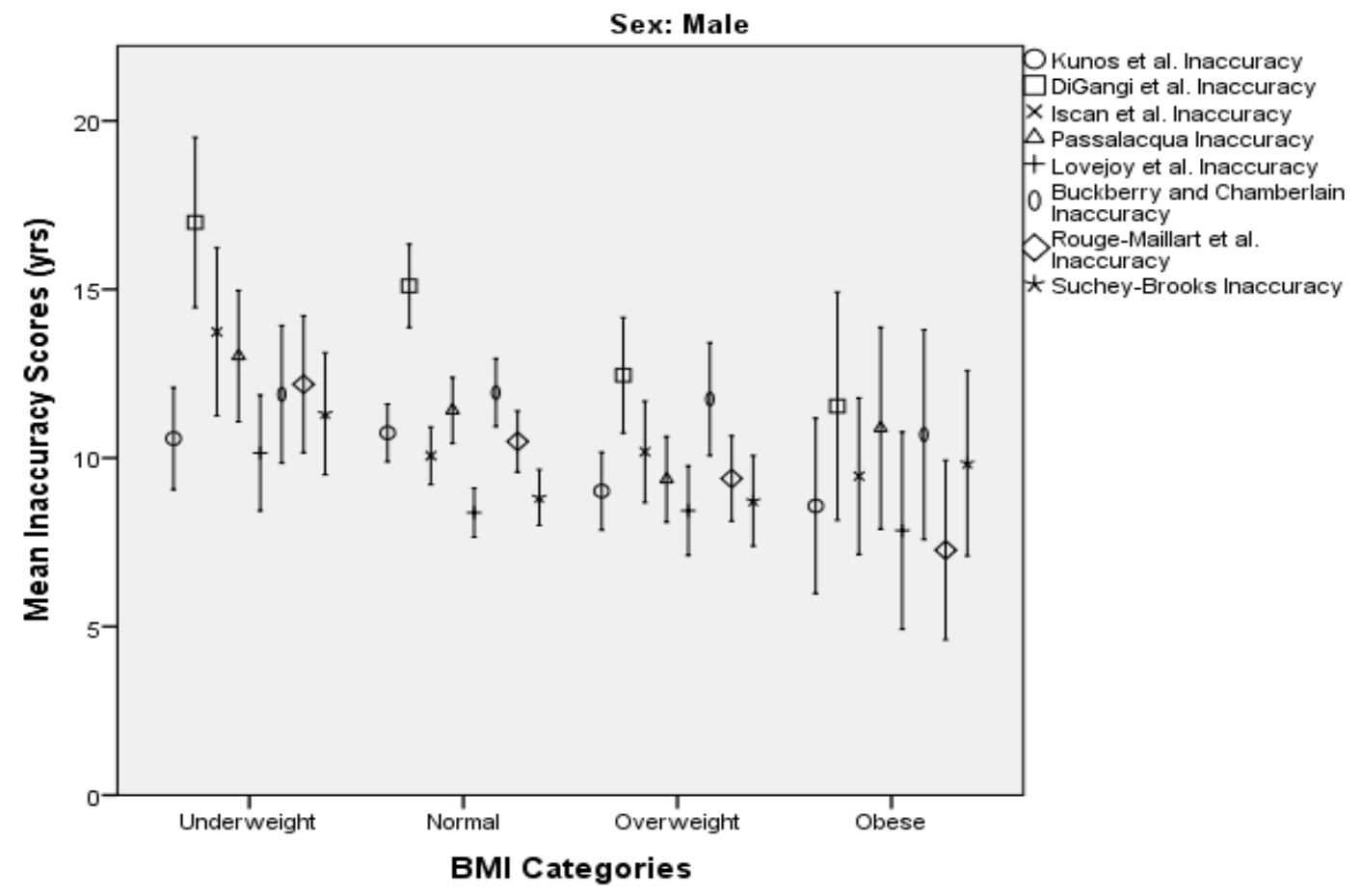

Error Bars: $95 \% \mathrm{Cl}$

Figure 27: Mean inaccuracy scores for the age estimation methods categorized by BMI for males. 


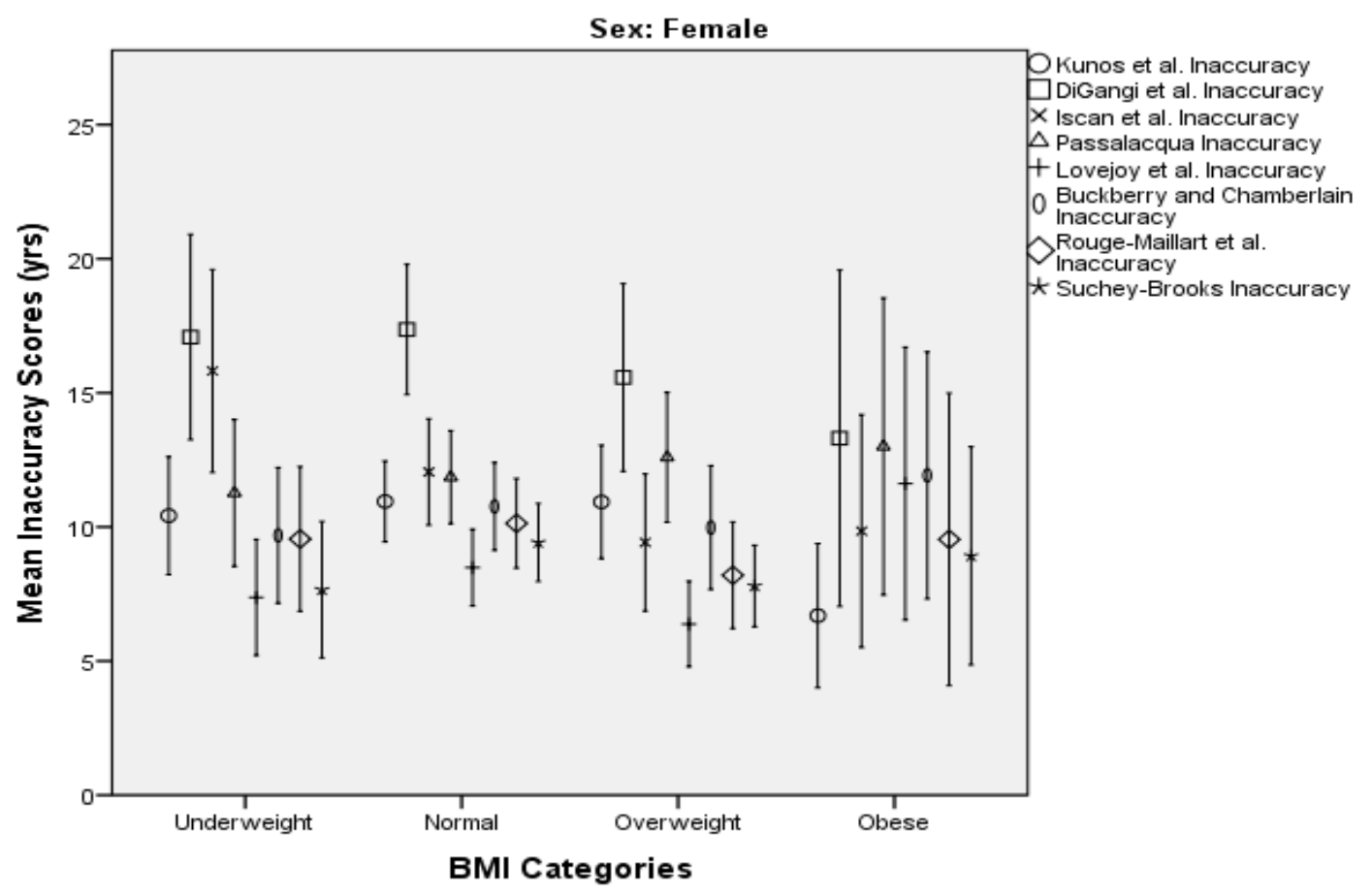

Error Bars: $95 \% \mathrm{Cl}$

Figure 28: Mean inaccuracy scores for the age estimation methods categorized by BMI for females.

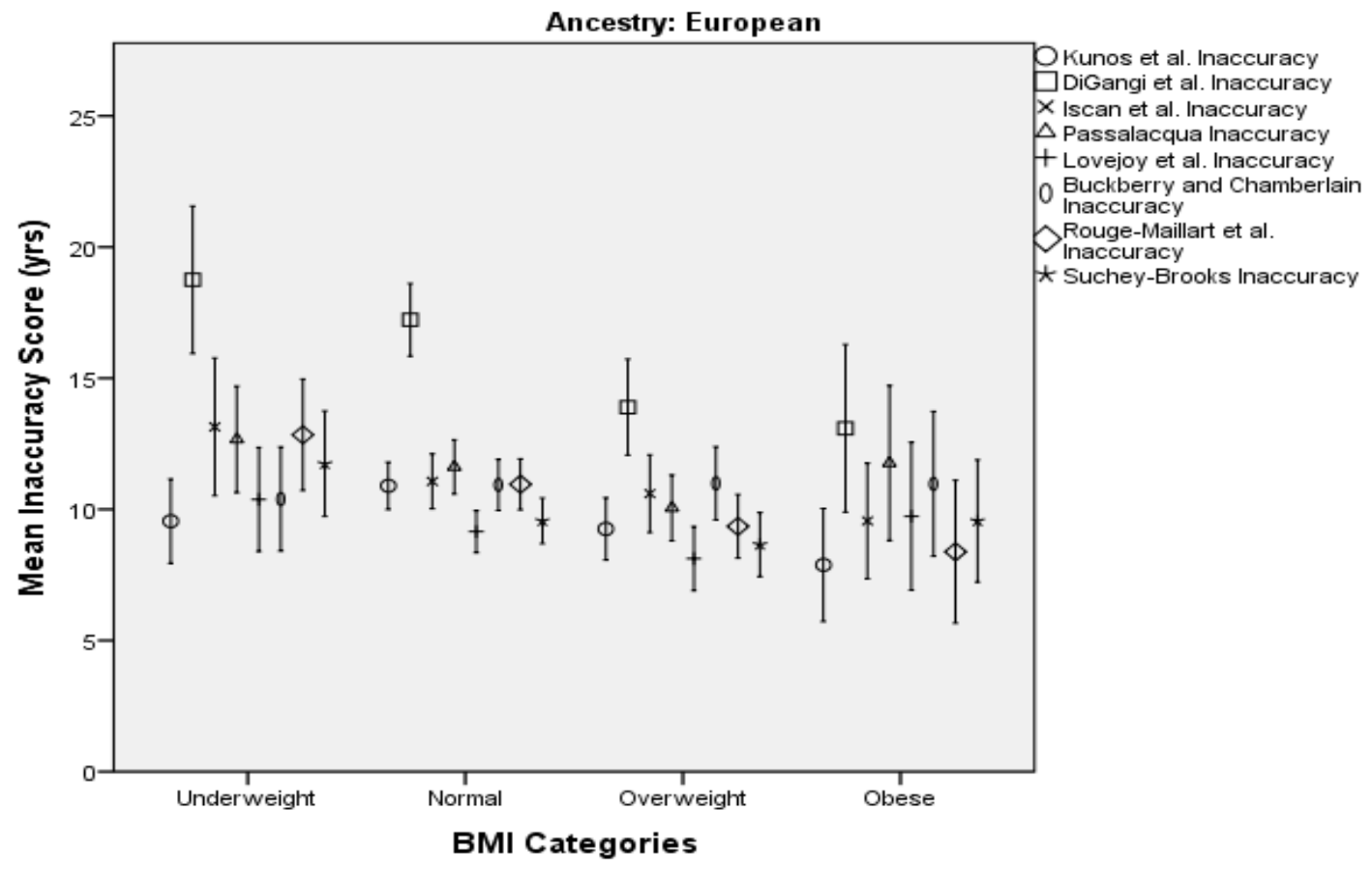

Error Bars: $95 \% \mathrm{Cl}$

Figure 29: Mean inaccuracy scores for the age estimation methods categorized by BMI for individuals of European ancestry. 


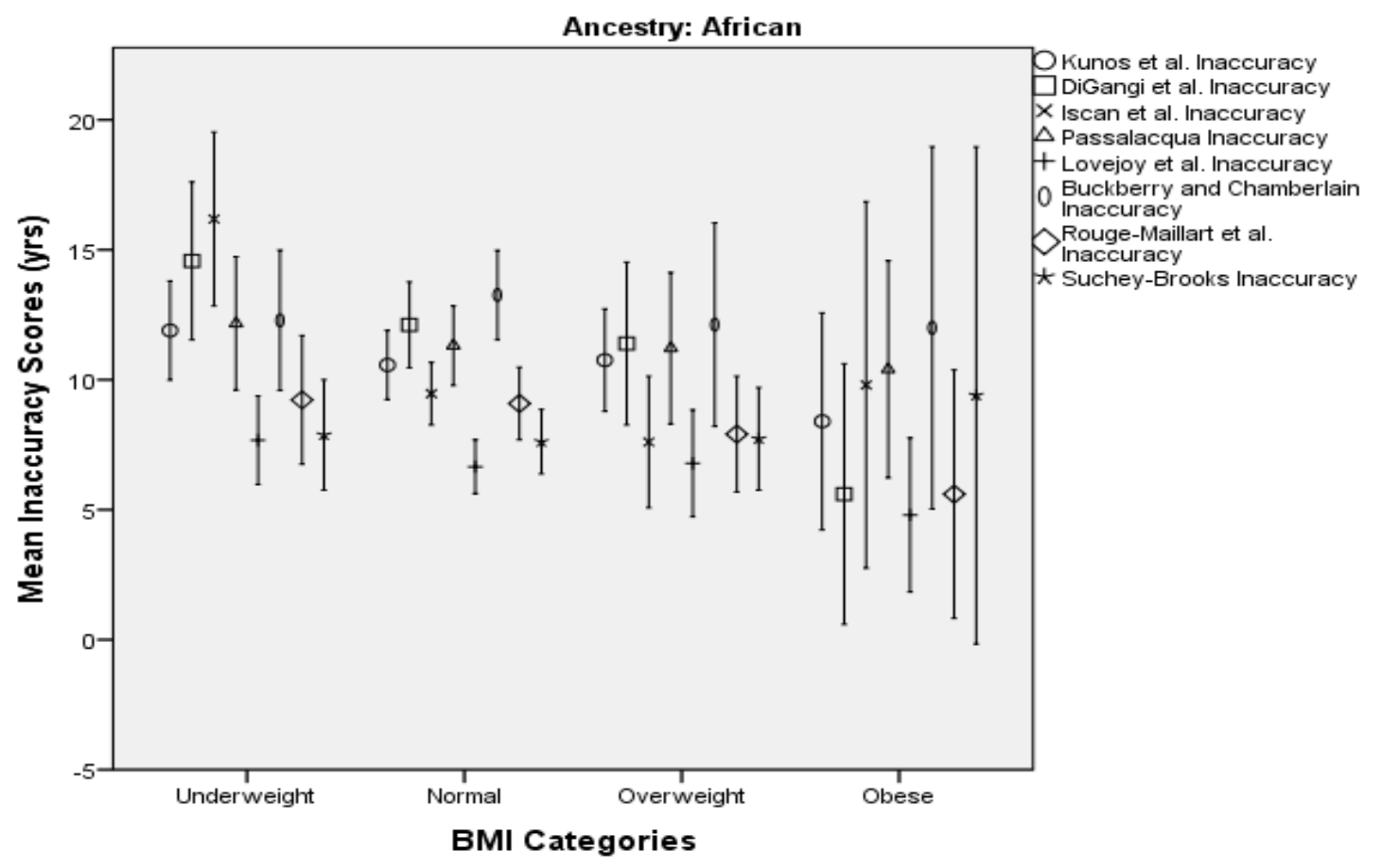

Error Bars: $95 \% \mathrm{Cl}$

Figure 30: Mean inaccuracy scores for the age estimation methods categorized by BMI for individuals of African ancestry.

\subsubsection{Bias}

For males, females, individuals of European ancestry, and individuals of African ancestry, there are statistically significant differences among the BMI groups for bias scores. The MANOVA effect size is estimated at $6.4 \%$ for males and $9.7 \%$ for females, suggesting that BMI has a larger effect for females than males using this model, though both are low effect sizes. Similarly, the MANOVA effect size is estimated at $6 \%$ for individuals of European ancestry and $9.1 \%$ for individuals of African ancestry, suggesting that BMI has a larger effect for individuals of African ancestry than individuals of European ancestry using this model, though both are low effect sizes. Although females and individuals of African ancestry have stronger differences among the mean bias scores of each BMI group according to the MANOVA, they are not as statistically significant as those of males and individuals of European ancestry because of small sample sizes in the obese group. 
Using the standardized coefficients from the MANOVA:

- Males have the highest contribution to the model from the İşcan et al., Rougé-Maillart et al., and Kunos et al. methods, which have the greatest variance among the BMI groups. The DiGangi et al., Passalacqua, Lovejoy et al., Buckberry and Chamberlain, and Suchey-Brooks methods have moderate contributions to the model, indicating that there are differences among the BMI group bias scores, but they are not as substantial as those from the other three methods (see Table 45).

- Females have the highest contribution to the model from the İşcan et al., DiGangi et al., and Kunos et al. methods, which have the greatest variance in the BMI group bias scores. The Rougé-Maillart et al. and Lovejoy et al. methods have the lowest bias scores, and the least amount of variance in their BMI group bias scores. The Passalacqua, Buckberry and Chamberlain, and Suchey-Brooks methods have moderate contributions to the model, indicating that there are differences among the BMI group bias scores, but they are not as substantial as those from the İşcan et al., DiGangi et al., and Kunos et al. methods (see Table 49).

- Individuals of European ancestry have the highest contribution to the model from the İşcan et al. method, which has the greatest amount of variance in the BMI group bias scores. All other methods make moderate contributions to the model, indicating that there are differences among their BMI group bias scores, but they are not as substantial as those from the İşcan et al. method (see Table 54).

- Individuals of African ancestry have the highest contribution to the model from the İscan et al., DiGangi et al., and Rougé-Maillart et al. methods, which have the most variance among their BMI bias scores. The Passalacqua, Lovejoy et al., and Buckberry and Chamberlain methods have moderate contributions to the model, indicating that there are differences among their BMI group bias scores, but they are not as substantial as those from the İşcan et al. method. The Kunos et al. and Suchey-Brooks methods do not make significant contributions, and have the least amount of variance in their BMI group bias scores (see Table 58). 
- The İşcan et al. method has the highest bias scores for all individuals.

The differences in group centroid values generated from the MANOVA for male, female, individuals of European, and individuals of African ancestry bias scores are significant. Underweight males and females have significantly higher negative bias scores compared to normal-sized, overweight, and obese males, and the Cohen's $d$ values indicate these are large effect sizes. Underweight individuals of European ancestry have significantly higher negative bias scores compared to normal-sized, overweight, and obese individuals of European ancestry, and the Cohen's $d$ values indicate these all have large effect sizes. Underweight individuals of African ancestry have significantly higher negative bias scores compared to normal-sized and overweight individuals of African ancestry, with large effect sizes. These results are corroborated by the discriminant function canonical analyses results: underweight individuals are under-aged more than normal-sized, overweight, and obese individuals (see Figure 21, Figure 22, Figure 25 and Figure 26).

Table 69 shows the bias scores for males and females separated by BMI. There are no significant differences among the BMI bias scores using the Lovejoy et al. method. The İşcan et al. method under-ages all underweight individuals significantly compared to individuals in all BMI groups. The Kunos et al., DiGangi et al., Passalacqua, and Suchey-Brooks methods under-age underweight males and individuals of European ancestry compared to obese males and individuals of European ancestry. The Buckberry and Chamberlain and Rougé-Maillart et al. methods under-age underweight Europeans compared to individuals in all other BMI groups. The İşcan et al. method under-ages all underweight individuals by the largest degree, and the DiGangi et al. method performs poorly overall (see Figure 31, Figure 32, Figure 33, Figure 34).

Discriminant function analyses show that bias scores are poor predictors of BMI. Obese males (30.8\%), overweight females (20\%), overweight individuals of European ancestry (31.1\%), and overweight individuals of African ancestry (36.4\%) have the lowest classification scores. Underweight males (57.5\%), females (65.8\%), individuals of European ancestry (56.5\%), and individuals of African ancestry (69.4\%) have the highest classification scores. These results indicate that bias scores cannot be used reliably to predict BMI groups. 


\begin{tabular}{|c|c|c|c|c|c|c|c|c|c|}
\hline & BMI & $\begin{array}{c}\text { Kunos } \\
\text { et al. }\end{array}$ & $\begin{array}{l}\text { DiGangi } \\
\text { et al. }\end{array}$ & $\begin{array}{l}\text { İşcan } \\
\text { et al. }\end{array}$ & $\begin{array}{l}\text { Passal- } \\
\text { acqua }\end{array}$ & $\begin{array}{c}\text { Lovejoy } \\
\text { et al. }\end{array}$ & $\begin{array}{l}\text { Buckberry \& } \\
\text { Chamberlain }\end{array}$ & $\begin{array}{c}\text { Rougé-Maillart } \\
\text { et al. }\end{array}$ & $\begin{array}{l}\text { Suchey- } \\
\text { Brooks }\end{array}$ \\
\hline \multirow[t]{4}{*}{ Males } & Underweight & 0.03 & -14.49 & \begin{tabular}{|l|}
-9.61 \\
\end{tabular} & -5.85 & -6.83 & 4.04 & -6.41 & -8.86 \\
\hline & Normal & 4.28 & -11.99 & 3.68 & -0.49 & -4.71 & 6.89 & -4.42 & -6.55 \\
\hline & Overweight & 4.96 & -10.84 & 1.84 & 1.36 & -4.31 & 9.36 & -3.23 & -3.87 \\
\hline & Obese & 5.96 & -8.23 & 0.08 & -0.27 & -5.46 & 8.23 & -4.42 & -6.23 \\
\hline \multirow[t]{4}{*}{ Females } & Underweight & 2.89 & -16.71 & -14.87 & 1.63 & -5.32 & 3.47 & -5.29 & -5.29 \\
\hline & Normal & 0.42 & -15.75 & -0.72 & -2.15 & -5.60 & 4.94 & -5.51 & -6.74 \\
\hline & Overweight & 4.31 & -12.02 & -4.27 & 0.96 & -4.20 & 5.49 & -3.49 & -4.02 \\
\hline & Obese & 4.23 & -11.15 & -3.54 & -1.77 & -9.15 & 5.92 & -5.54 & -4.46 \\
\hline \multirow{4}{*}{ European } & Underweight & -1.99 & \begin{tabular}{|l|}
-18.43 \\
\end{tabular} & -11.78 & -5.88 & -8.12 & 1.46 & -9.22 & -9.86 \\
\hline & Normal & 2.04 & -14.79 & 2.50 & -2.56 & -6.51 & 5.21 & -6.32 & -7.51 \\
\hline & Overweight & 4.09 & -11.73 & -0.78 & 0.48 & -4.91 & 7.60 & -1.14 & -4.48 \\
\hline & Obese & 4.94 & -9.74 & -1.38 & -0.59 & -6.97 & 7.79 & -5.03 & -6.56 \\
\hline \multirow[t]{4}{*}{ African } & Underweight & 5.08 & -10.65 & -10.63 & 0.00 & -3.84 & 7.22 & -1.47 & -4.69 \\
\hline & Normal & 6.14 & -8.73 & -0.60 & 2.90 & -1.28 & 9.10 & -0.52 & -4.45 \\
\hline & Overweight & 7.30 & -9.15 & 2.59 & 4.06 & -1.94 & 10.61 & -0.21 & -1.85 \\
\hline & Obese & 8.40 & -5.60 & 3.18 & -2.00 & -4.80 & 5.20 & -3.20 & 0.60 \\
\hline
\end{tabular}

Table 69: Bias scores (in years) for each age-at-death estimation method separated by BMI for males and females. Significant differences are noted by boxes.

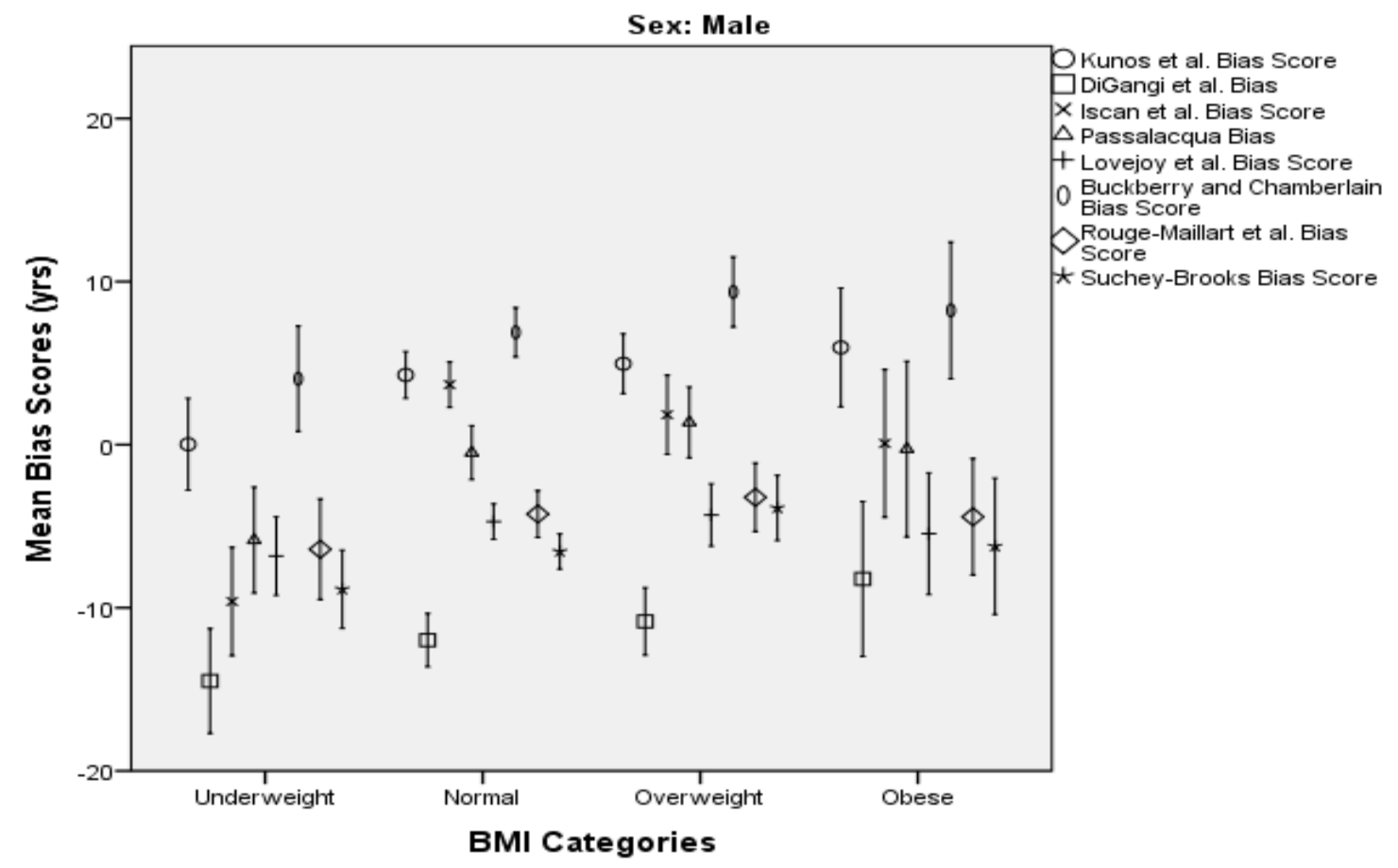

Error Bars: $95 \% \mathrm{Cl}$

Figure 31: Mean bias scores for the age estimation methods categorized by BMI for males. 


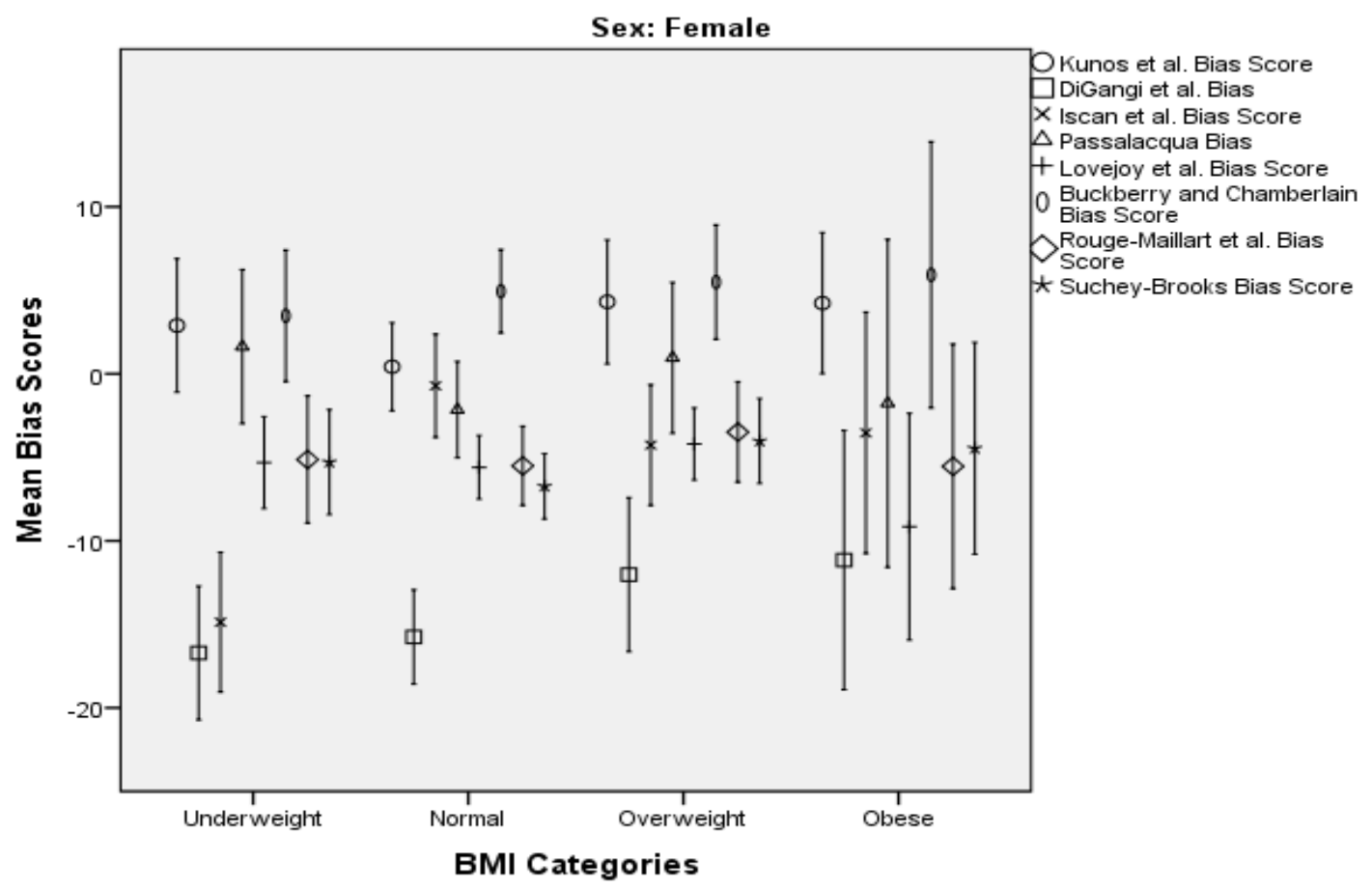

Error Bars: $95 \% \mathrm{Cl}$

Figure 32: Mean bias scores for the age estimation methods categorized by BMI for females.

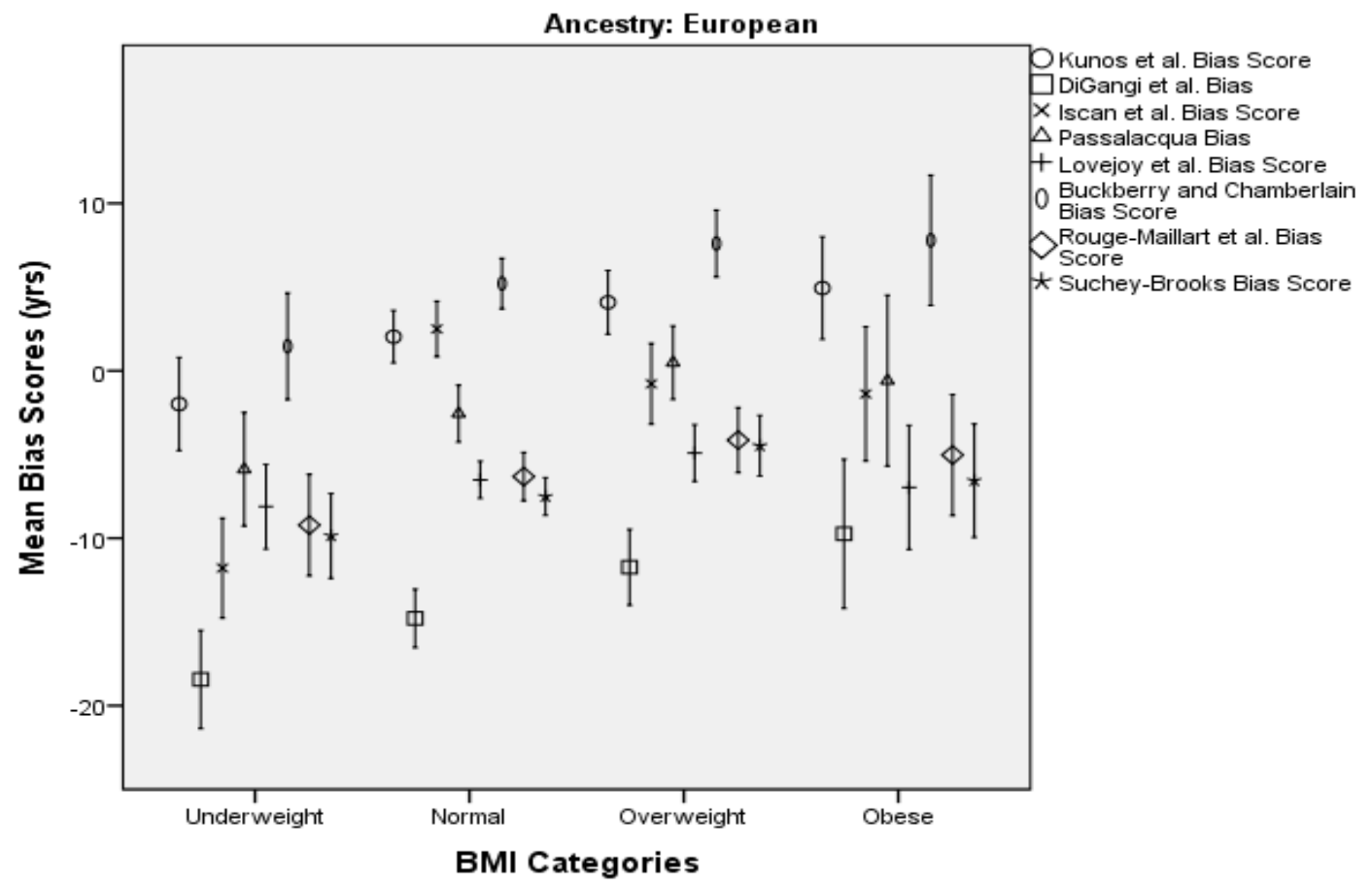

Error Bars: $95 \% \mathrm{Cl}$

Figure 33: Mean bias scores for the age estimation methods categorized by BMI for individuals of European ancestry. 


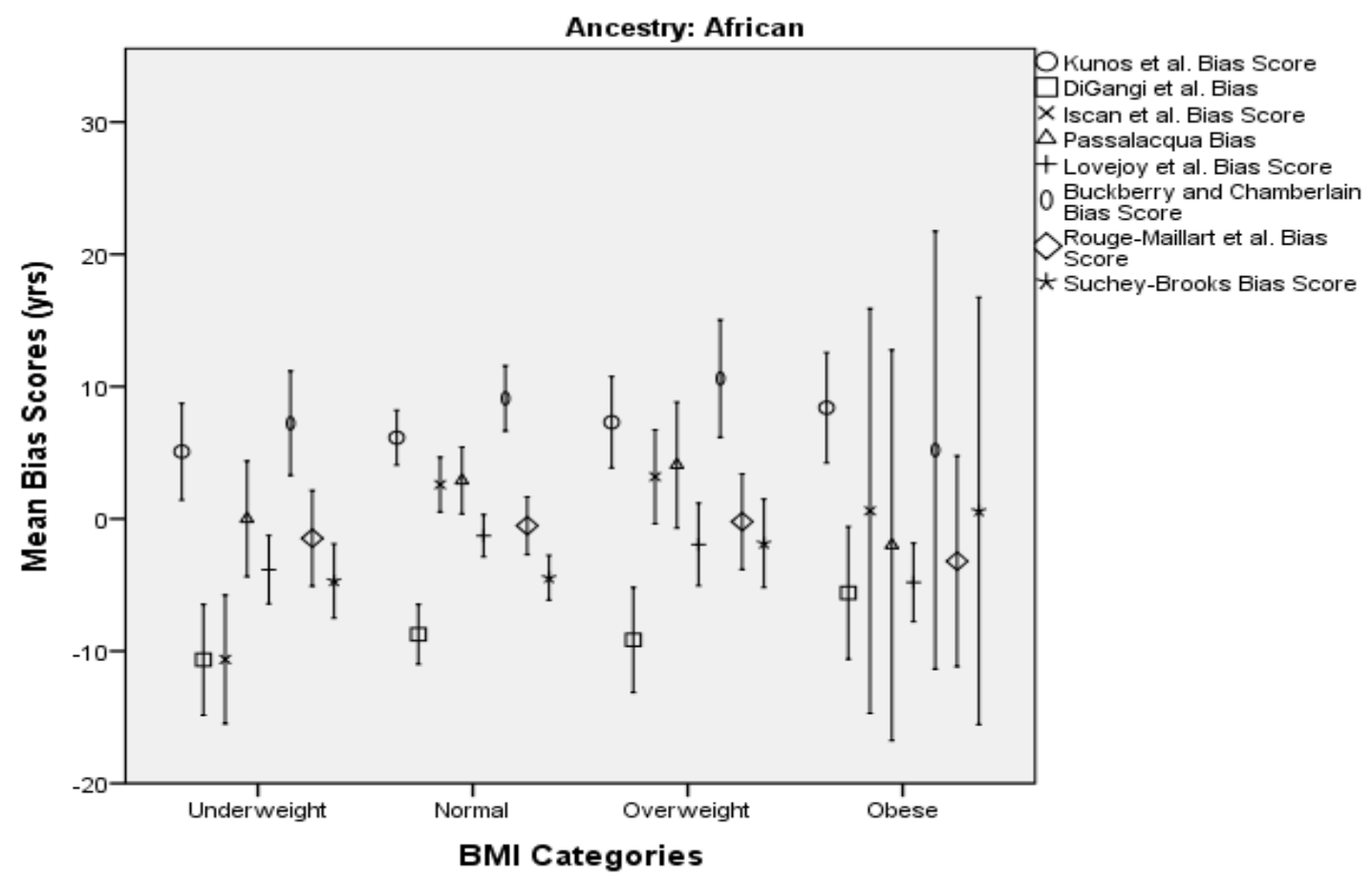

Error Bars: $95 \% \mathrm{Cl}$

Figure 34: Mean bias scores for the age estimation methods categorized by BMI for individuals of African ancestry. 


\subsection{Research Question II: Does stature influence skeletal age estimation?}

Figure 35 shows the sample distribution for stature. The average stature for this sample of 764 individuals is $1.70 \mathrm{~m}$ (range $1.30 \mathrm{~m}$ to $1.93 \mathrm{~m}$ ), $1.74 \mathrm{~m}$ for males (range $1.30 \mathrm{~m}$ to $1.83 \mathrm{~m}$ ), $1.61 \mathrm{~m}$ for females (range $1.30 \mathrm{~m}$ to $1.87 \mathrm{~m}$ ), $1.70 \mathrm{~m}$ for individuals of European ancestry (range $1.30 \mathrm{~m}$ to $1.93 \mathrm{~m}$ ), and $1.72 \mathrm{~m}$ for individuals of African ancestry (range $1.50 \mathrm{~m}$ to $1.92 \mathrm{~m}$ ). A cluster analysis was used to assign individuals into approximately equal, unbiased stature groups, and the results are shown in Figure 35 and Table 70.

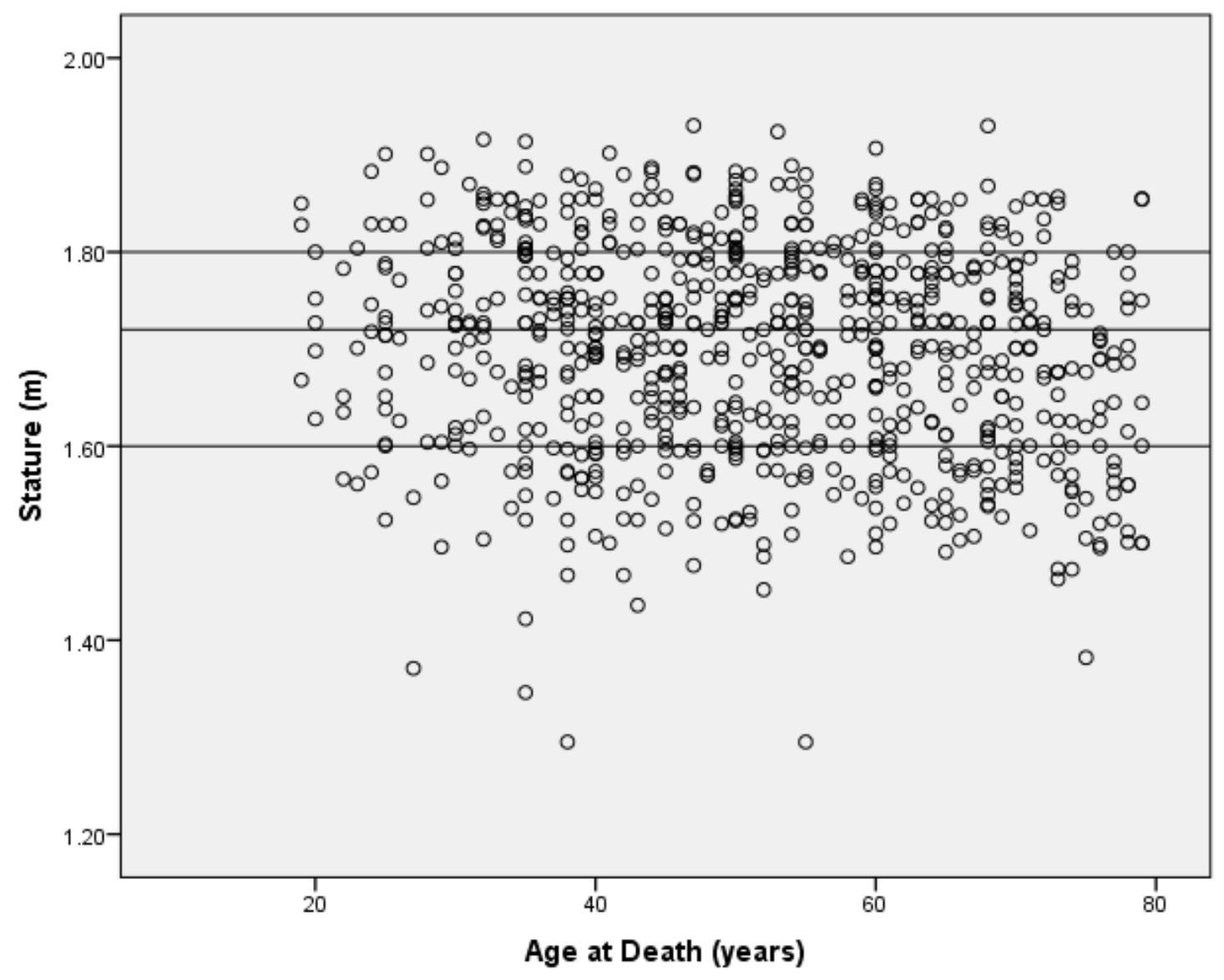

Figure 35: Stature distribution of the sample by age at death. Lines demarcate cluster analysis cut-off points.

\begin{tabular}{|c|c|c|c|}
\hline Group & n & Stature (m) & S.D. \\
\hline 1 & 198 & $1.20-1.60$ & 0.0533 \\
2 & 229 & $1.61-1.72$ & 0.0328 \\
3 & 230 & $1.73-1.80$ & 0.0259 \\
4 & 139 & $1.81-1.94$ & 0.0277 \\
\hline
\end{tabular}

Table 70: Stature group descriptive statistics. 
This section will test the influence of stature on age at death estimations. The sample will be separated by sex and ancestry, and differences between accuracy and bias scores between stature groups will be evaluated for each method using MANOVA and DFA.

\subsubsection{Sex}

\subsubsection{Accuracy}

\section{Males}

As shown in Table 36 of Section 3.3.1.1, the pattern of correlations observed among the accuracy scores are generally lower than ideal for a MANOVA. The Box's M value of 163.031 is associated with a $p$-value of 0.001 , which is significant. A covariance matrix (Appendix 19) was run to ensure that no covariance values were more than four times greater than each other. Although there are instances where the covariance values are greater than four times their value, typically associated with the Kunos et al. and Buckberry and Chamberlain methods, overall the covariance matrices between the stature groups were assumed to be equal for the purposes of the MANOVA.

A MANOVA was conducted to test the hypothesis that there would differences between stature group accuracy scores for each method. The MANOVA was significant with Pillai's Trace = $0.073, \mathrm{~F}(24,1479)=1.531, p=0.048$, indicating there are differences among the stature group accuracy scores. The multivariate effect size is estimated at 0.024 , which implies that $2.4 \%$ of the variance in the canonically derived DV is accounted for by the stature groups.

Three eigenvalues and canonical correlations were extracted by the MANOVA. The first eigenvalue is 0.054 and accounts for $71.0 \%$ of the model variance. The canonical correlation associated with the first eigenvalue is 0.226 , where $5.1 \%$ of the variance in the discriminant function derived scores is accounted for by stature group. The second eigenvalue is 0.017 and accounts for $22.3 \%$ of the model variance with a corresponding canonical correlation of 0.129 . The third eigenvalue is 0.005 and accounts for $6.7 \%$ of the model variance and a corresponding canonical correlation of 0.071 , which is not statistically significant [Wilks $\Lambda=0.994, \mathrm{~F}(6,493)=$ $0.417, p=0.868]$. 
The standardized discriminant function coefficients from the first eigenvalue were used to determine the statistical significance of the MANOVA, as it is the strongest. As seen in Table 71, the standardized discriminant function coefficients suggest that the four stature groups were maximally differentiated by a canonical variate with significant weightings from the RougéMaillart et al. (0.862), Buckberry and Chamberlain (-0.848), and DiGangi et al. (-0.630) methods accuracy scores. The standardized coefficients suggest relatively minimal individual contributions to the MANOVA effect from all other accuracy scores. The correlations between the accuracy scores and the canonically derived scores for all methods are weak to moderate (range $=-0.449$ to 0.628$)$.

\begin{tabular}{|l|l|l|l|}
\hline & \multicolumn{3}{|c|}{ Function 1 } \\
& Raw & Stand. & Struc. \\
\hline Kunos et al. & 0.035 & 0.242 & -0.008 \\
DiGangi et al. & -0.061 & -0.630 & 0.214 \\
İşcan et al. & 0.004 & 0.031 & 0.062 \\
Passalacqua & -0.014 & -0.117 & 0.006 \\
Lovejoy et al. & 0.027 & 0.184 & 0.494 \\
Buckberry \& Chamberlain & -0.098 & -0.848 & -0.499 \\
Rougé-Maillart et al. & 0.111 & 0.862 & 0.628 \\
Suchey-Brooks & 0.023 & 0.165 & 0.484 \\
\hline
\end{tabular}

Table 71: Discriminant function coefficients associated with the MANOVA for males. Note: Raw $=$ unstandardized coefficients, Stand. = standardized coefficients, Struc. $=$ structure coefficients.

To estimate the group centroids for the four stature groups, the sample inaccuracy scores were multiplied by the corresponding inaccuracy unstandardized discriminant function coefficients and then averaged across the samples. The means and standard deviations are listed in Table 72. An ANOVA with four levels in the IV was performed on the canonically derived accuracy score $\mathrm{DV}$, and is significant $[\mathrm{F}(3,8.879)=8.925, p<0.001]$.

\begin{tabular}{|c|c|c|c|}
\hline & n & Mean & S.D. \\
\hline $1.20-1.60 \mathrm{~m}$ & 55 & 0.249 & 1.038 \\
$1.61-1.72 \mathrm{~m}$ & 132 & -0.304 & 1.047 \\
$1.73-1.80 \mathrm{~m}$ & 191 & -0.089 & 1.000 \\
$1.81-1.93 \mathrm{~m}$ & 124 & -0.509 & 0.919 \\
\hline
\end{tabular}

Table 72: Means and Standard Deviations for the male canonically derived variables.

The Cohen's $d$ absolute values were as follows, from highest to lowest: Group 1 vs. Group $4=$ 0.776; Group 1 vs. Group 2 = 0.551; Group 1 vs. Group $3=0.337$; Group 2 vs. Group $3=0.213$; Group 2 vs. Group $4=0.207$; and Group 3 vs. Group $4=0.207$. The differences between Groups 
1 and 4 are suggestive of a large effect size; the differences between Groups 1 and 2 are suggestive of a medium effect size, and the differences between Groups 2 and 3, Groups 2 and 4, and Groups 3 and 4 are suggestive of a small effect size.

Table 73 shows the results from Tukey's $b$ post-hoc tests for unequal sample sizes. There are no significant differences among the stature group inaccuracy scores for males using the Kunos et al., DiGangi et al., İşcan et al., and Passalacqua methods. The inaccuracy scores for the Lovejoy et al., Rougé-Maillart et al., and Suchey-Brooks methods are higher for males in Group 1 compared to males in Group 4, while the inaccuracy scores for the Buckberry and Chamberlain method are higher for males in Group 4 compared to males in Group 1.

\begin{tabular}{|c|c|c|c|c|c|}
\hline \multirow[b]{2}{*}{ Method } & \multirow[b]{2}{*}{ Stature Group } & \multirow[b]{2}{*}{$\mathbf{n}$} & \multicolumn{3}{|c|}{ Subset (yrs) } \\
\hline & & & 1 & 2 & 3 \\
\hline \multirow[t]{4}{*}{ Kunos et al. } & Group 4 & 124 & 10.10 & & \\
\hline & Group 3 & 191 & 10.13 & & \\
\hline & Group 1 & 55 & 10.20 & & \\
\hline & Group 2 & 132 & 10.50 & & \\
\hline \multirow[t]{4}{*}{ DiGangi et al. } & Group 4 & 124 & 13.70 & & \\
\hline & Group 3 & 191 & 14.73 & & \\
\hline & Group 2 & 132 & 14.95 & & \\
\hline & Group 1 & 55 & 15.69 & & \\
\hline \multirow[t]{4}{*}{ İşcan et al. } & Group 4 & 124 & 10.34 & & \\
\hline & Group 3 & 191 & 10.56 & & \\
\hline & Group 2 & 132 & 10.83 & & \\
\hline & Group 1 & 55 & 11.44 & & \\
\hline \multirow[t]{4}{*}{ Passalacqua } & Group 4 & 124 & 10.47 & & \\
\hline & Group 1 & 55 & 10.65 & & \\
\hline & Group 3 & 191 & 11.17 & & \\
\hline & Group 2 & 132 & 12.12 & & \\
\hline \multirow[t]{4}{*}{ Lovejoy et al. } & Group 4 & 124 & 7.36 & & \\
\hline & Group 3 & 191 & 8.77 & 8.77 & \\
\hline & Group 2 & 132 & 8.98 & 8.98 & \\
\hline & Group 1 & 55 & & 10.31 & \\
\hline \multirow[t]{4}{*}{ Buckberry and Chamberlain } & Group 1 & 55 & 9.44 & & \\
\hline & Group 3 & 191 & 11.46 & 11.46 & \\
\hline & Group 2 & 132 & 12.30 & 12.30 & \\
\hline & Group 4 & 124 & & 12.94 & \\
\hline \multirow[t]{4}{*}{ Rougé-Maillart et al. } & Group 4 & 124 & 8.71 & & \\
\hline & Group 2 & 132 & 9.93 & 9.93 & \\
\hline & Group 3 & 191 & 11.21 & 11.21 & \\
\hline & Group 1 & 55 & & 12.09 & \\
\hline \multirow[t]{4}{*}{ Suchey-Brooks } & Group 4 & 124 & 7.82 & & \\
\hline & Group 3 & 191 & 9.22 & 9.22 & \\
\hline & Group 2 & 132 & 9.84 & 9.84 & \\
\hline & Group 1 & 55 & & 11.18 & \\
\hline
\end{tabular}

Table 73: Tukey's $b$ post-hoc test results for male accuracy scores separated by stature. Note: alpha level $=\mathbf{0 . 0 5}$ 
A DFA was applied to assess how well stature could be predicted from the accuracy scores of the eight age estimation methods. The cross-validated classification shows that only $37.8 \%$ of males are correctly classified into their stature group based on accuracy scores. Males in Group 1 are classified correctly at a rate of $0 \%$, Group 2 at a rate of $16.7 \%$, Group 3 at a rate of $79.6 \%$, and Group 4 at a rate of $12.9 \%$.

The discriminant scores from Function 1 and Function 2 were used to plot the sample on the discriminant dimensions. The Group 4 is associated with the largest group centroid (0.297), Group 2 is associated with the next largest group centroid (0.092), Group 3 is associated with the second smallest centroid (-0.124) and, finally, Group 1 is associated with the smallest group centroid (-0.463) (see Figure 36).

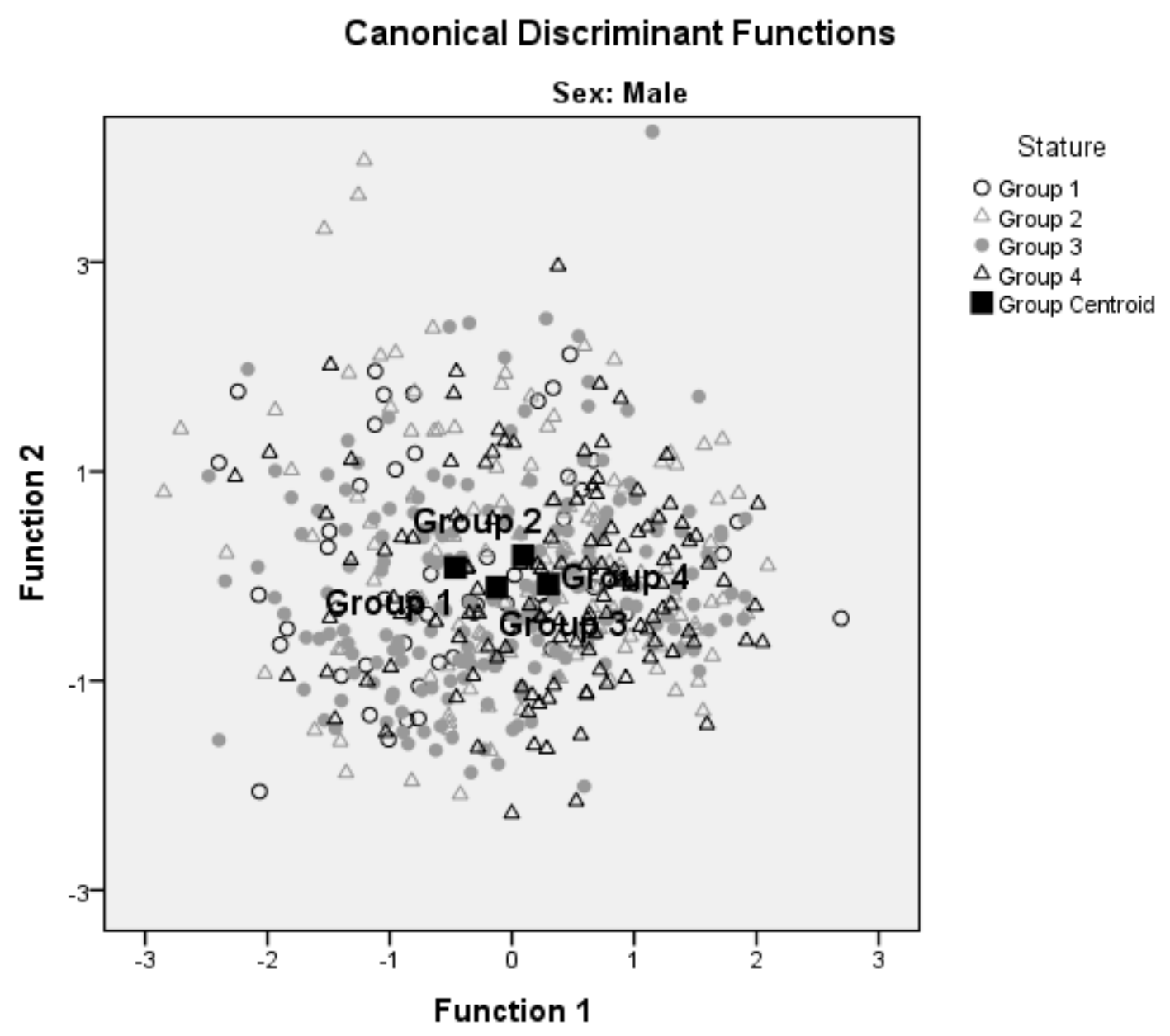

Figure 36: Canonically derived centroids for the stature groups for males. 


\section{Females}

As shown in Table 40 of Section 3.3.1.1, the pattern of correlations observed among the accuracy scores are generally lower than ideal for a MANOVA. Box's M value of 97.848 is associated with a $p$-value of 0.131 , which is not significant; therefore, the covariance between the stature groups were assumed to be equal for the purposes of the MANOVA.

A MANOVA was conducted to test the hypothesis that there would be differences between stature group accuracy scores for each method. The MANOVA effect was not statistically significant with Pillai's Trace $=0.142, \mathrm{~F}(24,567)=1.171, p=0.262$. The multivariate effect size is estimated at 0.047 , which implies that $4.7 \%$ of the variance in the canonically derived DV is accounted for by the stature groups. As none of the functions are significant, there is no relationship between the stature groups and accuracy scores for females.

A DFA was applied to assess how well stature could be predicted from the accuracy scores of the eight age estimation methods. The cross-validated classification shows that only $56.6 \%$ of females are correctly classified into their stature group based on accuracy scores. Females in Group 1 are classified correctly at a rate of $78.3 \%$, Group 2 at a rate of $39.7 \%$, and females in Group 3 and Group 4 are never classified in the correct stature group.

\subsubsection{Bias}

\section{Males}

As shown in Table 44 of Section 3.3.1.2, the pattern of correlations observed among the bias scores are generally strong for a MANOVA. The Box's M value of 110.863 is associated with a $p$-value of 0.512 , which is not significant; therefore, the covariance between the stature groups are equal for the purposes of the MANOVA.

A MANOVA was conducted to test the hypothesis that there would be differences between stature group bias scores for each method. The MANOVA was statistically significant with Pillai's Trace $=0.116, \mathrm{~F}(24,1479)=2.473, p<0.001$, indicating there are differences among the stature group bias scores. The multivariate effect size is estimated at 0.039 , which implies that $3.9 \%$ of the variance in the canonically derived DV is accounted for by the stature groups. 
Three eigenvalues and canonical correlations were extracted by the MANOVA. The first eigenvalue is 0.076 and accounts for $62.2 \%$ of the model variance. The canonical correlation associated with the first eigenvalue is 0.266 , where $7.1 \%$ of the variance in the discriminant function derived scores is accounted for by stature group. The second eigenvalue is 0.030 and accounts for $24.2 \%$ of the model variance with a corresponding canonical correlation of 0.170 . The third eigenvalue is 0.017 and accounts for $13.6 \%$ of the model variance and a corresponding canonical correlation of 0.128 , which is not statistically significant [Wilks $\Lambda=0.984, \mathrm{~F}(6,493)=$ $1.363, p=0.228]$.

The standardized discriminant function coefficients from the first eigenvalue were used to determine the statistical significance of the MANOVA, as it is the strongest. As seen in Table 74, the standardized discriminant function coefficients suggest that the stature groups are maximally differentiated by a canonical variate with significant weightings from the Rougé-Maillart et al. (1.073) and DiGangi et al. (-0.744), methods bias scores. The standardized coefficients suggest moderate individual contributions to the MANOVA effect from all other bias scores. The correlations between the bias scores and the canonically derived scores for all methods are positive and with weak to strong scores (range $=0.176$ to 0.702 ).

\begin{tabular}{|l|l|l|l|}
\hline & \multicolumn{3}{|c|}{ Function 1 } \\
& Raw & Stand. & Struc. \\
\hline Kunos et al. & 0.030 & 0.352 & 0.423 \\
DiGangi et al. & -0.055 & -0.744 & 0.176 \\
İscan et al. & 0.014 & 0.190 & 0.413 \\
Passalacqua & -0.012 & -0.170 & 0.297 \\
Lovejoy et al. & -0.050 & -0.487 & 0.452 \\
Buckberry \& Chamberlain & 0.020 & 0.250 & 0.702 \\
Rougé-Maillart et al. & 0.090 & 1.073 & 0.198 \\
Suchey-Brooks & 0.027 & 0.262 & 0.546 \\
\hline
\end{tabular}

Table 74: Discriminant function coefficients associated with the MANOVA for males. Note: Raw $=$ unstandardized coefficients, Stand. = standardized coefficients, Struc. = structure coefficients.

To estimate the group centroids for the stature groups, the sample bias scores were multiplied by the corresponding bias unstandardized discriminant function coefficients and then averaged across the samples. The means and standard deviations are listed in Table 75. An ANOVA with four levels in the IV was performed on the canonically derived bias score DV, and is statistically significant $[\mathrm{F}(3,27.214)=9.510, p<0.001]$. 


\begin{tabular}{|c|c|c|c|}
\hline & n & Mean & S.D. \\
\hline $1.20-1.60 \mathrm{~m}$ & 55 & -0.700 & 1.674 \\
$1.61-1.72 \mathrm{~m}$ & 132 & 0.168 & 1.674 \\
$1.73-1.80 \mathrm{~m}$ & 191 & -0.054 & 1.783 \\
$1.81-1.93 \mathrm{~m}$ & 124 & 0.697 & 1.569 \\
\hline
\end{tabular}

Table 75: Means and Standard Deviations for the male canonically derived variables.

The Cohen's $d$ absolute values were as follows, from highest to lowest: Group 1 vs. Group $4=$ 1.104; Group 1 vs. Group 2 =0.671; Group 3 vs. Group $4=0.576$; Group 1 vs. Group $3=0.487$; Group 2 vs. Group $3=0.415$; and Group 2 vs. Group $4=0.415$. The differences between Groups 1 and 4, and Groups 1 and 2 are suggestive of a large effect size; the differences between Groups 3 and 4, Groups 1 and 3, Groups 2 and 3 and Groups 2 and 4 are suggestive of a medium effect size.

Table 76 shows the results from Tukey's $b$ post-hoc tests for unequal sample sizes. There are no significant differences among the stature group bias scores for males using the DiGangi et al. and Passalacqua methods. The Kunos et al., Lovejoy et al., Buckberry and Chamberlain, and SucheyBrooks methods under-age males in Group 1 compared to males in Group 3. The İşcan et al. method under-age males in Group 1 compared to males in Groups 2, 3, and 4. The RougéMaillart et al. method under-age males in Group 1 compared to males in Groups 3 and 4. Males in Group 2 are under-aged compared to males in Group 4. 


\begin{tabular}{|c|c|c|c|c|c|}
\hline \multirow[b]{2}{*}{ Method } & \multirow[b]{2}{*}{ Stature } & \multirow[b]{2}{*}{$\mathbf{n}$} & \multicolumn{3}{|c|}{ Subset (yrs) } \\
\hline & & & 1 & 2 & 3 \\
\hline \multirow[t]{4}{*}{ Kunos et al. } & Group 1 & 55 & 0.49 & & \\
\hline & Group 2 & 132 & 3.59 & 3.59 & \\
\hline & Group 3 & 191 & 3.68 & 3.68 & \\
\hline & Group 4 & 124 & & 5.82 & \\
\hline \multirow[t]{4}{*}{ DiGangi et al. } & Group 3 & 191 & -12.54 & & \\
\hline & Group 2 & 132 & -12.36 & & \\
\hline & Group 1 & 55 & -12.24 & & \\
\hline & Group 4 & 124 & -10.43 & & \\
\hline \multirow[t]{4}{*}{ İşcan et al. } & Group 1 & 55 & -3.65 & & \\
\hline & Group 3 & 191 & & 0.70 & \\
\hline & Group 4 & 124 & & 2.03 & \\
\hline & Group 2 & 132 & & 2.30 & \\
\hline \multirow[t]{4}{*}{ Passalacqua } & Group 1 & 55 & -2.95 & & \\
\hline & Group 2 & 132 & -1.98 & & \\
\hline & Group 3 & 191 & -1.13 & & \\
\hline & Group 4 & 124 & 1.40 & & \\
\hline \multirow[t]{4}{*}{ Lovejoy et al. } & Group 1 & 55 & -7.62 & & \\
\hline & Group 2 & 132 & -5.58 & -5.58 & \\
\hline & Group 3 & 191 & -5.18 & -5.18 & \\
\hline & Group 4 & 124 & & -2.94 & \\
\hline \multirow[t]{4}{*}{ Buckberry and Chamberlain } & Group 1 & 55 & 3.40 & & \\
\hline & Group 3 & 191 & 5.27 & 5.27 & \\
\hline & Group 2 & 132 & 7.57 & 7.57 & \\
\hline & Group 4 & 124 & & 10.84 & \\
\hline \multirow[t]{4}{*}{ Rougé-Maillart et al. } & Group 1 & 55 & -8.67 & & \\
\hline & Group 2 & 132 & -6.04 & -6.04 & \\
\hline & Group 3 & 191 & & -3.96 & -3.96 \\
\hline & Group 4 & 124 & & & -0.37 \\
\hline \multirow[t]{4}{*}{ Suchey-Brooks } & Group 1 & 55 & -9.18 & & \\
\hline & Group 2 & 132 & -7.07 & -7.07 & \\
\hline & Group 3 & 191 & -6.69 & -6.69 & \\
\hline & Group 4 & 124 & & -3.66 & \\
\hline
\end{tabular}

Table 76: Tukey's $b$ post-hoc test results for male bias scores separated by stature. Note: alpha level $=\mathbf{0 . 0 5}$

A DFA was applied to assess how well stature could be predicted from the bias scores of the eight age estimation methods. The cross-validated classification shows that only $40.0 \%$ of males are correctly classified into their stature group based on bias scores. Males in Group 1 are classified correctly at a rate of $3.6 \%$, Group 2 at a rate of $20.5 \%$, Group 3 at a rate of $76.4 \%$, and Group 4 at a rate of $30.6 \%$.

The discriminant scores from Function 1 and Function 2 were used to plot the sample on the discriminant dimensions. Group 4 is associated with the largest group centroid (0.364), Group 2 is associated with the next largest group centroid (0.105), Group 3 is associated with the second 
smallest centroid (-0.157) and, finally, Group 1 is associated with the smallest group centroid (0.527) (see Figure 37).

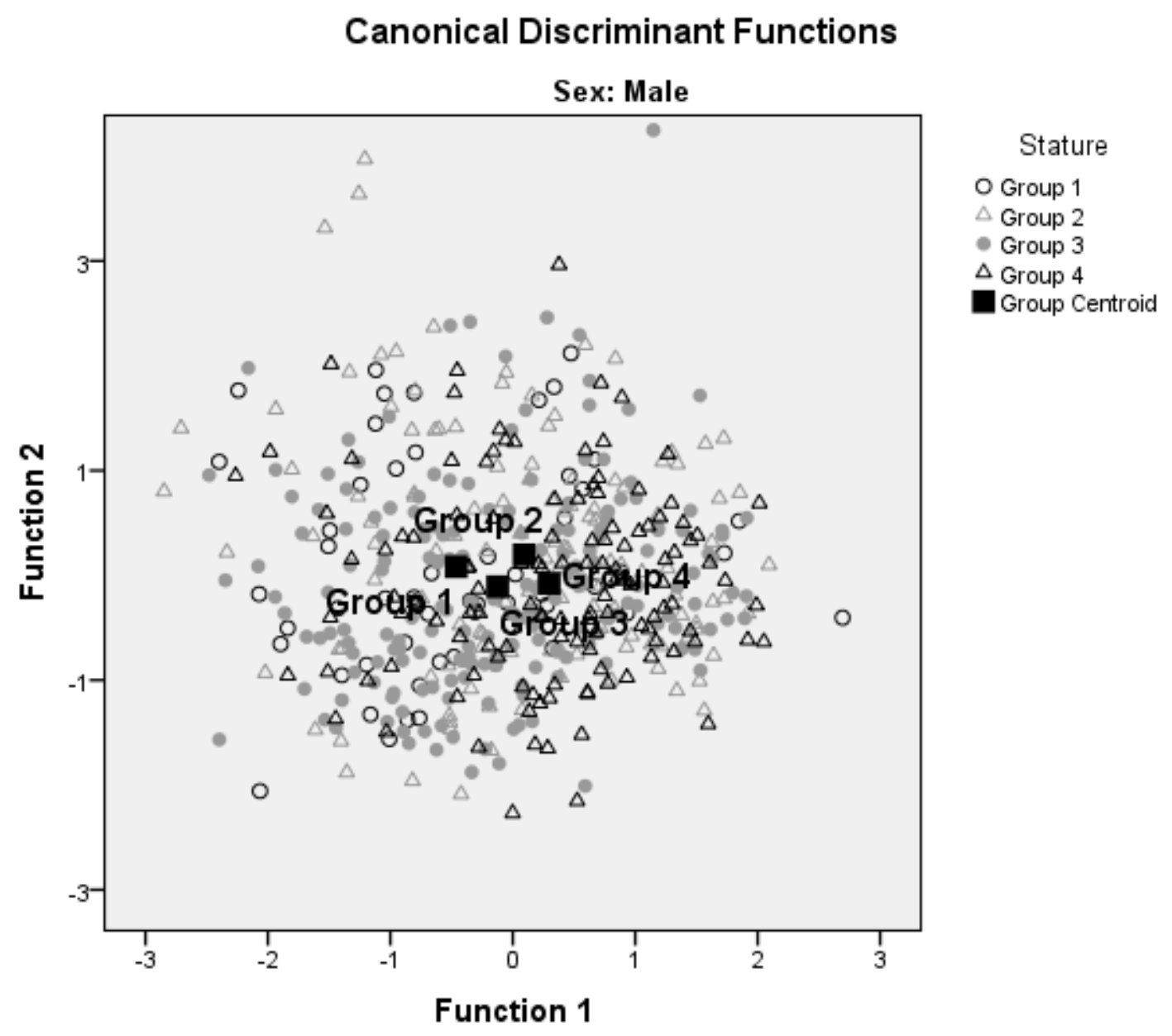

Figure 37: Canonically derived centroids for the stature groups for males.

\section{Females}

As shown in Table 48 of Section 3.3.1.2, the pattern of correlations observed among the bias scores are generally strong for a MANOVA. The Box's M value of 102.048 is associated with a $p$-value of 0.082 , which is not significant; therefore, the covariance observed between the stature groups are equal for the MANOVA.

A MANOVA was conducted to test the hypothesis that there would be differences between stature group bias scores for each method. The MANOVA was not statistically significant with Pillai's Trace $=0.118, \mathrm{~F}(24,567)=0.968, p=0.507$. The multivariate effect size is estimated at 
0.039 , which implies that $3.9 \%$ of the variance in the canonically derived DV is accounted for by the stature groups. As none of the functions are significant, there is no relationship between the stature groups and bias scores for females.

A DFA was applied to assess how well stature could be predicted from the bias scores of the eight age estimation methods. The cross-validated classification shows that only $51.7 \%$ of females are correctly classified into their stature group based on bias scores. Females in Group 1 are classified correctly at a rate of $84.0 \%$, Group 2 at a rate of $32.9 \%$, and females in Groups 3 and 4 are never classified correctly.

\subsubsection{Ancestry}

\subsubsection{Accuracy}

\section{European Ancestry}

As shown in Table 52 of Section 3.3.2.1, the pattern of correlations observed among the accuracy scores are generally lower than ideal for a MANOVA. The Box's M value of 163.518 is associated with a $p$-value of 0.001 , which is significant. A covariance matrix (Appendix 20) was run to ensure that no covariance values were more than four times greater than each other. Although there are instances where the covariance values are greater than four times their value, typically associated with the DiGangi et al. and Buckberry and Chamberlain methods, overall the covariance matrices between the stature groups were assumed to be equal for the purposes of the MANOVA.

A MANOVA was conducted to test the hypothesis that there would be differences between stature group accuracy scores for each method. The MANOVA was statistically significant with Pillai's Trace $=0.107, \mathrm{~F}(24,1464)=2.249, p=0.001$, indicating there are differences among the stature group accuracy scores. The multivariate effect size is estimated at 0.036 , which implies that $3.6 \%$ of the variance in the canonically derived DV is accounted for by the stature groups.

Three eigenvalues and canonical correlations were extracted by the MANOVA. The first eigenvalue is 0.073 and accounts for $65.1 \%$ of the model variance. The canonical correlation associated with the first eigenvalue is 0.262 , where $6.9 \%$ of the variance in the discriminant function derived scores is accounted for by stature group. The second eigenvalue is 0.033 and 
accounts for $29.0 \%$ of the model variance with a corresponding canonical correlation of 0.178 . The third eigenvalue is 0.007 and accounts for $5.9 \%$ of the model variance and a corresponding canonical correlation of 0.081 , which is not statistically significant [Wilks $\Lambda=0.993, F(6,488)=$ $0.540, p=0.778]$.

The standardized discriminant function coefficients from the first eigenvalue were used to determine the statistical significance of the MANOVA, as it was the strongest. As seen in Table 77, the standardized discriminant function coefficients suggest that the four stature groups were maximally differentiated by a canonical variate with significant weightings from the Buckberry and Chamberlain (0.784) and the Rougé-Maillart et al. (-0.875) methods accuracy scores. The standardized coefficients suggest minimal to moderate individual contributions to the MANOVA effect from all other accuracy scores. The correlations between the accuracy scores and the canonically derived scores for all methods are weak to moderate (range $=-0.633$ to 0.607 ).

\begin{tabular}{|l|l|l|l|}
\hline & \multicolumn{3}{|c|}{ Function 1 } \\
& Raw & Stand. & Struc. \\
\hline Kunos et al. & 0.010 & 0.068 & -0.161 \\
DiGangi et al. & 0.009 & 0.104 & 0.416 \\
İşcan et al. & -0.032 & -0.278 & 0.384 \\
Passalacqua & -0.002 & -0.015 & 0.140 \\
Lovejoy et al. & 0.024 & 0.170 & 0.306 \\
Buckberry \& Chamberlain & 0.099 & 0.784 & -0.633 \\
Rougé-Maillart et al. & -0.111 & -0.875 & 0.607 \\
Suchey-Brooks & 0.023 & 0.167 & 0.306 \\
\hline
\end{tabular}

Table 77: Discriminant function coefficients associated with the MANOVA for individuals of European ancestry. Note: Raw $=$ unstandardized coefficients, Stand. = standardized coefficients, Struc. $=$ structure coefficients.

To estimate the group centroids for the stature groups, the sample inaccuracy scores were multiplied by the corresponding inaccuracy unstandardized discriminant function coefficients and then averaged across the samples. The means and standard deviations are listed in Table 78. An ANOVA with four levels in the IV was performed on the canonically derived accuracy score $\mathrm{DV}$, and is statistically significant $[\mathrm{F}(3,12.139)=12.057, p<0.001]$.

\begin{tabular}{|c|c|c|c|}
\hline & $\mathbf{n}$ & Mean & S.D. \\
\hline $1.20-1.60 \mathrm{~m}$ & 120 & -0.184 & 1.020 \\
$1.61-1.72 \mathrm{~m}$ & 152 & 0.396 & 1.021 \\
$1.73-1.80 \mathrm{~m}$ & 147 & 0.117 & 0.977 \\
$1.81-1.93 \mathrm{~m}$ & 78 & 0.590 & 0.991 \\
\hline
\end{tabular}

Table 78: Means and Standard Deviations for individuals of European ancestry canonically derived variables. 
The Cohen's $d$ absolute values were as follows, from highest to lowest: Group 1 vs. Group $4=$ 0.771; Group 1 vs. Group $2=0.574$; Group 3 vs. Group $4=0.477$; Group 1 vs. Group $3=0.302$; Group 2 vs. Group $3=0.279$; and Group 2 vs. Group $4=0.193$. The differences between Groups 1 and 4 are suggestive of a large effect size; the differences between Groups 1 and 2, and Groups 3 and 4 are suggestive of a medium effect size; and the differences between Groups 1 and 3, Groups 2 and 3, and Groups 1 and 4 are suggestive of a small effect size.

Table 79 shows the results from Tukey's $b$ post-hoc tests for unequal sample sizes. There are no significant differences among the stature group accuracy scores for individuals of European ancestry using the Kunos et al., Passalacqua, Lovejoy et al., and Suchey-Brooks methods. The DiGangi et al. and Buckberry and Chamberlain methods accuracy scores for Group 1 are significantly lower than Group 4. The İşcan et al. method accuracy scores for Group 1 are significantly lower than Group 3 and Group 4. The Rougé-Maillart et al. method accuracy scores for Group 1 and Group 3 are significantly lower compared to Group 4.

A DFA was applied to assess how well stature could be predicted from the accuracy scores of the eight age estimation methods. The cross-validated classification shows that only $40.4 \%$ of individuals of European ancestry are correctly classified into their stature group based on accuracy scores. individuals of European ancestry in Group 1 are classified correctly at a rate of $28.3 \%$, Group 2 at a rate of $59.2 \%$, Group 3 at a rate of $51.0 \%$, and Group 4 at a rate of $2.6 \%$.

The discriminant scores from Function 1 and Function 2 were used to plot the sample on the discriminant dimensions. Group 4 is associated with the largest group centroid (0.385), Group 2 is associated with the next largest group centroid (0.192), Group 3 is associated with the second smallest centroid (-0.087) and, finally, Group 1 is associated with the smallest group centroid (0.386) (see Figure 38). 


\begin{tabular}{|c|c|c|c|c|c|}
\hline \multirow[b]{2}{*}{ Method } & \multirow[b]{2}{*}{ Stature } & \multirow[b]{2}{*}{$\mathbf{n}$} & \multicolumn{3}{|c|}{ Subset (yrs) } \\
\hline & & & 1 & 2 & 3 \\
\hline \multirow[t]{4}{*}{ Kunos et al. } & Group 3 & 147 & 9.29 & & \\
\hline & Group 1 & 120 & 10.02 & & \\
\hline & Group 4 & 78 & 10.28 & & \\
\hline & Group 2 & 152 & 10.86 & & \\
\hline \multirow[t]{4}{*}{ DiGangi et al. } & Group 4 & 78 & 13.76 & & \\
\hline & Group 3 & 147 & 15.27 & 15.27 & \\
\hline & Group 2 & 152 & 16.73 & 16.73 & \\
\hline & Group 1 & 120 & & 18.83 & \\
\hline \multirow{4}{*}{ İşcan et al. } & Group 3 & 147 & 10.17 & & \\
\hline & Group 4 & 78 & 10.40 & & \\
\hline & Group 2 & 152 & 10.74 & 10.74 & \\
\hline & Group 1 & 120 & & 13.31 & \\
\hline \multirow{4}{*}{ Passalacqua } & Group 4 & 78 & 10.63 & & \\
\hline & Group 3 & 147 & 11.22 & & \\
\hline & Group 2 & 152 & 11.52 & & \\
\hline & Group 1 & 120 & 11.93 & & \\
\hline \multirow[t]{4}{*}{ Lovejoy et al. } & Group 4 & 78 & 7.88 & & \\
\hline & Group 3 & 147 & 8.88 & & \\
\hline & Group 2 & 152 & 9.17 & & \\
\hline & Group 1 & 120 & 10.11 & & \\
\hline \multirow[t]{4}{*}{ Buckberry and Chamberlain } & Group 1 & 120 & 8.85 & & \\
\hline & Group 3 & 147 & 10.78 & 10.78 & \\
\hline & Group 2 & 152 & 11.30 & 11.30 & \\
\hline & Group 4 & 78 & & 13.35 & \\
\hline \multirow[t]{4}{*}{ Rougé-Maillart et al. } & Group 4 & 78 & 8.81 & & \\
\hline & Group 2 & 152 & 9.57 & 9.57 & \\
\hline & Group 3 & 147 & & 11.40 & 11.40 \\
\hline & Group 1 & 120 & & & 12.29 \\
\hline \multirow[t]{4}{*}{ Suchey-Brooks } & Group 4 & 78 & 8.04 & & \\
\hline & Group 3 & 147 & 9.56 & & \\
\hline & Group 2 & 152 & 9.86 & & \\
\hline & Group 1 & 120 & 10.51 & & \\
\hline
\end{tabular}

Table 79: Tukey's $b$ post-hoc test results for European accuracy scores separated by stature. Note: alpha level $=\mathbf{0 . 0 5}$ 


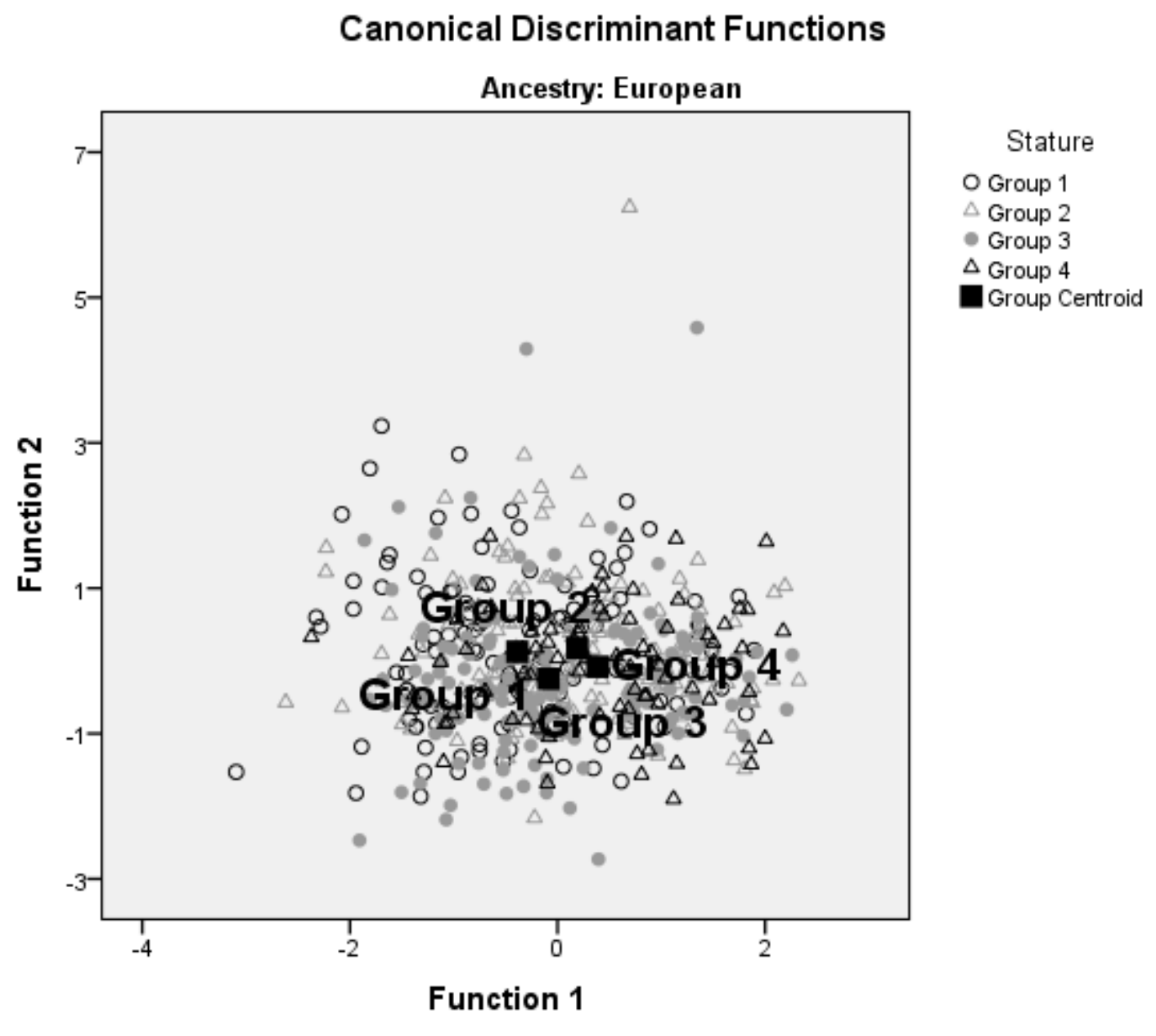

Figure 38: Canonically derived centroids for the stature groups for individuals of European ancestry.

\section{African Ancestry}

As shown in Table 56 of Section 3.3.2.1, the pattern of correlations observed among the accuracy scores are generally lower than ideal for a MANOVA. The Box's M value of 153.890 is associated with a $p$-value of 0.015 , which is not significant; therefore, the covariance between the stature groups were assumed to be equal for the purposes of the MANOVA.

A MANOVA was conducted to test the hypothesis that there would be differences between stature group accuracy scores for each method. The MANOVA was not statistically significant with Pillai's Trace $=0.131, \mathrm{~F}(24,582)=1.104, p=0.333$. The multivariate effect size is estimated at 0.044 , which implies that $4.4 \%$ of the variance in the canonically derived DV is accounted for by the stature groups. As none of the functions were significant, there is no relationship between the stature groups and accuracy scores for individuals of African ancestry. 
A DFA was applied to assess how well stature could be predicted from the accuracy scores of the eight age estimation methods. The cross-validated classification shows that only $36.9 \%$ of individuals of African ancestry are correctly classified into their stature group based on accuracy scores. individuals of African ancestry in Group 1 are classified correctly at a rate of $4.9 \%$, Group 2 at a rate of $49.1 \%$, Group 3 at a rate of $57.4 \%$, and Group 4 at a rate of $25.0 \%$.

\subsubsection{Bias}

\section{European Ancestry}

As shown in Table 60 of Section 3.3.2.2, the pattern of correlations observed among the bias scores are generally strong for a MANOVA. The Box's M value of 137.668 is associated with a $p$-value of 0.049 , which is not significant; therefore, the covariance between the stature groups were assumed to be equal for the purposes of the MANOVA.

A MANOVA was conducted to test the hypothesis that there would be differences between stature group bias scores for each method. The MANOVA was statistically significant with Pillai's Trace $=0.161, \mathrm{~F}(24,1464)=3.572, p<0.001$, indicating there are differences among the stature group bias scores. The multivariate effect size is estimated at 0.055 , which implies that $5.5 \%$ of the variance in the canonically derived DV is accounted for by stature groups.

Three eigenvalues and canonical correlations were extracted by the MANOVA. The first eigenvalue is equal to 0.127 and accounts for $69.7 \%$ of the model variance. The canonical correlation associated with the first eigenvalue is equal to 0.336 , where $11.3 \%$ of the variance in the discriminant function derived scores is accounted for by stature group. The second eigenvalue is equal to 0.039 and accounts for $21.2 \%$ of the model variance with a corresponding canonical correlation of 0.193 . The third eigenvalue is equal to 0.016 and accounts for $9.0 \%$ of the model variance and a corresponding canonical correlation of 0.127 , which is not statistically significant [Wilks $\Lambda=0.984, \mathrm{~F}(6,488)=1.331, p=0.241]$.

The standardized discriminant function coefficients from the first eigenvalue were used to determine the statistical significance of the MANOVA, as it is the strongest. As seen in Table 80, the standardized discriminant function coefficients suggest that the stature groups are maximally differentiated by a canonical variate with significant weighting from the Buckberry and 
Chamberlain (0.650), İşcan et al. (0.496), and Kunos et al. (0.753) method bias scores. The standardized coefficients also suggest relatively moderate individual contributions to the MANOVA effect from all bias scores. The correlations between the bias scores and the canonically derived scores for all methods are positive and with weak to moderate correlations (range $=0.244$ to 0.744 ).

\begin{tabular}{|l|l|l|l|}
\hline & \multicolumn{3}{|c|}{ Function 1 } \\
& Raw & Stand. & Struc. \\
\hline Kunos et al. & 0.063 & 0.753 & 0.585 \\
DiGangi et al. & -0.020 & -0.277 & 0.386 \\
İscan et al. & 0.036 & 0.496 & 0.587 \\
Passalacqua & -0.027 & -0.375 & 0.244 \\
Lovejoy et al. & -0.057 & -0.543 & 0.403 \\
Buckberry \& Chamberlain & 0.054 & 0.650 & 0.744 \\
Rougé-Maillart et al. & 0.035 & 0.397 & 0.680 \\
Suchey-Brooks & -0.019 & -0.182 & 0.375 \\
\hline
\end{tabular}

Table 80: Discriminant function coefficients associated with the MANOVA for individuals of European ancestry. Note: Raw $=$ unstandardized coefficients, Stand. $=$ standardized coefficients, Struc. $=$ structure coefficients.

To estimate the group centroids for the four stature groups, the sample bias scores were multiplied by the corresponding bias unstandardized discriminant function coefficients and then averaged across the samples. The means and standard deviations are listed in Table 81. An ANOVA with four levels in the IV was performed on the canonically derived bias score DV, and is not statistically significant $[\mathrm{F}(3,1.904)=2.012, p=0.111]$.

\begin{tabular}{|c|c|c|c|}
\hline & $\mathbf{n}$ & Mean & S.D. \\
\hline $1.20-1.60 \mathrm{~m}$ & 120 & 0.545 & 0.819 \\
$1.61-1.72 \mathrm{~m}$ & 152 & 0.659 & 1.011 \\
$1.73-1.80 \mathrm{~m}$ & 147 & 0.637 & 0.954 \\
$1.81-1.93 \mathrm{~m}$ & 78 & 0.887 & 1.138 \\
\hline
\end{tabular}

Table 81: Means and Standard Deviations for individuals of European ancestry canonically derived variables.

The Cohen's $d$ absolute values were as follows, from highest to lowest: Group 1 vs. Group $4=$ 0.352 ; Group 3 vs. Group $4=0.248$; Group 2 vs. Group $4=0.222$; Group 1 vs. Group $2=0.118$; Group 1 vs. Group $3=0.097$; and Group 2 vs. Group $3=0.023$. The differences between Groups 1 and 4, Groups 3 and 4, Groups 2 and 4, and Groups 1 and 2 are suggestive of a small effect size. There is no discernible difference between Groups 1 and 3 and Groups 2 and 3. 
Table 82 shows the results from Tukey's $b$ post-hoc tests for unequal sample sizes. There are no significant differences among the stature group bias scores for individuals of European ancestry using the Passalacqua method. The Kunos et al. and İşcan et al. methods significantly under-age individuals of European ancestry in Group 1 compared to those in Groups 2, 3, and 4. The DiGangi et al. method under-ages individuals of European ancestry in Group 1 compared to those in Group 4. The Lovejoy et al. method under-ages individuals of European ancestry in Groups 1 and 2 compared to those in Groups 3 and 4. The Buckberry and Chamberlain and Rougé-Maillart et al. methods significantly under-age individuals of European ancestry in Groups 1 compared to those in Groups 2 and 4, and individuals of European ancestry in Group 4 are over-aged compared to all other groups. The Suchey-Brooks method significantly over-ages individuals of European ancestry in Group 1 compared to those in Groups 1, 2, and 3. 


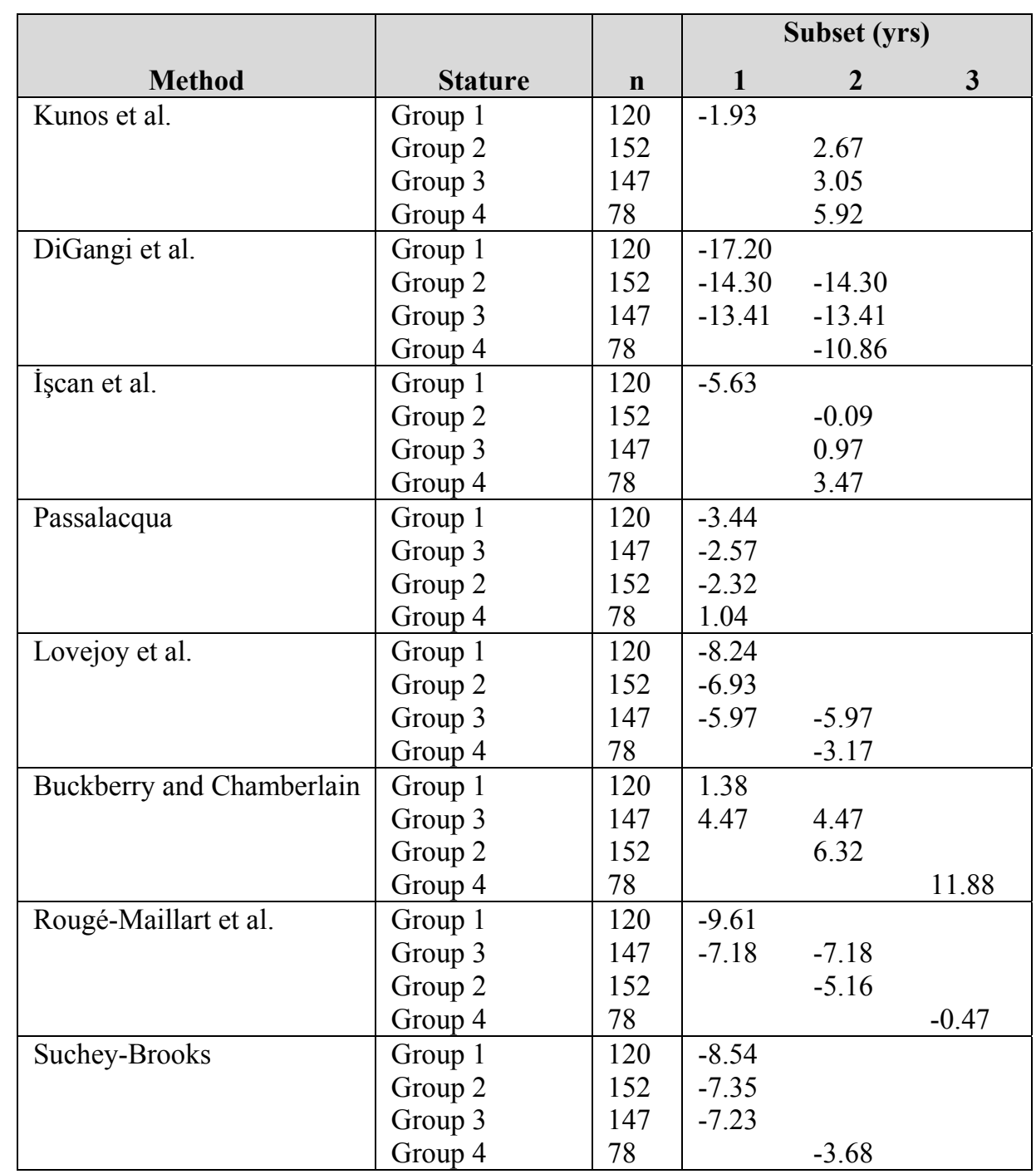

Table 82: Tukey's $b$ post-hoc test results for European bias scores separated by stature. Note: alpha level $=0.05$

A DFA was applied to assess how well stature group could be predicted from the bias scores of the eight age estimation methods. The cross-validated classification shows that only $39.6 \%$ of individuals of European ancestry are correctly classified into their stature group based on bias scores. individuals of European ancestry in Group 1 are classified correctly at a rate of 41.7\%, Group 2 at a rate of $48.7 \%$, Group 3 at a rate of $45.6 \%$, and Group 4 a rate of $11.5 \%$.

The discriminant scores from Function 1 and Function 2 were used to plot the sample on the discriminant dimensions. Group 4 is associated with the largest group centroid (0.525), Group 2 is associated with the next largest group centroid (0.172), Group 3 is associated with the second 
smallest centroid (-0.006) and, finally, Group 1 is associated with the smallest group centroid (0.552) (see Figure 39).

\section{Canonical Discriminant Functions}

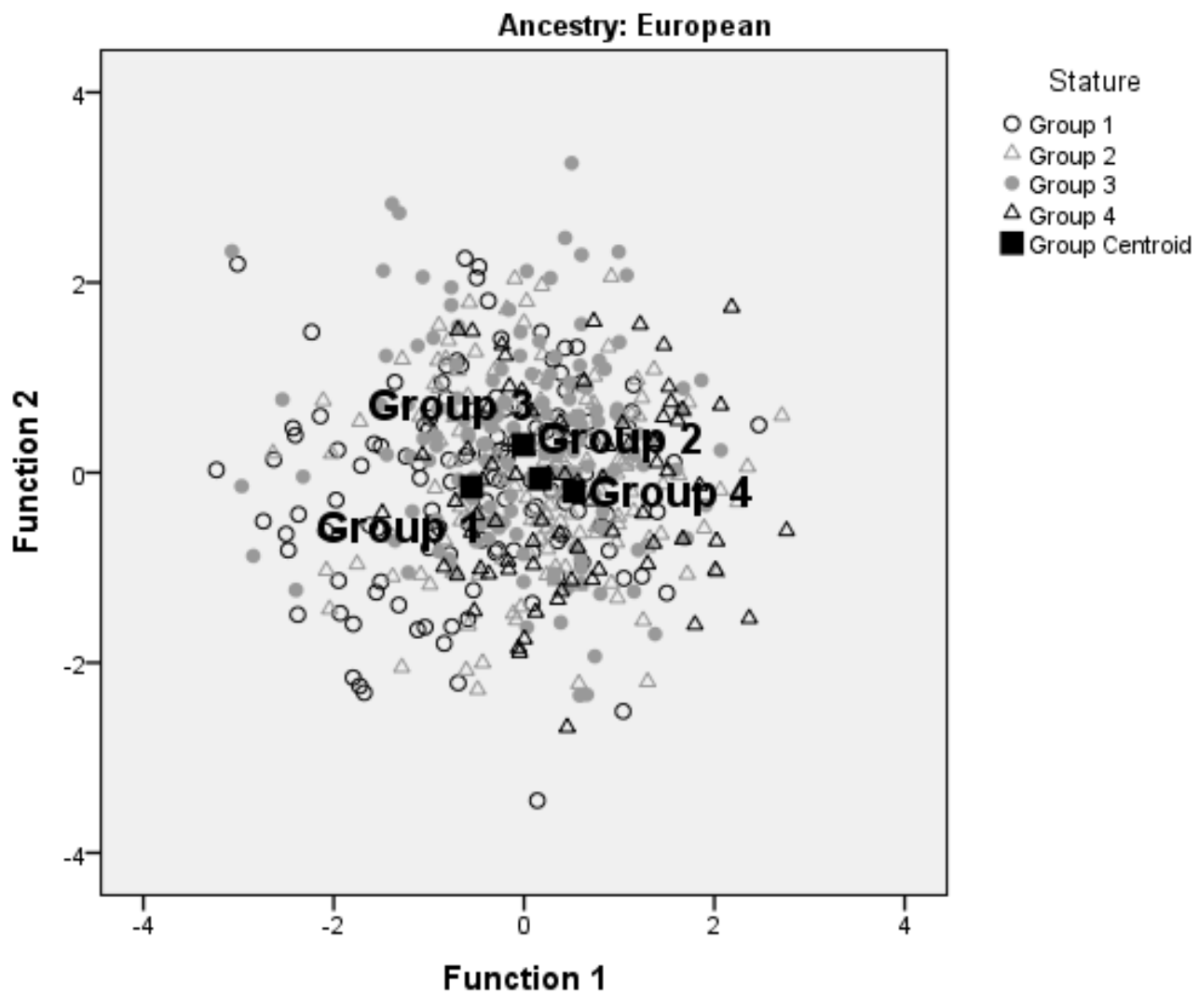

Figure 39: Canonically derived centroids for the stature groups for individuals of European ancestry.

\section{African Ancestry}

As shown in Table 64 of Section 3.3.2.2, the pattern of correlations observed among the bias scores are generally strong for a MANOVA. The Box's M value of 117.455 is associated with a $p$-value of 0.459 , which is not significant; therefore, the covariance between the stature groups were assumed to be equal for the purposes of the MANOVA.

A MANOVA was conducted to test the hypothesis that there would be differences between the stature group bias scores for each method. The MANOVA was not statistically significant, Pillai's Trace $=0.071, \mathrm{~F}(24,582)=0.587, p=0.942$. The multivariate effect size is estimated at 0.024 , which implies that $2.4 \%$ of the variance in the canonically derived DV is accounted for by 
the stature groups. As none of the functions were significant, there is no relationship between the stature groups and bias scores for individuals of African ancestry.

A DFA was applied to assess how well stature could be predicted from the bias scores of the eight age estimation methods. The cross-validated classification shows that only $31.5 \%$ of individuals of African ancestry are correctly classified into their stature group based on bias scores. individuals of African ancestry in Group 1 are classified correctly at a rate of $26.8 \%$, Group 2 at a rate of $22.6 \%$, Group 3 at a rate of $55.7 \%$, and Group 4 at a rate of $14.6 \%$.

\subsubsection{Results Summary}

\subsubsection{Accuracy}

For males and individuals of European ancestry, there are weak, statistically significant differences among the stature groups for accuracy scores. The MANOVA effect size is low at $2.4 \%$ and $3.6 \%$, respectively. For females and individuals of African ancestry, there are no statistically significant differences among the stature group accuracy scores. There are too few females in the tallest stature group to evaluate $(n=2)$.

Using the standardized coefficients from the MANOVA:

- Males have the highest contribution to the model from the DiGangi et al., Buckberry and Chamberlain, and Rougé-Maillart et al. methods, which have the most variance in their stature group accuracy scores. The Kunos et al. and Passalacqua methods have moderate contributions to the model, indicating that there are differences among the stature group accuracy scores, but they are not as substantial as those from the DiGangi et al., Buckberry and Chamberlain, and Rougé-Maillart et al. methods. The İşcan et al., Lovejoy et al., and Suchey-Brooks have little contribution to the model, and have the least amount of variance in their stature group accuracy scores (see Table 71).

- Individuals of European ancestry have the highest contribution to the model from the Buckberry and Chamberlain and Rougé-Maillart et al. methods, which have the greatest variance in the stature group accuracy scores. All other methods have moderate contributions to the model, indicating that there are differences among the stature group 
accuracy scores, but they are not as substantial as those from the Buckberry and Chamberlain and Rougé-Maillart et al. methods (see Table 53).

The differences in group centroid values generated from the MANOVA for the male and European accuracy scores are significant. Males and individuals of European ancestry in the short stature groups have significantly lower accuracy scores compared to males and individuals of European ancestry all other stature groups. Males in the second tallest group have significantly lower accuracy scores compared to males in the tallest stature group. Individuals of European ancestry in the second tallest stature group have significantly lower accuracy scores compared to males in the tallest stature group. The Cohen's $d$ values indicate the a large effect size between the shortest and tallest males and shortest and tallest Europeans, and a medium effect size between males in the shortest and second shortest groups. All other relationships have medium effect sizes. These results are corroborated by the discriminant function canonical analyses results: short males and short individuals of European ancestry have lower accuracy scores than tall males and tall individuals of European ancestry, while males and individuals of European ancestry in Groups 2 and 3 cluster between the two (see Figure 36 and Figure 38).

Table 83 shows the inaccuracy scores for males, females, individuals of European ancestry, and individuals of African ancestry separated by stature. There are no significant differences among the stature group accuracy scores for the Kunos et al. and Passalacqua methods. The DiGangi et al. and İşcan et al. methods accuracy scores for short individuals of European ancestry are significantly lower than tall individuals of European ancestry. The Lovejoy et al. and SucheyBrooks methods accuracy scores are lower for males in the shortest stature group compared to males in the tallest stature group. The Buckberry and Chamberlain and Rougé-Maillart et al. methods accuracy scores are lower for males and individuals of European ancestry in the tallest stature group compared to males and individuals of European ancestry in the shortest stature group. For females and individuals of African ancestry, there are no significant differences among the stature group accuracy scores. For all individuals, the DiGangi et al. method performs poorly (see Figure 40, Figure 41, Figure 42, and Figure 43). 


\begin{tabular}{|c|c|c|c|c|c|c|c|c|c|}
\hline \multicolumn{2}{|c|}{ Stature (m) } & $\begin{array}{l}\text { Kunos } \\
\text { et al. }\end{array}$ & $\begin{array}{c}\text { DiGangi } \\
\text { et al. }\end{array}$ & $\begin{array}{l}\text { İşcan } \\
\text { et al. }\end{array}$ & $\begin{array}{l}\text { Passal- } \\
\text { acqua }\end{array}$ & $\begin{array}{c}\text { Lovejoy } \\
\text { et al. }\end{array}$ & $\begin{array}{l}\text { Buckberry \& } \\
\text { Chamberlain }\end{array}$ & $\begin{array}{c}\text { Rougé-Maillart } \\
\text { et al. }\end{array}$ & $\begin{array}{l}\text { Suchey- } \\
\text { Brooks }\end{array}$ \\
\hline \multirow[t]{4}{*}{ Males } & $1.20-1.60$ & 10.20 & 15.69 & 11.44 & 10.65 & 10.31 & \begin{tabular}{|l|}
9.44 \\
\end{tabular} & 12.09 & 11.18 \\
\hline & $1.61-1.72$ & 10.50 & 14.95 & 10.83 & 12.12 & 8.98 & 12.30 & 9.93 & 9.84 \\
\hline & $1.73-1.80$ & 10.13 & 14.73 & 10.56 & 11.17 & 8.77 & 11.46 & 11.21 & 9.22 \\
\hline & $1.81-1.94$ & 10.10 & 13.70 & 10.34 & 10.47 & 7.36 & 12.94 & 8.71 & 7.82 \\
\hline \multirow[t]{3}{*}{ Females } & $1.20-1.60$ & 10.41 & 19.26 & 13.39 & 12.95 & 9.42 & 9.51 & 10.56 & 9.75 \\
\hline & $1.61-1.72$ & 11.28 & 16.01 & 11.08 & 11.89 & 8.00 & 11.89 & 9.12 & 8.77 \\
\hline & $1.73-1.80$ & 9.47 & 12.35 & 10.12 & 8.65 & 5.65 & 9.94 & 5.76 & 5.00 \\
\hline \multirow[t]{4}{*}{ European } & $1.20-1.60$ & 10.02 & 18.83 & 13.31 & 11.93 & 10.11 & 8.85 & \begin{tabular}{|l|}
12.29 \\
\end{tabular} & 10.51 \\
\hline & $1.61-1.72$ & 10.86 & 16.73 & 10.74 & 11.52 & 9.17 & 11.30 & 9.57 & 9.86 \\
\hline & $1.73-1.80$ & 9.29 & 15.27 & 10.17 & 11.22 & 8.88 & 10.78 & 11.40 & 9.56 \\
\hline & $1.81-1.94$ & 10.28 & 13.76 & 10.40 & 10.63 & 7.88 & 13.35 & 8.81 & 8.04 \\
\hline \multirow[t]{4}{*}{ African } & $1.20-1.60$ & 9.44 & 12.80 & 11.10 & 11.59 & 6.56 & 11.34 & 7.54 & 8.12 \\
\hline & $1.61-1.72$ & 11.62 & 10.87 & 10.72 & 14.13 & 6.70 & 14.60 & 9.87 & 8.23 \\
\hline & $1.73-1.80$ & 11.97 & 12.79 & 10.69 & 10.34 & 7.64 & 12.67 & 9.23 & 7.23 \\
\hline & $1.81-1.94$ & 9.85 & 13.38 & 10.75 & 9.90 & 6.38 & 12.25 & 8.33 & 7.54 \\
\hline
\end{tabular}

Table 83: Inaccuracy scores (in years) for each age-at-death estimation method separated by stature for males, females, individuals of European ancestry, and individuals of African ancestry. Significant differences are noted by boxes.

Discriminant function analyses show that accuracy scores are poor predictors of stature. Males in the shortest stature group and females in the tallest stature groups are never classified correctly. Tall individuals of European ancestry (2.6\%) and short individuals of African ancestry (4.9\%) have the lowest classification scores. Males in the second tallest stature group (79.6\%), females in the shortest stature group (78.3\%), individuals of European ancestry in the second shortest stature group (59.2\%), and individuals of African ancestry in the second tallest stature group (49.1\%) have the highest classification scores. These results indicate that accuracy scores cannot be used reliably to predict stature groups, except for males in the second tallest stature group and females in the shortest stature group. 


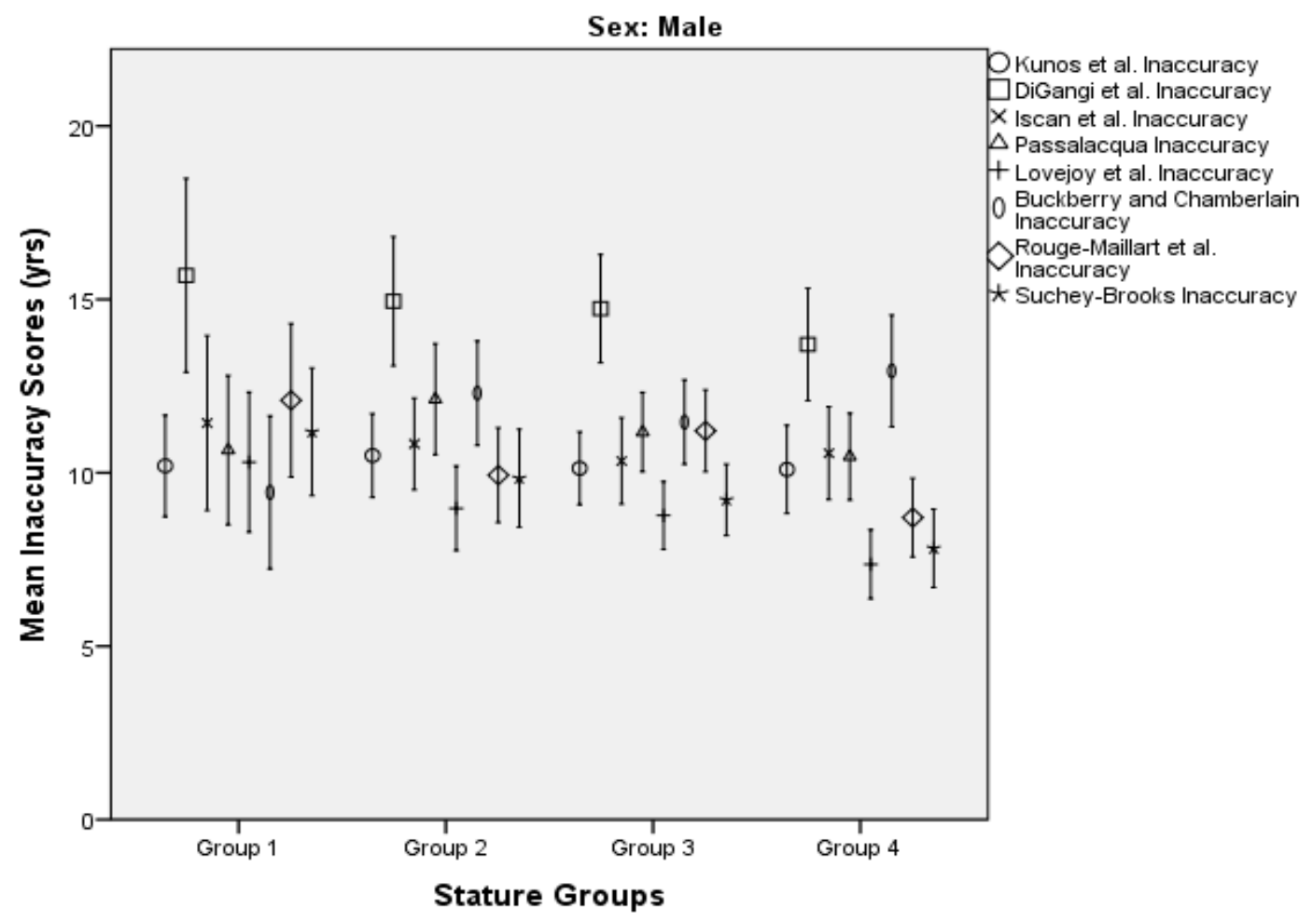

Error Bars: $95 \% \mathrm{Cl}$

Figure 40: Mean inaccuracy scores for the age estimation methods categorized by stature for males.

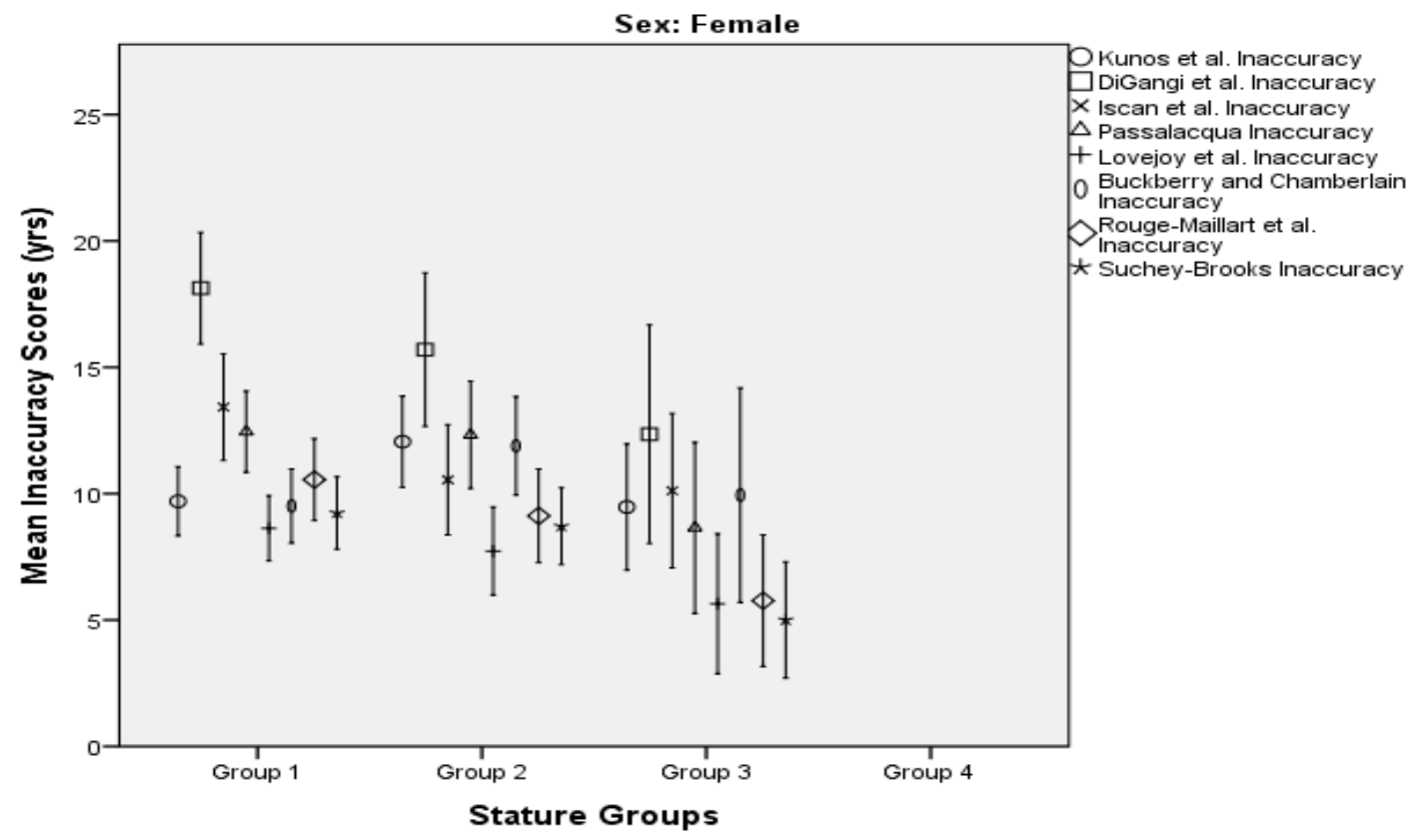

Error Bars: $95 \% \mathrm{Cl}$

Figure 41: Mean inaccuracy scores for the age estimation methods categorized by stature for females. 


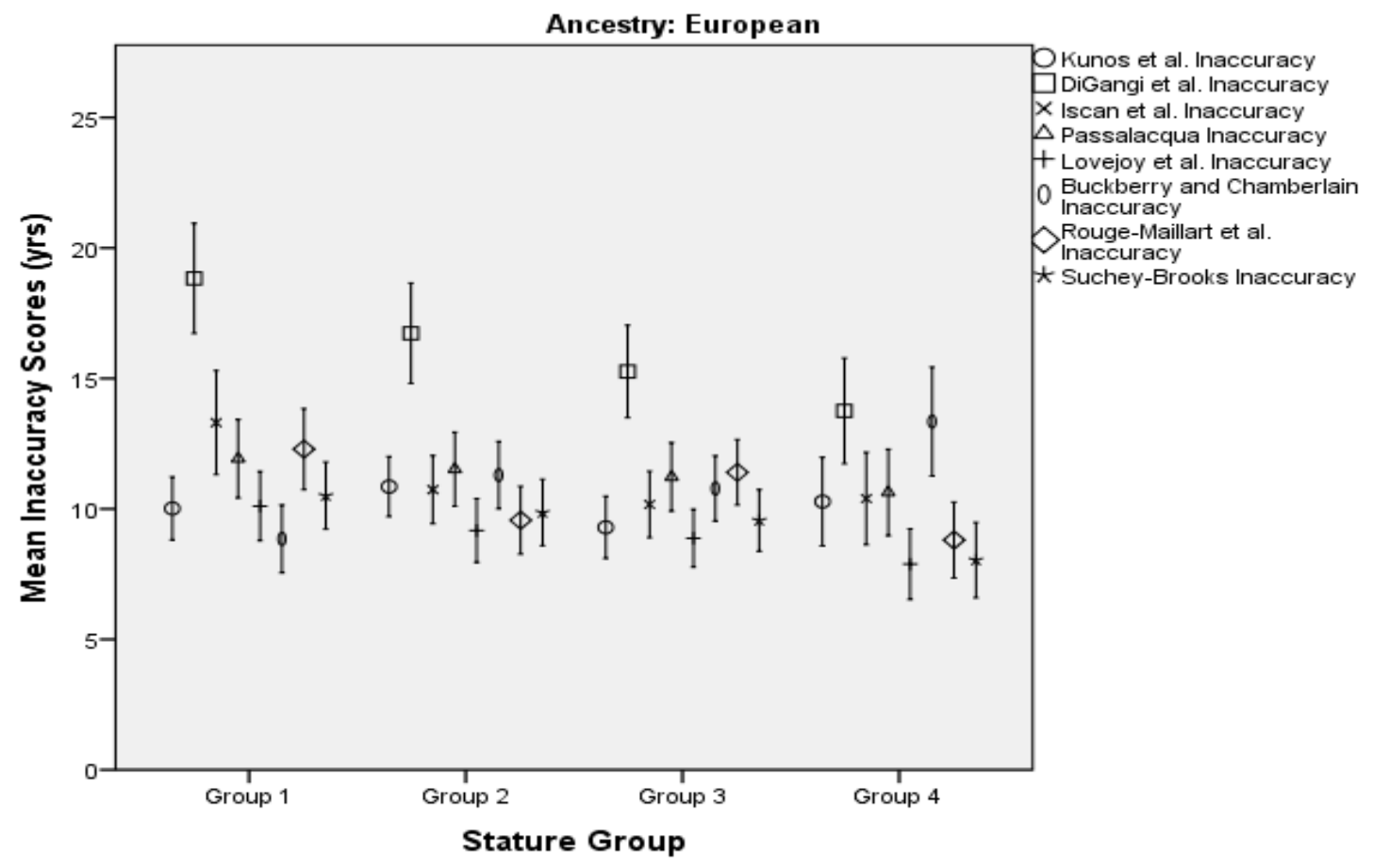

Error Bars: $95 \% \mathrm{Cl}$

Figure 42: Mean inaccuracy scores for the age estimation methods categorized by stature for individuals of European ancestry.

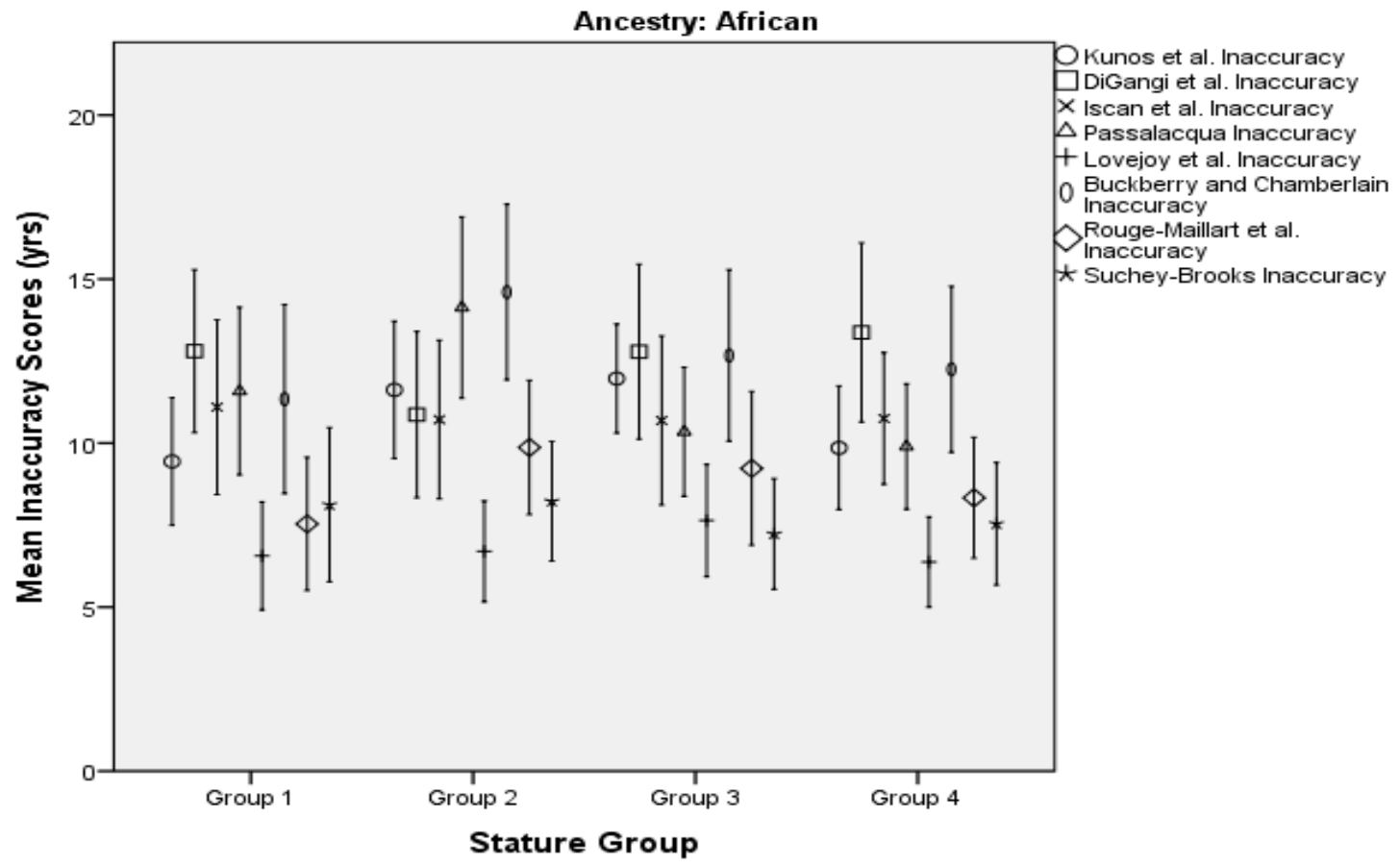

Error Bars: $95 \% \mathrm{Cl}$

Figure 43: Mean inaccuracy scores for the age estimation methods categorized by stature for individuals of African ancestry. 


\subsubsection{Bias}

For males and individuals of European ancestry, there are statistically significant differences among the stature groups for bias scores. The MANOVA effect sizes are weak at 3.9\% and $5.5 \%$, respectively. For females and individuals of European ancestry there are no statistically significant differences among the stature groups for bias scores.

Using the standardized coefficients from the MANOVA:

- Males have the highest contribution to the model from the DiGangi et al. and RougéMaillart et al. methods, which have the greatest amount of variance in their stature group bias scores. All other methods have moderate contributions to the model, indicating that there are differences among the stature group bias scores, but they are not as substantial as those from the DiGangi et al. and Rougé-Maillart et al. methods (see Table 74).

- Individuals of European ancestry have the highest contribution to the model from the İşcan et al., Buckberry and Chamberlain, and Kunos et al. methods, which have the greatest amount of variance in their stature group bias scores. All other methods have moderate contributions to the model, indicating that there are differences among the stature group bias scores, but they are not as substantial as those from the İşcan et al., Buckberry and Chamberlain, and Kunos et al. methods (see Table 54).

The differences in group centroid values generated from the MANOVA for the male bias scores are significant, but not for individuals of European ancestry. Short males are under-aged significantly compared to males in all other stature groups. The Cohen's $d$ values indicate these are large effect sizes between the shortest and tallest groups for males, and medium effect sizes for all other relationships. These results are corroborated by the discriminant function canonical analyses results: males and individuals of European ancestry in the short stature group are underaged more than males and individuals of European ancestry in the other stature categories, with the greatest difference between short and tall individuals (see Figure 37 and Figure 39).

Table 84 shows the bias scores for males, females, individuals of European ancestry, and individuals of African ancestry separated by stature. For the Kunos et al., İşcan et al., Lovejoy et al., Buckberry and Chamberlain, Rougé-Maillart et al. and Suchey-Brooks methods, males and 
individuals of European ancestry in the shortest stature group are under-aged significantly compared to males and individuals of European ancestry in the tallest stature group. For the DiGangi et al. and Passalacqua methods, individuals of European ancestry in the shortest stature group are under-aged significantly compared to individuals of European ancestry in the tallest stature group. For all individuals, the DiGangi et al. method performs poorly (see Figure 44, Figure 45, Figure 46, and Figure 47).

\begin{tabular}{|c|c|c|c|c|c|c|c|c|c|}
\hline \multicolumn{2}{|c|}{ Stature (m) } & $\begin{array}{c}\text { Kunos } \\
\text { et al. }\end{array}$ & $\begin{array}{c}\text { DiGangi } \\
\text { et al. }\end{array}$ & $\begin{array}{l}\text { İşcan } \\
\text { et al. }\end{array}$ & $\begin{array}{c}\text { Passal- } \\
\text { acqua }\end{array}$ & $\begin{array}{c}\text { Lovejoy } \\
\text { et al. }\end{array}$ & $\begin{array}{l}\text { Buckberry \& } \\
\text { Chamberlain }\end{array}$ & $\begin{array}{c}\text { Rougé-Maillart } \\
\text { et al. }\end{array}$ & $\begin{array}{l}\text { Suchey- } \\
\text { Brooks }\end{array}$ \\
\hline \multirow[t]{4}{*}{ Males } & $1.20-1.60$ & 0.49 & -12.24 & -3.65 & -2.95 & \begin{tabular}{|l|}
-7.62 \\
\end{tabular} & 3.40 & -8.67 & -9.18 \\
\hline & $1.61-1.72$ & 3.59 & -12.36 & 2.30 & -1.98 & -5.58 & 7.57 & -6.04 & -7.07 \\
\hline & $1.73-1.80$ & 3.68 & -12.54 & 0.70 & -1.13 & -5.18 & 5.27 & -3.96 & -6.69 \\
\hline & $1.81-1.94$ & 5.82 & -10.43 & 2.03 & 1.40 & -2.94 & 10.84 & -0.37 & -3.66 \\
\hline \multirow[t]{3}{*}{ Females } & $1.20-1.60$ & -0.42 & -16.60 & -4.61 & -2.04 & -6.52 & 2.98 & -6.59 & -7.27 \\
\hline & $1.61-1.72$ & 4.47 & -12.93 & -4.27 & 1.01 & -4.82 & 6.65 & -3.56 & -4.38 \\
\hline & $1.73-1.80$ & 4.41 & -12.35 & -3.41 & 0.18 & -2.12 & 7.82 & -2.00 & -1.12 \\
\hline \multirow[t]{4}{*}{ European } & $1.20-1.60$ & -1.93 & \begin{tabular}{|l|}
-17.20 \\
\end{tabular} & -5.63 & -3.44 & -8.24 & 1.38 & \begin{tabular}{|l|}
-9.61 \\
\end{tabular} & -8.54 \\
\hline & $1.61-1.72$ & 2.67 & -14.30 & -0.09 & -2.32 & -6.93 & 6.32 & -7.18 & -7.35 \\
\hline & $1.73-1.80$ & 3.05 & -13.41 & 0.97 & -2.57 & -5.97 & 4.47 & -5.16 & -7.23 \\
\hline & $1.81-1.94$ & 5.92 & -10.86 & 3.47 & 1.04 & -3.17 & 11.88 & -0.47 & -3.68 \\
\hline \multirow[t]{4}{*}{ African } & $1.20-1.60$ & 5.24 & -9.00 & -0.37 & 0.85 & -2.95 & 8.22 & -0.56 & -6.12 \\
\hline & $1.61-1.72$ & 7.85 & -7.58 & 0.11 & 3.11 & -0.66 & 9.89 & 0.02 & -2.57 \\
\hline & $1.73-1.80$ & 5.41 & -10.39 & -1.11 & 2.70 & -2.43 & 7.92 & -2.15 & -3.82 \\
\hline & $1.81-1.94$ & 5.90 & -9.58 & -0.75 & 1.98 & -2.50 & 9.21 & -0.04 & -3.83 \\
\hline
\end{tabular}

Table 84: Bias scores (in years) for each age-at-death estimation method separated by stature for males, females, individuals of European ancestry, and individuals of African ancestry. Significant differences are noted by boxes.

Discriminant function analyses show that bias scores are poor predictors of stature. Short males (3.6\%), tall females ( $0 \%$ ), tall individuals of European ancestry (11.5\%), and tall individuals of African ancestry (14.6\%) have the lowest classification scores. Males in the second tallest group (76.4\%), females in the shortest stature group (84.0\%), individuals of European ancestry in the second shortest stature group (48.7\%), and individuals of African ancestry in the second tallest stature group (55.7\%) have the highest classification scores. These results indicate that bias cannot be used reliably to predict stature groups, except for short females. 


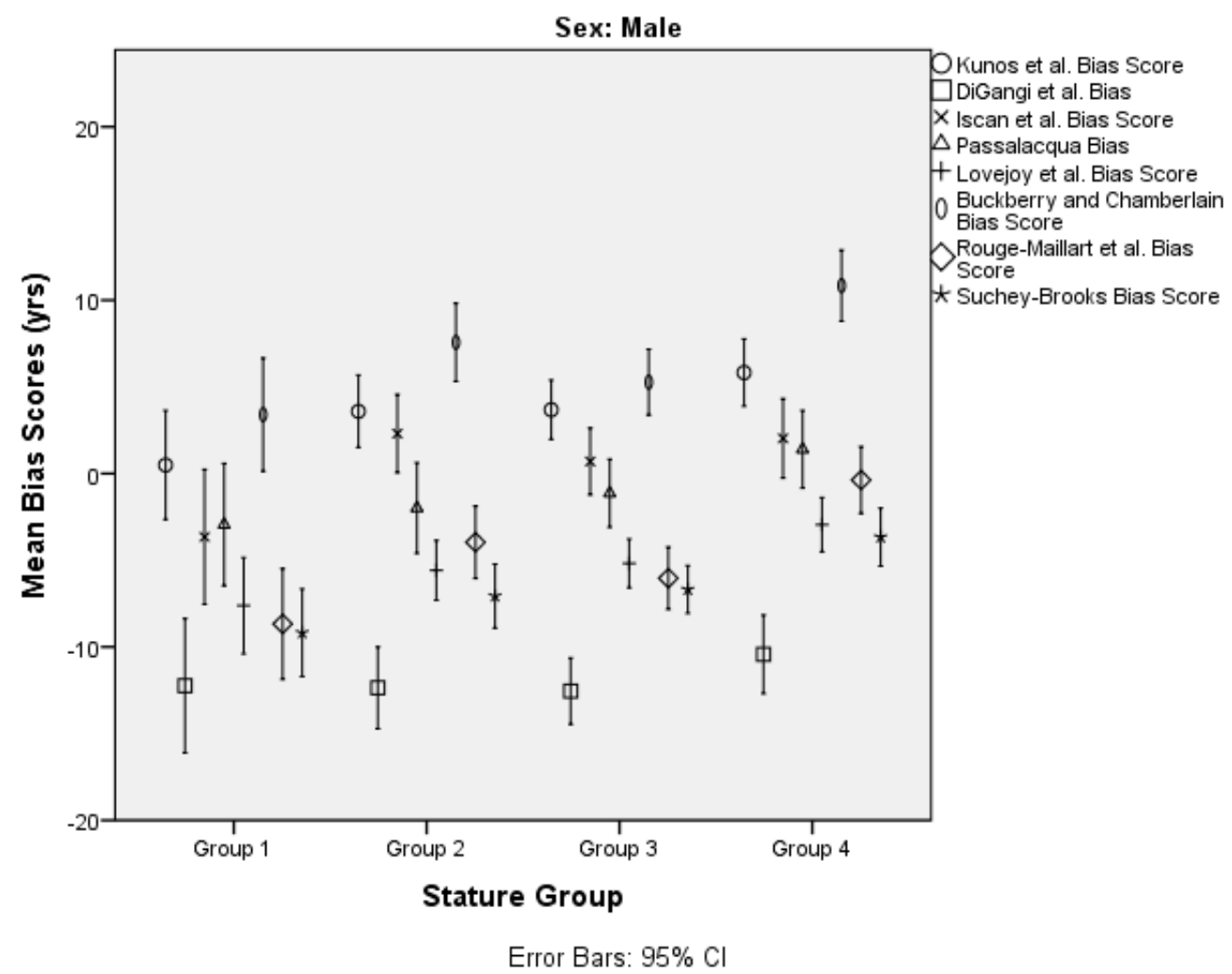

Figure 44: Mean bias scores for the age estimation methods categorized by stature for males.

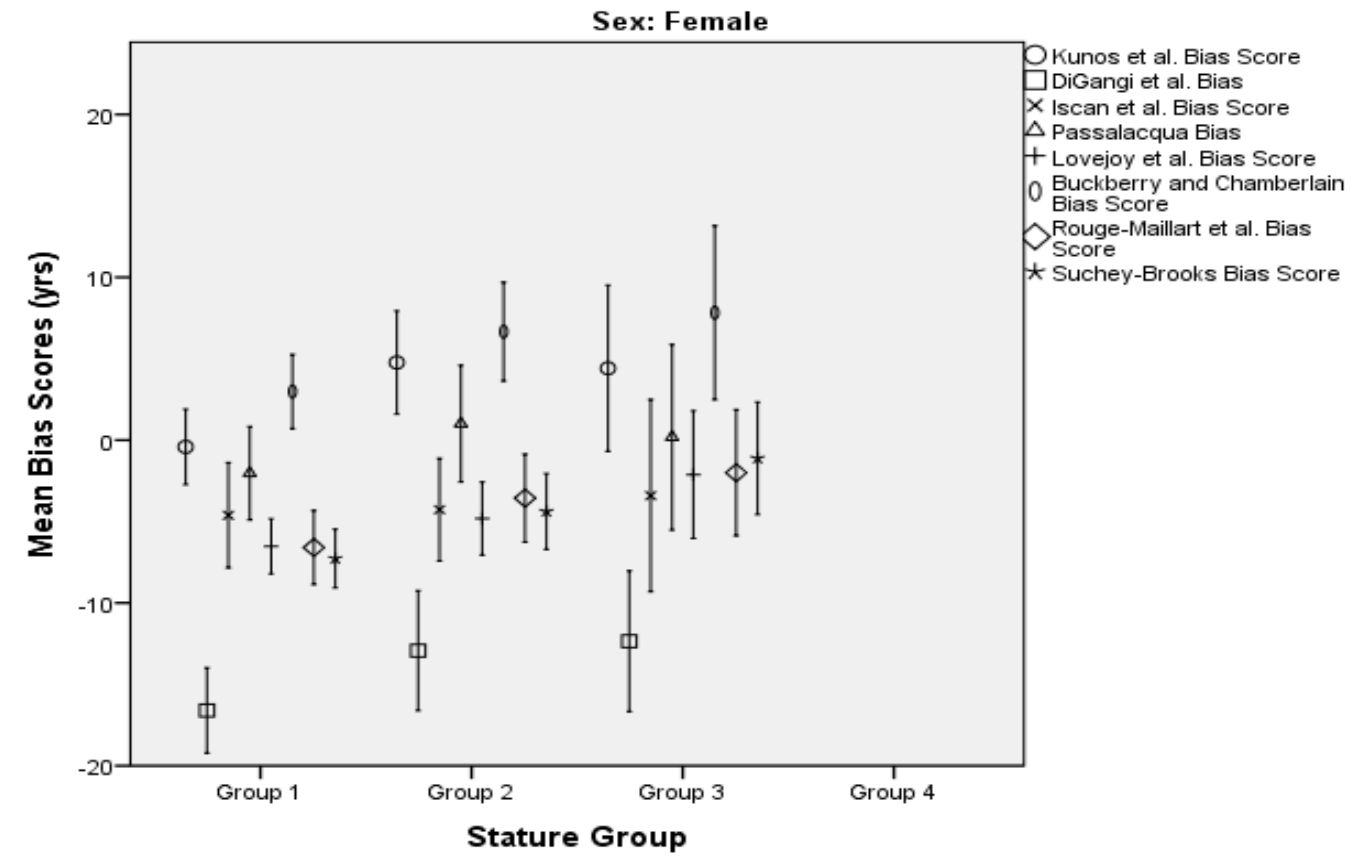

Error Bars: $95 \% \mathrm{Cl}$

Figure 45: Mean bias scores for the age estimation methods categorized by stature for females. 


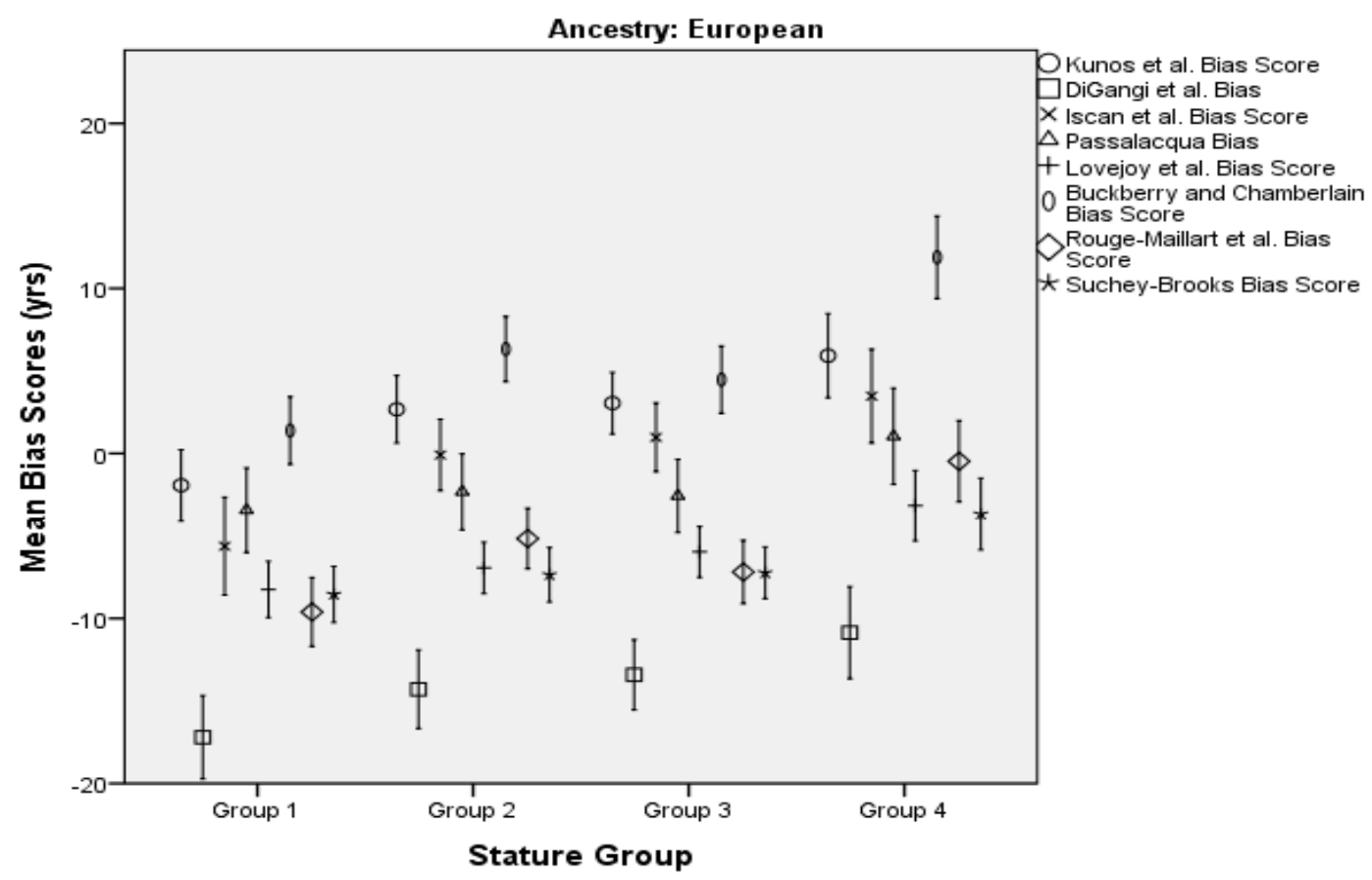

Error Bars: $95 \% \mathrm{Cl}$

Figure 46: Mean bias scores for the age estimation methods categorized by stature for individuals of European ancestry.

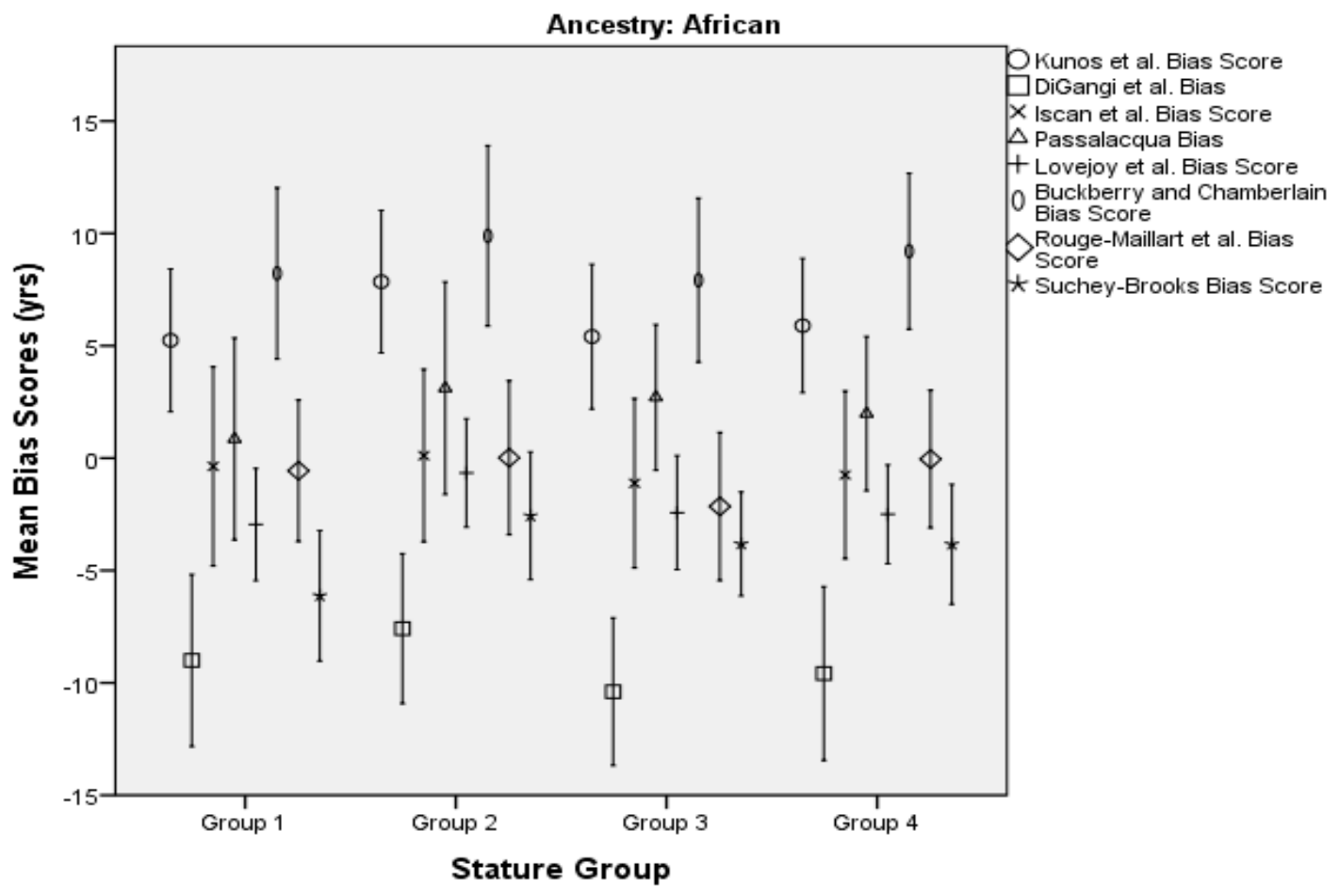

Error Bars: $95 \% \mathrm{Cl}$

Figure 47: Mean bias scores for the age estimation methods categorized by stature for individuals of African ancestry. 


\subsection{Research Question III: Does body mass influence skeletal age estimation?}

Figure 48 shows the sample distribution for body mass. The average body mass for this sample of 764 individuals is $65.66 \mathrm{~kg}$ (range $24.04 \mathrm{~kg}$ to $99.79 \mathrm{~kg}$ ), $68.89 \mathrm{~kg}$ for males (range $32.21 \mathrm{~kg}$ to $99.97 \mathrm{~kg}$ ), $57.88 \mathrm{~kg}$ for females (range $24.04 \mathrm{~kg}$ to $99.79 \mathrm{~kg}$ ), $66.66 \mathrm{~kg}$ for individuals of European ancestry (range $26.31 \mathrm{~kg}$ to $99.79 \mathrm{~kg}$ ), and $63.10 \mathrm{~kg}$ for individuals of African ancestry (range $24.04 \mathrm{~kg}$ to $99.79 \mathrm{~kg}$ ). A cluster analysis was used to assign individuals into equal, unbiased body mass groups, and the results are shown in Figure 48 and Table 85.

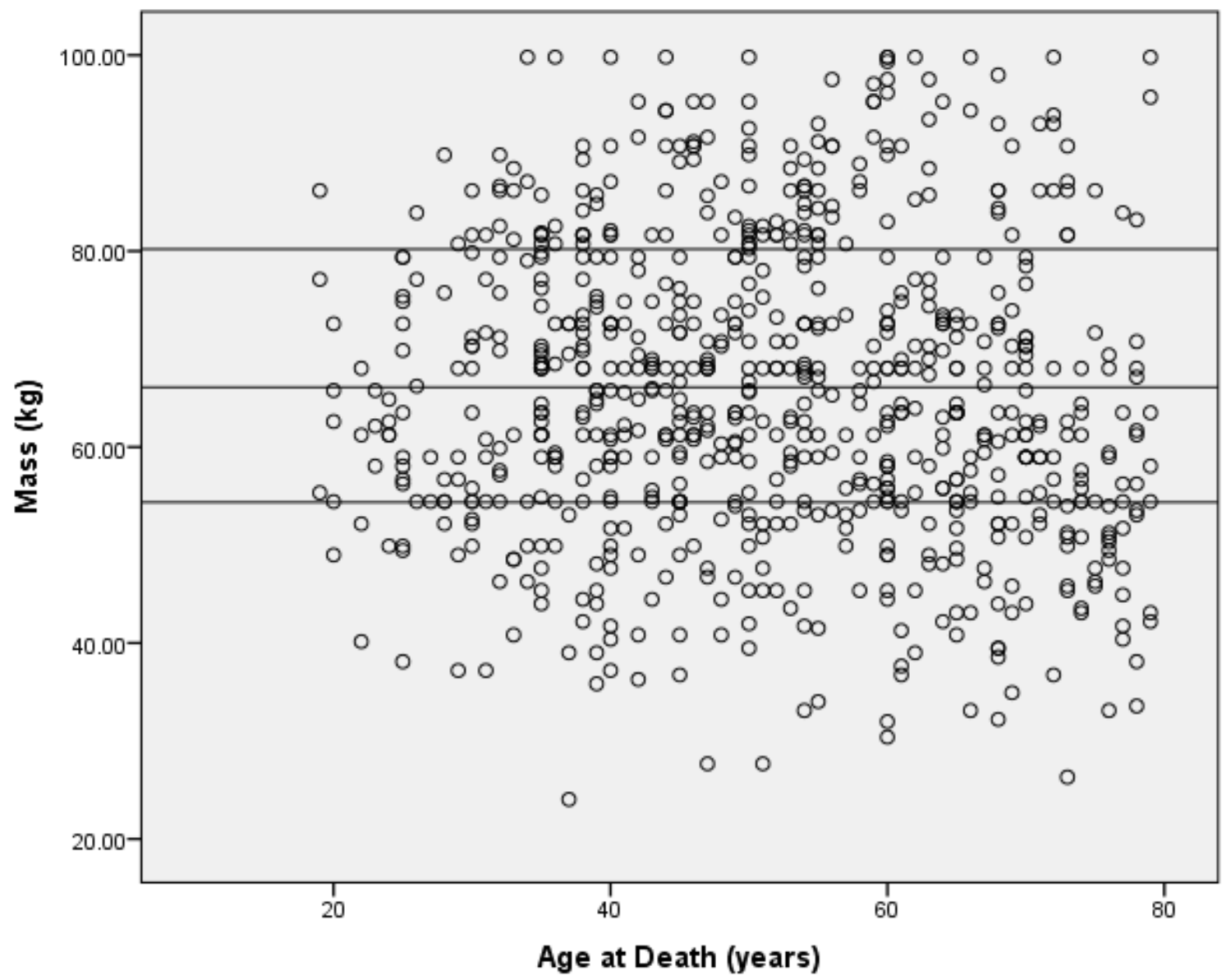

Figure 48: Body mass distribution of the sample by age at death. Lines demarcate cluster analysis cut-off points.

\begin{tabular}{|c|c|c|c|}
\hline Group & n & Mass (kg) & S.D. \\
\hline 1 & 166 & $24.04-54.37$ & 6.484 \\
2 & 240 & $54.38-66.10$ & 3.560 \\
3 & 202 & $66.11-80.20$ & 3.840 \\
4 & 156 & $80.21-99.79$ & 5.802 \\
\hline
\end{tabular}

Table 85: Body mass descriptive statistics. 
This section will test the influence of body mass on age at death estimations. The sample will be separated by sex and ancestry, and differences between accuracy and bias scores between body mass groups will be evaluated for each method using MANOVA and DFA.

\subsubsection{Sex}

\subsubsection{Accuracy}

\section{Males}

As shown in Table 36 of Section 3.3.1.1, the pattern of correlations observed among the accuracy scores are generally lower than ideal for a MANOVA. The Box's M value of 215.234 is associated with a $p$-value of $<0.001$, which is significant. A covariance matrix (Appendix 21) was run to ensure that no covariance values were more than four times greater than each other. Although there are instances where the covariance values are greater than four times their value, typically associated with the DiGangi et al. and Buckberry and Chamberlain methods, overall the covariance matrices between the body mass groups were assumed to be equal for the purposes of the MANOVA.

A MANOVA was conducted to test the hypothesis that there would be differences between body mass group accuracy scores for each method. The MANOVA was statistically significant with Pillai's Trace $=0.123, \mathrm{~F}(27,1479)=2.641, p<0.001$, indicating there are differences among the body mass group accuracy scores. The multivariate effect size is estimated at 0.041 , which implies that $4.1 \%$ of the variance in the canonically derived DV is accounted for by the body mass groups.

As the IV was associated with four levels, three eigenvalues and canonical correlations were extracted by the MANOVA. The first eigenvalue is 0.092 and accounts for $70.0 \%$ of the model variance. The canonical correlation associated with the first eigenvalue is 0.291 , where $8.5 \%$ of the variance in the discriminant function derived scores is accounted for by body mass. The second eigenvalue is 0.030 and accounts for $22.3 \%$ of the model variance with a corresponding canonical correlation of 0.169 . The third eigenvalue is 0.010 and accounts for $7.7 \%$ of the model variance and a corresponding canonical correlation of 0.100 , which is not statistically significant [Wilks $\Lambda=0.990, \mathrm{~F}(6,493)=0.832, p=0.546]$. 
The standardized discriminant function coefficients from the first eigenvalue were used to determine the statistical significance of the MANOVA, as it is the strongest. As seen in Table 86, the standardized discriminant function coefficients suggest that the four body mass groups were maximally differentiated by a canonical variate with significant weightings from the RougéMaillart et al. (0.486) and Suchey-Brooks (0.360) methods accuracy scores. The standardized coefficients suggest relatively moderate individual contributions to the MANOVA effect from all other accuracy scores. The correlations between the accuracy scores and the canonically derived scores for all methods are positive and moderate (range $=0.310$ to 0.692 ), except for the Buckberry and Chamberlain method, which has a weak negative correlation (-0.158).

\begin{tabular}{|l|l|l|l|}
\hline & \multicolumn{3}{|c|}{ Function 1 } \\
& Raw & Stand. & Struc. \\
\hline Kunos et al. & 0.046 & 0.323 & 0.321 \\
DiGangi et al. & 0.021 & 0.217 & 0.692 \\
İscan et al. & 0.040 & 0.324 & 0.535 \\
Passalacqua & 0.014 & 0.116 & 0.310 \\
Lovejoy et al. & -0.039 & -0.260 & 0.389 \\
Buckberry \& Chamberlain & -0.027 & -0.234 & -0.158 \\
Rougé-Maillart et al. & 0.064 & 0.486 & 0.688 \\
Suchey-Brooks & 0.055 & 0.390 & 0.686 \\
\hline
\end{tabular}

Table 86: Discriminant function coefficients associated with the MANOVA for males. Note: Raw $=$ unstandardized coefficients, Stand. = standardized coefficients, Struc. $=$ structure coefficients.

To estimate the group centroids for the body mass groups, the sample inaccuracy scores were multiplied by the corresponding inaccuracy unstandardized discriminant function coefficients and then averaged across the samples. The means and standard deviations are listed in Table 87. An ANOVA with four levels in the IV was performed on the canonically derived accuracy score $\mathrm{DV}$, and is significant $[\mathrm{F}(3,15.383)=15.342, p<0.001]$.

\begin{tabular}{|c|c|c|c|}
\hline & n & Mean & S.D. \\
\hline $24.04-54.37 \mathrm{~kg}$ & 75 & 2.222 & 1.356 \\
$54.38-66.10 \mathrm{~kg}$ & 151 & 2.205 & 1.100 \\
$66.11-80.20 \mathrm{~kg}$ & 156 & 1.601 & 0.771 \\
$80.21-99.79 \mathrm{~kg}$ & 120 & 1.601 & 0.868 \\
\hline
\end{tabular}

Table 87: Means and Standard Deviations for the male canonically derived variables.

The Cohen's $d$ absolute values were as follows, from highest to lowest: Group 1 vs. Group $3=$ 0.634; Group 2 vs. Group $3=0.625$; Group 1 vs. Group $4=0.605$; Group 2 vs. Group $4=0.605$; Group 1 vs. Group $2=0.016$; and Group 3 vs. Group $4=0.000$. The differences between males 
in Groups 1 and 3, Groups 2 and 3, Groups 1 and 4, and Groups 2 and 4 are suggestive of a medium effect size. There is no discernible difference between males in Groups 1 and 2, and Groups 3 and 4.

Table 88 shows the results from Tukey's $b$ post-hoc tests for unequal sample sizes. There are no significant differences among the body mass group accuracy scores for males using the Kunos et al., Lovejoy et al., and Buckberry and Chamberlain methods. The DiGangi et al. method inaccuracy scores for males in Group 2 are lower compared to males in Groups 3 and 4, while the inaccuracy scores for males in Group 1 are lower compared to males in Group 4. The RougéMaillart et al. method inaccuracy scores for males in Groups 1 and 2 are significantly higher compared to males in Groups 3 and 4. The İşcan et al. inaccuracy scores for males in Group 1 are significantly higher than those in Groups 3 and 4. The Passalacqua inaccuracy scores for males in Group 1 are significantly higher compared to those in Group 4. The Suchey-Brooks inaccuracy scores for males in Group 1 are significantly higher than those in Groups 3 and 4, and the inaccuracy scores for males in Group 2 are significantly higher than males in Group 3.

A DFA was applied to assess how well body mass could be predicted from the accuracy scores of the eight age estimation methods. The cross-validated classification shows that only $40.2 \%$ of males are correctly classified into their body mass group based on accuracy scores. Males in Group 1 are classified correctly at a rate of 5.3\%, Group 2 at a rate of $50.3 \%$, Group 3 at a rate of $60.9 \%$, and Group 4 at a rate of $22.5 \%$.

The discriminant scores from Function 1 and Function 2 were used to plot the sample on the discriminant dimensions. Group 1 is associated with the largest group centroid (0.347), Group 2 is associated with the next largest group centroid (0.329), Group 3 is associated with the second smallest centroid (-0.273) and, finally, Group 4 is associated with the smallest group centroid (0.275) (see Figure 49). 


\begin{tabular}{|c|c|c|c|c|c|}
\hline \multirow[b]{2}{*}{ Method } & \multirow[b]{2}{*}{ Body Mass } & \multirow[b]{2}{*}{$\mathbf{n}$} & \multicolumn{3}{|c|}{ Subset (yrs) } \\
\hline & & & 1 & 2 & 3 \\
\hline Kunos et al. & $\begin{array}{l}\text { Group } 4 \\
\text { Group } 3 \\
\text { Group } 2 \\
\text { Group 1 } \\
\end{array}$ & $\begin{array}{l}120 \\
156 \\
151 \\
75 \\
\end{array}$ & $\begin{array}{l}9.03 \\
10.07 \\
10.85 \\
11.23 \\
\end{array}$ & & \\
\hline DiGangi et al. & $\begin{array}{l}\text { Group } 4 \\
\text { Group } 3 \\
\text { Group } 1 \\
\text { Group } 2\end{array}$ & $\begin{array}{l}120 \\
156 \\
75 \\
151 \\
\end{array}$ & $\begin{array}{l}11.71 \\
13.47\end{array}$ & $\begin{array}{l}16.72 \\
17.14\end{array}$ & \\
\hline İşcan et al. & $\begin{array}{l}\text { Group } 3 \\
\text { Group } 4 \\
\text { Group } 2 \\
\text { Group 1 } \\
\end{array}$ & $\begin{array}{l}156 \\
120 \\
151 \\
75 \\
\end{array}$ & $\begin{array}{l}9.04 \\
10.02 \\
11.57\end{array}$ & $\begin{array}{l}11.57 \\
13.13 \\
\end{array}$ & \\
\hline Passalacqua & $\begin{array}{l}\text { Group } 4 \\
\text { Group } 3 \\
\text { Group } 2 \\
\text { Group } 1\end{array}$ & $\begin{array}{l}120 \\
156 \\
151 \\
75 \\
\end{array}$ & $\begin{array}{l}10.04 \\
10.87 \\
11.64\end{array}$ & $\begin{array}{l}10.87 \\
11.64 \\
12.80\end{array}$ & \\
\hline Lovejoy et al. & $\begin{array}{l}\text { Group } 4 \\
\text { Group } 3 \\
\text { Group } 2 \\
\text { Group 1 } \\
\end{array}$ & $\begin{array}{l}120 \\
156 \\
151 \\
75 \\
\end{array}$ & $\begin{array}{l}7.75 \\
8.07 \\
9.48 \\
9.59 \\
\end{array}$ & & \\
\hline Buckberry and Chamberlain & $\begin{array}{l}\text { Group } 1 \\
\text { Group } 2 \\
\text { Group } 4 \\
\text { Group } 3 \\
\end{array}$ & $\begin{array}{l}75 \\
151 \\
120 \\
156 \\
\end{array}$ & $\begin{array}{l}11.31 \\
11.39 \\
11.54 \\
12.71 \\
\end{array}$ & & \\
\hline Rougé-Maillart et al. & $\begin{array}{l}\text { Group } 4 \\
\text { Group } 3 \\
\text { Group } 1 \\
\text { Group } 2\end{array}$ & $\begin{array}{l}120 \\
156 \\
75 \\
151 \\
\end{array}$ & $\begin{array}{l}8.39 \\
9.31\end{array}$ & $\begin{array}{l}11.95 \\
12.20\end{array}$ & \\
\hline Suchey-Brooks & $\begin{array}{l}\text { Group } 3 \\
\text { Group } 4 \\
\text { Group } 2 \\
\text { Group } 1 \\
\end{array}$ & $\begin{array}{l}156 \\
120 \\
151 \\
75\end{array}$ & $\begin{array}{l}7.33 \\
8.65\end{array}$ & $\begin{array}{l}8.65 \\
10.27\end{array}$ & $\begin{array}{l}10.27 \\
11.21 \\
\end{array}$ \\
\hline
\end{tabular}

Table 88: Tukey's $b$ post-hoc test results for male accuracy scores separated by body mass. Note: alpha level $=\mathbf{0 . 0 5}$ 


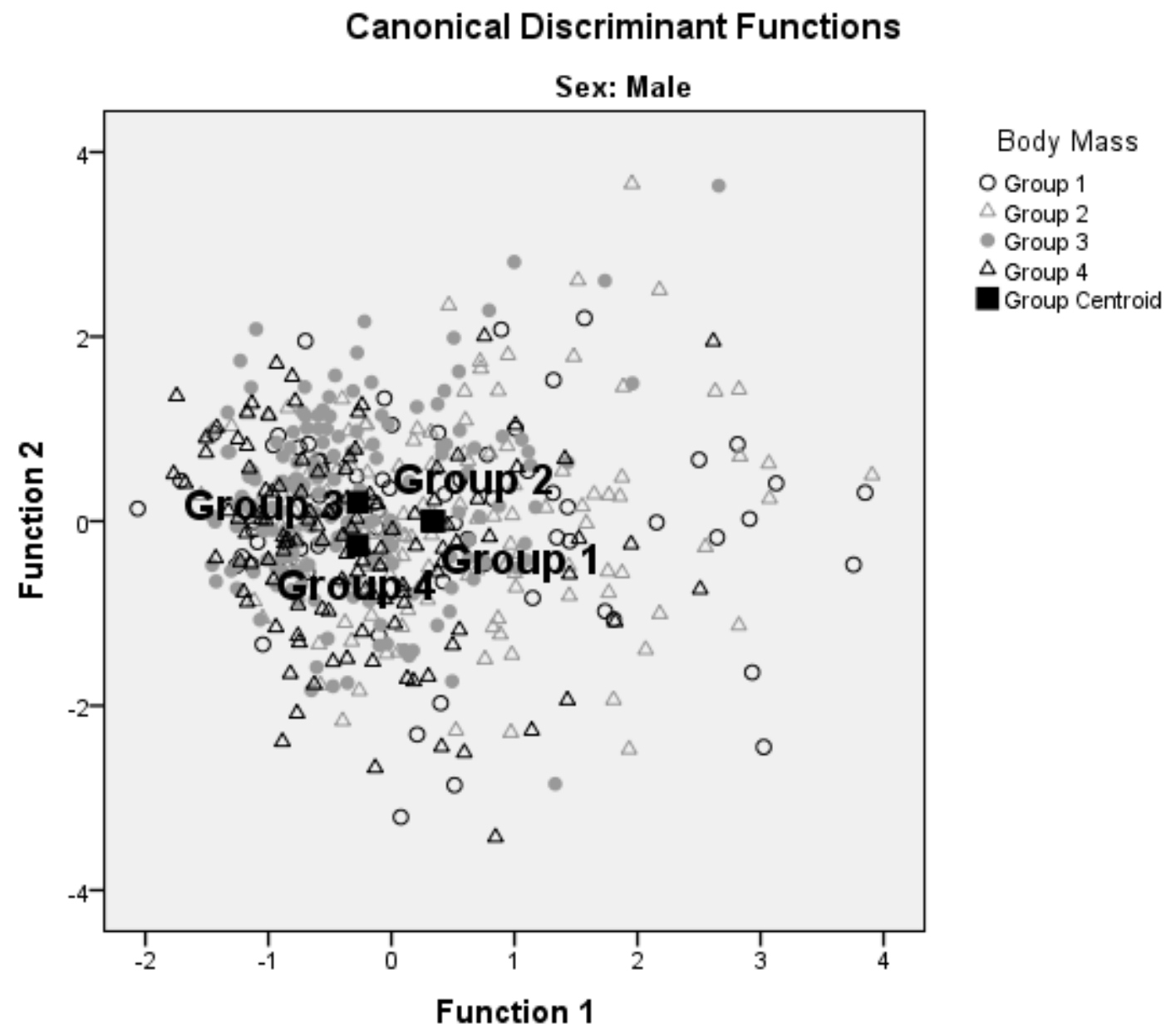

Figure 49: Canonically derived centroids for the body mass groups for males.

\section{Females}

As shown in Table 40 of Section 3.3.1.1, the pattern of correlations observed among the accuracy scores are generally lower than ideal for a MANOVA. The Box's M value of 197.613 is associated with a $p$-value $<0.001$, which is significant. A covariance matrix (Appendix 22) was run to ensure that no covariance values were more than four times greater than each other. Although there are instances where the covariance values are greater than four times their value, typically associated with the DiGangi et al. and Buckberry and Chamberlain methods, overall the covariance matrices between the body mass groups were assumed to be equal for the purposes of the MANOVA.

A MANOVA was conducted to test the hypothesis that there would be differences between body mass group accuracy scores for each method. The MANOVA effect was not statistically 
significant with Pillai's Trace $=0.138, \mathrm{~F}(24,567)=1.136, p=0.298$. The multivariate effect size is estimated at 0.046 , which implies that $4.6 \%$ of the variance in the canonically derived DV is accounted for by the body mass groups. As none of the functions were significant, there is no relationship between the body mass groups and accuracy scores for females.

A DFA was applied to assess how well body mass could be predicted from the accuracy scores of the eight age estimation methods. The cross-validated classification shows that only $46.5 \%$ of females are correctly classified into their body mass group based on accuracy scores. Females in Group 1 are classified correctly at a rate of $34.9 \%$, Group 2 at a rate of $81.0 \%$, and females in Groups 3 and 4 were never classified in the correct body mass group.

\subsubsection{Bias}

\section{Males}

As shown in Table 44 of Section 3.3.1.2, the pattern of correlations observed among the bias scores are generally strong for a MANOVA, and the Box's M value of 191.561 is associated with a $p$-value of $<0.001$, which is significant. A covariance matrix (Appendix 23) was run to ensure that no covariance values were more than four times greater than each other. Although there are instances where the covariance values are greater than four times their value, typically associated with the DiGangi et al. method, overall the covariance matrices between the body mass groups were assumed to be equal for the purposes of the MANOVA.

A MANOVA was conducted to test the hypothesis that there would be differences between body mass group bias scores for each method. The MANOVA was statistically significant with Pillai's Trace $=0.141, \mathrm{~F}(24,1479)=3.038, p<0.001$, indicating there are differences among the body

mass group accuracy scores. The multivariate effect size is estimated at 0.047 , which implies that $4.7 \%$ of the variance in the canonically derived DV is accounted for by the body mass groups.

As the IV was associated with four levels, three eigenvalues and canonical correlations were extracted by the MANOVA. The first eigenvalue is 0.089 and accounts for $58.9 \%$ of the model variance. The canonical correlation associated with the first eigenvalue is 0.286 , where $8.2 \%$ of the variance in the discriminant function derived scores is accounted for by body mass. The second eigenvalue is 0.058 and accounts for $38.0 \%$ of the model variance with a corresponding 
canonical correlation of 0.233 . The third eigenvalue is 0.005 and accounts for $3.1 \%$ of the model variance and a corresponding canonical correlation of 0.068 , which is not statistically significant [Wilks $\Lambda=0.995, \mathrm{~F}(6,493)=0.385, p=0.889]$.

The standardized discriminant function coefficients from the first eigenvalue were used to determine the statistical significance of the MANOVA, as it is the strongest. As seen in Table 89, the standardized discriminant function coefficients suggest that the body mass groups are maximally differentiated by a canonical variate with significant weightings from the İşcan et al. (0.850) and Kunos et al. (0.702) methods bias scores. The standardized coefficients suggest moderate individual contributions to the MANOVA effect from all bias scores, except the Rougé-Maillart et al. method, which has little contribution to the model (-0.007). The correlations between the bias scores and the canonically derived scores for all methods are positive and with weak to strong scores (range $=0.220$ to 0.888 ).

\begin{tabular}{|l|l|l|l|}
\hline & \multicolumn{3}{|c|}{ Function 1 } \\
& Raw & Stand. & Struc. \\
\hline Kunos et al. & 0.060 & 0.702 & 0.456 \\
DiGangi et al. & -0.022 & -0.294 & 0.220 \\
İşcan et al. & 0.065 & 0.850 & 0.888 \\
Passalacqua & 0.016 & 0.212 & 0.432 \\
Lovejoy et al. & -0.021 & -0.204 & 0.357 \\
Buckberry \& Chamberlain & 0.010 & 0.127 & 0.391 \\
Rougé-Maillart et al. & -0.001 & -0.007 & 0.381 \\
Suchey-Brooks & -0.030 & -0.294 & 0.257 \\
\hline
\end{tabular}

Table 89: Discriminant function coefficients associated with the MANOVA for males. Note: Raw $=$ unstandardized coefficients, Stand. = standardized coefficients, Struc. = structure coefficients.

To estimate the group centroids for the body mass groups, the sample bias scores were multiplied by the corresponding bias unstandardized discriminant function coefficients and then averaged across the samples. The means and standard deviations are listed in Table 90. An ANOVA with four levels in the IV was performed on the canonically derived bias score DV, and is statistically significant $[\mathrm{F}(3,14.706)=14.813, p<0.001]$.

\begin{tabular}{|c|c|c|c|}
\hline & n & Mean & S.D. \\
\hline $24.04-54.37 \mathrm{~kg}$ & 75 & 0.237 & 1.299 \\
$54.38-66.10 \mathrm{~kg}$ & 151 & 0.943 & 1.032 \\
$66.11-80.20 \mathrm{~kg}$ & 156 & 1.157 & 0.811 \\
$80.21-99.79 \mathrm{~kg}$ & 120 & 0.970 & 0.952 \\
\hline
\end{tabular}

Table 90: Means and Standard Deviations for the male canonically derived variables. 
The Cohen's $d$ absolute values were as follows, from highest to lowest: Group 1 vs. Group $3=$ 0.935; Group 1 vs. Group $4=0.704$; Group 1 vs. Group $2=0.667$; Group 3 vs. Group $4=0.200$; and Group 2 vs. Group $3=0.223$; and Group 2 vs. Group $4=0.027$. The differences between males in Groups 1 and 3, and Groups 1 and 4 are suggestive of a large effect size; differences between males in Groups 1 and 2 are suggestive of a medium effect size; the differences between males in Groups 3 and 4, and Groups 2 and 3 are suggestive of a small effect size. There is no discernible difference between males in Groups 2 and 4.

Table 91 shows the results from Tukey's $b$ post-hoc tests for unequal sample sizes. There are no differences among the body mass group bias scores using the DiGangi et al. method. Using the Kunos et al. method, males in Groups 1 and 2 are significantly under-aged compared to males in Groups 3 and 4. The İşcan et al. method under-ages males in Group 1 compared to males in Groups 2, 3, and 4. The Passalacqua, Rougé-Maillart et al. and Buckberry and Chamberlain methods show that males in Group 1 are under-aged significantly compared to males in Group 3 and 4. The Lovejoy et al. method under-ages males in Group 1 compared to Group 3. The Suchey-Brooks method under-ages males in Group 2 compared to males in Groups 3 and 4 and males in Group 1 are under-aged significantly under-aged compared to Group 4.

A DFA was applied to assess how well body mass could be predicted from the bias scores of the eight age estimation methods. The cross-validated classification shows that only $38.8 \%$ of males are correctly classified into their body mass group based on bias scores. Males in Group 1 are classified correctly at a rate of $26.7 \%$, Group 2 at a rate of $51.7 \%$, Group 3 at a rate of $49.4 \%$, and Group 4 at a rate of $16.7 \%$.

The discriminant scores from Function 1 and Function 2 were used to plot the sample on the discriminant dimensions. Group 3 is associated with the largest group centroid (0.248), Group 4 is associated with the next largest group centroid (0.059), Group 2 is associated with the second smallest centroid (0.033) and, finally, Group 1 is associated with the smallest group centroid (0.676) (see Figure 50). 


\begin{tabular}{|c|c|c|c|c|c|}
\hline \multirow[b]{2}{*}{ Method } & \multirow[b]{2}{*}{ Body Mass } & \multirow[b]{2}{*}{$\mathbf{n}$} & \multicolumn{3}{|c|}{ Subset (yrs) } \\
\hline & & & 1 & 2 & 3 \\
\hline \multirow[t]{4}{*}{ Kunos et al. } & Group 1 & 75 & 0.93 & & \\
\hline & Group 2 & 151 & 1.74 & & \\
\hline & Group 4 & 120 & & 5.34 & \\
\hline & Group 3 & 156 & & 6.11 & \\
\hline \multirow{4}{*}{ DiGangi et al. } & Group 2 & 151 & -14.54 & & \\
\hline & Group 1 & 75 & -13.12 & & \\
\hline & Group 4 & 120 & -10.34 & & \\
\hline & Group 3 & 156 & -10.08 & & \\
\hline \multirow[t]{4}{*}{ İşcan et al. } & Group 1 & 75 & -6.97 & & \\
\hline & Group 2 & 151 & & 1.57 & \\
\hline & Group 4 & 120 & & 1.75 & \\
\hline & Group 3 & 156 & & 3.62 & \\
\hline \multirow[t]{4}{*}{ Passalacqua } & Group 1 & 75 & -4.35 & & \\
\hline & Group 2 & 151 & -3.02 & -3.02 & \\
\hline & Group 4 & 120 & & 0.94 & \\
\hline & Group 3 & 156 & & 1.30 & \\
\hline \multirow[t]{4}{*}{ Lovejoy et al. } & Group 1 & 75 & -7.03 & & \\
\hline & Group 2 & 151 & -6.08 & -6.08 & \\
\hline & Group 4 & 120 & -4.03 & -4.03 & \\
\hline & Group 3 & 156 & & -3.72 & \\
\hline \multirow[t]{4}{*}{ Buckberry and Chamberlain } & Group 1 & 75 & 3.95 & & \\
\hline & Group 2 & 151 & 5.28 & 5.28 & \\
\hline & Group 3 & 156 & & 8.53 & \\
\hline & Group 4 & 120 & & 9.28 & \\
\hline \multirow[t]{4}{*}{ Rougé-Maillart et al. } & Group 1 & 75 & -7.15 & & \\
\hline & Group 2 & 151 & -5.96 & -5.96 & \\
\hline & Group 3 & 156 & & -2.81 & \\
\hline & Group 4 & 120 & & -2.71 & \\
\hline \multirow[t]{4}{*}{ Suchey-Brooks } & Group 2 & 151 & -9.28 & & \\
\hline & Group 1 & 75 & -7.36 & -7.36 & \\
\hline & Group 3 & 156 & & -4.90 & -4.90 \\
\hline & Group 4 & 120 & & & -3.77 \\
\hline
\end{tabular}

Table 91: Tukey's $b$ post-hoc test results for male bias scores separated by body mass. Note: alpha level $=\mathbf{0 . 0 5}$ 


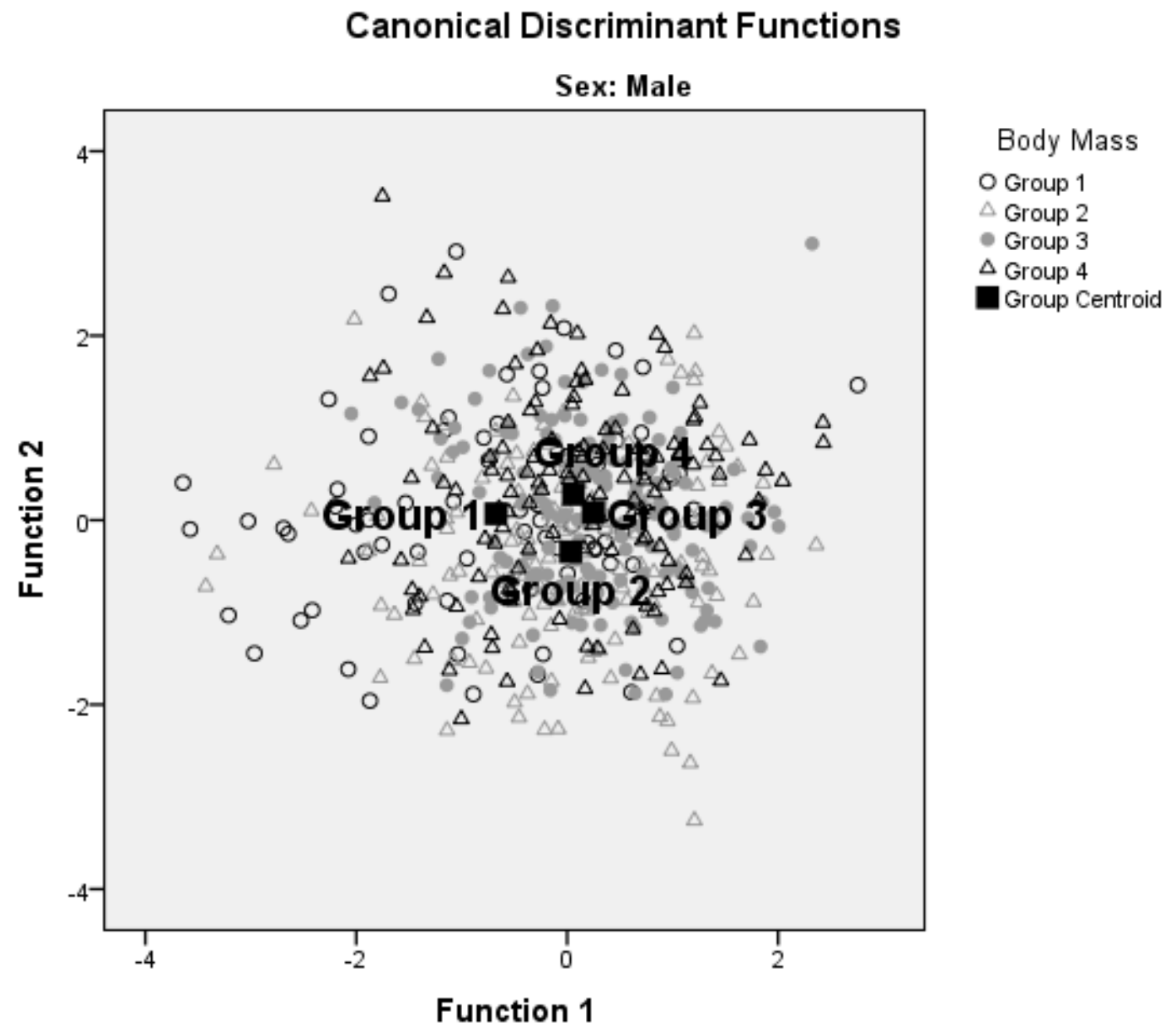

Figure 50: Canonically derived centroids for the body mass groups for males.

\section{Females}

As shown in Table 48 of Section 3.3.1.2, the pattern of correlations observed among the bias scores are generally strong for a MANOVA, and the Box's M value of 156.828 is associated with a $p$-value of 0.031 , which is not significant. The covariance between the body mass groups were assumed to be equal for the purposes of the MANOVA.

A MANOVA was conducted to test the hypothesis that there would be differences between body mass group bias scores for each method. The MANOVA effect was statistically significant with Pillai's Trace $=0.235, \mathrm{~F}(24,567)=2.004, p=0.003$, indicating there are differences among the body mass group bias scores. The multivariate effect size is estimated at 0.078 , which implies that $7.8 \%$ of the variance in the canonically derived DV is accounted for by the body mass groups. 
As the IV was associated with four levels, three eigenvalues and canonical correlations were extracted by the MANOVA. The first eigenvalue is 0.157 and accounts for $59.7 \%$ of the model variance. The canonical correlation associated with the first eigenvalue is 0.368 , where $13.5 \%$ of the variance in the discriminant function derived scores is accounted for by body mass. The second eigenvalue is 0.079 and accounts for $30.0 \%$ of the model variance with a corresponding canonical correlation of 0.270 . The third eigenvalue is 0.027 and accounts for $10.2 \%$ of the model variance and a corresponding canonical correlation of 0.162 , which is not statistically significant [Wilks $\Lambda=0.974, \mathrm{~F}(6,189)=0.846, p=0.536]$.

The standardized discriminant function coefficients from the first eigenvalues were used to determine the statistical significance of the MANOVA as it was the strongest. As seen in Table 92, the standardized discriminant function coefficients suggest that the body mass groups were maximally differentiated by a canonical variate with significant weightings from the DiGangi et al. (0.858), Kunos et al. (-0.770), and İşcan et al. (0.706) methods bias scores. The standardized coefficients suggest moderate to minimal individual contributions to the MANOVA effect from all other bias scores. The correlations between the bias scores and the canonically derived scores for all methods are positive with weak to strong correlations (range $=0.135$ to 0.773 ).

\begin{tabular}{|l|l|l|l|}
\hline & \multicolumn{3}{|c|}{ Function 1 } \\
& Raw & Stand. & Struc. \\
\hline Kunos et al. & -0.061 & -0.770 & 0.248 \\
DiGangi et al. & 0.061 & 0.858 & 0.400 \\
İşcan et al. & 0.049 & 0.706 & 0.773 \\
Passalacqua & -0.036 & -0.538 & 0.135 \\
Lovejoy et al. & 0.032 & 0.286 & 0.510 \\
Buckberry \& Chamberlain & -0.006 & -0.076 & 0.343 \\
Rougé-Maillart et al. & 0.031 & 0.347 & 0.536 \\
Suchey-Brooks & 0.021 & 0.198 & 0.349 \\
\hline
\end{tabular}

Table 92: Discriminant function coefficients associated with the MANOVA for females. Note: Raw $=$ unstandardized coefficients, Stand. $=$ standardized coefficients, Struc. $=$ structure coefficients.

To estimate the group centroids for the body mass groups, the sample bias scores were multiplied by the corresponding bias unstandardized discriminant function coefficients and then averaged across the samples. The means and standard deviations for each body mass group are in Table 93. An ANOVA with four levels in the IV was performed on the canonically derived bias score $\mathrm{DV}$, and is significant $[\mathrm{F}(3,10.270)=10.127, p<0.001]$. 


\begin{tabular}{|c|c|c|c|}
\hline & n & Mean & S.D. \\
\hline $24.04-54.37 \mathrm{~kg}$ & 69 & -2.195 & 1.097 \\
$54.38-66.10 \mathrm{~kg}$ & 84 & -1.302 & 0.899 \\
$66.11-80.20 \mathrm{~kg}$ & 29 & -1.583 & 0.893 \\
$80.21-99.79 \mathrm{~kg}$ & 16 & -1.812 & 1.307 \\
\hline
\end{tabular}

Table 93: Means and Standard Deviations for the female canonically derived variables.

The Cohen's $d$ absolute values were as follows, from highest to lowest: Group 1 vs. Group $3=$ 0.450; Group 1 vs. Group 4 = 0.337; Group 2 vs. Group 4 =0.244; Group 3 vs. Group 4 = 0.213; and Group 2 vs. Group $3=0.098$. The differences between individuals in Groups 1 and 3 and Groups 1 and 4 are suggestive of a medium effect size. The differences between individuals in Groups 2 and 4, and Groups 3 and 4 are suggestive of a small effect size. There is no discernible difference between individuals in Groups 2 and 3.

Table 94 shows the results from Tukey's $b$ post-hoc tests for unequal sample sizes. There are no significant differences among the body mass group bias scores for females using any method except the İşcan et al. method. The İşcan et al. method under-ages females in Group 1 significantly compared to females in Group 2.

A DFA was applied to assess how well body mass could be predicted from the bias scores of the eight age estimation methods. The cross-validated classification shows that only $53.0 \%$ of females are correctly classified into their body mass group based on bias scores. Females in Group 1 are classified correctly at a rate of $60.9 \%$, Group 2 at a rate of $72.6 \%$, Group 3 at a rate of $6.9 \%$, and no females in Group 4 are classified correctly.

The discriminant scores from Function 1 and Function 2 were used to plot the sample on the discriminant dimensions. Group 2 is associated with the largest group centroid (0.391), Group 3 is associated with the next largest group centroid (0.110), Group 4 is associated with the second smallest centroid (-0.116) and, finally, Group 1 is associated with the smallest group centroid (0.496) (see Figure 51). 


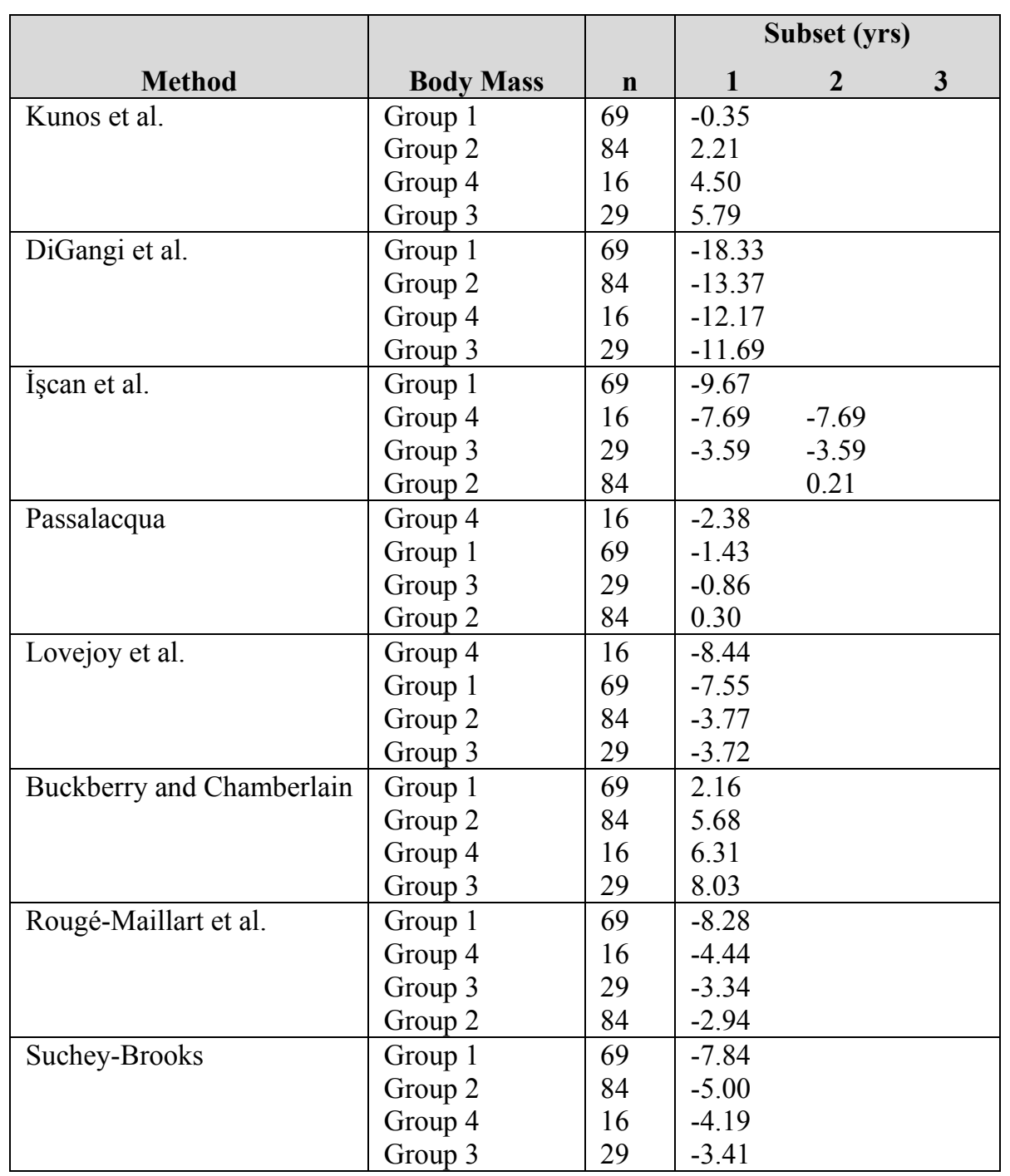

Table 94: Tukey's $b$ post-hoc test results for female bias scores separated by body mass. Note: alpha level $=\mathbf{0 . 0 5}$ 


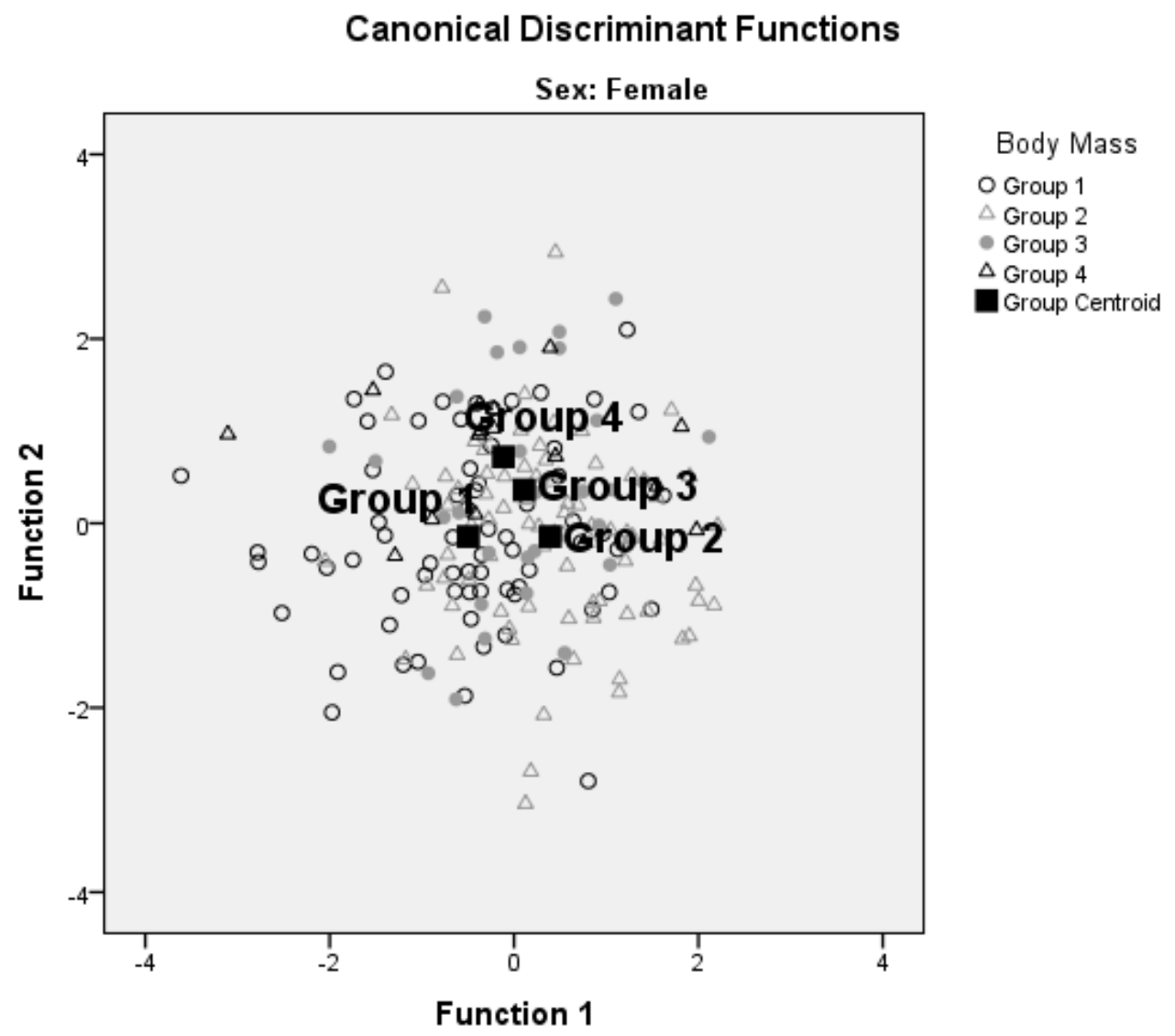

Figure 51: Canonically derived centroids for the body mass groups for females.

\subsubsection{Ancestry}

\subsubsection{Accuracy}

\section{European Ancestry}

As shown in Table 52 of Section 3.3.2.1, the pattern of correlations observed among the accuracy scores are generally lower than ideal for a MANOVA, and the Box's M value of 215.304 is associated with a $p$-value of $<0.001$, which is significant. A covariance matrix (Appendix 24) was run to ensure that no covariance values were more than four times greater than each other. Although there are instances where the covariance values are greater than four times their value, typically associated with the DiGangi et al., İşcan et al. and Buckberry and Chamberlain methods, overall the covariance matrices between the mass groups were assumed to be equal for the purposes of the MANOVA. 
A MANOVA was conducted to test the hypothesis that there would be differences between body mass group accuracy scores for each method. The MANOVA was statistically significant with Pillai's Trace $=0.126, \mathrm{~F}(24,1464)=2.675, p<0.001$, indicating there are differences among the body mass group accuracy scores. The multivariate effect size is estimated at 0.042 , which implies that $4.2 \%$ of the variance in the canonically derived DV is accounted for by the body mass groups.

As the IV was associated with four levels, three eigenvalues and canonical correlations were extracted by the MANOVA. The first eigenvalue is 0.097 and accounts for $71.2 \%$ of the model variance. The canonical correlation associated with the first eigenvalue is 0.297 , where $8.8 \%$ of the variance in the discriminant function derived scores is accounted for by body mass. The second eigenvalue is 0.034 and accounts for $24.7 \%$ of the model variance with a corresponding canonical correlation of 0.180 . The third eigenvalue is 0.006 and accounts for $4.1 \%$ of the model variance and a corresponding canonical correlation of 0.075 which is not statistically significant [Wilks $\Lambda=0.994, \mathrm{~F}(6,488)=0.456, p=0.841]$.

The standardized discriminant function coefficients from the first eigenvalue were used to determine the statistical significance of the MANOVA. As seen in Table 95, the standardized discriminant function coefficients suggest that the body mass groups were maximally differentiated by a canonical variate with significant weightings from the Rougé-Maillart et al. (0.529) and DiGangi et al. (0.454) methods accuracy scores. The standardized coefficients suggest relatively minimal individual contributions to the MANOVA effect from all accuracy scores. The correlations between the accuracy scores and the canonically derived scores for all methods are positive with weak to strong correlations (range $=0.165$ to 0.796 ), except for the Buckberry and Chamberlain method, which has a negative moderate correlation (-0.233). 


\begin{tabular}{|l|l|l|l|}
\hline & \multicolumn{3}{|c|}{ Function 1 } \\
& Raw & Stand. & Struc. \\
\hline Kunos et al. & 0.049 & 0.348 & 0.371 \\
DiGangi et al. & 0.042 & 0.454 & 0.796 \\
İşcan et al. & 0.020 & 0.172 & 0.427 \\
Passalacqua & -0.010 & -0.080 & 0.165 \\
Lovejoy et al. & -0.043 & -0.303 & 0.374 \\
Buckberry \& Chamberlain & -0.032 & -0.258 & -0.233 \\
Rougé-Maillart et al. & 0.068 & 0.529 & 0.695 \\
Suchey-Brooks & 0.031 & 0.226 & 0.596 \\
\hline
\end{tabular}

Table 95: Discriminant function coefficients associated with the MANOVA for individuals of European ancestry. Note: Raw = unstandardized coefficients, Stand. = standardized coefficients, Struc. $=$ structure coefficients.

To estimate the group centroids for the body mass groups, the sample inaccuracy scores were multiplied by the corresponding inaccuracy unstandardized discriminant function coefficients and then averaged across the samples. The means and standard deviations are listed in Table 96. An ANOVA with four levels in the IV was performed on the canonically derived accuracy score $\mathrm{DV}$, and is statistically significant $[\mathrm{F}(3,16.004)=15.867, p<0.001]$.

\begin{tabular}{|c|c|c|c|}
\hline & n & Mean & S.D. \\
\hline $24.04-54.37 \mathrm{~kg}$ & 100 & 1.982 & 1.299 \\
$54.38-66.10 \mathrm{~kg}$ & 150 & 1.798 & 1.075 \\
$66.11-80.20 \mathrm{~kg}$ & 139 & 1.335 & 0.814 \\
$80.21-99.79 \mathrm{~kg}$ & 108 & 1.190 & 0.791 \\
\hline
\end{tabular}

Table 96: Means and Standard Deviations for individuals of European ancestry canonically derived variables.

The Cohen's $d$ absolute values were as follows, from highest to lowest: Group 1 vs. Group $4=$ 0.778; Group 1 vs. Group 3 =0.642; Group 2 vs. Group $4=0.622$; Group 2 vs. Group $3=0.474$; Group 1 vs. Group $2=0.171$; and Group 3 vs. Group 4 =0.162. The differences between Group 1 and 4 are suggestive of a large effect size; the differences between Groups 1 and 3, Groups 2 and 4, and Groups 2 and 3 are suggestive of a medium effect size; and the differences between Groups 1 and 2, and Groups 3 and 4 are suggestive of a small effect size.

Table 97 shows the results from Tukey's $b$ post-hoc tests for unequal sample sizes. There are no significant differences among the body mass group accuracy scores for individuals of European ancestry using the Passalacqua, Lovejoy et al., and Buckberry and Chamberlain methods. The Kunos et al. method Group 1 inaccuracy scores are significantly higher than the Group 4 scores. The DiGangi et al. method inaccuracy scores for Group 1 are significantly higher than Groups 3 and 4, and Group 1 have higher inaccuracy scores compared to Group 3. The İşcan et al. Group 1 
inaccuracy scores are significantly higher than Group 3. The Rougé-Maillart et al. method Groups 1 and 2 inaccuracy scores are significantly higher compared to Groups 3 and 4 . The Suchey-Brooks method Group 2 inaccuracy scores are significantly higher than Groups 3 and 4, and the inaccuracy scores from Group 1 are significantly higher than Group 3.

\begin{tabular}{|c|c|c|c|c|c|}
\hline \multirow[b]{2}{*}{ Method } & \multirow[b]{2}{*}{ Body Mass } & \multirow[b]{2}{*}{$\mathbf{n}$} & \multicolumn{3}{|c|}{ Subset (yrs) } \\
\hline & & & 1 & 2 & 3 \\
\hline \multirow[t]{4}{*}{ Kunos et al. } & Group 4 & 108 & 8.82 & & \\
\hline & Group 3 & 139 & 9.75 & 9.75 & \\
\hline & Group 2 & 150 & 10.61 & 10.61 & \\
\hline & Group 1 & 100 & & 11.20 & \\
\hline \multirow[t]{4}{*}{ DiGangi et al. } & Group 4 & 108 & 12.23 & & \\
\hline & Group 3 & 139 & 15.04 & 15.04 & \\
\hline & Group 2 & 150 & & 18.21 & 18.21 \\
\hline & Group 1 & 100 & & & 19.78 \\
\hline \multirow[t]{4}{*}{ İşcan et al. } & Group 3 & 139 & 9.63 & & \\
\hline & Group 4 & 108 & 10.37 & 10.37 & \\
\hline & Group 2 & 150 & 11.92 & 11.92 & \\
\hline & Group 1 & 100 & & 12.88 & \\
\hline \multirow[t]{4}{*}{ Passalacqua } & Group 4 & 108 & 10.41 & & \\
\hline & Group 3 & 139 & 11.46 & & \\
\hline & Group 1 & 100 & 11.67 & & \\
\hline & Group 2 & 150 & 11.85 & & \\
\hline \multirow[t]{4}{*}{ Lovejoy et al. } & Group 3 & 139 & 8.25 & & \\
\hline & Group 4 & 108 & 8.31 & & \\
\hline & Group 2 & 150 & 9.79 & & \\
\hline & Group 1 & 100 & 10.14 & & \\
\hline \multirow[t]{4}{*}{ Buckberry and Chamberlain } & Group 1 & 100 & 9.66 & & \\
\hline & Group 2 & 150 & 10.81 & & \\
\hline & Group 4 & 108 & 11.26 & & \\
\hline & Group 3 & 139 & 11.53 & & \\
\hline \multirow[t]{4}{*}{ Rougé-Maillart et al. } & Group 4 & 108 & 8.55 & & \\
\hline & Group 3 & 139 & 9.37 & & \\
\hline & Group 2 & 150 & & 11.93 & \\
\hline & Group 1 & 100 & & 12.77 & \\
\hline \multirow[t]{4}{*}{ Suchey-Brooks } & Group 3 & 139 & 7.53 & & \\
\hline & Group 4 & 108 & 8.95 & 8.95 & \\
\hline & Group 1 & 100 & & 10.91 & 10.91 \\
\hline & Group 2 & 150 & & & 11.25 \\
\hline
\end{tabular}

Table 97: Tukey's $b$ post-hoc test results for European accuracy scores separated by body mass. Note: alpha level $=0.05$

A DFA was applied to assess how well body mass could be predicted from the accuracy scores of the eight age estimation methods. The cross-validated classification shows that only $34.6 \%$ of individuals of European ancestry are correctly classified into their body mass group based on accuracy scores. individuals of European ancestry in Group 1 are classified correctly at a rate of $10.0 \%$, Group 2 at a rate of $44.7 \%$, Group 3 at a rate of $51.1 \%$, and Group 4 at a rate of $22.2 \%$. 
The discriminant scores from Function 1 and Function 2 were used to plot the sample on the discriminant dimensions. Group 1 is associated with the largest group centroid (0.407), Group 2 is associated with the next largest group centroid (0.224), the Group 3 is associated with the second smallest centroid (-0.238) and, finally, Group 4 is associated with the smallest group centroid (-0.381) (see Figure 52).

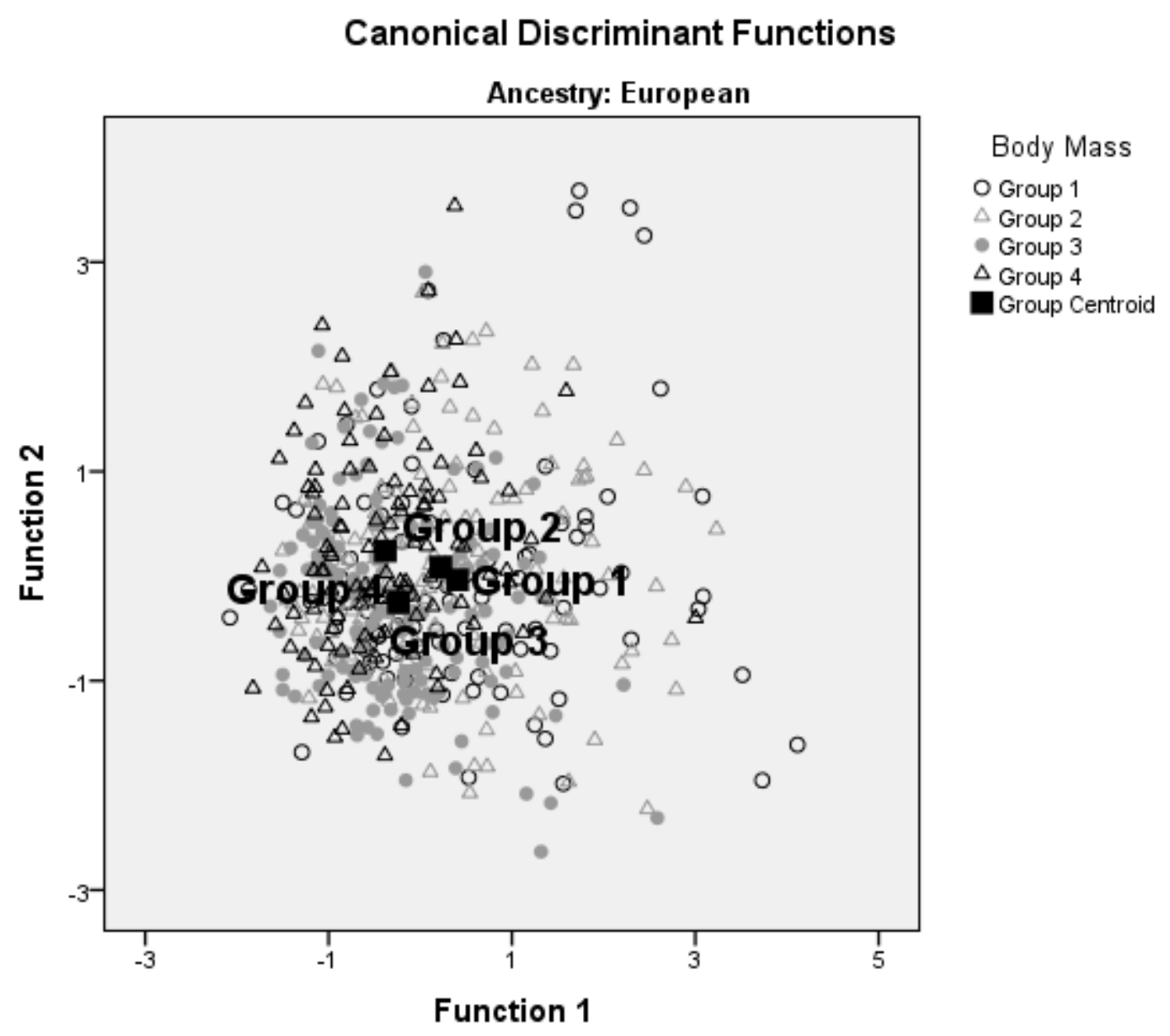

Figure 52: Canonically derived centroids for the body mass groups for individuals of European ancestry.

\section{African Ancestry}

As shown in Table 56 of Section 3.3.2.1, the pattern of correlations observed among the accuracy scores are generally lower than ideal for a MANOVA, and the Box's M value of 190.046 is associated with a $p$-value of $<0.001$, which is significant. A covariance matrix (Appendix 25) was run to ensure that no covariance values were more than four times greater than each other. Although there are instances where the covariance values are greater than four 
times their value, typically associated with the Kunos et al. and Buckberry and Chamberlain methods, overall the covariance matrices between the mass groups were assumed to be equal for the purposes of the MANOVA.

A MANOVA was conducted to test the hypothesis that there would be differences between body mass group accuracy scores for each method. The MANOVA was not statistically significant with Pillai's Trace $=0.172, \mathrm{~F}(24,582)=1.475, p=0.068$. The multivariate effect size is estimated at 0.057 , which implies that $5.7 \%$ of the variance in the canonically derived dependent variable is accounted for by the body mass groups. As none of the functions are significant, there is no relationship between the body mass groups and accuracy scores for individuals of African ancestry.

A DFA was applied to assess how well body mass could be predicted from the accuracy scores of the eight age estimation methods. The cross-validated classification shows that only $47.3 \%$ of individuals of African ancestry are correctly classified into their body mass group based on accuracy scores. individuals of African ancestry in Group 1 are classified correctly at a rate of $27.3 \%$, Group 2 at a rate of $87.1 \%$, Group 3 at a rate of $21.7 \%$. No individuals of African ancestry in Group 4 were classified correctly into their body mass group.

\subsubsection{Bias}

\section{European Ancestry}

As shown in Table 60 of Section 3.3.2.2, the pattern of correlations observed among the bias scores are generally strong for a MANOVA. The Box's M value of 168.123 is associated with a $p$-value of $<0.001$, which is significant. A covariance matrix (Appendix 26) was run to ensure that no covariance values were more than four times greater than each other. Although there are instances where the covariance values are greater than four times their value, typically associated with the İşcan et al. method, overall the covariance matrices between the body mass groups were assumed to be equal for the purposes of the MANOVA.

A MANOVA was conducted to test the hypothesis that there would be differences between body mass group bias scores for each method. The MANOVA was statistically significant with Pillai's Trace $=0.170, \mathrm{~F}(24,1464)=3.662, p<0.001$, indicating there are differences among the body 
mass bias scores. The multivariate effect size is estimated at 0.057 , which implies that $5.7 \%$ of the variance in the canonically derived DV is accounted for by the body mass groups.

As the IV was associated with four levels, three eigenvalues and canonical correlations were extracted by the MANOVA. The first eigenvalue is 0.116 and accounts for $62.5 \%$ of the model variance. The canonical correlation associated with the first eigenvalue is 0.322 , where $10.4 \%$ of the variance in the discriminant function derived scores is accounted for by body mass. The second eigenvalue is 0.061 and accounts for $32.8 \%$ of the model variance with a corresponding canonical correlation of 0.240 . The third eigenvalue is 0.009 and accounts for $4.7 \%$ of the model variance and a corresponding canonical correlation of 0.093 , which is not statistically significant [Wilks $\Lambda=0.991, \mathrm{~F}(6,488)=0.707, p=0.644]$.

The standardized discriminant function coefficients from the first eigenvalue were used to determine the statistical significance of the MANOVA, as it is the strongest. As seen in Table 98, the standardized discriminant function coefficients suggest that the body mass groups are maximally differentiated by a canonical variate with significant weighting from the İşcan et al. (0.715) and the Kunos et al. (0.545) methods bias scores. The standardized coefficients suggest relatively minimal to moderate individual contributions to the MANOVA effect from all other bias scores. The correlations between the bias scores and the canonically derived scores for all methods are positive and with moderate to strong correlations (range $=0.372$ to 0.744 ).

\begin{tabular}{|l|l|l|l|}
\hline & \multicolumn{3}{|c|}{ Function 1 } \\
& Raw & Stand. & Struc. \\
\hline Kunos et al. & 0.046 & 0.545 & 0.692 \\
DiGangi et al. & 0.019 & 0.251 & 0.601 \\
İşcan et al. & 0.052 & 0.715 & 0.744 \\
Passalacqua & -0.012 & -0.170 & 0.372 \\
Lovejoy et al. & -0.034 & 0.325 & 0.449 \\
Buckberry \& Chamberlain & 0.027 & 0.324 & 0.603 \\
Rougé-Maillart et al. & 0.006 & 0.070 & 0.571 \\
Suchey-Brooks & -0.021 & -0.208 & 0.410 \\
\hline
\end{tabular}

Table 98: Discriminant function coefficients associated with the MANOVA for individuals of European ancestry. Note: Raw $=$ unstandardized coefficients, Stand. = standardized coefficients, Struc. $=$ structure coefficients.

To estimate the group centroids for the body mass groups, the sample bias scores were multiplied by the corresponding bias unstandardized discriminant function coefficients and then averaged across the samples. The means and standard deviations are listed in Table 99. An ANOVA with 
four levels in the IV was performed on the canonically derived bias score DV, and is statistically significant $[\mathrm{F}(3,19.456)=19.047, p<0.001]$.

\begin{tabular}{|c|c|c|c|}
\hline & n & Mean & S.D. \\
\hline $24.04-54.37 \mathrm{~kg}$ & 100 & -0.352 & 1.248 \\
$54.38-66.10 \mathrm{~kg}$ & 150 & 0.336 & 1.007 \\
$66.11-80.20 \mathrm{~kg}$ & 139 & 0.588 & 0.904 \\
$80.21-99.79 \mathrm{~kg}$ & 108 & 0.494 & 0.895 \\
\hline
\end{tabular}

Table 99: Means and Standard Deviations for individuals of European ancestry canonically derived variables.

The Cohen's $d$ absolute values were as follows, from highest to lowest: Group 1 vs. Group $3=$ 0.918; Group 1 vs. Group $4=0.820$; Group 1 vs. Group $2=0.684$; Group 2 vs. Group $3=0.258$; Group 2 vs. Group $4=0.161$; and Group 3 vs. Group $4=0.099$. The differences between individuals of European ancestry in Groups 1 and 3, and Groups 1 and 4 are suggestive of a large effect size, the differences between individuals of European ancestry in Groups 1 and 2 are suggestive of a medium effect size, and the differences between individuals of European ancestry in Groups 2 and 3, Groups 2 and 4, and Groups 3 and 4 are suggestive of a small effect size.

Table 100 shows the results from Tukey's $b$ post-hoc tests for unequal sample sizes. The Kunos et al., DiGangi et al., and Suchey-Brooks methods significantly under-age individuals of European ancestry in Groups 1 and 2 compared to individuals of European ancestry in Groups 3 and 4. The İşcan et al. method under-ages individuals of European ancestry in Group 1 compared to individuals of European ancestry in Groups 2, 3, and 4. The Passalacqua and Lovejoy et al. methods significantly under-age individuals of European ancestry in Group 1 compared to individuals of European ancestry in Groups 3 and 4. The Buckberry and Chamberlain and Rougé-Maillart et al. methods significantly under-age individuals of European ancestry in Group 1 compared to individuals of European ancestry in Groups 3 and 4, and individuals of European ancestry in Group 2 are significantly under-aged compared to individuals of European ancestry in Group 4. 


\begin{tabular}{|c|c|c|c|c|c|}
\hline \multirow[b]{2}{*}{ Method } & \multirow[b]{2}{*}{ Body Mass } & \multirow[b]{2}{*}{ n } & \multicolumn{3}{|c|}{ Subset (yrs) } \\
\hline & & & 1 & 2 & 3 \\
\hline Kunos et al. & $\begin{array}{l}\text { Group 1 } \\
\text { Group } 2 \\
\text { Group } 4 \\
\text { Group } 3\end{array}$ & $\begin{array}{l}100 \\
150 \\
108 \\
139\end{array}$ & $\begin{array}{l}-2.50 \\
0.52\end{array}$ & $\begin{array}{l}4.99 \\
5.16\end{array}$ & \\
\hline DiGangi et al. & $\begin{array}{l}\text { Group 1 } \\
\text { Group } 2 \\
\text { Group } 3 \\
\text { Group } 4 \\
\end{array}$ & $\begin{array}{l}100 \\
150 \\
139 \\
108 \\
\end{array}$ & $\begin{array}{l}-19.70 \\
-16.47\end{array}$ & $\begin{array}{l}-11.45 \\
-10.40\end{array}$ & \\
\hline İşcan et al. & $\begin{array}{l}\text { Group } 1 \\
\text { Group } 4 \\
\text { Group } 2 \\
\text { Group } 3 \\
\end{array}$ & $\begin{array}{l}100 \\
108 \\
150 \\
139 \\
\end{array}$ & -7.62 & $\begin{array}{l}-0.37 \\
1.36 \\
2.32\end{array}$ & \\
\hline Passalacqua & $\begin{array}{l}\text { Group 1 } \\
\text { Group } 2 \\
\text { Group } 3 \\
\text { Group } 4 \\
\end{array}$ & $\begin{array}{l}100 \\
150 \\
139 \\
108 \\
\end{array}$ & $\begin{array}{l}-4.99 \\
-3.53\end{array}$ & $\begin{array}{l}-3.53 \\
-0.37 \\
0.15\end{array}$ & \\
\hline Lovejoy et al. & $\begin{array}{l}\text { Group } 1 \\
\text { Group } 2 \\
\text { Group } 4 \\
\text { Group } 3 \\
\end{array}$ & $\begin{array}{l}100 \\
150 \\
108 \\
139 \\
\end{array}$ & $\begin{array}{l}-8.86 \\
-7.07\end{array}$ & $\begin{array}{l}-7.07 \\
-5.15 \\
-4.78 \\
\end{array}$ & \\
\hline Buckberry and Chamberlain & $\begin{array}{l}\text { Group 1 } \\
\text { Group } 2 \\
\text { Group } 3 \\
\text { Group } 4 \\
\end{array}$ & $\begin{array}{l}100 \\
150 \\
139 \\
108 \\
\end{array}$ & $\begin{array}{l}1.08 \\
4.26\end{array}$ & $\begin{array}{l}4.26 \\
7.31\end{array}$ & $\begin{array}{l}7.31 \\
8.78 \\
\end{array}$ \\
\hline Rougé-Maillart et al. & $\begin{array}{l}\text { Group } 1 \\
\text { Group } 2 \\
\text { Group } 3 \\
\text { Group } 4 \\
\end{array}$ & $\begin{array}{l}100 \\
150 \\
139 \\
108 \\
\end{array}$ & $\begin{array}{l}-10.11 \\
-7.01\end{array}$ & $\begin{array}{l}-7.01 \\
-4.40\end{array}$ & $\begin{array}{r}-4.40 \\
-3.31 \\
\end{array}$ \\
\hline Suchey-Brooks & $\begin{array}{l}\text { Group } 2 \\
\text { Group 1 } \\
\text { Group } 3 \\
\text { Group 4 } \\
\end{array}$ & $\begin{array}{l}150 \\
100 \\
139 \\
108 \\
\end{array}$ & $\begin{array}{l}-9.46 \\
-8.79\end{array}$ & $\begin{array}{l}-5.23 \\
-4.32 \\
\end{array}$ & \\
\hline
\end{tabular}

Table 100: Tukey's $b$ post-hoc test results for European bias scores separated by body mass. Note: alpha level $=0.05$

A DFA was applied to assess how well body mass could be predicted from the bias scores of the eight age estimation methods. The cross-validated classification shows that only $38.8 \%$ of individuals of European ancestry are correctly classified into their body mass group based on bias scores. individuals of European ancestry in Group 1 are classified correctly at a rate of $41.0 \%$, Group 2 at a rate of $48.0 \%$, Group 3 at a rate of $38.8 \%$, and Group 4 at a rate of $24.1 \%$.

The discriminant scores from Function 1 and Function 2 were used to plot the sample on the discriminant dimensions. Group 3 is associated with the largest group centroid (0.282), Group 4 is associated with the next largest group centroid (0.187), Group 2 is associated with the second 
smallest centroid (0.036) and, finally, Group 1 is associated with the smallest group centroid (0.649) (see Figure 53).

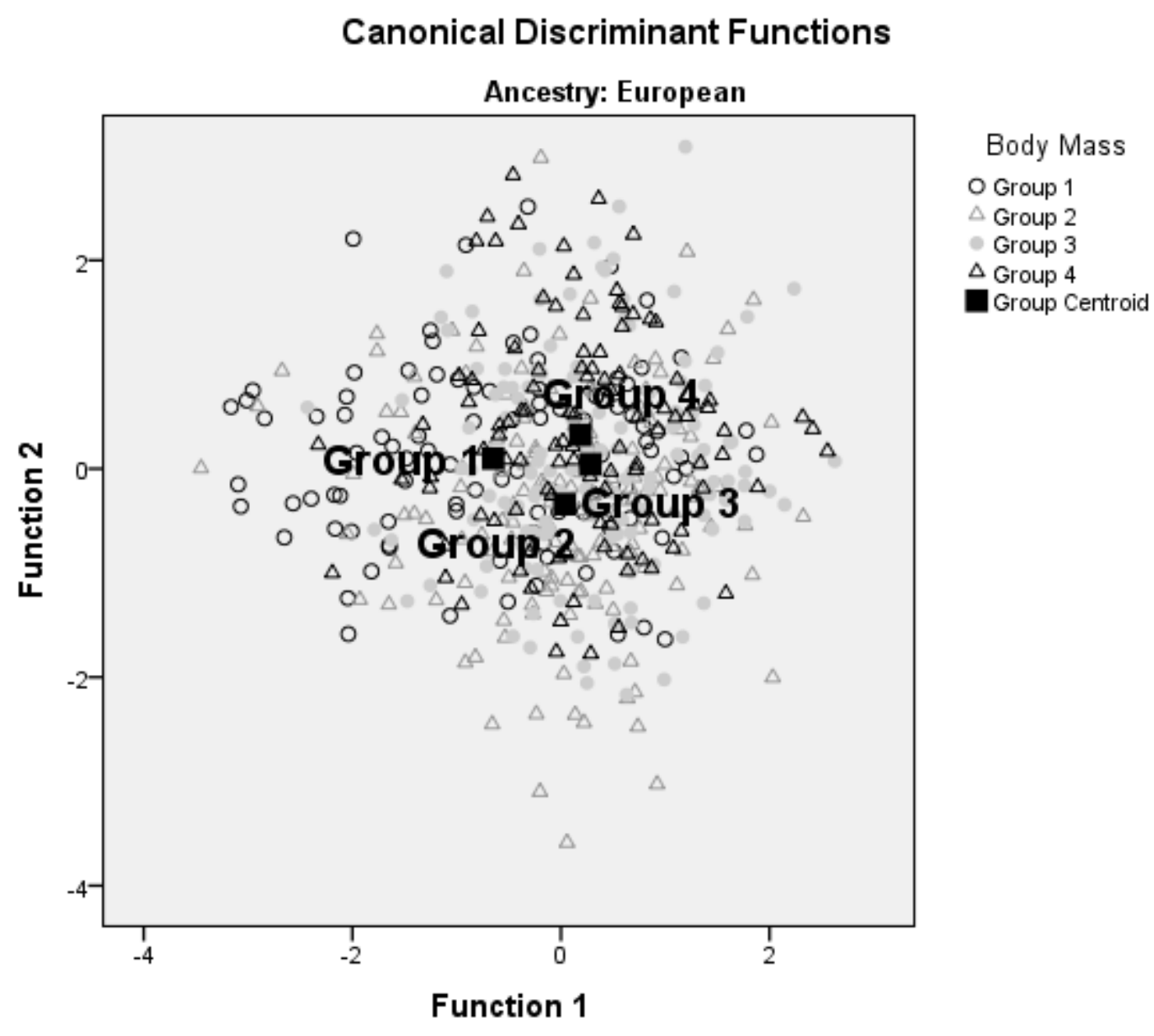

Figure 53: Canonically derived centroids for the body mass groups for individuals of European ancestry.

\section{African Ancestry}

As shown in Table 64 of Section 3.3.2.2, the pattern of correlations observed among the bias scores are generally strong for a MANOVA, and the Box's M value of 169.498 is associated with a $p$-value of 0.002 , which is significant. A covariance matrix (Appendix 27) was run to ensure that no covariance values were more than four times greater than each other. Although there are instances where the covariance values are greater than four times their value, typically associated with the İşcan et al. method, overall the covariance matrices between the body mass groups were assumed to be equal for the purposes of the MANOVA. 
A MANOVA was conducted to test the hypothesis that there would be differences between body mass group bias scores for each method. The MANOVA effect was statistically significant with Pillai's Trace $=0.228, \mathrm{~F}(24,582)=1.991, p=0.004$, indicating there are differences among the body mass group bias scores. The multivariate effect size is estimated at 0.076, which implies that $7.6 \%$ of the variance in the canonically derived DV is accounted for by the body mass groups.

As the IV was associated with four levels, three eigenvalues and canonical correlations were extracted by the MANOVA. The first eigenvalue is 0.168 and accounts for $65.5 \%$ of the model variance. The canonical correlation associated with the first eigenvalue is 0.379 , where $14.4 \%$ of the variance in the discriminant function derived scores is accounted for by body mass. The second eigenvalue is 0.060 and accounts for $23.6 \%$ of the model variance with a corresponding canonical correlation of 0.239 . The third eigenvalue is 0.028 and accounts for $10.9 \%$ of the model variance and a corresponding canonical correlation of 0.165 , which is not statistically significant [Wilks $\Lambda=0.973, \mathrm{~F}(6,194)=0.904, p=0.493$ ].

The standardized discriminant function coefficients from the first eigenvalue were used to determine the statistical significance of the MANOVA as it was the strongest. As seen in Table 101, the standardized discriminant function coefficients suggest that body mass groups were maximally differentiated by a canonical variate with significant weighting from the İşcan et al. (0.970) method bias scores. The standardized coefficients suggest minimal individual contributions to the MANOVA effect from all other bias scores. The correlations between the bias scores and the canonically derived scores for all methods are weak (range $=-0.071$ to 0.228), except for the İşcan et al. method, which has strong, positive correlations (0.946). 


\begin{tabular}{|l|l|l|l|}
\hline & \multicolumn{3}{|c|}{ Function 1 } \\
& Raw & Stand. & Struc. \\
\hline Kunos et al. & -0.046 & -0.514 & -0.038 \\
DiGangi et al. & 0.005 & 0.059 & -0.071 \\
İşcan et al. & 0.075 & 0.970 & 0.946 \\
Passalacqua & -0.001 & -0.019 & 0.064 \\
Lovejoy et al. & 0.017 & 0.145 & 0.228 \\
Buckberry \& Chamberlain & 0.015 & 0.192 & 0.135 \\
Rougé-Maillart et al. & -0.013 & -0.152 & 0.149 \\
Suchey-Brooks & 0.019 & 0.183 & 0.176 \\
\hline
\end{tabular}

Table 101: Discriminant function coefficients associated with the MANOVA for individuals of African ancestry. Note: Raw = unstandardized coefficients, Stand. = standardized coefficients, Struc. $=$ structure coefficients.

To estimate the group centroids for the body mass groups, the sample bias scores were multiplied by the corresponding bias unstandardized discriminant function coefficients and then averaged across the samples. The means and standard deviations for each body mass group are in Table 102. An ANOVA with four levels in the IV was performed on the canonically derived bias score $\mathrm{DV}$, and is statistically significant $[\mathrm{F}(3,11.255)=11.109, p<0.001]$.

\begin{tabular}{|c|c|c|c|}
\hline & n & Mean & S.D. \\
\hline $24.04-54.37 \mathrm{~kg}$ & 44 & -1.096 & 1.180 \\
$54.38-66.10 \mathrm{~kg}$ & 85 & -0.204 & 1.054 \\
$66.11-80.20 \mathrm{~kg}$ & 46 & -0.130 & 0.824 \\
$80.21-99.79 \mathrm{~kg}$ & 28 & 0.085 & 0.812 \\
\hline
\end{tabular}

Table 102: Means and Standard Deviations for the canonically derived variables for individuals of African ancestry.

The Cohen's $d$ absolute values were as follows, from highest to lowest: Group 1 vs. Group $4=$ 1.159; Group 1 vs. Group 3 =0.967; Group 1 vs. Group $2=0.852$; Group 2 vs. Group $4=0.290$; Group 3 vs. Group $4=0.238$; and Group 2 vs. Group $3=0.075$. The differences between individuals of African ancestry in Groups 1 and 4, Groups 1 and 3, and Groups 1 and 2 are suggestive of a large effect size; the difference between individuals of African ancestry in Groups 2 and 4, and Groups 3 and 4 are suggestive of a small effect size. There is no discernible difference between individuals of African ancestry in Groups 2 and 3.

Table 103 shows the results from Tukey's $b$ post-hoc tests for unequal sample sizes. There are no significant differences among the body mass group bias scores for individuals of African ancestry using any method except the İşcan et al. method. The İşcan et al. method under-ages individuals of African ancestry from Group 1 significantly compared to individuals of African ancestry in Groups 2, 3, and 4. 
A DFA was applied to assess how well body mass could be predicted from the bias scores of the eight age estimation methods. The cross-validated classification shows that only $46.3 \%$ of individuals of African ancestry are correctly classified into their body mass group based on bias scores. individuals of African ancestry in Group 1 are classified correctly at a rate of $40.9 \%$, Group 2 at a rate of $80.0 \%$, Group 3 at a rate of $10.9 \%$, and Group 4 at a rate of $10.7 \%$.

The discriminant scores from Function 1 and Function 2 were used to plot the sample on the discriminant dimensions. Group 4 is associated with the largest group centroid (0.424), Group 3 is associated with the next largest group centroid (0.206), Group 2 is associated with the second smallest centroid (0.137) and, finally, Group 1 is associated with the smallest group centroid (0.750) (see Figure 54). 


\begin{tabular}{|l|l|l|ll|}
\hline \multicolumn{1}{|c|}{ Method } & & & \multicolumn{2}{|c|}{ Subset (yrs) } \\
\hline Kunos et al. & Body Mass & $\mathbf{n}$ & $\mathbf{1}$ & $\mathbf{2}$ \\
& Group 2 & 85 & 4.35 & \\
& Group 4 & 28 & 6.21 & \\
& Group 1 & 44 & 6.73 \\
& Group 3 & 46 & 8.78 \\
\hline DiGangi et al. & Group 4 & 28 & -10.89 \\
& Group 2 & 85 & -9.98 \\
& Group 1 & 44 & -8.81 & \\
& Group 3 & 46 & -7.24 & \\
\hline İşcan et al. & Group 1 & 44 & -9.73 & \\
& Group 2 & 85 & & 0.60 \\
& Group 3 & 46 & & 2.98 \\
& Group 4 & 28 & & 4.54 \\
\hline Passalacqua & Group 2 & 85 & 1.15 \\
& Group 1 & 44 & 1.68 \\
& Group 4 & 28 & 2.11 \\
& Group 3 & 46 & 4.98 \\
\hline Lovejoy et al. & Group 1 & 44 & -3.68 \\
& Group 4 & 28 & -2.25 \\
& Group 2 & 85 & -2.06 \\
& Group 3 & 46 & -0.52 \\
\hline Buckberry and Chamberlain & Group 2 & 85 & 7.48 \\
& Group 1 & 44 & 7.66 \\
& Group 4 & 28 & 9.50 \\
& Group 3 & 46 & 11.89 \\
\hline Rougé-Maillart et al. & Group 1 & 44 & -2.18 \\
& Group 4 & 28 & -1.39 \\
& Group 2 & 85 & -1.13 \\
& Group 3 & 46 & 1.65 & \\
\hline Suchey-Brooks & Group 1 & 44 & -4.86 \\
& Group 2 & 85 & -4.73 \\
& Group 3 & 46 & -2.96 \\
& Group 4 & 28 & -1.86 \\
\hline
\end{tabular}

Table 103: Tukey's $b$ post-hoc test results for individuals of African ancestry bias scores separated by body mass. Note: alpha level $=0.05$ 


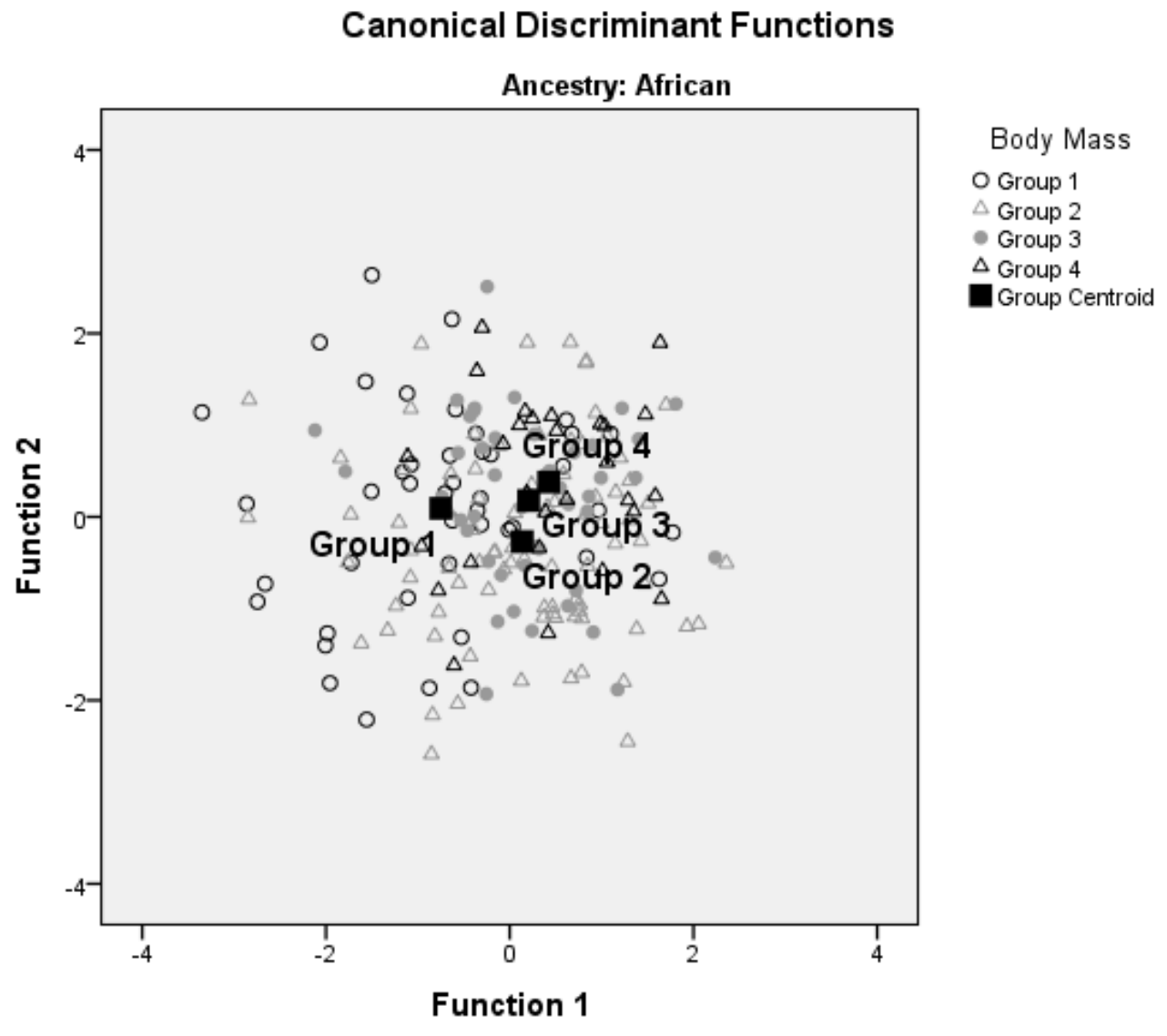

Figure 54: Canonically derived centroids for the body mass groups for individuals of African ancestry.

\subsubsection{Results Summary}

\subsubsection{Accuracy}

For males and individuals of European ancestry, there are statistically significant differences among the body mass groups for accuracy scores. The MANOVA effect size is low at $4.1 \%$ and $4.2 \%$, respectively. For females and individuals of African ancestry, there are no statistically significant differences among the body mass groups for accuracy scores.

Using the standardized coefficients from the MANOVA:

- Males have the highest contribution to the model from the Rougé-Maillart et al. and Suchey-Brooks methods, which have the most variance between body mass group accuracy scores. The Kunos et al., DiGangi et al., İşcan et al., Passalacqua, and Lovejoy et al. methods have moderate contributions to the model, indicating that there are 
differences among the body mass group accuracy scores for these methods, but they are not as substantial as those from the Rougé-Maillart et al. and Suchey-Brooks methods. The Buckberry and Chamberlain method has little to no contribution to the model, and has the least amount of variance in its body mass group accuracy scores (see Table 86).

- Individuals of European ancestry have the highest contribution to the model from the DiGangi et al. and Rougé-Maillart et al. methods, and the greatest variance in the body mass group accuracy scores. All other methods have moderate contributions to the model, indicating that there are differences among the body mass group accuracy scores for these methods, but they are not as substantial as those from the DiGangi et al. and RougéMaillart et al. methods (see Table 95).

The differences in group centroid values generated from the MANOVA for the male and European accuracy scores are significant. Males and individuals of European ancestry in the heaviest body mass groups have significantly higher accuracy scores compared to males and individuals of European ancestry in the lightest body mass groups. The Cohen's $d$ values indicate there is a medium effect size for males, and a strong effect size for individuals of European ancestry. These results are corroborated by the discriminant function canonical analyses results: lighter males and individuals of European ancestry have lower accuracy scores than heavier males and individuals of European ancestry, and the males and individuals of European ancestry in the lightest body mass groups cluster together, while the males in the heaviest body mass groups cluster together (see Figure 49 and Figure 52).

Table 104 shows the inaccuracy scores for males, females, individuals of European ancestry, and individuals of African ancestry separated by body mass. There are no differences in the body mass group accuracy scores for the Lovejoy et al. and Buckberry and Chamberlain methods. The Kunos et al. method accuracy scores for individuals of European ancestry in the lightest body mass group are lower compared to individuals of European ancestry in the heaviest body mass group. The DiGangi et al. method accuracy scores for males in the two lightest body mass groups are lower compared to males in heaviest body mass group, and individuals of European ancestry in the lightest body mass group have lower accuracy scores compared to individuals of European ancestry in the two heaviest body mass groups. The İşcan et al. method accuracy scores for 
males, individuals of European ancestry, and individuals of African ancestry in the lightest body mass group are significantly lower compared to individuals in the heaviest body mass groups. The Passalacqua accuracy scores for the lightest males and individuals of African ancestry are significantly lower compared to the heaviest males and individuals of African ancestry. The Rougé-Maillart et al. method accuracy scores for males and individuals of European ancestry in the two lightest body mass groups are significantly lower compared to males and individuals of European ancestry in the two heaviest body mass groups. The Suchey-Brooks accuracy scores for males in the lightest body mass group are significantly lower than those in the heaviest body mass groups; and individuals of European ancestry in the second lightest group have lower accuracy scores compared to the two heaviest groups, and individuals of European ancestry in the lightest body mass group have lower accuracy scores compared to individuals of European ancestry in the second heaviest body mass group. For females, there are no significant differences among the body mass group accuracy scores. For both all individuals, the DiGangi et al. method performs poorly (see Figure 55, Figure 56, Figure 57, and Figure 58).

\begin{tabular}{|c|c|c|c|c|c|c|c|c|c|}
\hline \multicolumn{2}{|c|}{ Body Mass (kg) } & $\begin{array}{c}\text { Kunos } \\
\text { et al. }\end{array}$ & $\begin{array}{c}\text { DiGangi } \\
\text { et al. }\end{array}$ & $\begin{array}{l}\text { İşcan } \\
\text { et al. }\end{array}$ & $\begin{array}{l}\text { Passal- } \\
\text { acqua }\end{array}$ & $\begin{array}{l}\text { Lovejoy } \\
\text { et al. }\end{array}$ & $\begin{array}{l}\text { Buckberry \& } \\
\text { Chamberlain }\end{array}$ & $\begin{array}{c}\text { Rougé-Maillart } \\
\text { et al. }\end{array}$ & $\begin{array}{l}\text { Suchey- } \\
\text { Brooks }\end{array}$ \\
\hline \multirow{4}{*}{ Males } & $24.04-54.37$ & 11.23 & 16.72 & 13.13 & 12.80 & 9.59 & 11.31 & \begin{tabular}{|l|}
11.95 \\
\end{tabular} & 10.27 \\
\hline & $54.38-66.10$ & 10.85 & 17.14 & L11.57 & 11.64 & 9.48 & 11.39 & 12.20 & 11.21 \\
\hline & $66.11-80.20$ & 10.07 & 13.47 & 9.04 & 10.87 & 8.07 & 12.71 & 9.31 & 7.33 \\
\hline & $80.21-99.79$ & 9.03 & 11.71 & 10.02 & 10.04 & 7.75 & 11.54 & 8.39 & 8.65 \\
\hline \multirow[t]{4}{*}{ Females } & $24.04-54.37$ & 12.09 & 19.87 & 14.36 & 11.96 & 9.29 & 10.22 & 11.93 & 10.01 \\
\hline & $54.38-66.10$ & 9.62 & 14.68 & 11.14 & 11.80 & 7.13 & 10.65 & 8.49 & 7.95 \\
\hline & $66.11-80.20$ & 10.90 & 15.97 & 9.66 & 13.14 & 6.55 & 10.17 & 8.17 & 7.48 \\
\hline & $80.21-99.79$ & 8.38 & 14.19 & 10.94 & 11.00 & 9.56 & 10.94 & 7.31 & 8.94 \\
\hline \multirow[t]{4}{*}{ European } & $24.04-54.37$ & 11.20 & 19.78 & 12.88 & 11.67 & 10.14 & 9.66 & 12.77 & \begin{tabular}{|l|}
10.91 \\
\end{tabular} \\
\hline & $54.38-66.10$ & 10.61 & 18.21 & 11.92 & 11.85 & 9.79 & 10.81 & 11.93 & 11.25 \\
\hline & $66.11-80.20$ & 9.75 & 15.04 & 9.63 & 11.46 & 8.25 & 11.53 & 9.37 & 7.53 \\
\hline & $80.21-99.79$ & 8.82 & 12.23 & 10.37 & 10.41 & 8.31 & 11.26 & 8.55 & 8.95 \\
\hline \multirow[t]{4}{*}{ African } & $24.04-54.37$ & 12.64 & 14.70 & \begin{tabular}{|l|}
15.64 \\
\end{tabular} & \begin{tabular}{|l|}
14.05 \\
\end{tabular} & 7.86 & 13.34 & 10.05 & 8.41 \\
\hline & $54.38-66.10$ & 10.05 & 12.82 & 10.53 & 11.44 & 6.62 & 11.69 & 9.01 & 7.93 \\
\hline & $66.11-80.20$ & 11.57 & 10.33 & 7.63 & 10.50 & 6.57 & 14.67 & 8.39 & 6.83 \\
\hline & $80.21-99.79$ & 9.43 & 11.11 & 9.18 & 9.18 & 6.61 & 12.29 & 7.18 & 7.64 \\
\hline
\end{tabular}

Table 104: Inaccuracy scores (in years) for each age-at-death estimation method separated by body mass for males, females, individuals of European ancestry, and individuals of African ancestry. Significant differences are noted by boxes. 


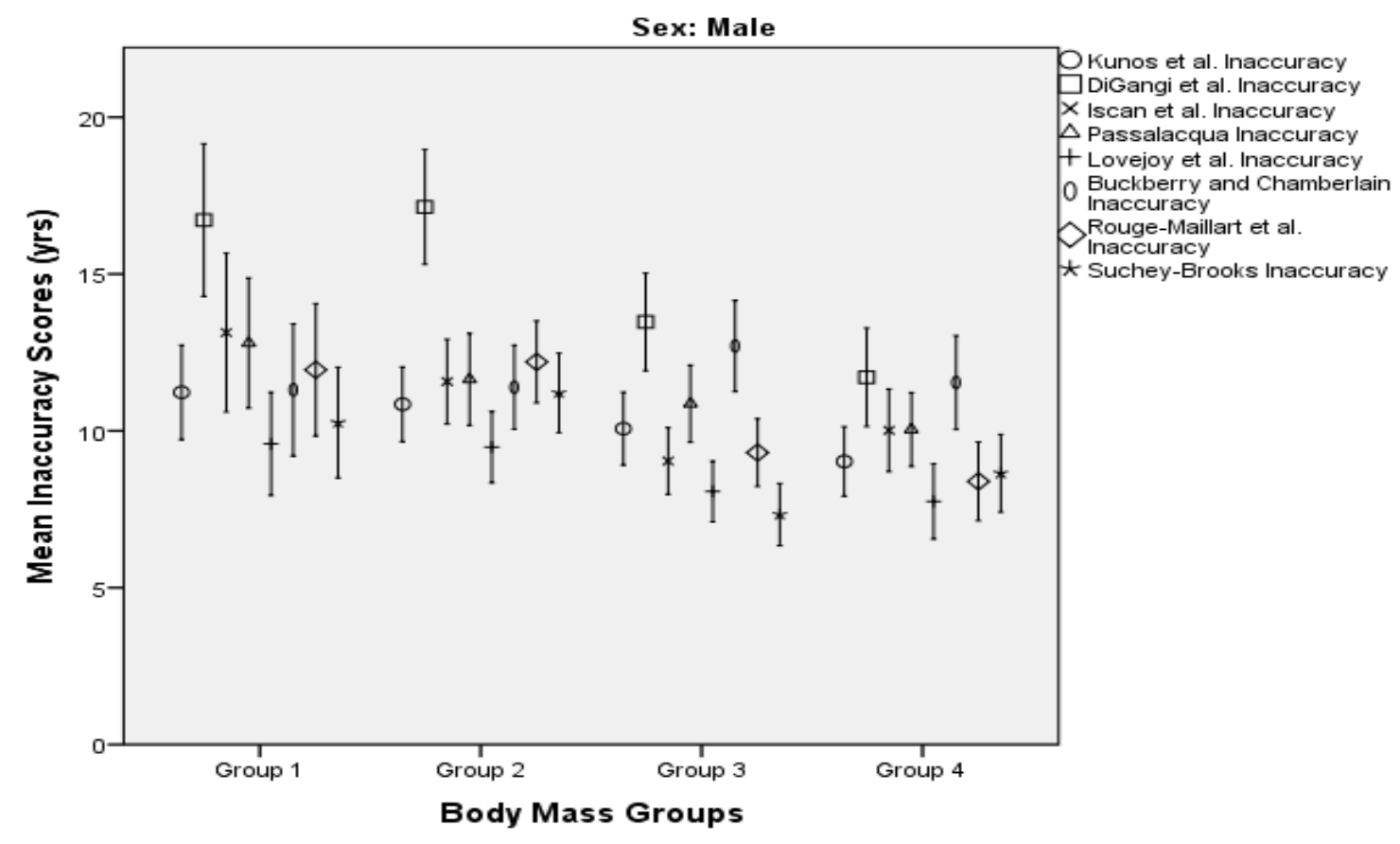

Error Bars: $95 \% \mathrm{Cl}$

Figure 55: Mean inaccuracy scores for the age estimation methods categorized by body mass for males.

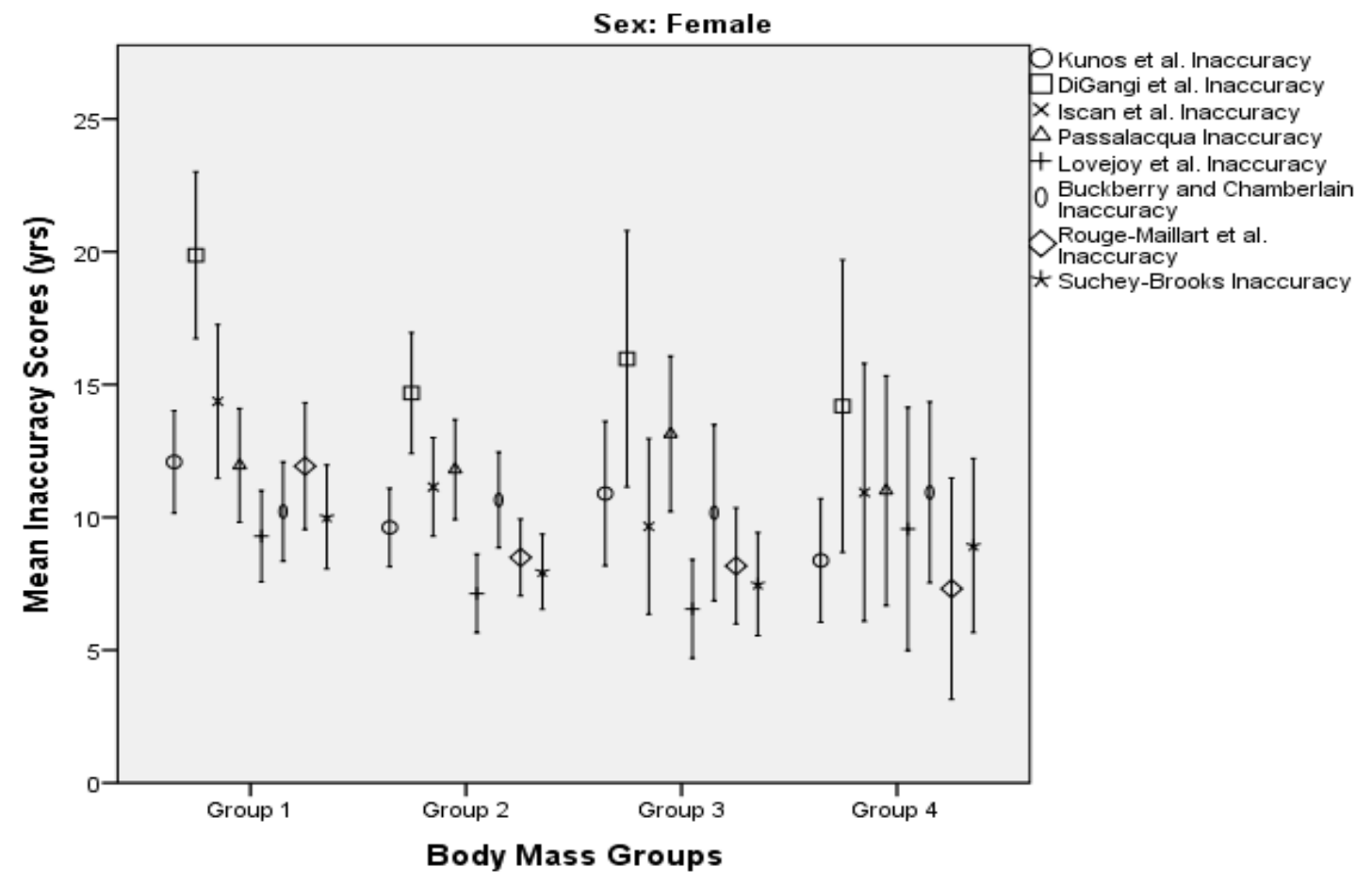

Error Bars: $95 \% \mathrm{Cl}$

Figure 56: Mean inaccuracy scores for the age estimation methods categorized by body mass for females. 


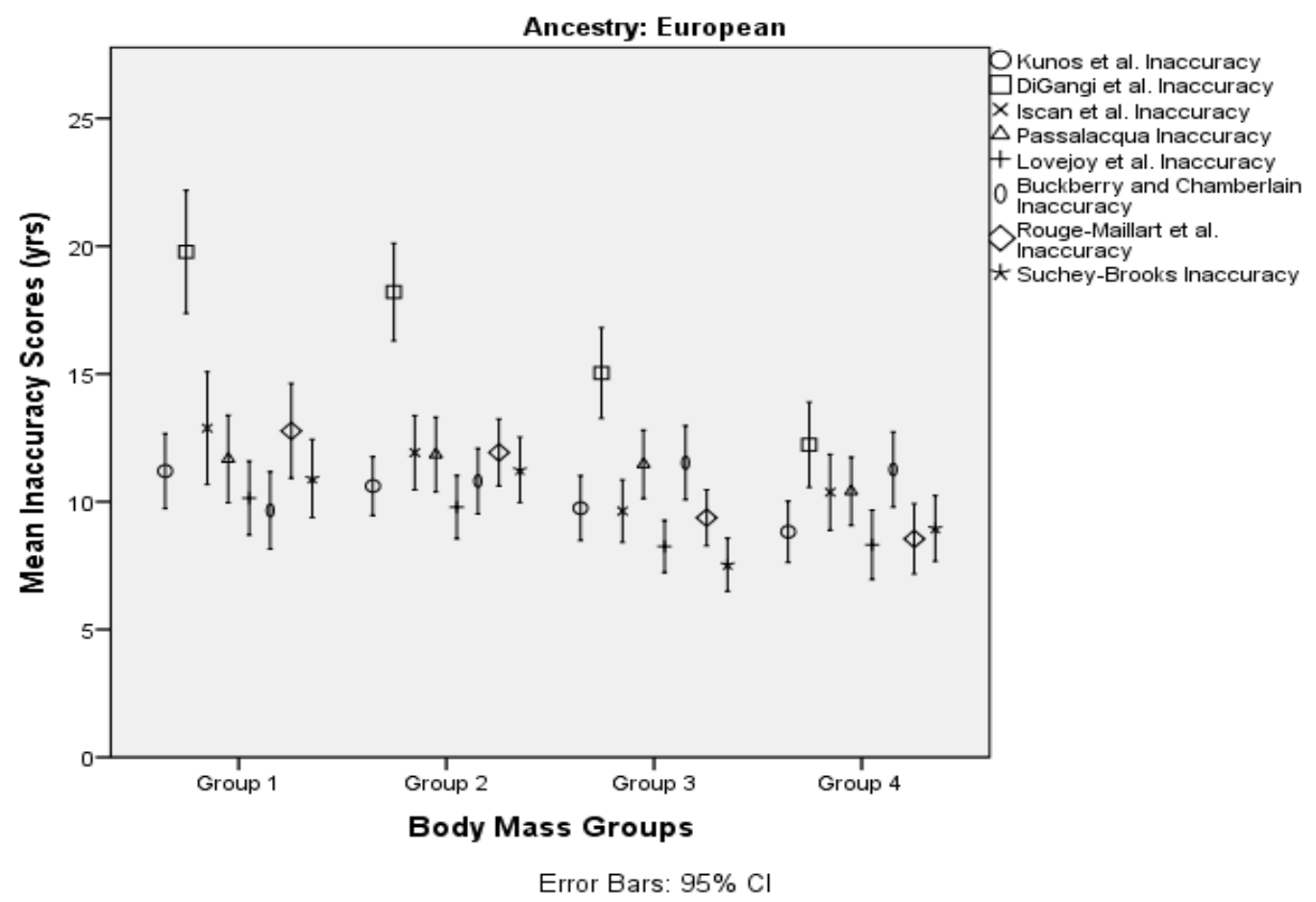

Figure 57: Mean inaccuracy scores for the age estimation methods categorized by body mass for individuals of European ancestry.

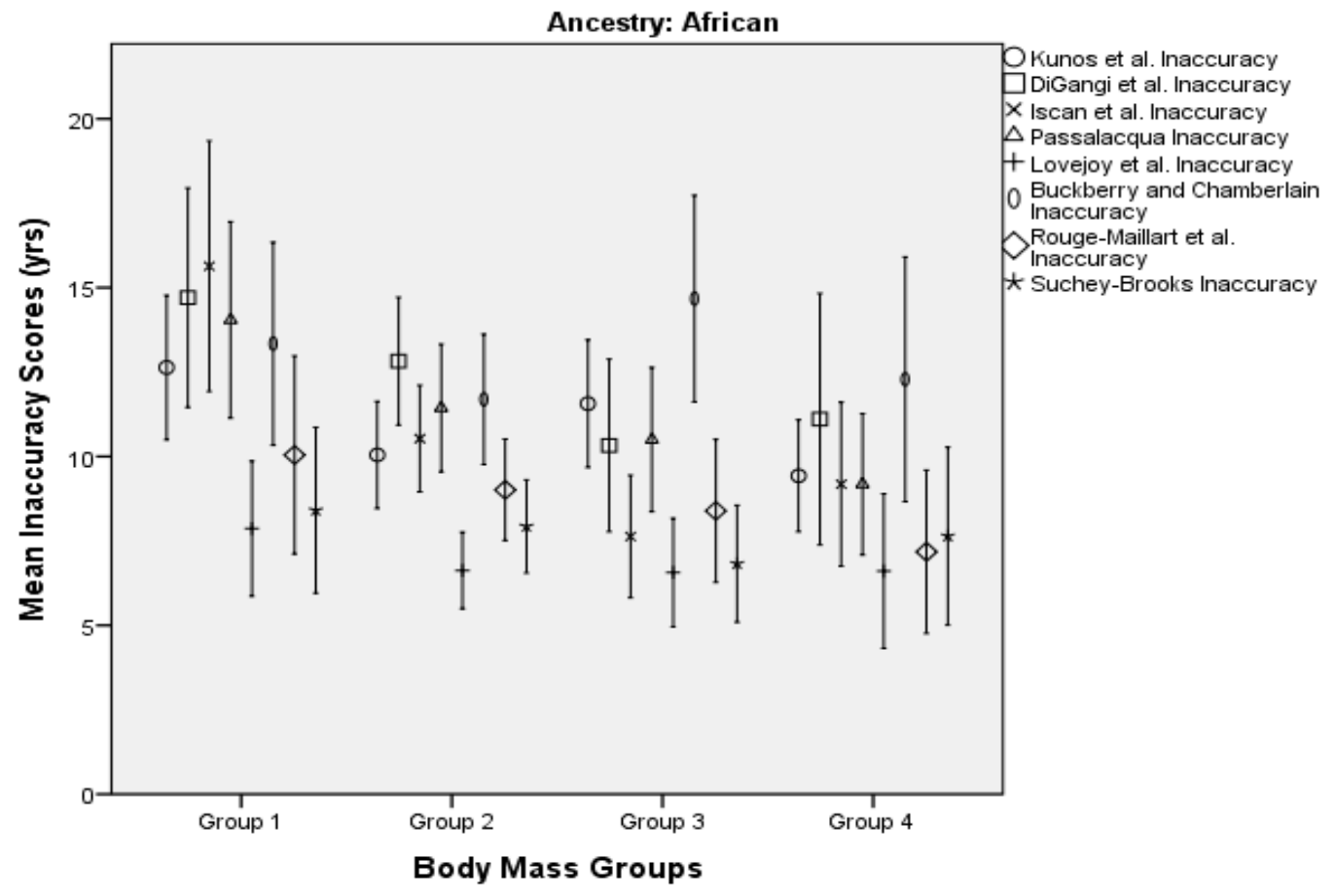

Error Bars: $95 \% \mathrm{Cl}$

Figure 58: Mean inaccuracy scores for the age estimation methods categorized by body mass for individuals of African ancestry. 
Discriminant function analyses show that accuracy scores are poor predictors of body mass. Light males (5.3\%), heavy females ( $0 \%$ ), light individuals of European ancestry (10\%), and heavy individuals of African ancestry $(0 \%)$ have the lowest classification scores. Males in the second heaviest body mass group (60.9\%), females in the second lightest body mass group (81\%), individuals of European ancestry in the second heaviest body mass group (51.1\%), and individuals of African ancestry in the second lightest body mass group (87.1\%) have the highest classification scores. These results indicate that accuracy scores cannot be used reliably to predict body mass groups, except for females and individuals of African ancestry in the second lightest body mass groups.

\subsubsection{Bias}

For males, females, individuals of European ancestry, and individuals of African ancestry there are statistically significant differences among the body mass groups for bias scores. The MANOVA effect size is $4.7 \%$ for males and $7.8 \%$ for females, suggesting that body mass has a larger effect for females than males using this model, though both have low effect sizes. Similarly, the MANOVA effect size is $5.7 \%$ for individuals of European ancestry and $7.6 \%$ for individuals of African ancestry, suggesting that body mass has a larger effect for individuals of African ancestry than individuals of European ancestry using this model, though both have low effect sizes. Similar to the BMI MANOVA results, although females and individuals of African ancestry have stronger differences among the mean bias scores of each body mass group according to the MANOVA, they are not as statistically significant as those of males and individuals of European ancestry because of small sample sizes in the heavier body mass groups.

Using the standardized coefficients from the MANOVA:

- Males have the highest contribution to the model from the Kunos et al. and İşcan et al. methods, which have the greatest variance in the body mass group bias scores. All other methods have moderate contributions to the model, indicating that there are differences among the body mass group bias scores for these methods, but they are not as substantial as those from the Kunos et al. and İşcan et al. methods (see Table 89). 
- Females have the highest contribution to the model from the Kunos et al., DiGangi et al. and İşcan et al. methods, which have the greatest variance in the body mass group bias scores compared to the other methods. All other methods have moderate contributions to the model, indicating that there are differences among the body mass group bias scores for these methods, but they are not as substantial as those from the other three methods (see Table 92).

- Individuals of European ancestry have the highest contribution to the model from the İşcan et al. and Kunos et al. methods, which have the greatest variance in the body mass group bias scores compared to the other methods. All other methods have moderate contributions to the model, indicating that there are differences among the body mass group bias scores for these methods, but they are not as substantial as those from the İşcan et al. and Kunos et al. methods (see Table 98).

- Individuals of African ancestry have the highest contribution to the model from the İşcan et al. method, which has the greatest variance in the body mass group bias scores compared to all other methods. The Lovejoy et al., Buckberry and Chamberlain, RougéMaillart et al., and Suchey-Brooks methods have moderate contributions, indicating that there are differences among the body mass group bias scores for these methods, but they are not as substantial as those from the İşcan et al. method. The Kunos et al., DiGangi et al., and Passalacqua methods have the lowest bias scores for individuals of African ancestry using this model, and the least amount of variance in their body mass group bias scores (see Table 101).

The differences in group centroid values generated from the MANOVA for the male, female, European, and African bias scores are significant. Males, individuals of European ancestry, and individuals of African ancestry in the lightest body mass group have significantly higher negative bias scores compared to individuals in all other body mass groups, and the Cohen's $d$ values indicate these are large effect sizes between the lightest and heaviest groups, and medium effect sizes for the other relationships. Females in the lightest body mass group have significantly higher negative bias scores compared to females in the heaviest body mass group, and the Cohen's $d$ value indicates this is a medium effect size. The results from the DFA 
corroborate these findings. These results are corroborated by the discriminant function canonical analyses results: males, females, individuals of European ancestry, and individuals of African ancestry in the lightest body mass group are under-aged more than individuals in the other body mass categories, with the greatest difference between lightest and heaviest groups (see Figure 50, Figure 51, Figure 53, and Figure 54).

Table 105 shows the bias scores for males, females, individuals of European ancestry, and individuals of African ancestry separated by body mass. For the Kunos et al. method, males and individuals of European ancestry in the two lightest body mass groups are under-aged compared to males and individuals of European ancestry in the two heaviest body mass groups. For the DiGangi et al. method, individuals of European ancestry in the two lightest body mass groups are under-aged compared to individuals of European ancestry in the two heaviest body mass groups. For the İşcan et al. method, all individuals in the lightest body mass group are under-aged compared to all other body mass groups. The Passalacqua, Lovejoy et al. Buckberry and Chamberlain, and Rougé-Maillart et al. methods significantly under-age males and individuals of European ancestry in the lightest body mass groups compared to males and individuals of European ancestry in the two heaviest body mass groups. The Suchey-Brooks method underages males in the two lightest body mass groups compared to the two heaviest groups; underages females in the lightest body mass group compared to females in the second heaviest group; and under-ages female individuals of European ancestry in the two lightest body mass groups compared to individuals of European ancestry in the two heaviest groups. For all individuals, the DiGangi et al. method performs poorly (see Figure 59, Figure 60, Figure 61, and Figure 62). 


\begin{tabular}{|c|c|c|c|c|c|c|c|c|c|}
\hline \multicolumn{2}{|c|}{ Body Mass (kg) } & $\begin{array}{c}\text { Kunos } \\
\text { et al. }\end{array}$ & $\begin{array}{l}\text { DiGangi } \\
\text { et al. }\end{array}$ & $\begin{array}{l}\text { İşcan } \\
\text { et al. }\end{array}$ & $\begin{array}{l}\text { Passal- } \\
\text { acqua }\end{array}$ & $\begin{array}{c}\text { Lovejoy } \\
\text { et al. }\end{array}$ & $\begin{array}{l}\text { Buckberry \& } \\
\text { Chamberlain }\end{array}$ & $\begin{array}{c}\text { Rougé-Maillart } \\
\text { et al. }\end{array}$ & $\begin{array}{l}\text { Suchey- } \\
\text { Brooks }\end{array}$ \\
\hline \multirow[t]{4}{*}{ Males } & $24.04-54.37$ & 0.93 & -13.12 & \begin{tabular}{|l|}
-6.97 \\
\end{tabular} & \begin{tabular}{|l|}
-4.35 \\
\end{tabular} & \begin{tabular}{|l|}
-7.03 \\
\end{tabular} & 3.95 & -7.15 & \begin{tabular}{|l|}
-7.36 \\
\end{tabular} \\
\hline & $54.38-66.10$ & 1.74 & -14.54 & 1.57 & -3.02 & -6.08 & 5.28 & -5.96 & -9.28 \\
\hline & $66.11-80.20$ & 5.34 & -10.08 & 3.62 & 1.30 & -3.72 & 8.53 & -2.81 & -4.90 \\
\hline & $80.21-99.79$ & 6.11 & -10.34 & 1.75 & 0.94 & -4.03 & 9.28 & -2.71 & -3.77 \\
\hline \multirow[t]{4}{*}{ Females } & $24.04-54.37$ & -0.35 & -18.33 & \begin{tabular}{|l|}
-9.67 \\
\end{tabular} & -1.43 & -7.55 & 2.16 & -8.28 & -7.84 \\
\hline & $54.38-66.10$ & 2.21 & -13.37 & 0.21 & 0.30 & -3.77 & 5.68 & -2.94 & -5.00 \\
\hline & $66.11-80.20$ & 4.50 & -12.17 & -3.59 & -0.86 & -3.72 & 8.03 & -3.34 & -3.41 \\
\hline & $80.21-99.79$ & 5.79 & -11.69 & -7.69 & -2.38 & -8.44 & 6.31 & -4.44 & -4.19 \\
\hline \multirow[t]{4}{*}{ European } & $24.04-54.37$ & -2.50 & \begin{tabular}{|l|}
-18.70 \\
\end{tabular} & -7.62 & -4.99 & -8.86 & 1.08 & -10.11 & \begin{tabular}{|l|}
-8.79 \\
\end{tabular} \\
\hline & $54.38-66.10$ & 0.52 & -16.47 & 1.36 & -3.53 & -7.07 & 4.26 & -7.01 & -9.46 \\
\hline & $66.11-80.20$ & 5.16 & -11.45 & 2.32 & -0.37 & -4.78 & 7.31 & -4.40 & -5.23 \\
\hline & $80.21-99.79$ & 4.99 & -10.40 & -0.37 & 0.15 & -5.15 & 8.78 & -3.31 & -4.32 \\
\hline \multirow[t]{4}{*}{ African } & $24.04-54.37$ & 6.37 & -8.61 & \begin{tabular}{|l|}
-9.73 \\
\end{tabular} & 1.68 & -3.68 & 7.66 & -2.18 & -4.86 \\
\hline & $54.38-66.10$ & 4.35 & -9.98 & 0.60 & 1.15 & -2.06 & 7.48 & -1.13 & -4.73 \\
\hline & $66.11-80.20$ & 8.78 & -7.24 & 2.98 & 4.98 & -0.52 & 11.89 & -1.65 & -2.96 \\
\hline & $80.21-99.79$ & 6.21 & -10.89 & 4.54 & 2.11 & -2.25 & 9.50 & -1.39 & -1.86 \\
\hline
\end{tabular}

Table 105: Bias scores (in years) for each age-at-death estimation method separated by body mass for males, females, individuals of European ancestry, and individuals of African ancestry. Significant differences are noted by boxes.

Discriminant function analyses show that bias scores are poor predictors of body mass. Light males $(3.6 \%)$, heavy females $(0 \%)$, heavy individuals of European ancestry $(24.1 \%)$, and heavy individuals of African ancestry (10.7\%) have the lowest classification scores. Males in the second heaviest group (76.4\%), females in the lightest body mass group (84.0\%), and individuals of European ancestry and individuals of African ancestry in the second lightest body mass groups (48\% and 80\%, respectively) have the highest classification scores. These results indicate that bias cannot be used reliably to predict body mass groups, except for females in the lightest body mass group and individuals of African ancestry in the second lightest body mass group. 


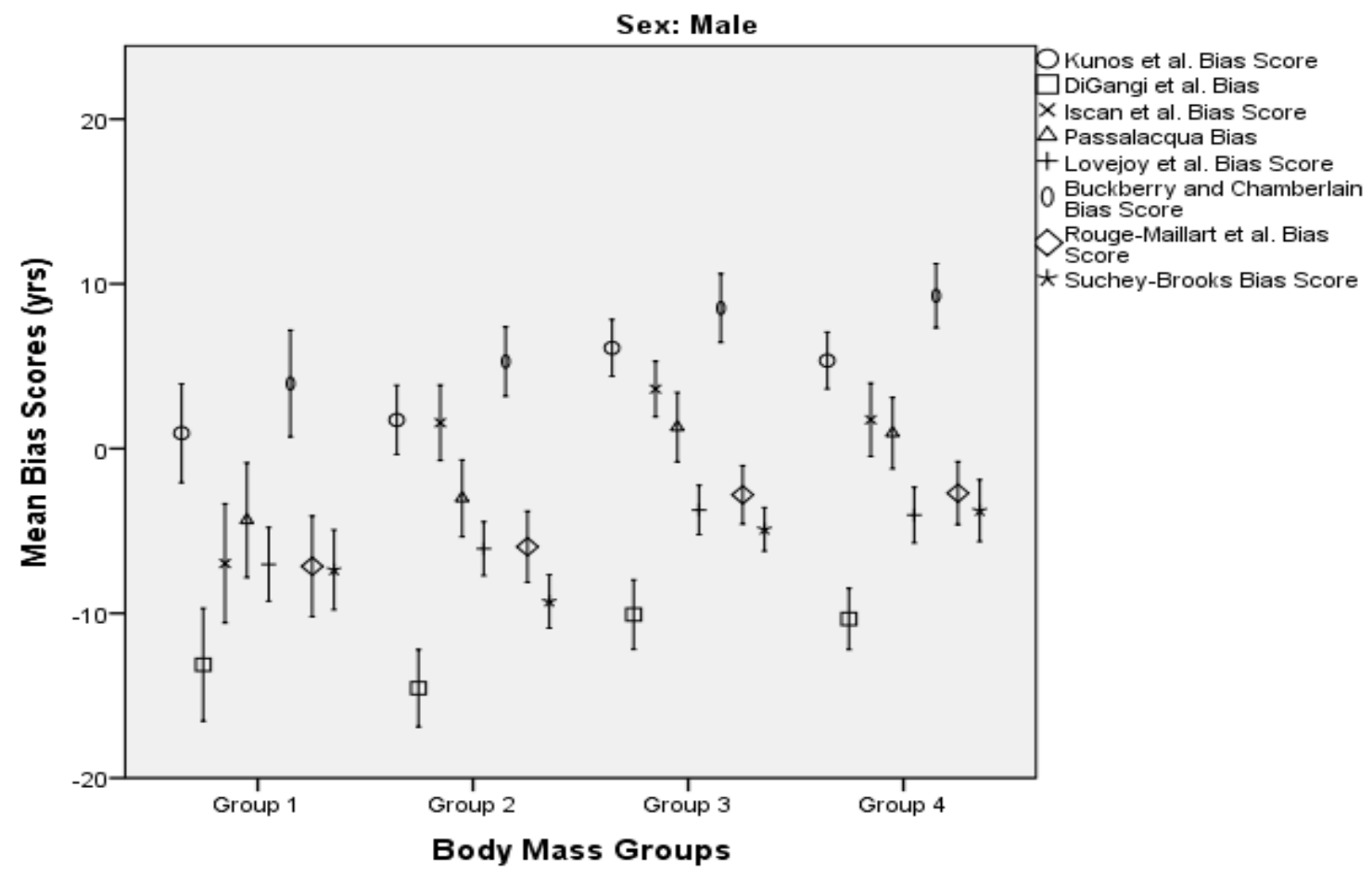

Error Bars: 95\% Cl

Figure 59: Mean bias scores for the age estimation methods categorized by body mass for males.

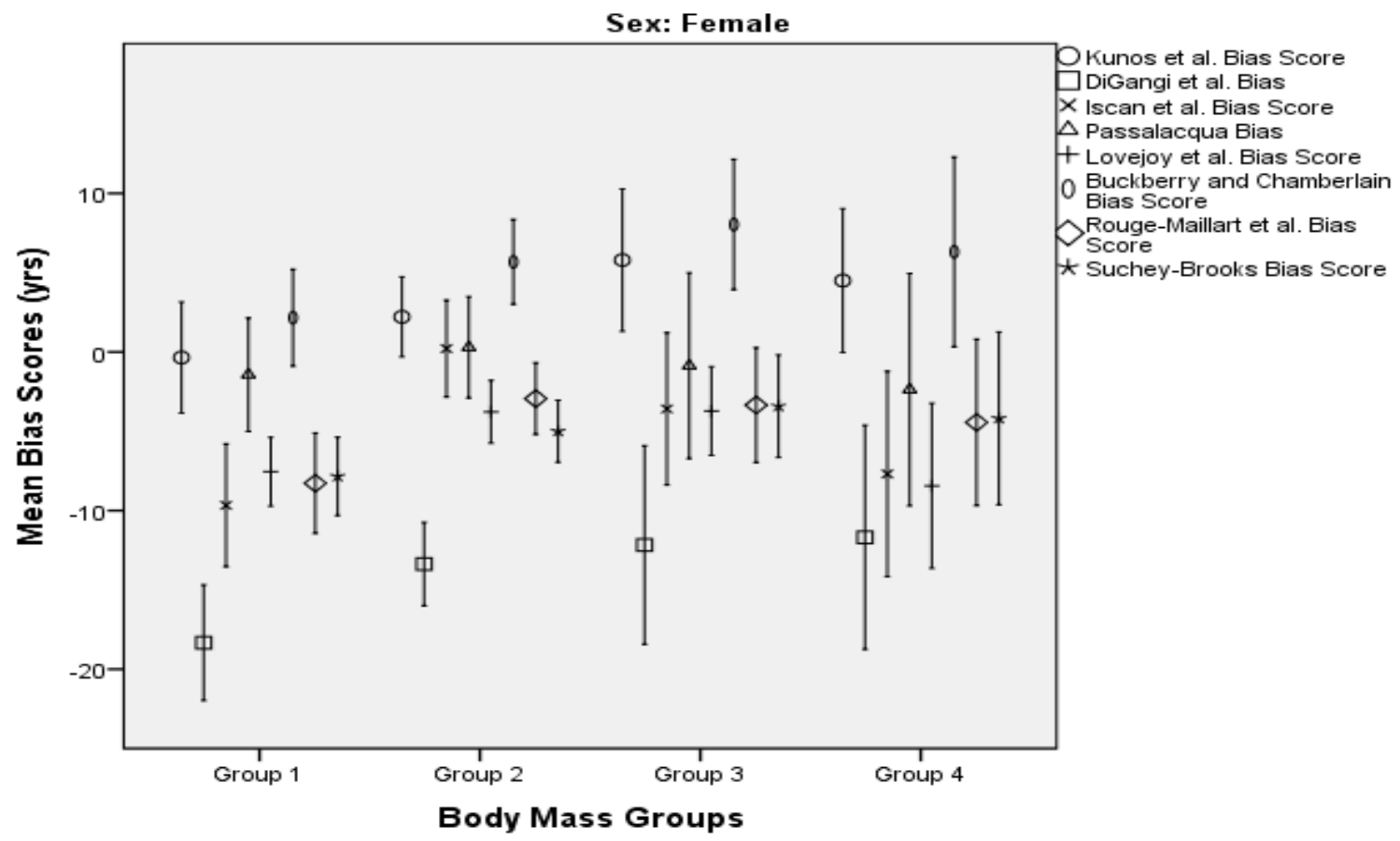

Error Bars: $95 \% \mathrm{Cl}$

Figure 60: Mean bias scores for the age estimation methods categorized by body mass for females. 


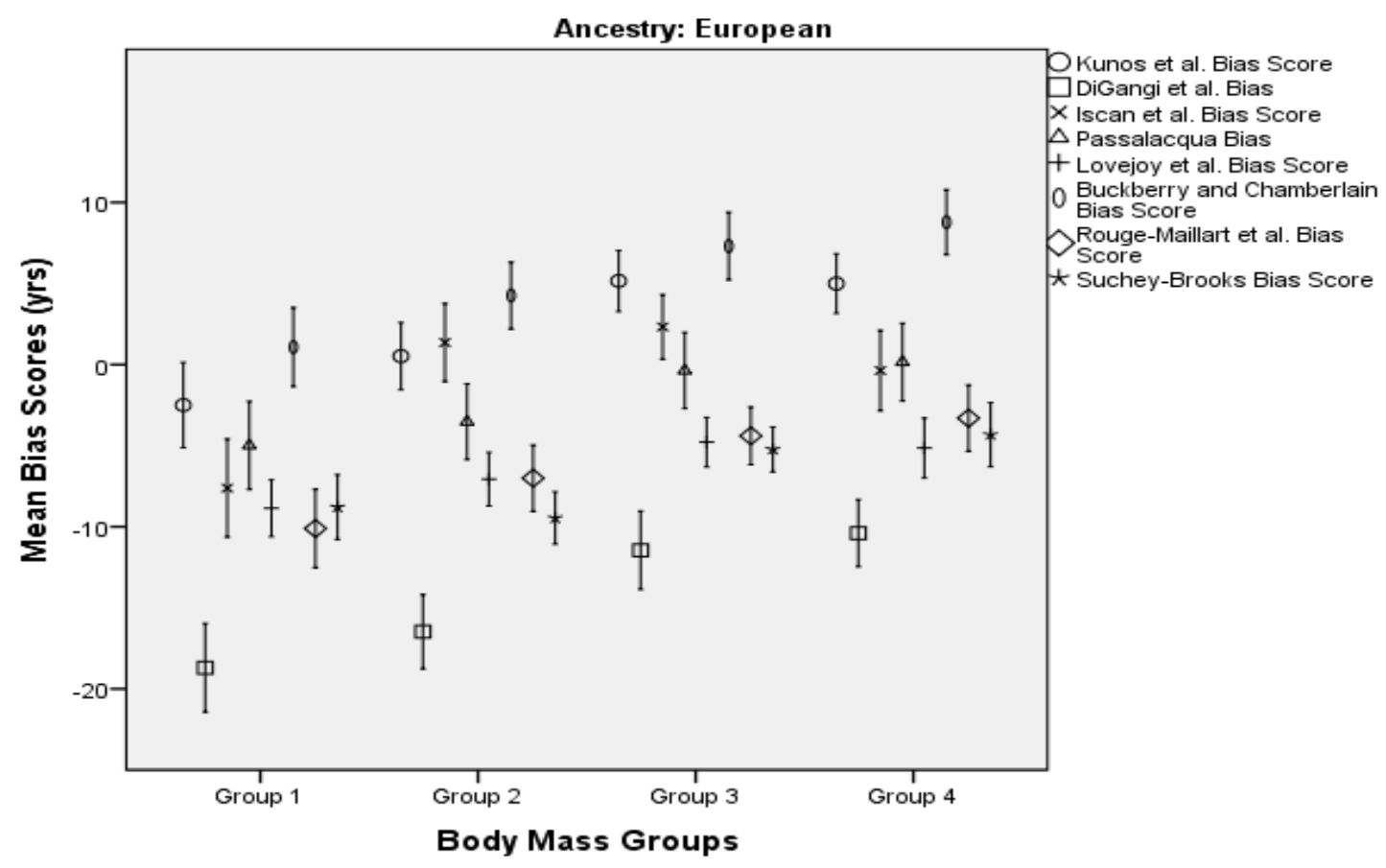

Error Bars: $95 \% \mathrm{Cl}$

Figure 61: Mean bias scores for the age estimation methods categorized by body mass for individuals of European ancestry.

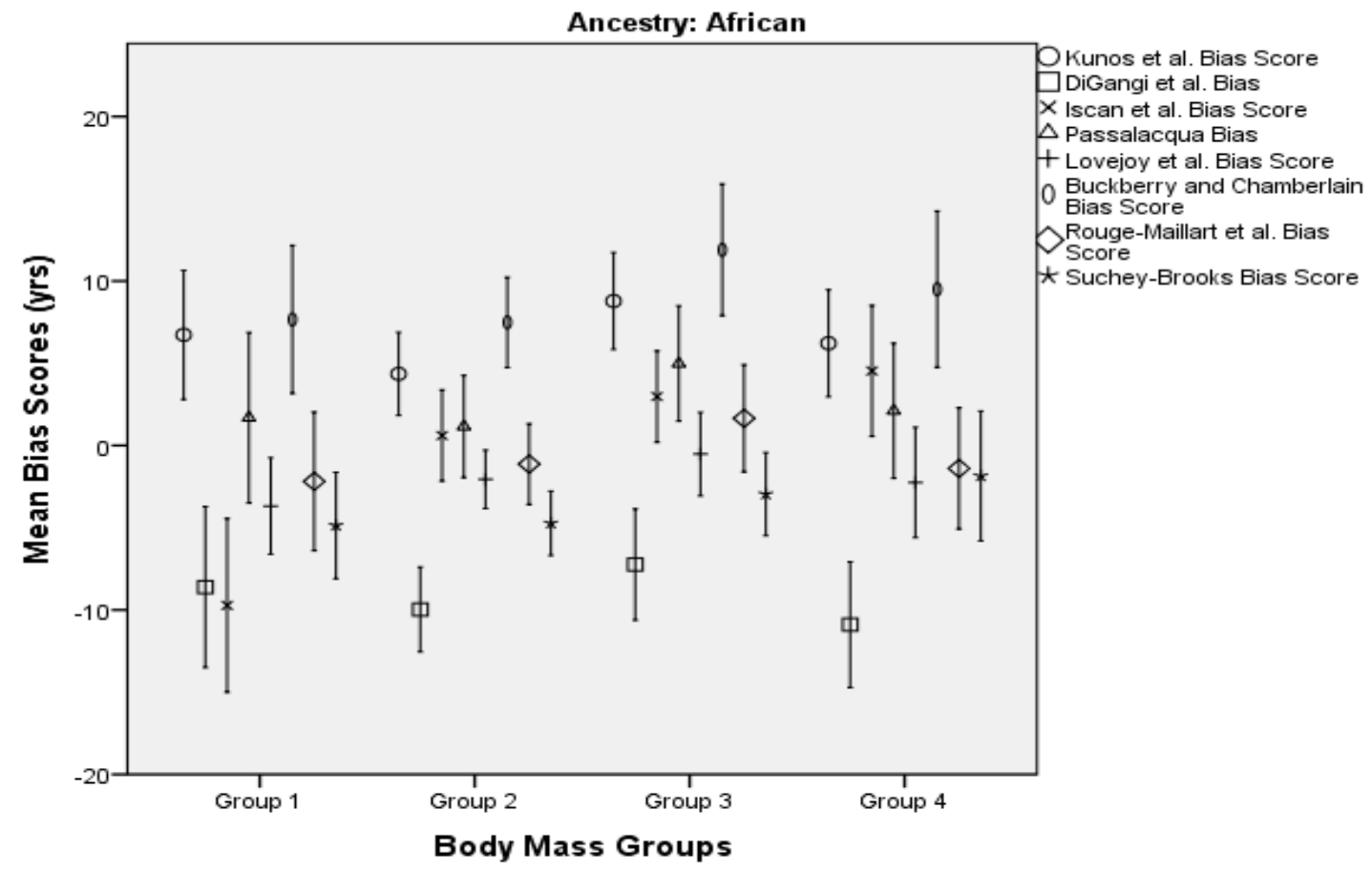

Error Bars: $95 \% \mathrm{Cl}$

Figure 62: Mean bias scores for the age estimation methods categorized by body mass for individuals of African ancestry. 


\subsection{Research Question IV: Are there differences between non- weight-bearing and weight-bearing joint age estimations?}

To test the differences between the non-weight-bearing rib age estimation methods (i.e. Kunos et al. and İşcan et al. methods) and the weight-bearing pelvic age estimation methods (i.e. Passalacqua, Lovejoy et al., Buckberry and Chamberlain, Rougé-Maillart et al., Suchey-Brooks methods), the accuracy and bias scores of each method were averaged into two groups: NonWeight Bearing (NWB) and Weight-Bearing (WB). The DiGangi et al. method was removed from these analyses as it has the lowest accuracy and precision scores for all methods. Table 106 shows the averages for each method and loading group.

\begin{tabular}{|l|c|c|}
\hline Method & Accuracy Score (yrs) & Bias Score (yrs) \\
\hline Kunos et al. & 10.43 & 3.11 \\
İşcan et al. & 11.17 & -0.7 \\
Non-Weight Bearing Joint Average & 10.80 & 1.21 \\
\hline Passalacqua & 11.45 & -1.13 \\
Lovejoy et al. & 8.65 & -5.42 \\
Buckberry and Chamberlain & 11.42 & 6.24 \\
Rougé-Maillart et al. & 10.34 & -5.01 \\
Suchey-Brooks & 9.22 & -6.26 \\
Weight-Bearing Joint Average & 10.22 & -2.62 \\
\hline
\end{tabular}

Table 106: Average accuracy and bias scores for the Non-Weight-Bearing and WeightBearing Joint groups.

The two weight-bearing joint groups were compared using paired sample t-tests to determine statistical significance between the two samples.

\subsubsection{Sex}

\subsubsection{Accuracy}

\section{Males}

Table 107 shows the average accuracy scores for each method as well as the average accuracy scores for the NWB and WB joint groups. A paired-sample t-test was conducted to compare NWB and WB joint accuracy scores to determine if there are differences between the group accuracy scores for males. There are no significant differences between the accuracy scores for $\operatorname{NWB}(\bar{x}=10.50$ years, $s . d .=5.73)$ and WB joints $(\bar{x}=10.06$ years, $s . d .=4.89) ; \mathrm{t}(513)=1.580$, $p=0.115$. 


\begin{tabular}{|l|c|}
\hline Method & Accuracy Score (yrs) \\
\hline Kunos et al. & 10.33 \\
İşcan et al. & 10.76 \\
Non-Weight Bearing Joint Average & 10.50 \\
\hline Passalacqua & 11.17 \\
Lovejoy et al. & 8.69 \\
Buckberry and Chamberlain & 11.94 \\
Rougé-Maillart et al. & 10.43 \\
Suchey-Brooks & 9.29 \\
Weight-Bearing Joint Average & 10.06 \\
\hline
\end{tabular}

Table 107: Average accuracy scores for the Non-Weight-Bearing and Weight-Bearing Joint groups for males.

When separated by BMI, there are no differences between the NWB and WB joint accuracy scores for males. When separated by stature, there are significant differences between the accuracy scores of males in Group 4; there is more error associated with the NWB joint age estimations than the WB joint age estimations for males in the tallest stature group. When separated by body mass, there are significant differences between the accuracy scores of males in Group 1; there is more error associated with the NWB joint age estimations than the WB joint age estimations for males in the lighest body mass group (see Table 108).

\begin{tabular}{|c|c|c|c|c|c|c|c|c|}
\hline & Group & & $\mathbf{n}$ & Score (yrs) & s.d. (yrs) & $\mathbf{t}$ & df & Sig (2-tail) \\
\hline \multirow[t]{8}{*}{ BMI } & \multirow[t]{2}{*}{ Underweight } & NWB Inaccuracy & 80 & 12.16 & $\begin{array}{l}7.55 \\
5.7\end{array}$ & \multirow[t]{2}{*}{1.029} & \multirow[t]{2}{*}{79} & \multirow[t]{2}{*}{0.307} \\
\hline & & WB Inaccuracy & 80 & 11.38 & 5.76 & & & \\
\hline & \multirow[t]{2}{*}{ Normal } & NWB Inaccuracy & 290 & 10.43 & 5.43 & \multirow[t]{2}{*}{1.200} & \multirow[t]{2}{*}{289} & \multirow{2}{*}{0.231} \\
\hline & & WB Inaccuracy & 290 & 9.98 & 4.81 & & & \\
\hline & \multirow{2}{*}{ Overweight } & NWB Inaccuracy & 117 & 9.89 & 5.09 & \multirow{2}{*}{0.449} & \multirow{2}{*}{116} & \multirow{2}{*}{0.654} \\
\hline & & WB Inaccuracy & 117 & 9.63 & 4.60 & & & \\
\hline & \multirow[t]{2}{*}{ Obese } & NWB Inaccuracy & 27 & 9.06 & 4.49 & \multirow[t]{2}{*}{0.178} & \multirow[t]{2}{*}{26} & \multirow{2}{*}{0.860} \\
\hline & & WB Inaccuracy & 27 & 8.84 & 3.54 & & & \\
\hline \multirow[t]{8}{*}{ Stature } & \multirow[t]{2}{*}{ Group 1} & NWB Inaccuracy & 55 & 10.82 & 6.26 & \multirow[t]{2}{*}{0.071} & \multirow[t]{2}{*}{54} & \multirow[t]{2}{*}{0.944} \\
\hline & & WB Inaccuracy & 55 & 10.76 & 5.08 & & & \\
\hline & \multirow[t]{2}{*}{ Group 2} & NWB Inaccuracy & 136 & 10.76 & 5.33 & \multirow[t]{2}{*}{0.735} & \multirow[t]{2}{*}{135} & \multirow{2}{*}{0.464} \\
\hline & & WB Inaccuracy & 136 & 10.39 & 5.18 & & & \\
\hline & \multirow{2}{*}{ Group 3} & NWB Inaccuracy & 195 & 10.29 & 6.13 & \multirow{2}{*}{0.391} & \multirow{2}{*}{194} & 0.696 \\
\hline & & WB Inaccuracy & 195 & 10.09 & 5.16 & & & \\
\hline & \multirow[t]{2}{*}{ Group 4} & NWB Inaccuracy & 128 & 10.43 & 5.31 & \multirow[t]{2}{*}{2.150} & 127 & 0.033 \\
\hline & & WB Inaccuracy & 128 & 9.36 & 3.96 & & & \\
\hline Body Mass & Group 1 & NWB Inaccuracy & 75 & 12.18 & 7.16 & 2.023 & 74 & 0.047 \\
\hline & & WB Inaccuracy & 75 & 10.76 & 5.84 & & & \\
\hline & Group 2 & NWB Inaccuracy & 152 & 11.20 & 6.26 & 0.225 & 151 & 0.823 \\
\hline & & WB Inaccuracy & 152 & 11.07 & 4.82 & & & \\
\hline & Group 3 & NWB Inaccuracy & 162 & 9.73 & 5.06 & 0.416 & 161 & 0.678 \\
\hline & & WB Inaccuracy & 162 & 9.52 & 4.68 & & & \\
\hline & Group 4 & NWB Inaccuracy & 125 & 9.66 & 4.53 & 1.105 & 124 & 0.271 \\
\hline & & WB Inaccuracy & 125 & 0.09 & 4.37 & & & \\
\hline
\end{tabular}

Table 108: Paired t-test results for male inaccuracy scores comparing NWB and WB joints separated by BMI, stature, and body mass. 


\section{Females}

Table 109 shows the average accuracy scores for each method as well as the average accuracy scores for the NWB and WB joint groups. A paired-sample t-test was conducted to compare NWB and WB joint accuracy scores to determine if there are differences between the group accuracy scores for females. There are significant differences between the accuracy scores for $\operatorname{NWB}(\bar{x}=11.32$ years, s.d. $=6.52)$ and WB joints $(\bar{x}=9.18$ years, s.d. $=4.97) ; \mathrm{t}(200)=4.556, p$ $<0.001$.

\section{Table 109: Average accuracy scores for the Non-Weight-Bearing and Weight-Bearing Joint groups for females.}

When separated by BMI, the accuracy scores are significantly different between NWB and WB joints for underweight, normal-sized, and overweight females, with the NWB joints showing the most error. When separated by stature, the accuracy scores are significantly different between NWB and WB joints for females in all stature groups, with the NWB joints showing the most error. When separated by body mass, there are significant differences between NWB and WB joint accuracy scores for females in Groups 1 and 2, with the NWB joints showing the most error (see Table 110). 


\begin{tabular}{|c|c|c|c|c|c|c|c|c|}
\hline & Group & & $\mathrm{n}$ & Score (yrs) & s.d. (yrs) & $\mathbf{t}$ & df & Sig (2-tail) \\
\hline \multirow[t]{8}{*}{ BMI } & \multirow[t]{2}{*}{ Underweight } & NWB Inaccuracy & 38 & 13.12 & 6.71 & \multirow[t]{2}{*}{4.891} & \multirow[t]{2}{*}{37} & \multirow[t]{2}{*}{0.001} \\
\hline & & WB Inaccuracy & 38 & 8.57 & 5.21 & & & \\
\hline & \multirow[t]{2}{*}{ Normal } & NWB Inaccuracy & 103 & 11.48 & 6.71 & \multirow[t]{2}{*}{2.685} & \multirow[t]{2}{*}{102} & \multirow[t]{2}{*}{0.008} \\
\hline & & WB Inaccuracy & 103 & 9.67 & 5.20 & & & \\
\hline & \multirow{2}{*}{ Overweight } & NWB Inaccuracy & 45 & 10.18 & 6.22 & \multirow{2}{*}{2.047} & \multirow[t]{2}{*}{44} & \multirow{2}{*}{0.047} \\
\hline & & WB Inaccuracy & 45 & 8.09 & 3.93 & & & \\
\hline & \multirow[t]{2}{*}{ Obese } & NWB Inaccuracy & 15 & 9.17 & 4.48 & \multirow[t]{2}{*}{-0.959} & \multirow[t]{2}{*}{14} & \multirow{2}{*}{0.352} \\
\hline & & WB Inaccuracy & 15 & 10.60 & 5.20 & & & \\
\hline \multirow[t]{6}{*}{ Stature } & \multirow[t]{2}{*}{ Group 1} & NWB Inaccuracy & 107 & 11.54 & 6.72 & \multirow[t]{2}{*}{3.289} & \multirow[t]{2}{*}{106} & \multirow[t]{2}{*}{0.001} \\
\hline & & WB Inaccuracy & 107 & 9.48 & 5.07 & & & \\
\hline & \multirow[t]{2}{*}{ Group 2} & NWB Inaccuracy & 75 & 11.40 & 6.74 & \multirow[t]{2}{*}{2.428} & \multirow[t]{2}{*}{74} & \multirow[t]{2}{*}{0.018} \\
\hline & & WB Inaccuracy & 75 & 9.38 & 5.01 & & & \\
\hline & \multirow{2}{*}{ Group 3} & NWB Inaccuracy & 17 & 9.79 & 4.22 & \multirow[t]{2}{*}{2.283} & \multirow[t]{2}{*}{16} & \multirow[t]{2}{*}{0.036} \\
\hline & & WB Inaccuracy & 17 & 6.59 & 3.53 & & & \\
\hline \multirow[t]{8}{*}{ Body Mass } & \multirow[t]{2}{*}{ Group 1} & NWB Inaccuracy & 70 & 13.16 & 7.00 & \multirow[t]{2}{*}{3.703} & 69 & 0.001 \\
\hline & & WB Inaccuracy & 70 & 10.31 & 5.75 & & & \\
\hline & Group 2 & NWB Inaccuracy & 84 & 10.38 & 6.03 & 2.487 & 83 & 0.015 \\
\hline & & WB Inaccuracy & 84 & 8.56 & 4.65 & & & \\
\hline & Group 3 & NWB Inaccuracy & 29 & 10.28 & 6.58 & 1.711 & 28 & 0.098 \\
\hline & & WB Inaccuracy & 29 & 8.10 & 3.41 & & & \\
\hline & Group 4 & NWB Inaccuracy & 18 & 10.25 & 5.52 & 0.484 & 17 & 0.634 \\
\hline & & WB Inaccuracy & 18 & 9.42 & 4.72 & & & \\
\hline
\end{tabular}

Table 110: Paired t-test results for female inaccuracy scores comparing NWB and WB joints separated by BMI, stature, and body mass.

\subsubsection{Bias}

\section{Males}

Table 111 shows the average bias scores for each method as well as the average accuracy scores for the NWB and WB joint groups. A paired-sample t-test was conducted to compare NWB and WB joint bias scores to determine if there are differences between the group bias scores for males. There are significant differences between the accuracy scores for $\operatorname{NWB}(\bar{x}=2.43$ years, s.d. $=9.81)$ and WB joints $(\bar{x}=-2.22$ years, s.d. $=10.01) ; \mathrm{t}(513)=13.071, p<0.001$.

\begin{tabular}{|l|c|}
\hline Method & Bias Score (yrs) \\
\hline Kunos et al. & 4.02 \\
İşcan et al. & 0.83 \\
Non-Weight Bearing Joint Average & 2.46 \\
\hline Passalacqua & -0.87 \\
Lovejoy et al. & -5.07 \\
Buckberry and Chamberlain & 7.04 \\
Rougé-Maillart et al. & -4.60 \\
Suchey-Brooks & -6.36 \\
Weight-Bearing Joint Average & -2.28 \\
\hline
\end{tabular}

Table 111: Average bias scores for the Non-Weight-Bearing and Weight-Bearing Joint groups for males. 
When separated by BMI, there are differences between the NWB and WB joint bias scores of normal-sized, overweight, and obese males; males in the WB groups are significantly under-aged compared to males in the NWB groups. When separated by stature, there are significant differences between the bias scores of males in all groups; males in the WB groups are significantly under-aged compared to males in the NWB groups. When separated by body mass, there are significant differences among the bias scores of males in Groups 2, 3, and 4; males in the WB group are under-aged compared to males in the NWB groups (see Table 112).

\begin{tabular}{|c|c|c|c|c|c|c|c|c|}
\hline & Group & & n & Score (yrs) & s.d. (yrs) & $\mathbf{t}$ & df & Sig (2-tail) \\
\hline BMI & $\begin{array}{l}\text { Underweight } \\
\text { Normal } \\
\text { Overweight } \\
\text { Obese }\end{array}$ & $\begin{array}{l}\text { NWB Bias } \\
\text { WB Bias } \\
\text { NWB Bias } \\
\text { WB Bias } \\
\text { NWB Bias } \\
\text { WB Bias } \\
\text { NWB Bias } \\
\text { WB Bias }\end{array}$ & $\begin{array}{c}80 \\
80 \\
290 \\
290 \\
117 \\
117 \\
27 \\
27\end{array}$ & $\begin{array}{c}-4.79 \\
-4.52 \\
4.05 \\
-2.11 \\
3.13 \\
-0.96 \\
3.28 \\
-1.99 \\
\end{array}$ & $\begin{array}{l}12.97 \\
11.32 \\
8.21 \\
9.96 \\
9.35 \\
9.44 \\
7.37 \\
7.90\end{array}$ & $\begin{array}{r}-0.311 \\
13.431 \\
5.989\end{array}$ & $\begin{array}{c}79 \\
289\end{array}$ & $\begin{array}{l}0.757 \\
<0.001 \\
<0.001 \\
0.002 \\
\end{array}$ \\
\hline Stature & $\begin{array}{l}\text { Group } 1 \\
\text { Group } 2 \\
\text { Group } 3 \\
\text { Group } 4\end{array}$ & $\begin{array}{l}\text { NWB Bias } \\
\text { WB Bias } \\
\text { NWB Bias } \\
\text { WB Bias } \\
\text { NWB Bias } \\
\text { WB Bias } \\
\text { NWB Bias } \\
\text { WB Bias }\end{array}$ & $\begin{array}{c}55 \\
55 \\
136 \\
136 \\
195 \\
195 \\
128 \\
128 \\
\end{array}$ & $\begin{array}{c}-1.58 \\
-5.52 \\
2.77 \\
-2.56 \\
2.36 \\
-3.10 \\
3.89 \\
0.90 \\
\end{array}$ & $\begin{array}{c}9.85 \\
9.51 \\
9.86 \\
10.45 \\
9.75 \\
9.99 \\
9.45 \\
9.03 \\
\end{array}$ & $\begin{array}{l}4.045 \\
7.629 \\
9.156 \\
4.392\end{array}$ & $\begin{array}{r}54 \\
135 \\
194 \\
127\end{array}$ & $\begin{array}{l}\leq 0.001 \\
<0.001 \\
\leq 0.001 \\
60.001 \\
\end{array}$ \\
\hline Body Mass & $\begin{array}{l}\text { Group } 1 \\
\text { Group } 2 \\
\text { Group } 3 \\
\text { Group } 4\end{array}$ & $\begin{array}{l}\text { NWB Bias } \\
\text { WB Bias } \\
\text { NWB Bias } \\
\text { WB Bias } \\
\text { NWB Bias } \\
\text { WB Bias } \\
\text { NWB Bias } \\
\text { WB Bias }\end{array}$ & $\begin{array}{c}75 \\
75 \\
152 \\
152 \\
162 \\
162 \\
125 \\
125 \\
\end{array}$ & $\begin{array}{c}-3.02 \\
-4.40 \\
1.71 \\
-3.96 \\
4.79 \\
-0.85 \\
3.50 \\
-0.57\end{array}$ & $\begin{array}{c}12.90 \\
10.65 \\
9.72 \\
10.62 \\
7.84 \\
9.60 \\
8.75 \\
8.81 \\
\end{array}$ & $\begin{array}{l}1.433 \\
8.558 \\
9.205 \\
5.992\end{array}$ & $\begin{array}{c}74 \\
151 \\
161\end{array}$ & $\begin{array}{c}0.156 \\
\leq 0.001 \\
\leq 0.001 \\
\leq 0.001 \\
\end{array}$ \\
\hline
\end{tabular}

Table 112: Paired t-test results for male bias scores comparing NWB and WB joints separated by BMI, stature, and body mass.

\section{Females}

Table 113 shows the average bias scores for each method as well as the average bias scores for the NWB and WB joint groups. A paired-sample t-test was conducted to compare NWB and WB joint bias scores to determine if there are differences between the group bias scores for females. There are significant differences between the bias scores for $\operatorname{NWB}(\bar{x}=-1.28$ years, $s . d .=10.94)$ and WB joints $(\bar{x}=-2.84$ years, s.d. $=9.03) ; \mathrm{t}(200)=2.770, p=0.006$. 


\begin{tabular}{|l|c|}
\hline Method & Bias Score (yrs) \\
\hline Kunos et al. & 0.93 \\
İşcan et al. & -4.73 \\
Non-Weight Bearing Joint Average & -1.90 \\
\hline Passalacqua & -1.76 \\
Lovejoy et al. & -6.27 \\
Buckberry and Chamberlain & 4.31 \\
Rougé-Maillart et al. & -5.98 \\
Suchey-Brooks & -6.00 \\
Weight-Bearing Joint Average & -3.44 \\
\hline
\end{tabular}

Table 113: Average bias scores for the Non-Weight-Bearing and Weight-Bearing Joint groups for females.

When separated by BMI, there are significant differences between the NWB and WB joint bias scores for underweight and normal-sized females; underweight females are under-aged using the NWB joints compared to WB joints, and normal-sized females are under-aged using the WB joints compared to the NWB joints. When separated by stature, there are significant differences between the NWB and WB joint bias scores for females in Groups 1; the WB joints significantly under-age short females compared to the NWB joints. When separated by body mass, there are significant differences between NWB and WB joint bias scores for females in Group 2, with the WB joints significantly under-aging females compared to the NWB joints (see Table 114).

\begin{tabular}{|c|c|c|c|c|c|c|c|c|}
\hline & Group & & $\mathrm{n}$ & Score (yrs) & s.d. (yrs) & $\mathbf{t}$ & df & Sig (2-tail) \\
\hline BMI & $\begin{array}{l}\text { Underweight } \\
\text { Normal } \\
\text { Overweight } \\
\text { Obese }\end{array}$ & $\begin{array}{l}\text { NWB Bias } \\
\text { WB Bias } \\
\text { NWB Bias } \\
\text { WB Bias } \\
\text { NWB Bias } \\
\text { WB Bias } \\
\text { NWB Bias } \\
\text { WB Bias }\end{array}$ & $\begin{array}{c}38 \\
38 \\
103 \\
103 \\
45 \\
45 \\
15 \\
15\end{array}$ & $\begin{array}{c}-5.99 \\
-3.07 \\
-0.23 \\
-3.24 \\
0.02 \\
-1.56 \\
-0.50 \\
-3.37\end{array}$ & $\begin{array}{c}11.27 \\
8.84 \\
11.41 \\
9.57 \\
9.28 \\
7.73 \\
9.03 \\
9.92\end{array}$ & $\begin{array}{l}-2.310 \\
3.717 \\
1.566\end{array}$ & $\begin{array}{c}37 \\
102\end{array}$ & $\begin{array}{c}0.027 \\
<0.001 \\
0.124 \\
0.099\end{array}$ \\
\hline Stature & $\begin{array}{l}\text { Group } 1 \\
\text { Group } 2 \\
\text { Group } 3\end{array}$ & $\begin{array}{l}\text { NWB Bias } \\
\text { WB Bias } \\
\text { NWB Bias } \\
\text { WB Bias } \\
\text { NWB Bias } \\
\text { WB Bias }\end{array}$ & $\begin{array}{l}107 \\
107 \\
75 \\
75 \\
17 \\
17 \\
\end{array}$ & $\begin{array}{c}-2.41 \\
-4.25 \\
-0.16 \\
-1.74 \\
0.50 \\
0.65 \\
\end{array}$ & $\begin{array}{c}11.76 \\
9.06 \\
10.24 \\
9.28 \\
8.66 \\
6.57 \\
\end{array}$ & $\begin{array}{r}2.281 \\
1.759 \\
-0.088\end{array}$ & $\begin{array}{c}106 \\
74\end{array}$ & $\begin{array}{l}0.025 \\
0.083 \\
0.931\end{array}$ \\
\hline Body Mass & $\begin{array}{l}\text { Group } 1 \\
\text { Group } 2 \\
\text { Group } 3 \\
\text { Group } 4\end{array}$ & $\begin{array}{l}\text { NWB Bias } \\
\text { WB Bias } \\
\text { NWB Bias } \\
\text { WB Bias } \\
\text { NWB Bias } \\
\text { WB Bias } \\
\text { NWB Bias } \\
\text { WB Bias }\end{array}$ & $\begin{array}{l}70 \\
70 \\
84 \\
84 \\
29 \\
29 \\
18 \\
18\end{array}$ & $\begin{array}{c}-5.06 \\
-5.37 \\
1.21 \\
-1.51 \\
1.10 \\
-0.61 \\
-2.08 \\
-2.81\end{array}$ & $\begin{array}{l}12.30 \\
9.86 \\
9.78 \\
8.58 \\
9.27 \\
7.26 \\
9.25 \\
8.71\end{array}$ & $\begin{array}{l}0.293 \\
3.276 \\
1.265 \\
0.438\end{array}$ & $\begin{array}{l}83 \\
28 \\
17\end{array}$ & \begin{tabular}{|l|}
\multicolumn{1}{l}{0.771} \\
0.002 \\
0.216 \\
0.667
\end{tabular} \\
\hline
\end{tabular}

Table 114: Paired t-test results for female bias scores comparing NWB and WB joints separated by BMI, stature, and body mass. 


\subsubsection{Ancestry}

\subsubsection{Accuracy}

\section{European Ancestry}

Table 115 shows the average accuracy scores for each method as well as the average accuracy scores for the NWB and WB joint groups. A paired-sample t-test was conducted to compare NWB and WB joint accuracy scores to determine if there are differences between the group accuracy scores for individuals of European ancestry. There are significant differences between the accuracy scores for NWB $(\bar{x}=10.70$ years, $s . d .=5.97)$ and WB joints $(\bar{x}=10.10$ years, s.d. $=4.95) ; \mathrm{t}(510)=2.042, p=0.042$.

\begin{tabular}{|l|c|}
\hline Method & Accuracy Score (yrs) \\
\hline Kunos et al. & 10.19 \\
İşcan et al. & 11.30 \\
Non-Weight Bearing Joint Average & 10.70 \\
\hline Passalacqua & 11.47 \\
Lovejoy et al. & 9.24 \\
Buckberry and Chamberlain & 10.87 \\
Rougé-Maillart et al. & 10.83 \\
Suchey-Brooks & 9.70 \\
Weight-Bearing Joint Average & 10.10 \\
\hline
\end{tabular}

Table 115: Average accuracy scores for the Non-Weight-Bearing and Weight-Bearing Joint groups for individuals of European ancestry.

When separated by BMI, there are no significant differences among the accuracy scores between NWB and WB joints for individuals of European ancestry. When separated by stature, there are significant differences among the accuracy scores between NWB and WB joints for individuals of European ancestry in Group 1, with the NWB joints showing the most error for short individuals. When separated by body mass, there are significant differences between NWB and WB joints for individuals of European ancestry in Group 1, with the NWB joints showing the most error for individuals in the lightest body mass group (see Table 116). 


\begin{tabular}{|c|c|c|c|c|c|c|c|c|}
\hline & Group & & $\mathbf{n}$ & Score (yrs) & s.d. (yrs) & $\mathbf{t}$ & df & Sig (2-tail) \\
\hline \multirow[t]{7}{*}{ BMI } & Underweight & NWB Inaccuracy & $\begin{array}{l}69 \\
69\end{array}$ & $\begin{array}{l}11.35 \\
1134\end{array}$ & $\begin{array}{l}7.27 \\
5.98\end{array}$ & 0.014 & 68 & 0.989 \\
\hline & \multirow[t]{2}{*}{ Normal } & $\begin{array}{l}\text { WB Inaccuracy } \\
\text { NWB Inaccuracy }\end{array}$ & $\begin{array}{c}09 \\
276\end{array}$ & $\begin{array}{l}11.04 \\
11.00\end{array}$ & $\begin{array}{l}.90 \\
5.97\end{array}$ & \multirow{2}{*}{1.970} & \multirow{2}{*}{275} & \multirow{2}{*}{0.050} \\
\hline & & WB Inaccuracy & 276 & 10.20 & 4.90 & & & \\
\hline & \multirow[t]{2}{*}{ Overweight } & NWB Inaccuracy & 129 & 10.17 & 5.48 & \multirow[t]{2}{*}{1.397} & \multirow[t]{2}{*}{128} & 0.165 \\
\hline & & WB Inaccuracy & 129 & 9.34 & 4.48 & & & \\
\hline & \multirow[t]{2}{*}{ Obese } & NWB Inaccuracy & 37 & 9.09 & 4.55 & \multirow[t]{2}{*}{-0.565} & \multirow[t]{2}{*}{36} & \multirow{2}{*}{0.575} \\
\hline & & WB Inaccuracy & 37 & 9.68 & 4.38 & & & \\
\hline \multirow[t]{8}{*}{ Stature } & \multirow[t]{2}{*}{ Gro } & NWB Inaccuracy & 121 & 11.64 & 6.75 & \multirow[t]{2}{*}{1.987} & \multirow[t]{2}{*}{120} & 0.049 \\
\hline & & WB Inaccuracy & 121 & 10.43 & 5.22 & & & \multirow{2}{*}{0.111} \\
\hline & \multirow[t]{2}{*}{ Group 2} & NWB Inaccuracy & 158 & 10.92 & 5.73 & \multirow[t]{2}{*}{1.604} & \multirow[t]{2}{*}{157} & \\
\hline & & WB Inaccuracy & 158 & 10.09 & 5.28 & & & \\
\hline & \multirow{2}{*}{ Group 3} & NWB Inaccuracy & 150 & 9.81 & 5.68 & \multirow[t]{2}{*}{-0.413} & \multirow{2}{*}{149} & \multirow[t]{2}{*}{0.680} \\
\hline & & WB Inaccuracy & 150 & 10.05 & 4.79 & & & \\
\hline & \multirow{2}{*}{ Group 4} & NWB Inaccuracy & 82 & 10.49 & 5.56 & \multirow{2}{*}{1.193} & \multirow[t]{2}{*}{81} & 0.236 \\
\hline & & WB Inaccuracy & 82 & 9.73 & 4.16 & & & \\
\hline Body Mass & Group 1 & NWB Inaccuracy & 101 & 12.01 & 6.94 & 2.059 & 100 & 0.042 \\
\hline & & WB Inaccuracy & 101 & 10.83 & 5.69 & & & \\
\hline & Group 2 & NWB Inaccuracy & 150 & 11.27 & 6.23 & 0.544 & 149 & 0.587 \\
\hline & & WB Inaccuracy & 150 & 10.94 & 5.11 & & & \\
\hline & Group 3 & NWB Inaccuracy & 145 & 9.88 & 5.55 & 0.923 & 144 & 0.358 \\
\hline & & WB Inaccuracy & 145 & 9.36 & 4.48 & & & \\
\hline & Group 4 & NWB Inaccuracy & 115 & 9.84 & 4.87 & 0.932 & 114 & 0.353 \\
\hline & & WB Inaccuracy & 115 & 9.30 & 4.35 & & & \\
\hline
\end{tabular}

Table 116: Paired t-test results for European accuracy scores comparing NWB and WB joints separated by BMI, stature, and body mass.

\section{African Ancestry}

Table 117 shows the average accuracy scores for each method as well as the average accuracy scores for the NWB and WB joint groups. A paired-sample t-test was conducted to compare NWB and WB joint accuracy scores to determine if there are differences between the group accuracy scores for individuals of African ancestry. There are significant differences between the accuracy scores for NWB $(\bar{x}=10.83$ years, s.d. $=5.99)$ and WB joints $(\bar{x}=9.08$ years, $s . d .=$ 4.81); $\mathrm{t}(203)=3.960, p<0.001$.

\begin{tabular}{|l|c|}
\hline Method & Accuracy Score (yrs) \\
\hline Kunos et al. & 11.03 \\
İşcan et al. & 10.85 \\
Non-Weight Bearing Joint Average & 10.94 \\
\hline Passalacqua & 11.42 \\
Lovejoy et al. & 7.15 \\
Buckberry and Chamberlain & 12.85 \\
Rougé-Maillart et al. & 9.06 \\
Suchey-Brooks & 7.96 \\
Weight-Bearing Joint Average & 9.22 \\
\hline
\end{tabular}

Table 117: Average accuracy scores for the Non-Weight-Bearing and Weight-Bearing Joint groups for individuals of African ancestry. 
When separated by BMI, the accuracy scores are significantly different between NWB and WB joints for underweight individuals of African ancestry, with the NWB joints showing the most error. When separated by stature, the accuracy scores are significantly different between NWB and WB joints for individuals of African ancestry in Groups 3 and 4, with the NWB joints showing the most error for individuals in the tallest stature groups. When separated by body mass, there are significant differences between NWB and WB joints for individuals of African ancestry in Groups 1 and 2, with the NWB joints showing the most error for individuals in the lightest body mass groups (see Table 118).

\begin{tabular}{|c|c|c|c|c|c|c|c|c|}
\hline & Group & & n & Score (yrs) & s.d. (yrs) & $\mathbf{t}$ & df & Sig (2-tail) \\
\hline \multirow[t]{8}{*}{ BMI } & \multirow[t]{2}{*}{ Underweight } & NWB Inaccuracy & 49 & 14.04 & 7.06 & \multirow[t]{2}{*}{5.400} & \multirow[t]{2}{*}{48} & \multirow[t]{2}{*}{0.001} \\
\hline & & WB Inaccuracy & 49 & 9.27 & 5.16 & & & \\
\hline & \multirow[t]{2}{*}{ Normal } & NWB Inaccuracy & 117 & 10.02 & 5.34 & \multirow[t]{2}{*}{1.440} & \multirow[t]{2}{*}{116} & 0.153 \\
\hline & & WB Inaccuracy & 117 & 9.17 & 4.86 & & & \multirow{3}{*}{0.552} \\
\hline & \multirow[t]{2}{*}{ Overweight } & NWB Inaccuracy & 33 & 9.18 & 5.12 & \multirow[t]{2}{*}{0.601} & \multirow[t]{2}{*}{32} & \\
\hline & & WB Inaccuracy & 33 & 8.64 & 4.42 & & & \\
\hline & \multirow{2}{*}{ Obese } & NWB Inaccuracy & 5 & 9.10 & 3.85 & \multirow[t]{2}{*}{0.566} & \multirow[t]{2}{*}{4} & \multirow[t]{2}{*}{0.602} \\
\hline & & WB Inaccuracy & 5 & 7.95 & 2.77 & & & \\
\hline \multirow[t]{8}{*}{ Stature } & \multirow[t]{2}{*}{ Group 1} & NWB Inaccuracy & 41 & 10.27 & 5.90 & \multirow[t]{2}{*}{1.940} & \multirow[t]{2}{*}{40} & \multirow[t]{2}{*}{0.059} \\
\hline & & WB Inaccuracy & 41 & 8.39 & 4.39 & & & \\
\hline & \multirow{2}{*}{ Group 2} & NWB Inaccuracy & 53 & 11.17 & 6.30 & \multirow{2}{*}{1.576} & \multirow{2}{*}{52} & 0.121 \\
\hline & & WB Inaccuracy & 53 & 9.85 & 4.72 & & & \multirow[b]{2}{*}{0.025} \\
\hline & \multirow[t]{2}{*}{ Group 3} & NWB Inaccuracy & 62 & 11.31 & 6.63 & 2.290 & 61 & \\
\hline & & WB Inaccuracy & 62 & 9.22 & 5.89 & \multirow{3}{*}{2.091} & & \\
\hline & \multirow[t]{2}{*}{ Group 4} & NWB Inaccuracy & 48 & 10.30 & 4.84 & & 47 & 0.042 \\
\hline & & WB Inaccuracy & 48 & 8.63 & 3.52 & & & \\
\hline Body Mass & Group 1 & NWB Inaccuracy & 44 & 14.14 & 7.22 & 4.102 & 43 & $<0.001$ \\
\hline & & WB Inaccuracy & 44 & 9.91 & 6.02 & & & \\
\hline & Group 2 & NWB Inaccuracy & 86 & 10.28 & 6.08 & 2.076 & 85 & 0.041 \\
\hline & & WB Inaccuracy & 86 & 8.84 & 4.21 & & & \\
\hline & Group 3 & NWB Inaccuracy & 46 & 9.60 & 4.50 & 0.572 & 45 & 0.570 \\
\hline & & WB Inaccuracy & 46 & 9.11 & 4.72 & & & \\
\hline & Group 4 & NWB Inaccuracy & 28 & 9.30 & 3.60 & 0.923 & 27 & 0.364 \\
\hline & & WB Inaccuracy & 28 & 8.43 & 4.62 & & & \\
\hline
\end{tabular}

Table 118: Paired t-test results for individuals of African ancestry accuracy scores comparing NWB and WB joints separated by BMI, stature, and body mass.

\subsubsection{Bias}

\section{European Ancestry}

Table 119 shows the average bias scores for each method as well as the average bias scores for the NWB and WB joint groups. A paired-sample t-test was conducted to compare NWB and WB joint bias scores to determine if there are differences between the group bias scores for individuals of European ancestry. There are significant differences between the bias scores for 
NWB $(\bar{x}=0.81$ years, $s . d .=10.43)$ and WB joints $(\bar{x}=-3.55$ years, $s . d .=9.62) ; \mathrm{t}(510)=12.259$, $p<0.001$.

\begin{tabular}{|l|c|}
\hline Method & Bias Score (yrs) \\
\hline Kunos et al. & 2.05 \\
İşcan et al. & -0.74 \\
Non-Weight Bearing Joint Average & 0.82 \\
\hline Passalacqua & -2.37 \\
Lovejoy et al. & -6.62 \\
Buckberry and Chamberlain & 5.28 \\
Rougé-Maillart et al. & -6.49 \\
Suchey-Brooks & -7.12 \\
Weight-Bearing Joint Average & -3.73 \\
\hline
\end{tabular}

Table 119: Average bias scores for the Non-Weight-Bearing and Weight-Bearing Joint groups for individuals of European ancestry.

When separated by BMI, there are significant differences between the NWB and WB joint bias scores for underweight, normal-sized, and obese individuals of European ancestry; the WB joints under-age individuals compared to the WB joints. When separated by stature, there are significant differences between the NWB and WB joint bias scores for all stature groups; the WB joints significantly under-age compared to the NWB joints. When separated by body mass, there are significant differences between NWB and WB joint bias scores for individuals of European ancestry in Groups 2, 3, and 4, with the WB joints significantly under-aging individuals compared to the NWB joints (see Table 120). 


\begin{tabular}{|c|c|c|c|c|c|c|c|c|}
\hline & Group & & $\mathrm{n}$ & Score (yrs) & s.d. (yrs) & $\mathbf{t}$ & df & Sig (2-tail) \\
\hline \multirow[t]{8}{*}{ BMI } & \multirow[t]{2}{*}{ Underweight } & NWB Bias & 69 & -6.88 & 11.09 & \multirow[t]{2}{*}{-0.510} & \multirow[t]{2}{*}{68} & \multirow[t]{2}{*}{0.612} \\
\hline & & WB Bias & 69 & -6.43 & 10.33 & & & \\
\hline & \multirow[t]{2}{*}{ Normal } & NWB Bias & 276 & 2.30 & 10.04 & \multirow[t]{2}{*}{12.425} & \multirow[t]{2}{*}{275} & \multirow[t]{2}{*}{$<0.001$} \\
\hline & & WB Bias & 276 & -3.74 & 9.72 & & & \\
\hline & \multirow{2}{*}{ Overweight } & NWB Bias & 129 & 1.51 & 9.75 & \multirow{2}{*}{5.124} & \multirow{2}{*}{128} & \multirow{2}{*}{ k0.001 } \\
\hline & & WB Bias & 129 & -1.84 & 8.90 & & & \\
\hline & \multirow[t]{2}{*}{ Obese } & NWB Bias & 37 & 1.58 & 8.25 & \multirow[t]{2}{*}{3.745} & \multirow[t]{2}{*}{36} & 0.001 \\
\hline & & WB Bias & 37 & -2.74 & 8.86 & & & \\
\hline \multirow[t]{8}{*}{ Stature } & Group 1 & NWB Bias & 121 & -3.67 & 11.63 & \multirow[t]{2}{*}{3.335} & \multirow[t]{2}{*}{120} & \multirow[t]{2}{*}{\begin{tabular}{|l|}
0.001 \\
\end{tabular}} \\
\hline & & WB Bias & 121 & -6.15 & 9.04 & & & \\
\hline & \multirow[t]{2}{*}{ Group 2} & NWB Bias & 158 & 0.97 & 10.07 & \multirow[t]{2}{*}{7.056} & \multirow[t]{2}{*}{157} & 0.001 \\
\hline & & WB Bias & 158 & -3.58 & 9.69 & & & \\
\hline & \multirow{2}{*}{ Group 3} & NWB Bias & 150 & 2.18 & 8.92 & \multirow[t]{2}{*}{9.440} & \multirow{2}{*}{149} & \multirow[t]{2}{*}{$<0.001$} \\
\hline & & WB Bias & 150 & -3.93 & 9.42 & & & \\
\hline & \multirow{2}{*}{ Group 4} & NWB Bias & 82 & 4.60 & 9.69 & \multirow[t]{2}{*}{4.419} & \multirow[t]{2}{*}{81} & $<0.001$ \\
\hline & & WB Bias & 82 & 1.03 & 9.22 & & & \\
\hline Body Mass & Group 1 & NWB Bias & 101 & -5.10 & 11.96 & 1.983 & 100 & 0.050 \\
\hline & & WB Bias & 101 & -6.65 & 9.44 & & & \\
\hline & Group 2 & NWB Bias & 150 & 0.94 & 10.20 & 8.585 & 149 & $<0.001$ \\
\hline & & WB Bias & 150 & -4.82 & 10.17 & & & \\
\hline & Group 3 & NWB Bias & 145 & 3.71 & 8.65 & 8.573 & 144 & 60.001 \\
\hline & & WB Bias & 145 & -1.87 & 9.09 & & & \\
\hline & Group 4 & NWB Bias & 115 & 2.17 & 9.36 & 4.930 & 114 & $<0.001$ \\
\hline & & WB Bias & 115 & -1.30 & 8.79 & & & \\
\hline
\end{tabular}

Table 120: Paired t-test results for European bias scores comparing NWB and WB joints separated by BMI, stature, and body mass.

\section{African Ancestry}

Table 121 shows the average bias scores for each method as well as the average bias scores for the NWB and WB joint groups. A paired-sample t-test was conducted to compare NWB and WB joint bias scores to determine if there are differences between the group bias scores for individuals of African ancestry. There are significant differences between the bias scores for $\operatorname{NWB}(\bar{x}=2.82$ years, s.d. $=9.71)$ and WB joints $(\bar{x}=0.51$ years, $s . d .=9.45) ; \mathrm{t}(203)=4.008, p$ $<0.001$.

\begin{tabular}{|l|c|}
\hline Method & Bias Score (yrs) \\
\hline Kunos et al. & 5.82 \\
İscan et al. & -0.73 \\
Non-Weight Bearing Joint Average & 2.78 \\
\hline Passalacqua & 2.05 \\
Lovejoy et al. & -2.35 \\
Buckberry and Chamberlain & 8.74 \\
Rougé-Maillart et al. & -1.17 \\
Suchey-Brooks & -4.02 \\
Weight-Bearing Joint Average & 0.28 \\
\hline
\end{tabular}

Table 121: Average bias scores for the Non-Weight-Bearing and Weight-Bearing Joint groups for individuals of African ancestry. 
When separated by BMI, there are significant differences between the NWB and WB joint bias scores for normal-sized and overweight individuals of African ancestry; the WB joints under-age individuals compared to the NWB joints. When separated by stature, there are significant differences between the NWB and WB joint bias scores for individuals of African ancestry in Groups 1, 2, and 3; the WB joints significantly under-age individuals compared to the NWB joints. When separated by body mass, there are significant differences between NWB and WB joint bias scores for individuals of African ancestry in Groups 2, 3, and 4, with the WB joints significantly under-aging individuals compared to the NWB joints (see Table 122).

\begin{tabular}{|c|c|c|c|c|c|c|c|c|}
\hline & Group & & $\mathrm{n}$ & Score (yrs) & s.d. (yrs) & $\mathbf{t}$ & df & Sig (2-tail) \\
\hline \multirow[t]{8}{*}{ BMI } & \multirow[t]{2}{*}{ Underweight } & NWB Bias & 49 & -2.78 & 13.83 & \multirow[t]{2}{*}{-1.657} & \multirow[t]{2}{*}{48} & \multirow[t]{2}{*}{0.104} \\
\hline & & WB Bias & 49 & -0.69 & 10.06 & & & \\
\hline & \multirow[t]{2}{*}{ Normal } & NWB Bias & 117 & 4.41 & 7.21 & \multirow[t]{2}{*}{5.157} & \multirow[t]{2}{*}{116} & \multirow[t]{2}{*}{0.001} \\
\hline & & WB Bias & 117 & 0.74 & 9.50 & & & \\
\hline & \multirow{2}{*}{ Overweight } & NWB Bias & 33 & 5.24 & 7.29 & \multirow[t]{2}{*}{2.993} & \multirow[t]{2}{*}{32} & \multirow[t]{2}{*}{0.005} \\
\hline & & WB Bias & 33 & 1.65 & 8.85 & & & \\
\hline & \multirow[t]{2}{*}{ Obese } & NWB Bias & 5 & 4.50 & 7.16 & \multirow[t]{2}{*}{1.136} & \multirow[t]{2}{*}{4} & \multirow[t]{2}{*}{0.319} \\
\hline & & WB Bias & 5 & -0.55 & 6.49 & & & \\
\hline \multirow[t]{8}{*}{ Stature } & \multirow[t]{2}{*}{ Group 1} & NWB Bias & 41 & 2.44 & 7.99 & \multirow[t]{2}{*}{2.310} & \multirow[t]{2}{*}{40} & \multirow[t]{2}{*}{0.026} \\
\hline & & WB Bias & 41 & -0.35 & 8.37 & & & \\
\hline & \multirow{2}{*}{ Group 2} & NWB Bias & 53 & 3.98 & 9.82 & \multirow[t]{2}{*}{2.040} & \multirow[t]{2}{*}{52} & \multirow[t]{2}{*}{\begin{tabular}{|l|}
0.046 \\
\end{tabular}} \\
\hline & & WB Bias & 53 & 1.67 & 10.12 & & & \\
\hline & \multirow[t]{2}{*}{ Group 3} & NWB Bias & 62 & 2.27 & 11.34 & \multirow[t]{2}{*}{2.098} & 61 & \multirow{2}{*}{\begin{tabular}{|l|}
0.040 \\
\end{tabular}} \\
\hline & & WB Bias & 62 & -0.06 & 10.24 & & & \\
\hline & \multirow{2}{*}{ Group 4} & NWB Bias & 48 & 2.57 & 8.80 & \multirow[t]{2}{*}{1.585} & 47 & 0.120 \\
\hline & & WB Bias & 48 & 0.71 & 8.61 & & & \\
\hline Body Mass & Group 1 & NWB Bias & 44 & -1.50 & 13.81 & -0.497 & 43 & 0.622 \\
\hline & & WB Bias & 44 & -0.77 & 10.97 & & & \\
\hline & Group 2 & NWB Bias & 86 & 2.56 & 8.79 & 3.261 & 85 & 0.002 \\
\hline & & WB Bias & 86 & -0.07 & 8.97 & & & \\
\hline & Group 3 & NWB Bias & 46 & 5.88 & 6.16 & 2.969 & 45 & 0.005 \\
\hline & & WB Bias & 46 & 2.52 & 9.14 & & & \\
\hline & Group 4 & NWB Bias & 28 & 5.38 & 6.74 & 2.970 & 27 & 0.006 \\
\hline & & WB Bias & 28 & 1.00 & 8.75 & & & \\
\hline
\end{tabular}

Table 122: Paired t-test results for individuals of African ancestry bias scores comparing NWB and WB joints separated by BMI, stature, and body mass. 


\subsubsection{Results Summary}

\subsubsection{Accuracy}

There are no differences between the non-weight-bearing (NWB) and weight-bearing (WB) joint surface accuracy scores for males and individuals of European ancestry when separated by BMI, but there are for females and individuals of African ancestry. Underweight, normal-sized, and overweight females and underweight individuals of African ancestry have more error associated with their age estimations using NWB joints compared to WB joints. When separated by stature, there is significantly more error associated with the NWB joint age estimations for males in the tallest stature group and individuals of European ancestry in the shortest stature group compared to the WB joints. For females, there is significantly more error associated with NWB joint age estimations compared to WB joints for all stature groups. For individuals of African ancestry, there is significantly more error associated with the NWB joint stature age estimations for individuals in the two tallest groups. When separated by body mass, there is significantly more error associated with the NWB joint age estimations for males in the heaviest body mass group, individuals of European ancestry in the lightest body mass group, and females and individuals of African ancestry in the two lightest body mass groups compared to the WB joints. NWB joints have more error associated with their age estimations (between 1 and 5 years) compared to WB joints, and most of the error is associated with tall and light individuals.

\subsubsection{Bias}

When separated by BMI, normal-sized, overweight, and obese males and individuals of European ancestry are under-aged significantly when using WB joints compared to NWB joints. Underweight females are under-aged using NWB joints compared to WB joints, and normalsized females are under-aged using WB joints compared to NWB joints. Underweight and normal-sized individuals of African ancestry are under-aged using the WB joints compared to the NWB joints. When separated by stature, males and individuals of European ancestry in all stature groups are under-aged using WB joints compared to NWB joints. Short females are under-aged using WB joints compared to NWB joints. Individuals of African ancestry in all stature groups except the tallest are under-aged using WB joints compared to NWB joints. When separated by body mass, all males, individuals of European ancestry, and individuals of African 
ancestry except for those in the lightest body mass groups are under-aged using WB joints compared to NWB joints. Females in the second lightest body mass group are under-aged using WB joints compared to NWB joints. Overall, WB joints are under-aged compared to NWB joints by approximately 2 to 6 years. 


\subsection{Additional Analyses}

For three of the methods used in the analysis - the Passalacqua sacrum method, the Buckberry and Chamberlain auricular surface method, and the Rougé-Maillart et al. auricular surface and acetabulum method - individual traits such as transverse organization, surface texture, porosity, and apical activity were assessed and scored separately. Further analyses were conducted on each of these features to ascertain whether there are different patterns among the BMI, stature, and body mass groups for these individual traits. One-way ANOVAs were used for these analyses.

There are seven features of the sacrum scored using the Passalacqua method: fusion between S2 and $\mathrm{S} 3$ on a scale of 1 to 2 , fusion between $\mathrm{S} 1$ and $\mathrm{S} 2$ on a scale of 1 to 2, surface changes on a scale of 1 to 2, apical changes on a scale of 1 to $2, \mathrm{~S} 1$ ring fusion on a scale of 1 to 3 , microporosity on a scale of 1 to 2 , and macroporosity on a scale of 1 to 2 . The lowest scores categorize early maturation stages while the highest scores categorize progressive degenerative changes. Fusion between S2 and S3 and fusion between S1 and S2 were not evaluated in the qualitative analysis. When separated by BMI, ANOVA tests show there are only statistically significant differences among the BMI groups for apical changes (Table 123). Tukey's $b$ posthoc tests show that the apical change scores for underweight and normal-sized individuals are significantly lower than those of obese individuals (see Table 124).

\begin{tabular}{|ll|r|r|r|r|r|}
\hline & & Sum of Squares & \multicolumn{1}{c|}{ df } & Mean Square & \multicolumn{1}{c|}{ F } & \multicolumn{1}{c|}{ Sig. } \\
\hline Surface Changes & Between Groups & 0.020 & 3 & 0.007 & 0.850 & 0.467 \\
& Within Groups & 5.933 & 755 & 0.008 & & \\
& Total & 5.953 & 758 & & & \\
Apical Changes & Between Groups & 1.580 & 3 & 0.527 & 3.548 & 0.014 \\
& Within Groups & 11.930 & 754 & 0.148 & & \\
S1 Ring Fusion & Total & 113.511 & 757 & & \\
& Between Groups & 1.119 & 3 & 0.373 & 1.429 & 0.233 \\
& Within Groups & 195.949 & 751 & 0.261 & & \\
Microporosity & Total & 197.068 & 754 & & \\
& Between Groups & 0.289 & 3 & 0.096 & 1.044 & 0.372 \\
& Within Groups & 69.684 & 754 & 0.092 & & \\
Macroporosity & Total & 69.974 & 757 & & & \\
& Between Groups & 0.531 & 3 & 0.177 & 0.748 & 0.523 \\
& Within Groups & 178.283 & 754 & 0.236 & & \\
\hline
\end{tabular}

Table 123: One-way ANOVA results for the Passalacqua sacrum method individual scoring features for BMI groups. 


\begin{tabular}{|c|c|c|c|c|}
\hline & & & & set \\
\hline & BMI & $\mathbf{n}$ & 1 & 2 \\
\hline Surface Changes & Normal & 406 & 1.99 & \\
\hline & Overweight & 170 & 1.99 & \\
\hline & Underweight & 134 & 2.00 & \\
\hline & Obese & 49 & 2.00 & \\
\hline Apical Changes & Underweight & 134 & 1.78 & \\
\hline & Normal & 406 & 1.80 & \\
\hline & Overweight & 170 & 1.86 & 1.86 \\
\hline & Obese & 49 & & 1.94 \\
\hline S1 Ring Fusion & Underweight & 134 & 2.35 & \\
\hline & Normal & 406 & 2.41 & \\
\hline & Overweight & 170 & 2.47 & \\
\hline & Obese & 49 & 2.50 & \\
\hline Microporosity & Overweight & 170 & 1.88 & \\
\hline & Normal & 406 & 1.89 & \\
\hline & Underweight & 134 & 1.91 & \\
\hline & Obese & 49 & 1.96 & \\
\hline Macroporosity & Underweight & 134 & 1.35 & \\
\hline & Overweight & 170 & 1.37 & \\
\hline & Normal & 406 & 1.39 & \\
\hline & Obese & 49 & 1.47 & \\
\hline
\end{tabular}

Table 124: Tukey's $b$ post-hoc tests for the Passalacqua method individual scoring features for BMI.

Similarly, when separated by stature, there are only significant differences among the BMI groups for apical changes (Table 125). Tukey's $b$ post-hoc tests show that the apical change scores for the Group 3 are significantly lower compared to individuals in Groups 1 and 2 (see Table 126).

\begin{tabular}{|ll|r|r|r|r|r|}
\hline & & Sum of Squares & df & Mean Square & F & Sig. \\
\hline Surface Changes & Between Groups & 0.010 & 3 & 0.003 & 0.418 & 0.740 \\
& Within Groups & 5.943 & 755 & 0.008 & & \\
& Total & 5.953 & 758 & & & \\
Apical Changes & Between Groups & 2.081 & 3 & 0.694 & 4.694 & 0.003 \\
& Within Groups & 111.430 & 754 & 0.148 & & \\
S1 Ring Fusion & Total & 113.511 & 757 & & \\
& Between Groups & 0.446 & 3 & 0.149 & 0.568 & 0.636 \\
& Within Groups & 196.621 & 751 & 0.262 & & \\
Microporosity & Total & 197.068 & 754 & & \\
& Between Groups & 0.512 & 3 & 0.171 & 1.854 & 0.136 \\
& Within Groups & 69.461 & 754 & 0.092 & & \\
Macroporosity & Total & 69.974 & 757 & & & \\
& Between Groups & 0.896 & 3 & 0.299 & 1.266 & 0.285 \\
& Within Groups & 177.918 & 754 & 0.236 & & \\
\hline
\end{tabular}

Table 125: One-way ANOVA results for the Passalacqua sacrum method individual scoring features for stature groups. 


\begin{tabular}{|l|l|c|cc|}
\hline & \multicolumn{2}{c|}{} & \multicolumn{2}{c|}{ Subset } \\
& Stature & n & 1 & 2 \\
\hline Surface Changes & Group 4 & 137 & 1.99 & \\
& Group 3 & 222 & 1.99 & \\
& Group 1 & 181 & 1.99 & \\
& Group 2 & 219 & 2.00 & \\
\hline Apical Changes & Group 3 & 222 & 1.74 & \\
& Group 4 & 137 & 1.80 & 1.80 \\
& Group 1 & 181 & & 1.86 \\
& Group 2 & 219 & & 1.87 \\
\hline S1 Ring Fusion & Group 4 & 137 & 2.39 & \\
& Group 1 & 181 & 2.40 & \\
& Group 2 & 219 & 2.40 & \\
& Group 3 & 222 & 2.45 & \\
\hline Microporosity & Group 1 & 181 & 1.86 & \\
& Group 3 & 222 & 1.90 & \\
& Group 4 & 137 & 1.92 & \\
& Group 2 & 219 & 1.92 & \\
\hline Macroporosity & Group 3 & 222 & 1.33 & \\
& Group 4 & 137 & 1.39 & \\
& Group 2 & 219 & 1.41 & \\
& Group 1 & 181 & 1.41 & \\
\hline
\end{tabular}

Table 126: Tukey's $b$ post-hoc tests for the Passalacqua method individual scoring features for stature.

When separated by body mass, there are no significant differences among the body mass group scoring features for the Passalacqua method (Table 127).

\begin{tabular}{|ll|r|r|r|r|r|}
\hline & & Sum of Squares & df & Mean Square & F & \multicolumn{1}{c|}{ Sig. } \\
\hline Surface Changes & Between Groups & 0.016 & 3 & 0.005 & 0.696 & 0.555 \\
& Within Groups & 5.936 & 755 & 0.008 & & \\
& Total & 5.953 & 758 & & & \\
Apical Changes & Between Groups & 0.660 & 3 & 0.220 & 1.470 & 0.221 \\
& Within Groups & 112.851 & 754 & 0.150 & & \\
S1 Ring Fusion & Total & 113.511 & 757 & & \\
& Between Groups & 1.060 & 3 & 0.353 & 1.354 & 0.256 \\
& Within Groups & 196.007 & 751 & 0.261 & & \\
Microporosity & Total & 197.068 & 754 & & \\
& Between Groups & 0.147 & 3 & 0.049 & 0.530 & 0.662 \\
& Within Groups & 69.826 & 754 & 0.093 & & \\
Macroporosity & Total & 69.974 & 757 & & & \\
& Between Groups & 1.150 & 3 & 0.383 & 1.627 & 0.182 \\
& Within Groups & 177.664 & 754 & 0.236 & & \\
\hline
\end{tabular}

Table 127: One-way ANOVA results for the Passalacqua sacrum method individual scoring features for body mass groups. 
There are five features of the auricular surface scored using the Buckberry and Chamberlain method: transverse organization on a scale of 1 to 5 , surface texture on a scale of 1 to 5 , microporosity on a scale of 1 to 3 , macroporosity on a scale of 1 to 3 , and apical activity on a scale of 1 to 3 . The lowest scores categorize early maturation stages while the highest scores categorize progressive degenerative changes. When separated by BMI, one-way ANOVA tests show there are statistically significant differences among the BMI groups for three of the five traits: surface texture, microporosity, and apical activity (Table 128). Tukey's $b$ post-hoc tests show that obese individuals have significantly higher scores for surface texture compared to the individuals in the other BMI groups; obese individuals have significantly higher microporosity scores compared to normal-size and overweight individuals; and underweight individuals have significantly lower apical activity compared to all BMI groups, obese individuals have significantly higher apical activity scores compared to all BMI groups, and normal-sized and overweight individuals apical activity scores are significantly different from underweight and obese individuals. Although not significant in the ANOVA, there are differences in the macroporosity scores; underweight individuals have significantly higher macroporosity scores compared to obese individuals (see Table 129).

\begin{tabular}{|ll|r|r|r|r|r|}
\hline & & Sum of Squares & df & Mean Square & F & Sig. \\
\hline Transverse & Between Groups & 3.795 & 3 & 1.265 & 1.493 & 0.215 \\
Organization & Within Groups & 641.960 & 758 & 0.847 & & \\
& Total & 645.755 & 761 & & & \\
Surface Texture & Between Groups & 25.537 & 3 & 8.512 & 7.014 & $<0.001$ \\
& Within Groups & 919.924 & 758 & 1.214 & & \\
Total & 945.461 & 761 & & \\
Microporosity & Between Groups & 7.476 & 3 & 2.492 & 5.199 & 0.001 \\
& Within Groups & 363.318 & 758 & 0.479 & & \\
Macroporosity & Total & 370.794 & 761 & & \\
& Between Groups & 3.353 & 3 & 1.118 & 2.373 & 0.069 \\
& Within Groups & 356.958 & 758 & 0.471 & & \\
Apical Activity & Botal & 360.311 & 761 & & & \\
& Between Groups & 10.221 & 3 & 3.407 & 8.773 & $<0.001$ \\
& Within Groups & 294.377 & 758 & 0.388 & & \\
& Total & 304.598 & 761 & & & \\
\hline
\end{tabular}

Table 128: One-way ANOVA results for the Buckberry and Chamberlain method individual scoring features for BMI groups. 


\begin{tabular}{|c|c|c|c|c|c|}
\hline & \multirow[b]{2}{*}{ BMI } & \multirow[b]{2}{*}{$\mathbf{n}$} & \multicolumn{3}{|c|}{ Subset } \\
\hline & & & 1 & 2 & 3 \\
\hline \multirow{4}{*}{$\begin{array}{l}\text { Transverse } \\
\text { Organization }\end{array}$} & Normal & 405 & 3.65 & & \\
\hline & Underweight & 136 & 3.66 & & \\
\hline & Overweight & 172 & 3.75 & & \\
\hline & Obese & 49 & 3.92 & & \\
\hline \multirow[t]{4}{*}{ Surface Texture } & Underweight & 136 & 3.40 & & \\
\hline & Normal & 405 & 3.75 & & \\
\hline & Overweight & 172 & 3.76 & & \\
\hline & Obese & 49 & & 4.18 & \\
\hline \multirow[t]{4}{*}{ Microporosity } & Normal & 405 & 2.31 & & \\
\hline & Overweight & 172 & 2.42 & & \\
\hline & Underweight & 136 & 2.47 & 2.47 & \\
\hline & Obese & 49 & & 2.67 & \\
\hline \multirow[t]{4}{*}{ Macroporosity } & Obese & 49 & 1.37 & & \\
\hline & Overweight & 172 & 1.45 & 1.45 & \\
\hline & Normal & 405 & 1.53 & 1.53 & \\
\hline & Underweight & 136 & & 1.62 & \\
\hline \multirow[t]{4}{*}{ Apical Activity } & Underweight & 136 & 2.04 & & \\
\hline & Normal & 405 & & 2.27 & \\
\hline & Overweight & 172 & & 2.27 & \\
\hline & Obese & 49 & & & 2.53 \\
\hline
\end{tabular}

Table 129: Tukey's $b$ post-hoc tests for the Buckberry and Chamberlain method individual scoring features for BMI.

When separated by stature, one-way ANOVA tests show there are statistically significant differences among stature groups for four of the five traits: surface texture, microporosity, macroporosity, and apical activity (Table 130). Tukey's $b$ post-hoc tests show that individuals in Group 2 have significantly higher surface texture scores compared to individuals in Group 1; individuals in Group 3 have significantly lower microporosity scores compared to individuals in Group 4; individuals in Group 1 have significantly higher macroporosity scores compared to individuals in all other stature groups; and individuals in Group 1 also have significantly lower apical activity scores compared to individuals in all other stature groups (see Table 131). 


\begin{tabular}{|ll|r|r|r|r|r|}
\hline & & Sum of Squares & df & Mean Square & \multicolumn{1}{|c|}{ F } & Sig. \\
\hline Transverse & Between Groups & 2.746 & 3 & 0.915 & 1.079 & 0.357 \\
Organization & Within Groups & 643.009 & 758 & 0.848 & & \\
& Total & 645.755 & 761 & & & \\
Surface Texture & Between Groups & 9.736 & 3 & 3.245 & 2.629 & 0.049 \\
& Within Groups & 935.724 & 758 & 1.234 & & \\
& Total & 945.461 & 761 & & \\
Microporosity & Between Groups & 4.042 & 3 & 1.347 & 2.785 & 0.040 \\
& Within Groups & 366.752 & 758 & 0.484 & & \\
& Total & 370.794 & 761 & & \\
Macroporosity & Between Groups & 9.040 & 3 & 3.013 & 6.502 & E0.001 \\
& Within Groups & 351.271 & 758 & 0.463 & & \\
& Total & 360.311 & 761 & & & \\
Apical Activity & Between Groups & 16.028 & 3 & 5.343 & 14.034 & E0.001 \\
& Within Groups & 288.570 & 758 & 0.381 & & \\
& Total & 304.598 & 761 & & & \\
\hline
\end{tabular}

Table 130: One-way ANOVA results for the Buckberry and Chamberlain method individual scoring features for stature groups.

\begin{tabular}{|l|l|c|cc|}
\hline \multicolumn{1}{|c}{} & \multicolumn{2}{c|}{} & \multicolumn{2}{c|}{ Subset } \\
& Stature & n & 1 & 2 \\
\hline Transverse & Group 1 & 184 & 3.64 & \\
& Group 3 & 223 & 3.66 & \\
& Group 2 & 219 & 3.69 & \\
& Group 4 & 136 & 3.82 & \\
\hline Surface Texture & Group 1 & 184 & 3.54 & \\
& Group 3 & 223 & 3.72 & 3.72 \\
& Group 4 & 136 & 3.78 & 3.78 \\
& Group 2 & 219 & & 3.84 \\
\hline Microporosity & Group 3 & 223 & 2.28 & \\
& Group 1 & 184 & 2.39 & 2.39 \\
& Group 2 & 219 & 2.43 & 2.43 \\
& Group 4 & 136 & & 2.48 \\
\hline Macroporosity & Group 3 & 230 & 1.39 & \\
& Group 2 & 219 & 1.49 & \\
& Group 4 & 136 & 1.52 & \\
& Group 1 & 196 & & 1.69 \\
\hline Apical Activity & Group 1 & 184 & 1.99 & \\
& Group 3 & 223 & & 2.30 \\
& Group 2 & 219 & & 2.32 \\
& Group 4 & 136 & & 2.36 \\
\hline
\end{tabular}

Table 131: Tukey's $b$ post-hoc tests for the Buckberry and Chamberlain method individual scoring features for stature.

When separated by body mass, one-way ANOVA tests show there are statistically significant differences among stature groups for three of the five traits: surface texture, macroporosity, and apical activity (Table 132). Tukey's $b$ post-hoc tests show that individuals in Group 1 have significantly lower surface texture scores compared to individuals in Groups 3 and 4; individuals in Group 1 have significantly higher macroporosity scores compared to individuals in Groups 3 
and 4; individuals in Groups 1 and 2 have significantly lower apical activity scores compared to individuals in Groups 3 and 4. Although not statistically significant in the ANOVA, there are differences for transverse organization; individuals in Group 2 have significantly lower scores compared to individuals in Group 4 (see Table 133).

\begin{tabular}{|ll|r|r|r|r|r|}
\hline & & Sum of Squares & df & Mean Square & \multicolumn{1}{c|}{ F } & \multicolumn{1}{c|}{ Sig. } \\
\hline Transverse & Between Groups & 6.541 & 3 & 2.180 & 2.585 & 0.052 \\
Organization & Within Groups & 639.214 & 758 & 0.843 & & \\
& Total & 645.755 & 761 & & & \\
Surface Texture & Between Groups & 17.918 & 3 & 5.973 & 4.881 & 0.002 \\
& Within Groups & 927.542 & 758 & 1.224 & & \\
& Total & 945.461 & 761 & & \\
Microporosity & Between Groups & 2.606 & 3 & 0.869 & 1.789 & 0.148 \\
& Within Groups & 368.188 & 758 & 0.486 & & \\
Macroporosity & Total & 370.794 & 761 & & \\
& Between Groups & 7.953 & 3 & 2.651 & 5.703 & 0.001 \\
& Within Groups & 352.358 & 758 & 0.465 & & \\
Apical Activity & Between Groups & 360.311 & 761 & & & \\
& Within Groups & 286.576 & 3 & 6.192 & 16.409 & \\
& Total & 30.023 & 758 & 0.377 & & \\
\hline
\end{tabular}

Table 132: One-way ANOVA results for the Buckberry and Chamberlain method individual scoring features for body mass groups.

\begin{tabular}{|l|l|c|cc|}
\hline & & & \multicolumn{2}{c|}{ Subset } \\
& Body Mass & n & 1 & 2 \\
\hline Transverse & Group 2 & 240 & 3.58 & \\
Organization & Group 1 & 165 & 3.67 & 3.67 \\
& Group 3 & 201 & 3.74 & 3.74 \\
& Group 4 & 156 & & 3.83 \\
\hline Surface Texture & Group 1 & 165 & 3.47 & \\
& Group 2 & 240 & 3.71 & 3.71 \\
& Group 3 & 201 & & 3.77 \\
& Group 4 & 156 & & 3.94 \\
\hline Microporosity & Group 2 & 240 & 2.32 & \\
& Group 3 & 201 & 2.37 & \\
& Group 4 & 156 & 2.45 & \\
& Group 1 & 165 & 2.46 & \\
\hline Macroporosity & Group 3 & 201 & 1.39 & \\
& Group 4 & 156 & 1.44 & \\
& Group 2 & 240 & 1.57 & 1.57 \\
& Group 1 & 165 & & 1.66 \\
\hline Apical Activity & Group 1 & 165 & 2.07 & \\
& Group 2 & 240 & 2.13 & \\
& Group 3 & 201 & & 2.35 \\
& Group 4 & 156 & \multicolumn{2}{|c|}{2.47} \\
\hline
\end{tabular}

Table 133: Tukey's $b$ post-hoc tests for the Buckberry and Chamberlain method individual scoring features for body mass. 
There are four features of the auricular surface and three features of the acetabulum scored using the Rougé-Maillart et al. method: transverse organization on a scale of 1 to 7 , surface texture on a scale of 1 to 5, porosity on a scale of 1 to 5, and apical activity on a scale of 1 to 3 for the auricular surface; the acetabular rim on a scale of 1 to 5 , the acetabular fossa porosity on a scale of 1 to 4 , and the apical activity of the posterior cornus on a scale of 1 to 3 for the acetabulum. The lowest scores categorize early maturation stages while the highest scores categorize progressive degenerative changes. When separated by BMI, one-way ANOVA tests show there are statistically significant differences among BMI groups for two of the seven traits: surface texture and auricular surface apical activity (Table 134). Tukey's $b$ post-hoc tests show that obese individuals have higher surface texture scores compared to individuals in the other BMI groups; and underweight individuals have significantly lower auricular surface apical activity compared to all other BMI groups, obese individuals have significantly higher apical activity scores compared to all other BMI groups, and normal-sized and overweight individuals are significantly different from underweight and obese individuals (Table 135).

\begin{tabular}{|ll|r|r|r|r|r|}
\hline & & Sum of Squares & df & Mean Square & F & Sig. \\
\hline Transverse & Between Groups & 2.466 & 3 & 0.822 & 0.905 & 0.438 \\
Organization & Within Groups & 687.792 & 757 & 0.909 & & \\
& Total & 690.258 & 760 & & & \\
Surface & Between Groups & 23.864 & 3 & 7.955 & 6.565 & \\
Texture & Within Groups & 917.258 & 757 & 1.212 & & \\
& Total & 941.122 & 760 & & \\
Porosity & Between Groups & 9.764 & 3 & 3.255 & 2.604 & 0.051 \\
& Within Groups & 946.115 & 757 & 1.250 & & \\
Apical Activity & Total & 955.879 & 760 & & \\
& Within Groups & 10.141 & 3 & 3.380 & 8.615 & \\
Total & 297.429 & 758 & 0.001 \\
Acetabular & Between Groups & 307.570 & 761 & & & \\
Rim & Within Groups & 5.943 & 3 & & \\
& Total & 570.446 & 758 & 0.981 & 2.632 & 0.051 \\
Acetabular & Between Groups & 2.153 & 761 & & & \\
Fossa & Within Groups & 479.460 & 758 & 0.718 & 1.134 & 0.334 \\
& Total & 481.613 & 761 & 0.633 & & \\
Acetabular & Between Groups & 1.937 & 3 & & & \\
Apical Activity & Within Groups & 344.668 & 758 & 0.646 & 1.420 & 0.236 \\
& Total & 346.605 & 761 & & & \\
\hline
\end{tabular}

Table 134: One-way ANOVA results for the Rougé-Maillart et al. method individual scoring features for BMI groups. 


\begin{tabular}{|c|c|c|c|c|c|}
\hline & & & & ubs & \\
\hline & BMI & $\mathbf{n}$ & 1 & 2 & 3 \\
\hline Transverse & Normal & 405 & 3.69 & & \\
\hline Organization & Underweight & 136 & 3.70 & & \\
\hline & Overweight & 171 & 3.74 & & \\
\hline & Obese & 49 & 3.92 & & \\
\hline Surface Texture & Underweight & 136 & 3.47 & & \\
\hline & Normal & 405 & 3.74 & & \\
\hline & Overweight & 171 & 3.75 & & \\
\hline & Obese & 49 & & 4.18 & \\
\hline Porosity & Overweight & 171 & 2.83 & & \\
\hline & Normal & 405 & 2.89 & & \\
\hline & Obese & 49 & 2.94 & & \\
\hline & Underweight & 144 & 3.16 & & \\
\hline Apical Activity & Underweight & 136 & 2.04 & & \\
\hline & Normal & 405 & & 2.26 & \\
\hline & Overweight & 171 & & 2.27 & \\
\hline & Obese & 49 & & & 2.53 \\
\hline Acetabular Rim & Overweight & 171 & 2.96 & & \\
\hline & Obese & 49 & 2.97 & & \\
\hline & Normal & 405 & 3.15 & & \\
\hline & Underweight & 136 & 3.17 & & \\
\hline Acetabular & Overweight & 171 & 1.85 & & \\
\hline Fossa & Underweight & 136 & 1.88 & & \\
\hline & Normal & 405 & 1.88 & & \\
\hline & Obese & 49 & 2.10 & & \\
\hline Acetabular & Underweight & 136 & 2.10 & & \\
\hline Apical Activity & Normal & 405 & 2.10 & & \\
\hline & Overweight & 171 & 2.18 & & \\
\hline & Obese & 49 & 2.27 & & \\
\hline
\end{tabular}

Table 135: Tukey's $b$ post-hoc tests for the Rougé-Maillart et al. method individual scoring features for BMI.

When separated by stature, one-way ANOVA tests show there are statistically significant differences among the stature groups for three of the seven traits: porosity, auricular surface apical activity, and acetabular rim (Table 136). Tukey's $b$ post-hoc tests show individuals in Groups 1, 2 and 4 are scored significantly higher than individuals in Group 3 for porosity. For auricular surface apical activity individuals in Group 1 are scored significantly lower than individuals in all other stature groups. For acetabular rim scores, individuals in Group 1 are scored significantly higher than individuals in all other stature groups. Although not statistically significant in the ANOVA, there are significant differences among the stature groups for the acetabular fossa scores; individuals in Group 1 have significantly lower scores compared to individuals in Group 4 (see Table 137). 


\begin{tabular}{|c|c|c|c|c|c|c|}
\hline & & Sum of Squares & df & Mean Square & $\mathbf{F}$ & Sig. \\
\hline \multirow{3}{*}{$\begin{array}{l}\text { Transverse } \\
\text { Organization }\end{array}$} & Between Groups & 1.814 & 3 & 0.605 & \multirow[t]{3}{*}{0.665} & \multirow[t]{3}{*}{0.574} \\
\hline & Within Groups & 688.444 & 757 & 0.909 & & \\
\hline & Total & 690.258 & 760 & & & \\
\hline Surface & Between Groups & 9.163 & 3 & 3.054 & \multirow[t]{3}{*}{2.481} & \multirow[t]{3}{*}{0.060} \\
\hline \multirow[t]{2}{*}{ Texture } & Within Groups & 931.960 & 757 & 1.231 & & \\
\hline & Total & 941.122 & 760 & & & \\
\hline \multirow[t]{3}{*}{ Porosity } & Between Groups & 23.652 & 3 & 7.884 & \multirow{3}{*}{6.402} & \multirow{3}{*}{$<0.001$} \\
\hline & Within Groups & 932.227 & 757 & 1.231 & & \\
\hline & Total & 955.879 & 760 & & & \\
\hline \multirow[t]{3}{*}{ Apical Activity } & Between Groups & 14.360 & 3 & 4.787 & \multirow[t]{3}{*}{12.375} & \multirow[t]{3}{*}{$<0.001$} \\
\hline & Within Groups & 293.209 & 758 & 0.387 & & \\
\hline & Total & 307.570 & 761 & & & \\
\hline Acetabular & Between Groups & 14.700 & 3 & 4.900 & \multirow[t]{3}{*}{6.613} & \multirow[t]{3}{*}{$<0.001$} \\
\hline \multirow[t]{2}{*}{ Rim } & Within Groups & 561.689 & 758 & 0.741 & & \\
\hline & Total & 576.390 & 761 & & & \\
\hline Acetabular & Between Groups & 4.444 & 3 & 1.481 & \multirow[t]{3}{*}{2.353} & \multirow[t]{3}{*}{0.071} \\
\hline \multirow[t]{2}{*}{ Fossa } & Within Groups & 477.168 & 758 & 0.630 & & \\
\hline & Total & 481.613 & 761 & & & \\
\hline \multirow{3}{*}{$\begin{array}{l}\text { Acetabular } \\
\text { Apical Activity }\end{array}$} & Between Groups & 1.694 & 3 & 0.565 & \multirow[t]{3}{*}{1.241} & \multirow[t]{3}{*}{0.294} \\
\hline & Within Groups & 344.911 & 758 & 0.455 & & \\
\hline & Total & 346.605 & 761 & & & \\
\hline
\end{tabular}

Table 136: One-way ANOVA results for the Rougé-Maillart et al. method individual scoring features for stature groups. 


\begin{tabular}{|c|c|c|c|c|}
\hline & & & & \\
\hline & Stature & $\mathbf{n}$ & 1 & 2 \\
\hline Transverse & Group 1 & 184 & 3.68 & \\
\hline Organization & Group 3 & 223 & 3.69 & \\
\hline & Group 2 & 218 & 3.72 & \\
\hline & Group 4 & 136 & 3.82 & \\
\hline Surface Texture & Group 1 & 184 & 3.54 & \\
\hline & Group 3 & 223 & 3.70 & \\
\hline & Group 4 & 136 & 3.78 & \\
\hline & Group 2 & 218 & 3.83 & \\
\hline Porosity & Group 3 & 223 & 2.67 & \\
\hline & Group 2 & 218 & & 2.94 \\
\hline & Group 4 & 136 & & 3.06 \\
\hline & Group 1 & 184 & & 3.12 \\
\hline Apical Activity & Group 1 & 184 & 2.00 & \\
\hline & Group 3 & 223 & & 2.30 \\
\hline & Group 2 & 218 & & 2.31 \\
\hline & Group 4 & 136 & & 2.35 \\
\hline Acetabular Rim & Group 3 & 223 & 2.95 & \\
\hline & Group 4 & 136 & 3.08 & \\
\hline & Group 2 & 218 & 3.10 & \\
\hline & Group 1 & 184 & & 3.33 \\
\hline Acetabular & Group 1 & 184 & 1.74 & \\
\hline Fossa & Group 3 & 223 & 1.88 & 1.88 \\
\hline & Group 2 & 218 & 1.90 & 1.90 \\
\hline & Group 4 & 136 & & 1.96 \\
\hline Acetabular & Group 4 & 136 & 2.07 & \\
\hline Apical Activity & Group 1 & 184 & 2.07 & \\
\hline & Group 3 & 223 & 2.12 & \\
\hline & Group 2 & 218 & 2.18 & \\
\hline
\end{tabular}

Table 137: Tukey's $b$ post-hoc tests for the Rougé-Maillart et al. method individual scoring features for stature.

When separated by body mass, one-way ANOVA tests show there are statistically significant differences among the body mass groups for four of the seven traits: surface texture, porosity, auricular surface apical activity, and acetabular rim (Table 138). Tukey's $b$ post-hoc tests show that individuals in Group 1 have significantly lower surface texture scores compared to individuals in Group 4; individuals in Group 1 have significantly higher porosity scores compared to individuals in Groups 3 and 4; individuals in Groups 1 and 2 have significantly lower auricular surface apical activity scores compared to individuals in Groups 3 and 4; and individuals in Group 1 have significantly higher acetabular rim scores compared to individuals in Group 4 (see Table 139). 


\begin{tabular}{|ll|r|r|r|r|r|}
\hline & & Sum of Squares & df & Mean Square & F & Sig. \\
\hline Transverse & Between Groups & 4.364 & 3 & 1.455 & 1.606 & 0.187 \\
Organization & Within Groups & 685.893 & 757 & 0.906 & & \\
& Total & 690.258 & 760 & & & \\
Surface & Between Groups & 15.257 & 3 & 5.086 & 4.158 & 0.006 \\
Texture & Within Groups & 925.865 & 757 & 1.223 & & \\
& Total & 941.122 & 760 & & & \\
Porosity & Between Groups & 14.214 & 3 & 4.738 & 3.809 & 0.010 \\
& Within Groups & 941.665 & 757 & 1.244 & & \\
Apical Activity & Total & 955.879 & 760 & & & \\
& Witheen Groups & 16.599 & 3 & 5.533 & 14.414 & \\
& Total Groups & 290.971 & 758 & 0.384 & & \\
Acetabular & Between Groups & 307.570 & 761 & & \\
Rim & Within Groups & 5.382 & 3 & 3.127 & 4.181 & \\
& Total & 576.008 & 758 & 0.748 & & \\
Acetabular & Between Groups & 2.420 & 761 & & & \\
Fossa & Within Groups & 479.193 & 758 & 0.807 & 1.276 & 0.282 \\
& Total & 481.613 & 761 & & \\
Acetabular & Between Groups & 1.362 & 3 & 0.632 & & \\
Apical Activity & Within Groups & 345.243 & 758 & 0.454 & 0.997 & 0.394 \\
& Total & 346.605 & 761 & & & \\
\hline
\end{tabular}

Table 138: One-way ANOVA results for the Rougé-Maillart et al. method individual scoring features for body mass groups. 


\begin{tabular}{|c|c|c|c|c|}
\hline & & & & set \\
\hline & Body Mass & $\mathbf{n}$ & 1 & 2 \\
\hline Transverse & Group 2 & 240 & 3.61 & \\
\hline Organization & Group 1 & 165 & 3.73 & \\
\hline & Group 3 & 201 & 3.77 & \\
\hline & Group 4 & 155 & 3.81 & \\
\hline Surface Texture & Group 1 & 165 & 3.49 & \\
\hline & Group 2 & 240 & 3.70 & 3.70 \\
\hline & Group 3 & 201 & 3.75 & 3.75 \\
\hline & Group 4 & 155 & & 3.92 \\
\hline Porosity & Group 3 & 201 & 2.80 & \\
\hline & Group 4 & 155 & 2.85 & \\
\hline & Group 2 & 240 & 2.92 & 2.92 \\
\hline & Group 1 & 165 & & 3.17 \\
\hline Apical Activity & Group 1 & 165 & 2.08 & \\
\hline & Group 2 & 240 & 2.13 & \\
\hline & Group 3 & 201 & & 2.34 \\
\hline & Group 4 & 155 & & 2.46 \\
\hline Acetabular Rim & Group 4 & 155 & 2.92 & \\
\hline & Group 3 & 201 & 3.08 & 3.08 \\
\hline & Group 2 & 240 & 3.15 & 3.15 \\
\hline & Group 1 & 165 & & 3.25 \\
\hline Acetabular & Group 1 & 165 & 1.79 & \\
\hline Fossa & Group 2 & 240 & 1.85 & \\
\hline & Group 3 & 201 & 1.88 & \\
\hline & Group 4 & 155 & 1.96 & \\
\hline Acetabular & Group 2 & 240 & 2.09 & \\
\hline Apical Activity & Group 3 & 201 & 2.09 & \\
\hline & Group 1 & 165 & 2.11 & \\
\hline & Group 4 & 155 & 2.20 & \\
\hline
\end{tabular}

Table 139: Tukey's $b$ post-hoc tests for the Rougé-Maillart et al. method individual scoring features for body mass. 


\section{Chapter 4: Discussion}

In the early 1920's, T. Wingate Todd developed the first recognized methods of estimating adult age at death from skeletal remains based on changes to the pubic symphysis and stage of fusion in cranial sutures. Since these early publications, many researchers have tested, revised, and created new methods of macroscopic age estimation based not only on the pubic symphysis and cranial sutures, but on the ribs, sacrum, auricular surface, acetabulum, and teeth. The success of these methods depends on their ability to correlate chronological age at death to biological age at death, both within and between populations, as well as their ability to produce accurate and precise results.

Several dozen validation and population-specific studies have shown that, while most methods work well on the skeletal collection they were developed on, there is variability in the results produced by these methods on individuals from differing populations and skeletal collections of similar spatial and temporal affiliation (for example, Katz and Suchey, 1989; Saunders et al., 1992; Russell et al., 1993; Loth et al., 1994; Baccino et al., 1999; Aktas et al., 2004; Djurić et al., 2007; Chen et al., 2008; Hens et al., 2008; Kimmerle et al., 2008; Rissech et al., 2011; Hens and Belcastro, 2012). Often age estimation methods are revised to reflect population differences, but in an archaeological or forensic context, it is not always possible to know the population of origin, or whether methods developed on contemporary populations should be applied to past populations. Assessing microscopic age tends to yield more accurate and precise estimations of an individual's age at death, especially for older individuals (Crowder and Rosella, 2007). However, microscopic methods are destructive, and permissions to perform these types of analyses are difficult to attain for archaeological remains. Biological anthropologists, therefore, often rely on evaluating macroscopic skeletal age changes.

To understand these macroscopic surface changes, we need to understand the changes occurring at the microscopic level. Age changes at the microscopic level reflect a multitude of complex interactions occurring at the same time-osteoblasts decrease in numbers while osteoclasts increase in numbers; osteocyte apoptosis increases, causing a weakening of the bone; the breakdown of collagen cross-links triggers increased osteoclast activity; non-collagenous proteins decrease in numbers, influencing bone's response rate to mechanical and homeostatic 
signals; BMD decreases; osteon size decreases - and, to complicate matters further, these interactions are influenced by health, diet, disease, physical activity, and genetics. These microscopic age changes translate into a breakdown of bone integrity on the surface-striae become granular, bone becomes porous, surface texture changes from billowed or ridged to amorphous and smooth, bone becomes lighter, osteophytic lipping occurs - and these changes are evaluated to estimate age at death.

My dissertation investigates the ways in which age-related skeletal surface changes are influenced by BMI, stature, and body mass through evaluating the age estimations generated from eight methods on 764 individuals with varying statures and body masses. Reliability was determined through accuracy and precision analyses. The results from this study demonstrate that body size does influence our age standards, and should be considered when estimating age at death, especially for individuals who are categorized in the underweight BMI group, short stature group, or light body mass group. The Kunos et al. first rib method, Lovejoy et al. auricular surface method, and Suchey-Brooks method are the least affected by body size, and in the absence of body size specific information, these more reliable methods should be used when possible.

Section 4.1 summarizes the findings for each method assessed. Section 4.2 analyzes whether BMI, stature, body mass, or joint surface have an influence on skeletal age estimation. Section 4.3 assesses the implications of this research for future work in paleodemography, paleoanthropology, and forensic anthropology.

\subsection{Age Method Summaries}

\subsubsection{Kunos et al. First Rib Method}

\section{$\underline{\text { Accuracy }}$}

$B M I$

For males and individuals of African ancestry, there are differences among the BMI group accuracy scores using the Kunos et al. method; however, these relationships are not significant. Similarly, for females, there are differences among the BMI group accuracy scores, but they are not significant. This can most likely be attributed to low sample sizes in the obese female group; there are only 13 females in the obese BMI group, and although obese females had higher 
accuracy scores (6.69 years) compared to underweight (10.42 years), overweight (10.93 years), and normal-sized females (10.95 years), the low sample sizes most likely contributed to this nonsignificant relationship. For individuals of European ancestry, individuals in the obese BMI group have higher accuracy scores ( 7.88 years) compared to underweight, normal-sized, and overweight individuals (range 9.25 years to 10.90 years). These results indicate that BMI is not a significant factor influencing the accuracy scores of the Kunos et al. method except for obese individuals of European ancestry.

\section{Stature}

For males, females, individuals of European ancestry, and individuals of African ancestry there no differences in accuracy scores among stature groups. Therefore, stature is not a factor influencing the accuracy scores using the Kunos et al. method.

\section{Body Mass}

For males and individuals of European ancestry, there are differences among the body mass group accuracy scores using the Kunos et al. method. For males, these differences are not significant among the groups, but for individuals of European ancestry, individuals in the lightest body mass group have significantly lower accuracy scores (11.20 years) compared to individuals of European ancestry in the heaviest body mass group (8.82 years). For females and individuals of African ancestry, there are no differences in accuracy scores among body mass groups. These results indicate that accuracy scores are only significantly different for individuals of European ancestry in the lightest and heaviest body mass groups.

\section{$\underline{\text { Bias }}$}

$B M I$

For males, females, individuals of European ancestry, and individuals of African ancestry, there are differences among the BMI groups for bias scores using the Kunos et al. method. Underweight males have significantly lower bias scores ( 0.03 years $)$ compared to obese males (5.96 years). For females and individuals of African ancestry, there are no significant differences among the BMI group bias scores; however, low sample sizes in the obese group likely affected these results. For females, overweight (4.23 years) and obese females (4.31 years) are over-aged by approximately 4 years compared to normal-sized females ( 0.42 years), and similarly, obese 
individuals of African ancestry (8.40 years) are over-aged by approximately 3 years compared to underweight individuals of African ancestry (5.08 years). For individuals of European ancestry, underweight individuals of European ancestry ( -1.99 years) are under-aged significantly compared to overweight (4.09 years) and obese individuals of European ancestry (4.94 years). These results show that underweight males and individuals of European ancestry are under-aged by 6 to 7 years, and underweight females and individuals of African ancestry are under-aged by 3 to 4 years, though not significant.

\section{Stature}

For males and individuals of European ancestry, there are differences among the stature group bias scores using the Kunos et al. method. Males in the shortest stature group ( 0.49 years) have significantly lower bias scores compared to males in the tallest stature group (5.82 years). For individuals of European ancestry, individuals in the shortest stature group (-1.93 years) underaged significantly compared to individuals in all other stature groups (range 2.67 years to 5.92 years). For females and individuals of African ancestry, there are no significant differences among the bias scores for individuals of differing statures. These results show that stature does influence the bias scores of males and individuals of European ancestry for the Kunos et al. method; males and individuals of European ancestry in the shortest stature group are under-aged by approximately 5 to 7 years. Stature is not a factor influencing the bias scores for females and individuals of African ancestry.

\section{Body Mass}

For males, females, individuals of European ancestry, and individuals of African ancestry, there are differences among the body mass group bias scores using the Kunos et al. method. Males and individuals of European ancestry in the two lightest body mass groups (0.93 years and 1.74 years, and -2.50 years and 0.52 years) have significantly lower bias scores compared to males and individuals of European ancestry in the two heaviest body mass groups (5.34 years and 6.11 years, and 4.99 years and 5.16 years). Females in the lightest body mass group ( -0.35 years) are under-aged compared to females in the two heaviest body mass groups (4.50 years and 5.79 years), but these differences are not significant due to small sample sizes. Similarly, for individuals of African ancestry, there are differences among the body mass group bias scores, but they are not significant. These results indicate that males and individuals of European ancestry in 
the lightest body mass groups are under-aged by 6 to 7 years, while there are no significant differences in bias scores for females and individuals of African ancestry due to sample sizes.

\begin{tabular}{|c|c|c|}
\hline & Accuracy & Bias \\
\hline BMI & $\begin{array}{l}\text { - BMI does not influence the } \\
\text { accuracy scores among males, } \\
\text { individuals of European } \\
\text { ancestry, and individuals of } \\
\text { African ancestry } \\
\text { - Trends towards higher accuracy } \\
\text { scores among obese females, but } \\
\text { is not significant }\end{array}$ & $\begin{array}{l}\text { - Males and individuals of } \\
\text { European ancestry in the } \\
\text { underweight BMI group are } \\
\text { under-aged by } 6 \text { to } 7 \text { years } \\
\text { - Females and individuals of } \\
\text { African ancestry in the } \\
\text { underweight BMI group are } \\
\text { under-aged by } 3 \text { to } 4 \text { years } \\
\text { (though not significant) } \\
\end{array}$ \\
\hline Stature & $\begin{array}{l}\text { - Stature does not affect accuracy } \\
\text { scores for males, females, } \\
\text { individuals of European } \\
\text { ancestry, or individuals of } \\
\text { African ancestry }\end{array}$ & $\begin{array}{l}\text { - Males and individuals of } \\
\text { European ancestry in the } \\
\text { shortest stature group are } \\
\text { significantly under-aged by } \\
\text { approximately } 5 \text { to } 7 \text { years } \\
\text { - Stature does not affect bias } \\
\text { scores for females and } \\
\text { individuals of African ancestry }\end{array}$ \\
\hline Body Mass & $\begin{array}{l}\text { - Individuals of European ancestry } \\
\text { in the lightest body mass group } \\
\text { have significantly lower } \\
\text { accuracy scores compared to } \\
\text { individuals of European ancestry } \\
\text { in the heaviest body mass group } \\
\text { - Body mass does not affect } \\
\text { accuracy scores for or males, } \\
\text { females, and individuals of } \\
\text { African ancestry }\end{array}$ & $\begin{array}{l}\text { - Males, females, and individuals } \\
\text { of European ancestry in the } \\
\text { lightest body mass groups are } \\
\text { under-aged by } 5 \text { to } 7 \text { years } \\
\text { - Body mass does not affect bias } \\
\text { scores for individuals of African } \\
\text { ancestry }\end{array}$ \\
\hline
\end{tabular}

Table 140: Summary of findings for the Kunos et al. method.

\subsubsection{DiGangi et al. First Rib Method}

\section{$\underline{\text { Accuracy }}$}

$B M I$

For males, individuals of European ancestry, and individuals of African ancestry, there are differences among the BMI group accuracy scores using the DiGangi et al. method. Obese males have significantly higher accuracy scores (11.54 years) compared to normal-sized (15.10 years) and underweight males (16.99 years), and obese individuals of European ancestry (13.09 years) have signifcantly higher accuracy scores compared to underweight individuals of European ancestry (18.75 years). For individuals of African ancestry, obese individuals (5.60 years) show significantly higher accuracy scores than underweight individuals (14.57 years). For females, there are differences among the BMI group accuracy scores, but they are not significant. Again, 
this can most likely be attributed to low sample sizes in the obese female group. Although obese females had higher accuracy scores (13.31 years) compared to underweight (17.08 years) and normal-sized females (17.36 years), the low sample sizes most likely contributed to this nonsignificant relationship. These results indicate that BMI only influences the accuracy scores of males, individuals of European ancestry, and individuals of African ancestry in the obese BMI group compared to males, individuals of European ancestry, and individuals of African ancestry in the underweight BMI group using the DiGangi et al. method; this pattern is similar for females, but not significant.

\section{Stature}

For males and individuals of European ancestry, there are differences among the stature group accuracy scores using the DiGangi et al. method. For males, these results are not significant. For individuals of European ancestry, individuals in the tallest stature group (13.76 years) have significantly higher accuracy scores compared to individuals in the shortest stature group (18.83 years). For females and individuals of African ancestry, there are no differences in stature group accuracy scores. Therefore, stature only affects the accuracy scores of individuals of European ancestry; tall individuals of European ancestry have higher accuracy scores compared to short individuals of European ancestry. Stature does not influence the accuracy scores of males, females, and individuals of African ancestry using the DiGangi et al. method.

\section{Body Mass}

For males and individuals of European ancestry, there are differences among the body mass group accuracy scores using the DiGangi et al. method. Males in the two heaviest body mass groups (11.71 years and 13.47 years) have significantly higher accuracy scores compared to males in the two lightest body mass groups (16.72 years and 17.14 years). For individuals of European ancestry, individuals in the heaviest body mass group have significantly higher accuracy scores (12.23 years) compared to individuals in the lightest body mass groups (18.21 years to 19.78 years). For females and individuals of African ancestry, there are no differences in body mass group accuracy scores. These results indicate that body mass only influences the accuracy scores of males and individuals of European ancestry in the heaviest body mass groups compared to males and individuals of European ancestry in the lightest body mass groups using the DiGangi et al. method. 


\section{$\underline{\text { Bias }}$}

BMI

For males and individuals of European ancestry, there are differences among the BMI groups for bias scores using the DiGangi et al. method. Underweight males are significantly under-aged (14.49 years) compared to obese males (-8.23 years), and underweight individuals of European ancestry are significantly under-aged (-18.43 years) compared to overweight ( -11.73 years) and obese individuals of European ancestry ( -9.74 years). For females and individuals of African ancestry, there are differences among the BMI group bias scores, but they are not significant. Underweight females and individuals of African ancestry (-16.71 years and -10.65 years) are under-aged compared to obese individuals of African ancestry ( -11.15 years and -5.60 years); however, due to small sample sizes, this relationship was not significant. These results show that males and individuals of European ancestry in the underweight BMI group are under-aged by 6 to 9 years compared to males and individuals of European ancestry in the obese BMI group, and females and individuals of African ancestry in the underweight BMI group are under-aged by 5 to 6 years compared to females and individuals of African ancestry in the obese BMI group, though they not significant.

\section{Stature}

For males, there are differences among the stature group bias scores using the DiGangi et al. method, but they are not significant. For individuals of European ancestry, there are differences in the bias scores, with individuals of European ancestry in the shortest stature group (-17.20 years) under-aged significantly compared to tall individuals of European ancestry (-10.86 years). For females and individuals of African ancestry, there are no significant differences among the bias scores for individuals of differing statures. These results indicate that stature only influences the bias scores of individuals of European ancestry; short individuals of European ancestry are under-aged compared to tall individuals of European ancestry by approximately 7 years. Stature does not affect the bias scores of males, females, and individuals of African ancestry for the DiGangi et al. method.

\section{Body Mass}

For males, there are differences among the body mass group bias scores using the DiGangi et al. method, but they are not significant. For individuals of European ancestry, there are differences 
among the body mass group bias scores; individuals of European ancestry in the two lightest body mass groups (-19.70 years and -16.47 years) are significantly under-aged compared to individuals of European ancestry in the two heaviest body mass groups (-11.45 years and -10.40 years). For females, there are differences among the body mass group bias scores using the DiGangi et al. method, but they are not significant. Females in the lightest body mass group (18.33 years) are under-aged by 5 to 7 years compared to females in all other body mass groups (13.37 years and -11.69 years), but these differences are not significant due to small sample sizes. For individuals of African ancestry, there are no differences among the body mass group bias scores using the DiGangi et al. method. These results indicate that individuals of European ancestry and females in the lightest body mass groups are under-aged by 5 to 8 years (though not significant for females), while there are no differences for males and individuals of African ancestry for the DiGangi et al. method. 


\begin{tabular}{|c|c|c|}
\hline & Accuracy & Bias \\
\hline BMI & $\begin{array}{l}\text { - Males, individuals of European } \\
\text { ancestry, and individuals of } \\
\text { African ancestry in the obese } \\
\text { BMI group have significantly } \\
\text { higher accuracy scores compared } \\
\text { to males, individuals of } \\
\text { European ancestry, and } \\
\text { individuals of African ancestry } \\
\text { in the underweight BMI group } \\
\text { - This pattern is similar for } \\
\text { females, but not significant }\end{array}$ & $\begin{array}{l}\text { - Males and individuals of } \\
\text { European ancestry in the } \\
\text { underweight BMI group are } \\
\text { under-aged by } 6 \text { to } 9 \text { years } \\
\text { - Females and individuals of } \\
\text { African ancestry in the } \\
\text { underweight BMI group are } \\
\text { under-aged by } 5 \text { to } 6 \text { years } \\
\text { (though not significant) }\end{array}$ \\
\hline Stature & $\begin{array}{l}\text { - Tall individuals of European } \\
\text { ancestry have higher accuracy } \\
\text { scores compared to short } \\
\text { individuals of European ancestry } \\
\text { - Stature does not affect the } \\
\text { accuracy scores of males, } \\
\text { females, and individuals of } \\
\text { African ancestry }\end{array}$ & $\begin{array}{l}\text { - Short individuals of European } \\
\text { ancestry are under-aged } \\
\text { compared to tall individuals of } \\
\text { European ancestry by } \\
\text { approximately } 7 \text { years } \\
\text { - Stature does not affect the bias } \\
\text { scores of males, females, and } \\
\text { individuals of African ancestry }\end{array}$ \\
\hline Body Mass & $\begin{array}{l}\text { - Males and individuals of } \\
\text { European ancestry in the } \\
\text { heaviest body mass groups have } \\
\text { higher accuracy scores compared } \\
\text { to males and individuals of } \\
\text { European ancestry in the lightest } \\
\text { body mass groups } \\
\text { - Body mass does not affect the } \\
\text { accuracy scores of females and } \\
\text { individuals of African ancestry }\end{array}$ & $\begin{array}{l}\text { - Individuals of European } \\
\text { ancestry and females in the } \\
\text { lightest body mass groups are } \\
\text { under-aged by } 5 \text { to } 8 \text { years } \\
\text { (though not significant for } \\
\text { females) } \\
\text { - Body mass does not affect the } \\
\text { bias scores of males and } \\
\text { individuals of African ancestry }\end{array}$ \\
\hline
\end{tabular}

Table 141: Summary of findings for the DiGangi et al. method.

\subsection{3 İşcan et al. Fourth Rib Method}

\section{Accuracy}

$B M I$

For males, females, and individuals of African ancestry, there are differences among the BMI group accuracy scores using the İşcan et al. method. Underweight males have significantly lower accuracy scores (13.74 years) compared to males in all other BMI groups (range 9.46 years to 10.18 years), underweight females (15.82 years) have lower accuracy scores compared to overweight ( 9.42 years) and obese females (9.85 years), and underweight individuals of African ancestry (16.18 years) have lower accuracy scores compared to overweight individuals of African ancestry (7.61 years). For individuals of European ancestry, there are no differences among the BMI group accuracy scores. These results indicate that BMI only influences the accuracy scores of males, females, and individuals of African ancestry in the underweight BMI 
group compared to males, females, and individuals of African ancestry in the overweight and obese BMI groups using the İşcan et al. method.

\section{Stature}

For males, females, and individuals of African ancestry, there are no differences among the stature group BMI accuracy scores. For individuals of European ancestry, there are differences among the accuracy scores; individuals in the shortest stature group (13.31 years) have significantly lower accuracy scores compared to individuals in the tallest stature groups (range 10.17 years to 10.40 years). Therefore, stature only affects the accuracy scores of individuals of European ancestry for the İşcan et al. method.

\section{Body Mass}

For males and individuals of European ancestry, there are differences among the body mass group accuracy scores using the İşcan et al. method. Males in the lightest body mass group (13.13 years) have significantly lower accuracy scores compared to males in the two heaviest body mass groups (11.71 years and 13.47 years for males), and individuals of European ancestry in the lightest body mass group (12.88 years) have significantly lower accuracy scores compared to individuals of European ancestry in the second heaviest body mass group ( 9.63 years). For females and individuals of African ancestry, there are no differences in the body mass accuracy scores. These results show that body mass only influences the accuracy scores of males and individuals of European ancestry in the heaviest body mass groups compared to males and individuals of European ancestry in the lightest body mass groups for the İşcan et al. method.

\section{$\underline{\text { Bias }}$}

$B M I$

For males and females, there are differences among the BMI groups for bias scores using the İşcan et al. method. Males and females in the underweight BMI group have significantly lower bias scores ( -9.91 years and -14.87 years) compared to males and females in all other BMI groups (range 0.08 years to 3.68 years for males, range -4.27 years to -0.72 years for females). For individuals of European ancestry and individuals of African ancestry, there are differences among the BMI group bias scores. Individuals of European ancestry and individuals of African ancestry in the underweight BMI group have significantly lower bias scores (-11.78 years and - 
10.63 years) compared to individuals in all other BMI groups (range - 1.38 years to 2.50 years for individuals of European ancestry, -0.60 years to 3.18 years for individuals of African ancestry). These results show that males, females, individuals of European ancestry, and individuals of African ancestry in the underweight BMI group are under-aged by 10 to 15 years compared to individuals in all other BMI groups using the İşcan et al. method.

\section{Stature}

For males and individuals of European ancestry, there are differences among bias scores. Males and individuals of European ancestry in the short stature group are significantly under-aged (3.65 years and -5.63 years) compared to males in all other stature groups (range 0.70 years to 2.30 years for males, -0.09 years to 3.47 years for individuals of European ancestry). For females and individuals of African ancestry, there are no significant differences among the stature group bias scores. These results indicate that stature only influences the bias scores of males and individuals of European ancestry in the shortest stature group, who are under-aged by approximately 3 to 5 years. Stature does not affect the bias scores of females and individuals of African ancestry for the İşcan et al. method.

\section{Body Mass}

For males, females, individuals of European ancestry, and individuals of African ancestry, there are differences among the body mass group bias scores using the İşcan et al. method. Males, individuals of European ancestry, and individuals of African ancestry in the lightest body mass group are significantly under-aged ( -6.97 years, -7.62 years, and -9.73 years) compared to males in all other body mass groups (range 1.57 years to 3.62 years for males, -0.37 years to 2.32 for individuals of European ancestry, and 0.60 years to 4.54 years for individuals of African ancestry). Females in the lightest body mass group ( -9.67 years) are under-aged compared to females in the second lightest body mass group (0.21 years). These results indicate that males, individuals of European ancestry, and individuals of African ancestry in the lightest body mass groups are under-aged by 7 to 15 years, while females in the lightest body mass group are underaged by 9 years compared to females in the second lightest body mass group for the İşcan et al. method. 


\begin{tabular}{|c|c|c|}
\hline & Accuracy & Bias \\
\hline BMI & $\begin{array}{l}\text { - Males, females, and individuals } \\
\text { of African ancestry in the } \\
\text { underweight BMI group have } \\
\text { significantly lower accuracy } \\
\text { scores compared to individuals } \\
\text { in the overweight and obese BMI } \\
\text { groups } \\
\text { - BMI does not affect the accuracy } \\
\text { scores for individuals of } \\
\text { European ancestry }\end{array}$ & $\begin{array}{l}\text { - Males, females, individuals of } \\
\text { European ancestry, and } \\
\text { individuals of African ancestry } \\
\text { in the underweight BMI group } \\
\text { are under-aged by } 10 \text { to } 12 \\
\text { years compared to individuals } \\
\text { in all other BMI groups }\end{array}$ \\
\hline Stature & $\begin{array}{l}\text { - Individuals of European ancestry } \\
\text { in the short stature group have } \\
\text { lower accuracy scores compared } \\
\text { to individuals in the tall stature } \\
\text { group } \\
\text { - Stature does not affect the } \\
\text { accuracy scores of males, } \\
\text { females, and individuals of } \\
\text { African ancestry }\end{array}$ & $\begin{array}{l}\text { - Males and individuals of } \\
\text { European ancestry in the short } \\
\text { stature group are under-aged by } \\
\text { approximately } 3 \text { to } 5 \text { years } \\
\text { - Stature does not affect the bias } \\
\text { scores of females and } \\
\text { individuals of African ancestry }\end{array}$ \\
\hline Body Mass & $\begin{array}{l}\text { - Males and individuals of } \\
\text { European ancestry in the } \\
\text { heaviest body mass groups have } \\
\text { higher accuracy scores compared } \\
\text { to males and individuals of } \\
\text { European ancestry in the lightest } \\
\text { body mass groups } \\
\text { - Body mass does not affect the } \\
\text { accuracy scores for females and } \\
\text { individuals of African ancestry }\end{array}$ & $\begin{array}{l}\text { - Males, individuals of European } \\
\text { ancestry, and individuals of } \\
\text { African ancestry in the lightest } \\
\text { body mass groups are under- } \\
\text { aged by } 7 \text { to } 15 \text { years } \\
\text { - Females in the lightest body } \\
\text { mass group are under-aged by } 9 \\
\text { years compared to females in } \\
\text { the second lightest body mass } \\
\text { group }\end{array}$ \\
\hline
\end{tabular}

Table 142: Summary of findings for the İşcan et al. method.

\subsubsection{Passalacqua Sacrum Method}

\section{Accuracy}

$B M I$

For males, females, individuals of European ancestry, and individuals of African ancestry, there are differences among the BMI group accuracy scores. Underweight males (13.74 years) have significantly lower accuracy compared to overweight males ( 9.46 years). For females, individuals of European ancestry, and individuals of African ancestry, the differences among BMI group accuracy scores are not significant. These results indicate that BMI only influences the accuracy scores between underweight and overweight males for the Passalacqua method.

\section{Stature}

For males, females, and individuals of African ancestry, there are no differences in accuracy scores among stature groups. For individuals of European ancestry, there are differences among 
the accuracy scores among the stature groups, but they are not significant. Therefore, stature plays no role in determining accuracy scores using the Passalacqua method.

\section{Body Mass}

For males and individuals of European ancestry, there are differences among the body mass group accuracy scores. Males in the lightest body mass (12.80 years) group have significantly lower accuracy scores compared to males in the heaviest body mass group (10.04 years). For females and individuals of African ancestry, there are no differences in the body mass group accuracy scores. These results indicate that accuracy scores are only significantly different between males in the lightest and heaviest body mass groups for the Passalacqua method.

\section{$\underline{\text { Bias }}$}

$B M I$

For males, females, individuals of European ancestry, and individuals of African ancestry, there are differences among the BMI group bias scores using the Passalacqua method. Males and individuals of European ancestry in the underweight BMI group are significantly under-aged (5.85 years and -5.88 years) compared to males and individuals of European ancestry (1.36 years and 0.48 years) in the overweight BMI group. For females and individuals of African ancestry, the differences are not significant. These results show that males and individuals of European ancestry in the underweight BMI group are under-aged by 5 to 6 years compared to males and individuals of European ancestry in the overweight BMI group, and there are no differences in bias scores among BMI groups for females and individuals of African ancestry using the Passalacqua method.

\section{Stature}

For males and individuals of European ancestry, there are differences among the stature group bias scores, but these differences are not significant. For females and individuals of African ancestry, there are no significant differences among the stature group bias scores. These results indicate that stature does not influence bias scores for the Passalacqua method.

\section{Body Mass}

For males, females, and individuals of European ancestry, there are differences among the body mass group bias scores. Males and individuals of European ancestry in the lightest body mass 
group ( -4.35 years and -4.99 years) are significantly under-aged compared to males in the two heaviest body mass groups ( 0.94 years and 1.30 years for males, -0.37 years and 0.15 years for individuals of European ancestry). For females, there are no significant differences among the body mass group bias scores. For individuals of African ancestry, there are no differences among the body mass group bias scores. These results indicate that males and individuals of European ancestry in the lightest body mass groups are under-aged by 4 to 5 years compared to males and individuals of European ancestry in the two heaviest body mass groups, while there are no differences for females and individuals of African ancestry using the Passalacqua method.

\begin{tabular}{|c|c|c|}
\hline & Accuracy & Bias \\
\hline BMI & $\begin{array}{l}\text { - Underweight males have lower } \\
\text { accuracy scores for compared to } \\
\text { overweight males } \\
\text { - BMI does not influence the } \\
\text { accuracy scores among females, } \\
\text { individuals of European } \\
\text { ancestry, and individuals of } \\
\text { African ancestry }\end{array}$ & $\begin{array}{l}\text { - Males and individuals of } \\
\text { European ancestry in the } \\
\text { underweight BMI group are } \\
\text { under-aged by } 5 \text { to } 6 \text { years } \\
\text { - There are no differences in bias } \\
\text { scores for females and } \\
\text { individuals of African ancestry }\end{array}$ \\
\hline Stature & $\begin{array}{l}\text { - Stature does not influence } \\
\text { accuracy scores }\end{array}$ & $\begin{array}{l}\text { - Stature does not influence bias } \\
\text { scores }\end{array}$ \\
\hline Body Mass & $\begin{array}{l}\text { - Males in the lightest group have } \\
\text { lower accuracy compared to } \\
\text { males in the heaviest group } \\
\text { - There are no differences among } \\
\text { body mass group accuracy scores } \\
\text { for females, individuals of } \\
\text { European ancestry, or } \\
\text { individuals of African ancestry }\end{array}$ & $\begin{array}{l}\text { - Males and individuals of } \\
\text { European ancestry in the } \\
\text { lightest body mass groups are } \\
\text { under-aged by } 4 \text { to } 5 \text { years } \\
\text { compared to males and } \\
\text { individuals of European } \\
\text { ancestry in the two heaviest } \\
\text { body mass groups } \\
\text { - There are no differences in bias } \\
\text { scores for females and } \\
\text { individuals of African ancestry }\end{array}$ \\
\hline
\end{tabular}

Table 143: Summary of findings for the Passalacqua method.

\subsubsection{Lovejoy et al. Auricular Surface Method}

\section{$\underline{\text { Accuracy }}$}

$B M I$

For males, individuals of European and African ancestry, there are differences among the BMI group accuracy scores; however, these relationships are not significant. For females, there are differences among the BMI group accuracy scores. Obese females (11.62 years) have significantly lower accuracy scores compared to females in all other BMI groups (range 6.38 
years to 8.48 years). These results indicate that BMI only influences the accuracy scores of obese females compared to females in the other BMI groups for the Lovejoy et al. method.

\section{Stature}

For males, females, and individuals of African ancestry there are no differences in accuracy scores among stature groups. For individuals of European ancestry, there are differences among the stature group accuracy scores, but they are not significant. Therefore, stature does not influence accuracy scores using the Lovejoy et al. method.

\section{Body Mass}

For males and individuals of European ancestry, there are differences among the body mass group accuracy scores; however, these differences are not significant among the groups. For females and individuals of African ancestry, there are no differences in accuracy scores among body mass groups. These results indicate that accuracy scores are not significantly different among the body mass groups using the Lovejoy et al. method.

\section{$\underline{\text { Bias }}$}

$B M I$

For males, individuals of European ancestry, and individuals of African ancestry, there are differences among the BMI groups for bias scores; however, they are not significant. For females, there are no differences among the BMI group bias scores. These results indicate that BMI does not influence bias scores for the Lovejoy et al. method.

\section{Stature}

For males and individuals of European ancestry, there are differences among bias scores, with males and individuals of European ancestry in the shortest stature group (-7.62 years and -8.24 years) having signifcantly lower bias scores compared to males in the tallest stature group (-2.94 years and -3.17 years). For females and individuals of African ancestry, there are no significant differences among the bias scores for individuals of differing statures. These results indicate that stature influences the bias scores of males and individuals of European ancestry for the Lovejoy et al. method; males and individuals of European ancestry in the short stature group are significantly under-aged by approximately 4 to 5 years compared to males and individuals of 
European ancestry in the tall stature group. Stature is not a factor that influences the bias scores of females and individuals of African ancestry.

\section{Body Mass}

For males, females, and individuals of European ancestry, there are differences among the body mass group bias scores. Males in the lightest body mass groups ( -7.03 years) have significantly lower bias scores compared to males in the second heaviest body mass groups ( -3.72 years). Females in the lightest body mass group ( -8.44 years) have significantly lower bias scores compared to females in the two heaviest body mass groups ( -3.77 years and -3.72 years), but these differences are not significant due to small sample sizes. Individuals of European ancestry in the lightest body mass group (-8.86 years) have significantly lower bias scores compared to individuals of European ancestry in the two heaviest body mass groups (-5.15 years and -4.78 years). For individuals of African ancestry, there are no significant differences among the body mass group bias scores. These results indicate that males, females, and individuals of European ancestry in the lightest body mass groups are under-aged by 3 to 5 years, while there are no differences among body mass bias scores for individuals of African ancestry using the Lovejoy et al. method. 


\begin{tabular}{|c|c|c|}
\hline & Accuracy & Bias \\
\hline BMI & $\begin{array}{l}\text { Obese females have significantly } \\
\text { lower accuracy scores compared } \\
\text { females in the other BMI groups } \\
\text { BMI does not influence the } \\
\text { accuracy scores among males, } \\
\text { individuals of European } \\
\text { ancestry, and individuals of } \\
\text { African ancestry }\end{array}$ & $\begin{array}{l}\text { - BMI does not influence bias } \\
\text { scores }\end{array}$ \\
\hline Stature & $\begin{array}{l}\text { - Stature does not influence } \\
\text { accuracy scores }\end{array}$ & $\begin{array}{l}\text { - Males and individuals of } \\
\text { European ancestry in the short } \\
\text { stature group are significantly } \\
\text { under-aged by } 4 \text { to } 5 \text { years } \\
\text { compared to males and } \\
\text { individuals of European } \\
\text { ancestry in the tall stature group } \\
\text { - Stature does not influence bias } \\
\text { scores for females and } \\
\text { individuals of African ancestry }\end{array}$ \\
\hline Body Mass & $\begin{array}{l}\text { - Individuals of European ancestry } \\
\text { in the lightest body mass group } \\
\text { have lower accuracy scores } \\
\text { compared to individuals of } \\
\text { European ancestry in the } \\
\text { heaviest body mass group } \\
\text { - Body mass does not influence } \\
\text { accuracy scores for males, } \\
\text { females, or individuals of } \\
\text { African ancestry }\end{array}$ & $\begin{array}{l}\text { - Males, females, and individuals } \\
\text { of European ancestry in the } \\
\text { lightest body mass groups are } \\
\text { under-aged by } 3 \text { to } 5 \text { years } \\
\text { - Body mass does not influence } \\
\text { bias scores for individuals of } \\
\text { African ancestry }\end{array}$ \\
\hline
\end{tabular}

Table 144: Summary of findings for the Lovejoy et al. method.

\subsubsection{Buckberry and Chamberlain Auricular Surface Method}

\section{$\underline{\text { Accuracy }}$}

$B M I$

For males, individuals of European ancestry, and individuals of African ancestry, there are no differences in accuracy scores among BMI groups. For females, there are differences among the BMI group accuracy scores; however, this relationship is not significant. These results indicate that BMI does not influence the accuracy scores for the Buckberry and Chamberlain method.

\section{Stature}

For males and individuals of European ancestry, there are differences among the stature group accuracy scores; males and individuals of European ancestry in the short staure groups (9.44 years and 8.85 years) have higher accuracy scores compared to males and individuals of European ancestry in the tall stature groups (12.94 years and 13.35 years). For females and 
individuals of African ancestry, there are no differences in stature group accuracy scores. These results indicate that stature only influences the accuracy scores of males and individuals of European ancestry in the short stature group compared to males and individuals of European ancestry in the tall stature groups for the Buckberry and Chamberlain method.

\section{Body Mass}

For males and individuals of European ancestry, there are differences among the body mass group accuracy scores; however, these differences are not significant among the groups. For females and individuals of African ancestry, there are no differences among stature group accuracy scores. These results indicate that body mass does not influence the accuracy scores for the Buckberry and Chamberlain method.

\section{$\underline{\text { Bias }}$}

$B M I$

For males, females, individuals of European ancestry, and individuals of African ancestry, there are differences among the BMI groups for bias scores; however, they are not significant except for individuals of European ancestry. Underweight individuals of European ancestry (1.46 years) have significantly lower bias scores compared to overweight ( 7.60 years) and obese individuals of European ancestry (7.79 years). These results indicate that BMI only affects bias scores of individuals of European ancestry; underweight individuals of European ancestry are under-aged by 6 years compared to overweight and obese individuals. BMI does not influence the bias scores for males, females, and individuals of African ancestry using the Buckberry and Chamberlain method.

\section{Stature}

For males and individuals of European ancestry, there are differences among stature group bias scores. Males in the shortest stature group ( 3.40 years) have significantly lower bias scores compared to males in the tallest stature group (10.84 years). Short individuals of European ancestry ( 1.38 years) have significantly lower bias scores compared to tall individuals of European ancestry (11.88 years) and individuals of European ancestry in the second shortest stature group (6.32 years). For females and individuals of African ancestry, there are no significant differences among the stature group bias scores. These results indicate that stature 
influences the bias scores of males and individuals of European ancestry; short males and individuals of European ancestry are significantly under-aged by approximately 7 to 12 years compared to tall males and individuals of European ancestry. Stature does not influence the bias scores of females and individuals of African ancestry for the Buckberry and Chamberlain method.

\section{Body Mass}

For males, females, and individuals of European ancestry, there are significant differences among the body mass group bias scores. Males and individuals of European ancestry in the lightest body mass groups ( 3.95 years and 1.08 years) have significantly lower bias scores compared to males in the heaviest body mass groups ( 8.53 years and 9.28 years for males, 7.31 years and 8.78 years for individuals of European ancestry). Females in the lightest body mass group (2.16 years) have significantly lower bias scores compared to females in the two heaviest body mass groups (6.31 years and 8.03 years), but these differences are not significant due to small sample sizes. For individuals of African ancestry, there are no significant differences among the body mass group bias scores. These results indicate that males, females, and individuals of European ancestry in the lightest body mass groups are under-aged by 4 to 8 years, while there are no differences for individuals of African ancestry using the Buckberry and Chamberlain method. 


\begin{tabular}{|c|c|c|}
\hline & Accuracy & Bias \\
\hline BMI & $\begin{array}{l}\text { - BMI does not influence the } \\
\text { accuracy scores }\end{array}$ & $\begin{array}{l}\text { - Underweight individuals of } \\
\text { European ancestry are under- } \\
\text { aged by } 6 \text { years compared to } \\
\text { overweight and obese } \\
\text { individuals of European } \\
\text { ancestry } \\
\text { - BMI does not influence the bias } \\
\text { scores for males, females, and } \\
\text { individuals of African ancestry }\end{array}$ \\
\hline Stature & $\begin{array}{l}\text { - Males and individuals of } \\
\text { European ancestry in the short } \\
\text { stature group have lower } \\
\text { accuracy scores compared to } \\
\text { males and individuals of } \\
\text { European ancestry in the tall } \\
\text { stature group } \\
\text { - Stature does not influence } \\
\text { accuracy scores of females and } \\
\text { individuals of African ancestry }\end{array}$ & $\begin{array}{l}\text { - Males and individuals of } \\
\text { European ancestry in the short } \\
\text { stature group are significantly } \\
\text { under-aged by approximately } 7 \\
\text { to } 12 \text { years compared to males } \\
\text { and individuals of European } \\
\text { ancestry in the tall stature group } \\
\text { - Stature does not influence the } \\
\text { bias scores of females and } \\
\text { individuals of African ancestry }\end{array}$ \\
\hline Body Mass & $\begin{array}{l}\text { - Body mass does not influence } \\
\text { accuracy scores }\end{array}$ & $\begin{array}{l}\text { - Males, females, and individuals } \\
\text { of European ancestry in the } \\
\text { lightest body mass groups are } \\
\text { under-aged by } 4 \text { to } 8 \text { years } \\
\text { - Body mass does not influence } \\
\text { the bias scores for individuals } \\
\text { of African ancestry }\end{array}$ \\
\hline
\end{tabular}

Table 145: Summary of findings for the Buckberry and Chamberlain method.

\subsubsection{Rougé-Maillart et al. Auricular Surface and Acetabulum Method}

\section{$\underline{\text { Accuracy }}$}

$B M I$

For males, and individuals of European ancestry there are differences among the BMI group accuracy scores. Obese males (7.27 years) have significantly higher accuracy scores compared to normal-sized (10.49 years) and underweight males (12.19 years). Obese individuals of European ancestry ( 8.38 years) have significantly higher accuracy scores compared to underweight individuals of European ancestry (12.84 years). For females and individuals of African ancestry, there are differences among the BMI group accuracy scores; however, they are not significant. These results indicate that BMI only influences the accuracy scores of underweight males and individuals of European ancestry, and it does not influence the accuracy scores for females and individuals of African ancestry for the Rougé-Maillart et al. method. 


\section{Stature}

For males and individuals of European ancestry, there are differences in accuracy scores among stature groups. Tall males ( 8.71 years) have significantly higher accuracy scores compared to short males (12.09 years), and tall individuals of European ancestry (8.81 years) have significantly higher accuracy scores compared to short individuals of European ancestry (12.29 years) and individuals of European ancestry in the second tallest stature group (11.40 years). For females and individuals of African ancestry, there are no differences in stature group accuracy scores. These results indicate that stature only influences the accuracy scores of males and individuals of European ancestry in the short stature group compared to males and individuals of European ancestry in the tall stature group for the Rougé-Maillart et al. method.

\section{Body Mass}

For males and individuals of European ancestry, there are differences among the body mass group accuracy scores. Males and individuals of European ancestry in the two heaviest body mass groups (8.39 years and 9.31 years for males, 8.55 years and 9.37 years for individuals of European ancestry) have significantly higher accuracy scores compared to males and individuals of European ancestry in the two lightest body mass groups (11.95 years and 12.20 years for males, 11.93 years and 12.77 years for individuals of European ancestry). For females and individuals of African ancestry, there are no differences in stature group accuracy scores. These results indicate that body mass influences the accuracy scores of males and individuals of European ancestry in the lightest body mass groups for the Rougé-Maillart et al. method.

\section{$\underline{\text { Bias }}$}

$B M I$

For males and individuals of African ancestry, there are differences among the BMI groups for bias scores; however, they are not significant. For individuals of European ancestry, there are differences among the BMI group bias scores; underweight individuals of European ancestry (9.22 years) have significantly lower bias scores compared to overweight individuals of European ancestry (-1.14 years). For females, there are no differences among the BMI group bias scores. These results indicate that BMI only influences the bias scores of individuals of European ancestry; underweight individuals of European ancestry are under-aged by 8 years compared to 
overweight individuals of European ancestry. BMI does not influence bias scores for males, females, and individuals of African ancestry using the Rougé-Maillart et al. method.

\section{Stature}

For males and individuals of European ancestry, stature provides a contribution to the differences among bias scores. Males in the shortest stature group (-8.67 years) have significantly lower bias scores compared to males in the tallest stature group ( -0.37 years). Individuals of European ancestry in the shortest stature group (-9.61 years) have significantly lower bias scores compared to individuals of European ancestry in the tallest stature group ( -0.47 years). For females and individuals of African ancestry, there are no significant differences among the bias scores for individuals of differing statures. These results indicate that stature only influences the bias scores of males and individuals of European ancestry for the Rougé-Maillart et al. method. Stature does not influence the bias scores for females and individuals of African ancestry.

\section{Body Mass}

For males, females, and individuals of European ancestry, there are differences among the body mass group bias scores. Males and individuals of European ancestry in the lightest body mass groups (-7.15 years and -10.11 years) have significantly lower bias scores compared to males in the heaviest body mass groups ( -2.81 years and -2.71 years for males, and -4.40 years and -3.31 years). Females in the lightest body mass group (-8.28 years) have significantly lower bias scores compared to females in the two heaviest body mass groups (-3.34 years and -2.94 years), but these differences are not significant due to small sample sizes. For individuals of African ancestry, there are no significant differences among the body mass group bias scores. These results indicate that males, females, and individuals of European ancestry in the lightest body mass groups are under-aged by 5 to 6 years, while there are no differences for individuals of African ancestry using the Rougé-Maillart et al. method. 


\begin{tabular}{|c|c|c|}
\hline & Accuracy & Bias \\
\hline BMI & $\begin{array}{l}\text { - Males and individuals of } \\
\text { European ancestry in the } \\
\text { underweight BMI group have } \\
\text { significantly lower accuracy } \\
\text { scores compared males and } \\
\text { individuals of European ancestry } \\
\text { in the obese BMI group } \\
\text { - BMI does not influence the } \\
\text { accuracy scores for females and } \\
\text { individuals of African ancestry }\end{array}$ & $\begin{array}{l}\text { - Underweight individuals of } \\
\text { European ancestry are under- } \\
\text { aged by } 8 \text { years compared to } \\
\text { overweight individuals of } \\
\text { European ancestry } \\
\text { - BMI does not influence bias } \\
\text { scores for males, females, and } \\
\text { individuals of African ancestry }\end{array}$ \\
\hline Stature & $\begin{array}{l}\text { - Males and individuals of } \\
\text { European ancestry in the short } \\
\text { stature group have lower } \\
\text { accuracy compared to males and } \\
\text { individuals of European ancestry } \\
\text { in the tall stature group } \\
\text { - Stature does not influence the } \\
\text { accuracy scores of females and } \\
\text { individuals of African ancestry }\end{array}$ & $\begin{array}{l}\text { - Males and individuals of } \\
\text { European ancestry in the short } \\
\text { stature group are significantly } \\
\text { under-aged by approximately } 8 \\
\text { to } 9 \text { years compared to males } \\
\text { and individuals of European } \\
\text { ancestry in the tall stature group } \\
\text { - Stature does not influence the } \\
\text { bias scores for females and } \\
\text { individuals of African ancestry }\end{array}$ \\
\hline Body Mass & $\begin{array}{l}\text { - Males and individuals of } \\
\text { European ancestry in the lightest } \\
\text { body mass groups have lower } \\
\text { accuracy scores compared to } \\
\text { males and individuals of } \\
\text { European ancestry in the } \\
\text { heaviest body mass groups } \\
\text { - Body mass does not influence } \\
\text { the accuracy scores for females } \\
\text { and individuals of African } \\
\text { ancestry }\end{array}$ & $\begin{array}{l}\text { - Males, females, and individuals } \\
\text { of European ancestry in the } \\
\text { lightest body mass groups are } \\
\text { under-aged by } 5 \text { to } 6 \text { years } \\
\text { - Body mass does not influence } \\
\text { bias scores for individuals of } \\
\text { African ancestry }\end{array}$ \\
\hline
\end{tabular}

Table 146: Summary of findings for the Rougé-Maillart et al. method.

\subsubsection{Suchey-Brooks Pubic Symphysis Method}

\section{$\underline{\text { Accuracy }}$}

$B M I$

For males, females, and individuals of European ancestry there are differences among the BMI group accuracy scores. For females, individuals of European ancestry and individuals of African ancestry, these differences are not significant. Overweight males (8.73 years) have higher accuracy scores compared to underweight males (11.31 years). These results indicate that BMI only influences the accuracy scores of underweight males compared overweight males.

\section{Stature}

For males and individuals of European ancestry, there are differences in the accuracy scores among stature groups; however, these differences are not significant for individuals of European 
ancestry. Tall males ( 7.82 years) have significantly higher accuracy scores compared to short males (11.18 years). For females and individuals of African ancestry, there are no differences in stature group accuracy scores. These results show that stature only influences the accuracy scores of short males compared to tall males for the Suchey-Brooks method.

\section{Body Mass}

For males and individuals of European ancestry, there are differences among the body mass group accuracy scores. Males in the two heaviest body mass groups have higher accuracy scores (7.33 years and 8.65 years for males) compared to males in the lightest body mass group (11.21 years). Individuals of European ancestry in the two heaviest body mass groups have higher accuracy scores ( 7.53 years and 8.95 years) compared to individuals of European ancestry in the second lightest body mass group (11.25 years). For females and individuals of African ancestry, there are no differences in body mass group accuracy scores. These results indicate that body mass only influences the accuracy scores of males and individuals of European ancestry in the lightest body mass groups compared to males and individuals of European ancestry in the heaviest body mass groups for the Suchey-Brooks method.

\section{$\underline{\text { Bias }}$}

$B M I$

For males, females, and individuals of European ancestry, there are differences among the BMI group bias scores. For females, there are no significant differences among the BMI group bias scores. Underweight males (-8.86 years) have significantly lower bias scores compared to overweight males (-3.87 years). Underweight individuals of European ancestry (-9.86 years) have significantly lower bias scores compared to overweight individuals of European ancestry (4.48 years). For individuals of African ancestry, there are no differences among the BMI group bias scores. These results indicate that BMI only influences the bias scores of males and individuals of European ancestry; underweight males and individuals of European ancestry are under-aged compared to overweight males and individuals of European ancestry by approximately 5 years. BMI does not influence bias scores for females and individuals of African ancestry using the Suchey-Brooks method. 


\section{Stature}

For males and individuals of European ancestry, there are differences among bias scores. Males in the shortest stature group (-9.18 years) have significantly lower bias scores compared to males in the tallest stature group (-3.66 years). Individuals of European ancestry in the tallest stature group (-3.68 years) have significantly lower bias scores compared to individuals of European ancestry in all other stature groups (range -8.54 years to -7.23 years). For females and individuals of African ancestry, there are no significant differences among the stature group bias scores. These results indicate that stature only influences the bias scores of short males, who are underaged by 6 years compared to tall males, and tall individuals of European ancestry, who are overaged 3 to 4 years compared to individuals of European ancestry in all other stature groups.

Stature does not influence the bias scores for females and individuals of African ancestry for the Suchey-Brooks method.

\section{Body Mass}

For males, females, and individuals of European ancestry, there are differences among the body mass group bias scores. Males in the two lightest body mass groups ( -9.28 years and -7.36 years) have significantly lower bias scores compared to males in the heaviest body mass group (-3.77 years). Females in the lightest body mass group (-7.84 years) have significantly lower bias scores compared to females in the two heaviest body mass groups ( -4.19 years and -3.41 years), but these differences are not significant due to small sample sizes. Individuals of European ancestry in the two lightest body mass groups ( -9.46 years and -8.79 years) have significantly lower bias scores compared to individuals of European ancestry in the two heaviest body mass groups (5.23 years and -4.32 years). For individuals of African ancestry, there are no significant differences among the body mass group bias scores. These results indicate that males, females, and individuals of European ancestry in the lightest body mass groups are under-aged by 4 to 6 years, while there are no differences for individuals of African ancestry using the Suchey-Brooks method. 


\begin{tabular}{|c|c|c|}
\hline & Accuracy & Bias \\
\hline BMI & $\begin{array}{l}\text { - Underweight males have } \\
\text { significantly lower accuracy } \\
\text { scores compared overweight } \\
\text { males } \\
\text { - BMI does not influence the } \\
\text { accuracy scores for females, } \\
\text { individuals of European } \\
\text { ancestry, and individuals of } \\
\text { African ancestry }\end{array}$ & $\begin{array}{l}\text { - Underweight males are under- } \\
\text { aged compared to obese males } \\
\text { by } 5 \text { years } \\
\text { - Underweight individuals of } \\
\text { European ancestry are under- } \\
\text { aged compared to overweight } \\
\text { individuals of European } \\
\text { ancestry by } 5 \text { years } \\
\text { - BMI does not influence bias } \\
\text { scores for females and } \\
\text { individuals of African ancestry }\end{array}$ \\
\hline Stature & $\begin{array}{l}\text { - Short males have lower accuracy } \\
\text { scores compared to tall males } \\
\text { - Stature does not influence the } \\
\text { accuracy scores of females, } \\
\text { individuals of European } \\
\text { ancestry, and individuals of } \\
\text { African ancestry }\end{array}$ & $\begin{array}{l}\text { - Short males in the shortest } \\
\text { stature group are under-aged by } \\
6 \text { years compared to tall males } \\
\text { - Individuals of European } \\
\text { ancestry in the tallest stature } \\
\text { group are over-aged } 3 \text { to } 4 \text { years } \\
\text { compared to individuals of } \\
\text { European ancestry in all other } \\
\text { stature groups } \\
\text { - Stature does not influence the } \\
\text { bias scores for females and } \\
\text { individuals of African ancestry }\end{array}$ \\
\hline Body Mass & $\begin{array}{l}\text { - Males and individuals of } \\
\text { European ancestry in the lightest } \\
\text { body mass groups have lower } \\
\text { accuracy scores compared to } \\
\text { males and individuals of } \\
\text { European ancestry in the } \\
\text { heaviest body mass groups } \\
\text { - Body mass does not influence } \\
\text { the accuracy scores for females } \\
\text { and individuals of African } \\
\text { ancestry }\end{array}$ & $\begin{array}{l}\text { Males, females, and individuals } \\
\text { of European ancestry in the } \\
\text { lightest body mass groups are } \\
\text { under-aged by } 4 \text { to } 6 \text { years } \\
\text { - Body mass does not influence } \\
\text { bias scores for individuals of } \\
\text { African ancestry }\end{array}$ \\
\hline
\end{tabular}

Table 147: Summary of findings for the Suchey-Brooks method.

Table 148 summarizes these findings, and shows that for most methods, underweight and lightweight males, females, and individuals of European ancestry, and short males and individuals of European ancestry have the lowest accuracy and highest bias scores, but are generally reliable to estimate age, except for the DiGangi et al. method, which has the overall lowest accuracy and bias scores. All methods are reliable for individuals of African ancestry except for the İşcan et al. method accuracy and bias scores for underweight and low body mass groups. The term "reliable" for the purposes of this chart indicates that there are no significant differences among the accuracy and bias scores for the BMI, stature, and body mass groups. 


\begin{tabular}{|c|c|c|c|c|c|c|c|c|c|}
\hline & & Kunos et al. & DiGangi et al. & İşcan et al. & Passalacqua & $\begin{array}{c}\text { Lovejoy et } \\
\text { al. }\end{array}$ & $\begin{array}{l}\text { Buckberry \& } \\
\text { Chamberlain }\end{array}$ & $\begin{array}{c}\text { Rougé- } \\
\text { Maillart et al. }\end{array}$ & $\begin{array}{l}\text { Suchey- } \\
\text { Brooks }\end{array}$ \\
\hline \multirow[t]{4}{*}{ BMI } & $\begin{array}{l}\text { Male } \\
\text { Accuracy } \\
\text { Bias }\end{array}$ & $\begin{array}{l}\text { Reliable } \\
\text { Underweight } \\
\text { under-aged }\end{array}$ & $\begin{array}{l}\text { Underweight } \\
\text { low accuracy } \\
\text { Underweight } \\
\text { under-aged }\end{array}$ & $\begin{array}{l}\text { Underweight } \\
\text { low accuracy } \\
\text { Underweight } \\
\text { under-aged }\end{array}$ & $\begin{array}{l}\text { Underweight } \\
\text { low accuracy } \\
\text { Underweight } \\
\text { under-aged } \\
\end{array}$ & $\begin{array}{l}\text { Reliable } \\
\text { Reliable }\end{array}$ & $\begin{array}{l}\text { Reliable } \\
\text { Reliable }\end{array}$ & $\begin{array}{l}\text { Obese high } \\
\text { accuracy } \\
\text { Reliable }\end{array}$ & $\begin{array}{l}\text { Underweight } \\
\text { low accuracy } \\
\text { Underweight } \\
\text { under-aged }\end{array}$ \\
\hline & $\begin{array}{l}\text { Female } \\
\text { Accuracy } \\
\text { Bias }\end{array}$ & $\begin{array}{l}\text { Reliable } \\
\text { Reliable }\end{array}$ & $\begin{array}{l}\text { Reliable } \\
\text { Reliable }\end{array}$ & $\begin{array}{l}\text { Underweight } \\
\text { low accuracy } \\
\text { Underweight } \\
\text { under-aged }\end{array}$ & $\begin{array}{l}\text { Reliable } \\
\text { Reliable }\end{array}$ & $\begin{array}{l}\text { Obese low } \\
\text { accuracy } \\
\text { Reliable }\end{array}$ & $\begin{array}{l}\text { Reliable } \\
\text { Reliable }\end{array}$ & $\begin{array}{l}\text { Reliable } \\
\text { Reliable }\end{array}$ & $\begin{array}{l}\text { Reliable } \\
\text { Reliable }\end{array}$ \\
\hline & $\begin{array}{l}\text { European } \\
\text { Accuracy } \\
\text { Bias }\end{array}$ & $\begin{array}{l}\text { Obese high } \\
\text { accuracy } \\
\text { Underweight } \\
\text { under-aged }\end{array}$ & $\begin{array}{l}\text { Underweight } \\
\text { low accuracy } \\
\text { Underweight } \\
\text { under-aged }\end{array}$ & $\begin{array}{l}\text { Reliable } \\
\text { Underweight } \\
\text { under-aged }\end{array}$ & $\begin{array}{l}\text { Reliable } \\
\text { Underweight } \\
\text { under-aged }\end{array}$ & $\begin{array}{l}\text { Reliable } \\
\text { Reliable }\end{array}$ & $\begin{array}{l}\text { Reliable } \\
\text { Underweight } \\
\text { under-aged }\end{array}$ & $\begin{array}{l}\text { Reliable } \\
\text { Underweight } \\
\text { under-aged }\end{array}$ & $\begin{array}{l}\text { Underweight } \\
\text { low accuracy } \\
\text { Underweight } \\
\text { under-aged }\end{array}$ \\
\hline & $\begin{array}{l}\text { African } \\
\text { Accuracy } \\
\text { Bias }\end{array}$ & $\begin{array}{l}\text { Reliable } \\
\text { Reliable }\end{array}$ & $\begin{array}{l}\text { Reliable } \\
\text { Reliable }\end{array}$ & $\begin{array}{l}\text { Underweight } \\
\text { low accuracy } \\
\text { Underweight } \\
\text { under-aged }\end{array}$ & $\begin{array}{l}\text { Reliable } \\
\text { Reliable }\end{array}$ & $\begin{array}{l}\text { Reliable } \\
\text { Reliable }\end{array}$ & $\begin{array}{l}\text { Reliable } \\
\text { Reliable }\end{array}$ & $\begin{array}{l}\text { Reliable } \\
\text { Reliable }\end{array}$ & $\begin{array}{l}\text { Reliable } \\
\text { Reliable }\end{array}$ \\
\hline \multirow[t]{4}{*}{ Stature } & $\begin{array}{l}\text { Male } \\
\text { Accuracy } \\
\text { Bias }\end{array}$ & $\begin{array}{l}\text { Reliable } \\
\text { Short under- } \\
\text { aged }\end{array}$ & $\begin{array}{l}\text { Reliable } \\
\text { Reliable }\end{array}$ & $\begin{array}{l}\text { Reliable } \\
\text { Short under- } \\
\text { aged }\end{array}$ & $\begin{array}{l}\text { Reliable } \\
\text { Reliable }\end{array}$ & $\begin{array}{l}\text { Underweight } \\
\text { low accuracy } \\
\text { Short under- } \\
\text { aged }\end{array}$ & $\begin{array}{l}\text { Underweight } \\
\text { low accuracy } \\
\text { Short under- } \\
\text { aged }\end{array}$ & $\begin{array}{l}\text { Underweight } \\
\text { low accuracy } \\
\text { Short under- } \\
\text { aged }\end{array}$ & $\begin{array}{l}\text { Underweight } \\
\text { low accuracy } \\
\text { Short under- } \\
\text { aged }\end{array}$ \\
\hline & $\begin{array}{l}\text { Female } \\
\text { Accuracy } \\
\text { Bias }\end{array}$ & $\begin{array}{l}\text { Reliable } \\
\text { Reliable }\end{array}$ & $\begin{array}{l}\text { Reliable } \\
\text { Reliable }\end{array}$ & $\begin{array}{l}\text { Reliable } \\
\text { Reliable }\end{array}$ & $\begin{array}{l}\text { Reliable } \\
\text { Reliable }\end{array}$ & $\begin{array}{l}\text { Reliable } \\
\text { Reliable }\end{array}$ & $\begin{array}{l}\text { Reliable } \\
\text { Reliable }\end{array}$ & $\begin{array}{l}\text { Reliable } \\
\text { Reliable }\end{array}$ & $\begin{array}{l}\text { Reliable } \\
\text { Reliable }\end{array}$ \\
\hline & $\begin{array}{l}\text { European } \\
\text { Accuracy } \\
\text { Bias }\end{array}$ & $\begin{array}{l}\text { Reliable } \\
\text { Short under- } \\
\text { aged }\end{array}$ & $\begin{array}{l}\text { Underweight } \\
\text { low accuracy } \\
\text { Short under- } \\
\text { aged }\end{array}$ & $\begin{array}{l}\text { Underweight } \\
\text { low accuracy } \\
\text { Short under- } \\
\text { aged }\end{array}$ & $\begin{array}{l}\text { Reliable } \\
\text { Short under- } \\
\text { aged }\end{array}$ & $\begin{array}{l}\text { Reliable } \\
\text { Short under- } \\
\text { aged }\end{array}$ & $\begin{array}{l}\text { Underweight } \\
\text { low accuracy } \\
\text { Short under- } \\
\text { aged }\end{array}$ & $\begin{array}{l}\text { Underweight } \\
\text { low accuracy } \\
\text { Short under- } \\
\text { aged }\end{array}$ & $\begin{array}{l}\text { Reliable } \\
\text { Short under- } \\
\text { aged }\end{array}$ \\
\hline & $\begin{array}{l}\text { African } \\
\text { Accuracy } \\
\text { Bias }\end{array}$ & $\begin{array}{l}\text { Reliable } \\
\text { Reliable }\end{array}$ & $\begin{array}{l}\text { Reliable } \\
\text { Reliable }\end{array}$ & $\begin{array}{l}\text { Reliable } \\
\text { Reliable }\end{array}$ & $\begin{array}{l}\text { Reliable } \\
\text { Reliable }\end{array}$ & $\begin{array}{l}\text { Reliable } \\
\text { Reliable }\end{array}$ & $\begin{array}{l}\text { Reliable } \\
\text { Reliable }\end{array}$ & $\begin{array}{l}\text { Reliable } \\
\text { Reliable }\end{array}$ & $\begin{array}{l}\text { Reliable } \\
\text { Reliable }\end{array}$ \\
\hline
\end{tabular}




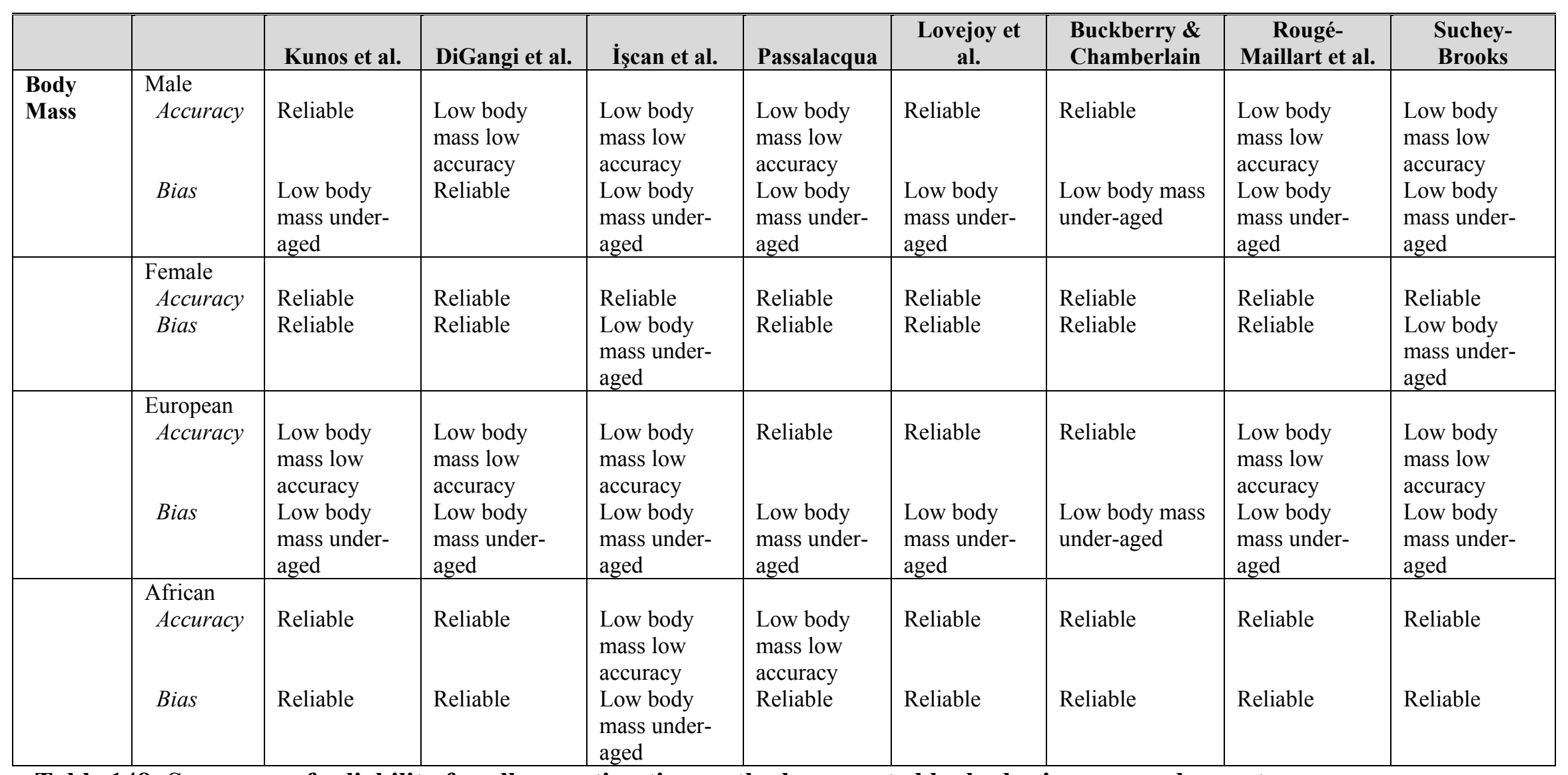

Table 148: Summary of reliability for all age estimation methods separated by body size, sex, and ancestry. 


\subsection{BMI, Stature, and Body Mass Influence Skeletal Age Estimation}

Three different patterns emerge from my data. First, individuals in the obese and underweight BMI groups, short and tall stature groups, and light and heavy body mass groups have significantly different reliability scores from each other. Second, individuals in the "middle" groups (i.e. individuals in the normal-sized and overweight BMI groups, second shortest and second tallest stature groups, and second lightest and second heaviest body mass groups) generally cluster together and have similar error and bias scores. Third, non-weight-bearing (NWB) joints have more error associated with their age estimations than weight-bearing (WB) joints, especially for individuals in the tall stature group and light body mass group, and WB joints are under-aged compared to NWB joints for individuals in the underweight BMI group, short stature group, and light body mass group. All of these patterns distinguish the individuals in the underweight BMI group, short stature group, and light body mass group from individuals in the other groups, especially individuals in the obese BMI group, tall stature group, and heavy weight group.

\subsubsection{The Influence of Stature on Age Estimation}

Stature does not have an influence on age estimations for most individuals, except males and individuals of European ancestry in the short stature group, who have lower accuracy scores and are under-aged compared to males and individuals of European ancestry in the tall stature group. There are few studies that consider stature in relation to skeletal aging except for those that identify short stature as an indicator of poor health, with the premise that short individuals have shorter life spans due to poor nutrition (Kemkes-Grottenthaler, 2005; Ferreira et al., 2008). The parsimonious explanation for the under-aging of short individuals in this study is that most individuals who were classified as short were also in the lightest body mass categories, especially for males and individuals of European ancestry.

Stature is most likely not a factor in skeletal aging because stature and body mass are expected to change in similar ratios (i.e. allometric scaling). The allometric relationship of stature to body mass is positive and linear (Heymsfield et al., 2007); my dissertation results suggest that the agerelated changes occurring to bone as body mass increases or decreases are accommodated by 
stature. As body mass increases or decreases, bone remodelling follows these principles of allometric scaling to accommodate these changes at the microscopic level, and these change appear to have little to no influence on skeletal aging except for males and individuals of European ancestry in the short stature group, who are under-aged.

\subsubsection{The Influence of Body Mass on Age Estimation}

Body mass influences skeletal age estimation for most methods and most individuals. Individuals in the lightest body mass group have more error associated with their age estimations compared to individuals in the heaviest body mass group. This relationship is significant for five of the eight methods for males and individuals of European ancestry, and two for individuals of African ancestry. There are no significant differences for females, but they do follow a similar pattern. Individuals in the lightest body mass group are under-aged compared to individuals in all other body mass groups. This relationship is significant for all eight methods for individuals of European ancestry, seven for males, two for females, and one for individuals of African ancestry. These results indicate that body mass has a stronger influence for males and individuals of European ancestry than females and individuals of African ancestry, but this may be a result of low sample sizes for females and individuals of African ancestry.

\subsubsection{The Influence of BMI on Age Estimation}

BMI is a combination of body mass and stature measurements. When considered separately, body mass has a stronger influence on skeletal age estimation than stature in this study. Although there are some differences in stature accuracy and bias scores among males and individuals of European ancestry, the low body mass groups demonstrate higher error and bias scores for all the age estimation methods, including females and individuals of African ancestry. This suggests that body mass is probably driving the BMI results, not stature, as the accuracy and bias scores between the body mass and BMI results are similar. Underweight individuals have more error associated with their age estimations and are under-aged compared to obese and/or overweight individuals. For males and individuals of European ancestry, these results are significant more often compared to females and individuals of African ancestry. 


\subsubsection{The Influence of Joint Surfaces on Age Estimation}

This study also examined the differences between NWB and weight-bearing WB joint age estimations. The NWB rib joints were found to have more error (between 1 and 5 years) associated with their age estimations compared to WB pelvic joints, and most of the error is associated with individuals in the tall stature group and light body mass group. The WB pelvic joints were found to under-age individuals by approximately 2 to 6 years compared to NWB rib joints in almost all BMI, stature, and body mass groups except individuals in the lightest body mass group. This finding suggests that remodelling affects pelvic joints less than rib joints for most individuals except for those in the lightest body mass groups.

\subsection{Factors that Affect Skeletal Aging}

Individuals who have an underweight BMI and are in the low body mass groups in this study generally have the lowest accuracy and highest negative bias scores for most age estimation methods, suggesting that underweight individuals are subject to a decreased rate of skeletal aging. Conversely, males, females, individuals of European ancestry, and individuals of African ancestry in the obese BMI group and heavy body mass group have the highest accuracy scores and lowest negative bias scores, suggesting that obesity accelerates skeletal aging.

There are a variety of factors that may contribute to the differences in age estimations among BMI, stature, and body mass groups: bone remodelling rates and BMD, nutrition, physical activity and occupation, and hormone levels. This section will look at each of these factors as potential explanations for the trends observed in this study.

\subsubsection{Bone Remodelling Rates and Bone Mineral Density (BMD)}

As an individual ages, the rates of bone removal outpace the rates of bone formation (Cao et al., 2005, 2007; Pietschmann et al., 2007), especially in post-menopausal women who have decreased levels of estrogen, which is important in bone formation (Kaptoge et al., 2003). Studies have shown that older bone might be preferentially selected for osteoclast resorption, and compounded with the decrease in bone matrix deposited by osteoblasts, the rate of bone removal occurs faster than bone deposition as an individual ages (Lee et al., 2005; Szulc and Seeman, 2009). These changes in bone remodelling rates influence BMD scores; most individuals reach 
their peak BMD around the age of 30 years, and after this time BMD begins to decrease in a predictable fashion (Lekamwasam et al., 2009). Coincidentally, these changes at the microscopic level also translate to changes at the macroscopic level. Between the ages of 30 and 40 years, when BMD is beginning to decline, the bone surface is beginning to show signs of aging - striae become dense and granular, billowing becomes smooth, microporosity begins to show on the surface - and these changes are evaluated by macroscopic age estimation methods. As an individual continues to age, and the rates of bone remodelling continue to outpace the rates of bone formation, BMD values decrease, and the surface of the bone reflects these changes - dense granularity becomes course, smooth surfaces become roughened and concave, macroporosity begins to replace microporosity, osteophytic activity occurs, and bone becomes more fragile. As demonstrated by this study, these surface changes are also influenced by body size; therefore, a greater understanding of how stature and body mass influence bone remodelling and BMD is required to explain these differences.

\subsubsection{Sex and Ancestry Differences in BMD}

Differences in BMD scores among males, females, individuals of European ancestry, and individuals of African ancestry are well established. On average, males generally have higher BMD than females (Nieves et al., 2005), and individuals of African ancestry have higher BMD compared to individuals of European ancestry (Finkelstein et al., 2002; Tracy et al., 2005). Though they follow the same pattern, the rates of bone remodelling have been shown to be faster in women compared to men, especially post-menopausal women (Kaptoge et al., 2003), and individuals of African ancestry have lower rates of bone remodelling compared to individuals of European ancestry (Han et al., 1997; Finkelstein et al., 2002). Similarly, European males have faster rates of bone remodelling compared to African males (Tracy et al., 2005), and European females have faster rates of modelling compared African females (Finkelstein et al., 2002). Most skeletal age estimation methods used in biological anthropology support these findings, and different rates of skeletal aging for sex and ancestry have been established (Işcan et al., 1984 a, 1985, 1987; Katz and Suchey, 1989; Brooks and Suchey, 1990; Yavuz et al., 1998). This study corroborates these findings, as males, females, individuals of European ancestry, and individuals of African ancestry have significantly different accuracy and bias scores from each other for most methods. As demonstrated in Section 3.2, females generally have higher negative bias 
scores compared to males for each age estimation method, and individuals of African ancestry generally have higher accuracy and lower bias scores compared to individuals of European ancestry, as would be expected with females and individuals of African ancestry exhibiting differing rates of bone remodelling.

Most skeletal age estimation methods were developed on males of European ancestry, with modifications for females and individuals of African ancestry available. Therefore, it is not surprising that males in this study have higher accuracy and lower bias scores compared to females, especially since females have higher rates of bone remodelling. For individuals of European and African ancestry, since most methods were developed on individuals of European ancestry who have faster rates of bone remodelling compared to individuals of African ancestry, it was expected that individuals of African ancestry would have lower accuracy and higher negative bias scores. As shown in Section 3.2, generally there are few differences between the accuracy scores of Europeans and Africans, and individuals of African ancestry show higher negative bias scores for half the methods (i.e. the İşcan et al., Lovejoy et al., Rougé-Maillart et al., and Suchey-Brooks methods). The Kunos et al., DiGangi et al., Passalacqua, and Buckberry and Chamberlain methods over-age individuals of African ancestry compared to individuals of European ancestry. Two are first rib methods, and two are pelvic methods, indicating that there is no pattern for these differences, and further research to explain these differences is warranted.

\subsubsection{Bone Remodelling and Body Size}

When considering the rates of bone remodelling as measured by BMD on individuals of differing body sizes, individuals in the underweight BMI and low body mass group generally display lower BMD than individuals who are within the normal, overweight, and obese BMI range, or heavier body masses, and have an increased risk for osteoporosis (Shah et al., 2011). Examining the ways in which undernutrition and obesity affect bone remodelling and BMD may help explain the differences in skeletal aging observed in this study.

\subsubsection{Undernutrition and BMD}

Often, underweight individuals are under-nourished or in poor health with inadequate energy intake, thus influencing their rates of bone remodelling and BMD. The combination of poor nutrition and low amounts of fat tissue have been implicated in lower bone turnover rates for 
underweight individuals (Coin et al., 2000, 2008). This low bone remodelling rate is protective to underweight individuals as the slower remodelling compensates for the lack of nutrients to support bone growth, but only to a certain extent. A lifetime of poor nutrition and low body mass will ultimately lead to low BMD, and increased risks of osteoporosis in older individuals (Coin et al., 2008). A recent study by Fernández-García and colleagues (2009) comparing "healthy" females with low body mass to "unhealthy" females with low body mass (i.e. females with anorexia nervosa) found no significant differences among BMD scores between the two groups, with both exhibiting lower than expected BMD compared to the control group of normal-sized females, indicating that nutrition may not be as important as body mass in skeletal health. This study has shown that low body mass is associated with the under-aging of individuals, suggesting the protective effect of low remodelling rates in underweight individuals is also seen on the bone surface and influences skeletal age estimations.

\subsubsection{Obesity and BMD}

When considering the rates of bone remodelling measured by BMD on obese individuals, the pattern of BMD is less clear. Obesity has been shown to both increase BMD and decrease BMD. Researchers who argue that obesity increases BMD have shown that as body mass increases, there is increased mechanical stress on bone, resulting in decreased bone resorption and higher BMD (Felson et al., 1993; Looker et al., 2001; Lim et al., 2004). Recently, however, studies have demonstrated a decrease in BMD for obese individuals. Researchers who argue that obesity decreases BMD do so based on the following evidence: First, obesity has been shown to decrease bone formation (i.e. osteoblastogenesis) while increasing fat formation (i.e. adipogenesis). Typically, mechanical loading promotes osteoblast differentiation and inhibits adipose formation; however, in obese individuals, the gene that promotes this action is down-regulated, leading to a decrease in osteoblast differentiation and an increase in adipocyte differentiation (Cao, 2011). Second, obesity has also been shown to increase bone resorption through the upregulation of pro-inflammatory genes, which stimulate osteoclast activity. There has also been evidence that bone marrow adipocytes might promote osteoclastogenesis (Cao, 2011). Third, obesity is associated with higher levels of leptin and decreased levels of adiponectin. Higher levels in leptin in obese animals have been found to be a negative regulator of bone mass, and decreased levels of adiponectin increase osteoclastogenesis and bone resorption (Cao, 2011). 
The results from this study show that individuals in the obese BMI group and heavy body mass group are over-aged compared to individuals in the underweight BMI group and light body mass group, suggesting support for the second of these two observations- - heavier individuals display increased rates of bone remodelling. Individuals in the obese BMI group and heavy body mass group in this study also show increased degenerative changes on the joint surfaces used in skeletal age estimation. For example, obese individuals have higher levels of apical activity on the sacrum and auricular surface, increased surface breakdown and porosity on the auricular surface, and increased activity on the acetabular rim compared to individuals in the underweight BMI group and lighter body mass group, resulting in higher age estimations in these heavily loaded areas.

Research on the ways in which visceral fat and muscle mass influence bone's remodelling might be one explanation for the over-aging of individuals in the obese BMI group and heavy body mass group compared to individuals in the underweight BMI group and light body mass group. Two studies have shown that differences in the ratio of visceral fat to lean muscle exhibit varied rates of bone loss (Gnudi et al., 2007; Bredella et al., 2011). Individuals with high body mass and more lean muscle, which decreases the pace of bone remodelling, had higher BMD values, and individuals with high body mass and more visceral fat, which increases the pace of bone remodelling, had lower BMD values. These results suggest that the accelerated skeletal aging of obese individuals observed in this study may be more dependent on the distribution and type of tissue (i.e. fat vs. muscle) rather than body mass or BMI group.

\subsubsection{Physical Activity and Occupation}

Another potential explanation for the pattern of under-aging individuals in the underweight BMI group and light body mass group observed in this study is physical activity. Most of the individuals in the underweight BMI group and light body mass group used in this study are from the Hamann-Todd collection (see Appendix 3 and Appendix 4), which is made up predominantly of European male migrant workers. The occupations recorded or found in census data for some individuals suggest that most worked labour intensive jobs (for example, bricklayer, iron worker, etc.: personal communication, Lyman Jellema, Cleveland Museum of Natural History). These labour intensive activities suggest high levels of mechanical loading on the bones, but the effect would be much less pronounced on underweight individuals compared to normal-sized and 
overweight individuals. Underweight individuals have less body mass driving the impact of laborious activities on skeletal loading, but they also most likely had higher levels of lean muscle mass compared to fat mass than normal-sized and overweight individuals. High amounts of lean muscle mass appear to have a protective effect on bone remodelling, and lead to increased BMD (Lekamwasam et al., 2009). If underweight individuals are just as active as normal-sized and overweight individuals with similar amounts of lean muscle mass but less fat mass, the results from this study suggest the combination of decreased mechanical load from body mass and increased lean muscle influences BMD and skeletal aging in a positive way - underweight individuals are under-aged significantly compared to individuals in all other body mass groups, especially obese individuals - and provides a plausible explanation as to why lighter individuals experience slower rates of skeletal aging, especially compared to heavy individuals.

One study by Campanacho and colleagues (2012) examined the influence of occupation on age estimations of the pubic symphysis on a male sample from the Coimbra Collection in Portugal. The authors defined occupation as "manual labour" or "non-manual labour" based on recorded employment and femoral robusticity. Individuals in the "robust" group were from the manual labour group, while individuals in the "fragile" group were from the non-manual labour group. Fourteen aspects of the pubic symphysis were analyzed, and the results showed that only the ligamentous outgrowths on the ventral beveling were significantly different between the manual and non-manual labour groups. This study by Campanacho et al. was the first to suggest that occupation does not influence the rate of degeneration of the pubic symphysis; however, the study did not take body size into consideration, nor did they assess skeletal age markers from other areas of the body. In my dissertation, the pubic symphysis has been shown to display low error rates except for short and underweight males. Similarly, short males and underweight males, females, and individuals of European ancestry are under-aged significantly compared to all other groups, with fewer signs of degeneration. Without knowledge of the body mass of the Coimbra Collection, it is difficult to compare the results of these two studies. If the males in the Coimbra Collection were underweight and/or short, which is not an unreasonable assumption for this late-19th to mid-20th century collection, it could explain why there were fewer differences among the robust and fragile groups. Underweight males in my dissertation with labour intensive occupations did not display accelerated signs of skeletal aging, but rather obese individuals with 
less labour intensive occupations experienced accelerated skeletal aging, suggesting that body size might play a bigger role in age estimation than physical activity.

Studies that have examined the physical activity levels of individuals of varying body masses have shown that individuals with high BMIs and body masses are less active than underweight, normal-sized, and overweight individuals, but they do perform small amounts of moderate and low-level activities (approximately 30 and 60 minutes each day) (Cooper et al., 2000; Davis et al., 2006). Although the amount of time heavier individuals spend being physically active is significantly lower than underweight, normal-sized, and overweight individuals, the increased weight-load of an obese individual would presumably have a larger impact on the skeletal system, causing increased degenerative changes on the pelvic joints not seen in underweight individuals, increasing their skeletal age estimations.

The NWB rib joints were found to have more error (between 1.5 and 5 years) associated with their age estimations compared to WB pelvic joints, and most of the error is associated with tall and light individuals. The WB pelvic joints were found to under-age individuals by approximately 2 to 6 years in almost all groups except the lightest body mass groups compared to NWB rib joints. BMD and the effect of mechanical loading and physical activity have been shown to be significantly different between WB and NWB joints (Tommerup et al., 1993; Nikander et al., 2006; Mikkola et al., 2008). It has been demonstrated that the WB tibia is affected by the environment significantly more than the NWB radius, indicating that there are bone remodelling differences between the two sites (Mikkola et al., 2008). The results of my dissertation show that there are differences in the accuracy and bias of the methods on NWB and WB joints, which might suggest that bone remodelling of the pelvis occurs more slowly than the ribs (i.e. the pelvis is under-aged compared to the ribs) in almost all groups except the underweight BMI group and light body mass group, indicating that the pelvis may be influenced more by external factors such as loading and activity. However, the rates of bone remodelling were not known or tested for the individuals in this study.

As previously shown, increases in lean muscle mass stimulate a protective effect in the weightbearing joints of physically active and heavy individuals, and may provide an explanation for the decreased age estimations of WB joints for all stature groups and average to heavier individuals. 
Weight-bearing exercise has been shown to be sufficient in stimulating periosteal bone formation in the femur, but not in the ribs, indicating that bone response to weight-bearing exercises is specific to the loaded, weight-bearing bones (Tommerup et al., 1993). Since the pelvis is heavily loaded and affected by physical activity more than the ribs, there would be an expected increase in BMD and decreased pace of bone remodelling, leading to younger age estimations of the pelvis. However, when the age methods are considered separately, this hypothesis breaks down as the İşcan et al. fourth rib method has the highest levels of inaccuracy and lowest bias scores, and is a NWB joint. Further research on how body mass influences skeletal aging at both NWB and WB joints is required to interpret these results.

\subsubsection{Hormone Levels}

Another potential explanation for the significantly different age estimations between underweight and obese individuals is hormones. Osteocyte apoptosis increases with tissue age causing a weakening of the bone independent of BMD, but not independent of fat content. Leptin, a protein hormone that plays a key role in regulating energy intake and expenditure, including appetite and hunger, metabolism, and behaviour, is one of the most important adiposederived hormones. Increased levels of leptin have been linked to obesity and induce osteocyte apoptosis (Gordeladze et al., 2002), and decreases lamellar bone formation while increasing cortical bone formation (Hamrick and Ferrari, 2008). It has been suggested that this increasing cortical bone formation may represent a mechanism for coping with increased body mass on obese individuals (Hamrick and Ferrari, 2008), and would help explain the over-aging of obese individuals observed in this study. Underweight individuals have decreased levels of leptin, which can have a protective effect against osteocyte apoptosis, and may also play a role in explaining the under-aging of lighter individuals compared to heavier individuals. Conversely, decreased leptin levels have also been shown to decrease bone formation markers, though not in conjuction with BMD (Fernández-García et al., 2009); therefore, the role of leptin in the underaging of underweight individuals requires further exploration. 


\subsection{Implications of Study Results for Paleodemography, Paleoanthropology, and Forensic Anthropology}

For biological anthropologists, reliable age estimations form the basis of work that interprets health, disease, and adaptation in past populations and communities. The results of this study indicate that all methods are reliable for males, females, Europeans, and Africans with average statures and body masses, but the age estimations of underweight individuals are not. The Kunos et al. method is the most reliable rib method, and the Lovejoy et al. and Suchey-Brooks methods are the most reliable pelvic methods. The DiGangi et al. method is the least reliable method overall with the lowest accuracy and highest bias scores for this sample. The İşcan et al. method under-ages underweight individuals by the highest amount for all methods, and should be used with caution if a population is known to have low body mass. The Buckberry and Chamberlain method over-ages individuals for this sample, which is consistent with other studies (Mulhern and Jones, 2005; Hens and Belcastro, 2012).

Often, the archaeological record appears to lack older individuals, and it is generally believed that life expectancy in past populations was 20 to 35 years (Paine and Harpending, 1998;

Roksandic and Armstrong, 2011). However, we know that the average stature of past populations was shorter and the average estimated body mass was lighter (see Table 3). The results of this study suggest that a reassessment of the age estimations that have been generated for past populations is warranted. The under-representation of infants and older adults can affect paleodemographic interpretations of fertility rates, death rates, mortality curves, and general health of past populations (see Cipriano-Bechtle et al., 1996; Guy et al., 1997; Paine and Harpending, 1998). If lighter and shorter individuals are under-aged between 5 to 15 years, as shown by this study, correcting this would significantly change our current understanding of past population life expectancy and population structure. By increasing the presence of older adults in the skeletal record, our interpretation of roles and dynamics within a group would change, as adult longevity is a measure of a population's success. Increasing the average age at death of a population by only 5 years shifts fertility and death rates significantly (Paine and Harpending, 1998), and would re-shape the ways we understand human longevity.

Some paleoanthropological studies focus on small-bodied human ancestors, and often researchers use current skeletal age estimation methods to infer ages at death of fossil specimens. 
As seen in Table 3, the stature and body mass estimations for early hominids are significantly different from those of current human populations. If the age estimations derived from our current standards have significantly different accuracy and bias scores for underweight individuals, the divergence from fossil forms may be even more extreme. With new information on the ways body size affects our age standards, researchers will have opportunities to reexamine skeletal materials and more accurately determine age at death, with the possibility of refining our knowledge about the lifespan of past human and ancestral populations.

Forensic anthropologists rely on accurate age estimations to create biological profiles and to narrow searches for missing persons. Recently, forensic anthropologists have acknowledged that obesity affects several aspects of a biological profile, including stature estimations (Adams and Herrmann, 2009), and there have been attempts to characterize features of the obese skeleton (Agostini and Ross, 2011; Moore and Schaefer, 2011). According to Statistics Canada, there are approximately 4.7 million obese individuals in Canada, which represents almost $20 \%$ of the adult population (Statistics Canada, 2012). Similarly, in the United States, the Centers for Disease Control reports that $35.7 \%$ of U.S. adults are obese (Ogden et al., 2012). Understanding the relationship of obesity to skeletal aging will allow forensic anthropologists to better estimate the age at death of human remains. This study has shown that individuals with low body mass and high body mass have significantly different accuracy and bias scores for almost all age estimations methods, but this difference is especially seen among males and individuals of European ancestry. The development of sex- and ancestry-specific formulae to account for body size could create more accurate age estimations and help law enforcement officers narrow the scope of their investigations and improve their effectiveness.

\subsection{Estimating Body Size of Skeletal Remains}

In biological anthropology, studies on body size are generally associated with stature and body mass calculations, sexual dimorphic relationships, and ecogeographic and population differences in body proportions. Stature is an important variable in both paleodemographic and forensic case studies. Stature can be associated with health and disease in a population (Steckel et al., 2002; Kemkes-Grottenthaler, 2005), and knowing a person's stature can narrow individual identification in forensic cases (Adams and Herrmann, 2009). Several methods of stature estimation have been developed using measurements of long bones and linear regression 
formulae. The most reliable are those using long bones directly associated with stature, such as the femur (Trotter and Gleser, 1952; Sjøvold, 1990; Ross and Konigsberg, 2002), while methods using other bones, including the upper limb (Mall et al., 2001; Celbis and Agritmis, 2006; Ozaslan et al., 2006), sternum (Menezes et al., 2011), sacrum (Karakas et al., 2010), metacarpals (Sagir, 2006), and metatarsals (Bidmos and Dayal, 2003; Bidmos, 2006; Cordeiro et al., 2009) have also been developed with some level of success. The Fully (Fully, 1956) and Revised Fully (Raxter et al., 2006, 2007) methods of stature estimation are the most accurate methods because they use all the elements comprised in vertical length - the cranium, vertebral column, sacrum, femur, tibia, talus, and calcaneus - and apply these measurements to a linear regression formula based on age and soft tissue (Maijanen, 2009; Auerbach, 2011). An interesting study by Adams and Hermann (2009) on stature reconstruction of dismembered, fleshed remains found that individuals with the highest BMI scores had the lowest correlations to known stature in life. Overall, stature is generally considered to be a reliable, measureable body size variable, and could be used in future calculations to determine which age methods are the most appropriate for individuals of differing statures. However, caution must be used when estimating stature of individuals with high BMIs.

Body mass is also important when considering health and disease, especially in relation to osteoporosis, as well as metabolic costs, mobility, brain size, longevity, thermoregulation, and so on (McHenry, 1992). The two most common methods of estimating body mass are from measurements of the maximum femoral head diameter and stature/ bi-iliac breadth (BIB). A test of both methods by Auerbach and Ruff (2004) demonstrate that they are both reliable with Pearson correlation values between 0.74 and 0.81 to known body mass. However, the femoral head diameter and BIB methods were not developed on individuals with high body masses or BMIs; therefore, these measurements and calculations do not consider heavier individuals. BIB body mass calculations are based on the assumption that human bodies can be compared to cylinders, and by applying surface area models to measurements of stature (length) and bi-iliac breadth (width), an estimation of body mass can be obtained (Ruff, 1994). As individuals become heavier, calculating the amount of subcutaneous fat surrounding the pelvis (or the width of the cylinder) based on skeletal measurements becomes more difficult, and the results less accurate. The method works well on elite athletes (Ruff, 2000) and distinguishing individuals from different ecogeographic regions based on body proportions (Ruff, 1994; Ruff et al., 2005; 
Pomeroy and Stock, 2012), and it has been used to estimate body mass for past populations (Ruff et al., 1993, 2006; Rafferty et al., 1995; Sealy and Pfeiffer, 2006; Kurki et al., 2009), but it is not commonly used to estimate body mass in modern populations. Therefore, predicting body mass using femoral head diameter or BIB measurements for obese individuals may be a challenge in cases of unknown individuals, and would make it difficult to apply the results of the current study to obese individuals.

Recently, researchers have begun to investigate the influence of body size on skeletal features. For example, Agostini and Ross (2011) analyzed the femoral cross-sections of 121 males of varying BMIs from the William Bass Collection. Their results show that there is a significant difference in medial-lateral femoral measurements of obese individuals compared to normalsized individuals. Obese individuals have larger medial-lateral cross-section diameters than individuals of normal BMIs, suggesting that an increase in body mass affects body mass-loading bones. The authors suggest the change in gait swing and increased loading on heel-toe impact in obese individuals may explain the increased bone deposition in the femur. The results of Agostini and Ross' study imply that it may be possible to determine obese individuals based on femoral shape, which would allow researchers to apply appropriate body-size adjusted age estimation methods in the future.

\subsection{Study Limitations}

There are several limitations of this study that should be considered. First, the body mass recorded for each individual is cadaver weight, which might not accurately reflect living weight. Second, as body mass for these individuals is only known at death, any fluctuations in weight throughout life are unknown. For example, if an individual gained or lost a substantial amount of weight before they died, only their weight at death is recorded, and it will not accurately reflect the life history of the individual. Third, BMD is not known for this population, but only inferred based on current studies of BMD. Fourth, the occupations, levels of physical activity, and general health are known for some, but not all of the individuals in this study. Fifth, the HamannTodd and William Bass Collections each have their own set of biases. The Hamann-Todd Collection mostly consists of unclaimed bodies of European male migrant workers from the early 20th century in Ohio, and the William Bass Collection consists mostly of donated bodies of males from the late 20th century in Tennessee. And sixth, the application of new body-size 
adjusted age estimation parameters is limited because our current standards of estimating body mass are poor, especially for modern populations with high rates of obesity. 


\section{Chapter 5: Conclusion}

When comparing the age estimation methods for this sample of 764 individuals, the İşcan et al. method consistently under-ages males, females, individuals of European ancestry, and individuals of African ancestry more than any other method, and the DiGangi et al. method is the most unreliable method with low accuracy (over 20 years in some cases) and high bias scores (under-aging individuals by almost 20 years). The Buckberry and Chamberlain method has comparable accuracy scores to the other methods, but over-ages individuals more than all other methods, which is consistent with findings from others who have tested this method (Falys et al., 2006; Hens and Belcastro, 2012). The Kunos et al., Lovejoy et al., and Suchey-Brooks methods are the most reliable age methods, as they have the highest accuracy and lowest bias scores among the BMI, stature, and body mass groups; the error rates for these three methods are between 8 years to 10 years, and typically underweight and short individuals are only under-aged by approximately 5 years compared to heavier and tall individuals.

Males and individuals of European ancestry, and females and individuals of African ancestry generally follow similar reliability trends. The age estimations of females and individuals of African ancestry are the least affected by BMI, stature, and body mass for this sample, and are most likely due to small sample sizes in the obese BMI group and heavy body mass group. Males and individuals of European ancestry in the underweight BMI group, short stature group, and lighter body mass group have between 3 years and 10 years of error associated with their age estimations, and they are typically under-aged between 5 years and 15 years.

Bone remodelling rates and BMD are influenced by body mass. Underweight individuals have lower rates of bone remodelling and lower BMD scores, and this study has shown that these lower remodelling rates are translate to age-related changes at the surface of bone. Underweight individuals are under-aged compared to overweight and obese individuals, providing a protective effect against skeletal aging. Low amounts of fat tissue have been shown to lower rates of bone turnover in underweight individuals, and underweight individuals in this study were found to follow this trend as they were under-aged with all age estimation methods, and there was more error associated with their age estimations compared to individuals in the other body mass groups, especially those from the heaviest body mass group. The results of the current study 
suggest that body mass and lean muscle mass might be more influential to BMD than nutritional status.

Obese individuals have been shown to display both low and high BMD scores. In this study, obese individuals are over-aged compared to underweight individuals, with increased degenerative changes on the joint surfaces used in skeletal age estimation. Lean muscle mass vs. fat muscle mass has been shown to influence bone remodelling rates in obese individuals. Obese individuals with higher amounts of muscle mass to fat mass have lower rates of bone turnover compared to obese individuals with higher amounts of fat mass to muscle mass. Obese individuals in this study were over-aged compared to underweight individuals, suggesting that they had high amounts of fat mass compared to muscle mass.

Physical activity and occupation are proposed as other ways to explain the differences in age estimations generated from individuals with differing body sizes I argue that underweight individuals who are physically active with greater amounts of lean muscle mass are under-aged compared to obese individuals because of the lower bone remodelling rates associated with lean muscle mass. Conversely, obese individuals who are moderately active with increased amounts of visceral fat are over-aged compared to underweight individuals because of the higher bone remodelling rates associated with fat mass. The mechanical stress of physical activity is increased on obese individuals, and combined with high amounts of fat mass and low amounts of lean muscle mass, bone remodelling rates increase, resulting in increased osteophytic activity and more degeneration of the joint. The individuals with low body mass in this study were born in the late 19th century and were labourers who performed activities with high levels of mechanical loading, and presumably they had higher levels of lean muscle mass compared to the obese individuals in this study who were born in the mid-20th century and engaged in less physically demanding occupations. Low body mass decreases bone remodelling rates, increases BMD and therefore, decreases the markers of aging observed on the osseous materials. The mechanical stress of physical activity is decreased in individuals with low body mass, and combined with high amounts of lean muscle mass and low amounts of fat mass, bone remodelling rates decrease, resulting in less osteophytic activity, lower microporosity scores, and overall less degeneration to the joint. 
This is the first study to show that body size influences skeletal age estimations, and the first study to show that skeletal age estimations are significantly different between weight-bearing and non-weight-bearing joints. 


\section{References}

Adachi T, Aonuma Y, Ito S, Tanaka M, Hojo M, Takano-Yamamoto T, and Kamioka H. 2009. Osteocyte calcium signaling response to bone matrix deformation. J Biomech 42:2507-12.

Adams B, and Byrd J. 2002. Interobserver variation of selected postcranial skeletal measurements. J Forensic Sci 47:1193-202.

Adams B, and Herrmann N. 2009. Estimation of living stature from selected anthropometric (soft tissue) measurements: applications for forensic anthropology. J Forensic Sci 54:753-760.

Agostini G, and Ross A. 2011. The effect of weight on the femur: a cross-sectional analysis. J Forensic Sci 56:339-343.

Aktas E, Kocak A, Aktas S, and Yemiscigil A. 2004. Intercostal variation for age estimation--are the standards for the right 4th rib applicable for other ribs? Coll Antropol 28 Suppl 2:267-272.

Albala C, Yáñez M, Devoto E, Sostin C, Zeballos L, and Santos J. 1996. Obesity as a protective factor for postmenopausal osteoporosis. Int J Obes Relat Metab Disord 20:1027-32.

Anderson M, Anderson D, and Wescott D. 2010. Estimation of adult skeletal age-at-death using the Sugeno fuzzy integral. Am J Phys Anthr. 142:30-41.

Anon. 2012. Medical Subject Headings. Natl. Libr. Med. [Internet]. Available from:

http://www.nlm.nih.gov/cgi/mesh/2011/MB_cgi?mode=\&term=Bone+Density

Ascádi G, and Nemeskéri J. 1970. History of human lifespan and mortality. . Budapest: Akademiai Kiado.

Auerbach B, and Ruff C. 2004. Human body mass estimation: a comparison of "morphometric" and "mechanical" methods. Am J Phys Anthr. 125:331-342.

Auerbach B. 2011. Methods for estimating missing human skeletal element osteometric dimensions employed in the revised fully technique for estimating stature. Am J Phys Anthr. 145:67-80. 
Aykroyd R, Lucy D, Pollard A, and Solheim T. 1997. Regression analysis in adult age estimation. Am J Phys Anthr. 104:259-265.

Baccino E, Ubelaker D, Hayek L, and Zerilli A. 1999. Evaluation of seven methods of estimating age at death from mature human skeletal remains. J Forensic Sci 44:931-936.

Bar-Shavit Z. 2007. The osteoclast: a multinucleated, hematopoietic-origin, bone-resorbing osteoimmune cell. J Cell Biochem 102:1130-9.

Bartko J. 1976. On various intraclass correlation reliability coefficients. Psychol Bull 83:176765.

Beauthier J, Lefevre P, Meunier M, Orban R, Polet C, Werquin J, and Quatrehomme G. 2010. Palatine Sutures as Age Indicator: A Controlled Study in the Elderly. J Forensic Sci 55:153-158.

Bedford M, Russell K, Lovejoy C, Meindl R, Simpson S, and Stuart-Macadam P. 1993. Test of the multifactorial aging method using skeletons with known ages-at-death from the Grant Collection. Am J Phys Anthr. 91:287-297.

Bednarek J, Bloch-Boguslawska E, and Sliwka K. 2002. [Use of morphologic changes in the pubic symphysis for age determination in the Polish male population]. Arch Med Sadowej Kryminol 52:295-304.

Bednarek J, and Sliwka K. 2004. [The problems concerning estimating age at death based on morphological features of adult skeletons]. Arch Med Sadowej Kryminol 54:264-270.

Berg G. 2008. Pubic bone age estimation in adult women. J Forensic Sci 53:569-577.

Bergot C, Prteux F, and Meunier A. 1988. Measurement of Anisotropic Vertebral Trabecular Bone Loss during Aging by Quantitative Image Analysis. Calcif Tissue Int 43:143-149.

Bidmos M, and Dayal M. 2003. Sex determination from the talus of South african whites by discriminant function analysis. Am J Forensic Med Pathol 24:322-328.

Bidmos M. 2006. Adult stature reconstruction from the calcaneus of South Africans of European descent. J Clin Forensic Med 13:247-252. 
Binford L, and Bindford S. 1968. New Perspectives in Archaeology. Chicago, IL: Aldine.

Bobinac D, Spanjol J, Zoricic S, and Maric I. 2003. Changes in articular cartilage and subchondral bone histomorphometry in osteoarthritic knee joints in humans. Bone 32:284-290.

Bocquet-Appel J, and Masset C. 1982. Farewell to paleodemography. J Hum Evol 12:321-33.

Bocquet-Appel J, and Masset C. 1996. Palaeodemography: expectancy and false hope. Am J Phys Anthr. 99:571-584.

Boldsen J, Milner G, Konigsberg L, and Wood J. 2002. Transition analysis: a new method for estimating age from skeletons. In: Hoppa R, Vaupel J, editors. Paleodemography: age distributions from skeletal samples. Cambridge: Cambridge University Press. p 73-106.

Bonneuil N. 2005. Fitting to a Distribution of Deaths by Age with Application to Paleodemography: The Route Closest to a Stable Population. Curr. Anthr. 46:S29-S45.

Boskey A, and Coleman R. 2010. Aging and bone. J Dent. Res 89:1333-48.

Bredella M, Torriani M, Ghomi RH, Thomas BJ, Brick DJ, Gerweck A V, Harrington LM, Breggia A, Rosen CJ, and Miller KK. 2011. Determinants of bone mineral density in obese premenopausal women. Bone 48:748-54.

Britz H, Thomas C, Clement J, and Cooper D. 2009. The relation of femoral osteon geometry to age, sex, height and weight. Bone 45:77-83.

Brooks S, and Suchey J. 1990. Skeletal age determination base on the Os Pubis: A Comparison of the Acsádi-Nemeskéri and Suchey-Brooks Methods. J Hum Evol 5:227-238.

Brooks S. 1955. Skeletal age at death: the reliability of cranial and pubic age indicators. Am J Phys Anthr. 13:567-597.

Buckberry J, and Chamberlain A. 2002. Age estimation from the auricular surface of the ilium: a revised method. Am J Phys Anthr. 119:231-239.

Calado R. 2009. Telomeres and marrow failure. Am Soc Hematol:338-43. 
Calce S, and Rogers T. 2011. Evaluation of age estimation technique: testing traits of the acetabulum to estimate age at death in adult males. J Forensic Sci 56:302-311.

Calce S. 2012. A new method to estimate adult age-at-death using the acetabulum. Am J Phys Anthr. 23:11-23.

Cameriere R, and Ferrante L. 2008. Age estimation in children by measurement of carpals and epiphyses of radius and ulna and open apices in teeth: a pilot study. Forensic Sci Int 174:60-63.

Campanacho V, Santos A, and Cardoso H. 2012. Assessing the influence of occupational and physical activity on the rate of degenerative change of the pubic symphysis in Portuguese males from the 19th to 20th century. Am J Phys Anthr. 148:371-8.

Cao J, Kurimoto P, Boudignon B, Rosen C, Lima F, and Halloran B. 2007. Aging impairs IGF-I receptor activation and induces skeletal resistance to IGF-I. J Bone Min. Res 22:1271-1279.

Cao J, Wronski T, Iwaniec U, Phleger L, Kurimoto P, Boudignon B, and Halloran B. 2005. Aging increases stromal/osteoblastic cell-induced osteoclastogenesis and alters the osteoclast precursor pool in the mouse. J Bone Min. Res 20:1659-68.

Cao JJ. 2011. Effects of obesity on bone metabolism. J Orthop Res 6:30.

Cardoso H. 2008a. Age estimation of adolescent and young adult male and female skeletons II, epiphyseal union at the upper limb and scapular girdle in a modern Portuguese skeletal sample. Am J Phys Anthr. 137:97-105.

Cardoso H. 2008b. Epiphyseal union at the innominate and lower limb in a modern Portuguese skeletal sample, and age estimation in adolescent and young adult male and female skeletons. Am J Phys Anthr. 135:161-170.

Carrington J. 2005. Aging bone and cartilage: cross-cutting issues. Biochem Biophys Res Commun 328:700-8.

Celbis O, and Agritmis H. 2006. Estimation of stature and determination of sex from radial and ulnar bone lengths in a Turkish corpse sample. Forensic Sci Int 158:135-139. 
Cerroni A, Tomlinson G, Turnquist J, and Grynpas M. 2000. Bone Mineral Density, Osteopenia, and Osteoporosis in the Rhesus Macaques of Cayo Santiago. Am J Phys Anthr. 113:389-410.

Chan G, and Duque G. 2002. Age-related bone loss: old bone, new facts. Gerontol 48:62-71.

Chen X, Zhang Z, and Tao L. 2008. Determination of male age at death in Chinese Han population: using quantitative variables statistical analysis from pubic bones. Forensic Sci Int 175:36-43.

Cipriano-Bechtle A, Grupe G, and Schroter P. 1996. Aging and life expectancy in the early Middle Ages. Homo 46:267-279.

Cohen J. 1992. A power primer. Psychol Bull 112:155-159.

Coin A, Perissinotto E, Enzi G, Zamboni M, Inelmen EM, Frigo a C, Manzato E, Busetto L, Buja A, and Sergi G. 2008. Predictors of low bone mineral density in the elderly: the role of dietary intake, nutritional status and sarcopenia. Eur. J Clin. Nutr. 62:802-9.

Coin A, Sergi P, Beninca L, Lupoli L, Cinti G, Ferrara L, Benedetti G, Tomasi G, Pisent C, and Enzi G. 2000. Bone Mineral Density and Body Composition in Underweight and Normal Elderly Subjects. Osteoporos Int 11:1043-1050.

Collins M, Nielsen-Marsh C, Hiller J, Smith C., Roberts J, Prigodich R, Wess T, Csapo J, Millard A, and Turner-Walker G. 2002. The survival of organic matter in bone: A review. Archaeometry 44:383-394.

Collins M, Riley M, Child A, and Turner-Walker G. 1995. A Basic Mathematical Simulation of the Chemical Degradation of Ancient Collagen. J Archaeol Sci 22:175-183.

Cooper A, Page A, Fox K, and Misson J. 2000. Physical activity patterns in normal, overweight and obese individuals using minute-by-minute accelerometry. Eur J Clin Nutr 54:887-94.

Cordeiro C, Muñoz-Barús J, Wasterlain S, Cunha E, and Vieira D. 2009. Predicting adult stature from metatarsal length in a Portuguese population. Forensic Sci Int 193:131 e1-4. 
Cox LGE, van Donkelaar CC, van Rietbergen B, Emans PJ, and Ito K. 2013. Alterations to the subchondral bone architecture during osteoarthritis: bone adaptation vs endochondral bone formation. Osteoarthr. Cartil. 21:331-8.

Cox M. 2000. Aging in adult skeletons. In: Human osteology in archaeology and forensic science. London: Greenwich Medical Media Ltd. p 61-81.

Crowder C, and Austin D. 2005. Age ranges of epiphyseal fusion in the distal tibia and fibula of contemporary males and females. J Forensic Sci 50:1001-1007.

Crowder C, and Rosella L. 2007. Assessment of intra- and intercostal variation in rib histomorphometry: its impact on evidentiary examination. J Forensic Sci 52:271-276.

Currey J. 1969. The relationship between the stiffness and the mineral content of bone. J Biomech 2:477-480.

Davis J, Hodges V, and Gillham M. 2006. Physical activity compliance: differences between overweight/obese and normal-weight adults. Obesity 14:2259-65.

DiGangi E, Bethard J, Kimmerle E, and Konigsberg L. 2009. A new method for estimating ageat-death from the first rib. Am J Phys Anthr. 138:164-176.

Djurić M, Djonić D, Nikolić S, Popović D, and Marinković J. 2007. Evaluation of the SucheyBrooks method for aging skeletons in the Balkans. J Forensic Sci 52:21-23.

Dorandeu A, Coulibaly B, Piercecchi-Marti M, Bartoli C, Gaudart J, Baccino E, and Leonetti G. 2008. Age-at-death estimation based on the study of frontosphenoidal sutures. Forensic Sci Int 177:47-51.

Dudar J, Pfeiffer S, and Saunders S. 1993. Evaluation of morphological and histological adult skeletal age-at-death estimation techniques using ribs. J Forensic Sci 38:677-685.

Enders C. 2003. Performing multivariate group comparisons following a statistically significant MANOVA. Meas. Eval. Couns. Dev. 36:40-56. 
Falys C, and Lewis M. 2011. Proposing a way forward: A review of standardisation in the use of age categories and ageing techniques in osteological analysis (2004-2009). Int J Osteoarchaeol 21:704-716.

Falys C, Schutkowski H, and Weston D. 2006. Auricular surface aging: worse than expected? A test of the revised method on a documented historic skeletal assemblage. Am J Phys Anthr. 130:508-513.

Felson D, Zhang Y, Hannan M, and Anderson J. 1993. Effects of weight and body mass index on bone mineral density in men and women: the Framingham study. J Bone Min. Res 8:567-73.

Felson D. 1996. Does excess weight cause osteoarthritis, and, if so, why? Ann Rheum Dis 55:668-671.

Fernández-García D, Rodríguez M, García Alemán J, García-Almeida JM, Picón MJ, FernándezAranda F, and Tinahones FJ. 2009. Thin healthy women have a similar low bone mass to women with anorexia nervosa. Br. J Nutr. 102:709.

Ferreira H, Moura F, Cabral Junior C, Florencio T, Vieira R, and de Assunção M. 2008. Short stature of mothers from an area endemic for undernutrition is associated with obesity, hypertension and stunted children: a population-based study in the semi-arid region of Alagoas, Northeast Brazil. Br. J Nutr. 101:1239-45.

Finkelstein JS, Lee M-LT, Sowers M, Ettinger B, Neer RM, Kelsey JL, Cauley J, Huang M-H, and Greendale G. 2002. Ethnic variation in bone density in premenopausal and early perimenopausal women: effects of anthropometric and lifestyle factors. J Clin Endocrinol Metab $87: 3057-67$.

Franklin D. 2010. Forensic age estimation in human skeletal remains: current concepts and future directions. Leg Med 12:1-7.

Frisancho A. 1984. New standards of weight and body composition by frame size and height for assessment of nutritional status of adults and the elderly. Am J Clin Nutr. 40:808-19.

Frost HM. 1960. Micropetrosis. J Bone Jt. Surg Am 42:144-50. 
Fully G. 1956. Une nouvelle methode de determination de la taille. Ann Med Leg. 36:266-73.

Galera V, Ubelaker D, and Hayek L. 1998. Comparison of macroscopic cranial methods of age estimation applied to skeletons from the Terry Collection. J Forensic Sci 43:933-939.

Garvin H, and Passalacqua N. 2012. Current practices by forensic anthropologists in adult skeletal age estimation. J Forensic Sci 57:427-433.

Gehring K, Haffner H, Weber D, and Graw M. 2002. Investigations on the reliability of determining an individual's age from the proximal femur. Homo 52:214-220.

Van Gerven D, and Armelagos G. 2003. A Century of Skeletal Biology and Paleopathology:

Contrasts, Contradictions, and Conflicts. Am Anthr. 105:53-64.

Van Gervin D, and Armelagos G. 1983. Farewell to paleodemography? Rumors of its death have been greatly exaggerated. J Hum Evol:353-360.

Getz S. 2011. An Investigation and Critique of the DiGangi et al. (2009) First Rib Aging Method. In: American Academy of Forensic Sciences. Chicago, IL. p 24.

Gilbert B, and McKern T. 1973. A method for aging the female Os pubis. Am J Phys Anthr. 38:31-38.

Ginter J. 2005. A test of the effectiveness of the revised maxillary suture obliteration method in estimating adult age at death. J Forensic Sci 50:1303-1309.

Gnudi S, Sitta E, and Fiumi N. 2007. Relationship between body composition and bone mineral density in women with and without osteoporosis: relative contribution of lean and fat mass. J Bone Min. Metab 25:326-32.

Gordeladze JO, Drevon C, Syversen U, and Reseland JE. 2002. Leptin stimulates human osteoblastic cell proliferation, de novo collagen synthesis, and mineralization: Impact on differentiation markers, apoptosis, and osteoclastic signaling. J Cell Biochem 85:825-36. 
Greco E, Fornari R, Rossi F, Santiemma V, Prossomariti G, Annoscia C, Aversa A, Brama M, Marini M, Donini LM, et al. 2010. Is obesity protective for osteoporosis? Evaluation of bone mineral density in individuals with high body mass index. Int J Clin Pract. 64:817-20.

Gruspier K, and Mullen G. 1991. Maxillary suture obliteration: a test of the Mann method. J Forensic Sci 36:512-519.

Grynpas M, Tupy J, and Sodek J. 1994. The Distribution of Soluble, Mineral-Bound, and Matrix-Bound Proteins in Osteoporotic and Normal Bones. Bone 15:505-513.

Guy H, Messet C, and Baud C. 1997. Infant Taphonomy. Int J Osteoarchaeol 7:221-229.

Hamrick MW, and Ferrari SL. 2008. Leptin and the sympathetic connection of fat to bone. Osteoporos Int 19:905-912.

Han ZH, Palnitkar S, Rao DS, Nelson D, and Parfitt M. 1997. Effects of ethnicity and age or menopause on the remodeling and turnover of iliac bone: implications for mechanisms of bone loss. J Bone Min. Res 12:498-508.

Harper G, and Crews D. 2000. Aging, senescence, and human variation. In: Stinson S, Bogin B, Huss-Ashmore R, O’Rourke D, editors. Human biology: An evolutionary and biocultural perspective. New York: Wiley-Liss. p 465-505.

Hartnett K. 2010a. Analysis of age-at-death estimation using data from a new, modern autopsy sample--part I: pubic bone. J Forensic Sci 55:1145-1151.

Hartnett K. 2010b. Analysis of age-at-death estimation using data from a new, modern autopsy sample--part II: sternal end of the fourth rib. J Forensic Sci 55:1152-1156.

Hayflick L. 1965. The limited in vitro lifetime of human diploid cell strains. Exp Cell Res 37:614-636.

Hayter A. 1986. The Maximum Familywise Error Rate of Fisher's Least Significant Difference Test. Am Stat. Assoc 81:1000-1005. 
Helmuth H. 1998. Body height, body mass and surface area of the Neandertals. Z Morphol Anthr. 82:1-12.

Henriksen K, Leeming D, and Byrjalsen I. 2007. Osteoclasts prefer aged bone. Osteoporos Int 18:751-759.

Hens S, and Belcastro G. 2012. Auricular surface aging: a blind test of the revised method on historic Italians from Sardinia. Forensic Sci Int 214:209 e1-5.

Hens S, Rastelli E, and Belcastro G. 2008. Age estimation from the human os coxa: a test on a documented Italian collection. J Forensic Sci 53:1040-1043.

Hershkovitz I, Latimer B, Dutour O, Jellema L, Wish-Baratz S, Rothschild C, and Rothschild B. 1997. Why do we fail in aging the skull from the sagittal suture? Am J Phys Anthr. 103:393-399.

Heuberger R, Domina T, and MacGillivray M. 2007. Body scanning as a new anthropometric measurement tool for health-risk assessment. Int J Consum. Stud. 32:34-40.

Heymsfield SB, Gallagher D, Mayer L, Beetsch J, and Pietrobelli A. 2007. Scaling of human body composition to stature: new insights into body mass index. Am J Clin Nutr. 86:82-91.

Holliday T, and Ruff C. 1997. Ecogeographical patterning and stature prediction in fossil hominids: component on M.R. Feldesman and R.L. Fountain, American Journal of Physical Anthropology (1996) 100:207-224. Am J Phys Anthr. 103:137-140.

Holliday T. 1997. Postcranial evidence of cold adaptation in European Neandertals. Am J Phys Anthr. 104:245-258.

Holliday T. 2002. Body size and postcranial robusticity of European Upper Paleolithic hominins. J Hum Evol 43:513-528.

Hoppa R, and Vaupel J. 2002a. The Rostock Manifesto for paleodemography. In: Hoppa R, Vaupel J, editors. Paleodemography: age distributions from skeletal samples. Cambridge: Cambridge University Press. p 1-8. 
Hoppa R, and Vaupel J. 2002b. Paleodemography: Age Distributions from Skeletal Samples. Cambridge University Press.

Howell D. 2007. Statistical methods for psychology. Belmont, CA: Thompson Wadsworth.

Huberty C, and Petoskey M. 2000. Multivariate analysis of variance and covariance. In: Tinsley H, Brown S, editors. Handbook of applied multivariate statistics and mathematical modeling. New York, NY: Academic Press.

IBM Corp. 2012. IBM SPSS Statistics for Windows.

Işcan M, Loth S, and Wright R. 1984a. Age estimation from the rib by phase analysis: white males. J Forensic Sci 29:1094-1104.

Işcan M, Loth S, and Wright R. 1984b. Metamorphosis at the sternal rib end: a new method to estimate age at death in white males. Am J Phys Anthr. 65:147-156.

Işcan M, Loth S, and Wright R. 1985. Age estimation from the rib by phase analysis: white females. J Forensic Sci 30:853-863.

Işcan M, Loth S, and Wright R. 1987. Racial variation in the sternal extremity of the rib and its effect on age determination. J Forensic Sci 32:452-466.

Jackson A, Stanforth PR, Gagnon J, Rankinen T, Leon S, Rao DC, Skinner JS, Bouchard C, and Wilmore JH. 2002. Appropriate body-mass index for Asian populations and its implications for policy and intervention strategies. Int J Obes. 26:789-96.

Jankauskas R, Barakauskas S, and Bojarun R. 2001. Incremental lines of dental cementum in biological age estimation. Homo 52:59-71.

Jiang Y, Mishima H, Sakai S, Liu Y, Ohyabu Y, and Uemura T. 2008. Gene expression analysis of major lineage-defining factors in human bone marrow cells: effect of aging, gender, and agerelated disorders. J Orthop Res 26:910-7.

Jilka R, Weinstein R, Parfitt A, and Manolagas S. 2007. Quantifying Osteoblast and Osteocyte Apoptosis: Challenges and Rewards. J Bone Min. Res 22:1492-1501. 
Johnson C, and Field C. 1993. Using fixed effect model multivariate analysis of variance in marine biology and ecology. Ocean. Mar. Biol. Annu. Rev. 31:177-221.

Jones W. 2003. Using Trabecular Architecture of the Proximal Femur to Determine Age at Death: An Accuracy Test of Two Methods. Dep. Geogr. Anthropol. M.A.:59.

Kappelman J. 1996. The evolution of body mass and relative brain size in fossil hominids. J Hum Evol 30:243-276.

Kaptoge S, Dalzell N, Loveridge N, Beck T, Khaw K, and Reeve J. 2003. Effects of gender, anthropometric variables, and aging on the evolution of hip strength in men and women aged over 65. Bone 32:561-570.

Karakas H, Celbis O, Harma A, and Alicioglu B. 2010. Total body height estimation using sacrum height in Anatolian Caucasians: multidetector computed tomography-based virtual anthropometry. Skelet. Radiol 40:623-630.

Katz D, and Suchey J. 1989. Race differences in pubic symphyseal aging patterns in the male. Am J Phys Anthr. 80:167-172.

Katzmarzyk P, and Leonard W. 1998. Climatic influences on human body size and proportions: ecological adaptations and secular trends. Am J Phys Anthr. 106:483-503.

Kemkes-Grottenthaler A. 2005. The short die young: the interrelationship between stature and longevity-evidence from skeletal remains. Am J Phys Anthr. 128:340-347.

Kieser J, Preston C, and Evans W. 1983. Skeletal Age at Death : an Evaluation of the Miles Method of Ageing. J Archaeol Sci 10:9-12.

Kimmerle E, Prince D, and Berg G. 2008. Inter-observer variation in methodologies involving the pubic symphysis, sternal ribs, and teeth. J Forensic Sci 53:594-600.

Kloss F, and Gassner R. 2006. Bone and aging: effects on the maxillofacial skeleton. Exp Gerontol 41:123-9. 
Konigsberg L, Herrmann N, Wescott D, and Kimmerle E. 2008. Estimation and evidence in forensic anthropology: age-at-death. J Forensic Sci 53:541-557.

Kunos C, Simpson S, Russell K, and Hershkovitz I. 1999. First rib metamorphosis: its possible utility for human age-at-death estimation. Am J Phys Anthr. 110:303-323.

Kurki H, Ginter J, Stock J, and Pfeiffer S. 2009. Body size estimation of small-bodied humans: Applicability of current methods. Am J Phys Anthr. in press.

Kurki H. 2005. Use of the first rib for adult age estimation: A test of one method. Int J Osteoarchaeol. 15:342-350.

Landis J, and Koch G. 1977. The measurement of observer agreement for categorical data. Biometrics 33:159-174.

Lee C, Chang I, Fletcher M, and Tarantal A. 2005. Effect of age on the frequency, cell cycle, and lineage maturation of rhesus monkey (Macaca mulatta) CD34+ and hematopoietic progenitor cells. Pediatr Res 58:315-22.

Lee S, Lee S, Lee J, Park H, and Kim Y. 2008. Age estimation of Korean children based on dental maturity. Forensic Sci Int 178:125-131.

Lekamwasam S, Weerarathna T, Rodrigo M, Arachchi WK, and Munidasa D. 2009. Association between bone mineral density, lean mass, and fat mass among healthy middle-aged premenopausal women: a cross-sectional study in southern Sri Lanka. J Bone Min. Metab 27:838.

Leonard W, and Katzmarzyk P. 2010. Body Size and Shape: Climatic and Nutritional Influences on Human Body Morphology. In: Muehlenbein M, editor. Human Evolutionary Biology. New York, NY: Cambridge University Press.

Lim S, Joung H, Shin C, Lee H, Kim K, Shin E, Kim H, Lim M, and Cho S. 2004. Body composition changes with age have gender-specific impacts on bone mineral density. Bone $35: 792-8$. 
Looker A, Beck T, and Orwoll E. 2001. Does body size account for gender differences in femur bone density and geometry? J Bone Min. Res 16:1291-9.

Loth S, Işcan M, and Scheuerman E. 1994. Intercostal variation at the sternal end of the rib. Forensic Sci Int 65:135-143.

Lovejoy C, Meindl R, Mensforth R, and Barton T. 1985a. Multifactorial determination of skeletal age at death: a method and blind tests of its accuracy. Am J Phys Anthr. 68:1-14.

Lovejoy C, Meindl R, Pryzbeck T, and Mensforth R. 1985b. Chronological metamorphosis of the auricular surface of the ilium: a new method for the determination of adult skeletal age at death. Am J Phys Anthr. 68:15-28.

Lovejoy C. 1985. Dental wear in the Libben population: its functional pattern and role in the determination of adult skeletal age at death. Am J Phys Anthr. 68:47-56.

Madry H, van Dijk CN, and Mueller-Gerbl M. 2010. The basic science of the subchondral bone. Knee Surg Sport. Traumatol Arthrosc 18:419-33.

Maijanen H. 2009. Testing anatomical methods for stature estimation on individuals from the W. M. Bass Donated Skeletal Collection. J Forensic Sci 54:746-752.

Mall G, Hubig M, Buttner A, Kuznik J, Penning R, and Graw M. 2001. Sex determination and estimation of stature from the long bones of the arm. Forensic Sci Int 117:23-30.

Manjubala I, Liu Y, Epari D, Roschger P, Schell H, Fratzl P, and Duda G. 2009. Spatial and temporal variations of mechanical properties and mineral content of the external callus during bone healing. Bone 45:185-92.

Manolagas S, and Parfitt A. 2010. What old means to bone. Trends Endocrinol Metab 21:36974.

Martrille L, Ubelaker D, Cattaneo C, Seguret F, Tremblay M, and Baccino E. 2007. Comparison of four skeletal methods for the estimation of age at death on white and black adults. J Forensic Sci 52:302-307. 
McCalden R, McGeough J, Barker M, and Court-Brown C. 1993. Age-related changes in the tensile properties of cortical bone: The relative importance of changes in porosity, mineralization, and microstructure. J Bone Jt. Surg Am 75:1193-1205.

McCormick W. 1980. Mineralization of the costal cartilages as an indicator of age: preliminary observations. J Forensic Sci 25:736-741.

McDade T. 2003. Life history theory and the immune system: steps toward a human ecological immunology. Yrbk Phys Anthr. 46:100-125.

McHenry H. 1992. Body size and proportions in early hominids. Am J Phys Anthr. 87:407-431.

McHenry H. 2005. How big were early hominids? Evol Anthr. 1:15-20.

McKern T, and Stewart T. 1957. Skeletal Age Changes in Young American Males, Analyzed from the Standpoint of Identification. Natick, Massachusetts: Headquarters, Quartermaster Research and Development Command.

McNeil C, Raymer G, Doherty T, Marsh G, and Rice C. 2009. Geometry of a weight-bearing and non-weight-bearing bone in the legs of young, old, and very old men. Calcif Tissue Int 85:22-30.

Meindl R, Lovejoy C, Mensforth R, and Walker R. 1985. A revised method of age determination using the os pubis, with a review and tests of accuracy of other current methods of pubic symphyseal aging. Am J Phys Anthr. 68:29-45.

Meindl R, Russell K, and Lovejoy C. 1990. Reliability of age at death in the Hamann-Todd collection: validity of subselection procedures used in blind tests of the summary age technique. Am J Phys Anthr. 83:349-357.

Meinl A, Huber C, Tangl S, Gruber G, Teschler-Nicola M, and Watzek G. 2008. Comparison of the validity of three dental methods for the estimation of age at death. Forensic Sci Int 178:96105.

Meissner C, and Ritz-Timme S. 2010. Molecular pathology and age estimation. Forensic Sci Int 203:34-43. 
Menezes R, Nagesh K, Monteiro F, Kumar G, Kanchan T, Uysal S, Rao P, Rastogi P, Lobo S, and Kalthur S. 2011. Estimation of stature from the length of the sternum in South Indian females. J Forensic Leg Med 18:242-245.

Merritt C. 2013. Testing the accuracy of adult skeletal age estimation methods: original methods versus revised and newer methods. vis-à-vis Explor. Anthropol. 1:71-88.

Meyers L, Gamst G, and Guarino A. 2006. Applied multivariate research: Design and interpretation. Thousand Oaks, CA: Sage Publications, Inc.

Mikkola T, Sipila S, Rantanen T, Sievanen H, Suominen H, Kaprio J, Koskenvuo M, Kauppinen M, and Heinonen A. 2008. Genetic and environmental influence on structural strength of weightbearing and non-weight-bearing bone: a twin study. J Bone Min. Res 23:492-498.

Milner G, and Boldsen J. 2012. Estimation : Where We Are and Where Should We Go. In: Dirkmaat D, editor. A Companion to Forensic Anthropology. First. Blackwell Publishing Ltd. p 224-238.

Moore M, and Schaefer E. 2011. A comprehensive regression tree to estimate body weight from the skeleton. J Forensic Sci 56:1115-22.

Mosekilde L. 1998. Aging of bone. Rev Clin Gerontol:281-296.

Mulhern D, and Jones E. 2005. Test of revised method of age estimation from the auricular surface of the ilium. Am J Phys Anthr. 126:61-65.

Murray K, and Murray T. 1991. A test of the auricular surface aging technique. J Forensic Sci 36:1162-1169.

Nagaoka T, and Hirata K. 2007. Reconstruction of paleodemographic characteristics from skeletal age at death distributions: perspectives from Hitotsubashi, Japan. Am J Phys Anthr. 134:301-311. 
Nagaoka T, and Hirata K. 2008. Demographic structure of skeletal populations in historic Japan: a new estimation of adult age-at-death distributions based on the auricular surface of the ilium. J Arch Sci 35:1370-1377.

Nagar Y, and Hershkovitz I. 2004. Interrelationship between various aging methods, and their relevance to palaeodemography. J Hum Evol 19:145.

Nakagawa S. 2004. A farewell to Bonferroni: the problems of low statistical power and publication bias. Behav. Ecol. 15:1044-1045.

Nance J. 1987. Reliability, validity, and quantitative methods in archaeology. In: Aldenderfer M, editor. Quantitative research in archaeology. Newbury Park: Sage Publications, Inc. p 245-93.

Neufeld R, and Gardner R. 1990. Data aggregation in evaluating psychological constructs:

Multivariate and logical deductive considerations. J Math Psychol. 34:276-296.

Nieves J, Formica C, Ruffing J, Zion M, Garrett P, Lindsay R, and Cosman F. 2005. Males have larger skeletal size and bone mass than females, despite comparable body size. J Bone Min. Res 30:529-535.

Nikander R, Sievanen H, Uusi-Rasi K, Heinonen A, and Kannus P. 2006. Loading modalities and bone structures at nonweight-bearing upper extremity and weight-bearing lower extremity: a pQCT study of adult female athletes. Bone 39:886-894.

Ode JJ, Pivarnik JM, Reeves MJ, and Knous JL. 2007. Body mass index as a predictor of percent fat in college athletes and nonathletes. Med. Sci. Sports Exerc. 39:403-9.

Van Oers R, Ruimerman R, van Rietbergen B, Hilbers P, and Huiskes R. 2008. Relating osteon diameter to strain. Bone 43:476-82.

Oettlé C, and Steyn M. 2000. Age estimation from sternal ends of ribs by phase analysis in South African Blacks. J Forensic Sci 45:1071-1079.

Ogden C, Carroll M, Kit B, and Flegal K. 2012. Prevalence of Obesity in the United States, 2009-2010. National Center for Health Statistics (NCHS). 
Osborne D, Simmons T, and Nawrocki S. 2004. Reconsidering the auricular surface as an indicator of age at death. J Forensic Sci 49:905-911.

Ozaslan A, Koc S, Ozaslan I, and Tugcu H. 2006. Estimation of stature from upper extremity. Mil Med 171:288-291.

Paine R, and Harpending H. 1998. Effect of sample bias on paleodemographic fertility estimates. Am J Phys Anthr. 105:231-240.

Paine R. 1989. Model life table fitting by maximum likelihood estimation: a procedure to reconstruct paleodemographic characteristics from skeletal age distributions. Am J Phys Anthr. 79:51-61.

Parfitt A, Mathews C, Villanueva A, Kleerekoper M, Frame B, and Rao D. 1983. Relationships between Surface, Volume, and Thickness of Iliac Trabecular Bone in Aging and in Osteoporosis: Implications for the microanatomic and cellular mechanisms of bone loss. J Clin Invest 72:13961409.

Passalacqua N. 2009. Forensic age-at-death estimation from the human sacrum. J Forensic Sci $54: 255-262$.

Pietschmann P, Skalicky M, Kneissel M, Rauner M, Hofbauer G, Stupphann D, and Viidik A. 2007. Bone structure and metabolism in a rodent model of male senile osteoporosis. Exp Gerontol 42:1099-108.

Pomeroy E, and Stock J. 2012. Estimation of stature and body mass from the skeleton among coastal and mid-altitude Andean populations. Am J Phys Anthr. 147:264-79.

Powers R. 1962. The disparity between known age and age as estimated by cranial suture closure. Man 62:52-54.

Rafferty K, Walker A, Ruff C, Rose M, and Andrews P. 1995. Postcranial estimates of body weight in Proconsul, with a note on a distal tibia of P. major from Napak, Uganda. Am J Phys Anthr. 97:391-402. 
Raxter M, Auerbach B, and Ruff C. 2006. Revision of the Fully technique for estimating statures. Am J Phys Anthr. 130:374-384.

Raxter M, Ruff C, and Auerbach B. 2007. Technical note: revised fully stature estimation technique. Am J Phys Anthr. 133:817-818.

Rissech C, Estabrook G, Cunha E, and Malgosa A. 2006. Using the acetabulum to estimate age at death of adult males. J Forensic Sci 51:213-29.

Rissech C, Wilson J, Winburn A, Turbón D, and Steadman D. 2011. A comparison of three established age estimation methods on an adult Spanish sample. Int J Leg. Med 126:145-155.

Robbins Schug G, Brandt E, and Lukacs J. 2012. Cementum annulations, age estimation, and demographic dynamics in Mid-Holocene foragers of North India. Homo 63:94-109.

Rogers T. 2009. Skeletal Age Estimation. In: Blau S, Ubelaker D, editors. Handbook of Forensic Anthropology and Archaeology. Walnut Creek, CA: Left Coast Press. p 208-221.

Roksandic M, and Armstrong S. 2011. Using the life history model to set the stage(s) of growth and senescence in bioarchaeology and paleodemography. Am J Phys Anthr. 145:337-347.

Romero-Corral A, Somers VK, Sierra-Johnson J, Thomas RJ, Collazo-Clavell ML, Korinek J, Allison TG, Batsis J, Sert-Kuniyoshi FH, and Lopez-Jimenez F. 2008. Accuracy of body mass index in diagnosing obesity in the adult general population. Int J Obes. 32:959-66.

Rosenberg K, Zune L, and Ruff C. 2006. Body size, body proportions, and encephalization in a Middle Pleistocene archaic human from northern China. Proc Natl Acad Sci USA 103:35523556.

Ross A, and Konigsberg L. 2002. New formulae for estimating stature in the Balkans. J Forensic Sci 47:165-7.

Rougé-Maillart C, Jousset N, Vielle B, Gaudin A, and Telmon N. 2007. Contribution of the study of acetabulum for the estimation of adult subjects. Forensic Sci Int 171:103-110. 
Rougé-Maillart C, Telmon N, Rissech C, Malgosa A, and Rougé D. 2004. The determination of male adult age at death by central and posterior coxal analysis--a preliminary study. J Forensic Sci 49:208-214.

Rougé-Maillart C, Vielle B, Jousset N, Chappard D, Telmon N, and Cunha E. 2009.

Development of a method to estimate skeletal age at death in adults using the acetabulum and the auricular surface on a Portuguese population. Forensic Sci Int 188:91-95.

Ruff C, Holt B, Sladék V, Berner M, Murphy Jr. W, zur Nedden D, Seidler H, and Recheis W. 2006. Body size, body proportions, and mobility in the Tyrolean "Iceman." J Hum Evol 51:91101.

Ruff C, Niskanen M, Junno J, and Jamison P. 2005. Body mass prediction from stature and biiliac breadth in two high latitude populations, with application to earlier higher latitude humans. J Hum Evol 48:381-392.

Ruff C, Trinkaus E, and Holliday T. 1997. Body mass and encephalization in Pleistocene Homo. Nature 387:173-176.

Ruff C, Trinkaus E, Walker A, and Larsen C. 1993. Postcranial robusticity in Homo. I: Temporal trends and mechanical interpretation. Am J Phys Anthr. 91:21-53.

Ruff C. 1994. Morphological adaptation to climate in modern and fossil hominids. Am J Phys Anthr. 37:65-107.

Ruff C. 2000. Body mass prediction from skeletal frame size in elite athletes. Am J Phys Anthr. 113:507-517.

Ruff C. 2002. Variation in human body size and shape. Ann Rev Anthr. 31:211-232.

Ruff C. 2010. Body size and body shape in early hominins - implications of the Gona Pelvis. J Hum Evol 58:166-178. 
Rush EC, Freitas I, and Plank LD. 2009. New standards of weight and body composition by frame size and height for assessment of nutritional status of adults and the elderly. Br. J Nutr. 102:632-41.

Russell K, Simpson S, Genovese J, Kinkel M, Meindl R, and Lovejoy C. 1993. Independent test of the fourth rib aging technique. Am J Phys Anthr. 92:53-62.

Sagir M. 2006. Estimation stature from X-rays of metacarpals in the Turkish population. Anthr. Anz 64:377-388.

Samma S, Kagebayashi Y, Yasukawa M, Fukui Y, Ozono S, Hirao Y, Sato H, and Okajima E. 1997. Sequential changes of urinary pyridinoline and deoxypyridinoline as markers of metastatic bone tumor in patients with prostate cancer: a preliminary study. Jpn J Clin Oncol 27:369-74.

Saunders S, Fitzgerald C, Rogers T, Dudar J, and McKillop H. 1992. A test of several methods of skeletal age estimation using a documented archaeological sample. Can Soc Forensic Sci J 25:97-118.

Scheuer L, and Black S. 2000. Developmental Juvenile Osteology. San Diego, CA: Academic Press.

Schmitt A, and Murail P. 2004. Is the first rib a reliable indicator of age at death assessment? Test of the method developed by Kunos et al (1999). Homo 54:207-214.

Schmitt A. 2004. Age-at-death assessment using the os pubis and the auricular surface of the ilium: a test on an identified Asian sample. Int J Osteoarchaeol. 14:1-6.

Scott E. 1979. Dental Wear Scoring Technique. Am J Phys Anthr. 51:213-218.

Sealy J, and Pfeiffer S. 2006. Diet, Body Size, and Landscape Use among Holocene People in the Southern Cape, South Africa. Curr. Anthr. 41:642-655.

Shah K, Armamento-Villareal R, Parimi N, Chode S, Sinacore DR, Hilton TN, Napoli N, Qualls C, and Villareal DT. 2011. Exercise Training in Obese Older Adults Prevents Increase in Bone 
Turnover and Attenuates Decrease in Hip Bone Mineral Density Induced by Weight Loss Despite Decline in Bone-Acitve Hormones. J Bone Min. Res 26:2851-9.

Singer R. 1953. Estimation of age from cranial suture closure: a report on its unreliability. Forensic Med I:52-59.

Sinha A, and Gupta V. 1995. A study on estimation of age from pubic symphysis. Forensic Sci Int 75:73-78.

Sitchon M, and Hoppa R. 2005. Assessing age-related morphology of the pubic symphysis from digital images versus direct observation. J Forensic Sci 50:791-795.

Sjøvold T. 1990. Estimation of stature from long bones utilizing the line of organic correlation. Hum. Evol. 5:431-447.

Solheim T. 1993. A new method for dental age estimation in adults. Forensic Sci Int 59:137147.

Somerville J, Aspden R, Armour K, Armour K, and Reid D. 2004. Growth of C57BL/6 mice and the material and mechanical properties of cortical bone from the tibia. Calcif Tiss Int 74:469-75.

Statistics Canada. 2012. Overweight and obese adults (self-reported). Gov. Canada [Internet]. Available from: http://www.statcan.gc.ca/pub/82-625-x/2013001/article/11840-eng.htm

Steckel R, Rose J, Spencer Larsen C, and Walker P. 2002. Skeletal health in the Western Hemisphere from 4000 B.C. to the present. Evol Anthr. 11:142-155.

Stillwell RC, Dworkin I, Shingleton AW, and Frankino WA. 2011. Experimental manipulation of body size to estimate morphological scaling relationships in Drosophila. J Vis Exp:4-7.

Storey R. 2007. An elusive paleodemography? A comparison of two methods for estimating the adult age distribution of deaths at late Classic Copan, Honduras. Am J Phys Anthr. 132:40-47.

Stull K, and James D. 2010. Determination of age-at-death using the acetabulum. In: Latham K, Finnegan M, editors. Age estimation of the human skeleton. Springfield, IL: Charles C Thomas. p 134-146. 
Suchey J, Wisely D, and Katz D. 1986. Evaluation of the Todd and McKern- Stewart methods for aging the male os pubis. In: Reichs K, editor. Forensic osteology: advances in the identification of human remains. Springfield, IL: C.C. Thomas. p 33-67.

Suchey J. 1979. Problems in the aging of females using the Os pubis. Am J Phys Anthr. 51:467470.

Szilvassy J, and Kritscher H. 1990. Estimation of chronological age in man based on the spongy structure of long bones. Anthr. Anz 3:289-298.

Szulc P, and Seeman E. 2009. Thinking inside and outside the envelopes of bone: dedicated to PDD. Osteoporos Int 20:1281-1288.

Tan K, Chow W, Lam J, Lam B, Bucala R, Betteridge J, and Ip M. 2006. Advanced glycation endproducts in nondiabetic patients with obstructive sleep apnea. Sleep 29:329-33.

Tang S, Zeenath U, and Vashishth D. 2007. Effects of non-enzymatic glycation on cancellous bone fragility. Bone 40:1144-51.

Todd T, and Lyon D. 1925. Cranial suture closure its progress and age relationship. Part 2ectocranial closure in adult males of white stock. Am J Phys Anthr. 8:47-71.

Todd T. 1920. Age changes in the pubic bone: I. White male pubis. Am J Phys Anthr. 3:467470.

Todd T. 1921. Age changes in the pubic bone. Am J Phys Anthr. 4:1-70.

Tommerup L, Raab D, Crenshaw T, and Smith E. 1993. Does weight-bearing exercise affect non-weight-bearing bone? J Bone Min. Res 8:1053-1058.

Tracy JK, Meyer W, Flores RH, Wilson PD, and Hochberg MC. 2005. Racial Differences in Rate of Decline in Bone Mass in Older Men: The Baltimore Men's Osteoporosis Study. J Bone 20:1228-34.

Trotter M, and Gleser G. 1952. Estimation of stature from long bones of American Whites and Negroes. Am J Phys Anthr. 10:463-514. 
Tsuboyama T, Takahashi K, Matsushita M, Okumura H, Yamamuro T, Umezawa M, and Takeda T. 1989. Decreased endosteal formation during cortical bone modelling in SAM-P/6 mice with a low peak bone mass. Bone Miner. 7:1-12.

Vashishth D, Gibson G, Khoury J, Schaffler M, Kimura J, and Fyhrie D. 2001. Influence of nonenzymatic glycation on biomechanical properties of cortical bone. Bone 28:195-201.

Viguet-Carrin S, Follet H, Gineyts E, Roux J, Munoz F, Chapurlat R, Delmas P, and Bouxsein M. 2010. Association between collagen cross-links and trabecular microarchitecture properties of human vertebral bone. Bone 46:342-7.

Walker R, and Lovejoy C. 1985. Radiographic changes in the clavicle and proximal femur and their use in the determination of skeletal age at death. Am J Phys Anthr. 68:67-78.

White T, and Folkens P. 2000. Human Osteology. 2nd ed. San Diego, CA: Elsevier Science \& Technology Books.

White T, and Folkens P. 2005. The Human Bone Manual. San Diego, CA: Elsevier Academic Press.

WHO Expert Consultation. 2004. Appropriate body-mass index for Asian populations and its implications for policy and intervention strategies. Lancet 363:157-163.

World Health Organization. 2013. The WHO Global Database on Body Mass Index (BMI). Available from: http://apps.who.int/bmi/index.jsp?introPage=intro_3.html

Yavuz M, Işcan M, and Cöloğlu S. 1998. Age assessment by rib phase analysis in Turks. Forensic Sci Int 98:47-54.

Yoder C, Ubelaker D, and Powell J. 2001. Examination of variation in sternal rib end morphology relevant to age assessment. J Forensic Sci 46:223-227.

Youden W. 1998. Experimentation and measurement. (Inc. DP, editor.). Mineola, NY. 
Zhao L, Jiang H, Papasian C, Maulik D, Drees B, Hamilton J, and Deng H. 2008. Correlation of Obesity and Osteoporosis: Effect of Fat Mass on the Determination of Osteoporosis. J Bone Jt. Surg Am 23:17-29.

Zhou S, Greenberger J, Epperly M, Goff J, Adler C, Leboff M, and Glowacki J. 2008. Agerelated intrinsic changes in human bone-marrow-derived mesenchymal stem cells and their differentiation to osteoblasts. Aging Cell 7:335-43.

Zioupos P, and Currey J. 1998. Changes in the stiffness, strength, and toughness of human cortical bone with age. Bone 22:57-66. 


\section{Appendix 1}

\begin{tabular}{|c|c|c|c|c|c|c|c|c|}
\hline $\begin{array}{l}\text { Hamann-Todd } \\
\text { Collection }\end{array}$ & $\begin{array}{l}<1.54 \mathrm{~m} \\
(<5.0 \mathrm{ft})\end{array}$ & $\begin{array}{c}1.55-1.62 \mathrm{~m} \\
(5.1-5.3 \mathrm{ft})\end{array}$ & $\begin{array}{c}1.63-1.70 \mathrm{~m} \\
(5.4-5.6 \mathrm{ft})\end{array}$ & $\begin{array}{c}1.72-1.78 \mathrm{~m} \\
(5.7-5.9 \mathrm{ft})\end{array}$ & $\begin{array}{l}1.79-1.84 \mathrm{~m} \\
(5.10-6.0 \mathrm{ft})\end{array}$ & $\begin{array}{c}1.85-1.92 \mathrm{~m} \\
(6.1-6.3 \mathrm{ft})\end{array}$ & $\begin{array}{l}>1.93 \mathrm{~m} \\
(>6.4 \mathrm{ft})\end{array}$ & Total \\
\hline $\begin{array}{l}<45.0 \mathrm{~kg} \\
(<100 \mathrm{lbs})\end{array}$ & 49 & 99 & 162 & 147 & 44 & 8 & 0 & 514 \\
\hline $\begin{array}{l}45.4-56.5 \mathrm{~kg} \\
(100-124 \mathrm{lbs})\end{array}$ & 34 & 114 & 215 & 245 & 100 & 22 & 1 & 731 \\
\hline $\begin{array}{l}56.7-67.6 \mathrm{~kg} \\
(125-149 \mathrm{lbs})\end{array}$ & 22 & 89 & 346 & 380 & 152 & 32 & 4 & 1015 \\
\hline $\begin{array}{l}\text { 68.0-79.0kg } \\
(150-174 \mathrm{lbs})\end{array}$ & 6 & 22 & 109 & 127 & 99 & 28 & 1 & 336 \\
\hline $\begin{array}{l}\text { 79.4-89.8kg } \\
\text { (175-199lbs) }\end{array}$ & 0 & 1 & 9 & 29 & 32 & 13 & 1 & 85 \\
\hline $\begin{array}{l}90.2-101.6 \mathrm{~kg} \\
(200-224 \mathrm{lbs})\end{array}$ & 1 & 1 & 6 & 7 & 8 & 5 & 1 & 29 \\
\hline $\begin{array}{l}>102.0 \mathrm{~kg} \\
(>225 \mathrm{lbs})\end{array}$ & 0 & 1 & 2 & 0 & 2 & 1 & 0 & 1 \\
\hline Total & 112 & 327 & 841 & 930 & 402 & 96 & 8 & 2717 \\
\hline
\end{tabular}

Appendix 1: Stature and body mass distribution of the Hamann-Todd Collection. 


\section{Appendix 2}

\begin{tabular}{|c|c|c|c|c|c|c|c|c|}
\hline $\begin{array}{c}\text { William Bass } \\
\text { Collection }\end{array}$ & $\begin{array}{l}<1.54 \mathrm{~m} \\
(<5.0 \mathrm{ft})\end{array}$ & $\begin{array}{c}1.55-1.62 \mathrm{~m} \\
(5.1-5.3 \mathrm{ft})\end{array}$ & $\begin{array}{c}1.63-1.70 \mathrm{~m} \\
(5.4-5.6 \mathrm{ft})\end{array}$ & $\begin{array}{c}1.72-1.78 \mathrm{~m} \\
(5.7-5.9 \mathrm{ft})\end{array}$ & $\begin{array}{l}1.79-1.84 \mathrm{~m} \\
(5.10-6.0 \mathrm{ft})\end{array}$ & $\begin{array}{c}1.85-1.92 \mathrm{~m} \\
(6.1-6.3 \mathrm{ft})\end{array}$ & $\begin{array}{l}>1.93 \mathrm{~m} \\
(>6.4 \mathrm{ft})\end{array}$ & Total \\
\hline $\begin{array}{l}<45.0 \mathrm{~kg} \\
(<100 \mathrm{lbs})\end{array}$ & 5 & 7 & 7 & 1 & 0 & 0 & 0 & 20 \\
\hline $\begin{array}{l}45.4-56.5 \mathrm{~kg} \\
(100-124 \mathrm{lbs})\end{array}$ & 10 & 18 & 28 & 9 & 4 & 2 & 0 & 71 \\
\hline $\begin{array}{l}56.7-67.6 \mathrm{~kg} \\
(125-149 \mathrm{lbs}) \\
\end{array}$ & 7 & 13 & 27 & 28 & 12 & 3 & 0 & 90 \\
\hline $\begin{array}{l}68.0-79.0 \mathrm{~kg} \\
(150-174 \mathrm{lbs})\end{array}$ & 2 & 12 & 38 & 47 & 30 & 12 & 1 & 142 \\
\hline $\begin{array}{l}79.4-89.8 \mathrm{~kg} \\
(175-199 \mathrm{lbs}) \\
\end{array}$ & 4 & 7 & 16 & 23 & 19 & 11 & 1 & 81 \\
\hline $\begin{array}{l}90.2-101.6 \mathrm{~kg} \\
(200-224 \mathrm{lbs})\end{array}$ & 0 & 4 & 11 & 13 & 12 & 13 & 0 & 53 \\
\hline $\begin{array}{l}>102.0 \mathrm{~kg} \\
(>225 \mathrm{lbs}) \\
\end{array}$ & 1 & 10 & 14 & 27 & 30 & 11 & 4 & 97 \\
\hline Total & 29 & 71 & 141 & 148 & 107 & 52 & 6 & 554 \\
\hline
\end{tabular}

Appendix 2: Stature and body mass distribution of the William Bass Collection. 


\section{Appendix 3}

\begin{tabular}{|c|c|c|c|c|c|c|c|c|}
\hline $\begin{array}{l}\text { Hamann-Todd } \\
\text { Collection }\end{array}$ & $\begin{array}{l}<1.54 \mathrm{~m} \\
(<5.0 \mathrm{ft})\end{array}$ & $\begin{array}{l}1.55-1.62 \mathrm{~m} \\
(5.1-5.3 \mathrm{ft})\end{array}$ & $\begin{array}{c}1.63-1.70 \mathrm{~m} \\
(5.4-5.6 \mathrm{ft})\end{array}$ & $\begin{array}{l}1.72-1.78 \mathrm{~m} \\
(5.7-5.9 \mathrm{ft})\end{array}$ & $\begin{array}{l}1.79-1.84 m \\
(5.10-6.0 f t)\end{array}$ & $\begin{array}{c}1.85-1.92 \mathrm{~m} \\
(6.1-6.3 \mathrm{ft})\end{array}$ & $\begin{array}{l}>1.93 \mathrm{~m} \\
(>6.4 \mathrm{ft})\end{array}$ & Total \\
\hline $\begin{array}{l}<45.0 \mathrm{~kg} \\
(<100 \mathrm{lbs})\end{array}$ & 19 & 42 & 0 & 0 & 0 & 0 & 0 & 61 \\
\hline $\begin{array}{l}45.4-56.5 \mathrm{~kg} \\
(100-124 \mathrm{lbs})\end{array}$ & 19 & 27 & 26 & 28 & 26 & 0 & 0 & 126 \\
\hline $\begin{array}{l}56.7-67.6 \mathrm{~kg} \\
(125-149 \mathrm{lbs})\end{array}$ & 18 & 28 & 28 & 30 & 29 & 13 & 0 & 146 \\
\hline $\begin{array}{l}\text { 68.0-79.0kg } \\
(150-174 \mathrm{lbs})\end{array}$ & 5 & 15 & 26 & 30 & 28 & 9 & 0 & 113 \\
\hline $\begin{array}{l}\text { 79.4-89.8kg } \\
\text { (175-199lbs) }\end{array}$ & 0 & 0 & 8 & 25 & 25 & 12 & 0 & 70 \\
\hline $\begin{array}{l}90.2-101.6 \mathrm{~kg} \\
(200-224 \mathrm{lbs}) \\
\end{array}$ & 0 & 0 & 6 & 6 & 5 & 3 & 0 & 20 \\
\hline $\begin{array}{l}>102.0 \mathrm{~kg} \\
(>225 \mathrm{lbs}) \\
\end{array}$ & 0 & 0 & 0 & 0 & 0 & 0 & 0 & 0 \\
\hline Total & 61 & 112 & 94 & 119 & 113 & 37 & 0 & 536 \\
\hline
\end{tabular}

Appendix 3: Stature and body mass distribution of the final sample selected from the Hamann-Todd Collection. 


\section{Appendix 4}

\begin{tabular}{|c|c|c|c|c|c|c|c|c|}
\hline $\begin{array}{c}\text { William Bass } \\
\text { Collection } \\
\end{array}$ & $\begin{array}{l}<1.54 \mathrm{~m} \\
(<5.0 \mathrm{ft})\end{array}$ & $\begin{array}{c}1.55-1.62 \mathrm{~m} \\
(5.1-5.3 \mathrm{ft})\end{array}$ & $\begin{array}{c}1.63-1.70 \mathrm{~m} \\
(5.4-5.6 \mathrm{ft})\end{array}$ & $\begin{array}{c}1.72-1.78 \mathrm{~m} \\
(5.7-5.9 \mathrm{ft})\end{array}$ & $\begin{array}{l}1.79-1.84 \mathrm{~m} \\
(5.10-6.0 \mathrm{ft})\end{array}$ & $\begin{array}{l}1.85-1.92 \mathrm{~m} \\
(6.1-6.3 \mathrm{ft})\end{array}$ & $\begin{array}{l}>1.93 \mathrm{~m} \\
(>6.4 \mathrm{ft})\end{array}$ & Total \\
\hline $\begin{array}{l}<45.0 \mathrm{~kg} \\
(<100 \mathrm{lbs})\end{array}$ & 5 & 5 & 0 & 0 & 0 & 0 & 0 & 10 \\
\hline $\begin{array}{l}45.4-56.5 \mathrm{~kg} \\
(100-124 \mathrm{lbs})\end{array}$ & 7 & 10 & 15 & 8 & 3 & 0 & 0 & 43 \\
\hline $\begin{array}{l}56.7-67.6 \mathrm{~kg} \\
(125-149 \mathrm{lbs})\end{array}$ & 2 & 9 & 15 & 16 & 9 & 0 & 0 & 51 \\
\hline $\begin{array}{l}\text { 68.0-79.0kg } \\
(150-174 \mathrm{lbs})\end{array}$ & 0 & 8 & 18 & 12 & 16 & 10 & 0 & 64 \\
\hline $\begin{array}{l}\text { 79.4-89.8kg } \\
\text { (175-199lbs) }\end{array}$ & 0 & 6 & 11 & 15 & 13 & 9 & 0 & 54 \\
\hline $\begin{array}{l}90.2-101.6 \mathrm{~kg} \\
(200-224 \mathrm{lbs})\end{array}$ & 0 & 0 & 9 & 9 & 10 & 10 & 0 & 44 \\
\hline $\begin{array}{l}>102.0 \mathrm{~kg} \\
(>225 \mathrm{lbs}) \\
\end{array}$ & 0 & 0 & 0 & 0 & 0 & 0 & 0 & 0 \\
\hline Total & 14 & 44 & 68 & 60 & 51 & 29 & 0 & 260 \\
\hline
\end{tabular}

Appendix 4: Stature and body mass distribution of the final sample selected from the William Bass Collection. 
Appendix 5

\begin{tabular}{|c|c|c|c|c|c|c|c|c|c|c|c|c|c|}
\hline & $\begin{array}{l}\text { Age } \\
\text { Categories } \\
\text { (years) }\end{array}$ & n & Min & Max & Mean & $\begin{array}{c}\text { Std. } \\
\text { Deviation }\end{array}$ & Variance & $\begin{array}{r}\text { Skew } \\
\text { Statistic }\end{array}$ & $\begin{array}{l}\text { ess } \\
\text { Std. } \\
\text { Error }\end{array}$ & $\begin{array}{r}\text { Kurt } \\
\text { Statistic }\end{array}$ & $\begin{array}{l}\text { sis } \\
\text { Std. } \\
\text { Error }\end{array}$ & $\begin{array}{c}\text { K-S } \\
\mathbf{Z}\end{array}$ & $\begin{array}{c}\text { Asymp. Sig. } \\
\text { (2-tailed) }\end{array}$ \\
\hline \multirow[t]{8}{*}{ Male } & $19-29$ & 34 & 22 & 62 & 43.21 & 9.673 & 93.562 & -0.533 & 0.403 & -0.221 & 0.788 & 0.131 & 0.148 \\
\hline & $30-39$ & 94 & 32 & 66 & 49.28 & 7.047 & 49.665 & 0.170 & 0.249 & -0.175 & 0.493 & 0.126 & 0.001 \\
\hline & $40-49$ & 114 & 36 & 70 & 54.97 & 6.737 & 45.389 & -0.378 & 0.226 & -0.512 & 0.449 & 0.112 & 0.001 \\
\hline & $50-59$ & 113 & 43 & 70 & 57.39 & 6.315 & 39.883 & -0.492 & 0.227 & -0.356 & 0.451 & 0.129 & $<0.001$ \\
\hline & $60-69$ & 117 & 37 & 76 & 59.23 & 7.086 & 50.214 & -0.412 & 0.224 & 0.915 & 0.444 & 0.093 & 0.014 \\
\hline & $70-79$ & 64 & 48 & 75 & 61.41 & 5.642 & 31.832 & -0.260 & 0.299 & -0.018 & 0.590 & 0.120 & 0.023 \\
\hline & $80-89$ & 11 & 54 & 71 & 64.73 & 5.061 & 25.618 & -0.846 & 0.661 & 0.735 & 1.279 & 0.219 & 0.147 \\
\hline & Total & 547 & 22 & 76 & 55.62 & 8.494 & 72.148 & -0.609 & 0.104 & 0.573 & 0.209 & 0.101 & $<0.001$ \\
\hline \multirow[t]{8}{*}{ Female } & $19-29$ & 18 & 24 & 44 & 36.89 & 6.570 & 43.163 & -0.694 & 0.536 & -0.609 & 1.038 & 0.178 & 0.135 \\
\hline & $30-39$ & 43 & 28 & 66 & 47.26 & 7.725 & 59.671 & 0.148 & 0.361 & 0.550 & 0.709 & 0.110 & 0.200 \\
\hline & $40-49$ & 43 & 28 & 70 & 51.28 & 8.452 & 71.444 & -0.160 & 0.361 & 0.421 & 0.709 & 0.091 & 0.200 \\
\hline & $50-59$ & 37 & 40 & 67 & 55.70 & 7.516 & 56.492 & -0.514 & 0.388 & -0.423 & 0.759 & 0.138 & 0.071 \\
\hline & $60-69$ & 40 & 35 & 68 & 55.43 & 7.096 & 50.353 & -0.588 & 0.374 & 0.809 & 0.733 & 0.115 & 0.200 \\
\hline & $70-79$ & 40 & 38 & 71 & 58.90 & 8.851 & 78.349 & -0.958 & 0.374 & 0.206 & 0.733 & 0.149 & 0.025 \\
\hline & $80-89$ & 12 & 50 & 67 & 58.83 & 6.264 & 39.242 & -0.155 & 0.637 & -1.655 & 1.232 & 0.196 & 0.200 \\
\hline & Total & 233 & 24 & 71 & 52.54 & 9.782 & 95.689 & -0.404 & 0.159 & -0.281 & 0.318 & 0.067 & 0.013 \\
\hline \multirow[t]{8}{*}{ European } & $19-29$ & 21 & 24 & 62 & 42.52 & 9.590 & 91.962 & -0.097 & 0.501 & -0.207 & 0.972 & 0.116 & 0.200 \\
\hline & $30-39$ & 73 & 37 & 66 & 49.88 & 6.342 & 40.221 & 0.418 & 0.281 & -0.170 & 0.555 & 0.154 & $<0.001$ \\
\hline & $40-49$ & 106 & 37 & 70 & 54.55 & 6.937 & 48.117 & -0.222 & 0.235 & -0.356 & 0.465 & 0.082 & 0.078 \\
\hline & $50-59$ & 123 & 43 & 70 & 57.50 & 6.122 & 37.482 & -0.498 & 0.218 & -0.333 & 0.433 & 0.114 & $<0.001$ \\
\hline & $60-69$ & 132 & 35 & 76 & 58.52 & 7.325 & 53.656 & -0.424 & 0.211 & 0.801 & 0.419 & 0.085 & 0.021 \\
\hline & $70-79$ & 82 & 38 & 75 & 60.54 & 7.189 & 51.684 & -0.952 & 0.266 & 1.257 & 0.526 & 0.129 & 0.002 \\
\hline & $80-89$ & 19 & 50 & 71 & 61.89 & 6.632 & 43.988 & -0.584 & 0.524 & -0.820 & 1.014 & 0.198 & 0.049 \\
\hline & Total & 556 & 24 & 76 & 56.21 & 8.119 & 65.911 & -0.507 & 0.104 & .0308 & 0.207 & 0.085 & $<0.001$ \\
\hline \multirow[t]{8}{*}{ African } & $19-29$ & 29 & 22 & 56 & 39.52 & 8.963 & 80.330 & -0.268 & 0.434 & -0.621 & 0.845 & 0.099 & 0.200 \\
\hline & $30-39$ & 62 & 28 & 66 & 47.15 & 8.194 & 67.143 & 0.206 & 0.304 & -0.098 & 0.599 & 0.106 & 0.082 \\
\hline & $40-49$ & 49 & 28 & 65 & 52.61 & 8.289 & 68.701 & -0.543 & 0.340 & 0.110 & 0.668 & 0.113 & 0.151 \\
\hline & $50-59$ & 25 & 40 & 70 & 54.44 & 8.661 & 75.007 & -0.187 & 0.464 & -1.012 & 0.902 & 0.139 & 0.200 \\
\hline & $60-69$ & 24 & 40 & 72 & 56.96 & 7.012 & 49.172 & -0.629 & 0.475 & 1.152 & 0.918 & 0.153 & 0.153 \\
\hline & $70-79$ & 22 & 40 & 70 & 60.09 & 6.989 & 48.848 & -1.236 & 0.491 & 1.993 & 0.953 & 0.153 & 0.197 \\
\hline & $80-89$ & 3 & 54 & 67 & 60.00 & 6.557 & 43.000 & 0.670 & 1.225 & - & - & 0.277 & - \\
\hline & Total & 214 & 22 & 72 & 50.83 & 10.108 & 102.162 & -0.361 & 0.166 & -0.332 & 0.331 & 0.083 & 0.001 \\
\hline Other & $19-29$ & 2 & 44 & 50 & 47.00 & 4.243 & 18.000 & - & - & - & - & 0.260 & - \\
\hline \multirow{7}{*}{ Ancestry } & $30-39$ & 2 & - & - & - & - & - & - & - & - & - & - & - \\
\hline & $40-49$ & 2 & 50 & 62 & 56.55 & 8.485 & 72.000 & - & - & - & - & 0.260 & - \\
\hline & $50-59$ & 2 & 54 & 59 & 56.50 & 3.536 & 12.500 & - & - & - & - & 0.260 & - \\
\hline & $60-69$ & 1 & - & - & - & - & - & - & - & - & - & - & - \\
\hline & $70-79$ & 0 & - & - & - & - & - & - & - & - & - & - & - \\
\hline & $80-89$ & 1 & - & - & - & - & - & - & - & - & - & - & - \\
\hline & Total & 10 & 44 & 62 & 53.60 & 5.929 & 35.156 & 0.183 & 0.687 & -0.811 & 1.334 & 0.228 & 0.150 \\
\hline \multirow[t]{8}{*}{ Total } & $19-29$ & 52 & 22 & 62 & 41.02 & 9.173 & 84.137 & -0.203 & .0330 & -0.398 & 0.650 & 0.083 & 0.200 \\
\hline & $30-39$ & 137 & 28 & 66 & 48.64 & 7.299 & 53.276 & 0.123 & 0.207 & 0.066 & 0.411 & 0.112 & $<0.001$ \\
\hline & $40-49$ & 157 & 28 & 70 & 53.96 & 7.406 & 54.845 & -0.416 & 0.194 & 0.038 & 0.385 & 0.089 & 0.004 \\
\hline & $50-59$ & 150 & 40 & 70 & 56.97 & 6.645 & 44.160 & -0.540 & 0.198 & -0.279 & 0.394 & 0.109 & $<0.001$ \\
\hline & $60-69$ & 157 & 35 & 76 & 58.26 & 7.259 & 52.694 & -0.426 & 0.194 & 0.796 & 0.385 & 0.085 & 0.008 \\
\hline & $70-79$ & 104 & 38 & 75 & 60.44 & 7.116 & 50.637 & -0.986 & 0.237 & 1.269 & 0.469 & 0.135 & $<0.001$ \\
\hline & $80-89$ & 23 & 50 & 71 & 61.65 & 6.350 & 40.328 & -0.483 & 0.481 & -0.865 & 0.935 & 0.174 & 0.069 \\
\hline & Total & 780 & 22 & 76 & 54.70 & 9.003 & 81.063 & -0.577 & 0.088 & 0.263 & 0.175 & 0.089 & $<0.001$ \\
\hline
\end{tabular}

Appendix 5: Descriptive statistics for the Kunos et al. method. 
Appendix 6

\begin{tabular}{|c|c|c|c|c|c|c|c|c|c|c|c|c|c|}
\hline & $\begin{array}{l}\text { Age } \\
\text { Categories } \\
\text { (years) }\end{array}$ & n & Min & Max & Mean & $\begin{array}{c}\text { Std. } \\
\text { Deviation }\end{array}$ & Variance & Statistic & $\begin{array}{l}\text { ess } \\
\text { Std. } \\
\text { Error }\end{array}$ & Statistic & $\begin{array}{l}\text { sis } \\
\text { Std. } \\
\text { Error }\end{array}$ & $\begin{array}{c}\text { K-S } \\
\mathbf{Z}\end{array}$ & $\begin{array}{c}\text { Asymp. Sig. } \\
\text { (2-tailed) }\end{array}$ \\
\hline \multirow[t]{8}{*}{ Male } & $19-29$ & 33 & 12 & 57 & 27.52 & 10.826 & 117.195 & 0.692 & 0.409 & 0.667 & 0.798 & 0.218 & $<0.001$ \\
\hline & $30-39$ & 92 & 15 & 57 & 32.80 & 9.229 & 85.170 & 1.103 & 0.251 & 0.935 & 0.498 & 0.317 & $<0.001$ \\
\hline & $40-49$ & 111 & 25 & 66 & 38.65 & 9.024 & 81.430 & 0.849 & 0.229 & 0.070 & 0.455 & 0.292 & $<0.001$ \\
\hline & $50-59$ & 112 & 25 & 61 & 41.91 & 8.819 & 77.776 & 0.145 & 0.228 & -0.629 & 0.453 & 0.192 & $<0.001$ \\
\hline & $60-69$ & 116 & 20 & 66 & 43.30 & 9.916 & 98.334 & 0.233 & 0.255 & -0.515 & 0.446 & 0.179 & $<0.001$ \\
\hline & $70-79$ & 62 & 25 & 66 & 45.52 & 9.498 & 90.221 & -0.070 & 0.304 & -0.673 & 0.599 & 0.162 & $<0.001$ \\
\hline & $80-89$ & 11 & 32 & 61 & 49.09 & 8.526 & 72.691 & -0.463 & 0.661 & -0.008 & 1.279 & 0.187 & 0.200 \\
\hline & Total & 537 & 12 & 66 & 39.66 & 10.681 & 114.077 & 0.181 & 0.105 & -0.465 & 0.210 & 0.214 & $<0.001$ \\
\hline \multirow[t]{8}{*}{ Female } & $19-29$ & 18 & 12 & 32 & 21.17 & 6.483 & 42.029 & 0.082 & 0.536 & -1.246 & 1.038 & 0.278 & 0.001 \\
\hline & $30-39$ & 42 & 12 & 58 & 30.49 & 10.696 & 114.399 & 0.897 & 0.361 & 1.150 & 0.709 & 0.258 & $<0.001$ \\
\hline & $40-49$ & 42 & 15 & 58 & 33.26 & 10.397 & 108.100 & 0.821 & 0.361 & 0.393 & 0.709 & 0.292 & $<0.001$ \\
\hline & $50-59$ & 36 & 20 & 61 & 39.33 & 11.454 & 131.200 & 0.312 & 0.393 & -1.038 & 0.768 & 0.239 & $<0.001$ \\
\hline & $60-69$ & 39 & 25 & 50 & 36.69 & 7.991 & 63.850 & 0.296 & 0.378 & -1.113 & 0.741 & 0.286 & $<0.001$ \\
\hline & $70-79$ & 39 & 20 & 66 & 44.74 & 12.734 & 162.143 & -0.122 & 0.378 & -1.140 & 0.741 & 0.149 & 0.029 \\
\hline & $80-89$ & 11 & 25 & 61 & 42.36 & 13.567 & 184.055 & 0.218 & 0.661 & -1.409 & 1.279 & 0.148 & 0.200 \\
\hline & Total & 229 & 12 & 66 & 35.72 & 12.301 & 151.308 & 0.449 & 0.161 & -0.483 & 0.320 & 0.235 & $<0.001$ \\
\hline \multirow[t]{8}{*}{ European } & $19-29$ & 21 & 15 & 50 & 27.33 & 10.618 & 112.733 & 0.474 & 0.501 & -0.565 & 0.972 & 0.194 & 0.039 \\
\hline & $30-39$ & 71 & 12 & 57 & 32.72 & 9.595 & 92.062 & 0.618 & 0.285 & 0.531 & 0.563 & 0.290 & $<0.001$ \\
\hline & $40-49$ & 104 & 15 & 66 & 37.06 & 9.948 & 98.968 & 0.695 & 0.237 & 0.253 & 0.469 & 0.300 & $<0.001$ \\
\hline & $50-59$ & 121 & 20 & 61 & 41.69 & 9.159 & 83.851 & 0.079 & 0.220 & -0.585 & 0.437 & 0.189 & $<0.001$ \\
\hline & $60-69$ & 130 & 20 & 66 & 42.03 & 9.899 & 97.999 & 0.308 & 0.212 & -0.450 & 0.422 & 0.183 & $<0.001$ \\
\hline & $70-79$ & 79 & 20 & 66 & 45.00 & 10.917 & 119.179 & -0.081 & 0.271 & -0.740 & 0.535 & 0.136 & 0.001 \\
\hline & $80-89$ & 19 & 25 & 61 & 45.32 & 12.202 & 148.895 & -0.248 & 0.524 & -1.178 & 1.014 & 0.147 & 0.200 \\
\hline & Total & 545 & 12 & 66 & 39.77 & 10.928 & 119.431 & 0.179 & 0.105 & -0.466 & 0.209 & 0.207 & $<0.001$ \\
\hline \multirow[t]{8}{*}{ African } & $19-29$ & 29 & 12 & 57 & 23.79 & 9.500 & 90.241 & 1.306 & 0.434 & 4.051 & 0.845 & 0.208 & 0.002 \\
\hline & $30-39$ & 62 & 12 & 58 & 31.44 & 10.052 & 101.037 & 1.295 & 0.304 & 1.626 & 0.599 & 0.300 & $<0.001$ \\
\hline & $40-49$ & 48 & 25 & 61 & 37.15 & 9.401 & 88.383 & 0.611 & 0.343 & -0.315 & 0.674 & 0.270 & $<0.001$ \\
\hline & $50-59$ & 25 & 25 & 61 & 39.60 & 11.475 & 131.667 & 0.390 & 0.464 & -1.150 & 0.902 & 0.266 & $<0.001$ \\
\hline & $60-69$ & 24 & 25 & 61 & 39.92 & 9.744 & 94.949 & 0.352 & 0.472 & -0.614 & 0.918 & 0.250 & $<0.001$ \\
\hline & $70-79$ & 22 & 25 & 61 & 46.00 & 10.614 & 112.667 & -0.345 & 0.491 & -0.943 & 0.953 & 0.168 & 0.107 \\
\hline & $80-89$ & 2 & 44 & 57 & 50.50 & 9.192 & 84.500 & - & - & - & - & 0.260 & - \\
\hline & Total & 212 & 12 & 61 & 35.30 & 11.829 & 139.916 & 0.428 & 0.167 & -0.482 & 0.333 & 0.247 & $<0.001$ \\
\hline Other & $19-29$ & 1 & - & - & - & - & - & - & - & - & - & - & - \\
\hline \multirow[t]{7}{*}{ Ancestry } & $30-39$ & 2 & 25 & 32 & 28.50 & 4.950 & 24.500 & - & - & - & - & 0.260 & - \\
\hline & $40-49$ & 2 & 39 & 44 & 41.50 & 3.536 & 12.500 & - & - & - & - & 0.260 & - \\
\hline & $50-59$ & 2 & 32 & 44 & 38.00 & 8.485 & 72.000 & - & - & - & - & 0.260 & - \\
\hline & $60-69$ & 1 & - & - & - & - & - & - & - & - & - & - & - \\
\hline & $70-79$ & 0 & - & - & - & - & - & - & - & - & - & - & - \\
\hline & $80-89$ & 1 & - & - & - & - & - & - & - & - & - & - & - \\
\hline & Total & 9 & 25 & 44 & 35.22 & 7.791 & 60.694 & -0.052 & 0.717 & -1.650 & 1.400 & 0.216 & 0.200 \\
\hline \multirow[t]{8}{*}{ Total } & $19-29$ & 51 & 12 & 57 & 25.27 & 9.934 & 98.683 & 0.897 & 0.333 & 1.253 & 0.656 & 0.171 & 0.001 \\
\hline & $30-39$ & 135 & 12 & 58 & 32.07 & 9.740 & 94.869 & 0.946 & 0.209 & 0.944 & 0.414 & 0.295 & $<0.001$ \\
\hline & $40-49$ & 154 & 15 & 66 & 37.14 & 9.701 & 94.110 & 0.651 & 0.195 & 0.082 & 0.389 & 0.286 & $<0.001$ \\
\hline & $50-59$ & 148 & 20 & 61 & 41.23 & 9.550 & 91.198 & 0.123 & 0.199 & -0.738 & 0.396 & 0.193 & $<0.001$ \\
\hline & $60-69$ & 155 & 20 & 66 & 41.64 & 9.872 & 97.466 & 0.324 & 0.195 & -0.486 & 0.387 & 0.197 & $<0.001$ \\
\hline & $70-79$ & 101 & 20 & 66 & 45.22 & 10.807 & 116.792 & -0.133 & 0.240 & -0.802 & 0.476 & 0.138 & $<0.001$ \\
\hline & $80-89$ & 22 & 25 & 61 & 45.73 & 11.581 & 134.113 & -0.308 & 0.491 & -0.960 & 0.953 & 0.153 & $<0.001$ \\
\hline & Total & 766 & 12 & 66 & 38.48 & 11.326 & 128.273 & 0.211 & 0.088 & -0.512 & 0.176 & 0.216 & $<0.001$ \\
\hline
\end{tabular}

Appendix 6: Descriptive statistics for the DiGangi et al. method. 
Appendix 7

\begin{tabular}{|c|c|c|c|c|c|c|c|c|c|c|c|c|c|}
\hline & $\begin{array}{l}\text { Age } \\
\text { Categories } \\
\text { (years) }\end{array}$ & n & Min & Max & Mean & $\begin{array}{c}\text { Std. } \\
\text { Deviation }\end{array}$ & Variance & Statistic & $\begin{array}{l}\text { Iess } \\
\text { Std. } \\
\text { Error }\end{array}$ & Statistic & $\begin{array}{l}\text { sis } \\
\text { Std. } \\
\text { Error }\end{array}$ & $\begin{array}{c}\text { K-S } \\
\mathbf{Z}\end{array}$ & $\begin{array}{c}\text { Asymp. Sig. } \\
\text { (2-tailed) }\end{array}$ \\
\hline \multirow[t]{8}{*}{ Male } & $19-29$ & 34 & 17 & 59 & 28.62 & 9.979 & 99.577 & 1.084 & 0.403 & 1.391 & 0.788 & 0.260 & $<0.001$ \\
\hline & $30-39$ & 93 & 22 & 72 & 38.43 & 10.266 & 104.574 & 0.517 & 0.250 & 0.080 & 0.495 & 0.220 & $<0.001$ \\
\hline & $40-49$ & 111 & 26 & 72 & 45.75 & 10.561 & 111.536 & 0.303 & 0.229 & 0.173 & 0.455 & 0.198 & $<0.001$ \\
\hline & $50-59$ & 112 & 28 & 72 & 48.33 & 11.204 & 125.521 & 0.364 & 0.225 & -0.305 & 0.453 & 0.208 & $<0.001$ \\
\hline & $60-69$ & 116 & 26 & 72 & 51.12 & 12.321 & 151.811 & 0.122 & 0.225 & -0.510 & 0.446 & 0.191 & $<0.001$ \\
\hline & $70-79$ & 66 & 26 & 72 & 52.02 & 13.953 & 194.692 & -0.032 & 0.295 & -0.985 & 0.582 & 0.158 & $<0.001$ \\
\hline & $80-89$ & 11 & 50 & 76 & 65.18 & 10.610 & 112.564 & -0.774 & 0.661 & -1.454 & 1.279 & 0.376 & $<0.001$ \\
\hline & Total & 534 & 17 & 76 & 46.26 & 13.309 & 177.133 & 0.209 & 0.105 & -0.429 & 0.209 & 0.175 & $<0.001$ \\
\hline \multirow[t]{8}{*}{ Female } & $19-29$ & 19 & 14 & 51 & 29.21 & 12.730 & 162.064 & 0.602 & 0.524 & -0.867 & 1.014 & 0.222 & 0.014 \\
\hline & $30-39$ & 43 & 14 & 65 & 33.02 & 10.809 & 116.833 & 0.859 & 0.361 & 0.611 & 0.709 & 0.307 & $<0.001$ \\
\hline & $40-49$ & 44 & 17 & 65 & 34.55 & 11.605 & 134.672 & 0.450 & 0.357 & -0.496 & 0.702 & 0.214 & $<0.001$ \\
\hline & $50-59$ & 34 & 17 & 65 & 42.68 & 10.968 & 120.286 & 0.135 & 0.403 & 0.364 & 0.788 & 0.243 & $<0.001$ \\
\hline & $60-69$ & 35 & 17 & 76 & 44.66 & 16.381 & 268.350 & 0.295 & 0.398 & -0.596 & 0.778 & 0.155 & 0.033 \\
\hline & $70-79$ & 32 & 17 & 76 & 48.19 & 16.630 & 276.544 & 0.278 & 0.414 & -0.567 & 0.809 & 0.189 & 0.005 \\
\hline & $80-89$ & 11 & 23 & 65 & 43.91 & 13.262 & 175.891 & -0.243 & 0.661 & -0.371 & 1.279 & 0.202 & 0.200 \\
\hline & Total & 218 & 14 & 76 & 39.15 & 14.530 & 211.112 & 0.553 & 0.165 & -0.065 & 0.328 & 0.174 & $<0.001$ \\
\hline \multirow[t]{8}{*}{ European } & $19-29$ & 21 & 17 & 51 & 30.95 & 10.176 & 103.548 & 0.492 & 0.501 & -0.488 & 0.972 & 0.233 & 0.004 \\
\hline & $30-39$ & 73 & 17 & 72 & 39.64 & 10.612 & 112.621 & 0.258 & 0.281 & 0.007 & 0.555 & 0.188 & $<0.001$ \\
\hline & $40-49$ & 103 & 17 & 72 & 44.41 & 11.140 & 124.107 & 0.219 & 0.238 & 0.472 & 0.472 & 0.187 & $<0.001$ \\
\hline & $50-59$ & 119 & 28 & 72 & 47.80 & 11.025 & 121.552 & 0.301 & 0.222 & -0.306 & 0.440 & 0.189 & $<0.001$ \\
\hline & $60-69$ & 129 & 17 & 76 & 50.17 & 13.827 & 191.174 & -0.015 & 0.213 & -0.483 & 0.423 & 0.154 & $<0.001$ \\
\hline & $70-79$ & 77 & 23 & 76 & 52.04 & 14.207 & 201.827 & 0.017 & 0.274 & -0.817 & 0.541 & 0.152 & $<0.001$ \\
\hline & $80-89$ & 18 & 23 & 72 & 55.11 & 15.091 & 227.752 & -0.336 & 0.536 & -0.749 & 1.038 & 0.202 & 0.051 \\
\hline & Total & 540 & 17 & 76 & 46.81 & 13.304 & 177.004 & .0210 & 0.105 & -0.345 & 0.210 & 0.155 & $<0.001$ \\
\hline \multirow[t]{8}{*}{ African } & $19-29$ & 30 & 14 & 59 & 27.40 & 11.714 & 137.214 & 1.128 & 0.427 & 0.753 & 0.833 & 0.246 & $<0.001$ \\
\hline & $30-39$ & 61 & 14 & 65 & 33.36 & 9.871 & 97.434 & 0.974 & 0.306 & 1.088 & 0.604 & 0.297 & $<0.001$ \\
\hline & $40-49$ & 50 & 17 & 65 & 38.30 & 12.593 & 158.582 & 0.251 & 0.337 & -0.892 & 0.662 & 0.173 & 0.001 \\
\hline & $50-59$ & 25 & 17 & 72 & 42.60 & 11.446 & 131.000 & 0.307 & 0.464 & 1.191 & 0.902 & 0.230 & 0.001 \\
\hline & $60-69$ & 21 & 23 & 72 & 46.71 & 12.096 & 146.314 & -0.070 & 0.501 & 0.104 & 0.972 & 0.226 & 0.006 \\
\hline & $70-79$ & 21 & 17 & 76 & 46.10 & 16.766 & 281.909 & 0.366 & 0.501 & -0.653 & 0.972 & 0.166 & 0.136 \\
\hline & $80-89$ & 3 & 23 & 76 & 49.67 & 26.502 & 702.333 & -0.057 & 1.225 & - & - & 0.176 & - \\
\hline & Total & 211 & 14 & 76 & 37.61 & 13.672 & 186.935 & 0.577 & 0.167 & -0.078 & 0.333 & 0.190 & $<0.001$ \\
\hline Other & $19-29$ & 2 & - & - & - & - & - & - & - & - & - & - & - \\
\hline \multirow[t]{7}{*}{ Ancestry } & $30-39$ & 2 & 26 & 39 & 32.50 & 9.192 & 84.500 & - & - & - & - & 0.260 & - \\
\hline & $40-49$ & 2 & 50 & 59 & 54.50 & 6.364 & 40.500 & - & - & - & - & 0.260 & - \\
\hline & $50-59$ & 2 & 39 & 72 & 55.50 & 23.335 & 544.500 & - & - & - & - & 0.260 & - \\
\hline & $60-69$ & 1 & - & - & - & - & - & - & - & - & - & - & - \\
\hline & $70-79$ & 0 & - & - & - & - & - & - & - & - & - & - & - \\
\hline & $80-89$ & 1 & - & - & - & - & - & - & - & - & - & - & - \\
\hline & Total & 10 & 26 & 72 & 44.00 & 15.535 & 241.333 & 0.540 & 0.687 & -0.761 & 1.334 & 0.202 & 0.200 \\
\hline \multirow[t]{8}{*}{ Total } & $19-29$ & 53 & 14 & 59 & 28.83 & 10.926 & 119.374 & 0.838 & 0.327 & 0.150 & 0.644 & 0.247 & $<0.001$ \\
\hline & $30-39$ & 136 & 14 & 72 & 36.72 & 10.676 & 113.981 & 0.534 & 0.208 & 0.021 & 0.413 & 0.219 & $<0.001$ \\
\hline & $40-49$ & 155 & 17 & 72 & 42.57 & 11.956 & 142.948 & 0.100 & 0.195 & -0.150 & 0.387 & 0.172 & $<0.001$ \\
\hline & $50-59$ & 146 & 17 & 72 & 47.01 & 11.367 & 139.214 & 0.296 & 0.201 & -0.110 & 0.399 & 0.197 & $<0.001$ \\
\hline & $60-69$ & 151 & 17 & 76 & 49.62 & 13.591 & 184.703 & 0.016 & 0.197 & -0.434 & 0.392 & 0.160 & $<0.001$ \\
\hline & $70-79$ & 98 & 17 & 76 & 50.77 & 14.903 & 222.099 & 0.040 & 0.244 & -0.813 & 0.483 & 0.153 & $<0.001$ \\
\hline & $80-89$ & 22 & 23 & 76 & 54.55 & 15.996 & 255.879 & -0.415 & 0.491 & -0.632 & 0.953 & 0.181 & $<0.001$ \\
\hline & Total & 761 & 14 & 76 & 44.22 & 14.034 & 196.951 & 0.237 & 0.089 & -0.417 & 0.177 & 0.152 & $<0.001$ \\
\hline
\end{tabular}

Appendix 7: Descriptive statistics for the İşcan et al. method. 
Appendix 8

\begin{tabular}{|c|c|c|c|c|c|c|c|c|c|c|c|c|c|}
\hline & $\begin{array}{l}\text { Age } \\
\text { Categories } \\
\text { (years) }\end{array}$ & n & Min & Max & Mean & $\begin{array}{c}\text { Std. } \\
\text { Deviation }\end{array}$ & Variance & $\begin{array}{r}\text { Skew } \\
\text { Statistic }\end{array}$ & $\begin{array}{l}\text { ess } \\
\text { Std. } \\
\text { Error }\end{array}$ & $\begin{array}{r}\text { Kurt } \\
\text { Statistic }\end{array}$ & $\begin{array}{l}\text { sis } \\
\text { Std. } \\
\text { Error }\end{array}$ & $\begin{array}{c}\text { K-S } \\
\mathbf{Z}\end{array}$ & $\begin{array}{c}\text { Asymp. Sig. } \\
\text { (2-tailed) }\end{array}$ \\
\hline \multirow[t]{8}{*}{ Male } & $19-29$ & 35 & 16 & 63 & 35.34 & 12.804 & 163.938 & 0.229 & 0.398 & -0.695 & 0.778 & 0.260 & $<0.001$ \\
\hline & $30-39$ & 95 & 28 & 63 & 44.32 & 10.324 & 106.580 & 0.090 & 0.247 & -0.049 & 0.490 & 0.326 & $<0.001$ \\
\hline & $40-49$ & 112 & 23 & 63 & 49.11 & 12.960 & 167.970 & -0.379 & 0.228 & -1.000 & 0.453 & 0.251 & $<0.001$ \\
\hline & $50-59$ & 114 & 28 & 63 & 53.31 & 10.340 & 106.923 & -0.476 & 0.226 & -0.798 & 0.449 & 0.326 & $<0.001$ \\
\hline & $60-69$ & 119 & 28 & 63 & 55.66 & 9.665 & 93.411 & -0.818 & 0.222 & -0.511 & 0.440 & 0.390 & $<0.001$ \\
\hline & $70-79$ & 67 & 28 & 63 & 57.12 & 9.507 & 90.379 & -1.306 & 0.293 & 0.683 & 0.578 & 0.433 & $<0.001$ \\
\hline & $80-89$ & 11 & 45 & 63 & 58.09 & 8.408 & 70.691 & -1.189 & 0.661 & -0.764 & 1.279 & 0.448 & $<0.001$ \\
\hline & Total & 553 & 16 & 63 & 50.84 & 12.298 & 151.237 & -0.574 & 0.104 & -0.563 & 0.207 & 0.282 & $<0.001$ \\
\hline \multirow[t]{8}{*}{ Female } & $19-29$ & 18 & 23 & 63 & 40.50 & 12.761 & 162.853 & 0.167 & 0.536 & -0.928 & 1.038 & 0.249 & 0.004 \\
\hline & $30-39$ & 43 & 16 & 63 & 46.05 & 12.670 & 160.522 & -0.250 & 0.361 & -0.483 & 0.709 & 0.258 & $<0.001$ \\
\hline & $40-49$ & 45 & 28 & 63 & 44.16 & 10.831 & 117.316 & 0.094 & 0.354 & -0.252 & 0.695 & 0.309 & $<0.001$ \\
\hline & $50-59$ & 37 & 28 & 63 & 50.86 & 9.470 & 89.676 & 0.230 & 0.388 & -0.890 & 0.759 & 0.381 & $<0.001$ \\
\hline & $60-69$ & 40 & 45 & 63 & 54.45 & 9.103 & 82.869 & -0.104 & 0.374 & -2.097 & 0.733 & 0.351 & $<0.001$ \\
\hline & $70-79$ & 39 & 45 & 63 & 57.15 & 8.428 & 71.028 & -0.768 & 0.378 & -1.458 & 0.741 & 0.423 & $<0.001$ \\
\hline & $80-89$ & 11 & 45 & 63 & 61.36 & 5.427 & 29.455 & -3.317 & 0.661 & 11.000 & 1.279 & 0.528 & $<0.001$ \\
\hline & Total & 233 & 16 & 63 & 50.04 & 11.780 & 138.774 & -0.411 & 0.159 & -0.585 & 0.318 & 0.254 & $<0.001$ \\
\hline \multirow[t]{8}{*}{ European } & $19-29$ & 22 & 16 & 51 & 36.23 & 10.980 & 120.565 & -0.479 & 0.491 & -1.256 & 0.953 & 0.333 & $<0.001$ \\
\hline & $30-39$ & 74 & 28 & 63 & 45.04 & 11.046 & 122.012 & 0.074 & 0.279 & -0.407 & 0.552 & 0.299 & $<0.001$ \\
\hline & $40-49$ & 105 & 28 & 63 & 49.59 & 11.839 & 140.167 & -0.305 & 0.236 & -0.846 & 0.467 & 0.251 & $<0.001$ \\
\hline & $50-59$ & 124 & 28 & 63 & 52.60 & 10.426 & 108.698 & -0.367 & 0.217 & -0.853 & 0.431 & 0.309 & $<0.001$ \\
\hline & $60-69$ & 134 & 28 & 63 & 55.63 & 9.375 & 87.890 & -0.657 & 0.209 & -0.976 & 0.416 & 0.389 & $<0.001$ \\
\hline & $70-79$ & 84 & 28 & 63 & 56.58 & 9.007 & 82.391 & -0.864 & 0.263 & -0.698 & 0.520 & 0.415 & $<0.001$ \\
\hline & $80-89$ & 18 & 45 & 63 & 61.00 & 5.821 & 33.882 & -2.706 & 0.536 & 5.977 & 1.038 & 0.523 & $<0.001$ \\
\hline & Total & 561 & 16 & 63 & 51.99 & 11.432 & 130.689 & -0.565 & 0.103 & -0.542 & 0.206 & 0.301 & $<0.001$ \\
\hline \multirow[t]{8}{*}{ African } & $19-29$ & 29 & 16 & 63 & 36.59 & 13.847 & 191.751 & 0.422 & 0.434 & -0.790 & 0.845 & 0.250 & $<0.001$ \\
\hline & $30-39$ & 62 & 16 & 63 & 44.53 & 11.377 & 129.433 & -0.091 & 0.304 & -0.087 & 0.599 & 0.307 & $<0.001$ \\
\hline & $40-49$ & 50 & 23 & 63 & 44.14 & 13.257 & 175.756 & 0.066 & 0.337 & -1.100 & 0.662 & 0.226 & $<0.001$ \\
\hline & $50-59$ & 25 & 45 & 63 & 53.16 & 8.980 & 80.640 & 0.213 & 0.464 & -2.092 & 0.902 & 0.338 & $<0.001$ \\
\hline & $60-69$ & 24 & 28 & 63 & 53.54 & 10.346 & 107.042 & -0.546 & 0.472 & -0.602 & 0.918 & 0.320 & $<0.001$ \\
\hline & $70-79$ & 22 & 28 & 63 & 59.23 & 9.008 & 81.136 & -2.566 & 0.491 & 6.546 & 0.953 & 0.481 & $<0.001$ \\
\hline & $80-89$ & 3 & 45 & 63 & 51.00 & 120.392 & 108.00 & 1.732 & 1.225 & - & - & 0.385 & - \\
\hline & Total & 215 & 16 & 63 & 46.97 & 13.227 & 174.943 & -0.295 & 0.166 & -0.829 & 0.330 & 0.231 & $<0.001$ \\
\hline Other & $19-29$ & 2 & 45 & 63 & 54.00 & 12.728 & 162.00 & - & - & - & - & 0.260 & - \\
\hline \multirow[t]{7}{*}{ Ancestry } & $30-39$ & 2 & 45 & 51 & 48.00 & 4.243 & 18.000 & - & - & - & - & 0.260 & - \\
\hline & $40-49$ & 2 & 28 & 45 & 36.50 & 12.021 & 144.500 & - & - & - & - & 0.260 & - \\
\hline & $50-59$ & 2 & 45 & 63 & 54.00 & 12.728 & 162.000 & - & - & - & - & 0.260 & - \\
\hline & $60-69$ & 1 & - & - & - & - & - & - & - & - & - & - & - \\
\hline & $70-79$ & 0 & - & - & - & - & - & - & - & - & - & - & - \\
\hline & $80-89$ & 1 & - & - & - & - & - & - & - & - & - & - & - \\
\hline & Total & 10 & 28 & 63 & 51.10 & 11.780 & 138.767 & -0.552 & 0.687 & -0.140 & 1.334 & 0.244 & 0.094 \\
\hline \multirow[t]{8}{*}{ Total } & $19-29$ & 53 & 16 & 63 & 37.09 & 12.904 & 166.510 & 0.188 & 0.327 & -0.773 & 0.644 & 0.258 & $<0.001$ \\
\hline & $30-39$ & 138 & 23 & 63 & 44.86 & 11.090 & 122.986 & -0.018 & 0.206 & -0.250 & 0.410 & 0.302 & $<0.001$ \\
\hline & $40-49$ & 157 & 23 & 63 & 47.69 & 12.556 & 157.652 & -0.203 & 0.194 & -0.979 & 0.385 & 0.234 & $<0.001$ \\
\hline & $50-59$ & 151 & 28 & 63 & 52.71 & 10.158 & 103.181 & -0.310 & 0.197 & -0.921 & 0.392 & 0.308 & $<0.001$ \\
\hline & $60-69$ & 159 & 28 & 63 & 55.36 & 9.513 & 90.497 & -0.651 & 0.192 & -0.887 & 0.363 & 0.380 & $<0.001$ \\
\hline & $70-79$ & 106 & 28 & 63 & 57.13 & 9.084 & 82.516 & -1.146 & 0.235 & 0.139 & 0.465 & 0.430 & $<0.001$ \\
\hline & $80-89$ & 22 & 45 & 63 & 59.73 & 7.106 & 50.494 & -1.773 & 0.491 & 1.250 & 0.953 & 0.496 & $<0.001$ \\
\hline & Total & 786 & 16 & 63 & 50.60 & 12.145 & 147.493 & -0.523 & 0.087 & -0.580 & 0.174 & 0.273 & $<0.001$ \\
\hline
\end{tabular}


Appendix 9

\begin{tabular}{|c|c|c|c|c|c|c|c|c|c|c|c|c|c|}
\hline & $\begin{array}{l}\text { Age } \\
\text { Categories } \\
\text { (years) }\end{array}$ & n & Min & Max & Mean & $\begin{array}{c}\text { Std. } \\
\text { Deviation }\end{array}$ & Variance & $\begin{array}{r}\text { Skew } \\
\text { Statistic }\end{array}$ & $\begin{array}{l}\text { ess } \\
\text { Std. } \\
\text { Error }\end{array}$ & $\begin{array}{r}\text { Kurt } \\
\text { Statistic }\end{array}$ & $\begin{array}{l}\text { sis } \\
\text { Std. } \\
\text { Error }\end{array}$ & $\begin{array}{c}\text { K-S } \\
\mathbf{Z}\end{array}$ & $\begin{array}{c}\text { Asymp. Sig. } \\
\text { (2-tailed) }\end{array}$ \\
\hline \multirow[t]{8}{*}{ Male } & $19-29$ & 22 & 22 & 42 & 31.39 & 4.286 & 18.371 & 0.560 & 0.409 & 1.100 & 0.798 & 0.292 & $<0.001$ \\
\hline & $30-39$ & 95 & 27 & 65 & 38.46 & 5.923 & 35.081 & 1.421 & 0.247 & 4.063 & 0.490 & 0.271 & $<0.001$ \\
\hline & $40-49$ & 115 & 32 & 65 & 43.21 & 5.857 & 34.307 & 1.050 & 0.226 & 2.070 & 0.447 & 0.217 & $<0.001$ \\
\hline & $50-59$ & 115 & 32 & 65 & 48.83 & 7.237 & 52.367 & 0.538 & 0.226 & 0.205 & 0.447 & 0.226 & $<0.001$ \\
\hline & $60-69$ & 120 & 37 & 65 & 52.49 & 6.291 & 39.580 & 0.646 & 0.221 & 0.033 & 0.438 & 0.264 & $<0.001$ \\
\hline & $70-79$ & 68 & 42 & 65 & 55.75 & 5.966 & 35.593 & 0.382 & 0.291 & -0.466 & 0.574 & 0.365 & $<0.001$ \\
\hline & $80-89$ & 11 & 47 & 65 & 60.36 & 6.712 & 45.055 & -0.995 & 0.661 & -0.550 & 1.279 & 0.391 & $<0.001$ \\
\hline & Total & 557 & 22 & 65 & 46.73 & 9.394 & 88.240 & 0.158 & 0.104 & -0.424 & 0.207 & 0.136 & $<0.001$ \\
\hline \multirow[t]{8}{*}{ Female } & $19-29$ & 19 & 27 & 37 & 29.89 & 3.035 & 9.211 & 0.498 & 0.524 & -0.502 & 1.014 & 0.304 & $<0.001$ \\
\hline & $30-39$ & 43 & 27 & 54 & 35.65 & 5.847 & 34.185 & 1.119 & 0.361 & 1.278 & 0.709 & 0.269 & $<0.001$ \\
\hline & $40-49$ & 45 & 32 & 54 & 40.16 & 4.306 & 18.543 & 0.789 & 0.354 & 1.234 & 0.695 & 0.257 & $<0.001$ \\
\hline & $50-59$ & 37 & 37 & 65 & 47.22 & 7.091 & 50.285 & 0.835 & 0.388 & 0.078 & 0.759 & 0.283 & $<0.001$ \\
\hline & $60-69$ & 41 & 32 & 65 & 52.90 & 8.726 & 76.140 & -0.141 & 0.369 & -0.486 & 0.724 & 0.206 & $<0.001$ \\
\hline & $70-79$ & 40 & 42 & 65 & 56.40 & 7.692 & 59.169 & -0.305 & 0.374 & -0.870 & 0.733 & 0.247 & $<0.001$ \\
\hline & $80-89$ & 12 & 47 & 65 & 57.75 & 8.001 & 64.023 & -0.340 & 0.637 & -1.833 & 1.232 & 0.318 & $<0.001$ \\
\hline & Total & 237 & 27 & 65 & 45.46 & 11.138 & 124.054 & 0.313 & 0.158 & -0.861 & 0.315 & 0.158 & $<0.001$ \\
\hline \multirow[t]{8}{*}{ European } & $19-29$ & 21 & 27 & 42 & 31.05 & 4.068 & 16.548 & 0.996 & 0.501 & 1.192 & 0.972 & 0.265 & $<0.001$ \\
\hline & $30-39$ & 74 & 27 & 54 & 37.53 & 5.341 & 28.527 & 0.961 & 0.279 & 1.118 & 0.552 & 0.269 & $<0.001$ \\
\hline & $40-49$ & 108 & 32 & 65 & 42.54 & 5.873 & 34.494 & 1.139 & 0.233 & 2.735 & 0.461 & 0.222 & $<0.001$ \\
\hline & $50-59$ & 125 & 32 & 65 & 48.46 & 7.384 & 54.525 & 0.653 & 0.217 & 0.050 & 0.430 & 0.211 & $<0.001$ \\
\hline & $60-69$ & 135 & 37 & 65 & 52.83 & 6.679 & 44.605 & 0.404 & 0.209 & -0.168 & 0.414 & 0.267 & $<0.001$ \\
\hline & $70-79$ & 86 & 42 & 65 & 56.02 & 6.925 & 47.952 & -0.045 & 0.260 & -0.753 & 0.514 & 0.301 & $<0.001$ \\
\hline & $80-89$ & 19 & 47 & 65 & 58.68 & 7.227 & 52.228 & -0.474 & 0.524 & -1.448 & 1.014 & 0.335 & $<0.001$ \\
\hline & Total & 568 & 27 & 65 & 47.79 & 9.585 & 91.869 & 0.144 & 0.103 & -0.575 & 0.205 & 0.145 & $<0.001$ \\
\hline \multirow[t]{8}{*}{ African } & $19-29$ & 30 & 22 & 42 & 30.67 & 3.925 & 15.402 & 0.524 & 0.427 & 1.529 & 0.833 & 0.267 & $<0.001$ \\
\hline & $30-39$ & 62 & 27 & 65 & 37.44 & 6.745 & 45.496 & 1.464 & 0.304 & 4.017 & 0.599 & 0.235 & $<0.001$ \\
\hline & $40-49$ & 50 & 37 & 54 & 41.96 & 5.103 & 26.039 & 0.930 & 0.337 & 0.256 & 0.662 & 0.237 & $<0.001$ \\
\hline & $50-59$ & 25 & 37 & 65 & 48.44 & 6.733 & 45.340 & 0.114 & 0.464 & 0.240 & 0.902 & 0.196 & 0.015 \\
\hline & $60-69$ & 25 & 32 & 65 & 51.76 & 8.283 & 68.607 & 0.148 & 0.464 & 0.235 & 0.902 & 0.237 & 0.001 \\
\hline & $70-79$ & 22 & 47 & 65 & 55.86 & 5.462 & 29.838 & 0.747 & 0.491 & -0.108 & 0.953 & 0.406 & $<0.001$ \\
\hline & $80-89$ & 3 & - & - & - & - & - & - & - & - & - & - & - \\
\hline & Total & 217 & 22 & 65 & 42.71 & 10.122 & 102.448 & 0.488 & 0.165 & -0.389 & 0.329 & 0.156 & $<0.001$ \\
\hline Other & $19-29$ & 1 & - & - & - & - & - & - & - & - & - & - & - \\
\hline \multirow[t]{7}{*}{ Ancestry } & $30-39$ & 2 & 42 & 47 & 44.50 & 3.536 & 12.500 & - & - & - & - & 0.260 & - \\
\hline & $40-49$ & 2 & 37 & 47 & 42.00 & 7.071 & 50.000 & - & - & - & - & 0.260 & - \\
\hline & $50-59$ & 2 & - & - & - & - & - & - & - & - & - & - & - \\
\hline & $60-69$ & 1 & - & - & - & - & - & - & - & - & - & - & - \\
\hline & $70-79$ & 0 & - & - & - & - & - & - & - & - & - & - & - \\
\hline & $80-89$ & 1 & - & - & - & - & - & - & - & - & - & - & - \\
\hline & Total & 9 & 32 & 47 & 43.11 & 5.465 & 29.861 & -1.289 & 0.717 & 0.770 & 1.400 & 0.317 & 0.009 \\
\hline \multirow[t]{8}{*}{ Total } & $19-29$ & 52 & 22 & 42 & 30.85 & 3.913 & 15.309 & 0.692 & 0.330 & 1.220 & 0.650 & 0.269 & $<0.001$ \\
\hline & $30-39$ & 138 & 27 & 65 & 37.59 & 6.022 & 36.259 & 1.228 & 0.206 & 2.982 & 0.410 & 0.249 & $<0.001$ \\
\hline & $40-49$ & 160 & 32 & 65 & 42.35 & 5.624 & 31.625 & 1.095 & 0.192 & 2.260 & 0.381 & 0.225 & $<0.001$ \\
\hline & $50-59$ & 152 & 32 & 65 & 48.44 & 7.212 & 52.010 & 0.596 & 0.197 & 0.100 & 0.391 & 0.211 & $<0.001$ \\
\hline & $60-69$ & 161 & 32 & 65 & 52.60 & 6.965 & 48.505 & 0.311 & 0.191 & -0.049 & 0.380 & 0.252 & $<0.001$ \\
\hline & $70-79$ & 108 & 42 & 65 & 55.99 & 6.630 & 43.953 & 0.041 & 0.233 & -0.654 & 0.461 & 0.322 & $<0.001$ \\
\hline & $80-89$ & 23 & 47 & 65 & 59.00 & 7.367 & 54.273 & -0.604 & 0.481 & -1.357 & 0.935 & 0.358 & $<0.001$ \\
\hline & Total & 794 & 22 & 65 & 46.35 & 9.956 & 99.128 & 0.193 & 0.087 & -0.588 & 0.173 & 0.133 & $<0.001$ \\
\hline
\end{tabular}

Appendix 9: Descriptive statistics for the Lovejoy et al. method. 
Appendix 10

\begin{tabular}{|c|c|c|c|c|c|c|c|c|c|c|c|c|c|}
\hline & $\begin{array}{l}\text { Age } \\
\text { Categories } \\
\text { (years) }\end{array}$ & n & Min & Max & Mean & $\begin{array}{c}\text { Std. } \\
\text { Deviation }\end{array}$ & Variance & Statistic & $\begin{array}{l}\text { ess } \\
\text { Std. } \\
\text { Error }\end{array}$ & $\begin{array}{r}\text { Kurt } \\
\text { Statistic }\end{array}$ & $\begin{array}{l}\text { sis } \\
\text { Std. } \\
\text { Error }\end{array}$ & $\begin{array}{c}\text { K-S } \\
\mathbf{Z}\end{array}$ & $\begin{array}{c}\text { Asymp. Sig. } \\
\text { (2-tailed) }\end{array}$ \\
\hline \multirow[t]{8}{*}{ Male } & $19-29$ & 33 & 17 & 72 & 40.55 & 12.096 & 146.318 & 0.517 & 0.409 & -0.031 & 0.798 & 0.220 & $<0.001$ \\
\hline & $30-39$ & 95 & 29 & 72 & 52.31 & 11.380 & 129.512 & -0.456 & 0.247 & -0.592 & 0.490 & 0.223 & $<0.001$ \\
\hline & $40-49$ & 115 & 29 & 72 & 57.23 & 10.233 & 104.708 & -0.802 & 0.226 & 0.000 & 0.447 & 0.233 & $<0.001$ \\
\hline & $50-59$ & 115 & 38 & 72 & 62.59 & 8.094 & 65.507 & -1.183 & 0.226 & 1.706 & 0.447 & 0.235 & $<0.001$ \\
\hline & $60-69$ & 120 & 29 & 72 & 63.00 & 8.760 & 76.739 & -1.449 & 0.221 & 2.506 & 0.438 & 0.224 & $<0.001$ \\
\hline & $70-79$ & 68 & 51 & 72 & 64.97 & 7.295 & 53.223 & -0.811 & 0.291 & -0.555 & 0.574 & 0.257 & $<0.001$ \\
\hline & $80-89$ & 11 & 60 & 72 & 69.55 & 3.908 & 15.273 & -1.670 & 0.661 & 2.657 & 1.279 & 0.371 & $<0.001$ \\
\hline & Total & 557 & 17 & 72 & 58.94 & 11.381 & 129.523 & -1.014 & 0.104 & 0.456 & 0.207 & 0.226 & $<0.001$ \\
\hline \multirow[t]{8}{*}{ Female } & $19-29$ & 18 & 17 & 51 & 32.61 & 9.160 & 83.899 & 0.447 & 0.536 & 0.594 & 1.038 & 0.264 & 0.002 \\
\hline & $30-39$ & 43 & 17 & 72 & 45.12 & 15.190 & 230.724 & 0.156 & 0.361 & -1.315 & 0.709 & 0.192 & $<0.001$ \\
\hline & $40-49$ & 45 & 17 & 72 & 52.78 & 12.367 & 152.949 & -0.711 & 0.354 & 0.052 & 0.695 & 0.209 & $<0.001$ \\
\hline & $50-59$ & 37 & 29 & 72 & 61.43 & 10.474 & 109.697 & -1.386 & 0.388 & 1.858 & 0.759 & 0.229 & $<0.001$ \\
\hline & $60-69$ & 41 & 38 & 72 & 61.12 & 7.342 & 53.910 & -1.347 & 0.369 & 2.736 & 0.724 & 0.238 & $<0.001$ \\
\hline & $70-79$ & 40 & 51 & 75 & 66.68 & 5.903 & 34.840 & -1.434 & 0.374 & 1.739 & 0.733 & 0.322 & $<0.001$ \\
\hline & $80-89$ & 12 & 67 & 75 & 70.33 & 2.462 & 6.601 & -0.812 & 0.637 & -1.650 & 0.637 & 0.417 & $<0.001$ \\
\hline & Total & 236 & 17 & 72 & 56.42 & 14.813 & 219.419 & -0.889 & 0.158 & -0.363 & 0.316 & 0.235 & $<0.001$ \\
\hline \multirow[t]{8}{*}{ European } & $19-29$ & 21 & 17 & 60 & 38.81 & 12.291 & 151.062 & -0.126 & 0.501 & -0.951 & 0.972 & 0.220 & 0.009 \\
\hline & $30-39$ & 74 & 29 & 67 & 49.22 & 12.820 & 164.364 & -0.189 & 0.279 & -1.211 & 0.552 & 0.190 & $<0.001$ \\
\hline & $40-49$ & 108 & 29 & 72 & 56.69 & 10.243 & 104.928 & -0.681 & 0.233 & -0.153 & 0.461 & 0.201 & $<0.001$ \\
\hline & $50-59$ & 125 & 29 & 72 & 62.76 & 8.468 & 71.700 & -1.452 & 0.217 & 2.821 & 0.430 & 0.244 & $<0.001$ \\
\hline & $60-69$ & 135 & 29 & 72 & 63.37 & 8.520 & 72.593 & -1.509 & 0.209 & 2.772 & 0.414 & 0.235 & $<0.001$ \\
\hline & $70-79$ & 86 & 51 & 72 & 65.66 & 6.693 & 44.791 & -0.952 & 0.260 & -0.059 & 0.514 & 0.265 & $<0.001$ \\
\hline & $80-89$ & 19 & 60 & 72 & 70.05 & 3.308 & 10.942 & -1.822 & 0.524 & 3.450 & 1.014 & 0.406 & $<0.001$ \\
\hline & Total & 568 & 17 & 72 & 59.78 & 11.519 & 132.678 & -1.180 & 0.103 & 0.895 & 0.205 & 0.231 & $<0.001$ \\
\hline \multirow[t]{8}{*}{ African } & $19-29$ & 29 & 17 & 72 & 36.97 & 11.617 & 134.963 & 1.266 & 0.434 & 1.885 & 0.845 & 0.258 & $<0.001$ \\
\hline & $30-39$ & 62 & 17 & 72 & 50.79 & 13.442 & 180.693 & -0.531 & 0.304 & -0.539 & 0.599 & 0.232 & $<0.001$ \\
\hline & $40-49$ & 50 & 17 & 72 & 54.16 & 12.556 & 157.647 & -0.856 & 0.337 & 0.082 & 0.662 & 0.279 & $<0.001$ \\
\hline & $50-59$ & 25 & 38 & 72 & 59.95 & 9.944 & 98.873 & -0.740 & 0.464 & -0.102 & 0.902 & 0.201 & 0.011 \\
\hline & $60-69$ & 25 & 38 & 72 & 62.68 & 8.102 & 65.643 & -1.122 & 0.464 & 2.247 & 0.902 & 0.250 & $<0.001$ \\
\hline & $70-79$ & 22 & 51 & 72 & 65.36 & 7.525 & 56.623 & -1.219 & 0.491 & 0.172 & 0.953 & 0.359 & $<0.001$ \\
\hline & $80-89$ & 3 & 67 & 72 & 68.67 & 2.887 & 8.333 & 1.732 & 1.225 & - & - & 0.385 & - \\
\hline & Total & 216 & 17 & 72 & 53.88 & 14.141 & 199.954 & -0.633 & 0.166 & -0.635 & 0.330 & 0.209 & $<0.001$ \\
\hline Other & $19-29$ & 1 & - & - & - & - & - & - & - & - & - & - & - \\
\hline \multirow{7}{*}{ Ancestry } & $30-39$ & 2 & 51 & 67 & 59.00 & 11.314 & 128.00 & - & - & - & - & 0.260 & - \\
\hline & $40-49$ & 2 & 60 & 67 & 63.50 & 4.950 & 24.500 & - & - & - & - & 0.260 & - \\
\hline & $50-59$ & 2 & 60 & 67 & 63.50 & 4.950 & 24.500 & - & - & - & - & 0.260 & - \\
\hline & $60-69$ & 1 & - & - & - & - & - & - & - & - & - & - & - \\
\hline & $70-79$ & 0 & - & - & - & - & - & - & - & - & - & - & - \\
\hline & $80-89$ & 1 & - & - & - & - & - & - & - & - & - & - & - \\
\hline & Total & 9 & 38 & 72 & 61.00 & 10.583 & 112.000 & -1.488 & 0.717 & 2.041 & 1.400 & 0.270 & 0.057 \\
\hline \multirow[t]{8}{*}{ Total } & $19-29$ & 51 & 17 & 72 & 37.75 & 11.698 & 136.834 & 0.629 & 0.333 & 0.272 & 0.656 & 0.217 & $<0.001$ \\
\hline & $30-39$ & 138 & 17 & 72 & 50.07 & 13.068 & 170.762 & -0.353 & 0.206 & -0.911 & 0.410 & 0.210 & $<0.001$ \\
\hline & $40-49$ & 160 & 17 & 72 & 55.98 & 11.020 & 121.440 & -0.828 & 0.192 & 0.203 & 0.381 & 0.230 & $<0.001$ \\
\hline & $50-59$ & 152 & 29 & 75 & 62.31 & 8.710 & 75.857 & -1.306 & 0.197 & 2.009 & 0.391 & 0.238 & $<0.001$ \\
\hline & $60-69$ & 161 & 29 & 72 & 63.29 & 8.414 & 70.793 & -1.452 & 0.191 & 2.632 & 0.380 & 0.223 & $<0.001$ \\
\hline & $70-79$ & 108 & 51 & 72 & 65.60 & 6.834 & 46.709 & -1.007 & 0.233 & -0.034 & 0.461 & 0.285 & $<0.001$ \\
\hline & $80-89$ & 23 & 60 & 72 & 69.69 & 3.183 & 10.134 & -1.605 & 0.481 & 2.722 & 0.935 & 0.392 & $<0.001$ \\
\hline & Total & 793 & 17 & 72 & 58.19 & 12.544 & 157.364 & -1.035 & 0.087 & 0.331 & 0.173 & 0.232 & $<0.001$ \\
\hline
\end{tabular}

Appendix 10: Descriptive statistics for the Buckberry and Chamberlain method. 


\section{Appendix 11}

\begin{tabular}{|c|c|c|c|c|c|c|c|c|c|c|c|c|c|}
\hline & $\begin{array}{l}\text { Age } \\
\text { Categories } \\
\text { (years) }\end{array}$ & n & Min & Max & Mean & $\begin{array}{c}\text { Std. } \\
\text { Deviation }\end{array}$ & Variance & Statistic & $\begin{array}{l}\text { ess } \\
\text { Std. } \\
\text { Error }\end{array}$ & $\begin{array}{r}\text { Kurt } \\
\text { Statistic }\end{array}$ & $\begin{array}{l}\text { sis } \\
\text { Std. } \\
\text { Error }\end{array}$ & $\begin{array}{c}\text { K-S } \\
\mathbf{Z}\end{array}$ & $\begin{array}{c}\text { Asymp. Sig. } \\
\text { (2-tailed) }\end{array}$ \\
\hline \multirow[t]{8}{*}{ Male } & $19-29$ & 34 & 22 & 48 & 34.76 & 6.858 & 47.034 & 0.789 & 0.403 & -0.165 & 0.788 & 0.315 & $<0.001$ \\
\hline & $30-39$ & 94 & 22 & 59 & 40.26 & 7.949 & 63.181 & 0.489 & 0.249 & 0.353 & 0.493 & 0.303 & $<0.001$ \\
\hline & $40-49$ & 115 & 30 & 59 & 45.45 & 7.558 & 57.127 & 0.034 & 0.226 & -0.367 & 0.447 & 0.275 & $<0.001$ \\
\hline & $50-59$ & 115 & 38 & 73 & 49.54 & 9.236 & 85.303 & 0.514 & 0.226 & -0.154 & 0.447 & 0.244 & $<0.001$ \\
\hline & $60-69$ & 120 & 90 & 73 & 51.55 & 8.217 & 67.527 & 0.158 & 0.221 & 0.177 & 0.438 & 0.267 & $<0.001$ \\
\hline & $70-79$ & 68 & 38 & 73 & 53.35 & 9.048 & 81.874 & 0.212 & 0.291 & -0.119 & 0.574 & 0.234 & $<0.001$ \\
\hline & $80-89$ & 11 & 48 & 73 & 60.82 & 8.909 & 79.364 & 0.203 & 0.661 & -0.670 & 1.279 & 0.308 & 0.004 \\
\hline & Total & 557 & 22 & 73 & 47.35 & 10.002 & 100.044 & 0.224 & 0.104 & -0.168 & 0.207 & 0.207 & $<0.001$ \\
\hline \multirow[t]{8}{*}{ Female } & $19-29$ & 18 & 22 & 38 & 30.44 & 5.803 & 33.673 & -0.086 & 0.536 & -0.904 & 1.038 & 0.253 & 0.003 \\
\hline & $30-39$ & 43 & 30 & 59 & 37.70 & 8.002 & 64.025 & 0.657 & 0.361 & -0.593 & 0.709 & 0.251 & $<0.001$ \\
\hline & $40-49$ & 45 & 30 & 59 & 41.27 & 7.820 & 61.155 & 0.510 & 0.354 & -0.147 & 0.695 & 0.284 & $<0.001$ \\
\hline & $50-59$ & 37 & 30 & 59 & 48.78 & 8.597 & 73.901 & -0.187 & 0.388 & -1.017 & 0.759 & 0.210 & $<0.001$ \\
\hline & $60-69$ & 41 & 38 & 73 & 53.27 & 9.872 & 97.451 & 0.278 & 0.369 & -0.299 & 0.724 & 0.215 & $<0.001$ \\
\hline & $70-79$ & 40 & 38 & 73 & 54.28 & 10.110 & 102.204 & 0.248 & 0.374 & -0.396 & 0.733 & 0.208 & $<0.001$ \\
\hline & $80-89$ & 12 & 48 & 73 & 59.50 & 7.574 & 57.364 & 0.472 & 0.637 & 0.823 & 1.232 & 0.360 & $<0.001$ \\
\hline & Total & 236 & 22 & 73 & 46.17 & 11.814 & 139.577 & 0.247 & 0.158 & -0.520 & 0.316 & 0.171 & $<0.001$ \\
\hline \multirow[t]{8}{*}{ European } & $19-29$ & 21 & 22 & 48 & 33.14 & 6.150 & 37.829 & 0.266 & 0.501 & 0.503 & 0.972 & 0.267 & $<0.001$ \\
\hline & $30-39$ & 74 & 22 & 59 & 38.78 & 7.796 & 60.775 & 0.392 & 0.279 & -0.378 & 0.552 & 0.243 & $<0.001$ \\
\hline & $40-49$ & 108 & 30 & 59 & 44.56 & 7.902 & 62.436 & 0.217 & 0.233 & -0.540 & 0.461 & 0.233 & $<0.001$ \\
\hline & $50-59$ & 125 & 30 & 73 & 49.37 & 9.171 & 84.105 & 0.461 & 0.209 & -0.070 & 0.430 & 0.247 & $<0.001$ \\
\hline & $60-69$ & 135 & 30 & 73 & 51.77 & 8.430 & 71.059 & 0.121 & 0.209 & 0.032 & 0.414 & 0.250 & $<0.001$ \\
\hline & $70-79$ & 86 & 38 & 73 & 53.84 & 8.893 & 79.079 & 0.271 & 0.260 & -0.054 & 0.514 & 0.233 & $<0.001$ \\
\hline & $80-89$ & 19 & 48 & 73 & 61.53 & 7.820 & 61.152 & 0.313 & 0.524 & -0.375 & 1.014 & 0.364 & $<0.001$ \\
\hline & Total & 568 & 22 & 73 & 48.13 & 10.321 & 106.525 & 0.163 & 0.103 & -0.243 & 0.205 & 0.200 & $<0.001$ \\
\hline \multirow[t]{8}{*}{ African } & $19-29$ & 29 & 22 & 48 & 32.97 & 6.962 & 48.463 & 0.764 & 0.434 & 0.464 & 0.845 & 0.320 & $<0.001$ \\
\hline & $30-39$ & 61 & 22 & 59 & 40.15 & 8.350 & 69.728 & 0.652 & 0.306 & 0.279 & 0.604 & 0.306 & $<0.001$ \\
\hline & $40-49$ & 50 & 30 & 59 & 43.52 & 7.856 & 61.724 & -0.023 & 0.337 & -0.440 & 0.662 & 0.276 & $<0.001$ \\
\hline & $50-59$ & 25 & 38 & 59 & 49.20 & 9.069 & 82.250 & -0.112 & 0.464 & -1.689 & 0.902 & 0.260 & $<0.001$ \\
\hline & $60-69$ & 25 & 38 & 73 & 52.32 & 9.245 & 85.477 & 0.590 & 0.454 & 0.336 & 0.902 & 0.280 & $<0.001$ \\
\hline & $70-79$ & 22 & 38 & 73 & 53.14 & 11.470 & 131.552 & 0.242 & 0.491 & -0.759 & 0.953 & 0.195 & 0.028 \\
\hline & $80-89$ & 3 & 48 & 53 & 55.33 & 6.351 & 40.333 & -1.732 & 1.225 & - & - & 0.385 & - \\
\hline & Total & 215 & 22 & 73 & 43.97 & 10.702 & 114.532 & 0.403 & 0.166 & -0.209 & 0.330 & 0.209 & $<0.001$ \\
\hline Other & $19-29$ & 2 & 30 & 48 & 39.00 & 12.728 & 162.00 & - & - & - & - & 0.260 & - \\
\hline \multirow[t]{7}{*}{ Ancestry } & $30-39$ & 2 & 38 & 48 & 43.00 & 7.071 & 50.000 & - & - & - & - & 0.260 & - \\
\hline & $40-49$ & 2 & - & - & - & - & - & - & - & - & - & - & - \\
\hline & $50-59$ & 2 & - & - & - & - & - & - & - & - & - & - & - \\
\hline & $60-69$ & 1 & - & - & - & - & - & - & - & - & - & - & - \\
\hline & $70-79$ & 0 & - & - & - & - & - & - & - & - & - & - & - \\
\hline & $80-89$ & 1 & - & - & - & - & - & - & - & - & - & - & - \\
\hline & Total & 10 & 30 & 73 & 47.70 & 10.791 & 116.456 & 1.076 & 0.687 & 3.976 & 1.334 & 0.389 & $<0.001$ \\
\hline \multirow[t]{8}{*}{ Total } & $19-29$ & 52 & 22 & 48 & 33.27 & 6.780 & 45.965 & 0.620 & 0.330 & 0.225 & 0.650 & 0.301 & $<0.001$ \\
\hline & $30-39$ & 137 & 22 & 59 & 39.45 & 8.025 & 64.397 & 0.515 & 0.207 & -0.019 & 0.411 & 0.273 & $<0.001$ \\
\hline & $40-49$ & 160 & 30 & 59 & 44.28 & 7.839 & 61.446 & 0.127 & 0.192 & -0.485 & 0.381 & 0.251 & $<0.001$ \\
\hline & $50-59$ & 152 & 30 & 73 & 49.32 & 9.065 & 82.167 & 0.381 & 0.197 & -0.266 & 0.391 & 0.236 & $<0.001$ \\
\hline & $60-69$ & 161 & 30 & 73 & 51.99 & 8.669 & 75.150 & 0.243 & 0.191 & 0.071 & 0.380 & 0.255 & $<0.001$ \\
\hline & $70-79$ & 108 & 38 & 73 & 53.69 & 9.419 & 88.719 & 0.240 & 0.233 & -0.253 & 0.461 & 0.223 & $<0.001$ \\
\hline & $80-89$ & 23 & 48 & 73 & 60.13 & 8.075 & 65.209 & 0.331 & 0.481 & -0.313 & 0.935 & 0.338 & $<0.001$ \\
\hline & Total & 793 & 22 & 73 & 47.00 & 10.580 & 111.941 & 0.209 & 0.087 & -0.274 & 0.173 & 0.190 & $<0.001$ \\
\hline
\end{tabular}

Appendix 11: Descriptive statistics for the Rougé-Maillart et al. method. 


\section{Appendix 12}

\begin{tabular}{|c|c|c|c|c|c|c|c|c|c|c|c|c|c|}
\hline & $\begin{array}{l}\text { Age } \\
\text { Categories } \\
\text { (years) }\end{array}$ & n & Min & Max & Mean & $\begin{array}{c}\text { Std. } \\
\text { Deviation }\end{array}$ & Variance & Statistic & $\begin{array}{l}\text { ess } \\
\text { Std. } \\
\text { Error }\end{array}$ & $\begin{array}{r}\text { Kurt } \\
\text { Statistic }\end{array}$ & $\begin{array}{l}\text { sis } \\
\text { Std. } \\
\text { Error }\end{array}$ & $\begin{array}{c}\text { K-S } \\
\mathbf{Z}\end{array}$ & $\begin{array}{c}\text { Asymp. Sig. } \\
\text { (2-tailed) }\end{array}$ \\
\hline \multirow[t]{8}{*}{ Male } & $19-29$ & 35 & 18 & 35 & 27.46 & 6.657 & 44.314 & -0.048 & 0.398 & -1.596 & 0.778 & 0.243 & $<0.001$ \\
\hline & $30-39$ & 95 & 23 & 46 & 36.06 & 5.565 & 30.975 & 0.675 & 0.247 & -0.093 & 0.490 & 0.376 & $<0.001$ \\
\hline & $40-49$ & 115 & 29 & 61 & 43.24 & 7.450 & 55.502 & 0.533 & 0.226 & 0.390 & 0.447 & 0.296 & $<0.001$ \\
\hline & $50-59$ & 115 & 35 & 61 & 47.94 & 7.775 & 60.444 & 0.472 & 0.226 & -0.244 & 0.447 & 0.372 & $<0.001$ \\
\hline & $60-69$ & 120 & 35 & 61 & 50.58 & 7.822 & 61.180 & 0.301 & 0.221 & -1.182 & 0.438 & 0.380 & $<0.001$ \\
\hline & $70-79$ & 68 & 46 & 61 & 55.49 & 7.286 & 53.089 & -0.561 & 0.291 & -1.737 & 0.574 & 0.408 & $<0.001$ \\
\hline & $80-89$ & 11 & 46 & 61 & 56.91 & 7.006 & 49.091 & -1.189 & 0.661 & -0.764 & 1.279 & 0.448 & $<0.001$ \\
\hline & Total & 559 & 18 & 61 & 45.38 & 10.510 & 110.468 & -0.030 & 0.103 & -0.481 & 0.206 & 0.247 & $<0.001$ \\
\hline \multirow[t]{8}{*}{ Female } & $19-29$ & 19 & 19 & 38 & 29.32 & 5.991 & 35.895 & -0.007 & 0.524 & -0.710 & 1.014 & 0.190 & 0.071 \\
\hline & $30-39$ & 43 & 25 & 48 & 36.28 & 5.767 & 33.254 & 0.421 & 0.361 & 0.196 & 0.706 & 0.266 & $<0.001$ \\
\hline & $40-49$ & 45 & 25 & 60 & 39.91 & 8.050 & 64.810 & 0.795 & 0.354 & 0.952 & 0.695 & 0.327 & $<0.001$ \\
\hline & $50-59$ & 37 & 31 & 60 & 48.59 & 7.988 & 63.803 & 0.000 & 0.388 & -0.501 & 0.759 & 0.286 & $<0.001$ \\
\hline & $60-69$ & 40 & 38 & 60 & 53.00 & 7.646 & 58.462 & -0.522 & 0.374 & -0.966 & 0.733 & 0.320 & $<0.001$ \\
\hline & $70-79$ & 38 & 48 & 60 & 56.21 & 5.653 & 31.954 & -0.826 & 0.383 & -1.395 & 0.750 & 0.433 & $<0.001$ \\
\hline & $80-89$ & 12 & 48 & 60 & 57.00 & 5.427 & 29.455 & -1.327 & 0.637 & -0.326 & 1.232 & 0.460 & $<0.001$ \\
\hline & Total & 234 & 19 & 61 & 45.52 & 11.265 & 126.895 & $0-.097$ & 0.159 & -1.071 & 0.317 & 0.187 & $<0.001$ \\
\hline \multirow[t]{8}{*}{ European } & $19-29$ & 22 & 18 & 38 & 28.00 & 6.655 & 44.286 & -0.215 & 0.491 & -1.401 & 0.953 & 0.183 & 0.054 \\
\hline & $30-39$ & 74 & 23 & 48 & 36.08 & 5.812 & 33.774 & 0.563 & 0.233 & 0.350 & 0.461 & 0.249 & $<0.001$ \\
\hline & $40-49$ & 108 & 25 & 61 & 42.84 & 7.729 & 59.741 & 0.513 & 0.233 & 0.350 & 0.461 & 0.242 & $<0.001$ \\
\hline & $50-59$ & 125 & 35 & 61 & 48.82 & 7.635 & 58.297 & 0.392 & 0.217 & -0.503 & 0.430 & 0.295 & $<0.001$ \\
\hline & $60-69$ & 135 & 35 & 61 & 51.98 & 7.735 & 59.828 & 0.023 & 0.209 & -1.369 & 0.414 & 0.274 & $<0.001$ \\
\hline & $70-79$ & 85 & 46 & 61 & 55.69 & 6.742 & 45.453 & -0.637 & 0.261 & -1.589 & 0.517 & 0.386 & $<0.001$ \\
\hline & $80-89$ & 19 & 46 & 61 & 56.21 & 6.469 & 41.842 & -0.875 & 0.524 & -1.320 & 1.014 & 0.405 & $<0.001$ \\
\hline & Total & 568 & 18 & 61 & 47.24 & 10.287 & 105.814 & -0.179 & 0.103 & -0.614 & 0.205 & 0.195 & $<0.001$ \\
\hline \multirow[t]{8}{*}{ African } & $19-29$ & 30 & 18 & 38 & 28.13 & 6.410 & 41.085 & 0.025 & 0.427 & -1.209 & 0.833 & 0.188 & 0.009 \\
\hline & $30-39$ & 62 & 25 & 48 & 36.23 & 5.493 & 30.178 & 0.610 & 0.304 & 0.230 & 0.599 & 0.233 & $<0.001$ \\
\hline & $40-49$ & 50 & 25 & 61 & 41.00 & 7.827 & 61.265 & 0.689 & 0.337 & 0.689 & 0.662 & 0.209 & $<0.001$ \\
\hline & $50-59$ & 25 & 31 & 61 & 45.12 & 7.928 & 62.860 & 0.403 & 0.464 & 0.349 & 0.902 & 0.264 & $<0.001$ \\
\hline & $60-69$ & 24 & 35 & 61 & 48.29 & 7.328 & 53.694 & 0.620 & 0.472 & 0034 & 0.918 & 0.308 & $<0.001$ \\
\hline & $70-79$ & 21 & 46 & 61 & 55.84 & 6.830 & 46.648 & -0.771 & 0.501 & -1.515 & 0.972 & 0.390 & $<0.001$ \\
\hline & $80-89$ & 3 & 60 & 61 & 60.67 & 0.333 & 61.00 & -1.732 & 1.225 & - & - & 0.385 & $<0.001$ \\
\hline & Total & 215 & 18 & 61 & 40.86 & 10.511 & 110.479 & 0.348 & 0.166 & -0.306 & 0.330 & 0.165 & $<0.001$ \\
\hline Other & $19-29$ & 2 & 23 & 35 & 29.00 & 8.485 & 72.000 & - & - & - & - & 0.260 & - \\
\hline \multirow[t]{7}{*}{ Ancestry } & $30-39$ & 2 & - & - & - & - & - & - & - & - & - & - & - \\
\hline & $40-49$ & 2 & - & - & - & - & - & - & - & - & - & - & - \\
\hline & $50-59$ & 2 & 35 & 46 & 40.50 & 7.778 & 60.500 & - & - & - & - & 0.260 & \\
\hline & $60-69$ & 1 & - & - & - & - & - & - & - & - & - & - & - \\
\hline & $70-79$ & 0 & - & - & - & - & - & - & - & - & - & - & - \\
\hline & $80-89$ & 1 & - & - & - & - & - & - & - & - & - & - & - \\
\hline & Total & 10 & 23 & 60 & 39.90 & 10.005 & 100.100 & 0.485 & 0.687 & 1.134 & 1.334 & 0.212 & 0.200 \\
\hline \multirow[t]{8}{*}{ Total } & $19-29$ & 54 & 18 & 38 & 28.11 & 6.436 & 41.421 & -0.079 & 0.325 & -1.298 & 0.639 & 0.173 & $<0.001$ \\
\hline & $30-39$ & 138 & 23 & 48 & 36.13 & 5.609 & 31.457 & 0.587 & 0.206 & -0.051 & 0.410 & 0.247 & $<0.001$ \\
\hline & $40-49$ & 160 & 25 & 61 & 42.31 & 7.745 & 59.987 & 0.534 & 0.192 & 0.367 & 0.381 & 0.227 & $<0.001$ \\
\hline & $50-59$ & 152 & 31 & 61 & 48.10 & 7.805 & 60.924 & 0.352 & 0.197 & -0.364 & 0.391 & 0.281 & $<0.001$ \\
\hline & $60-69$ & 160 & 35 & 61 & 51.34 & 7.814 & 61.055 & 0.102 & 0.192 & -1.271 & 0.381 & 0.278 & $<0.001$ \\
\hline & $70-79$ & 106 & 46 & 61 & 55.75 & 6.727 & 45.258 & -0.653 & 0.235 & -1.562 & 0.465 & 0.387 & $<0.001$ \\
\hline & $80-89$ & 23 & 46 & 61 & 56.96 & 6.086 & 37.043 & -1.174 & 0.481 & -0.608 & 0.935 & 0.431 & $<0.001$ \\
\hline & Total & 793 & 18 & 61 & 45.42 & 10.732 & 115.165 & -0.051 & 0.087 & -0.683 & 0.173 & 0.179 & $<0.001$ \\
\hline
\end{tabular}

Appendix 12: Descriptive statistics for the Suchey-Brooks et al. method. 


\section{Appendix 13}

\begin{tabular}{|c|c|c|c|c|c|c|c|c|c|}
\hline BMI Catego & ries & $\begin{array}{c}\text { Kunos } \\
\text { et al. }\end{array}$ & $\begin{array}{c}\text { DiGangi } \\
\text { et al. }\end{array}$ & $\begin{array}{l}\text { İşcan } \\
\text { et al. }\end{array}$ & Passalacqua & $\begin{array}{c}\text { Lovejoy } \\
\text { et al. }\end{array}$ & $\begin{array}{l}\text { Buckberry \& } \\
\text { Chamberlain } \\
\end{array}$ & $\begin{array}{c}\text { Rougé- } \\
\text { Maillart et al. }\end{array}$ & $\begin{array}{l}\text { Suchey- } \\
\text { Brooks }\end{array}$ \\
\hline Underweight & Kunos et al. & 46.374 & 20.919 & 28.178 & 12.137 & 12.115 & 19.698 & 22.650 & 4.413 \\
\hline & DiGangi et al. & 20.919 & 128.418 & 76.794 & 33.734 & 46.660 & -30.558 & 61.610 & 52.118 \\
\hline & İşcan et al. & & & 125.28 & & & & & \\
\hline & & 28.178 & 76.794 & & 32.032 & 37.331 & 1.793 & 51.759 & 31.058 \\
\hline & Passalacqua & 12.137 & 33.734 & 32.032 & 76.430 & 18.389 & -1.896 & 26.729 & 17.347 \\
\hline & Lovejoy et al. & 12.115 & 46.660 & 37.331 & 18.389 & 59.673 & 1.334 & 50.972 & 29.940 \\
\hline & $\begin{array}{l}\text { Buckberry \& } \\
\text { Chamberlain }\end{array}$ & 19.698 & -30.558 & 1.793 & -1.896 & 1.334 & 83.975 & 17.338 & -19.344 \\
\hline & $\begin{array}{l}\text { Rougé-Maillart } \\
\text { et al. }\end{array}$ & 22.650 & 61.610 & 51.759 & 26.729 & 50.972 & 17.338 & 83.319 & 38.751 \\
\hline & Suchey-Brooks & 4.413 & 52.118 & 31.058 & 17.347 & 29.940 & -19.344 & 38.751 & 66.268 \\
\hline Normal & Kunos et al. & 54.205 & -2.422 & 5.403 & 12.143 & 1.356 & 29.061 & 6.824 & 0.152 \\
\hline & DiGangi et al. & -2.422 & 112.466 & 17.919 & 13.378 & 36.480 & -26.716 & 38.871 & 43.699 \\
\hline & İşcan et al. & 5.403 & 17.919 & 53.753 & 2.404 & -0.337 & -2.280 & 2.462 & 4.548 \\
\hline & Passalacqua & 12.143 & 13.378 & 2.404 & 71.050 & 11.789 & 10.029 & 11.715 & 7.177 \\
\hline & Lovejoy et al. & 1.356 & 36.480 & -0.337 & 11.789 & 38.874 & -2.829 & 28.415 & 23.091 \\
\hline & $\begin{array}{l}\text { Buckberry \& } \\
\text { Chamberlain }\end{array}$ & 29.061 & -26.716 & -2.280 & 10.029 & -2.829 & 74.733 & 10.010 & -13.379 \\
\hline & $\begin{array}{l}\text { Rougé-Maillart } \\
\text { et al. }\end{array}$ & 6.824 & 38.871 & 2.462 & 11.715 & 28.415 & 10.010 & 60.651 & 23.675 \\
\hline & Suchey-Brooks & 0.152 & 43.699 & 4.548 & 7.177 & 23.091 & -13.379 & 23.675 & 50.383 \\
\hline Overweight & Kunos et al. & 37.174 & -3.302 & -2.948 & 2.434 & 0.231 & 19.904 & 1.956 & -2.876 \\
\hline & DiGangi et al. & -3.302 & 82.085 & 6.485 & -4.268 & 21.369 & -26.709 & 21.133 & 26.217 \\
\hline & İşcan et al. & -2.948 & 6.485 & 63.398 & -2.608 & -4.025 & 5.166 & 5.249 & 2.481 \\
\hline & Passalacqua & 2.434 & -4.268 & -2.608 & 45.169 & 4.519 & -0.641 & 9.068 & 0.935 \\
\hline & Lovejoy et al. & 0.231 & 21.369 & -4.025 & 4.519 & 49.367 & -4.099 & 27.039 & 19.707 \\
\hline & & & & & & & & & \\
\hline & Chamberlain & 19.904 & -26.709 & 5.166 & -0.641 & -4.099 & 78.650 & 0.055 & -18.208 \\
\hline & $\begin{array}{l}\text { Rougé-Maillart } \\
\text { et al. }\end{array}$ & 1.956 & 21.133 & 5.249 & 9.068 & 27.039 & 0.055 & 44.993 & 20.456 \\
\hline & Suchey-Brooks & -2.876 & 26.217 & 2.481 & 0.935 & 19.707 & -18.208 & 20.456 & 50.310 \\
\hline Obese & Kunos et al. & 41.454 & -20.403 & 4.683 & 11.629 & -14.708 & 18.505 & -15.362 & -21.948 \\
\hline & DiGangi et al. & -20.403 & 70.098 & -4.938 & 7.065 & 26.286 & -23.948 & 38.569 & 10.246 \\
\hline & İşcan et al. & 4.683 & -4.938 & 32.978 & -4.265 & -12.606 & 15.108 & 9.951 & -3.606 \\
\hline & Passalacqua & 11.629 & 7.065 & -4.265 & 54.906 & 6.422 & 20.643 & 7.232 & 7.222 \\
\hline & Lovejoy et al. & -14.708 & 26.286 & -12.606 & 6.422 & 52.375 & -25.849 & 17.083 & 17.055 \\
\hline & $\begin{array}{l}\text { Buckberry \& } \\
\text { Chamberlain }\end{array}$ & 18.505 & -23.948 & 15.108 & 20.643 & -25.849 & 59.422 & -5.434 & -17.169 \\
\hline & $\begin{array}{l}\text { Rougé-Maillart } \\
\text { et al. }\end{array}$ & -15.362 & 38.569 & 9.951 & 7.232 & 17.083 & -5.434 & 43.325 & 16.643 \\
\hline & Suchey-Brooks & -21.948 & 10.246 & -3.606 & 7.222 & 17.055 & -17.169 & 16.643 & 46.295 \\
\hline
\end{tabular}




\section{Appendix 14}

\begin{tabular}{|c|c|c|c|c|c|c|c|c|c|}
\hline BMI Catego & ries & $\begin{array}{c}\text { Kunos } \\
\text { et al. }\end{array}$ & \begin{tabular}{|c|}
$\begin{array}{c}\text { DiGangi } \\
\text { et al. }\end{array}$ \\
\end{tabular} & $\begin{array}{l}\text { İşcan } \\
\text { et al. }\end{array}$ & Passalacqua & \begin{tabular}{|c|}
$\begin{array}{c}\text { Lovejoy } \\
\text { et al. }\end{array}$ \\
\end{tabular} & $\begin{array}{l}\text { Buckberry \& } \\
\text { Chamberlain } \\
\end{array}$ & \begin{tabular}{|c|} 
Rougé- \\
Maillart et al.
\end{tabular} & $\begin{array}{l}\text { Suchey- } \\
\text { Brooks }\end{array}$ \\
\hline Underweight & Kunos et al. & 159.62 & 167.10 & 145.079 & 116.401 & 105.059 & 128.164 & 135.327 & 98.997 \\
\hline & DiGangi et al. & 167.101 & 208.101 & 158.293 & 130.099 & 106.504 & 129.879 & 143.720 & 104.701 \\
\hline & İşcan et al. & 145.079 & 158.293 & 222.823 & 108.815 & 102.729 & 133.555 & 137.567 & 87.351 \\
\hline & Passalacqua & 116.401 & 130.099 & 108.815 & 213.572 & 93.075 & 121.096 & 114.911 & 88.536 \\
\hline & Lovejoy et al. & 105.059 & 106.504 & 102.729 & 93.075 & 116.830 & 133.550 & 129.339 & 75.090 \\
\hline & $\begin{array}{l}\text { Buckberry \& } \\
\text { Chamberlain }\end{array}$ & 128.164 & 129.879 & 133.555 & 121.096 & 133.550 & 210.568 & 174.168 & 92.235 \\
\hline & $\begin{array}{l}\text { Rougé- } \\
\text { Maillart et al. }\end{array}$ & 135.327 & 143.720 & 137.567 & 114.911 & 129.339 & 174.168 & 192.094 & 102.336 \\
\hline & $\begin{array}{l}\text { Suchey- } \\
\text { Brooks }\end{array}$ & 98.997 & 104.701 & 87.351 & 88.536 & 75.090 & 92.235 & 102.336 & 116.323 \\
\hline Normal & Kunos et al. & 709 & 151.586 & $\begin{array}{l}-12.375 \\
\end{array}$ & 108.674 & 83.212 & 114.445 & 111.245 & 79.369 \\
\hline & DiGar & 151.586 & 197.256 & -38.269 & 109.291 & 83.638 & 113.714 & 112.330 & 83.204 \\
\hline & İşc & -12.375 & -38.269 & 141.839 & -4.859 & 7.474 & 3.263 & 6.653 & 8.710 \\
\hline & Pass & 108.674 & 109.291 & -4.859 & 201.430 & 79.128 & 106.078 & 102.023 & 69.583 \\
\hline & $y$ et al. & 83.212 & 83.638 & 7.474 & 79.128 & 87.012 & 92.288 & 90.729 & 57.532 \\
\hline & $\begin{array}{l}\text { Buckberry \& } \\
\text { Chamberlain }\end{array}$ & 114.445 & 113.714 & 3.263 & 106.078 & 92.288 & 170.114 & 140.456 & 74.212 \\
\hline & $\begin{array}{l}\text { Rougé- } \\
\text { Maillart et al. }\end{array}$ & 111.245 & 112.330 & 6.653 & 102.023 & 90.729 & 140.456 & 152.926 & 76.364 \\
\hline & $\begin{array}{l}\text { Suchey- } \\
\text { Brooks }\end{array}$ & 79.369 & 83.204 & 8.710 & 69.583 & 57.532 & 74.212 & 76.364 & 85.547 \\
\hline Overweight & Kunos et al. & 94.384 & 82.125 & 27.012 & 62.215 & 54.466 & 65.307 & 66.193 & 70.041 \\
\hline & DiGangi et al. & 82.125 & 120.120 & 2.504 & 41.087 & 46.831 & 52.105 & 53.560 & 60.621 \\
\hline & İşcan et al. & 27.012 & 2.504 & 164.615 & 42.858 & 51.564 & 45.510 & 43.962 & 47.993 \\
\hline & Passalacqua & 62.215 & 41.087 & 42.858 & 131.775 & 55.214 & 53.738 & 70.120 & 45.320 \\
\hline & Lovejoy et al. & 54.466 & 46.831 & 51.564 & 55.214 & 102.454 & 78.398 & 87.434 & 53.186 \\
\hline & $\begin{array}{l}\text { Buckberry \& } \\
\text { Chamberlain }\end{array}$ & 65.307 & 52.105 & 45.510 & 53.738 & 78.398 & 129.389 & 104.432 & 64.018 \\
\hline & $\begin{array}{l}\text { Rougé- } \\
\text { Maillart et al. }\end{array}$ & 66.193 & 53.560 & 43.962 & 70.120 & 87.434 & 104.432 & 123.480 & 71.029 \\
\hline & $\begin{array}{l}\text { Suchey- } \\
\text { Brooks }\end{array}$ & 70.041 & 60.621 & 47.993 & 45.320 & 53.186 & 64.018 & 71.029 & 112.039 \\
\hline Obese & Kunos et al. & 80.998 & 77.951 & 5.803 & 54.389 & 48.422 & 60.129 & 62.743 & 42.271 \\
\hline & t al. & 77.951 & 138.105 & 11.498 & 54.495 & 66.809 & 69.375 & 74.658 & 56.105 \\
\hline & & 5.803 & 11.498 & 126.074 & 45.742 & 22.957 & 5.262 & 20.154 & -25.822 \\
\hline & Passalacqua & 54.389 & 54.495 & 45.742 & 178.045 & 73.311 & 85.025 & 64.282 & 53.815 \\
\hline & Lovejoy et al. & 48.422 & 66.809 & 22.957 & 73.311 & 85.378 & 56.791 & 44.077 & 39.129 \\
\hline & $\begin{array}{l}\text { Buckberry \& } \\
\text { Chamberlain }\end{array}$ & 60.129 & 69.375 & 5.262 & 85.025 & 56.791 & 107.865 & 72.382 & 69.655 \\
\hline & $\begin{array}{l}\text { Rougé- } \\
\text { Maillart et al. }\end{array}$ & 62.743 & 74.658 & 20.154 & 64.282 & 44.077 & 72.382 & 77.934 & 47.618 \\
\hline & $\begin{array}{l}\text { Suchey- } \\
\text { Brooks }\end{array}$ & 42.271 & 56.105 & -25.822 & 53.815 & 39.129 & 69.655 & 47.618 & 106.745 \\
\hline
\end{tabular}




\section{Appendix 15}

\begin{tabular}{|c|c|c|c|c|c|c|c|c|c|}
\hline \multicolumn{2}{|c|}{ BMI Categories } & $\begin{array}{c}\text { Kunos } \\
\text { et al. }\end{array}$ & $\begin{array}{c}\text { DiGangi } \\
\text { et al. }\end{array}$ & \begin{tabular}{|c|}
$\begin{array}{c}\text { İşcan et } \\
\text { al. }\end{array}$ \\
\end{tabular} & \begin{tabular}{|l|} 
Passalacqua \\
\end{tabular} & $\begin{array}{c}\begin{array}{c}\text { Lovejoy } \\
\text { et al. }\end{array} \\
\end{array}$ & \begin{tabular}{|l|} 
Buckberry \& \\
Chamberlain \\
\end{tabular} & $\begin{array}{c}\text { Rougé- } \\
\text { Maillart et al. } \\
\end{array}$ & $\begin{array}{l}\text { Suchey- } \\
\text { Brooks }\end{array}$ \\
\hline \multirow[t]{8}{*}{ Underweight } & Kunos et al. & 147.502 & 113.653 & 99.393 & 124.879 & 66.020 & 78.024 & 112.364 & 79.780 \\
\hline & DiGangi et al. & 113.653 & 148.319 & 72.339 & 84.785 & 56.310 & 48.021 & 89.688 & 50.410 \\
\hline & İşcan et al. & 99.393 & 72.339 & 162.171 & 112.942 & 52.070 & 27.558 & 73.315 & 88.661 \\
\hline & Passalacqua & 124.879 & 84.785 & 112.942 & 196.888 & 62.475 & 94.720 & 115.896 & 99.863 \\
\hline & Lovejoy et al. & 66.020 & 56.310 & 52.070 & 62.475 & 70.060 & 49.181 & 74.633 & 39.690 \\
\hline & $\begin{array}{l}\text { Buckberry \& } \\
\text { Chamberlain }\end{array}$ & 78.024 & 48.021 & 27.558 & 94.720 & 49.181 & 143.283 & 107.469 & 55.600 \\
\hline & $\begin{array}{l}\text { Rougé- } \\
\text { Maillart et al. }\end{array}$ & 112.364 & 89.688 & 73.315 & 115.896 & 74.633 & 107.469 & 134.063 & 78.799 \\
\hline & $\begin{array}{l}\text { Suchey- } \\
\text { Brooks }\end{array}$ & 79.780 & 50.410 & 88.661 & 99.863 & 39.690 & 55.600 & 78.799 & 91.346 \\
\hline \multirow[t]{8}{*}{ Normal } & Kunos et al. & 179.929 & 171.391 & 47.354 & 125.538 & 86.472 & 96.679 & 101.247 & 90.481 \\
\hline & DiGangi et al. & 171.391 & 206.860 & 26.276 & 122.878 & 81.722 & 89.084 & 98.502 & 78.380 \\
\hline & İşcan et al. & 47.354 & 26.276 & 247.809 & 77.240 & 56.043 & 63.215 & 81.523 & 45.459 \\
\hline & Passalacqua & 125.538 & 122.878 & 77.240 & 215.176 & 86.971 & 97.209 & 107.548 & 89.762 \\
\hline & Lovejoy et al. & 86.472 & 81.722 & 56.043 & 86.971 & 93.966 & 80.133 & 88.969 & 64.041 \\
\hline & $\begin{array}{l}\text { Buckberry \& } \\
\text { Chamberlain }\end{array}$ & 96.679 & 89.084 & 63.215 & 97.209 & 80.133 & 161.818 & 118.376 & 62.996 \\
\hline & $\begin{array}{l}\text { Rougé- } \\
\text { Maillart et al. }\end{array}$ & 101.247 & 98.502 & 81.523 & 107.548 & 88.969 & 118.376 & 145.421 & 74.621 \\
\hline & $\begin{array}{l}\text { Suchey- } \\
\text { Brooks }\end{array}$ & 90.481 & 78.380 & 45.459 & 89.762 & 64.041 & 62.996 & 74.621 & 98.513 \\
\hline \multirow[t]{8}{*}{ Overweight } & Kunos et al. & 152.765 & 160.621 & 23.403 & 100.923 & 46.677 & 72.117 & 67.837 & 64.643 \\
\hline & DiGangi et al. & 160.621 & 235.931 & 31.312 & 148.044 & 38.314 & 68.284 & 62.512 & 71.113 \\
\hline & İşcan et al. & 23.403 & 31.312 & 144.609 & 52.124 & 28.991 & 36.452 & 38.117 & 45.403 \\
\hline & Passalacqua & 100.923 & 148.044 & 52.124 & 226.362 & 60.195 & 36.090 & 62.478 & 68.976 \\
\hline & Lovejoy et al. & 46.677 & 38.314 & 28.991 & 60.195 & 51.800 & 47.714 & 54.195 & 28.405 \\
\hline & $\begin{array}{l}\text { Buckberry \& } \\
\text { Chamberlain }\end{array}$ & 72.117 & 68.284 & 36.452 & 36.090 & 47.714 & 129.983 & 83.585 & 39.534 \\
\hline & $\begin{array}{l}\text { Rougé- } \\
\text { Maillart et al. }\end{array}$ & 67.837 & 62.512 & 38.117 & 62.478 & 54.195 & 83.585 & 100.074 & 47.489 \\
\hline & $\begin{array}{l}\text { Suchey- } \\
\text { Brooks }\end{array}$ & 64.643 & 71.113 & 45.403 & 68.976 & 28.405 & 39.534 & 47.489 & 71.295 \\
\hline \multirow[t]{8}{*}{ Obese } & Kunos et al. & 48.859 & 71.788 & 7.551 & 62.526 & 32.122 & 29.019 & 17.218 & 34.449 \\
\hline & DiGangi et al. & 71.788 & 164.808 & 56.410 & 58.538 & 71.474 & 54.571 & 50.410 & 42.673 \\
\hline & İşcan et al. & 7.551 & 56.410 & 142.936 & 67.051 & 107.494 & 74.955 & 112.103 & 44.731 \\
\hline & Passalacqua & 62.526 & 58.538 & 67.051 & 263.692 & 78.455 & 124.353 & 103.968 & 149.615 \\
\hline & Lovejoy et al. & 32.122 & 71.474 & 107.494 & 78.455 & 126.308 & 97.487 & 120.410 & 49.256 \\
\hline & $\begin{array}{l}\text { Buckberry \& } \\
\text { Chamberlain }\end{array}$ & 29.019 & 54.571 & 74.955 & 124.353 & 97.487 & 174.077 & 126.705 & 53.628 \\
\hline & $\begin{array}{l}\text { Rougé- } \\
\text { Maillart et al. }\end{array}$ & 17.218 & 50.410 & 112.103 & 103.968 & 120.410 & 126.705 & 146.603 & 58.814 \\
\hline & $\begin{array}{l}\text { Suchey- } \\
\text { Brooks } \\
\end{array}$ & 34.449 & 42.673 & 44.731 & 149.615 & 49.256 & 53.628 & 58.814 & 109.936 \\
\hline
\end{tabular}




\section{Appendix 16}

\begin{tabular}{|c|c|c|c|c|c|c|c|c|c|}
\hline \multicolumn{2}{|c|}{ BMI Categories } & $\begin{array}{c}\text { Kunos et } \\
\text { al. }\end{array}$ & $\begin{array}{c}\text { DiGangi } \\
\text { et al. }\end{array}$ & $\begin{array}{c}\text { İşcan et } \\
\text { al. }\end{array}$ & Passalacqua & $\begin{array}{c}\text { Lovejoy et } \\
\text { al. }\end{array}$ & $\begin{array}{l}\text { Buckberry \& } \\
\text { Chamberlain } \\
\end{array}$ & $\begin{array}{c}\text { Rougé- } \\
\text { Maillart et al. }\end{array}$ & $\begin{array}{l}\text { Suchey- } \\
\text { Brooks }\end{array}$ \\
\hline \multirow[t]{8}{*}{ Underweight } & Kunos et al. & 44.780 & 30.314 & 23.478 & 11.025 & 22.378 & 8.840 & 26.795 & 11.058 \\
\hline & DiGangi et al. & 30.314 & 136.747 & 76.977 & 23.446 & 56.285 & -17.932 & 68.857 & 46.817 \\
\hline & İşcan et al. & 23.478 & 76.977 & 119.567 & 18.475 & 39.592 & 0.531 & 53.597 & 35.421 \\
\hline & Passalacqua & 11.025 & 23.446 & 18.475 & 71.284 & 21.054 & 5.706 & 24.475 & 18.985 \\
\hline & Lovejoy et al. & 22.378 & 56.285 & 39.592 & 21.054 & 67.974 & 10.527 & 57.282 & 27.820 \\
\hline & $\begin{array}{l}\text { Buckberry \& } \\
\text { Chamberlain }\end{array}$ & 8.840 & -17.932 & 0.531 & 5.706 & 10.527 & 67.977 & 13.387 & -8.073 \\
\hline & $\begin{array}{l}\text { Rougé-Maillart } \\
\text { et al. }\end{array}$ & 26.795 & 68.857 & 53.597 & 24.475 & 57.282 & 13.387 & 78.077 & 42.884 \\
\hline & Suchey-Brooks & 11.058 & 46.817 & 35.421 & 18.985 & 27.820 & -8.073 & 42.884 & 69.931 \\
\hline \multirow[t]{8}{*}{ Normal } & Kunos et al. & 56.772 & 12.278 & 5.335 & 14.957 & 4.123 & 22.034 & 10.641 & 4.029 \\
\hline & DiGangi et al. & 12.278 & 134.723 & 25.520 & 13.829 & 42.287 & -26.247 & 44.302 & 42.274 \\
\hline & İşcan et al. & 5.335 & 25.520 & 76.483 & 9.715 & 3.813 & -2.693 & 10.420 & 6.679 \\
\hline & Passalacqua & 14.957 & 13.829 & 9.715 & 74.562 & 13.840 & 6.381 & 17.585 & 11.552 \\
\hline & Lovejoy et al. & 4.123 & 42.287 & 3.813 & 13.840 & 45.280 & -5.861 & 31.073 & 26.147 \\
\hline & $\begin{array}{l}\text { Buckberry \& } \\
\text { Chamberlain }\end{array}$ & 22.034 & -26.247 & -2.693 & 6.381 & -5.861 & 66.283 & 6.045 & -10.250 \\
\hline & $\begin{array}{l}\text { Rougé-Maillart } \\
\text { et al. }\end{array}$ & 10.641 & 44.302 & 10.420 & 17.585 & 31.073 & 6.045 & 65.386 & 26.409 \\
\hline & Suchey-Brooks & 4.029 & 42.274 & 6.679 & 11.552 & 26.147 & -10.250 & 26.409 & 53.029 \\
\hline \multirow[t]{8}{*}{ Overweight } & Kunos et al. & 43.827 & 0.465 & 0.847 & 3.299 & -1.412 & 13.300 & 0.067 & -3.391 \\
\hline & DiGangi et al. & 0.465 & 103.815 & 13.130 & 2.337 & 16.724 & -19.241 & 19.459 & 27.616 \\
\hline & İşcan et al. & 0.847 & 13.130 & 68.259 & 4.577 & -2.016 & 1.071 & 3.482 & 2.563 \\
\hline & Passalacqua & 3.299 & 2.337 & 4.577 & 48.947 & 1.728 & -5.735 & 10.484 & 1.309 \\
\hline & Lovejoy et al. & -1.412 & 16.724 & -2.016 & 1.728 & 46.572 & -2.925 & 27.221 & 18.092 \\
\hline & $\begin{array}{l}\text { Buckberry \& } \\
\text { Chamberlain }\end{array}$ & 13.300 & -19.241 & 1.071 & -5.735 & -2.925 & 60.620 & 1.548 & -14.986 \\
\hline & $\begin{array}{l}\text { Rougé-Maillart } \\
\text { et al. }\end{array}$ & 0.067 & 19.459 & 3.482 & 10.484 & 27.221 & 1.548 & 45.966 & 19.817 \\
\hline & Suchey-Brooks & -3.391 & 27.616 & 2.563 & 1.309 & 18.092 & -14.986 & 19.817 & 46.509 \\
\hline \multirow[t]{8}{*}{ Obese } & Kunos et al. & 38.107 & -20.838 & -2.660 & 5.396 & -17.123 & 11.815 & -19.742 & -19.296 \\
\hline & DiGangi et al. & -20.838 & 83.719 & 8.798 & 4.234 & 37.357 & -14.694 & 44.208 & 16.525 \\
\hline & İşcan et al. & -2.660 & 8.798 & 39.830 & -0.380 & -0.332 & 17.320 & 23.477 & -3.867 \\
\hline & Passalacqua & 5.396 & 4.234 & -0.380 & 71.701 & 14.330 & 14.023 & 18.305 & 17.014 \\
\hline & Lovejoy et al. & -17.123 & 37.357 & -0.332 & 14.330 & 65.291 & -22.675 & 33.013 & 23.304 \\
\hline & $\begin{array}{l}\text { Buckberry \& } \\
\text { Chamberlain }\end{array}$ & 11.815 & -14.694 & 17.320 & 14.023 & -22.675 & 62.575 & 1.830 & -17.589 \\
\hline & $\begin{array}{l}\text { Rougé-Maillart } \\
\text { et al. }\end{array}$ & -19.742 & 44.208 & 23.477 & 18.305 & 33.013 & 1.830 & 60.910 & 26.780 \\
\hline & Suchey-Brooks & -19.296 & 16.525 & -3.867 & 17.014 & 23.304 & -17.589 & 26.780 & 44.557 \\
\hline
\end{tabular}




\section{Appendix 17}

\begin{tabular}{|c|c|c|c|c|c|c|c|c|c|}
\hline \multicolumn{2}{|c|}{ BMI Categories } & \begin{tabular}{|c|}
$\begin{array}{c}\text { Kunos et } \\
\text { al. }\end{array}$ \\
\end{tabular} & $\begin{array}{l}\text { DiGangi } \\
\text { et al. }\end{array}$ & $\begin{array}{l}\text { İşcan et } \\
\text { al. }\end{array}$ & Passalacqua & $\begin{array}{c}\text { Lovejoy et } \\
\text { al. }\end{array}$ & $\begin{array}{l}\text { Buckberry \& } \\
\text { Chamberlain }\end{array}$ & $\begin{array}{c}\text { Rougé- } \\
\text { Maillart et al. }\end{array}$ & $\begin{array}{l}\text { Suchey- } \\
\text { Brooks }\end{array}$ \\
\hline \multirow[t]{8}{*}{ Underweight } & Kunos et al. & 133.338 & 120.712 & 102.364 & 99.601 & 88.649 & 95.376 & 114.341 & 79.086 \\
\hline & DiGangi et al. & 120.712 & 148.779 & 99.919 & 80.360 & 78.464 & 82.455 & 102.904 & 59.946 \\
\hline & İşcan et al. & 102.364 & 99.919 & 154.026 & 78.166 & 73.084 & 91.604 & 97.283 & 62.292 \\
\hline & Passalacqua & 99.601 & 80.360 & 78.166 & 198.957 & 85.440 & 105.034 & 106.570 & 85.645 \\
\hline & Lovejoy et al. & 88.649 & 78.464 & 73.084 & 85.440 & 110.398 & 107.525 & 111.901 & 60.355 \\
\hline & $\begin{array}{l}\text { Buckberry \& } \\
\text { Chamberlain }\end{array}$ & 95.376 & 82.455 & 91.604 & 105.034 & 107.525 & 175.370 & 140.264 & 69.726 \\
\hline & $\begin{array}{l}\text { Rougé-Maillart } \\
\text { et al. }\end{array}$ & 114.341 & 102.904 & 97.283 & 106.570 & 111.901 & 140.264 & 159.173 & 86.400 \\
\hline & Suchey-Brooks & 79.086 & 59.946 & 62.292 & 85.645 & 60.355 & 69.726 & 86.400 & 111.214 \\
\hline \multirow[t]{8}{*}{ Normal } & Kunos et al. & 171.792 & 167.678 & 18.771 & 118.714 & 87.155 & 114.424 & 110.598 & 83.380 \\
\hline & DiGangi et al. & 167.678 & 213.165 & -6.542 & 114.267 & 84.438 & 109.537 & 107.141 & 81.205 \\
\hline & İşcan et al. & 18.771 & -6.542 & 193.122 & 34.162 & 27.699 & 28.347 & 35.963 & 25.271 \\
\hline & Passalacqua & 118.714 & 114.267 & 34.162 & 203.458 & 79.282 & 102.570 & 102.664 & 72.828 \\
\hline & Lovejoy et al. & 87.155 & 84.438 & 27.699 & 79.282 & 86.775 & 86.991 & 85.823 & 56.469 \\
\hline & $\begin{array}{l}\text { Buckberry \& } \\
\text { Chamberlain }\end{array}$ & 114.424 & 109.537 & 28.347 & 102.570 & 86.991 & 158.995 & 129.688 & 70.286 \\
\hline & $\begin{array}{l}\text { Rougé-Maillart } \\
\text { et al. }\end{array}$ & 110.598 & 107.141 & 35.963 & 102.664 & 85.823 & 129.688 & 145.818 & 71.037 \\
\hline & Suchey-Brooks & 83.380 & 81.205 & 25.271 & 72.828 & 56.469 & 70.286 & 71.037 & 88.184 \\
\hline \multirow[t]{8}{*}{ Overweight } & Kunos et al. & 113.306 & 107.380 & 28.848 & 74.353 & 51.124 & 61.450 & 61.277 & 68.357 \\
\hline & DiGangi et al. & 107.380 & 159.720 & 15.940 & 69.719 & 41.488 & 49.572 & 47.782 & 63.857 \\
\hline & İşcan et al. & 28.848 & 15.940 & 180.901 & 47.157 & 48.864 & 56.263 & 47.973 & 50.387 \\
\hline & Passalacqua & 74.353 & 69.719 & 47.157 & 150.698 & 53.816 & 48.634 & 65.622 & 52.686 \\
\hline & Lovejoy et al. & 51.124 & 41.488 & 48.864 & 53.816 & 88.793 & 69.177 & 77.823 & 43.423 \\
\hline & $\begin{array}{l}\text { Buckberry \& } \\
\text { Chamberlain }\end{array}$ & 61.450 & 49.572 & 56.263 & 48.634 & 69.177 & 124.226 & 96.861 & 53.229 \\
\hline & $\begin{array}{l}\text { Rougé-Maillart } \\
\text { et al. }\end{array}$ & 61.277 & 47.782 & 47.973 & 65.622 & 77.823 & 96.861 & 116.881 & 60.429 \\
\hline & Suchey-Brooks & 68.357 & 63.857 & 50.387 & 52.686 & 43.423 & 53.229 & 60.429 & 101.855 \\
\hline \multirow[t]{8}{*}{ Obese } & Kunos et al. & 76.966 & 83.561 & 5.340 & 61.449 & 48.699 & 59.169 & 52.847 & 37.845 \\
\hline & DiGangi et al. & 83.561 & 162.564 & 32.862 & 64.070 & 77.507 & 75.844 & 75.402 & 46.910 \\
\hline & İșcan et al. & 5.340 & 32.862 & 132.001 & 44.647 & 59.678 & 36.222 & 51.049 & 1.719 \\
\hline & Passalacqua & 61.449 & 64.070 & 44.647 & 213.947 & 85.442 & 115.178 & 83.528 & 98.237 \\
\hline & Lovejoy et al. & 48.699 & 77.507 & 59.678 & 85.442 & 112.878 & 80.188 & 77.213 & 41.775 \\
\hline & $\begin{array}{l}\text { Buckberry \& } \\
\text { Chamberlain }\end{array}$ & 59.169 & 75.844 & 36.222 & 115.178 & 80.188 & 123.987 & 94.479 & 67.791 \\
\hline & $\begin{array}{l}\text { Rougé-Maillart } \\
\text { et al. }\end{array}$ & 52.847 & 75.402 & 51.049 & 83.528 & 77.213 & 94.479 & 107.242 & 55.650 \\
\hline & Suchey-Brooks & 37.845 & 46.910 & 1.719 & 98.237 & 41.775 & 67.791 & 55.650 & 94.375 \\
\hline
\end{tabular}




\section{Appendix 18}

\begin{tabular}{|c|c|c|c|c|c|c|c|c|c|}
\hline \multicolumn{2}{|c|}{ BMI Categories } & \begin{tabular}{|c|}
$\begin{array}{c}\text { Kunos et } \\
\text { al. }\end{array}$ \\
\end{tabular} & $\begin{array}{c}\text { DiGangi } \\
\text { et al. }\end{array}$ & $\begin{array}{l}\text { İşcan et } \\
\text { al. }\end{array}$ & Passalacqua & $\begin{array}{c}\text { Lovejoy et } \\
\text { al. }\end{array}$ & $\begin{array}{l}\text { Buckberry \& } \\
\text { Chamberlain }\end{array}$ & $\begin{array}{c}\text { Rougé- } \\
\text { Maillart et al. }\end{array}$ & $\begin{array}{l}\text { Suchey- } \\
\text { Brooks }\end{array}$ \\
\hline \multirow[t]{8}{*}{ Underweight } & Kunos et al. & 162.118 & 155.367 & 157.428 & 133.438 & 82.486 & 110.794 & 116.643 & 96.120 \\
\hline & DiGangi et al. & 155.367 & 212.565 & 175.662 & 129.375 & 85.859 & 107.879 & 122.375 & 98.017 \\
\hline & İşcan et al. & 157.428 & 175.662 & 287.571 & 130.271 & 98.480 & 108.916 & 136.176 & 110.239 \\
\hline & Passalacqua & 133.438 & 129.375 & 130.271 & 230.792 & 71.333 & 101.021 & 105.417 & 97.583 \\
\hline & Lovejoy et al. & 82.486 & 85.859 & 98.480 & 71.333 & 80.181 & 90.213 & 93.120 & 58.386 \\
\hline & $\begin{array}{l}\text { Buckberry \& } \\
\text { Chamberlain }\end{array}$ & 110.794 & 107.879 & 108.916 & 101.021 & 90.213 & 188.928 & 143.753 & 77.055 \\
\hline & $\begin{array}{l}\text { Rougé-Maillart } \\
\text { et al. }\end{array}$ & 116.643 & 122.375 & 136.176 & 105.417 & 93.120 & 143.753 & 159.046 & 85.355 \\
\hline & Suchey-Brooks & 96.120 & 98.017 & 110.239 & 97.583 & 58.386 & 77.055 & 85.355 & 95.259 \\
\hline \multirow[t]{8}{*}{ Normal } & Kunos et al. & 126.990 & 122.998 & -22.482 & 88.171 & 63.830 & 92.516 & 90.342 & 71.271 \\
\hline & DiGangi et al. & 122.998 & 151.571 & -45.880 & 90.219 & 59.840 & 90.068 & 90.687 & 71.034 \\
\hline & İşcan et al. & -22.482 & -45.880 & 126.697 & -20.287 & 4.694 & 2.165 & 6.601 & 2.317 \\
\hline & Passalacqua & 88.171 & 90.219 & -20.287 & 189.467 & 66.415 & 93.654 & 84.355 & 68.049 \\
\hline & Lovejoy et al. & 63.830 & 59.840 & 4.694 & 66.415 & 74.810 & 80.820 & 80.004 & 54.527 \\
\hline & $\begin{array}{l}\text { Buckberry \& } \\
\text { Chamberlain }\end{array}$ & 92.516 & 90.068 & 2.165 & 93.654 & 80.820 & 180.807 & 132.089 & 65.429 \\
\hline & $\begin{array}{l}\text { Rougé-Maillart } \\
\text { et al. }\end{array}$ & 90.342 & 90.687 & 6.601 & 84.355 & 80.004 & 132.089 & 140.339 & 74.984 \\
\hline & Suchey-Brooks & 71.271 & 71.034 & 2.317 & 68.049 & 54.527 & 65.429 & 74.984 & 84.110 \\
\hline \multirow[t]{8}{*}{ Overweight } & Kunos et al. & 95.155 & 88.610 & 8.756 & 60.481 & 48.575 & 83.936 & 76.973 & 62.234 \\
\hline & DiGangi et al. & 88.610 & 125.633 & -9.753 & 72.884 & 48.978 & 82.220 & 79.811 & 57.492 \\
\hline & İşcan et al. & 8.756 & -9.753 & 99.966 & 30.332 & 20.520 & 6.324 & 9.727 & 27.847 \\
\hline & Passalacqua & 60.481 & 72.884 & 30.332 & 180.059 & 58.684 & 41.618 & 65.326 & 42.428 \\
\hline & Lovejoy et al. & 48.575 & 48.978 & 20.520 & 58.684 & 77.309 & 63.400 & 68.576 & 49.678 \\
\hline & $\begin{array}{l}\text { Buckberry \& } \\
\text { Chamberlain }\end{array}$ & 83.936 & 82.220 & 6.324 & 41.618 & 63.400 & 157.371 & 95.820 & 65.312 \\
\hline & $\begin{array}{l}\text { Rougé-Maillart } \\
\text { et al. }\end{array}$ & 76.973 & 79.811 & 9.727 & 65.326 & 68.576 & 95.820 & 103.797 & 70.408 \\
\hline & Suchey-Brooks & 62.234 & 57.492 & 27.847 & 42.428 & 49.678 & 65.312 & 70.408 & 88.945 \\
\hline \multirow[t]{8}{*}{ Obese } & Kunos et al. & 11.300 & 8.550 & 20.950 & 31.500 & 2.900 & -6.850 & 5.100 & 21.700 \\
\hline & DiGangi et al. & 8.550 & 16.300 & -16.050 & 3.500 & 6.150 & -2.100 & -5.400 & 48.200 \\
\hline & İşcan et al. & 20.950 & -16.050 & 151.800 & 133.500 & -2.150 & -17.400 & 45.900 & -70.700 \\
\hline & Passalacqua & 31.500 & 3.500 & 133.500 & 141.500 & 4.000 & -42.250 & 31.000 & -20.000 \\
\hline & Lovejoy et al. & 2.900 & 6.150 & -2.150 & 4.000 & 5.700 & 10.450 & 4.300 & 16.600 \\
\hline & $\begin{array}{l}\text { Buckberry \& } \\
\text { Chamberlain }\end{array}$ & -6.850 & -2.100 & -17.400 & -42.250 & 10.450 & 177.700 & 63.800 & 48.350 \\
\hline & $\begin{array}{l}\text { Rougé-Maillart } \\
\text { et al. }\end{array}$ & 5.100 & -5.400 & 45.900 & 31.000 & 4.300 & 63.800 & 41.200 & -3.600 \\
\hline & Suchey-Brooks & 21.700 & 48.200 & -70.700 & -20.000 & 16.600 & 48.350 & -3.600 & 169.300 \\
\hline
\end{tabular}




\section{Appendix 19}

\begin{tabular}{|c|c|c|c|c|c|c|c|c|c|}
\hline \multicolumn{2}{|c|}{ Stature Categories } & \multirow{2}{*}{\begin{tabular}{|c|}
$\begin{array}{c}\text { Kunos } \\
\text { et al. }\end{array}$ \\
29.237 \\
\end{tabular}} & \multirow{2}{*}{$\begin{array}{c}\begin{array}{c}\text { DiGangi } \\
\text { et al. }\end{array} \\
13.341\end{array}$} & \multirow{2}{*}{\begin{tabular}{|c|}
$\begin{array}{c}\text { İşcan et } \\
\text { al. }\end{array}$ \\
20.170 \\
\end{tabular}} & \multirow{2}{*}{\begin{tabular}{|r|} 
Passalacqua \\
7.311 \\
\end{tabular}} & \multirow{2}{*}{\begin{tabular}{|c|}
$\begin{array}{c}\text { Lovejoy } \\
\text { et al. }\end{array}$ \\
-3.489
\end{tabular}} & \multirow{2}{*}{\begin{tabular}{|r|}
$\begin{array}{l}\text { Buckberry \& } \\
\text { Chamberlain }\end{array}$ \\
22.763 \\
\end{tabular}} & \multirow{2}{*}{\begin{tabular}{|c}
$\begin{array}{c}\text { Rougé- } \\
\text { Maillart et al. }\end{array}$ \\
8.185
\end{tabular}} & \multirow{2}{*}{\begin{tabular}{|r|}
$\begin{array}{c}\text { Suchey- } \\
\text { Brooks }\end{array}$ \\
.852 \\
\end{tabular}} \\
\hline Group 1 & Kunos et al. & & & & & & & & \\
\hline & DiGangi et al. & 13.341 & 106.662 & 28.211 & 13.613 & 29.931 & -15.992 & 42.195 & 26.205 \\
\hline & İşcan et al. & 20.170 & 28.211 & 86.991 & 12.413 & 3.807 & 28.084 & 15.460 & 7.919 \\
\hline & Passalacqua & 7.311 & 13.613 & 12.413 & 63.341 & 21.998 & 10.616 & 24.569 & 2.805 \\
\hline & Lovejoy et al. & -3.489 & 29.931 & 3.807 & 21.998 & 55.810 & -.471 & 37.897 & 21.332 \\
\hline & $\begin{array}{l}\text { Buckberry \& } \\
\text { Chamberlain }\end{array}$ & 22.763 & -15.992 & 28.084 & 10.616 & -.471 & 66.436 & 6.404 & -2.062 \\
\hline & $\begin{array}{l}\text { Rougé- } \\
\text { Maillart et al. }\end{array}$ & 8.185 & 42.195 & 15.460 & 24.569 & 37.897 & 6.404 & 66.973 & 25.761 \\
\hline & $\begin{array}{l}\text { Suchey- } \\
\text { Brooks }\end{array}$ & .852 & 26.205 & 7.919 & 2.805 & 21.332 & -2.062 & 25.761 & 46.189 \\
\hline \multirow[t]{8}{*}{ Group 2} & Kunos et al. & 48.924 & 1.340 & .443 & 24.000 & 3.706 & 26.927 & 13.485 & -1.714 \\
\hline & DiGangi et al. & 1.340 & 116.844 & 21.854 & 33.503 & 43.984 & -27.061 & 48.027 & 52.808 \\
\hline & İşcan et al. & .443 & 21.854 & 58.858 & 1.410 & 8.332 & -1.760 & 18.317 & 10.248 \\
\hline & Passalacqua & 24.000 & 33.503 & 1.410 & 86.229 & 28.491 & 12.918 & 30.482 & 26.676 \\
\hline & Lovejoy et al. & 3.706 & 43.984 & 8.332 & 28.491 & 50.251 & -8.459 & 35.067 & 34.103 \\
\hline & $\begin{array}{l}\text { Buckberry \& } \\
\text { Chamberlain }\end{array}$ & 26.927 & -27.061 & -1.760 & 12.918 & -8.459 & 76.561 & 7.371 & -23.708 \\
\hline & $\begin{array}{l}\text { Rougé- } \\
\text { Maillart et al. }\end{array}$ & 13.485 & 48.027 & 18.317 & 30.482 & 35.067 & 7.371 & 62.782 & 31.523 \\
\hline & $\begin{array}{l}\text { Suchey- } \\
\text { Brooks }\end{array}$ & -1.714 & 52.808 & 10.248 & 26.676 & 34.103 & -23.708 & 31.523 & 67.188 \\
\hline \multirow[t]{8}{*}{ Group 3} & Kunos et al. & 53.851 & 7.714 & 11.008 & 7.198 & 4.236 & 23.318 & 7.625 & -2.355 \\
\hline & DiGangi et al. & 7.714 & 119.597 & 35.123 & 12.010 & 39.012 & -19.013 & 45.561 & 44.754 \\
\hline & İşcan et al. & 11.008 & 35.123 & 75.868 & 12.415 & 5.726 & -6.579 & 12.539 & 9.414 \\
\hline & Passalacqua & 7.198 & 12.010 & 12.415 & 64.281 & 3.782 & 2.241 & 6.632 & 2.972 \\
\hline & Lovejoy et al. & 4.236 & 39.012 & 5.726 & 3.782 & 46.705 & 4.270 & 36.106 & 21.840 \\
\hline & $\begin{array}{l}\text { Buckberry \& } \\
\text { Chamberlain }\end{array}$ & 23.318 & -19.013 & -6.579 & 2.241 & 4.270 & 72.629 & 13.798 & -9.676 \\
\hline & $\begin{array}{l}\text { Rougé- } \\
\text { Maillart et al. }\end{array}$ & 7.625 & 45.561 & 12.539 & 6.632 & 36.106 & 13.798 & 68.166 & 27.627 \\
\hline & $\begin{array}{l}\text { Suchey- } \\
\text { Brooks }\end{array}$ & -2.355 & 44.754 & 9.414 & 2.972 & 21.840 & -9.676 & 27.627 & 52.120 \\
\hline \multirow[t]{8}{*}{ Group 4} & Kunos et al. & 51.096 & -14.101 & 3.441 & 2.946 & -.523 & 27.250 & 1.988 & 1.237 \\
\hline & DiGangi et al. & -14.101 & 82.943 & 10.983 & -3.819 & 19.345 & -41.670 & 20.644 & 24.036 \\
\hline & İşcan et al. & 3.441 & 10.983 & 56.849 & 1.002 & .647 & 4.183 & 4.377 & 6.873 \\
\hline & Passalacqua & 2.946 & -3.819 & 1.002 & 49.682 & -.220 & 3.860 & 4.015 & -2.274 \\
\hline & Lovejoy et al. & -.523 & 19.345 & .647 & -.220 & 31.404 & -8.651 & 15.228 & 13.032 \\
\hline & $\begin{array}{l}\text { Buckberry \& } \\
\text { Chamberlain }\end{array}$ & 27.250 & -41.670 & 4.183 & 3.860 & -8.651 & 82.045 & 6.607 & -18.735 \\
\hline & $\begin{array}{l}\text { Rougé- } \\
\text { Maillart et al. }\end{array}$ & 1.988 & 20.644 & 4.377 & 4.015 & 15.228 & 6.607 & 40.826 & 12.525 \\
\hline & $\begin{array}{l}\text { Suchey- } \\
\text { Brooks }\end{array}$ & 1.237 & 24.036 & 6.873 & -2.274 & 13.032 & -18.735 & 12.525 & 40.359 \\
\hline
\end{tabular}


Appendix 20

\begin{tabular}{|c|c|c|c|c|c|c|c|c|c|}
\hline \multicolumn{2}{|c|}{ Stature Categories } & \multirow{2}{*}{$\begin{array}{c}\begin{array}{c}\text { Kunos et } \\
\text { al. }\end{array} \\
44.739\end{array}$} & \multirow{2}{*}{$\begin{array}{c}\begin{array}{c}\text { DiGangi } \\
\text { et al. }\end{array} \\
29.062\end{array}$} & \multirow{2}{*}{\begin{tabular}{|c|}
$\begin{array}{c}\text { İşcan et } \\
\text { al. }\end{array}$ \\
8.701
\end{tabular}} & \multirow{2}{*}{$\begin{array}{r}\text { Passalacqua } \\
8.186\end{array}$} & \multirow{2}{*}{\begin{tabular}{|c|}
$\begin{array}{c}\text { Lovejoy et } \\
\text { al. }\end{array}$ \\
7.292 \\
\end{tabular}} & \multirow{2}{*}{\begin{tabular}{|r|}
$\begin{array}{c}\text { Buckberry \& } \\
\text { Chamberlain }\end{array}$ \\
3.423
\end{tabular}} & \multirow{2}{*}{$\begin{array}{r}\begin{array}{c}\text { Rougé- } \\
\text { Maillart et al. }\end{array} \\
14.810\end{array}$} & \multirow{2}{*}{$\begin{array}{r}\begin{array}{r}\text { Suchey- } \\
\text { Brooks }\end{array} \\
7.109\end{array}$} \\
\hline Group 1 & Kunos et al. & & & & & & & & \\
\hline & DiGangi et al. & 29.062 & 136.056 & 40.867 & -3.887 & 38.380 & -10.445 & 49.049 & 28.817 \\
\hline & İşcan et al. & 8.701 & 40.867 & 121.223 & 20.200 & 16.412 & 9.055 & 30.119 & 22.691 \\
\hline & Passalacqua & 8.186 & -3.887 & 20.200 & 69.213 & 7.832 & 4.753 & 17.980 & 8.627 \\
\hline & Lovejoy et al. & 7.292 & 38.380 & 16.412 & 7.832 & 53.492 & .840 & 38.019 & 23.306 \\
\hline & $\begin{array}{l}\text { Buckberry \& } \\
\text { Chamberlain }\end{array}$ & 3.423 & -10.445 & 9.055 & 4.753 & 0.840 & 51.540 & 8.960 & -0.125 \\
\hline & $\begin{array}{l}\text { Rougé-Maillart } \\
\text { et al. }\end{array}$ & 14.810 & 49.049 & 30.119 & 17.980 & 38.019 & 8.960 & 73.839 & 34.287 \\
\hline & Suchey-Brooks & 7.109 & 28.817 & 22.691 & 8.627 & 23.306 & -0.125 & 34.287 & 50.454 \\
\hline \multirow[t]{8}{*}{ Group 2} & Kunos et al. & 51.674 & 11.385 & 4.213 & 22.996 & 4.323 & 18.692 & 12.970 & 1.655 \\
\hline & DiGangi et al. & 11.385 & 144.291 & 33.756 & 29.499 & 43.960 & -23.767 & 50.405 & 51.943 \\
\hline & İşcan et al. & 4.213 & 33.756 & 66.155 & 2.601 & 9.522 & -4.372 & 18.077 & 5.202 \\
\hline & Passalacqua & 22.996 & 29.499 & 2.601 & 77.880 & 26.156 & 9.269 & 27.976 & 21.337 \\
\hline & Lovejoy et al. & 4.323 & 43.960 & 9.522 & 26.156 & 58.341 & -6.799 & 40.055 & 34.395 \\
\hline & $\begin{array}{l}\text { Buckberry \& } \\
\text { Chamberlain }\end{array}$ & 18.692 & -23.767 & -4.372 & 9.269 & -6.799 & 64.514 & 5.884 & -16.376 \\
\hline & $\begin{array}{l}\text { Rougé-Maillart } \\
\text { et al. }\end{array}$ & 12.970 & 50.405 & 18.077 & 27.976 & 40.055 & 5.884 & 65.625 & 31.973 \\
\hline & Suchey-Brooks & 1.655 & 51.943 & 5.202 & 21.337 & 34.395 & -16.376 & 31.973 & 63.074 \\
\hline \multirow[t]{8}{*}{ Group 3} & Kunos et al. & 53.277 & 10.901 & 7.388 & 5.475 & 2.899 & 19.105 & 5.567 & -2.267 \\
\hline & DiGangi et al. & 10.901 & 117.717 & 24.900 & 13.652 & 39.807 & -13.695 & 40.406 & 41.111 \\
\hline & İşcan et al. & 7.388 & 24.900 & 60.950 & 8.277 & -0.411 & -5.627 & 3.733 & 5.089 \\
\hline & Passalacqua & 5.475 & 13.652 & 8.277 & 64.641 & 6.329 & -0.101 & 12.135 & 6.819 \\
\hline & Lovejoy et al. & 2.899 & 39.807 & -.411 & 6.329 & 46.190 & -1.616 & 32.317 & 22.665 \\
\hline & $\begin{array}{l}\text { Buckberry \& } \\
\text { Chamberlain }\end{array}$ & 19.105 & -13.695 & -5.627 & -0.101 & -1.616 & 58.473 & 6.424 & -10.843 \\
\hline & $\begin{array}{l}\text { Rougé-Maillart } \\
\text { et al. }\end{array}$ & 5.567 & 40.406 & 3.733 & 12.135 & 32.317 & 6.424 & 58.913 & 25.172 \\
\hline & Suchey-Brooks & -2.267 & 41.111 & 5.089 & 6.819 & 22.665 & -10.843 & 25.172 & 52.440 \\
\hline \multirow[t]{8}{*}{ Group 4} & Kunos et al. & 56.465 & -19.788 & 4.588 & 2.937 & -0.422 & 31.810 & 0.951 & 0.508 \\
\hline & DiGangi et al. & -19.788 & 80.706 & 2.059 & 0.726 & 18.010 & -43.655 & 20.147 & 16.581 \\
\hline & İşcan et al. & 4.588 & 2.059 & 61.645 & 6.059 & -0.187 & 13.159 & 10.610 & 2.816 \\
\hline & Passalacqua & 2.937 & .726 & 6.059 & 54.159 & 2.567 & 1.884 & 5.005 & 1.027 \\
\hline & Lovejoy et al. & -0.422 & 18.010 & -0.187 & 2.567 & 35.870 & -5.115 & 17.848 & 9.056 \\
\hline & $\begin{array}{l}\text { Buckberry \& } \\
\text { Chamberlain }\end{array}$ & 31.810 & -43.655 & 13.159 & 1.884 & -5.115 & 85.658 & 8.353 & -15.988 \\
\hline & $\begin{array}{l}\text { Rougé-Maillart } \\
\text { et al. }\end{array}$ & .951 & 20.147 & 10.610 & 5.005 & 17.848 & 8.353 & 41.430 & 11.540 \\
\hline & Suchey-Brooks & .508 & 16.581 & 2.816 & 1.027 & 9.056 & -15.988 & 11.540 & 41.102 \\
\hline
\end{tabular}


Appendix 21

\begin{tabular}{|c|c|c|c|c|c|c|c|c|c|}
\hline \multicolumn{2}{|c|}{ Body Mass Categories } & \multirow{2}{*}{$\begin{array}{l}\begin{array}{c}\text { Kunos } \\
\text { et al. }\end{array} \\
42.853\end{array}$} & \multirow{2}{*}{$\begin{array}{c}\begin{array}{c}\text { DiGangi } \\
\text { et al. }\end{array} \\
17.362\end{array}$} & \multirow{2}{*}{\begin{tabular}{|c|}
$\begin{array}{c}\text { İşcan et } \\
\text { al. }\end{array}$ \\
20.618 \\
\end{tabular}} & \multirow{2}{*}{\begin{tabular}{|r|} 
Passalacqua \\
21.222 \\
\end{tabular}} & \multirow{2}{*}{$\begin{array}{c}\begin{array}{c}\text { Lovejoy } \\
\text { et al. }\end{array} \\
7.676\end{array}$} & \multirow{2}{*}{\begin{tabular}{|r|}
$\begin{array}{l}\text { Buckberry \& } \\
\text { Chamberlain }\end{array}$ \\
17.848
\end{tabular}} & \multirow{2}{*}{\begin{tabular}{|c}
$\begin{array}{c}\text { Rougé- } \\
\text { Maillart et al. }\end{array}$ \\
22.796
\end{tabular}} & \multirow{2}{*}{$\begin{array}{r}\begin{array}{r}\text { Suchey- } \\
\text { Brooks }\end{array} \\
11.047\end{array}$} \\
\hline Group 1 & Kunos et al. & & & & & & & & \\
\hline & DiGangi et al. & 17.362 & 111.907 & 76.592 & 29.457 & 45.139 & -15.697 & 59.904 & 39.941 \\
\hline & İşcan et al. & 20.618 & 76.592 & 120.901 & 32.919 & 41.475 & 5.810 & 54.575 & 36.059 \\
\hline & Passalacqua & 21.222 & 29.457 & 32.919 & 81.405 & 22.795 & 12.049 & 24.692 & 17.108 \\
\hline & Lovejoy et al. & 7.676 & 45.139 & 41.475 & 22.795 & 51.381 & 7.304 & 47.640 & 24.882 \\
\hline & $\begin{array}{l}\text { Buckberry \& } \\
\text { Chamberlain }\end{array}$ & 17.848 & -15.697 & 5.810 & 12.049 & 7.304 & 83.837 & 22.706 & -4.542 \\
\hline & $\begin{array}{l}\text { Rougé- } \\
\text { Maillart et al. }\end{array}$ & 22.796 & 59.904 & 54.575 & 24.692 & 47.640 & 22.706 & 83.970 & 36.217 \\
\hline & $\begin{array}{l}\text { Suchey- } \\
\text { Brooks }\end{array}$ & 11.047 & 39.941 & 36.059 & 17.108 & 24.882 & -4.542 & 36.217 & 58.793 \\
\hline \multirow[t]{8}{*}{ Group 2} & Kunos et al. & 54.810 & 7.421 & 16.354 & 5.492 & 4.361 & 28.740 & 7.024 & -0.661 \\
\hline & DiGangi et al. & 7.421 & 129.934 & 27.034 & 28.237 & 41.366 & -36.095 & 41.619 & 56.710 \\
\hline & İşcan et al. & 16.354 & 27.034 & 70.460 & 8.338 & 1.383 & -2.784 & 3.219 & 5.265 \\
\hline & Passalacqua & 5.492 & 28.237 & 8.338 & 82.991 & 23.001 & 5.601 & 24.498 & 14.750 \\
\hline & Lovejoy et al. & 4.361 & 41.366 & 1.383 & 23.001 & 49.998 & -7.990 & 37.263 & 28.870 \\
\hline & $\begin{array}{l}\text { Buckberry \& } \\
\text { Chamberlain }\end{array}$ & 28.740 & -36.095 & -2.784 & 5.601 & -7.990 & 69.400 & 3.589 & -25.430 \\
\hline & $\begin{array}{l}\text { Rougé- } \\
\text { Maillart et al. }\end{array}$ & 7.024 & 41.619 & 3.219 & 24.498 & 37.263 & 3.589 & 66.360 & 26.451 \\
\hline & $\begin{array}{l}\text { Suchey- } \\
\text { Brooks }\end{array}$ & -0.661 & 56.710 & 5.265 & 14.750 & 28.870 & -25.430 & 26.451 & 62.275 \\
\hline \multirow[t]{8}{*}{ Group 3} & Kunos et al. & 53.963 & -12.382 & -1.061 & 13.197 & -1.624 & 35.898 & 3.204 & -8.598 \\
\hline & DiGangi et al. & -12.382 & 96.328 & 9.091 & -1.691 & 25.282 & -26.124 & 27.731 & 26.725 \\
\hline & İşcan et al. & -1.061 & 9.091 & 45.147 & -4.511 & -4.977 & -2.131 & -1.812 & -2.594 \\
\hline & Passalacqua & 13.197 & -1.691 & -4.511 & 60.272 & -0.049 & 7.767 & 2.784 & -0.006 \\
\hline & Lovejoy et al. & -1.624 & 25.282 & -4.977 & -0.049 & 37.653 & 0.085 & 20.204 & 18.125 \\
\hline & $\begin{array}{l}\text { Buckberry \& } \\
\text { Chamberlain }\end{array}$ & 35.898 & -26.124 & -2.131 & 7.767 & 0.085 & 84.442 & 13.511 & -7.740 \\
\hline & $\begin{array}{l}\text { Rougé- } \\
\text { Maillart et al. }\end{array}$ & 3.204 & 27.731 & -1.812 & 2.784 & 20.204 & 13.511 & 46.653 & 15.981 \\
\hline & $\begin{array}{l}\text { Suchey- } \\
\text { Brooks }\end{array}$ & -8.598 & 26.725 & -2.594 & -0.006 & 18.125 & -7.740 & 15.981 & 39.385 \\
\hline \multirow[t]{8}{*}{ Group 4} & Kunos et al. & 37.403 & -5.631 & -4.563 & 4.528 & -1.658 & 11.869 & 0.478 & -1.773 \\
\hline & DiGangi et al. & -5.631 & 75.318 & 0.719 & -0.097 & 25.918 & -20.765 & 27.367 & 25.468 \\
\hline & İşcan et al. & -4.563 & 0.719 & 53.075 & -1.463 & -3.853 & 9.604 & 8.246 & 3.981 \\
\hline & Passalacqua & 4.528 & -0.097 & -1.463 & 42.192 & 2.229 & 3.011 & 4.538 & 1.351 \\
\hline & Lovejoy et al. & -1.658 & 25.918 & -3.853 & 2.229 & 44.105 & -8.275 & 24.359 & 19.021 \\
\hline & $\begin{array}{l}\text { Buckberry \& } \\
\text { Chamberlain }\end{array}$ & 11.869 & -20.765 & 9.604 & 3.011 & -8.275 & 68.469 & 1.282 & -16.893 \\
\hline & $\begin{array}{l}\text { Rougé- } \\
\text { Maillart et al. }\end{array}$ & .478 & 27.367 & 8.246 & 4.538 & 24.359 & 1.282 & 48.257 & 21.021 \\
\hline & $\begin{array}{l}\text { Suchey- } \\
\text { Brooks }\end{array}$ & -1.773 & 25.468 & 3.981 & 1.351 & 19.021 & -16.893 & 21.021 & 47.019 \\
\hline
\end{tabular}

Appendix 21: Covariance matrix for males separated by body mass for accuracy scores. 
Appendix 22

\begin{tabular}{|c|c|c|c|c|c|c|c|c|c|}
\hline \multicolumn{2}{|c|}{ Body Mass Categories } & \multirow{2}{*}{$\begin{array}{l}\begin{array}{c}\text { Kunos } \\
\text { et al. }\end{array} \\
64.404\end{array}$} & \multirow{2}{*}{$\begin{array}{c}\begin{array}{c}\text { DiGangi } \\
\text { et al. }\end{array} \\
30.659\end{array}$} & \multirow{2}{*}{ 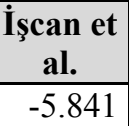 } & \multirow{2}{*}{$\begin{array}{r}\text { Passalacqua } \\
24.416\end{array}$} & $\begin{array}{l}\begin{array}{l}\text { Lovejoy } \\
\text { et al. }\end{array} \\
\end{array}$ & \multirow{2}{*}{\begin{tabular}{|r|}
$\begin{array}{l}\text { Buckberry \& } \\
\text { Chamberlain }\end{array}$ \\
7.687 \\
\end{tabular}} & \multirow{2}{*}{$\begin{array}{r}\begin{array}{c}\text { Rougé- } \\
\text { Maillart et al. }\end{array} \\
30.051\end{array}$} & \multirow{2}{*}{$\begin{array}{r}\begin{array}{c}\text { Suchey- } \\
\text { Brooks }\end{array} \\
9.572\end{array}$} \\
\hline Group 1 & Kunos et al. & & & & & 16.504 & & & \\
\hline & DiGangi et al. & 30.659 & 171.086 & 47.607 & -2.697 & 61.906 & -20.765 & 74.652 & 51.943 \\
\hline & İşcan et al. & -5.841 & 47.607 & 144.823 & 9.560 & 27.511 & -12.227 & 37.365 & 45.465 \\
\hline & Passalacqua & 24.416 & -2.697 & 9.560 & 79.454 & 10.160 & 14.333 & 29.997 & 16.633 \\
\hline & Lovejoy et al. & 16.504 & 61.906 & 27.511 & 10.160 & 51.179 & -1.461 & 48.168 & 29.863 \\
\hline & $\begin{array}{l}\text { Buckberry \& } \\
\text { Chamberlain }\end{array}$ & 7.687 & -20.765 & -12.227 & 14.333 & -1.461 & 60.408 & 12.369 & -8.709 \\
\hline & $\begin{array}{l}\text { Rougé- } \\
\text { Maillart et al. }\end{array}$ & 30.051 & 74.652 & 37.365 & 29.997 & 48.168 & 12.369 & 98.156 & 48.751 \\
\hline & $\begin{array}{l}\text { Suchey- } \\
\text { Brooks }\end{array}$ & 9.572 & 51.943 & 45.465 & 16.633 & 29.863 & -8.709 & 48.751 & 66.338 \\
\hline \multirow{8}{*}{ Group 2} & Kunos et al. & 46.190 & 16.997 & 13.212 & 12.585 & 8.846 & -0.121 & 3.562 & 6.982 \\
\hline & DiGangi et al. & 16.997 & 109.667 & 23.673 & 0.561 & 27.693 & -15.100 & 19.966 & 26.647 \\
\hline & İşcan et al. & 13.212 & 23.673 & 72.919 & 14.885 & 8.812 & 7.652 & 12.484 & 2.935 \\
\hline & Passalacqua & 12.585 & .561 & 14.885 & 75.272 & 7.677 & 4.098 & 9.377 & 5.990 \\
\hline & Lovejoy et al. & 8.846 & 27.693 & 8.812 & 7.677 & 46.284 & -4.292 & 27.827 & 24.115 \\
\hline & $\begin{array}{l}\text { Buckberry \& } \\
\text { Chamberlain }\end{array}$ & -0.121 & -15.100 & 7.652 & 4.098 & -4.292 & 68.759 & 4.652 & -0.378 \\
\hline & $\begin{array}{l}\text { Rougé- } \\
\text { Maillart et al. }\end{array}$ & 3.562 & 19.966 & 12.484 & 9.377 & 27.827 & 4.652 & 44.301 & 19.987 \\
\hline & $\begin{array}{l}\text { Suchey- } \\
\text { Brooks }\end{array}$ & 6.982 & 26.647 & 2.935 & 5.990 & 24.115 & -0.378 & 19.987 & 42.431 \\
\hline \multirow[t]{8}{*}{ Group 3} & Kunos et al. & 50.953 & -13.218 & 23.392 & 3.372 & -5.869 & 29.197 & -7.482 & -1.448 \\
\hline & DiGangi et al. & -13.218 & 160.677 & 51.845 & 15.898 & -0.087 & -34.387 & 20.613 & 26.374 \\
\hline & İşcan et al. & 23.392 & 51.845 & 75.591 & 43.549 & 7.590 & -5.796 & 4.919 & 10.280 \\
\hline & Passalacqua & 3.372 & 15.898 & 43.549 & 59.195 & 5.350 & -13.275 & 3.654 & 1.038 \\
\hline & Lovejoy et al. & -5.869 & -0.087 & 7.590 & 5.350 & 23.828 & 6.044 & 15.473 & -1.597 \\
\hline & $\begin{array}{l}\text { Buckberry \& } \\
\text { Chamberlain }\end{array}$ & 29.197 & -34.387 & -5.796 & -13.275 & 6.044 & 76.148 & -4.995 & -8.158 \\
\hline & $\begin{array}{l}\text { Rougé- } \\
\text { Maillart et al. }\end{array}$ & -7.482 & 20.613 & 4.919 & 3.654 & 15.473 & -4.995 & 33.076 & 6.628 \\
\hline & $\begin{array}{l}\text { Suchey- } \\
\text { Brooks }\end{array}$ & -1.448 & 26.374 & 10.280 & 1.038 & -1.597 & -8.158 & 6.628 & 26.044 \\
\hline \multirow[t]{8}{*}{ Group 4} & Kunos et al. & 19.050 & -18.008 & 1.558 & -5.267 & -19.558 & 6.492 & -13.725 & -12.442 \\
\hline & DiGangi et al. & -18.008 & 106.829 & 42.079 & -7.000 & 47.954 & -8.054 & 33.004 & 21.413 \\
\hline & İşcan et al. & 1.558 & 42.079 & 82.996 & -13.933 & 19.371 & -24.538 & 10.754 & 4.396 \\
\hline & Passalacqua & -5.267 & -7.000 & -13.933 & 66.000 & 27.867 & -21.867 & 19.467 & 31.467 \\
\hline & Lovejoy et al. & -19.558 & 47.954 & 19.371 & 27.867 & 73.863 & -16.029 & 53.346 & 26.904 \\
\hline & $\begin{array}{l}\text { Buckberry \& } \\
\text { Chamberlain }\end{array}$ & 6.492 & -8.054 & -24.538 & -21.867 & -16.029 & 40.863 & -0.913 & -7.204 \\
\hline & $\begin{array}{l}\text { Rougé- } \\
\text { Maillart et al. }\end{array}$ & -13.725 & 33.004 & 10.754 & 19.467 & 53.346 & -0.913 & 61.029 & 28.421 \\
\hline & $\begin{array}{l}\text { Suchey- } \\
\text { Brooks }\end{array}$ & -12.442 & 21.413 & 4.396 & 31.467 & 26.904 & -7.204 & 28.421 & 37.796 \\
\hline
\end{tabular}


Appendix 23

\begin{tabular}{|c|c|c|c|c|c|c|c|c|c|}
\hline \multicolumn{2}{|c|}{ Body Mass Categories } & \multirow{2}{*}{$\begin{array}{c}\begin{array}{c}\text { Kunos } \\
\text { et al. }\end{array} \\
169.712\end{array}$} & \multirow{2}{*}{$\begin{array}{c}\begin{array}{c}\text { DiGangi } \\
\text { et al. }\end{array} \\
175.424\end{array}$} & \multirow{2}{*}{\begin{tabular}{|c|}
$\begin{array}{c}\text { İşcan et } \\
\text { al. }\end{array}$ \\
124.650 \\
\end{tabular}} & \multirow{2}{*}{\begin{tabular}{|r|} 
Passalacqua \\
126.274 \\
\end{tabular}} & \multirow{2}{*}{$\begin{array}{c}\begin{array}{c}\text { Lovejoy } \\
\text { et al. }\end{array} \\
97.187\end{array}$} & \multirow{2}{*}{\begin{tabular}{|r}
$\begin{array}{l}\text { Buckberry \& } \\
\text { Chamberlain }\end{array}$ \\
121.172 \\
\end{tabular}} & \multirow{2}{*}{\begin{tabular}{|r|}
$\begin{array}{c}\text { Rougé- } \\
\text { Maillart et al. }\end{array}$ \\
135.950
\end{tabular}} & \multirow{2}{*}{$\begin{array}{c}\begin{array}{c}\text { Suchey- } \\
\text { Brooks }\end{array} \\
93.503\end{array}$} \\
\hline Group 1 & Kunos et al. & & & & & & & & \\
\hline & DiGangi et al. & 175.424 & 220.783 & 127.422 & 133.458 & 102.808 & 126.629 & 146.752 & 97.267 \\
\hline & İşcan et al. & 124.650 & 127.422 & 246.432 & 110.523 & 80.798 & 115.907 & 115.896 & 82.185 \\
\hline & Passalacqua & 126.274 & 133.458 & 110.523 & 228.311 & 96.072 & 112.630 & 109.003 & 92.711 \\
\hline & Lovejoy et al. & 97.187 & 102.808 & 80.798 & 96.072 & 94.486 & 108.539 & 108.037 & 61.761 \\
\hline & $\begin{array}{l}\text { Buckberry \& } \\
\text { Chamberlain }\end{array}$ & 121.172 & 126.629 & 115.907 & 112.630 & 108.539 & 197.619 & 163.762 & 82.359 \\
\hline & $\begin{array}{l}\text { Rougé- } \\
\text { Maillart et al. }\end{array}$ & 135.950 & 146.752 & 115.896 & 109.003 & 108.037 & 163.762 & 176.857 & 93.406 \\
\hline & $\begin{array}{l}\text { Suchey- } \\
\text { Brooks }\end{array}$ & 93.503 & 97.267 & 82.185 & 92.711 & 61.761 & 82.359 & 93.406 & 110.720 \\
\hline \multirow[t]{8}{*}{ Group 2} & Kunos et al. & 170.236 & 170.595 & 2.712 & 119.995 & 99.179 & 130.469 & 131.484 & 100.272 \\
\hline & DiGangi et al. & 170.595 & 212.730 & -26.989 & 122.522 & 98.783 & 126.216 & 128.282 & 103.108 \\
\hline & İşcan et al. & 2.712 & -26.989 & 202.727 & 12.238 & 27.306 & 24.823 & 24.631 & 24.799 \\
\hline & Passalacqua & 119.995 & 122.522 & 12.238 & 210.260 & 92.385 & 123.886 & 121.014 & 76.828 \\
\hline & Lovejoy et al. & 99.179 & 98.783 & 27.306 & 92.385 & 103.327 & 108.176 & 113.257 & 72.684 \\
\hline & $\begin{array}{l}\text { Buckberry \& } \\
\text { Chamberlain }\end{array}$ & 130.469 & 126.216 & 24.823 & 123.886 & 108.176 & 171.898 & 154.095 & 85.853 \\
\hline & $\begin{array}{l}\text { Rougé- } \\
\text { Maillart et al. }\end{array}$ & 131.484 & 128.282 & 24.631 & 121.014 & 113.257 & 154.095 & 180.398 & 92.744 \\
\hline & $\begin{array}{l}\text { Suchey- } \\
\text { Brooks }\end{array}$ & 100.272 & 103.108 & 24.799 & 76.828 & 72.684 & 85.853 & 92.744 & 102.162 \\
\hline \multirow[t]{8}{*}{ Group 3} & Kunos et al. & 118.472 & 122.105 & -5.409 & 84.186 & 69.860 & 97.929 & 83.372 & 53.492 \\
\hline & DiGangi et al. & 122.105 & 176.859 & -22.546 & 80.662 & 73.344 & 101.505 & 92.073 & 59.524 \\
\hline & İşcan et al. & -5.409 & -22.546 & 114.212 & -1.193 & 14.778 & 1.352 & 5.707 & 5.717 \\
\hline & Passalacqua & 84.186 & 80.662 & -1.193 & 177.386 & 65.149 & 84.608 & 77.845 & 53.388 \\
\hline & Lovejoy et al. & 69.860 & 73.344 & 14.778 & 65.149 & 89.246 & 92.183 & 79.463 & 45.926 \\
\hline & $\begin{array}{l}\text { Buckberry \& } \\
\text { Chamberlain }\end{array}$ & 97.929 & 101.505 & 1.352 & 84.608 & 92.183 & 173.748 & 127.408 & 65.978 \\
\hline & $\begin{array}{l}\text { Rougé- } \\
\text { Maillart et al. }\end{array}$ & 83.372 & 92.073 & 5.707 & 77.845 & 79.463 & 127.408 & 125.911 & 59.548 \\
\hline & $\begin{array}{l}\text { Suchey- } \\
\text { Brooks }\end{array}$ & 53.492 & 59.524 & 5.717 & 53.388 & 45.926 & 65.978 & 59.548 & 69.370 \\
\hline \multirow[t]{8}{*}{ Group 4} & Kunos et al. & 90.765 & 74.681 & 27.221 & 60.978 & 46.280 & 56.611 & 61.236 & 65.592 \\
\hline & DiGangi et al. & 74.681 & 105.706 & 8.628 & 48.047 & 37.644 & 43.977 & 47.092 & 56.921 \\
\hline & İşcan et al. & 27.221 & 8.628 & 151.164 & 41.700 & 35.227 & 35.078 & 38.023 & 36.235 \\
\hline & Passalacqua & 60.978 & 48.047 & 41.700 & 142.980 & 51.175 & 60.117 & 68.034 & 48.518 \\
\hline & Lovejoy et al. & 46.280 & 37.644 & 35.227 & 51.175 & 88.268 & 63.429 & 72.422 & 48.999 \\
\hline & $\begin{array}{l}\text { Buckberry \& } \\
\text { Chamberlain }\end{array}$ & 56.611 & 43.977 & 35.078 & 60.117 & 63.429 & 116.050 & 91.625 & 60.221 \\
\hline & $\begin{array}{l}\text { Rougé- } \\
\text { Maillart et al. }\end{array}$ & 61.236 & 47.092 & 38.023 & 68.034 & 72.422 & 91.625 & 111.872 & 64.368 \\
\hline & $\begin{array}{l}\text { Suchey- } \\
\text { Brooks }\end{array}$ & 65.592 & 56.921 & 36.235 & 48.518 & 48.999 & 60.221 & 64.368 & 108.164 \\
\hline
\end{tabular}


Appendix 24

\begin{tabular}{|c|c|c|c|c|c|c|c|c|c|}
\hline \multicolumn{2}{|c|}{ Body Mass Categories } & $\begin{array}{l}\text { Kunos } \\
\text { et al. }\end{array}$ & $\begin{array}{c}\text { DiGangi } \\
\text { et al. }\end{array}$ & \begin{tabular}{|c|}
$\begin{array}{c}\text { İşcan et } \\
\text { al. }\end{array}$ \\
\end{tabular} & Passalacqua & $\begin{array}{c}\begin{array}{c}\text { Lovejoy } \\
\text { et al. }\end{array} \\
\end{array}$ & \begin{tabular}{|l|} 
Buckberry \& \\
Chamberlain \\
\end{tabular} & \begin{tabular}{|c|} 
Rougé- \\
Maillart et al.
\end{tabular} & $\begin{array}{l}\text { Suchey- } \\
\text { Brooks }\end{array}$ \\
\hline \multirow[t]{8}{*}{ Group 1} & Kunos et al. & 54.404 & 35.651 & 8.287 & 18.855 & 16.436 & 7.564 & 32.602 & 17.523 \\
\hline & DiGangi et al. & 35.651 & 147.264 & 59.771 & 15.300 & 57.162 & -12.823 & 70.100 & 40.556 \\
\hline & İşcan et al. & 8.287 & 59.771 & 123.460 & 22.172 & 34.148 & -2.577 & 47.437 & 36.636 \\
\hline & Passalacqua & 18.855 & 15.300 & 22.172 & 74.264 & 18.663 & 14.866 & 31.287 & 17.818 \\
\hline & Lovejoy et al. & 16.436 & 57.162 & 34.148 & 18.663 & 53.192 & 4.977 & 44.921 & 23.336 \\
\hline & $\begin{array}{l}\text { Buckberry \& } \\
\text { Chamberlain }\end{array}$ & 7.564 & -12.823 & -2.577 & 14.866 & 4.977 & 58.004 & 16.386 & -.324 \\
\hline & $\begin{array}{l}\text { Rougé- } \\
\text { Maillart et al. }\end{array}$ & 32.602 & 70.100 & 47.437 & 31.287 & 44.921 & 16.386 & 87.431 & 41.706 \\
\hline & $\begin{array}{l}\text { Suchey- } \\
\text { Brooks }\end{array}$ & 17.523 & 40.556 & 36.636 & 17.818 & 23.336 & -.324 & 41.706 & 59.275 \\
\hline \multirow{8}{*}{ Group 2} & Kunos et al. & 50.870 & 20.007 & 11.895 & 6.887 & 8.649 & 13.797 & 5.287 & 3.512 \\
\hline & DiGangi et al. & 20.007 & 140.125 & 34.587 & 21.623 & 42.769 & -28.242 & 42.868 & 51.526 \\
\hline & İşcan et al. & 11.895 & 34.587 & 80.799 & 15.276 & 4.614 & -3.613 & 10.148 & 3.282 \\
\hline & Passalacqua & 6.887 & 21.623 & 15.276 & 82.064 & 21.343 & 2.185 & 21.908 & 16.796 \\
\hline & Lovejoy et al. & 8.649 & 42.769 & 4.614 & 21.343 & 58.867 & -5.189 & 41.971 & 33.462 \\
\hline & $\begin{array}{l}\text { Buckberry \& } \\
\text { Chamberlain }\end{array}$ & 13.797 & -28.242 & -3.613 & 2.185 & -5.189 & 63.029 & 1.798 & -17.328 \\
\hline & $\begin{array}{l}\text { Rougé- } \\
\text { Maillart et al. }\end{array}$ & 5.287 & 42.868 & 10.148 & 21.908 & 41.971 & 1.798 & 66.001 & 28.676 \\
\hline & $\begin{array}{l}\text { Suchey- } \\
\text { Brooks }\end{array}$ & 3.512 & 51.526 & 3.282 & 16.796 & 33.462 & -17.328 & 28.676 & 63.060 \\
\hline \multirow[t]{8}{*}{ Group 3} & Kunos et al. & 57.088 & -9.368 & 4.016 & 14.899 & -4.661 & 33.959 & -0.731 & -10.198 \\
\hline & DiGangi et al. & -9.368 & 112.194 & 14.100 & 6.027 & 21.078 & -25.418 & 24.124 & 25.089 \\
\hline & İşcan et al. & 4.016 & 14.100 & 52.988 & 1.264 & -4.755 & .955 & 0.580 & -3.180 \\
\hline & Passalacqua & 14.899 & 6.027 & 1.264 & 63.497 & 1.354 & -2.106 & 6.696 & 2.659 \\
\hline & Lovejoy et al. & -4.661 & 21.078 & -4.755 & 1.354 & 37.291 & -.691 & 20.354 & 15.785 \\
\hline & $\begin{array}{l}\text { Buckberry \& } \\
\text { Chamberlain }\end{array}$ & 33.959 & -25.418 & 0.955 & -2.106 & -0.691 & 74.367 & 7.425 & -6.840 \\
\hline & $\begin{array}{l}\text { Rougé- } \\
\text { Maillart et al. }\end{array}$ & -.731 & 24.124 & 0.580 & 6.696 & 20.354 & 7.425 & 42.526 & 15.031 \\
\hline & $\begin{array}{l}\text { Suchey- } \\
\text { Brooks }\end{array}$ & -10.198 & 25.089 & -3.180 & 2.659 & 15.785 & -6.840 & 15.031 & 38.338 \\
\hline \multirow[t]{8}{*}{ Group 4} & Kunos et al. & 39.642 & -9.473 & -4.093 & 3.213 & -6.271 & 12.298 & -2.314 & -4.709 \\
\hline & DiGangi et al. & -9.473 & 76.011 & 2.184 & 1.615 & 28.011 & -14.453 & 24.956 & 22.730 \\
\hline & İşcan et al. & -4.093 & 2.184 & 60.591 & -1.349 & -2.239 & 9.118 & 8.600 & 1.662 \\
\hline & Passalacqua & 3.213 & 1.615 & -1.349 & 48.636 & 7.300 & 3.697 & 9.841 & 6.066 \\
\hline & Lovejoy et al. & -6.271 & 28.011 & -2.239 & 7.300 & 50.442 & -13.176 & 26.275 & 20.155 \\
\hline & $\begin{array}{l}\text { Buckberry \& } \\
\text { Chamberlain }\end{array}$ & 12.298 & -14.453 & 9.118 & 3.697 & -13.176 & 59.670 & 2.436 & -17.371 \\
\hline & $\begin{array}{l}\text { Rougé- } \\
\text { Maillart et al. }\end{array}$ & -2.314 & 24.956 & 8.600 & 9.841 & 26.275 & 2.436 & 52.157 & 20.979 \\
\hline & $\begin{array}{l}\text { Suchey- } \\
\text { Brooks }\end{array}$ & -4.709 & 22.730 & 1.662 & 6.066 & 20.155 & -17.371 & 20.979 & 45.577 \\
\hline
\end{tabular}

Appendix 24: Covariance matrix for individuals of European ancestry separated by body mass for accuracy scores. 
Appendix 25

\begin{tabular}{|c|c|c|c|c|c|c|c|c|c|}
\hline \multicolumn{2}{|c|}{ Body Mass Categories } & \multirow{2}{*}{$\begin{array}{c}\begin{array}{c}\text { Kunos et } \\
\text { al. }\end{array} \\
49.493\end{array}$} & \multirow{2}{*}{$\begin{array}{r}\begin{array}{c}\text { DiGangi } \\
\text { et al. }\end{array} \\
3.727\end{array}$} & \multirow{2}{*}{$\begin{array}{c}\begin{array}{c}\text { Isscan et } \\
\text { al. }\end{array} \\
5.237\end{array}$} & \multirow{2}{*}{$\begin{array}{r}\text { Passalacqua } \\
28.691\end{array}$} & \multirow{2}{*}{$\begin{array}{c}\begin{array}{c}\text { Lovejoy et } \\
\text { al. }\end{array} \\
3.577\end{array}$} & \multirow{2}{*}{$\begin{array}{r}\begin{array}{r}\text { Buckberry \& } \\
\text { Chamberlain }\end{array} \\
20.918\end{array}$} & \multirow{2}{*}{$\begin{array}{c}\begin{array}{c}\text { Rougé- } \\
\text { Maillart et al. }\end{array} \\
14.459\end{array}$} & \multirow{2}{*}{$\begin{array}{r}\begin{array}{c}\text { Suchey- } \\
\text { Brooks }\end{array} \\
-3.825\end{array}$} \\
\hline Group 1 & Kunos et al. & & & & & & & & \\
\hline & DiGangi et al. & 3.727 & 114.073 & 82.658 & 17.549 & 34.982 & -19.920 & 49.874 & 47.821 \\
\hline & İşcan et al. & 5.237 & 82.658 & 148.702 & 15.203 & 40.414 & -11.734 & 49.110 & 54.245 \\
\hline & Passalacqua & 28.691 & 17.549 & 15.203 & 91.347 & 16.378 & 3.728 & 22.510 & 19.121 \\
\hline & Lovejoy et al. & 3.577 & 34.982 & 40.414 & 16.378 & 43.283 & 5.024 & 50.332 & 32.336 \\
\hline & $\begin{array}{l}\text { Buckberry \& } \\
\text { Chamberlain }\end{array}$ & 20.918 & -19.920 & -11.734 & 3.728 & 5.024 & 97.625 & 28.054 & -14.073 \\
\hline & $\begin{array}{l}\text { Rougé-Maillart } \\
\text { et al. }\end{array}$ & 14.459 & 49.874 & 49.110 & 22.510 & 50.332 & 28.054 & 93.161 & 38.562 \\
\hline & Suchey-Brooks & -3.825 & 47.821 & 54.245 & 19.121 & 32.336 & -14.073 & 38.562 & 65.224 \\
\hline \multirow[t]{8}{*}{ Group 2} & Kunos et al. & 54.045 & -5.468 & 20.987 & 9.753 & 1.887 & 27.634 & 8.547 & .849 \\
\hline & DiGangi et al. & -5.468 & 77.004 & 6.154 & 10.947 & 18.088 & -25.031 & 13.740 & 29.821 \\
\hline & İşcan et al. & 20.987 & 6.154 & 53.419 & 2.088 & .797 & 9.997 & -1.518 & 4.395 \\
\hline & Passalacqua & 9.753 & 10.947 & 2.088 & 76.915 & 9.725 & 10.337 & 13.007 & 1.257 \\
\hline & Lovejoy et al. & 1.887 & 18.088 & .797 & 9.725 & 27.690 & -6.378 & 19.243 & 14.175 \\
\hline & $\begin{array}{l}\text { Buckberry \& } \\
\text { Chamberlain }\end{array}$ & 27.634 & -25.031 & 9.997 & 10.337 & -6.378 & 79.905 & 11.242 & -11.605 \\
\hline & $\begin{array}{l}\text { Rougé-Maillart } \\
\text { et al. }\end{array}$ & 8.547 & 13.740 & -1.518 & 13.007 & 19.243 & 11.242 & 48.559 & 17.644 \\
\hline & Suchey-Brooks & .849 & 29.821 & 4.395 & 1.257 & 14.175 & -11.605 & 17.644 & 40.995 \\
\hline \multirow[t]{8}{*}{ Group 3} & Kunos et al. & 40.340 & -14.455 & 1.658 & 4.222 & 6.718 & 32.144 & 9.485 & 1.812 \\
\hline & DiGangi et al. & -14.455 & 74.047 & 13.923 & -14.811 & 14.234 & -25.469 & 29.270 & 29.169 \\
\hline & İşcan et al. & 1.658 & 13.923 & 37.171 & 6.967 & -.942 & -9.879 & -6.852 & 6.179 \\
\hline & Passalacqua & 4.222 & -14.811 & 6.967 & 51.811 & -4.111 & 24.144 & -10.800 & -7.867 \\
\hline & Lovejoy et al. & 6.718 & 14.234 & -.942 & -4.111 & 29.229 & 12.344 & 16.463 & 11.989 \\
\hline & $\begin{array}{l}\text { Buckberry \& } \\
\text { Chamberlain }\end{array}$ & 32.144 & -25.469 & -9.879 & 24.144 & 12.344 & 106.047 & 24.597 & -9.258 \\
\hline & $\begin{array}{l}\text { Rougé-Maillart } \\
\text { et al. }\end{array}$ & 9.485 & 29.270 & -6.852 & -10.800 & 16.463 & 24.597 & 50.821 & 12.447 \\
\hline & Suchey-Brooks & 1.812 & 29.169 & 6.179 & -7.867 & 11.989 & -9.258 & 12.447 & 33.925 \\
\hline \multirow[t]{8}{*}{ Group 4} & Kunos et al. & 18.254 & 2.434 & -2.746 & 4.587 & 6.915 & 6.873 & 4.698 & 4.492 \\
\hline & DiGangi et al. & 2.434 & 92.247 & 17.980 & -10.612 & 30.636 & -38.550 & 37.388 & 33.225 \\
\hline & İşcan et al. & -2.746 & 17.980 & 39.189 & -9.589 & 1.851 & -6.720 & 6.374 & 12.251 \\
\hline & Passalacqua & 4.587 & -10.612 & -9.589 & 29.115 & -4.446 & -12.794 & -10.107 & -1.786 \\
\hline & Lovejoy et al. & 6.915 & 30.636 & 1.851 & -4.446 & 34.840 & 7.709 & 29.925 & 17.336 \\
\hline & $\begin{array}{l}\text { Buckberry \& } \\
\text { Chamberlain }\end{array}$ & 6.873 & -38.550 & -6.720 & -12.794 & 7.709 & 87.323 & -3.016 & -8.598 \\
\hline & $\begin{array}{l}\text { Rougé-Maillart } \\
\text { et al. }\end{array}$ & 4.698 & 37.388 & 6.374 & -10.107 & 29.925 & -3.016 & 38.967 & 23.659 \\
\hline & Suchey-Brooks & 4.492 & 33.225 & 12.251 & -1.786 & 17.336 & -8.598 & 23.659 & 46.238 \\
\hline
\end{tabular}


Appendix 26

\begin{tabular}{|c|c|c|c|c|c|c|c|c|c|}
\hline \multicolumn{2}{|c|}{ Body Mass Categories } & $\begin{array}{c}\begin{array}{c}\text { Kunos et } \\
\text { al. }\end{array} \\
\end{array}$ & $\begin{array}{c}\begin{array}{c}\text { DiGangi } \\
\text { et al. }\end{array} \\
\end{array}$ & $\begin{array}{c}\text { İşcan et } \\
\text { al. }\end{array}$ & Passalacqua & $\begin{array}{c}\text { Lovejoy et } \\
\text { al. }\end{array}$ & $\begin{array}{l}\text { Buckberry \& } \\
\text { Chamberlain } \\
\end{array}$ & $\begin{array}{c}\text { Rougé- } \\
\text { Maillart et al. }\end{array}$ & $\begin{array}{l}\begin{array}{l}\text { Suchey- } \\
\text { Brooks }\end{array} \\
\end{array}$ \\
\hline \multirow[t]{8}{*}{ Group 1} & Kunos et al. & 174.798 & 154.202 & 85.061 & 107.449 & 84.293 & 102.242 & 124.227 & 87.217 \\
\hline & DiGangi et al. & 154.202 & 189.242 & 78.107 & 88.916 & 79.129 & 89.390 & 114.195 & 68.078 \\
\hline & İşcan et al. & 85.061 & 78.107 & 232.379 & 92.946 & 52.037 & 78.787 & 88.325 & 70.334 \\
\hline & Passalacqua & 107.449 & 88.916 & 92.946 & 186.677 & 73.029 & 93.312 & 104.456 & 80.402 \\
\hline & Lovejoy et al. & 84.293 & 79.129 & 52.037 & 73.029 & 77.758 & 74.211 & 81.399 & 48.778 \\
\hline & $\begin{array}{l}\text { Buckberry \& } \\
\text { Chamberlain }\end{array}$ & 102.242 & 89.390 & 78.787 & 93.312 & 74.211 & 151.084 & 123.999 & 67.155 \\
\hline & $\begin{array}{l}\text { Rougé-Maillart } \\
\text { et al. }\end{array}$ & 124.227 & 114.195 & 88.325 & 104.456 & 81.399 & 123.999 & 148.907 & 84.286 \\
\hline & Suchey-Brooks & 87.217 & 68.078 & 70.334 & 80.402 & 48.778 & 67.155 & 84.286 & 101.461 \\
\hline \multirow[t]{8}{*}{ Group 2} & Kunos et al. & 163.996 & 161.174 & 14.959 & 117.954 & 91.438 & 109.300 & 108.024 & 88.724 \\
\hline & DiGangi et al. & 161.174 & 200.640 & -15.426 & 116.125 & 85.331 & 102.278 & 101.554 & 86.647 \\
\hline & İşcan et al. & 14.959 & -15.426 & 221.977 & 43.553 & 41.299 & 41.040 & 46.177 & 33.328 \\
\hline & Passalacqua & 117.954 & 116.125 & 43.553 & 210.828 & 93.602 & 111.279 & 115.231 & 81.998 \\
\hline & Lovejoy et al. & 91.438 & 85.331 & 41.299 & 93.602 & 105.016 & 102.219 & 106.060 & 69.868 \\
\hline & $\begin{array}{l}\text { Buckberry \& } \\
\text { Chamberlain }\end{array}$ & 109.300 & 102.278 & 41.040 & 111.279 & 102.219 & 162.328 & 136.069 & 71.718 \\
\hline & $\begin{array}{l}\text { Rougé-Maillart } \\
\text { et al. }\end{array}$ & 108.024 & 101.554 & 46.177 & 115.231 & 106.060 & 136.069 & 159.778 & 77.051 \\
\hline & Suchey-Brooks & 88.724 & 86.647 & 33.328 & 81.998 & 69.868 & 71.718 & 77.051 & 100.304 \\
\hline \multirow[t]{8}{*}{ Group 3} & Kunos et al. & 126.004 & 137.471 & 3.919 & 96.087 & 65.292 & 89.219 & 75.614 & 53.529 \\
\hline & DiGangi et al. & 137.471 & 207.786 & -9.374 & 101.028 & 68.903 & 93.206 & 81.138 & 60.859 \\
\hline & İşcan et al. & 3.919 & -9.374 & 141.018 & 6.670 & 22.075 & 12.298 & 15.433 & 8.365 \\
\hline & Passalacqua & 96.087 & 101.028 & 6.670 & 195.654 & 63.493 & 69.911 & 69.296 & 56.937 \\
\hline & Lovejoy et al. & 65.292 & 68.903 & 22.075 & 63.493 & 82.823 & 80.817 & 70.695 & 38.434 \\
\hline & $\begin{array}{l}\text { Buckberry \& } \\
\text { Chamberlain }\end{array}$ & 89.219 & 93.206 & 12.298 & 69.911 & 80.817 & 154.346 & 112.261 & 56.122 \\
\hline & $\begin{array}{l}\text { Rougé-Maillart } \\
\text { et al. }\end{array}$ & 75.614 & 81.138 & 15.433 & 69.296 & 70.695 & 112.261 & 111.574 & 49.749 \\
\hline & Suchey-Brooks & 53.529 & 60.859 & 8.365 & 56.937 & 38.434 & 56.122 & 49.749 & 67.932 \\
\hline \multirow[t]{8}{*}{ Group 4} & Kunos et al. & 93.093 & 78.688 & 32.006 & 67.646 & 45.662 & 55.297 & 54.978 & 62.875 \\
\hline & DiGangi et al. & 78.688 & 117.887 & 26.103 & 53.732 & 38.838 & 42.976 & 41.644 & 52.655 \\
\hline & İşcan et al. & 32.006 & 26.103 & 169.002 & 48.672 & 46.739 & 51.524 & 46.147 & 42.440 \\
\hline & Passalacqua & 67.646 & 53.732 & 48.672 & 157.940 & 56.480 & 77.127 & 72.560 & 62.151 \\
\hline & Lovejoy et al. & 45.662 & 38.838 & 46.739 & 56.480 & 93.473 & 64.817 & 75.590 & 45.372 \\
\hline & $\begin{array}{l}\text { Buckberry \& } \\
\text { Chamberlain }\end{array}$ & 55.297 & 42.976 & 51.524 & 77.127 & 64.817 & 109.857 & 89.632 & 58.525 \\
\hline & $\begin{array}{l}\text { Rougé-Maillart } \\
\text { et al. }\end{array}$ & 54.978 & 41.644 & 46.147 & 72.560 & 75.590 & 89.632 & 114.850 & 61.395 \\
\hline & Suchey-Brooks & 62.875 & 52.655 & 42.440 & 62.151 & 45.372 & 58.525 & 61.395 & 107.623 \\
\hline
\end{tabular}

Appendix 26: Covariance matrix for individuals of European ancestry separated by body mass for bias scores. 
Appendix 27

\begin{tabular}{|c|c|c|c|c|c|c|c|c|c|}
\hline \multicolumn{2}{|c|}{ Body Mass Categories } & \multirow{2}{*}{$\begin{array}{c}\begin{array}{c}\text { Kunos et } \\
\text { al. }\end{array} \\
166.575\end{array}$} & \multirow{2}{*}{$\begin{array}{l}\begin{array}{c}\text { DiGangi } \\
\text { et al. }\end{array} \\
179.015\end{array}$} & \multirow{2}{*}{\begin{tabular}{|l|}
$\begin{array}{c}\text { İşcan et } \\
\text { al. }\end{array}$ \\
147.076
\end{tabular}} & \multirow{2}{*}{$\begin{array}{r}\text { Passalacqua } \\
152.400\end{array}$} & \multirow{2}{*}{$\begin{array}{c}\begin{array}{c}\text { Lovejoy et } \\
\text { al. }\end{array} \\
93.810\end{array}$} & \multirow{2}{*}{$\begin{array}{r}\begin{array}{r}\text { Buckberry \& } \\
\text { Chamberlain }\end{array} \\
118.277\end{array}$} & \multirow{2}{*}{$\begin{array}{r}\begin{array}{c}\text { Rougé- } \\
\text { Maillart et al. }\end{array} \\
133.786\end{array}$} & \multirow{2}{*}{$\begin{array}{c}\begin{array}{c}\text { Suchey- } \\
\text { Brooks }\end{array} \\
100.061\end{array}$} \\
\hline Group 1 & Kunos et al. & & & & & & & & \\
\hline & DiGangi et al. & 179.015 & 259.405 & 170.148 & 152.312 & 102.293 & 131.344 & 151.839 & 107.527 \\
\hline & İşcan et al. & 147.076 & 170.148 & 302.063 & 134.670 & 89.493 & 103.816 & 127.934 & 93.915 \\
\hline & Passalacqua & 152.400 & 152.312 & 134.670 & 290.315 & 103.406 & 131.215 & 138.871 & 129.928 \\
\hline & Lovejoy et al. & 93.810 & 102.293 & 89.493 & 103.406 & 92.687 & 105.227 & 114.245 & 69.630 \\
\hline & $\begin{array}{l}\text { Buckberry \& } \\
\text { Chamberlain }\end{array}$ & 118.277 & 131.344 & 103.816 & 131.215 & 105.227 & 219.718 & 173.774 & 87.164 \\
\hline & $\begin{array}{l}\text { Rougé-Maillart } \\
\text { et al. }\end{array}$ & 133.786 & 151.839 & 127.934 & 138.871 & 114.245 & 173.774 & 191.548 & 104.002 \\
\hline & Suchey-Brooks & 100.061 & 107.527 & 93.915 & 129.928 & 69.630 & 87.164 & 104.002 & 113.376 \\
\hline \multirow[t]{8}{*}{ Group 2} & Kunos et al. & 137.017 & 124.801 & 4.083 & 100.553 & 63.366 & 91.018 & 86.261 & 77.582 \\
\hline & DiGangi et al. & 124.801 & 142.690 & -23.062 & 100.496 & 56.275 & 79.274 & 75.301 & 69.970 \\
\hline & İşcan et al. & 4.083 & -23.062 & 165.243 & 1.967 & 27.548 & 22.910 & 23.710 & 17.157 \\
\hline & Passalacqua & 100.553 & 100.496 & 1.967 & 207.893 & 65.604 & 85.663 & 82.365 & 62.363 \\
\hline & Lovejoy et al. & 63.366 & 56.275 & 27.548 & 65.604 & 67.794 & 67.517 & 72.076 & 48.111 \\
\hline & $\begin{array}{l}\text { Buckberry \& } \\
\text { Chamberlain }\end{array}$ & 91.018 & 79.274 & 22.910 & 85.663 & 67.517 & 161.634 & 114.908 & 58.701 \\
\hline & $\begin{array}{l}\text { Rougé-Maillart } \\
\text { et al. }\end{array}$ & 86.261 & 75.301 & 23.710 & 82.365 & 72.076 & 114.908 & 129.447 & 68.166 \\
\hline & Suchey-Brooks & 77.582 & 69.970 & 17.157 & 62.363 & 48.111 & 58.701 & 68.166 & 81.985 \\
\hline \multirow[t]{8}{*}{ Group 3} & Kunos et al. & 98.218 & 93.814 & -17.049 & 44.906 & 49.995 & 90.643 & 79.012 & 54.387 \\
\hline & DiGangi et al. & 93.814 & 129.475 & -15.405 & 56.372 & 47.495 & 95.151 & 90.337 & 60.988 \\
\hline & İşcan et al. & -17.049 & -15.405 & 87.622 & 8.955 & -5.300 & -13.269 & -9.541 & 3.979 \\
\hline & Passalacqua & 44.906 & 56.372 & 8.955 & 139.177 & 51.677 & 85.353 & 65.437 & 48.490 \\
\hline & Lovejoy et al. & 49.995 & 47.495 & -5.300 & 51.677 & 73.011 & 81.520 & 66.548 & 47.023 \\
\hline & $\begin{array}{l}\text { Buckberry \& } \\
\text { Chamberlain }\end{array}$ & 90.643 & 95.151 & -13.269 & 85.353 & 81.520 & 181.610 & 121.050 & 64.227 \\
\hline & $\begin{array}{l}\text { Rougé-Maillart } \\
\text { et al. }\end{array}$ & 79.012 & 90.337 & -9.541 & 65.437 & 66.548 & 121.050 & 120.010 & 64.660 \\
\hline & Suchey-Brooks & 54.387 & 60.988 & 3.979 & 48.490 & 47.023 & 64.227 & 64.660 & 72.620 \\
\hline \multirow[t]{8}{*}{ Group 4} & Kunos et al. & 70.397 & 67.384 & 3.177 & 45.939 & 43.722 & 50.667 & 60.606 & 58.228 \\
\hline & DiGangi et al. & 67.384 & 97.136 & -28.022 & 44.988 & 49.843 & 49.389 & 63.007 & 64.947 \\
\hline & İşcan et al. & 3.177 & -28.022 & 105.221 & 2.459 & 10.213 & -.907 & 14.070 & 8.402 \\
\hline & Passalacqua & 45.939 & 44.988 & 2.459 & 111.877 & 28.102 & -1.944 & 35.044 & 23.762 \\
\hline & Lovejoy et al. & 43.722 & 49.843 & 10.213 & 28.102 & 74.861 & 65.019 & 65.343 & 52.556 \\
\hline & $\begin{array}{l}\text { Buckberry \& } \\
\text { Chamberlain }\end{array}$ & 50.667 & 49.389 & -.907 & -1.944 & 65.019 & 150.259 & 93.944 & 63.148 \\
\hline & $\begin{array}{l}\text { Rougé-Maillart } \\
\text { et al. }\end{array}$ & 60.606 & 63.007 & 14.070 & 35.044 & 65.343 & 93.944 & 90.396 & 62.614 \\
\hline & Suchey-Brooks & 58.228 & 64.947 & 8.402 & 23.762 & 52.556 & 63.148 & 62.614 & 103.238 \\
\hline
\end{tabular}

